\title{
nanomaterials
}

Innovative

Advanced

Materials for

Energy Storage

and Beyond

Synthesis, Characterization and Applications

Edited by

Vijay Kumar Thakur

Printed Edition of the Special Issue Published in Nanomaterials 


\section{Innovative Advanced Materials for Energy Storage and Beyond}





\section{Innovative Advanced Materials for Energy Storage and Beyond: Synthesis, Characterization and Applications}

Editor

Vijay Kumar Thakur 
Editor

Vijay Kumar Thakur

Biorefining and Advanced

Materials Research Centre

UK

Scotland's Rural College (SRUC)

UK

Editorial Office

MDPI

St. Alban-Anlage 66

4052 Basel, Switzerland

This is a reprint of articles from the Special Issue published online in the open access journal Nanomaterials (ISSN 2079-4991) (available at: https://www.mdpi.com/journal/nanomaterials/ special_issues/eenergy_storage_innovative).

For citation purposes, cite each article independently as indicated on the article page online and as indicated below:

LastName, A.A.; LastName, B.B.; LastName, C.C. Article Title. Journal Name Year, Article Number, Page Range.

ISBN 978-3-03943-370-4 (Hbk)

ISBN 978-3-03943-371-1 (PDF)

(C) 2020 by the authors. Articles in this book are Open Access and distributed under the Creative Commons Attribution (CC BY) license, which allows users to download, copy and build upon published articles, as long as the author and publisher are properly credited, which ensures maximum dissemination and a wider impact of our publications.

The book as a whole is distributed by MDPI under the terms and conditions of the Creative Commons license CC BY-NC-ND. 


\section{Contents}

About the Editor $\ldots \ldots \ldots \ldots \ldots \ldots \ldots \ldots \ldots \ldots$ vii

Preface to "Innovative Advanced Materials for Energy Storage and Beyond: Synthesis,

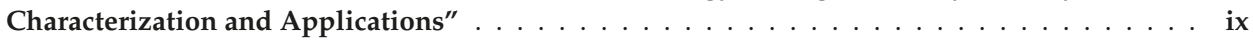

Vijay Kumar Thakur

Innovative Advanced Materials for Energy Storage and Beyond: Synthesis,

Characterisation and Applications

Reprinted from: Nanomaterials 2020, 10, 1817, doi:10.3390/nano10091817 . . . . . . . . . . . . .

Aleksei Llusco, Mario Grageda and Svetlana Ushak

Kinetic and Thermodynamic Studies on Synthesis of Mg-Doped $\mathrm{LiMn}_{2} \mathrm{O}_{4}$ Nanoparticles

Reprinted from: Nanomaterials 2020, 10, 1409, doi:10.3390/nano10071409 . . . . . . . . . . . . .

Yasi Jiang, Yiyang Pan, Wanhua Wu, Kaiying Luo, Zhitao Rong, Sihang Xie, Wencai Zuo, Jingya Yu, Ruibo Zhang, Donghuan Qin, Wei Xu, Dan Wang and Lintao Hou

Hole Transfer Layer Engineering for CdTe Nanocrystal Photovoltaics with Improved Efficiency

Reprinted from: Nanomaterials 2020, 10, 1348, doi:10.3390/nano10071348 . . . . . . . . . . . . 33

Thang Phan Nguyen and Il Tae Kim

$\mathrm{W}_{2} \mathrm{C} / \mathrm{WS}_{2}$ Alloy Nanoflowers as Anode Materials for Lithium-Ion Storage

Reprinted from: Nanomaterials 2020, 10, 1336, doi:10.3390/nano10071336 . . . . . . . . . . . 45

Badria M. Al-Shehri, Mohd Shkir, A. S. Khder, Ajeet Kaushik and Mohamed S. Hamdy

Noble Metal Nanoparticles Incorporated Siliceous TUD-1 Mesoporous Nano-Catalyst for Low-Temperature Oxidation of Carbon Monoxide

Reprinted from: Nanomaterials 2020, 10, 1067, doi:10.3390/nano10061067 . . . . . . . . . . . . 57

Alexander Teklit Tesfaye, Hanna Sopha, Angela Ayobi, Raul Zazpe,

Jhonatan Rodriguez-Pereira, Jan Michalicka, Ludek Hromadko, Siowwoon Ng,

Zdenek Spotz, Jan Prikryl, Jan M. Macak and Thierry Djenizian

$\mathrm{TiO}_{2}$ Nanotube Layers Decorated with $\mathrm{Al}_{2} \mathrm{O}_{3} / \mathrm{MoS}_{2} / \mathrm{Al}_{2} \mathrm{O}_{3}$ as Anode for Li-ion Microbatteries

with Enhanced Cycling Stability

Reprinted from: Nanomaterials 2020, 10, 953, doi:10.3390/nano10050953 . . . . . . . . . . . . . 7

Samarjeet Singh Siwal, Qibo Zhang, Changbin Sun and Vijay Kumar Thakur

Graphitic Carbon Nitride Doped Copper-Manganese Alloy as High-Performance Electrode

Material in Supercapacitor for Energy Storage

Reprinted from: Nanomaterials 2020, 10, 2, doi:10.3390/nano10010002 . . . . . . . . . . . 83

Maria Gombotz, Veronika Pregartner, Ilie Hanzu and H. Martin R. Wilkening

Fluoride-Ion Batteries: On the Electrochemical Stability of Nanocrystalline $\mathrm{La}_{0.9} \mathrm{Ba}_{0.1} \mathrm{~F}_{2.9}$ against Metal Electrodes

Reprinted from: Nanomaterials 2019, 9, 1517, doi:10.3390/nano9111517 . . . . . . . . . . . . 977

Hye-Min Lee, Kwan-Woo Kim, Young-Kwon Park, Kay-Hyeok An, Soo-Jin Park and Byung-Joo Kim

Activated Carbons from Thermoplastic Precursors and Their Energy Storage Applications

Reprinted from: Nanomaterials 2019, 9, 896, doi:10.3390/nano9060896 . . . . . . . . . . . . . 111 
Zhencai Dong, Chao Xu, Yongmin Wu, Weiping Tang, Shufeng Song, Jianyao Yao, Zhengyong Huang, Zhaoyin Wen, $\mathrm{Li}$ Lu and Ning Hu

Dual Substitution and Spark Plasma Sintering to Improve Ionic Conductivity of Garnet $\mathrm{Li}_{7} \mathrm{La}_{3} \mathrm{Zr}_{2} \mathrm{O}_{12}$

Reprinted from: Nanomaterials 2019, 9, 721, doi:10.3390/nano9050721 . . . . . . . . . . . . 127

Marta Cabello, Gregorio F. Ortiz, Pedro Lavela and José L. Tirado

On the Beneficial Effect of $\mathrm{MgCl}_{2}$ as Electrolyte Additive to Improve the Electrochemical Performance of $\mathrm{Li}_{4} \mathrm{Ti}_{5} \mathrm{O}_{12}$ as Cathode in $\mathrm{Mg}$ Batteries

Reprinted from: Nanomaterials 2019, 9, 484, doi:10.3390/nano9030484

Ibrahim A. Ahmad, Hyun-Kyung Kim, Suleyman Deveci and R. Vasant Kumar

Non-Isothermal Crystallisation Kinetics of Carbon Black- Graphene-Based

Multimodal-Polyethylene Nanocomposites

Reprinted from: Nanomaterials 2019, 9, 110, doi:10.3390/nano9010110 _ . . . . . . . . . . . . 153

Glaydson Simões dos Reis, Sylvia H. Larsson, Helinando Pequeno de Oliveira, Mikael Thyrel and Eder Claudio Lima

Sustainable Biomass Activated Carbons as Electrodes for Battery and Supercapacitors-A Mini-Review

Reprinted from: Nanomaterials 2020, 10, 1398, doi:10.3390/nano10071398 _ . . . . . . . . . . . 173

Ibrahim A. Ahmad, Hyun-Kyung Kim, Suleyman Deveci and R. Vasant Kumar

Correction: Ahmad, I.A., et al. Non-Isothermal Crystallisation Kinetics of Carbon Black-Graphene-Based Multimodal-Polyethylene Nanocomposites. Nanomaterials, 2019, 9, 100 Reprinted from: Nanomaterials 2019, 9, 392, doi:10.3390/nano9030392 . . . . . . . . . . . . . . 197 


\section{About the Editor}

Vijay Kumar Thakur is currently Professor of Biomass at the Biorefining and Advanced Materials Research Centre at SRUC, Edinburgh, UK, and also serves as Adjunct Professor at the Research School of Polymeric Materials, Jiangsu University, China; Visiting Professor at Shiv Nadar University, India; and Visitor at Cranfield University, UK. He has previously held faculty positions at Cranfield University, UK; Washington State University, USA; and Nanyang Technological University, Singapore. His research activities span the disciplines of Biorefining, Chemistry, Chemical Engineering, Manufacturing, Materials Science, and Nanotechnology as well as all aspects of Sustainable and Advanced Materials. He has been PI/Co-I on several projects sponsored by BAE Systems, EPSRC (EP/T024607/1), Royal Academy of Engineering (IAPP-33-24/01/2017; IAPP18-19 295), UKIERI (DST/INT/UK/P-164/2017), Innovate UK, and others. He has published over 200 SCI journal articles, 2 patents, 50 books, and 37 book chapters in areas concerning polymers, nanotechnology, and materials science. He serves on the editorial board of several SCI journals (e.g., Nature Scientific Reports, Industrial Crops \& Products, Journal of Renewable Materials, Advances in Polymer Technology, International Journal of Polymer Analysis and Characterization, Polymers for Advanced Technologies, Biomolecules, Nanomaterials, Surfaces and Interfaces, Sustainable Chemistry and Pharmacy, Current Opinion in Green and Sustainable Chemistry, and Nano-Structures \& Nano-Objects) as an Editor or Editorial Advisory Board member. 



\section{Preface to "Innovative Advanced Materials for Energy Storage and Beyond: Synthesis, Characterization and Applications"}

Recently, advanced materials have attracted considerable interest owing to their possible applications in different fields such as in catalysts, supercapacitors, capacitors, batteries, and other energy storage systems. Many of the 21st century's advancing technologies, e.g., electric vehicles (and hybrids), portable electronic devices, and renewable energy systems, drive the demand for high-performance energy storage systems. The increasing demand for processable, lightweight, flexible energy storage materials has motivated researchers from both academia and industry to develop and manufacture new materials that offer excellent properties depending on the targeted applications, including environmental applications. Building upon the different potential of the advanced materials for several applications, this book aims at presenting the current state-of-the-art in new advanced materials to address the various challenging issues researchers have been confronted with in this field for many applications, especially energy storage. This book features several chapters covering the most recent advances that address novel and state-of-the-art topics from active research in innovative advanced materials and hybrid materials, concerning not only their synthesis, preparation, and characterization but especially focusing on the applications of such materials in which they have exhibited outstanding performance. This book is targeted at readers from different disciplines, including materials science, chemistry, physics, and nanotechnology, among others.

In summary, this book advances not only our understanding of the emerging and significant role of innovative materials in several fields, but also of the numerous challenges and future research directions needed to fully explore their outstanding features in practical ways.

Vijay Kumar Thakur

Editor 



\title{
Editorial
}

\section{Innovative Advanced Materials for Energy Storage and Beyond: Synthesis, Characterisation and Applications}

\author{
Vijay Kumar Thakur ${ }^{1,2}$ \\ 1 Biorefining and Advanced Materials Research Center, Scotland's Rural College (SRUC), \\ Kings Buildings, Edinburgh EH9 3JG, UK; Vijay.Thakur@sruc.ac.uk \\ 2 Department of Mechanical Engineering, School of Engineering, Shiv Nadar University, \\ Uttar Pradesh 201314, India
}

Received: 7 September 2020; Accepted: 10 September 2020; Published: 11 September 2020

Recently, advanced materials have attracted considerable interest owing to their possible applications in different fields such as in catalysts, supercapacitors, capacitors, batteries and other energy storage systems [1-3]. Many of the 21st century's advancing technologies, e.g., electric vehicles (and hybrids), portable electronic devices, and renewable energy systems, drive the demand for high-performance energy storage systems [4]. The increasing demand for processable, lightweight, flexible energy storage materials has motivated researchers from both academia and industry to develop and manufacture new materials that offer excellent properties depending on the targeted applications, including environmental applications $[5,6]$. Building upon the different potential of the advanced materials for several applications, this Special Issue has been aimed at presenting the current state-of-the-art in new advanced materials to address the various challenging issues researchers have been confronted with in this field for many applications, especially for energy storage. In this issue, we have featured 12 papers that include one excellent review "Sustainable Biomass Activated Carbons as Electrodes for Battery and Supercapacitors-A Mini-Review" and one communication article. In this Special Issue, we have covered the most recent advances that address novel and state-of-the-art topics from active researchers in innovative advanced materials and hybrid materials, concerning not only their synthesis, preparation and characterisation, but especially focusing on the applications of such materials with outstanding performances. This Special Issue has targeted readers from different disciplines.

Comprehensive and fundamental research has been published in this Special Issue, with the very first contribution from University of Cambridge researchers entitled "Non-Isothermal Crystallisation Kinetics of Carbon Black-Graphene-Based Multimodal-Polyethylene Nanocomposites". In this work, Ahmad et al. have reported their findings on the carbon black-graphene reinforced High Density Polyethylene (HDPE) composites based on crystallisation kinetics [7]. In this work, the different types of composite materials were prepared using the varying ratio of the filler (carbon black/graphene) from 0.1 to $5 \mathrm{wt} . \%$ using the non-isothermal conditions. The graphene content along with the cooling rate was found to have a great impact on the crystallisation behaviour (the non-isothermal of the PE-g nanocomposites). It was found that the PE-g relative peak crystallisation temperature improved with the reduction in the cooling rate for a selected reinforcement (e.g., graphene content). At a specified cooling rate, it was found to increase progressively with an enhancement in the graphene concentration as well as transformation in the nucleation mechanism. It was concluded from the study that the polyethene (PE)-g nanocomposite's non-isothermal crystallisation behaviour depends considerably on both the content of graphene and the cooling rate.

Cabello et al., in their work, have explored the usage of $\mathrm{MgCl}_{2}$ as an electrolyte to increase the $\mathrm{Li}_{4} \mathrm{Ti}_{5} \mathrm{O}_{12}$ (LTO) electrochemical performance as the novel cathode in next-generation $\mathrm{Mg}$ batteries [8]. 
Various compositions of the electrolyte were investigated to study the usage of LTO electrodes in $\mathrm{Mg}$ batteries. It was demonstrated in this study that the first discharge, as well as charge profile, exhibited a plateau among $0.4-0.3 \mathrm{~V}-1.35 \mathrm{~V} \mathrm{Mg}{ }^{2+/} \mathrm{Mg}_{0}$, respectively, using a solution of $0.5 \mathrm{M}$ $\mathrm{Mg}(\mathrm{TFSI})_{2}+0.13 \mathrm{M} \mathrm{MgCl}_{2} \cdot 6 \mathrm{H}_{2} \mathrm{O}$ in DME. Subsequently, at $0.6-0.5 \mathrm{~V}$, the potential was sustained on further discharges. The authors reported to have attained 175 and $290 \mathrm{mAh} \mathrm{g}^{-1}$ capacities, corresponding to the establishment of $\mathrm{Mg}_{1.5} \mathrm{~L}_{14} \mathrm{Ti}_{5} \mathrm{O}_{12}$, and $\mathrm{Mg}_{2.5} \mathrm{Li}_{4} \mathrm{Ti}_{5} \mathrm{O}_{12}$, respectively. The authors also emphasised that further work is needed to advance the LTO capacity retention over a huge number of cycles. In another interesting work, Dong and co-workers have reported their findings on enhancing the Garnet $\mathrm{Li}_{7} \mathrm{La}_{3} \mathrm{Zr}_{2} \mathrm{O}_{12}$ (as promising electrolyte) ionic conductivity via spark plasma sintering and dual substitution [9]. In this work, the authors have explored the use of $\mathrm{Ta}$ for $\mathrm{Zr}$ and $\mathrm{Mg}$ for $\mathrm{Li}$ as the dual substitution strategy to analyse the structure and performance of garnet $\mathrm{Li}_{7} \mathrm{La}_{3} \mathrm{Zr}_{2} \mathrm{O}_{12}$. The garnet, having an arrangement of $\mathrm{Li}_{6.5} \mathrm{Mg}_{0.05} \mathrm{La}_{3} \mathrm{Zr}_{1.6} \mathrm{Ta}_{0.4} \mathrm{O}_{12}$, exhibited a single cubic phase with an ionic conductivity of $6.1 \times 10-4 \mathrm{~S} \mathrm{~cm}^{-1}$, which was better in comparison to the pristine $\mathrm{Li}_{6.6} \mathrm{La}_{3} \mathrm{Zr}_{1.6} \mathrm{Ta}_{0.4}$ $\mathrm{O}_{12}$. It was concluded from the study that the spark plasma sintering (SPS) densified the garnets and enhanced their ionic conductivities [9].

Lee et al., in their work, reported on the development of activated carbons from thermoplastic precursors and used them for energy storage applications [10]. The low-density polyethene (LDPE) was used to prepare the activated carbons (PE-AC) as novel electrode materials for an electric double-layer capacitor (EDLC). Methods such as carbonisation, cross-linking, and subsequent activation under different conditions were used. Different characterisation techniques, such as Cs-corrected field-emission transmission electron microscope, field-emission scanning electron microscope, and X-ray diffraction analysis, were used to analyse the surface morphologies as well as the structural characteristics. Brunauer-Emmett-Teller, Barrett-Joyner-Halenda equations and nonlocal density functional theory were used to confirm and characterise the nitrogen adsorption isotherm-desorption. The research demonstrated that with the enhancement in the activation time, total pore volume and the specific surface area and of the activated samples increased. The total pore volume $\left(0.86 \mathrm{~cm}^{3} / \mathrm{g}\right)$, specific surface area $\left(1600 \mathrm{~m}^{2} / \mathrm{g}\right)$, and mesopore volume $\left(0.3 \mathrm{~cm}^{3} / \mathrm{g}\right)$ of the PE-AC were observed and the PE-AC demonstrated a higher by $35 \%$ mesopore volume ratio. It was concluded from the study that the LDPE's structural characteristics and the activation conditions have been found to affect the electrode materials performance [10].

In addition to the Li-ion batteries, recently there has been a great thrust on exploring other alternatives. In this direction, ceramic fluorine ion conductors that exhibit much better ionic conductivity in comparison to others have recently emerged as the most promising materials and are currently being explored in fluorine-ion batteries (FIBs) as a new class of solid-state electrolytes. In the same line, we have an interesting article on fluoride-ion batteries. In this work, authors have reported on the nanocrystalline $\mathrm{La}_{0.9} \mathrm{Ba}_{0.1} \mathrm{~F}_{2.9}$ electrochemical stabilities against metal electrodes [11]. They analysed the electrochemical stability of numerous metal electrodes having the potential to act as current collector materials in the state-of-the-art fluorine-ion batteries. It was concluded from the study that most of the tested metals were not in stable contact with the $\mathrm{La}_{0.9} \mathrm{Ba}_{0.1} \mathrm{~F}_{2.9}$ and the FIBs, hence, the selection of current collectors will be an important issue [11]. Siwal et al. have, on the other hand, reported on the usage of graphitic carbon nitride $(\mathrm{gCN})$ as an innovative support material for the synthesis of copper-manganese alloy $\left(\mathrm{CuMnO}_{2}\right)$ [12]. Different characterisation techniques such as optical and spectroscopic were used to confirm the formation of $\mathrm{CuMnO}_{2}-\mathrm{gCN}$. The synthesised catalyst in the alkaline media was used as the energy storage material that demonstrated decent catalytic behaviour in supercapacitors applications. For example, the $\mathrm{CuMnO}_{2}-\mathrm{gCN}$ modified GCE demonstrated improved electrochemical performance in comparison to that of the $\mathrm{Cu}_{2} \mathrm{O}-\mathrm{gCN}$ electrode [12].

Tesfaye et al. have reported their work on the development of li-ion microbatteries [13]. In this work, the atomic layer deposition (ALD) method was used to decorate $\mathrm{MoS}_{2}$ in a homogenous way. Different techniques, such as energy dispersive X-ray spectroscopy, scanning transmission electron microscopy, chronopotentiometry and X-ray photoelectron spectroscopy, were used to investigate the 
electrochemical performance, morphology and structure of the $\mathrm{Al}_{2} \mathrm{O}_{3} / \mathrm{MoS}_{2} / \mathrm{Al}_{2} \mathrm{O}_{3}$-decorated $\mathrm{TiO}_{2}$ nanotube layers (TNTs). It was concluded from the study that TNTs decorated using $\mathrm{Al}_{2} \mathrm{O}_{3} / \mathrm{MoS}_{2} / \mathrm{Al}_{2} \mathrm{O}_{3}$, demonstrated as three times higher, and deliver aerial capacity in comparison to $\mathrm{MoS}_{2}$-decorated TNTs [13]. In another work, Al-Shehri et al. have reported their work on the design and development of nano-catalysts where authors have used noble metal nanoparticles to support mesoporous silica [14]. Authors were able to incorporate the $\mathrm{M}_{0}$ nanoparticles of (Pt $\mathrm{Rh}$, or $\mathrm{Au}$, Pd) having a 5-10 nm average size into the siliceous TUD-1 mesoporous material employing a sol-gel method that was surfactant-free. The $\mathrm{CO}$ oxidation was used at a low temperature to analyse the catalytic performance of synthesised nano-catalysts as a model system. The Au-TUD-1 catalyst among all the studied catalysts was found to demonstrate the highest catalytic performance followed by Pt-TUD-1 and Pd-TUD-1. On the other hand, at a higher temperature, the Rh-TUD-1 displayed the lowermost activity. It was reported that the developed catalysts exhibit salient features for promising applications in several fields, such as respiratory/escape masks for removing gases, air purification, devices for self-rescue breathing, refuge chambers, and numerous others [14].

Among various types of materials being used for energy storage in Li-Ion batteries, MXenes and 2D transition metal dichalcogenides are rapidly emerging as promising candidates for several applications including batteries and supercapacitors [15]. MXene is a new class of nanomaterials that were first described in 2011. MXene is generally derived from the ternary structured MAX phases and contain metal carbides, carbonitrides and nitrides. The latter currently comprise over 60 known phases. In this Special Issue, in an interesting paper, Nguyen et al. have reported their studies on the synthesis of new materials such as $\mathrm{W}_{2} \mathrm{C} / \mathrm{WS}_{2}$ alloy nanoflowers (NF) to be used as an anode in lithium-ion storage [16]. A well-established facile hydrothermal methodology was used to fabricate $\mathrm{W}_{2} \mathrm{C} / \mathrm{WS}_{2} \mathrm{NFs}$ at low temperature. The authors were able to control the particle size in the range of $200 \mathrm{~nm}^{-1} \mu \mathrm{m}$ and these NFs demonstrated hexagonal structures of $\mathrm{W}_{2} \mathrm{C}$ and $\mathrm{WS}_{2}$ along with high purity. Subsequently, these NF alloys were used in lithium-ion batteries (LIBs) as anode materials. It was concluded from the study that the prepared $\mathrm{W}_{2} \mathrm{C} / \mathrm{WS}_{2}$ alloy $\mathrm{NFs}$ showed great potential for applications in energy storage as well as conversion [16].

Along with lithium-ion batteries and supercapacitors, solar cells are another class of requisite energy source that are being explored as renewable alternatives to petrochemical resources. The unique properties of the solar cells include that they never use fossil fuels and also have zero contribution to greenhouse gases. However, to obtain the solar cell with the desired efficiency, the materials used in them should exhibit appropriate sunlight absorbing efficiency and ability to convert them to electricity. One of the best solutions for this is that photovoltaic power conversion efficiency can be realised through the combination of dissimilar solar cells with complementary absorption ranges.

Jiang et al., in their interesting work, have reported on the solution processing of CdTe nanocrystal (NC) solar cells [17]. In this work authors have reported on the development of 2,2',7,7'-tetrakis [N, N-di(4-methoxyphenyl) amino]-9,9'-spirobifluorene (Spiro) as a hole transfer layer (HTL) for solution-processed CdTe NC solar cells. It was reported from the study that through the annealing treatment there was an increment in the hole mobility as well as conductivity of the NC solar cells having Spiro HTL. With the annealing temperature in the range of $100-130^{\circ} \mathrm{C}$, simultaneous improvements were reported for CdTe NC solar cells in Voc, Jsc, and fill factor (FF). It was concluded from the study that the Jsc, Voc, and power conversion efficiency (PCE) of the developed NC solar cells increase simultaneously because of the reduced contact resistance as well as an improved built-in electric field [17].

In another interesting study, Llusco et al. have reported their findings on "the kinetic and thermodynamic Studies on Synthesis of Mg-doped $\mathrm{LiMn}_{2} \mathrm{O}_{4}$ Nanoparticles" [18]. In this work, different types of nanoparticles were synthesised using an ultrasound-assisted Pechini-type sol-gel process and the impact of $\mathrm{Mg}$ doping amount on thermal decomposition of the prepared precursors was investigated in detail. In this work, four types of thermal decomposition zones were well-defined using the synthesis precursors mass-loss profiles such as (i) dehydration, (2) polymeric matrix decomposition, 
(3) carbonate decomposition and formation of manganese oxide spinel, and (4) manganese oxide spinel decomposition. In this work, the polymeric matrix's thermal disintegration was recognised as the key zone encompassing fundamental reactions initiating $\mathrm{LiMn}_{2} \mathrm{O}_{4}$ spinel phase formation. Authors have also mentioned plans on studying the electrochemical properties of the synthesised materials in the follow-up work [18].

Lignocellulosic biomass-based materials, such as natural cellulosic fibres, straw, plants and wood, represent some of the most biorenewable raw materials for the development of numerous chemicals and materials [19-21]. Indeed, the development of high-value products from different biomass has become very necessary to advance the commercial sustainability and viability of future biomaterials and bioenergy processes [22]. In Biorefinery, generally, the carbohydrate fraction of the lignocellulose is converted into higher-quality products, whereas the residual lignin and other materials are discarded/burned. However, the different components of any biomass contain different components such as nanocrystal cellulose, hemicellulose and lignin that can be converted into valuable materials, for example, as electrode materials in battery and supercapacitors [23]. In this Special Issue, dos Reis et al., in their detailed review article, have summarised the recent developments on the usage of different types of biomass as electrode materials in batteries and supercapacitors in energy storage application [23]. Various pyrolysis and experimental conditions were described in detail for the production of biomass-derived carbon electrodes (CEs). It was concluded in this study that the biomass-based carbon materials represent a "sustainable way" for the uprising energy storage industry. A different challenge that one faces during these carbon electrode (CE) syntheses was also summarised [23].

To summarise, this Special Issue covers the most relevant advanced materials, such as sustainable carbonaceous materials for a wide range of energy storage applications, including batteries supercapacitors, solar cells and beyond. It is also believed that this Special Issue will provide new directions on advanced applications of different classes of advanced and functional materials.

Author Contributions: V.K.T. solely contributed to the editorial. Author has read and agreed to the published version of the manuscript.

Funding: This research received no external funding.

Acknowledgments: Together with the publisher, especially Erika Zhao, we would like to express our sincere thanks to all the co-authors for their outstanding contributions. Additionally, the time and efforts dedicated by the learned reviewers are highly appreciated. The endless support from the members of the Editorial Office of Nanomaterials for their help, promptness, administrative and editorial support during this long period from the point of designing the issue and throughout its implementation and completion is also highly acknowledged.

Conflicts of Interest: The author declares no conflict of interest.

\section{References}

1. Shrestha, R.G.; Maji, S.; Shrestha, L.K.; Ariga, K. Nanoarchitectonics of Nanoporous Carbon Materials in Supercapacitors Applications. Nanomaterials 2020, 10, 639. [CrossRef]

2. Liu, J.; Long, J.; Du, S.; Sun, B.; Zhu, S.; Li, J. Three-Dimensionally Porous Li-Ion and Li-S Battery Cathodes: A Mini Review for Preparation Methods and Energy-Storage Performance. Nanomaterials 2019, 9, 441. [CrossRef]

3. Wei, W.; Thakur, V.K.; Chew, Y.M.J.; Li, S. Towards next generation "smart" tandem catalysts with sandwiched mussel-inspired layer switch. Mater. Today Chem. 2020, 17, 100286. [CrossRef]

4. Siwal, S.S.; Zhang, Q.; Devi, N.; Thakur, V.K. Carbon-Based Polymer Nanocomposite for High-Performance Energy Storage Applications. Polymers 2020, 12, 505. [CrossRef]

5. Chen, S.; Skordos, A.; Thakur, V.K. Functional nanocomposites for energy storage: Chemistry and new horizons. Mater. Today Chem. 2020, 17, 100304. [CrossRef]

6. Thakur, S.; Sharma, B.; Verma, A.; Chaudhary, J.; Tamulevicius, S.; Thakur, V.K. Recent progress in sodium alginate based sustainable hydrogels for environmental applications. J. Clean. Prod. 2018, 198, 143-159. [CrossRef] 
7. Ahmad, I.A.; Kim, H.-K.; Deveci, S.; Kumar, R.V. Non-Isothermal Crystallisation Kinetics of Carbon BlackGraphene-Based Multimodal-Polyethylene Nanocomposites. Nanomaterials 2019, 9, 110. [CrossRef]

8. Cabello, M.; Ortiz, G.F.; Lavela, P.; Tirado, J.L. On the Beneficial Effect of $\mathrm{MgCl}_{2}$ as Electrolyte Additive to Improve the Electrochemical Performance of $\mathrm{Li}_{4} \mathrm{Ti}_{5} \mathrm{O}_{12}$ as Cathode in Mg Batteries. Nanomaterials 2019, 9, 484. [CrossRef]

9. Dong, Z.; Xu, C.; Wu, Y.; Tang, W.; Song, S.; Yao, J.; Huang, Z.; Wen, Z.; Lu, L.; Hu, N. Dual Substitution and Spark Plasma Sintering to Improve Ionic Conductivity of Garnet $\mathrm{Li}_{7} \mathrm{La}_{3} \mathrm{Zr}_{2} \mathrm{O}_{12}$. Nanomaterials 2019, 9, 721. [CrossRef]

10. Lee, H.-M.; Kim, K.-W.; Park, Y.-K.; An, K.-H.; Park, S.-J.; Kim, B.-J. Activated Carbons from Thermoplastic Precursors and Their Energy Storage Applications. Nanomaterials 2019, 9, 896. [CrossRef]

11. Gombotz, M.; Pregartner, V.; Hanzu, I.; Wilkening, H.M.R. Fluoride-Ion Batteries: On the Electrochemical Stability of Nanocrystalline La0.9Ba0.1F2.9 against Metal Electrodes. Nanomaterials 2019, 9, 1517. [CrossRef]

12. Siwal, S.S.; Zhang, Q.; Sun, C.; Thakur, V.K. Graphitic Carbon Nitride Doped Copper-Manganese Alloy as High-Performance Electrode Material in Supercapacitor for Energy Storage. Nanomaterials 2020, 10, 2. [CrossRef]

13. Tesfaye, A.T.; Sopha, H.; Ayobi, A.; Zazpe, R.; Rodriguez-Pereira, J.; Michalicka, J.; Hromadko, L.; Ng, S.; Spotz, Z.; Prikryl, J.; et al. $\mathrm{TiO}_{2}$ Nanotube Layers Decorated with $\mathrm{Al}_{2} \mathrm{O}_{3} / \mathrm{MoS}_{2} / \mathrm{Al}_{2} \mathrm{O}_{3}$ as Anode for Li-ion Microbatteries with Enhanced Cycling Stability. Nanomaterials 2020, 10, 953. [CrossRef]

14. Al-Shehri, B.M.; Shkir, M.; Khder, A.S.; Kaushik, A.; Hamdy, M.S. Noble Metal Nanoparticles Incorporated Siliceous TUD-1 Mesoporous Nano-Catalyst for Low-Temperature Oxidation of Carbon Monoxide. Nanomaterials 2020, 10, 1067. [CrossRef]

15. Das, L.; Habib, K.; Saidur, R.; Aslfattahi, N.; Yahya, S.M.; Rubbi, F. Improved Thermophysical Properties and Energy Efficiency of Aqueous Ionic Liquid/MXene Nanofluid in a Hybrid PV/T Solar System. Nanomaterials 2020, 10, 1372. [CrossRef]

16. Nguyen, T.P.; Kim, I.T. W2C/WS2 Alloy Nanoflowers as Anode Materials for Lithium-Ion Storage. Nanomaterials 2020,10, 1336. [CrossRef]

17. Jiang, Y.; Pan, Y.; Wu, W.; Luo, K.; Rong, Z.; Xie, S.; Zuo, W.; Yu, J.; Zhang, R.; Qin, D.; et al. Hole Transfer Layer Engineering for CdTe Nanocrystal Photovoltaics with Improved Efficiency. Nanomaterials 2020, 10, 1348. [CrossRef]

18. Llusco, A.; Grageda, M.; Ushak, S. Kinetic and Thermodynamic Studies on Synthesis of Mg-Doped LiMn2O4 Nanoparticles. Nanomaterials 2020, 10, 1409. [CrossRef]

19. Singha, A.S.; Thakur, V.K. Fabrication and Characterization of H. sabdariffa Fiber-Reinforced Green Polymer Composites. Polym.-Plast. Technol. Eng. 2009, 48, 482-487. [CrossRef]

20. Singha, A.S.; Thakur, V.K. Synthesis and Characterization of Pine Needles Reinforced RF Matrix Based Biocomposites. Available online: https://www.hindawi.com/journals/jchem/2008/395827/ (accessed on 7 September 2020).

21. Singha, A.S.; Thakur, V.K. Mechanical, Thermal and Morphological Properties of Grewia Optiva Fiber/Polymer Matrix Composites. Polym.-Plast. Technol. Eng. 2009, 48, 201-208. [CrossRef]

22. Ates, B.; Koytepe, S.; Ulu, A.; Gurses, C.; Thakur, V.K. Chemistry, Structures, and Advanced Applications of Nanocomposites from Biorenewable Resources. Chem. Rev. 2020, 120, 9304-9362. [CrossRef]

23. Dos Reis, G.S.; Larsson, S.H.; De Oliveira, H.P.; Thyrel, M.; Claudio Lima, E. Sustainable Biomass Activated Carbons as Electrodes for Battery and Supercapacitors-A Mini-Review. Nanomaterials 2020, 10, 1398. [CrossRef]

(C) 2020 by the author. Licensee MDPI, Basel, Switzerland. This article is an open access article distributed under the terms and conditions of the Creative Commons Attribution (CC BY) license (http://creativecommons.org/licenses/by/4.0/). 



\title{
Kinetic and Thermodynamic Studies on Synthesis of Mg-Doped $\mathrm{LiMn}_{2} \mathrm{O}_{4}$ Nanoparticles
}

\author{
Aleksei Llusco, Mario Grageda * and Svetlana Ushak \\ Departamento de Ingeniería Química y Procesos de Minerales and Center for Advanced Study of Lithium and \\ Industrial Minerals (CELiMIN), Universidad de Antofagasta, Campus Coloso, Av Universidad de Antofagasta, \\ 02800 Antofagasta, Chile; aleksei.llusco@uantof.cl (A.L.); svetlana.ushak@uantof.cl (S.U.) \\ * Correspondence: mario.grageda@uantof.cl
}

Received: 4 June 2020; Accepted: 13 July 2020; Published: 19 July 2020

\begin{abstract}
In this work, a first study on kinetics and thermodynamics of thermal decomposition for synthesis of doped $\mathrm{LiMn}_{2} \mathrm{O}_{4}$ nanoparticles is presented. The effect of $\mathrm{Mg}$ doping concentration on thermal decomposition of synthesis precursors, prepared by ultrasound-assisted Pechini-type sol-gel process, and its significance on nucleation and growth of $\mathrm{Mg}$-doped $\mathrm{LiMn}_{2} \mathrm{O}_{4}$ nanoparticles was studied through a method based on separation of multistage processes in single-stage reactions by deconvolution and transition state theory. Four zones of thermal decomposition were identified: Dehydration, polymeric matrix decomposition, carbonate decomposition and spinel formation, and spinel decomposition. Kinetic and thermodynamic analysis focused on the second zone. First-order Avrami-Erofeev equation was selected as reaction model representing the polymer matrix thermal decomposition. Kinetic and thermodynamic parameters revealed that $\mathrm{Mg}$ doping causes an increase in thermal inertia on conversion rate, and $\mathrm{CO}_{2}$ desorption was the limiting step for formation of thermodynamically stable spinel phases. Based on thermogravimetry experiments and the effect of $\mathrm{Mg}$ on thermal decomposition, an optimal two-stage heat treatment was determined for preparation of $\mathrm{LiMg}_{x} \mathrm{Mn}_{2-x} \mathrm{O}_{4}(\mathrm{x}=0.00,0.02,0.05,0.10)$ nanocrystalline powders as promising cathode materials for lithium-ion batteries. Crystalline structure, morphology, and stoichiometry of synthesized powders were characterized by XRD, FE-SEM, and AAS, respectively.
\end{abstract}

Keywords: Lithium-ion batteries; $\mathrm{LiMn}_{2} \mathrm{O}_{4}$ nanoparticles; Mg-doped; kinetic and thermodynamic; thermogravimetric analysis; Pechini-type sol-gel process

\section{Introduction}

Lithium-ion batteries (LIBs) have been widely used in consumer electronics because of their remarkable characteristics, such as high energy and power density, low self-discharge rate, no memory effect, and long lifetime. In addition, LIBs have become the most attractive candidates as electrochemical storage systems for stationary applications, as well as power sources for sustainable electromobility and back-up supply applications [1-4].

Currently, there are five main technologies of LIBs used for portable applications, electric vehicles (EVs), and power supply systems: $\mathrm{LiCoO}_{2}, \mathrm{LiNi}_{1-\mathrm{x}-\mathrm{y}} \mathrm{Mn}_{\mathrm{x}} \mathrm{Co}_{\mathrm{y}} \mathrm{O}_{2}, \mathrm{LiNi}_{0.8} \mathrm{Co}_{0.15} \mathrm{Al}_{0.05} \mathrm{O}_{2}, \mathrm{LiFePO}_{4}$, and $\mathrm{LiMn}_{2} \mathrm{O}_{4}$ [5-8]. Among the existing cathode materials, $\mathrm{LiMn}_{2} \mathrm{O}_{4}$ (LMO) has been considered as one of the most viable cathodes for large-scale applications due to its several advantages such as easy preparation, low cost, abundance of raw materials, environmental friendliness, high cell voltage, and high rate capacity [9-11].

LMO crystallizes into a cubic crystal structure of $\mathrm{Fd} \overline{3} \mathrm{~m}$ space group with $\mathrm{O}$ ions at (32e) sites forming a compact, cubic, close-packed array. Tetrahedral (8a) sites are occupied by $\mathrm{Li}^{+}$ions, while octahedral (16d) sites are occupied by $\mathrm{Mn}^{3+} / \mathrm{Mn}^{4+}$ ions. The remaining half of cationic octahedral sites in the structure are vacant (16c) sites [12]. $\mathrm{Li}^{+}$ions occupying tetrahedral sites (8a) share 
common faces with four adjacent empty octahedral sites in position (16c). This lattice provides a three-dimensional structure of (16c)-(8a)-(16c) transport paths through which lithium ions diffuse during insertion/deinsertion reactions $[13,14]$.

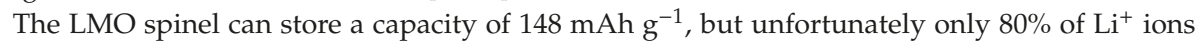
can be deinserted from cathode material at a potential of $3-4.3 \mathrm{~V} \mathrm{vs}$. $\mathrm{Li}^{+} / \mathrm{Li}$, providing a maximum practical capacity of $120 \mathrm{mAh} \mathrm{g}^{-1}$. About $20 \%$ of ions remain in the lattice and do not take part in insertion during cycling, resulting not only in low efficiency lithium utilization but also a potential safety problem when battery voltage exceeds cut-off voltage. In such abuse condition, remaining lithium ions in cathode material may be deinserted from the structure and deposited on anode surface, causing an internal short circuit in the battery $[15,16]$.

Additionally, LMO presents severe problems of fading capacity during cycling, especially when temperature is above $55^{\circ} \mathrm{C}$. Reasons potentially responsible for poor electrochemical performance are (1) dissolution of $\mathrm{Mn}$ attributed to a disproportionation reaction of $\mathrm{Mn}^{3+}$ ion on the surface of particles and subsequent deposition of soluble $\mathrm{Mn}^{2+}$ ion in electrolyte on the negative electrode, which could lead to a decrease in active $\mathrm{Mn}^{3+}$ content and an increase in cell impedance; (2) Jahn-Teller distortion responsible for irreversible phase transition of the LMO spinel from a cubic phase to a tetragonal phase resulting in structural damage so that it blocks $\mathrm{Li}^{+}$transport channels; and (3) high voltage-charge plateau and large amount of $\mathrm{Mn}^{4+}$ existing after full charge, which could accelerate electrolyte decomposition [17-19].

To solve these problems, several strategies were used by researchers: Partial replacement of Mn or O to stabilize host structure; surface modification to improve the interface; particle size, pore structure, and morphology to improve kinetic performance by reducing length of lithium ions' and electrons' transport paths [20]. Of all these approaches, (1) partial substitution of $\mathrm{Mn}^{3+}$ ions and (2) particle size control have proven to be effective in improving rate capability, cycle life, and discharge capacity at elevated temperatures of LMO [21].

Partial substitution of $\mathrm{Mn}^{3+}$ ions increases oxidation state of $\mathrm{Mn}$ in bulk LMO resulting in a strengthening of chemical bond between metal ions and oxide due to stronger chemical bonds of dopant, which prevent $\mathrm{Mn}^{3+}$ ions' dissolution in electrolyte through dismutation reaction, and suppression of Jahn-Teller distortion [22]. Cation doping includes $\mathrm{Li}^{+}, \mathrm{Ni}^{2+}, \mathrm{Zn}^{2+}, \mathrm{Mg}^{2+}, \mathrm{Al}^{3+}, \mathrm{Cr}^{3+}$, $\mathrm{Co}^{3+}, \mathrm{Ga}^{3+}, \mathrm{Ti}^{4+}$, etc. [23]. Among potential doping elements, a transition nonmetal like $\mathrm{Mg}$ attracted a lot of attention due to its good electronic conductivity and its ability to stabilize the LMO host crystal structure $[18,22,24-31]$ in addition to having many advantages, such as abundance, nontoxicity, low cost, and being lighter than transition metal elements.

On the other hand, particle size control at nanoscale has generated much attention for development of high-rate cathodes for LIBs, because nanometric or nanostructured materials facilitate rapid ion diffusion and electronic transport, increase electrode-electrolyte contact area, and improve electrolyte infiltration, allowing better power performance [32].

However, successful application of the above strategies for LMO spinel preparation depends largely on heat treatment conditions applied, i.e., temperature, atmosphere, and cooling rate, because these define the quality of powders through their physical characteristics, such as crystal morphology, exact composition, particle size, density, surface area, and their rechargeability into lithium ion battery cathodes. Therefore, particular attention must be placed in the determination of heat treatment parameters for synthesis of LMO spinels in order to obtain single-phase compounds with desired stoichiometry.

Pioneering research has studied in depth, by means of thermal analysis techniques, the decomposition of raw materials used in synthesis of LMO spinels by reaction in solid state and sol-gel, mainly, and thermal stability of spinel phase at high temperatures and different atmospheres [33-39]. However, only in [40] a dynamic study was carried out to determine kinetic parameters that were used as a theoretical basis to establish the optimal heat treatment conditions for 
synthesis of a stoichiometric LMO spinel by coprecipitation method, while no research was carried out on study of kinetics' synthesis of doped LMO spinels.

Due to lack of theoretical information on the synthesis of doped LMO spinels, the main objective of this work was to develop a method of kinetic and thermodynamic analysis based on separation of multistage processes into one-stage reactions by deconvolution of the conversion rate curves obtained from thermogravimetry measurements. This allows for quantifying the effect of magnesium doping on thermal decomposition of precursors obtained by ultrasound-assisted, Pechini-type sol-gel process (PSG) at different concentrations of magnesium $(x=0.00,0.02,0.05,0.10)$.

The method developed here comprises (1) deconvolution of conversion rate curves, (2) kinetic analysis of resulting individual curves to obtain a reaction model and kinetic parameters, (3) kinetic analysis of entire multistage process using the data obtained in each of the single-stage reactions, and (4) calculation of thermodynamic functions by means of transition state theory.

PSG is a solution technique used in preparation of materials that emerged as an alternative to conventional solid-state chemistry. This synthesis method is characterized by its ability to produce complex inorganic materials such as ternary and quaternary oxides at low process temperatures and shorter synthesis times. In addition, it offers several advantages, viz., low cost, homogeneous mixing at molecule level, low processing temperatures, use of an aqueous-based processing system, and proper control of stoichiometry, morphology, and particle size [41-43]. Application of the PSG method for preparation of LMO compounds was reported in previous investigations. Liu et al. [44] studied the influence of calcination temperature and effect of Ni doping on formation of LMO phase and determined that low calcination temperatures and high Ni ion concentration could favor formation of locally disordered crystallographic structures that would improve their cyclability and electrochemical performance. Han et al. [45] described effects of molar ratio of ethylene glycol (EG) to citric acid (CA) and calcination temperature on physicochemical and electrochemical properties of LMO. They found that at a temperature of $800{ }^{\circ} \mathrm{C}$, the increase in EG/CA ratio resulted in an increase in homogeneity and surface area of spinel powders as well as their specific capacity and cyclability. Son et al. [46] reported the improvement of $\mathrm{LMO}$ electrochemical performance by partial replacement of $\mathrm{Mn}$ by $\mathrm{Co}, \mathrm{Cu}$, and $\mathrm{Ga}$, which improved structural stability due to an increase in average Mn oxidation state, and surface modification by Ag particles' coating, which in turn improved electrical conductivity and reduced surface overpotential of cathodic powders. In addition, they established that cyclability of cathodic materials was maintained regardless of synthesis temperature and particle size. Xiong et al. [47] studied $\mathrm{LMO}$ doping with multiple cations $(\mathrm{Cu}, \mathrm{Al}$, and $\mathrm{Ti})$ and established that multiple doping was effective in improving retention capacity at temperatures of $25{ }^{\circ} \mathrm{C}$ to $50{ }^{\circ} \mathrm{C}$, maintaining a high rate capability up to $12 \mathrm{C}$ (C represents the numerical value of rated capacity of a battery, in $\mathrm{Ah}$ ) and reducing Mn dissolution. Amaral et al. [48] reported time and temperature effects of thermal treatment for Ga- and Al-doped LMO synthesis. They identified spinel phase formation at a temperature of $750{ }^{\circ} \mathrm{C}$ for a calcination time of $2 \mathrm{~h}$ and determined that the specific capacity of doped ones was lower than pure spinel. Here, PSG was useful to apply two improvement strategies, such as (1) particle size control at nanometer scale and (2) partial substitution of $\mathrm{Mn}^{3+}$ ions with $\mathrm{Mg}^{2+}$ ions, to stabilize host structure and improve electrochemical performance of the LMO spinel as a cathode material for LIBs.

Sources of $\mathrm{Li}$ and $\mathrm{Mg}$, used as raw materials in the preparation of precursors, such as $\mathrm{Li}_{2} \mathrm{CO}_{3}$ (Albemarle) and $\mathrm{Mg}(\mathrm{OH})_{2}$ (obtained from the bischofite $\mathrm{MgCl}_{2}{ }^{*} 6 \mathrm{H}_{2} \mathrm{O}$, which is an industrial waste derived from lithium production), respectively, came from the Salar de Atacama, Chile.

\section{Materials and Methods}

\subsection{Synthesis of $\mathrm{Mg}$-Doped $\mathrm{LiMn}_{2} \mathrm{O}_{4}$ Nanoparticles}

Synthesis precursors were prepared by ultrasound-assisted, Pechini-type sol-gel method. The raw materials used as a source of metal ions were lithium carbonate $\mathrm{Li}_{2} \mathrm{CO}_{3}$ (battery grade $\geq 99.5 \%$, Albemarle, Antofagasta, Chile), manganese acetate tetrahydrate $\mathrm{Mn}\left(\mathrm{CH}_{3} \mathrm{CO}_{2}\right)_{2}{ }^{*} 4 \mathrm{H}_{2} \mathrm{O}(\geq 99 \%$, 
Sigma Aldrich, St. Louis, MO, United States), and magnesium hydroxide $\mathrm{Mg}(\mathrm{OH})_{2}(\geq 99 \%$, CELIMIN, Antofagasta, Chile). Citric acid $\mathrm{C}_{3} \mathrm{H}_{4} \mathrm{OH}(\mathrm{COOH})_{3}(\mathrm{CA}$, Sigma Aldrich, St. Louis, MO, United States) and ethylene glycol $\mathrm{HOC}_{2} \mathrm{H}_{4} \mathrm{OH}$ (EG, Sigma Aldrich, St. Louis, MO, United States) were used as complexing and polymerization agents, respectively.

An initial solution was obtained by dissolving metal ion precursors in stoichiometric molar amounts in deionized water, taking into account four different concentrations of magnesium doping $(x=0.00,0.02,0.05,0.10)$ and an excess of $5 \%$ lithium ions. Then, an equimolar solution of CA and EG in deionized water was added. The molar ratio between metal ions and CA was equal to 1:1. Both aqueous solutions were mixed by mechanical agitation at room temperature.

The resulting solution $\mathrm{pH}$ was adjusted to 6 by the addition of a $30 \mathrm{wt}$. \% solution of ammonia $\mathrm{NH}_{3}$ in water. Increase in $\mathrm{pH}$ guaranteed deprotonation of two carboxylic groups from the CA (middle carboxylic group with $\mathrm{p} K_{\mathrm{a} 1}=3.13$ and terminal carboxylic group with $\mathrm{p} K_{\mathrm{a} 2}=4.76 ; \mathrm{p} K_{\mathrm{a} 1}$ and $\mathrm{p} K_{\mathrm{a} 2}$ are acid dissociation constants) facilitating the formation of stable chelate complexes between metal ions and $\mathrm{CA}$, in addition to preventing segregation of metal ions as precipitates.

The "sol" obtained was heated to $80^{\circ} \mathrm{C}$ and then sonicated for $2.5 \mathrm{~h}$ at a frequency of $37 \mathrm{KHz}$ and a power of $120 \mathrm{~W}$ by means of an ultrasonic bath (Elmasonic P 30H, Singen, Germany). Simultaneously, continuous mixing was maintained on the "sol" through a mechanical agitator at a rotation speed of $220 \mathrm{rpm}$. Cavitation was used to catalyze the condensation reaction between metal citrate complexes and EG. Condensation process is schematically represented in Figure 1.

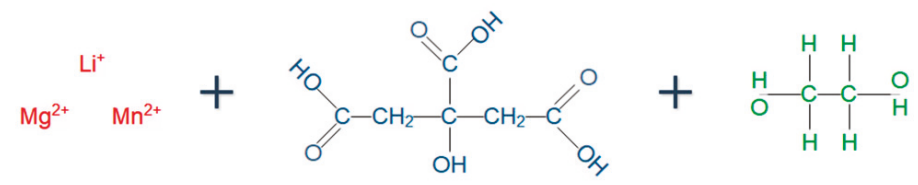

Metal ions

Citric acid

Ethylene glycol

$\mathrm{pH}=6, \mathrm{NH}_{4} \mathrm{OH}$

$\mathrm{Mg}^{2+}-\mathrm{O}_{\mathrm{C}}$

Ester

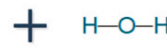

Water

Figure 1. Schematic representation of condensation process between metal cations $\left(\mathrm{Li}^{+}, \mathrm{Mg}^{2+}\right.$, and $\mathrm{Mn}^{2+}$ ), citric acid, and ethylene glycol from the initial stage of the Pechini-type sol-gel method.

After the mixing process, the "sol" was heated at a constant temperature of $120^{\circ} \mathrm{C}$ by means of a heating plate (IKA C-MAG HS 10 digital, Staufen, Germany). Then, viscosity of the "sol" increased dramatically due to the polyesterification process that resulted in formation of a "gel", which immobilizes metal complexes in a rigid organic polymer network.

The "gel" obtained was dried in an oven (Thermo Scientific Thermolyne F47900, Waltham, MA, United States) at a temperature of $170{ }^{\circ} \mathrm{C}$ for $18 \mathrm{~h}$ resulting in formation of a rigid and fragile porous structure or "xerogel". The "xerogel" or synthesis precursor obtained was ground in an agate mortar for subsequent thermogravimetric (TG) analysis. Precursors with magnesium concentrations of 0.00 , $0.02,0.05$, and 0.10 were identified as SP, SPMg-1, SPMg-2, and SPMg- 3 , respectively.

A two-stage heat treatment was programmed in a muffle furnace (Nabertherm L 40/12/B410, Lilienthal, Germany), based on results obtained from TG analysis, to obtain $\mathrm{LiMg}_{x} \mathrm{Mn}_{2-\mathrm{x}} \mathrm{O}_{4}(\mathrm{x}=0.00$, 
$0.02,0.05,0.10)$ nanocrystalline cathode powders. At the first stage, synthesis precursors were calcined in air at $500{ }^{\circ} \mathrm{C}$ for $4 \mathrm{~h}$ and at the second stage, spinel oxides were sintered in air at $750{ }^{\circ} \mathrm{C}$ for $12 \mathrm{~h}$.

Obtained cathode material powders were identified as LMO, LMOMg-1, LMOMg-2, and LMOMg-3 for the magnesium doping concentrations of $0.00,0.02,0.05$ and 0.10 , respectively.

\subsection{Materials' Characterization}

Thermogravimetric analysis (TG, NETZSCH STA 449 F3 Jupiter, Selb, Germany) was used to examine the thermal decomposition of synthesis precursors. Samples' mass was recorded at a heating rate of $10{ }^{\circ} \mathrm{C} \mathrm{min}-1$ from room temperature $25^{\circ} \mathrm{C}$ to $950{ }^{\circ} \mathrm{C}$ in a dynamic atmosphere of extra pure synthetic air.

A $4 \mathrm{M} \mathrm{HCl}$ solution was used to digest spinel powder in solution with a solid-to-liquid ratio of $1 \mathrm{~g}$ : $50 \mathrm{~mL}$, and then the lithium, magnesium, and manganese contents of cathode materials were determined by atomic absorption spectrometry (AAS, VARIAN SpectrAA-220 FS-Agilent, Santa Clara, CA, United States) using air/acetylene flame. Powder X-ray diffraction (XRD, Bruker D8 Advance-A25, Billerica, MA, United States) was used to identify the crystalline phase of prepared materials. The diffraction patterns were recorded using a radiation source from $\mathrm{CuK} \alpha(\lambda=1.5406 \AA)$ over a range of $2 \theta$ of $2-70^{\circ}$ with a step size of $0.02^{\circ}$. On the basis of the $X$-ray diffraction data, structural parameters of synthetized spinels were refined using the Rietveld method as implemented in the FullProf suite.

Particle size and morphology of powder samples were studied by field emission scanning electron microscopy (FE-SEM, Hitachi SU5000, Tokyo, Japan).

\subsection{Kinetic Principle of Solid-State Reactions}

Kinetics of a thermally stimulated solid-state reaction are defined through the conversion rate $\frac{\mathrm{d} \alpha}{\mathrm{dt}}$, which is described by two independent functions: $k(T)$ represents the influence of temperature and $f(\alpha)$ represents the influence of conversion [36-38], as shown in Equation (1)

$$
\frac{\mathrm{d} \alpha}{\mathrm{dt}}=\mathrm{k}(\mathrm{T}) \mathrm{f}(\alpha)
$$

where $\alpha$ is the degree of conversion of reaction from 0 to 1 as process proceeds from start to finish, $T$ is the absolute temperature $(K), k(T)$ is a temperature-dependent rate constant $\left(s^{-1}\right)$, and $f(\alpha)$ is the differential function of conversion or reaction model that describes the rate-limiting stage mechanism of different types of solid-state reactions.

Reaction rate dependence on temperature $\mathrm{k}(\mathrm{T})$ was parameterized by Arrhenius' law [49,50]:

$$
\mathrm{k}(\mathrm{T})=\mathrm{A} \exp \left(-\frac{\mathrm{E}_{\mathrm{a}}}{\mathrm{RT}}\right)
$$

where $\mathrm{A}$ is the pre-exponential factor $\left(\mathrm{s}^{-1}\right), \mathrm{E}_{\mathrm{a}}$ is the activation energy $\left(\mathrm{kJ} \mathrm{mol}^{-1}\right), \mathrm{R}$ is the universal gas constant $\left(8.314 \mathrm{~J} \mathrm{~mol}^{-1} \mathrm{~K}^{-1}\right)$, and $\mathrm{T}$ is the absolute temperature.

The Sestak-Berggren (SB) equation [51,52] was applied to determine reaction models $f(\alpha)$ that describe the behavior of decomposition kinetics of synthesis precursors.

$$
f(\alpha)=(1-\alpha)^{n} \alpha^{m}[-\ln (1-\alpha)]^{p}
$$

where $n, m$, and $p$ are kinetic exponents. The appropriate combination of $n, m$, and $p$ allows numerous mathematical descriptions of different empirical kinetic models to be expressed. The $(1-\alpha)^{\mathrm{n}}, \alpha^{\mathrm{m}}$, and $[-\ln (1-\alpha)]^{\mathrm{p}}$ represent three different mechanisms of interface reaction, diffusion, and nucleation, respectively. Different $\mathrm{SB}(\mathrm{n}, \mathrm{m}, \mathrm{p})$ models commonly used to describe kinetics of solid-state reactions can be found in literature $[53,54]$. 
Under non-isothermal heating conditions, linear change in temperature over time is represented by [55]:

$$
\beta=\frac{\mathrm{dT}}{\mathrm{dt}}=\mathrm{constant}
$$

where $\beta$ is the heating rate.

Entering Equations (2) to (4) in Equation (1), the kinetic equation is obtained under a non-isothermal linear heating program:

$$
\frac{\mathrm{d} \alpha}{\mathrm{dT}}=\frac{\mathrm{A}}{\beta} \exp \left(-\frac{\mathrm{E}_{\mathrm{a}}}{\mathrm{RT}}\right)(1-\alpha)^{\mathrm{n}} \alpha^{\mathrm{m}}[-\ln (1-\alpha)]^{\mathrm{p}} .
$$

\subsection{Deconvolution Function}

The Fraser-Suzuki equation [56] (asymmetric Gaussian equation) was used as fitting function for the deconvolution process of conversion rate curves representing complex solid-state reactions as an overlap of individual processes.

$$
\mathrm{Y}=\mathrm{a}_{0} \exp \left[-\ln 2\left[\frac{\ln \left(1+2 \mathrm{a}_{3} \frac{\mathrm{X}-\mathrm{a}_{1}}{\mathrm{a}_{2}}\right)}{\mathrm{a}_{3}}\right]^{2}\right]
$$

where $\mathrm{a}_{0}, \mathrm{a}_{1}, \mathrm{a}_{2}$, and $\mathrm{a}_{3}$ are the amplitude, position, half-width, and asymmetry of the curve, respectively.

\section{Results and Discussion}

\subsection{Thermogravimetric Data Analysis}

Initially, experimental data of thermogravimetry (TG) and its derivatives (DTG) were normalized using Equations (7) and (8), respectively, in order to standardize mass-loss curves of precursors with different magnesium concentrations. Normalized TG was represented by $M$, where $m$ is the mass in time $(\mathrm{t})$ and $\mathrm{m}_{\mathrm{o}}$ the initial mass at $25{ }^{\circ} \mathrm{C}$. Normalized DTG was represented by $\frac{\mathrm{dM}}{\mathrm{dt}}$, where $\frac{\mathrm{dm}}{\mathrm{dt}}$ corresponds to experimental DTG in $\mathrm{mg} \mathrm{s}^{-1}$ :

$$
\begin{gathered}
\mathrm{M}=\frac{\mathrm{m}}{\mathrm{m}_{\mathrm{o}}} \cdot 100 \% \\
\frac{\mathrm{dM}}{\mathrm{dt}}=\frac{\mathrm{dm}}{\mathrm{dt}} \frac{1}{\mathrm{~m}_{\mathrm{o}}} \cdot 100 \%=\mathrm{DTG} \frac{1}{\mathrm{~m}_{\mathrm{o}}} \cdot 100 \% .
\end{gathered}
$$

To perform kinetic analysis, experimental conversion $\alpha_{\exp }[50,57,58]$ and conversion rate $\left(\frac{\mathrm{d} \alpha}{\mathrm{dt}}\right)_{\exp }$ through Equations (9) and (10) were determined, respectively, where $M_{0}, M$, and $M_{f}$ are standardized masses at the beginning, at time $t$, and at reaction end, respectively.

$$
\begin{gathered}
\alpha_{\exp }=\frac{M_{o}-M}{M_{o}-M_{f}} \\
\left(\frac{d \alpha}{d t}\right)_{\exp }=-\frac{d M}{d t} \frac{1}{\left(M_{o}-M_{f}\right)}
\end{gathered}
$$

\subsection{Thermal Decomposition of Synthesis Precursors}

Considering different magnesium concentrations used as doping agent, the thermal decomposition of synthesis precursors, at a heating rate of $10{ }^{\circ} \mathrm{C} \mathrm{min}^{-1}$ in a temperature range of $25{ }^{\circ} \mathrm{C}$ to $950{ }^{\circ} \mathrm{C}$, was divided into four roughly separate zones: (1) Dehydration, (2) polymeric matrix decomposition, (3) carbonate decomposition and spinel formation, and (4) spinel decomposition. Figure 2a,b presents 
normalized mass-loss curves $(\mathrm{M})$ and its derivative $\left(\frac{\mathrm{dM}}{\mathrm{dt}}\right)$ as a function of temperature according to Equations (1) and (2), respectively.

(a)
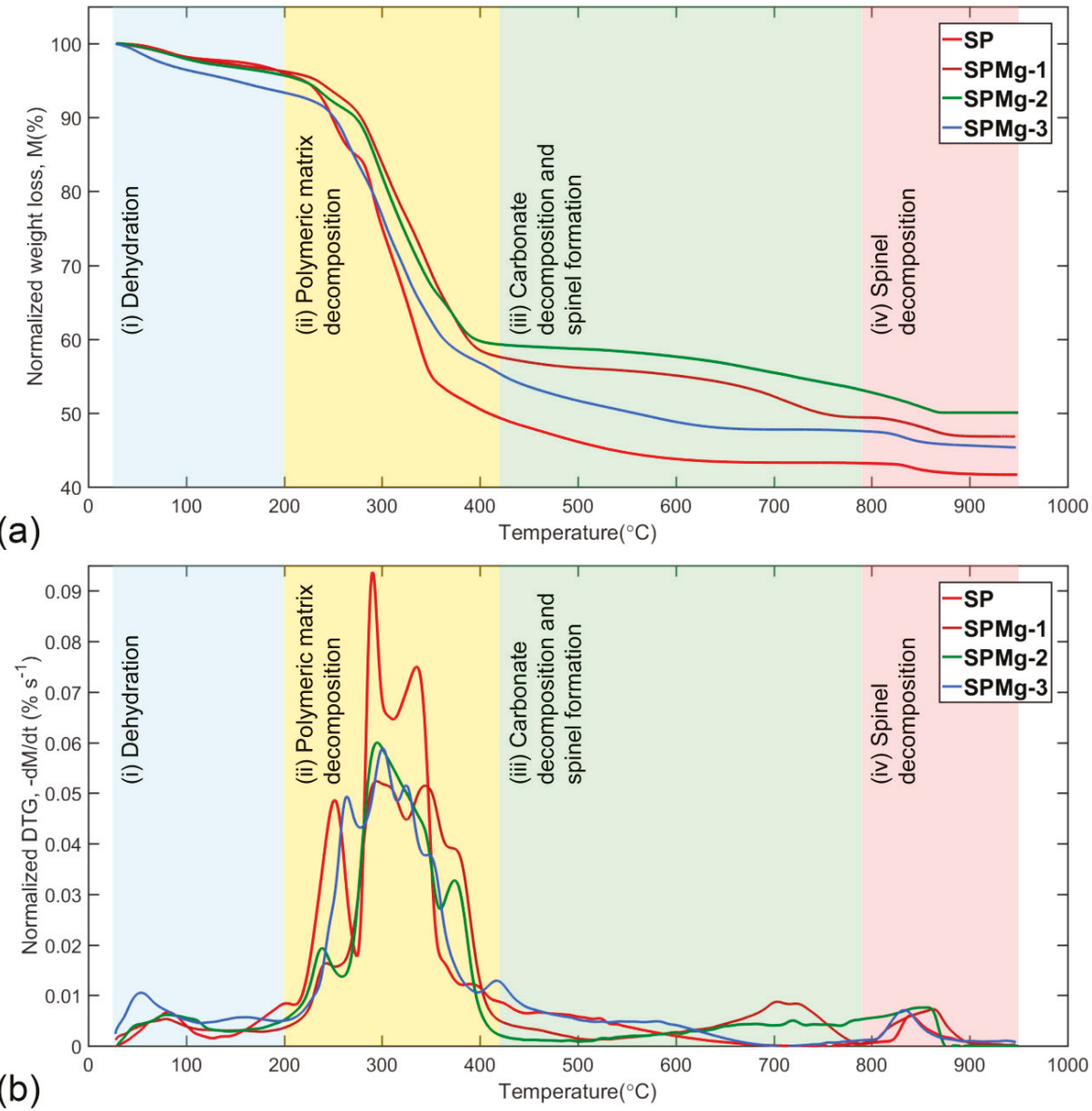

Figure 2. Normalized curves of (a) mass loss, M, and (b) DTG, as a function of temperature, of thermal decomposition of synthesis precursors divided into four zones: (1) Dehydration, (2) polymeric matrix decomposition, (3) carbonate decomposition and spinel formation, and (4) spinel decomposition.

Dehydration: The first zone $\left(25^{\circ} \mathrm{C}\right.$ to $\left.200{ }^{\circ} \mathrm{C}\right)$ is related to the dehydration reaction, where the mass loss of the residual and adsorbed water of the synthesis precursors was recorded in a range of $2.19 \%$ to $6.45 \%$ in normalized TG curves (Figure $2 \mathrm{a}$ ), and was observed as a small and wide peak in normalized DTG curves (Figure $2 \mathrm{~b}$ ) in a mass-loss rate range of $0.53 \times 10^{-2} \% \mathrm{~s}^{-1}$ to $1.05 \times 10^{-2} \% \mathrm{~s} \mathrm{~s}^{-1}$ (Table 1). A steeper mass loss observed for the SPMg-3 precursor was related to a decrease in precursor density. This was due to the fact that high $\mathrm{Mg}$ concentration decreases precursor density, favoring formation of a more porous structure than that which could occlude a greater quantity of volatiles during gel-drying process. 
Table 1. Percentages and maximum rates of mass loss of the thermal decomposition zones of the synthesis precursors.

\begin{tabular}{|c|c|c|c|c|c|}
\hline & & Stage 1 & Stage 2 & Stage 3 & Stage 4 \\
\hline Sample & Temperature range & $25^{\circ} \mathrm{C}-200^{\circ} \mathrm{C}$ & $200^{\circ} \mathrm{C}-420^{\circ} \mathrm{C}$ & $420^{\circ} \mathrm{C}-790^{\circ} \mathrm{C}$ & $790^{\circ} \mathrm{C}-950^{\circ} \mathrm{C}$ \\
\hline \multirow{2}{*}{$\begin{array}{c}S P \\
x=0.00\end{array}$} & Mass loss (\%) & 2.19 & 46.02 & 8.51 & 1.61 \\
\hline & $\begin{array}{l}\text { Max. decomposition } \\
\text { rate }\left(\% \mathrm{~s}^{-1}\right)\end{array}$ & $0.67 \times 10^{-2}$ & $9.37 \times 10^{-2}$ & $1.22 \times 10^{-2}$ & $0.6 \times 10^{-2}$ \\
\hline \multirow{2}{*}{$\begin{array}{l}\text { SPMg-1 } \\
x=0.02\end{array}$} & Mass loss (\%) & 3.35 & 40.65 & 6.6 & 2.58 \\
\hline & $\begin{array}{l}\text { Max. decomposition } \\
\text { rate }\left(\% \mathrm{~s}^{-1}\right)\end{array}$ & $0.53 \times 10^{-2}$ & $5.24 \times 10^{-2}$ & $0.87 \times 10^{-2}$ & $0.73 \times 10^{-2}$ \\
\hline \multirow{2}{*}{$\begin{array}{l}\text { SPMg-2 } \\
x=0.05\end{array}$} & Mass loss (\%) & 3.13 & 38.2 & 4.94 & 3.69 \\
\hline & $\begin{array}{l}\text { Max. decomposition } \\
\text { rate }\left(\% \mathrm{~s}^{-1}\right)\end{array}$ & $0.61 \times 10^{-2}$ & $6 \times 10^{-2}$ & $0.5 \times 10^{-2}$ & $0.76 \times 10^{-2}$ \\
\hline \multirow{2}{*}{$\begin{array}{l}\text { SPMg-3 } \\
x=0.10\end{array}$} & Mass loss (\%) & 6.45 & 36.61 & 9.16 & 2.31 \\
\hline & $\begin{array}{c}\text { Max. decomposition } \\
\text { rate }\left(\% \mathrm{~s}^{-1}\right)\end{array}$ & $1.05 \times 10^{-2}$ & $5.89 \times 10^{-2}$ & $1.29 \times 10^{-2}$ & $0.71 \times 10^{-2}$ \\
\hline
\end{tabular}

Decomposition of polymeric matrix: The second zone $\left(200{ }^{\circ} \mathrm{C}\right.$ to $\left.420^{\circ} \mathrm{C}\right)$ is mainly associated with removal of the organic part of synthesis precursors, which contains the metal ions in a homogeneous composition in a polymeric network with a rigid structure.

In this zone, synthesis precursors record the highest mass loss in normalized TG curves of Figure $2 \mathrm{a}$, between $36.61 \%$ and $46.02 \%$, as a result of thermal decomposition process of the polymeric matrix that takes place through complex solid-state reactions and whose mass-loss rates overlap, as shown in Figure $2 b$, with maximum values of $5.24 \times 10^{-2} \% \mathrm{~s}^{-1}$ to $9.37 \times 10^{-2} \% \mathrm{~s}^{-1}$ (Table 1).

Thermal decomposition of polymeric matrix is divided into two parts. The first part comprises only endothermic transformations in dry air such as evolution of $\mathrm{NH}_{3}$ (Equation (11)) which removes the concentration of $\mathrm{NH}^{4+}$ species that are part of metal complex [59], and decomposition of citrate anion through evolution of $\mathrm{H}_{2} \mathrm{O}$ (Equation (12)) and $\mathrm{CO}_{2}$ (Equation (13)) [60-62], while the second part comprises exothermic transformations in dry air such as thermo-oxidative decomposition of organic composition (Equations (14)-(16)) [63].

- Ammonia evolution reaction:

$$
2 \mathrm{NH}_{4}^{+}+\frac{1}{2} \mathrm{O}_{2}+\text { heat } \rightarrow 2 \mathrm{NH}_{3}+\mathrm{H}_{2} \mathrm{O}
$$

- Dehydroxylation reaction:

$$
\begin{gathered}
\mathrm{Li}_{2}\left(\mathrm{Mg}_{\mathrm{x}} \mathrm{Mn}_{2-\mathrm{x}}\right)_{2}\left(\mathrm{C}_{6} \mathrm{H}_{6} \mathrm{O}_{7}\right)_{5}+\text { heat } \rightarrow \mathrm{Li}_{2}\left(\mathrm{Mg}_{\mathrm{x}} \mathrm{Mn}_{2-\mathrm{x}}\right)_{2}\left(\mathrm{C}_{6} \mathrm{H}_{4} \mathrm{O}_{6}\right)_{5}+5 \mathrm{H}_{2} \mathrm{O} \\
\text { citrate complex aconitate complex }
\end{gathered}
$$

- Decarboxylation reaction:

$$
\begin{gathered}
\mathrm{Li}_{2}\left(\mathrm{Mg}_{\mathrm{x}} \mathrm{Mn}_{2-\mathrm{x}}\right)_{2}\left(\mathrm{C}_{6} \mathrm{H}_{4} \mathrm{O}_{6}\right)_{5}+\text { heat } \rightarrow \mathrm{Li}_{2}\left(\mathrm{Mg}_{\mathrm{x}} \mathrm{Mn}_{2-\mathrm{x}}\right)_{2}\left(\mathrm{C}_{5} \mathrm{H}_{4} \mathrm{O}_{4}\right)_{5}+5 \mathrm{CO}_{2} \\
\text { aconitate complex itaconate/citraconate complex }
\end{gathered}
$$

- Thermo-oxidative reaction of organic composition:

$$
\begin{aligned}
& 2 \mathrm{Li}_{2}\left(\mathrm{C}_{5} \mathrm{H}_{4} \mathrm{O}_{4}\right)+9 \mathrm{O}_{2} \rightarrow 2 \mathrm{Li}_{2} \mathrm{O}+10 \mathrm{CO}_{2}+4 \mathrm{H}_{2} \mathrm{O}+\text { heat } \\
& 2 \mathrm{Mg}\left(\mathrm{C}_{5} \mathrm{H}_{4} \mathrm{O}_{4}\right)+9 \mathrm{O}_{2} \rightarrow 2 \mathrm{MgO}+10 \mathrm{CO}_{2}+4 \mathrm{H}_{2} \mathrm{O}+\text { heat }
\end{aligned}
$$




$$
4 \mathrm{Mn}\left(\mathrm{C}_{5} \mathrm{H}_{4} \mathrm{O}_{4}\right)+19 \mathrm{O}_{2} \rightarrow 2 \mathrm{Mn}_{2} \mathrm{O}_{3}+20 \mathrm{CO}_{2}+8 \mathrm{H}_{2} \mathrm{O}+\text { heat }
$$

As a consequence of dehydroxylation and subsequent decarboxylation of the metal complex, $\mathrm{Li}^{+}$, $\mathrm{Mg}^{2+}$, and $\mathrm{Mn}^{2+}$ ions are uncoordinated from their ligands and are available to form mixed oxide with spinel structure after organic composition combustion of precursors. However, an intermediate phase composed of oxides and carbonates was obtained instead of a pure spinel phase.

Formation of intermediate carbonates occurs as a result of chemisorption of $\mathrm{CO}_{2}$, a volatile product from decomposition of organics, by a fraction of metal oxides. This behavior was clearly observed in Figure $2 \mathrm{~b}$ as a long tail after the last peak of polymeric matrix decomposition [64-66].

Carbonate decomposition and spinel formation: The third zone $\left(420^{\circ} \mathrm{C}\right.$ to $\left.790{ }^{\circ} \mathrm{C}\right)$ comprises decomposition of the intermediate phase carbonates to obtain a stable oxide phase with spinel structure.

With increasing temperature, additional heat applied to samples induces desorption of $\mathrm{CO}_{2}$ from metal oxides and formation of target phase as a solid-state solution of lithium, magnesium, and manganese oxides (Equation (17)). Therefore, $\mathrm{CO}_{2}$ removal from precursors was the only limiting step for formation of a thermodynamically stable spinel phase in this zone.

Manganese spinel formation as solid-state solution:

$$
\frac{(1+\mathrm{y})}{2} \mathrm{Li}_{2} \mathrm{O}+\mathrm{xMgO}+\frac{(1+\mathrm{y}-2 \mathrm{x})}{2} \mathrm{Mn}_{2} \mathrm{O}_{3}+(1-\mathrm{y}+\mathrm{x}) \mathrm{MnO}_{2} \rightarrow \mathrm{Li}_{1+\mathrm{y}} \mathrm{Mg}_{\mathrm{x}} \mathrm{Mn}_{2-\mathrm{x}} \mathrm{O}_{4}
$$

However, only undoped magnesium precursor formed a pure and stable cubic spinel phase between $700^{\circ} \mathrm{C}$ and $800{ }^{\circ} \mathrm{C}$, a temperature range in which mass of formed phase remained constant (Figure 2a) with mass-loss rate equal to 0 (Figure 2b).

In contrast, magnesium-doped precursors did not form a pure spinel phase and maintained a mixed composition of oxides and carbonates with a $\mathrm{CO}_{2}$ mass retention of $7.09 \%, 11.01 \%$, and $2.36 \%$ (Figure 2a) for magnesium concentrations of $0.02,0.05$, and 0.1 , respectively, compared to pure phase of nonmagnesium precursor in the same temperature range.

Taking into account the decomposition order of carbonates with temperature $\mathrm{MnCO}_{3} \sim$ $515^{\circ} \mathrm{C} 680{ }^{\circ} \mathrm{C}<\mathrm{MgCO}_{3} \sim 620^{\circ} \mathrm{C} 650{ }^{\circ} \mathrm{C}<\mathrm{Li}_{2} \mathrm{CO}_{3} \sim 700{ }^{\circ} \mathrm{C} 1100{ }^{\circ} \mathrm{C}$ [67-70], stable (SPMg-1 and SPMg-3) and intermediate (SPMg-2) phases at the end of this zone would be mainly composed of a mixed metal oxide with an $\mathrm{Li}_{2} \mathrm{CO}_{3}$ excess.

Spinel decomposition: The fourth zone $\left(790{ }^{\circ} \mathrm{C}\right.$ to $\left.950{ }^{\circ} \mathrm{C}\right)$ is mainly associated with oxygen loss from spinel structure, which recorded a mass loss of $1.61 \%$ to $3.69 \%$ on normalized TG curves (Figure 2a) and was observed as a small and wide peak (for magnesium-doped precursors due to superimposition of $\mathrm{Li}_{2} \mathrm{CO}_{3}$ decomposition rate) on normalized DTG curves (Figure 2b) in a mass-loss rate range of $0.6 \times 10^{-2} \% \mathrm{~s}^{-1}$ to $0.76 \times 10^{-2} \% \mathrm{~s} \mathrm{~s}^{-1}$ (Table 1 ).

Continuous mass decrease due to gradual loss of oxygen from spinel phase promotes diffusion of lithium to particles' surface, where disproportionation reaction takes place resulting in (1) formation of a stable rock-salt phase $\mathrm{Li}_{2} \mathrm{MnO}_{3}$ and (2) change of crystalline symmetry of spinel from cubic to tetragonal due to $\mathrm{Mn}^{3+}$ concentration increase, which decreases average oxidation state of manganese below 3.5 [36,71-73]. Disproportionation reaction of spinel phase is represented by the following equation:

$$
\mathrm{LiMn}_{2} \mathrm{O}_{4} \rightarrow \mathrm{Li}_{1-2 \delta} \mathrm{Mn}_{2-\delta} \mathrm{O}_{4-3 \delta-\delta},+\delta \mathrm{Li}_{2} \mathrm{MnO}_{3}+\frac{\delta \prime}{2} \mathrm{O}_{2}
$$

With increasing temperature, a higher oxygen removal causes a new phase transformation as a result of the reaction between manganese-rich spinel phase and $\mathrm{Li}_{2} \mathrm{MnO}_{3}$ phase to produce $\mathrm{LiMnO}_{2}[71,72]$ according to the following equation:

$$
\mathrm{LiMn}_{2} \mathrm{O}_{4}+\mathrm{Li}_{2} \mathrm{MnO}_{3} \rightarrow 3 \mathrm{LiMnO}_{2}+\frac{1}{2} \mathrm{O}_{2}
$$


The percentages and maximum rates of mass loss of each of the decomposition zones of the synthesis precursors are detailed in Table 1, according to the magnesium doping concentrations.

\subsection{Determination of Thermal Decomposition Kinetic Parameters of Polymeric Matrix}

Analysis of decomposition kinetics of synthesis precursors was focused on the second zone, because decomposition of polymeric matrix encompasses fundamental transformation processes that initiate the formation of a thermodynamically stable spinel phase after removal of organic composition. In this second zone, synthesis precursors' conversion was affected by magnesium concentration causing a displacement of conversion curves at higher temperatures compared to nondoped SP precursor as shown in Figure 3a. Displacement observed in conversion of SPMg-1, SPMg-2, and SPMg-3 precursors was inversely proportional to magnesium concentration and would be related to a decrease in thermal conductivity of samples due to an increase in thermal inertia.
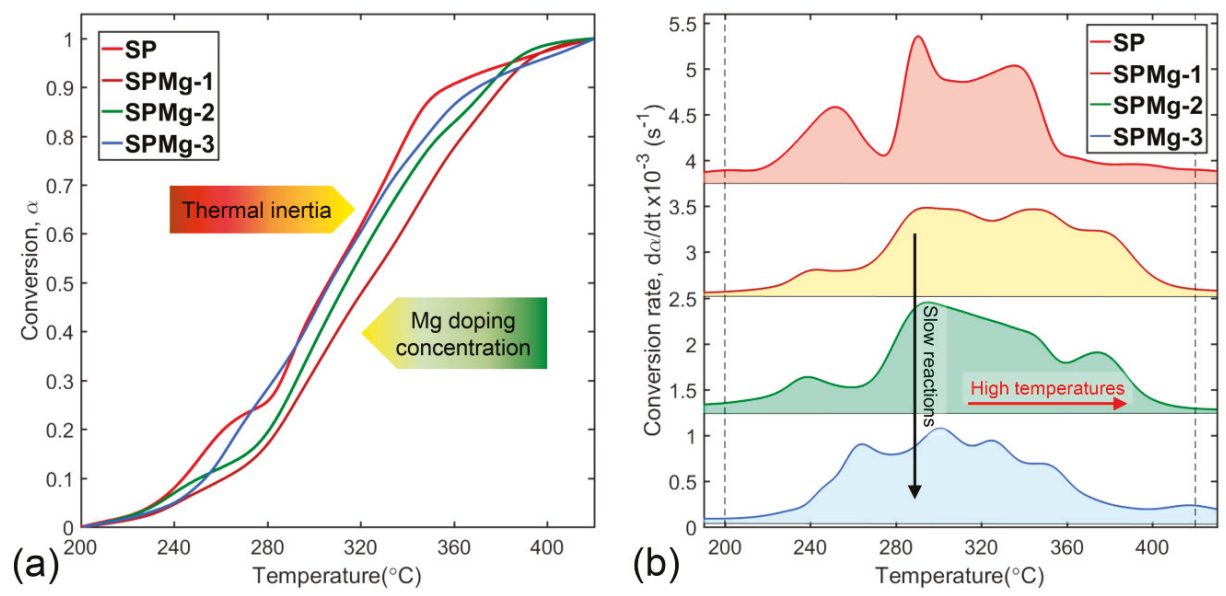

Figure 3. Curves of (a) conversion and (b) conversion rates' evolution of synthesis precursors with different magnesium doping concentrations.

As explained in Section 3.2, continuous availability of $\mathrm{CO}_{2}$ during polymeric matrix decomposition, first from decarboxylation reaction (Equation (13)) and secondly from organics' combustion (Equations (14)-(16)), promoted carbonates' formation as secondary phases, which would be the cause of increase in thermal inertia due to the fact that they require more energy to desorb $\mathrm{CO}_{2}$ and form a pure and stable spinel phase. Taking into account that $\mathrm{CO}_{2}$ amount released during thermal decomposition was equivalent for all precursors, the SPMg-1 precursor with lower concentration of magnesium showed a higher propensity to $\mathrm{CO}_{2}$ sorption and carbonates' formation as secondary phases compared to the SPMg-3 precursor with higher concentration of magnesium. Therefore, a higher concentration of magnesium doping in precursors would reduce secondary phases' formation and, consequently, thermal inertia.

Thermal inertia effects on multiple stages of polymeric matrix decomposition are shown in more detail in Figure 3b where peak positions of conversion rates of the SPMg-1, SPMg-2, and SPMg-3 precursors, compared to nondoped SP precursor, experienced a decrease in height and a shift toward higher temperatures in inverse proportion to magnesium doping concentration. This behavior revealed that magnesium incorporation decreases conversion speeds (slow reactions) and causes a delay in decomposition process, which is related to a higher energy consumption (high temperatures) to complete conversion. 
To quantify the effect of magnesium doping concentration on polymeric matrix thermal decomposition, complex solid-state reactions represented by conversion rate curves (Figure 3b) were separated into five single-stage reactions using the deconvolution function of Equation (6).

Kinetic analysis of resulting individual curves, as independent reaction stages, was carried out using the linear form of Equation (5) [74]:

$$
\ln \left(\beta \frac{\mathrm{d} \alpha}{\mathrm{dT}}\right)=\ln (\mathrm{A})-\frac{\mathrm{E}_{\mathrm{a}}}{\mathrm{RT}}+\operatorname{nln}(1-\alpha)+\operatorname{mln} \alpha+\operatorname{pln}[-\ln (1-\alpha)]
$$

Reaction model $(f(\alpha))$ and the approximate Arrhenius parameters ( $E_{a}$ and $\left.A\right)$ for each individual reaction were obtained from Equation (20) by multiple linear regression and results were obtained as shown in Table 2.

Table 2. Reaction models and kinetic parameters of each single reaction of polymeric matrix decomposition process of precursors with different magnesium doping concentrations.

\begin{tabular}{|c|c|c|c|c|}
\hline Synthesis Precursor & Peak Number & Reaction Model & $\mathrm{E}_{\mathrm{a}}\left(\mathrm{kJ} \mathrm{\textrm {mol } ^ { - 1 } )}\right.$ & $\log (\mathrm{A})$ \\
\hline \multirow{5}{*}{$\begin{array}{c}\text { SP } \\
x=0.00\end{array}$} & 1 & \multirow{5}{*}{$\begin{array}{l}\text { Avrami-Erofeev } \\
\text { equation, } n=1\end{array}$} & 157.68 & 13.77 \\
\hline & 2 & & 249.19 & 21.72 \\
\hline & 3 & & 133.79 & 12.80 \\
\hline & 4 & & 189.41 & 14.56 \\
\hline & 5 & & 257.35 & 18.78 \\
\hline \multirow{5}{*}{$\begin{array}{l}\text { SPMg-1 } \\
x=0.02\end{array}$} & 1 & \multirow{5}{*}{$\begin{array}{l}\text { Avrami-Erofeev } \\
\text { equation, } n=1\end{array}$} & 135.66 & 11.95 \\
\hline & 2 & & 187.88 & 15.43 \\
\hline & 3 & & 170.99 & 14.67 \\
\hline & 4 & & 157.76 & 12.44 \\
\hline & 5 & & 180.74 & 13.65 \\
\hline \multirow{5}{*}{$\begin{array}{l}\text { SPMg-2 } \\
x=0.05\end{array}$} & 1 & \multirow{5}{*}{$\begin{array}{l}\text { Avrami-Erofeev } \\
\text { equation, } n=1\end{array}$} & 123.54 & 11.56 \\
\hline & 2 & & 206.82 & 17.86 \\
\hline & 3 & & 101.50 & 6.95 \\
\hline & 4 & & 261.91 & 20.42 \\
\hline & 5 & & 206.18 & 14.63 \\
\hline \multirow{5}{*}{$\begin{array}{l}\text { SPMg-3 } \\
x=0.10\end{array}$} & 1 & \multirow{5}{*}{$\begin{array}{l}\text { Avrami-Erofeev } \\
\text { equation, } n=1\end{array}$} & 209.10 & 18.09 \\
\hline & 2 & & 148.30 & 11.91 \\
\hline & 3 & & 198.30 & 16.33 \\
\hline & 4 & & 194.48 & 15.21 \\
\hline & 5 & & 181.01 & 12.44 \\
\hline
\end{tabular}

For kinetic analysis of entire thermal decomposition process of polymeric matrix, total reaction rate of complex solid-state reactions was expressed as the sum of five individual kinetic processes according to a scheme of successive reactions [75-78]:

$$
\frac{\mathrm{d} \alpha}{\mathrm{dt}}=\sum_{\mathrm{i}=1}^{\mathrm{r}} \mathrm{c}_{\mathrm{i}} \frac{\mathrm{d} \alpha_{\mathrm{i}}}{\mathrm{dt}}
$$

where $\mathrm{r}$ is the number of individual reactions and $c_{i}$ is the weighting coefficient representing the contribution factor of each reaction $i$. Likewise, weighting coefficients were subject to two restrictions: $\mathrm{c}_{\mathrm{i}} \geq 0$ and $\sum \mathrm{c}_{\mathrm{i}}=1$.

Parameters for the proposed scheme, $A_{i}, E_{a i}, f\left(\alpha_{i}\right)$, and $c_{i}$ were refined using a nonlinear least-squares technique. The objective function $(\mathrm{OF})$ used was defined by the following expression:

$$
\mathrm{OF}=\min \sum_{\mathrm{j}=1}^{\mathrm{N}}\left[\left(\frac{\mathrm{d} \alpha}{\mathrm{dt}}\right)_{\exp }-\left(\frac{\mathrm{d} \alpha}{\mathrm{dt}}\right)_{\mathrm{cal}}\right]^{2}
$$


where $\left(\frac{\mathrm{d} \alpha}{\mathrm{dt}}\right)_{\exp }$ and $\left(\frac{\mathrm{d} \alpha}{\mathrm{dt}}\right)_{\text {cal }}$ represent experimental and calculated conversion rates, respectively, $\mathrm{j}$ refers to a point in the experiment, and $\mathrm{N}$ is the total number of experimental points.

Solution to the kinetic problem posed in Equation (21) was achieved by fit convergence between experimental conversion rate curves (red, dotted line) and calculated curves (black line) composed of five separate stages of reaction (shaded area curves), as shown in Figure 4.
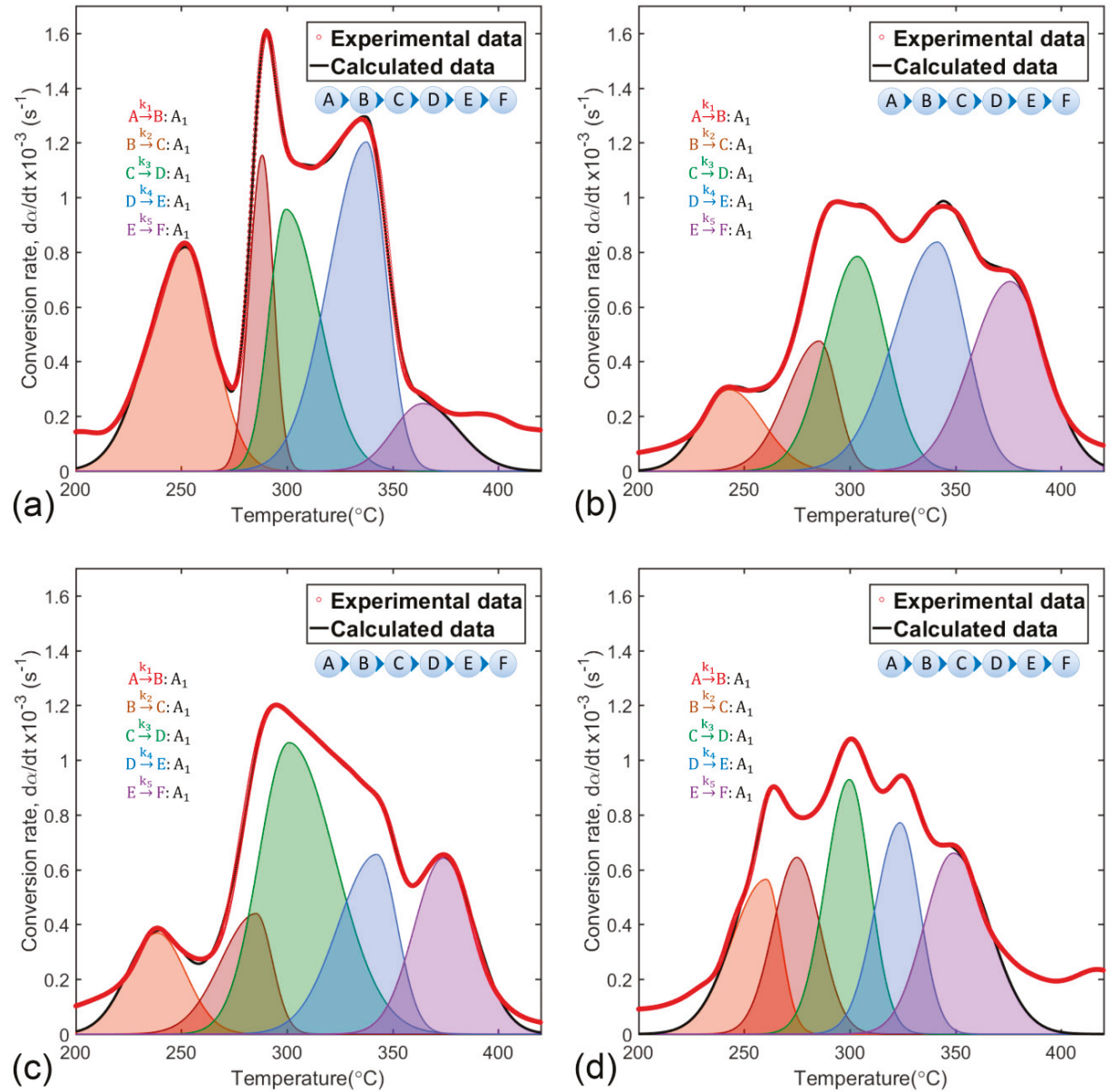

Figure 4. Experimental and calculated conversion rate curves based on a scheme of five successive reactions of polymeric matrix decomposition of the synthesis precursors (a) SP, (b) SPMg-1, (c) SPMg-2, and (d) SPMg-3.

Adjustment results validated the scheme of successive reactions as the sequence of processes representing polymeric matrix thermal decomposition. Thus, complex solid-state reactions would result from linear combination of individual data $\left(\frac{\mathrm{d} \alpha_{\mathrm{i}}}{\mathrm{dt}}\right)$ and would be represented by the scheme formed by the Equations (23) to (27).

- Dehydroxylation reaction:

$$
\mathrm{A} \stackrel{\mathrm{k}_{1}}{\rightarrow} \mathrm{B}+\mathrm{H}_{2} \mathrm{O} \uparrow
$$


- Decarboxylation reaction:

$$
\mathrm{B} \stackrel{\mathrm{k}_{2}}{\rightarrow} \mathrm{C}+\mathrm{CO}_{2} \uparrow
$$

- Multistage combustion reaction:

$$
\begin{aligned}
& \mathrm{C} \stackrel{\mathrm{k}_{3}}{\rightarrow} \mathrm{D}+\mathrm{CO}_{2} \uparrow \\
& \mathrm{D} \stackrel{\mathrm{k}_{4}}{\rightarrow} \mathrm{E}+\mathrm{CO}_{2} \uparrow \\
& \mathrm{E} \stackrel{\mathrm{k}_{5}}{\rightarrow} \mathrm{F}+\mathrm{CO}_{2} \uparrow
\end{aligned}
$$

where $\mathrm{A}$ is the dry synthesis precursor after dehydration; B, C, D, and E are solid intermediate products; $\mathrm{F}$ is the final solid product; and $\mathrm{k}_{\mathrm{i}}$ is reaction rate constant (subscripts $\mathrm{i}$ from 1 to 5 correspond to reactions 23 to 27 , respectively).

First-order Avrami-Erofeev equation, $\mathrm{n}=1$, which considers a mechanism of random nucleation followed by an instantaneous growth of nuclei $[54,56,79,80]$, was the kinetic model function $\mathrm{f}(\alpha)$, which fitted each of the reactions of the polymeric matrix decomposition process.

Avrami-Erofeev general equation of nucleation and nuclei growth:

$$
\mathrm{A}_{\mathrm{n}}=\mathrm{n}(1-\alpha)[-\ln (1-\alpha)]^{\frac{\mathrm{n}-1}{\mathrm{n}}}
$$

For $\mathrm{n}=1$ :

$$
\mathrm{A}_{1}=(1-\alpha)
$$

Arrhenius parameters $\left(E_{a}\right.$ and $\left.\log (A)\right)$, contribution factors $\left(c_{i}\right)$, peak temperatures $\left(T_{p}\right)$, and correlation coefficients $\left(R^{2}\right)$ obtained from the fit procedure based on a scheme of five successive reactions were listed in Table 3 .

Average values for $E_{a}$ and $\log (A)$ were calculated taking into account contribution of each of the reaction stages and are illustrated in Figure 5a according to their magnesium doping composition.
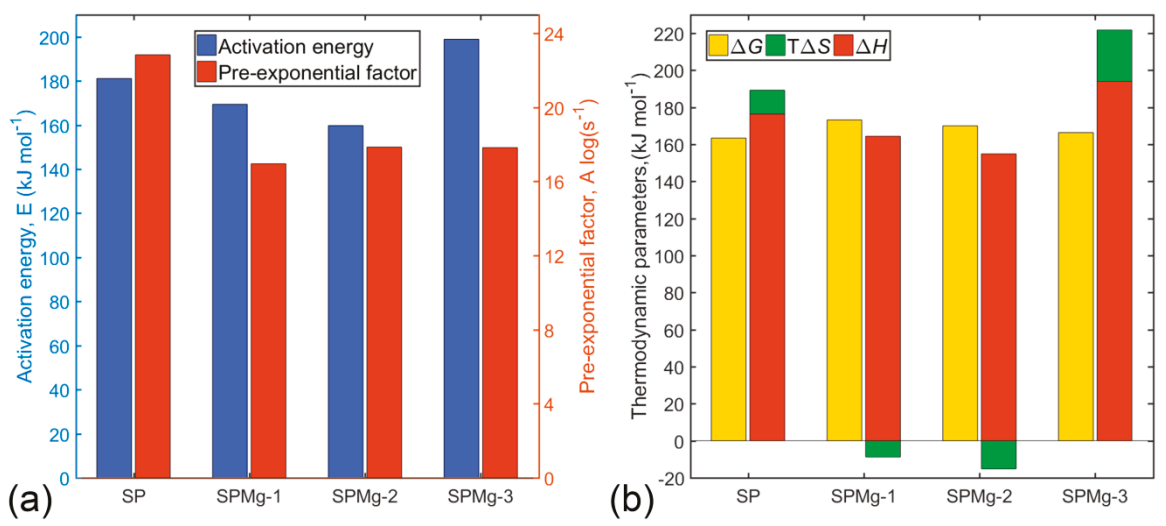

Figure 5. Average values for (a) $\mathrm{E}_{\mathrm{a}}$ and $\log (\mathrm{A})$, and (b) $\Delta \mathrm{G}^{\neq}, \mathrm{T}_{\mathrm{p}} \Delta \mathrm{S}^{\ddagger}$ and $\Delta \mathrm{H}^{\ddagger}$ from polymer matrix thermal decomposition process of synthesis precursors prepared with different $\mathrm{Mg}$ doping concentrations.

High values of $E_{a}$ and $\log (A)$ might be related to high mass losses and, consequently, to lower $\mathrm{CO}_{2}$ sorption, as is the case of SP and SPMg-3 precursors, whereas low values might be related to lower mass losses due to higher $\mathrm{CO}_{2}$ sorption, as is the case of SPMg-2 and SPMg-1 precursors.

Thus, existence of an inverse relationship between Arrhenius parameters and mass retention, as a result of $\mathrm{CO}_{2}$ sorption, which is responsible for carbonates' formation in intermediate phases, 
would agree with the order of mass loss of precursors in the third thermal decomposition zone (SP $>$ SPM-3 > SPMg-1 > SPMg-2), as shown in Figure 2, and would indicate that high values of $\mathrm{E}_{\mathrm{a}}$ and $\log (\mathrm{A})$ are related to the formation of thermodynamically stable spinel phases in an organic content post-combustion stage with a lower energy requirement for decomposition of intermediate phases through $\mathrm{CO}_{2}$ desorption.

Table 3. Kinetic parameters, contribution factors, peak temperatures, and correlation coefficients from fit of experimental conversion rates of polymeric matrix thermal decomposition with a scheme of five successive reactions.

\begin{tabular}{|c|c|c|c|c|c|c|}
\hline $\begin{array}{l}\text { Synthesis } \\
\text { Precursor }\end{array}$ & $\begin{array}{c}\text { Peak } \\
\text { Number }\end{array}$ & $\mathrm{c}_{\mathrm{i}}$ & $\mathrm{T}_{\mathrm{p}}\left({ }^{\circ} \mathrm{C}\right)$ & $\mathrm{E}_{\mathrm{a}}\left(\mathrm{kJ} \mathrm{mol} \mathrm{mo}^{-1}\right)$ & $\log (\mathrm{A})$ & $\mathbf{R}^{2}$ \\
\hline \multirow{6}{*}{$\begin{array}{c}\text { SP } \\
x=0.00\end{array}$} & 1 & 0.23 & 251.94 & 160.57 & 14.07 & \multirow{6}{*}{0.98} \\
\hline & 2 & 0.12 & 288.36 & 265.02 & 23.75 & \\
\hline & 3 & 0.23 & 299.17 & 129.57 & 9.90 & \\
\hline & 4 & 0.30 & 330.75 & 181.37 & 13.78 & \\
\hline & 5 & 0.12 & 343.27 & 233.96 & 18.07 & \\
\hline & Total & 1.00 & Average & 181.13 & 22.84 & \\
\hline \multirow{6}{*}{$\begin{array}{l}\text { SPMg-1 } \\
x=0.02\end{array}$} & 1 & 0.07 & 242.99 & 142.64 & 12.44 & \multirow{6}{*}{0.99} \\
\hline & 2 & 0.15 & 285.67 & 209.40 & 17.78 & \\
\hline & 3 & 0.21 & 303.59 & 165.53 & 13.04 & \\
\hline & 4 & 0.30 & 341.46 & 159.56 & 11.59 & \\
\hline & 5 & 0.27 & 375.87 & 168.39 & 11.48 & \\
\hline & Total & 1.00 & Average & 169.41 & 16.96 & \\
\hline \multirow{6}{*}{$\begin{array}{l}\text { SPMg-2 } \\
x=0.05\end{array}$} & 1 & 0.10 & 238.71 & 149.12 & 13.24 & \multirow{6}{*}{0.95} \\
\hline & 2 & 0.13 & 285.52 & 213.13 & 18.13 & \\
\hline & 3 & 0.43 & 300.99 & 94.02 & 6.30 & \\
\hline & 4 & 0.14 & 342.55 & 240.03 & 18.61 & \\
\hline & 5 & 0.21 & 374.04 & 215.91 & 15.44 & \\
\hline & Total & 1.00 & Average & 159.77 & 17.86 & \\
\hline \multirow{6}{*}{$\begin{array}{l}\text { SPMg-3 } \\
x=0.10\end{array}$} & 1 & 0.14 & 260.59 & 207.85 & 18.70 & \multirow{6}{*}{0.92} \\
\hline & 2 & 0.14 & 275.00 & 154.45 & 12.86 & \\
\hline & 3 & 0.24 & 299.86 & 211.79 & 17.53 & \\
\hline & 4 & 0.23 & 323.86 & 218.74 & 17.33 & \\
\hline & 5 & 0.26 & 348.98 & 189.34 & 13.87 & \\
\hline & Total & 1.00 & Average & 198.92 & 17.91 & \\
\hline
\end{tabular}

The main impact of magnesium doping on thermal decomposition kinetics was elucidated between $\mathrm{SP}$ and SPMg-3 precursors. Where increase of $\mathrm{E}_{\mathrm{a}}$ and decrease of $\log (\mathrm{A})$ observed in SPMg-3 precursor, compared to SP precursor, would demonstrate that magnesium incorporation, as a doping agent, reduces reaction rates of polymeric matrix decomposition because it favors a greater $\mathrm{CO}_{2}$ sorption.

\subsection{Transition State Thermodynamic Parameters of Polymeric Matrix Thermal Decomposition}

Thermodynamic parameters such as the changes of the enthalpy, Gibbs' free energy, and entropy for the activated complex were obtained by combining Arrhenius equations (Equation (2)) and Eyring. The latter, derived from transition state theory (activated complex) [81], represents constant rate of a chemical reaction according to the following expression [82-84]:

$$
\mathrm{k}=\kappa \frac{\mathrm{k}_{\mathrm{B}} \mathrm{T}_{\mathrm{p}}}{\mathrm{h}} \exp \left(\frac{\Delta \mathrm{S}^{\ddagger}}{\mathrm{R}}\right) \exp \left(-\frac{\Delta \mathrm{H}^{\neq}}{\mathrm{RT}}\right)
$$

where $\mathrm{K}$ is the transmission coefficient and can be considered close to unity, $\Delta \mathrm{S}^{\neq}$and $\Delta \mathrm{H}^{\neq}$are the entropy and enthalpy changes of the activated complex, respectively, $\mathrm{k}_{\mathrm{B}}$ is Boltzmann's constant 
$\left(1.381 \times 10^{-23} \mathrm{~J} \mathrm{~K}^{-1}\right), \mathrm{h}$ is Plank's constant $\left(6.626 \times 10^{-34} \mathrm{~J} \mathrm{~s}\right)$, and $\mathrm{T}_{\mathrm{p}}$ is the peak temperature on a DTG curve.

Entropy change, linked to the pre-exponential factor, was calculated according to the formula:

$$
\Delta S^{\neq}=R \ln \left(\frac{\mathrm{Ah}}{\operatorname{kek}_{\mathrm{B}} \mathrm{T}_{\mathrm{p}}}\right)
$$

where e is Euler's number (2.7183).

Enthalpy change was determined by activation energy with the expression:

$$
\Delta \mathrm{H}^{\neq}=\mathrm{E}-\mathrm{RT}_{\mathrm{p}}
$$

Finally, Gibbs' free energy change in active complex formation from reagents was calculated using the well-known thermodynamic equation:

$$
\Delta \mathrm{G}^{\neq}=\Delta \mathrm{H}^{\neq}-\mathrm{T}_{\mathrm{p}} \Delta \mathrm{S}^{\neq}
$$

Values for $\Delta S^{\neq}, \Delta H^{\neq}$, and $\Delta G^{\neq}$, listed in Table 4 , were calculated at temperature peaks $T_{\text {pi }}$, because these temperatures characterize the highest rate of each of five polymeric matrix thermal decomposition reactions. Average values of thermodynamic parameters were illustrated as shown in Figure $5 \mathrm{~b}$ according to magnesium doping concentration.

\begin{tabular}{|c|c|c|c|c|c|c|}
\hline $\begin{array}{l}\text { Synthesis } \\
\text { Precursor }\end{array}$ & $\begin{array}{c}\text { Peak } \\
\text { Number }\end{array}$ & $c_{i}$ & $T_{p}(K)$ & $\begin{array}{c}\Delta S^{\neq} \\
\left(\mathrm{J} \mathrm{mol}^{-1} \mathrm{~K}^{-1}\right)\end{array}$ & $\begin{array}{c}\Delta \mathrm{H}^{\neq} \\
\left(\mathrm{kJ} \mathrm{mol} \mathbf{~ m o l}^{-1}\right)\end{array}$ & $\begin{array}{c}\Delta \mathrm{G}^{\neq} \\
\left(\mathrm{kJ} \mathrm{mol} \mathrm{mol}^{-1}\right)\end{array}$ \\
\hline \multirow{6}{*}{$\begin{array}{c}S P \\
x=0.00\end{array}$} & 1 & 0.23 & 525.09 & 11.40 & 156.21 & 150.22 \\
\hline & 2 & 0.12 & 561.51 & 196.19 & 260.35 & 150.18 \\
\hline & 3 & 0.23 & 572.32 & -69.07 & 124.81 & 164.34 \\
\hline & 4 & 0.30 & 603.90 & 4.69 & 176.35 & 173.51 \\
\hline & 5 & 0.12 & 616.42 & 86.63 & 228.83 & 175.44 \\
\hline & Total & 1.00 & Average & 22.40 & 176.35 & 163.42 \\
\hline \multirow{6}{*}{$\begin{array}{l}\text { SPMg-1 } \\
x=0.02\end{array}$} & 1 & 0.07 & 516.14 & -19.74 & 138.35 & 148.53 \\
\hline & 2 & 0.15 & 558.82 & 81.91 & 204.75 & 158.98 \\
\hline & 3 & 0.21 & 576.74 & -9.02 & 160.74 & 165.94 \\
\hline & 4 & 0.30 & 614.61 & -37.46 & 154.45 & 177.48 \\
\hline & 5 & 0.27 & 649.02 & -39.85 & 163.00 & 188.86 \\
\hline & Total & 1.00 & Average & -12.91 & 164.42 & 173.19 \\
\hline \multirow{6}{*}{$\begin{array}{l}\text { SPMg-2 } \\
x=0.05\end{array}$} & 1 & 0.10 & 511.86 & -4.31 & 144.86 & 147.07 \\
\hline & 2 & 0.13 & 558.67 & 88.63 & 208.49 & 158.97 \\
\hline & 3 & 0.43 & 574.14 & -138.01 & 89.25 & 168.48 \\
\hline & 4 & 0.14 & 615.70 & 96.92 & 234.91 & 175.24 \\
\hline & 5 & 0.21 & 647.19 & 35.91 & 210.53 & 187.29 \\
\hline & Total & 1.00 & Average & -28.04 & 154.88 & 170.04 \\
\hline \multirow{6}{*}{$\begin{array}{l}\text { SPMg-3 } \\
x=0.10\end{array}$} & 1 & 0.14 & 533.74 & 99.92 & 203.41 & 150.08 \\
\hline & 2 & 0.14 & 548.15 & -12.04 & 149.89 & 156.49 \\
\hline & 3 & 0.24 & 573.01 & 76.97 & 207.03 & 162.92 \\
\hline & 4 & 0.23 & 597.01 & 72.84 & 213.78 & 170.29 \\
\hline & 5 & 0.26 & 622.13 & 6.18 & 184.17 & 180.32 \\
\hline & Total & 1.00 & Average & 48.39 & 194.08 & 166.37 \\
\hline
\end{tabular}

Table 4. The $\Delta \mathrm{S}^{\neq}, \Delta \mathrm{H}^{\neq}$, and $\Delta \mathrm{G}^{\neq}$values for formation of activated complexes in the polymeric matrix thermal decomposition zone of doped synthesis precursors with different concentrations of magnesium. 
Positive $\Delta \mathrm{G}^{\neq}$and $\Delta \mathrm{H}^{\neq}$values for all precursors showed that formation of activated complexes, in each of the polymeric matrix decomposition reactions, corresponds to nonspontaneous processes involving introduction of heat.

As shown in Figure 5b, entropy values for SP and SPMg-3 precursors are positive, while for SPMg-1 and SPMg-2 precursors they are negative. These might mean that activated complexes of SP and SPMg-3 precursors were less structured or organized compared to initial reagents, which would indicate that formation of active complexes would be accompanied by an increase in total system entropy $\left(\Delta S^{\neq}>0\right)$. In contrast, formation of activated complexes of SPMg-1 and SPMg-2 precursors would be related to a decrease in entropy $\left(\Delta S^{\neq}<0\right)$. Therefore, in terms of transition state theory or activated complex, polymeric matrix thermal decomposition reactions can be interpreted as "fast" for SP and SPMg-3 precursors, which favor formation of spinel phases, and "slow" for SPMg-1 and SPMg-2 precursors, which result in formation of intermediate oxide-carbonate phases due to a high $\mathrm{CO}_{2}$ sorption.

\subsection{Stoichiometric, Structural, and Morphological Analysis}

According to results obtained from TG analysis and effect of Mg concentration on kinetics and thermodynamics of synthesis precursors' thermal decomposition, an optimal two-stage heat treatment program was applied to prepare oxide powders with $\mathrm{LiMg}_{x} \mathrm{Mn}_{2-\mathrm{x}} \mathrm{O}_{4}(\mathrm{x}=0.00,0.02,0.05,0.10)$ spinel phase: A first stage of calcination in atmospheric air at $500{ }^{\circ} \mathrm{C}$ for $4 \mathrm{~h}$ to ensure complete combustion of precursors' polymeric matrix with negligible $\mathrm{CO}_{2}$ sorption and a second stage to desorb $\mathrm{CO}_{2}$ residues and sinter spinel oxide powders in air atmosphere at $750{ }^{\circ} \mathrm{C}$ for $12 \mathrm{~h}$.

$\mathrm{Li} / \mathrm{Mn} / \mathrm{Mg}$ cation ratios for $\mathrm{LiMg}_{\mathrm{x}} \mathrm{Mn}_{2-x} \mathrm{O}_{4}$ nanomaterials measured by AAS are given in Table 5 . Cationic composition results revealed that conditions established in the heat treatment program partially modified stoichiometry of spinels, allowing to preserve a fraction of the excess Li used in precursors' preparation, which reduced molar ratio and increased average valence of Mn above its corresponding nominal composition.

Table 5. $\mathrm{LiMg}_{\mathrm{x}} \mathrm{Mn}_{2-\mathrm{x}} \mathrm{O}_{4}(\mathrm{x}=0.00,0.02,0.05,0.10)$ chemical composition as determined by AAS and the average $\mathrm{Mn}$ valence.

\begin{tabular}{ccccc}
\hline \multirow{2}{*}{ Sample Name } & \multicolumn{2}{c}{ Nominal } & \multicolumn{2}{c}{ Experimental } \\
\cline { 2 - 5 } & Stoichiometry & Average Mn Valence & Stoichiometry & Average Mn Valence \\
\hline LMO & $\mathrm{LiMn}_{2} \mathrm{O}_{4}$ & 3.50 & $\mathrm{Li}_{1.03} \mathrm{Mn}_{1.97} \mathrm{O}_{4}$ & 3.54 \\
$\mathrm{LMOMg}-1$ & $\mathrm{LiMg}_{0.02} \mathrm{Mn}_{1.98} \mathrm{O}_{4}$ & 3.52 & $\mathrm{Li}_{1.01} \mathrm{Mg}_{0.02} \mathrm{Mn}_{1.97} \mathrm{O}_{4}$ & 3.53 \\
$\mathrm{LMOMg}-2$ & $\mathrm{LiMg}_{0.05} \mathrm{Mn}_{1.95} \mathrm{O}_{4}$ & 3.54 & $\mathrm{Li}_{1.03} \mathrm{Mg}_{0.05} \mathrm{Mn}_{1.92} \mathrm{O}_{4}$ & 3.57 \\
LMOMg-3 & $\mathrm{LiMg}_{0.10} \mathrm{Mn}_{1.90} \mathrm{O}_{4}$ & 3.58 & $\mathrm{Li}_{1.01} \mathrm{Mg}_{0.10} \mathrm{Mn}_{1.89} \mathrm{O}_{4}$ & 3.59 \\
\hline
\end{tabular}

Figure 6 shows $\mathrm{XRD}$ patterns of $\mathrm{LiMg}_{\mathrm{x}} \mathrm{Mn}_{2-\mathrm{x}} \mathrm{O}_{4}(\mathrm{x}=0.00,0.02,0.05,0.10)$ samples. All diffraction peaks (111), (311), (222), (400), (331), (511), (440), and (531) show good consistency with standard $\mathrm{LiMn}_{2} \mathrm{O}_{4}$ diffraction peaks from International Centre for Diffraction Data (ICDD No. 00-035-0782), respectively.

This indicates that $\mathrm{LiMg}_{x} \mathrm{Mn}_{2-\mathrm{x}} \mathrm{O}_{4}$ samples possess the cubic spinel structure with $\mathrm{Fd} \overline{3} \mathrm{~m}$ space group of $\mathrm{LiMn}_{2} \mathrm{O}_{4}$, suggesting that $\mathrm{Mg}^{2+}$ doping does not change the intrinsic cubic symmetry of spinel structure. No impurities such as $\mathrm{L}_{2} \mathrm{MnO}_{3}, \mathrm{LiMnO}_{2}, \mathrm{Mn}_{2} \mathrm{O}_{3}$, or $\mathrm{MnO} \chi$ were detected, which provides evidence of high purity of synthesized products. In addition, sharpness of the main peaks (111), (311), and (400) indicates that samples have high crystallinity.

On the other hand, the diffraction peak for the lattice plane $(220)\left(2 \theta \approx 30.9^{\circ}\right)$, which arises only from diffraction of tetrahedral sites (8a) and could not be observed in an LMO XRD pattern due to low scattering ability of lithium atoms, was not observed in diffraction patterns of $\mathrm{LiMg}_{\mathrm{x}} \mathrm{Mn}_{2-\mathrm{x}} \mathrm{O}_{4}$ $(\mathrm{x}=0.00,0.02,0.05,0.10)$ samples in Figure 6, which suggests that $\mathrm{Mg}^{2+}$ ions used in doping only occupy octahedral sites (16d) in substitution of manganese ions [18,24]. 

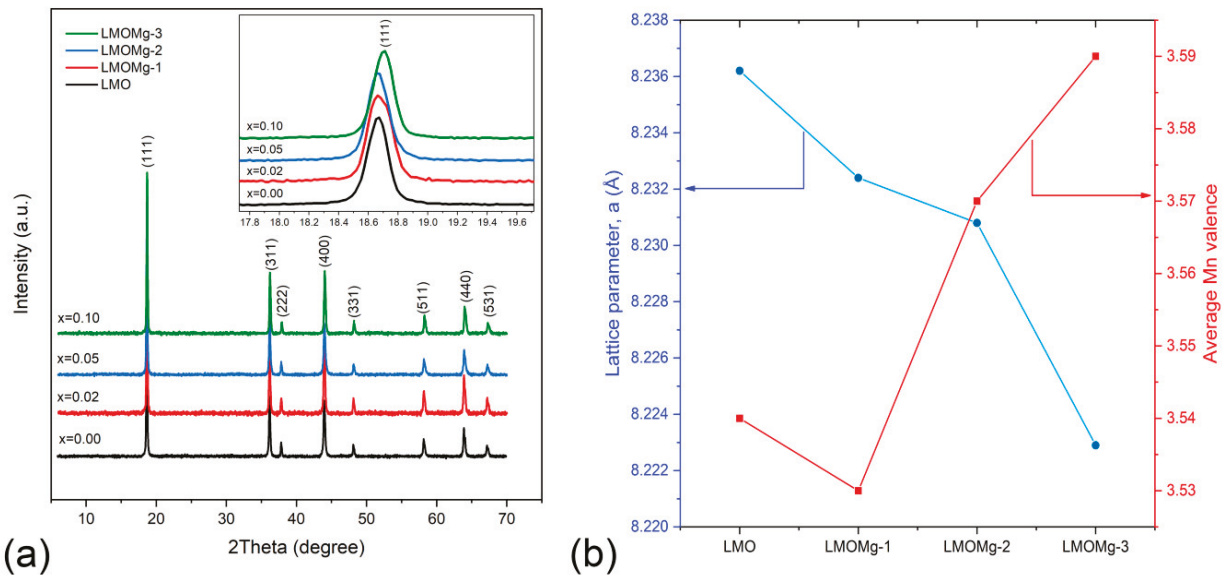

Figure 6. (a) $\mathrm{LiMg}_{x} \mathrm{Mn}_{2-\mathrm{x}} \mathrm{O}_{4}(\mathrm{x}=0.00,0.02,0.05,0.10)$ nanometer powders' diffraction patterns. Inset shows displacement of peak (111) towards higher angles with increase of $x$. (b) Decrease of cell parameter " $a$ " and raised average Mn valence with increasing doping concentration of $\mathrm{Mg}$.

Refinement of synthetized spinels was performed using eight well-defined diffraction lines with indexing in a Fd $\overline{3} \mathrm{~m}$ space group cubic system. Figure 7 shows Rietveld refinement results. Calculated unit cell parameters are listed in Table 6.

Table 6. Rietveld refinement, crystal parameters, and crystallite size for $\operatorname{LiMg}_{x} \mathrm{Mn}_{2-\mathrm{x}} \mathrm{O}_{4}(\mathrm{x}=0.00,0.02$, $0.05,0.10)$ samples.

\begin{tabular}{ccccc}
\hline Sample Name & LMO & LMOMg-1 & LMOMg-2 & LMOMg-3 \\
\hline Symmetry & \multicolumn{3}{c}{ cubic } \\
Space group & 8.2362 & 8.2324 & 8.2308 & 8.2229 \\
\hline Lattice parameter $(\AA)$ & 557.9358 & 557.6075 & 556.0020 \\
Unit cell volume $\left(\AA^{\circ}\right)$ & 558.6968 & 4.71 & 5.52 & 5.12 \\
\hline $\mathrm{R}_{\mathrm{p}}(\%)$ & 5.47 & 5.92 & 7.03 & 6.64 \\
$\mathrm{R}_{\mathrm{wp}}(\%)$ & 6.95 & 2.02 & 3.02 & 2.64 \\
$\chi^{2}$ & 2.96 & 0.82 & 0.87 & 0.83 \\
$\mathrm{I}^{2}(311) / \mathrm{I}(400)$ & 0.87 & 0.170 & 0.152 & 0.146 \\
$\mathrm{FWHM}_{111}\left({ }^{\circ}\right)$ & 0.148 & 0.173 & 0.171 & 0.167 \\
$\mathrm{FWHM}_{311}\left({ }^{\circ}\right)$ & 0.155 & 0.175 & 0.183 & 0.178 \\
$\mathrm{FWHM}_{400}\left({ }^{\circ}\right)$ & 0.159 & 50.47 & 51.91 & 53.45 \\
Dc Average $(\mathrm{nm})$ & 56.51 & &
\end{tabular}

A gradual decrease in lattice parameter was observed with increasing magnesium concentration " $x$ ". This is due to differences in ion radius between $\mathrm{Mn}^{3+}(0.645 \AA)$ and $\mathrm{Mn}^{4+}(0.53 \AA)$ ions. When $\mathrm{Mg}^{2+}$ is doped at $\mathrm{Mn}^{3+}$ site of the spinel structure, the number of $\mathrm{Mn}^{4+}$ ions increases in order to maintain charge balance condition resulting in an increase in average Mn valence (Figure 6b), which suppresses Jahn-Teller distortion $[85,86]$. Therefore, as shown in Figure 6b, lattice parameter "a" of the unit cell decreased with increasing magnesium content. This behavior was also manifested as a slight shift of peaks toward higher angles, as can be seen in the inset within Figure 6a. Lattice contraction due to substitution with $\mathrm{Mg}$ ion was consistent with results previously reported by Subramania et al. [87]. 

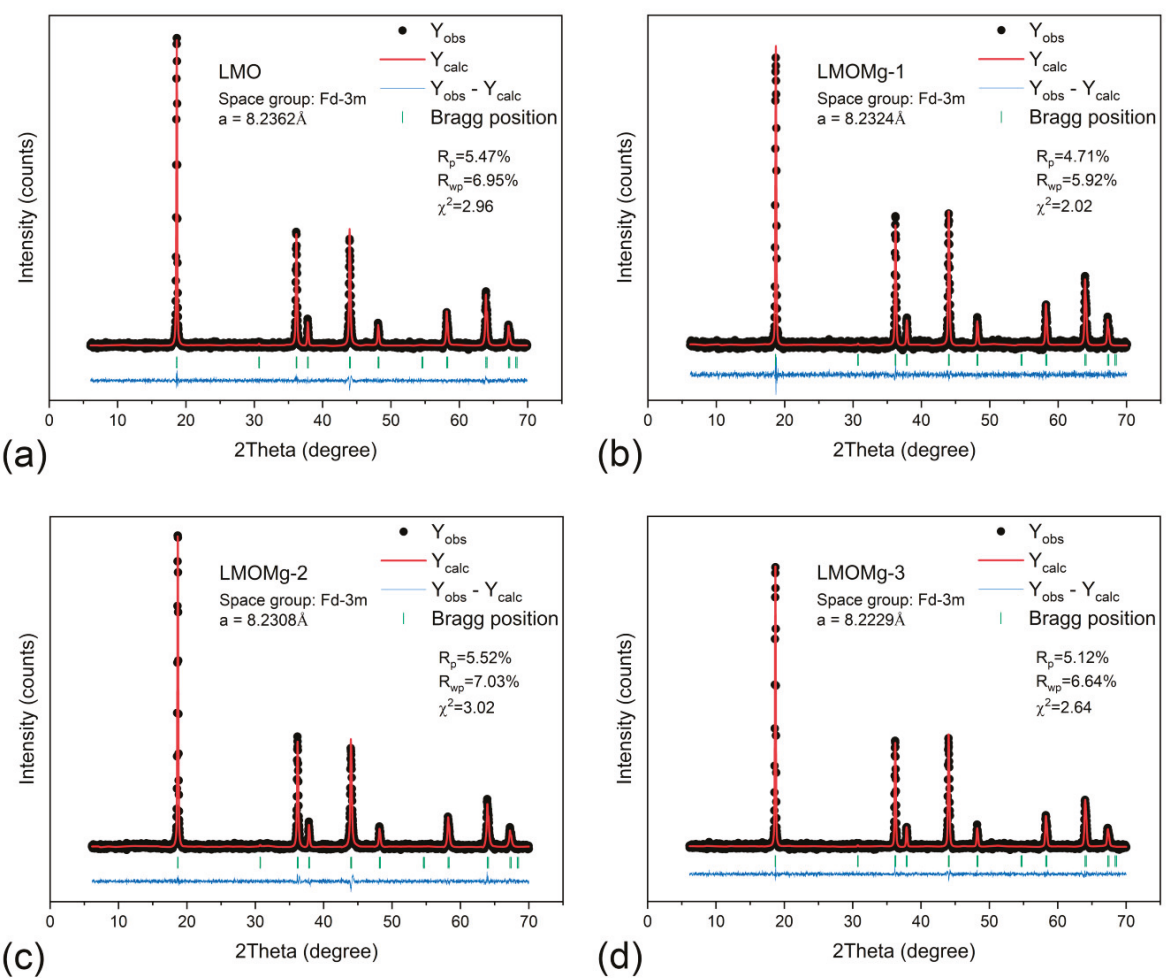

Figure 7. Rietveld refinement results of powder X-ray diffraction (XRD) data from magnesium-doped manganese spinels: (a) LMO, (b) LMOMg-1, (c) LMOMg-2, and (d) LMOMg-3. Data points are shown as black dots. The calculated pattern is shown with a solid red line. Vertical green bars show Bragg peak positions. A blue line at the bottom shows the difference between data and calculated intensities.

The atom location confused degree, which is closely related to the electrochemical properties of the LMO and represents the exchange of atomic sites between lithium and manganese ions that lead to the formation of an anti-spinel structure $[88,89]$, was analyzed through the intensity ratio between the $\mathrm{I}(311) / \mathrm{I}(400)$ peaks. In Table 6, values obtained for the $\mathrm{I}(311) / \mathrm{I}(400)$ ratio were close to a theoretical value of 1.86, corresponding to a LMO spinel without exchange of atomic sites [90], which would indicate that $\mathrm{LiMg}_{x} \mathrm{Mn}_{2-x} \mathrm{O}_{4}$ samples have an insignificant degree of confusion and, therefore, would imply high structural stability of the $\mathrm{Mn}_{2} \mathrm{O}_{4}$ spinel framework.

Scherrer's formula (Equation (34)) [91,92] and full width at half maximum (FWHM) for the main diffraction peaks (111), (311), and (400) were used to describe crystallite size variation in spinels prepared with magnesium doping. Obtained data were summarized as listed in Table 6.

$$
\mathrm{Dc}=\frac{\mathrm{k} \lambda}{\beta \cos \theta}
$$

where crystallite size is denoted by Dc, shape factor or Scherrer constant k is approximately 0.94 for spherical crystals with cubic symmetry, $\lambda$ is the average wavelength of the X-ray beam used $(\mathrm{CuK} \alpha$, $\lambda=1.54178 \AA$ ), $\beta$ is FWHM of the highest intensity peaks, and $\theta$ is Bragg angle in radians.

Results showed that nondoped magnesium spinel had the largest average crystallite size, while for magnesium-doped spinels, average crystallite size increased with increasing doping concentration. This behavior reflected existence of an inverse relationship between nucleation rate and crystallite 
growth with thermal inertia increase, caused by $\mathrm{CO}_{2}$ chemisorption as a result of addition of magnesium. In this way, crystallite size would reflect the amount of energy consumed in $\mathrm{CO}_{2}$ desorption and formation of a thermodynamically stable spinel phase, i.e., small crystallites are resulting from higher energy consumption and vice versa for large crystallites.

Morphology of synthesized nanocrystalline powders was observed in the micrographs shown in Figure 8. $\mathrm{LiMg}_{x} \mathrm{Mn}_{2-\mathrm{x}} \mathrm{O}_{4}$ spinel samples presented a truncated octahedral morphology (insets within Figure 8), which contains mainly truncated planes (111) with a small portion of (100) and (110) planes. The (111) faces possess lowest surface energy, a most dense arrangement of Mn atoms, and can form a stable layer at solid electrolyte interface and mitigate Mn dissolution, thus improving cycle stability, while (100) and (110) truncated faces, with less dense arrangement of ions, are aligned to $\mathrm{Li}^{+}$diffusion channels, therefore increasing discharge capacity and facilitating rate capabilities [93-95].
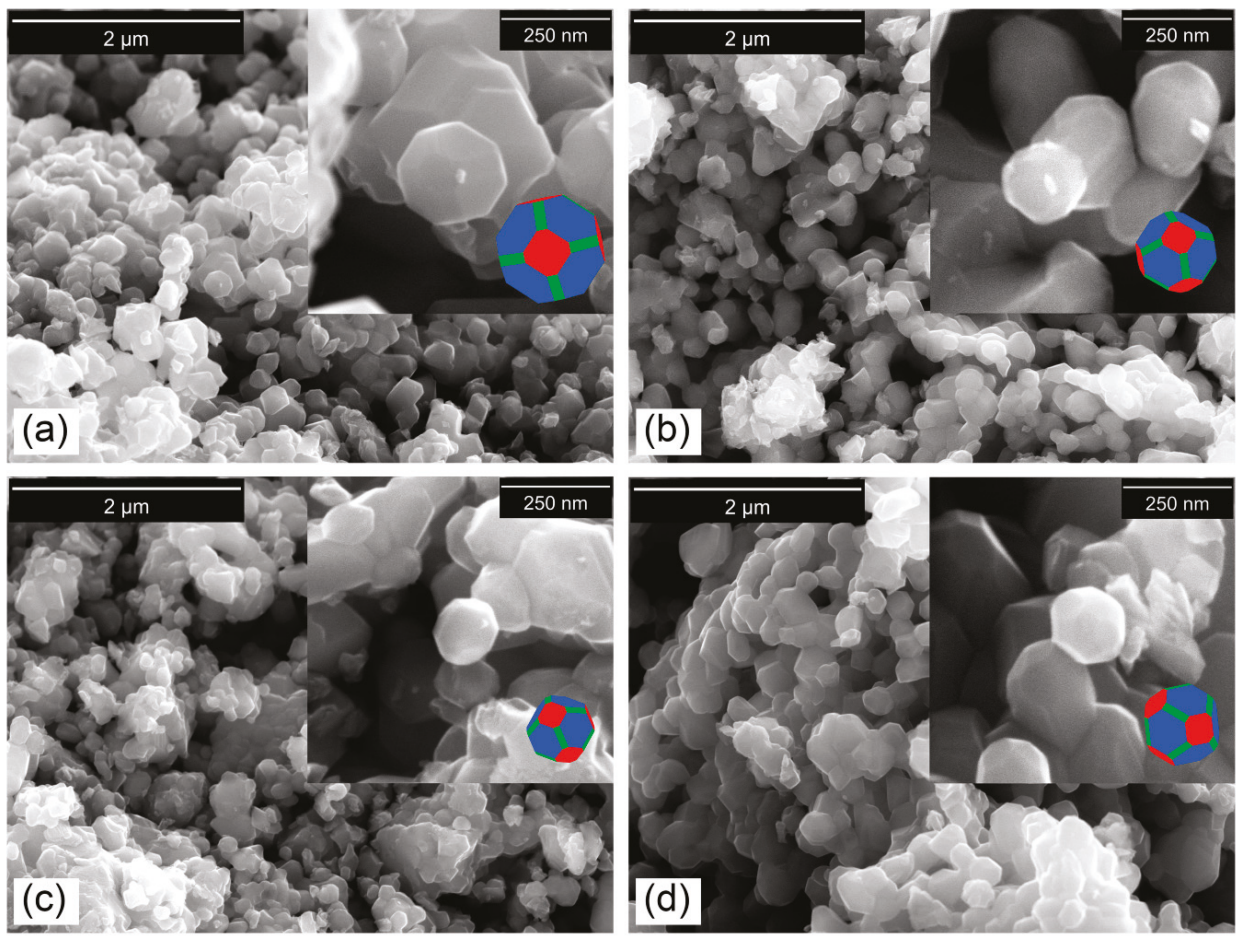

Figure 8. FE-SEM images of the nanometric powders of magnesium-doped manganese spinels: (a) LMO, (b) LMOMg-1, (c) LMOMg-2, and (d) LMOMg-3. Insets show truncated octahedral-type morphology of primary particles that make up spinel powders. The (111) planes in blue, (100) planes in red, and (110) planes in green.

On the other hand, as shown in Figure 8, primary particles would be in a slightly agglomerated state, which could be beneficial to provide a good material-packing density leading to higher bulk capacity.

The particle size distribution was determined by measuring the equivalent circle diameter of the primary particles. The resulting values were plotted on histograms and cumulative curves as shown in Figure 9. The frequency distribution was adjusted with a Gaussian function and the results on average diameters of nanoparticles are summarized in Table 7. 

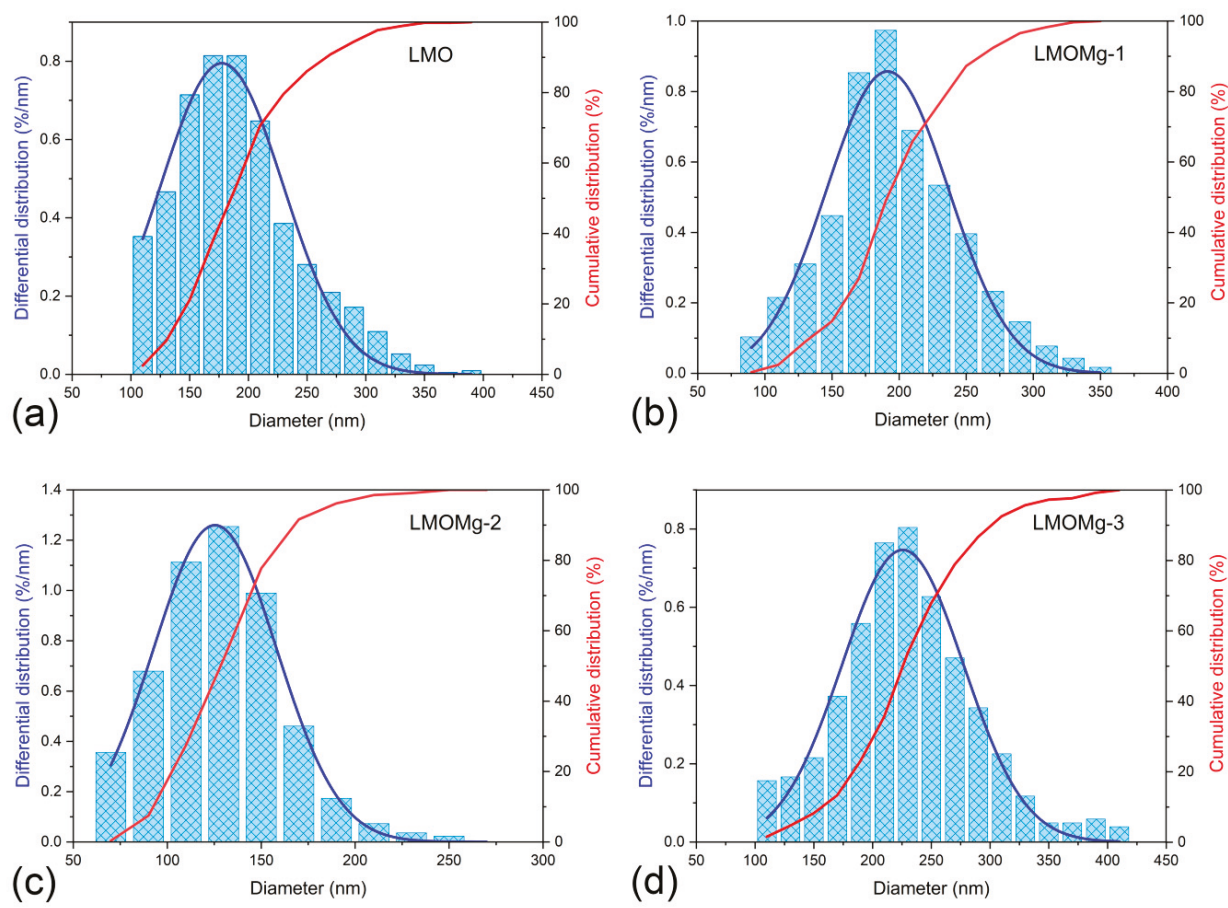

Figure 9. Differential and cumulative distribution of particle size of the nanometric powders of magnesium-doped manganese spinels: (a) LMO, (b) LMOMg-1, (c) LMOMg-2, and (d) LMOMg-3.

Table 7. Results of statistical analysis of the particle size distribution for $\mathrm{LiMg}_{x} \mathrm{Mn}_{2-\mathrm{x}} \mathrm{O}_{4}(\mathrm{x}=0.00,0.02$, $0.05,0.10)$ samples.

\begin{tabular}{ccccc}
\hline Sample & LMO & LMOMg-1 & LMOMg-2 & LMOMg-3 \\
\hline Mean diameter $(\mathrm{nm})$ & 177.5 & 191.4 & 125.4 & 225.7 \\
Standard Deviation $(\mathrm{nm})$ & 52.3 & 45.7 & 32.9 & 51.8 \\
\hline
\end{tabular}

The variation of the mean diameter of the primary particles with the magnesium doping concentration was consistent with the kinetic and thermodynamic parameters obtained, because large particle sizes are related to fast reactions and with lower energy consumption for spinel phase formation.

\section{Conclusions}

Through mass-loss profiles of synthesis precursors, four thermal decomposition zones were defined: (1) Dehydration, (2) polymeric matrix decomposition, (3) carbonate decomposition and formation of manganese oxide spinel, and (4) manganese oxide spinel decomposition. Thermal decomposition of polymeric matrix was identified as the main zone that encompassed fundamental reactions initiating formation of a thermodynamically stable $\mathrm{LiMn}_{2} \mathrm{O}_{4}$ spinel phase.

In the polymeric matrix decomposition zone, magnesium incorporation favored $\mathrm{CO}_{2}$ chemisorption reaction and decreased the thermal conductivity of synthesis precursors. Inverse variation of thermal inertia with magnesium concentration caused a displacement of conversion curves at high temperatures and a decrease in conversion rate.

The nonlinear least-squares technique was applied to determine kinetic triplets, $\left(\mathrm{E}_{\mathrm{a}}, \mathrm{A}\right.$, and $\mathrm{f}(\alpha)$ ), by adjusting conversion rate profiles with a scheme of five successive reactions. The first-order Avrami-Erofeev equation was the reaction model that represented the polymeric matrix decomposition 
zone, and high average Arrhenius parameters values ( $\mathrm{E}_{\mathrm{a}}$ and $\mathrm{A}$ ) would be related to low $\mathrm{CO}_{2}$ sorption and lower energy requirement for pure spinel phase formation with and without magnesium doping.

Thermodynamic functions $\left(\Delta \mathrm{S}^{\neq}, \Delta \mathrm{G}^{\neq}\right.$, and $\left.\Delta \mathrm{H}^{\neq}\right)$revealed that activated complexes' formation would be associated with nonspontaneous endothermic processes. Evaluation of $\Delta S^{\neq}$revealed that thermal decomposition of the SPMg-1 and SPMg-2 precursors with low magnesium content would be associated with slow reactions $\left(\Delta \mathrm{S}^{\neq}<0\right)$, while fast reactions would be related to the SP and SPMg-3 precursors without doping and with higher magnesium concentration, respectively.

From analysis of kinetic and thermodynamic results, it was established that $\mathrm{CO}_{2}$ desorption was the limiting step in formation of thermodynamically stable spinel phases with and without magnesium doping.

Based on TG experiments and the effect of magnesium on kinetics and thermodynamics of thermal decomposition of synthesis precursors, a two-stage heat treatment program was determined for synthesis of $\mathrm{LiMg}_{\mathrm{x}} \mathrm{Mn}_{2-\mathrm{x}} \mathrm{O}_{4}(\mathrm{x}=0.00,0.02,0.05,0.10)$ : Calcination at $500{ }^{\circ} \mathrm{C}$ for $4 \mathrm{~h}$ and sintering at $750{ }^{\circ} \mathrm{C}$ for $12 \mathrm{~h}$. The result was a series of nanometric powders, in a mean diameter range of $125.4 \pm 32.9 \mathrm{~nm}$ to $225.7 \pm 51.8 \mathrm{~nm}$ of pure phase with truncated octahedral morphology and cubic structure of $\mathrm{LiMn}_{2} \mathrm{O}_{4}$ spinel with $\mathrm{Fd} \overline{3} \mathrm{~m}$ space group.

Heat treatment conditions partially modified stoichiometry of the prepared spinels due to retention of an excess lithium fraction, which decreased manganese molar ratio but increased its average oxidation state.

Replacement of $\mathrm{Mn}^{3+}$ by $\mathrm{Mg}^{2+}$ did not change the cubic spinel structure but caused a unit cell shrinkage, where cell parameter " $a$ " decreased in inverse proportion to an increase in " $x$ ".

Growth rate of the primary particles of spinel powder was affected by magnesium concentration and, consequently, by the amount of $\mathrm{CO}_{2}$ chemisorption. Thus, large crystals were formed from precursors with lower $\mathrm{CO}_{2}$ sorption and vice versa for small crystals.

The method developed for kinetic and thermodynamic analysis proved to be a powerful tool for obtaining theoretical information useful for determining optimal heat treatment parameters for preparing high crystallinity, structural stability, and homogeneous morphology of $\mathrm{LiMg}_{\mathrm{x}} \mathrm{Mn}_{2-\mathrm{x}} \mathrm{O}_{4}$ compounds. All these characteristics make them promising cathode materials for lithium ion batteries. A deep study of their electrochemical properties is planned to be carried out in future work.

Author Contributions: Conceptualization, A.L., S.U., and M.G.; methodology, A.L.; software, A.L.; formal analysis, A.L., S.U., and M.G.; investigation, A.L. and M.G.; data curation, A.L.; writing-original draft preparation, A.L. and M.G.; writing-review and editing, M.G. and S.U.; supervision, M.G.; funding acquisition, M.G. and S.U. All authors have read and agreed to the published version of the manuscript.

Funding: Research presented in this article was funded by Programa Formación de Capital Humano Avanzado from Comisión Nacional de Investigación Científica y Tecnológica (CONICYT-PCHA/DoctoradoNacional/2015-21151464), Fondo de Financiamiento de Centros de Investigación en Áreas Prioritarias (ANID/FONDAP/15110019) Fondo Nacional de Desarrollo Científico y Tecnológico (FONDECYT REGULAR N 1191347) and Programa Ingeniería 2030 from Corporación de Fomento de la Producción (ING2030 CORFO 16ENI2-71940).

Acknowledgments: The authors are grateful for contribution of the MAINI-UCN (Universidad Católica del Norte, Antofagasta, Chile) Scientific Equipment Unit, for providing access to FE-SEM SU5000 Hitachi equipment.

Conflicts of Interest: The authors declare no conflict of interest.

\section{References}

1. Stan, A.; Świerczyński, M.; Stroe, D.; Teodorescu, R.; Andreasen, S.J. Lithium ion battery chemistries from renewable energy storage to automotive and back-up power applications-An overview. In Proceedings of the 2014 International Conference on Optimization of Electrical and Electronic Equipment (OPTIM), Brain, Romania, 22-24 May 2014; pp. 713-720.

2. Nitta, N.; Wu, F.; Lee, J.T.; Yushin, G. Li-ion battery materials: Present and future. Mater. Today 2015, 18, 252-264. [CrossRef]

3. Zhang, H.; Zhao, H.; Khan, M.A.; Zou, W.; Xu, J.; Zhang, L.; Zhang, J. Recent progress in advanced electrode materials, separators, and electrolytes for lithium batteries. J. Mater. Chem. A 2018, 6, 20564-20620. [CrossRef] 
4. Bresser, D.; Hosoi, K.; Howell, D.; Li, H.; Zeisel, H.; Amine, K.; Passerini, S. Perspectives of automotive battery R\&D in China, Germany, Japan, and the USA. J. Power Sources 2018, 382, 176-178. [CrossRef]

5. Liu, X.; Li, K.; Li, X. The Electrochemical Performance and Applications of Several Popular Lithium-ion Batteries for Electric Vehicles-A Review. Biomed. Eng. Syst. Technol. 2018, 925, 201-213. [CrossRef]

6. Miao, Y.; Hynan, P.; von Jouanne, A.; Yokochi, A. Current Li-Ion Battery Technologies in Electric Vehicles and Opportunities for Advancements. Energies 2019, 12, 1074. [CrossRef]

7. Ding, Y.; Cano, Z.P.; Yu, A.; Lu, J.; Chen, Z. Automotive Li-Ion Batteries: Current Status and Future Perspectives. Electrochem. Energy Rev. 2019, 2, 1-28. [CrossRef]

8. Zubi, G.; Dufo-López, R.; Carvalho, M.; Pasaoglu, G. The lithium-ion battery: State of the art and future perspectives. Renew. Sustain. Energy Rev. 2018, 89, 292-308. [CrossRef]

9. Blomgren, G.E. The Development and Future of Lithium Ion Batteries. J. Electrochem. Soc. 2016, 164, A5019-A5025. [CrossRef]

10. Potapenko, A.V.; Kirillov, S.A. Lithium manganese spinel materials for high-rate electrochemical applications. J. Energy Chem. 2014, 23, 543-558. [CrossRef]

11. Ahmad, M. Review on Synthesis, Characterizations, and Electrochemical Properties of Cathode Materials for Lithium Ion Batteries. J. Mater. Sci. Eng. 2016, 5. [CrossRef]

12. Xiao, W.; Xin, C.; Li, S.; Jie, J.; Gu, Y.; Pan, F.; Zheng, J.-X. Insight into fast Li diffusion in Li-excess spinel lithium manganese oxide. J. Mater. Chem. A 2018, 6, 9893-9898. [CrossRef]

13. Julien, C.M.; Mauger, A.; Zaghib, K.; Groult, H. Comparative Issues of Cathode Materials for Li-Ion Batteries. Inorganics 2014, 2, 132-154. [CrossRef]

14. Manthiram, A. A reflection on lithium-ion battery cathode chemistry. Nat. Commun. 2020, 11, 1-9. [CrossRef] [PubMed]

15. Tang, D.; Ben, L.; Sun, Y.; Chen, B.; Yang, Z.; Gu, L.; Huang, X. Electrochemical behavior, and surface structural change of LiMn2O4charged to 5.1 V. J. Mater. Chem. A 2014, 2, 14519-14527. [CrossRef]

16. Tomaszewska, A.; Chu, Z.; Feng, X.; O’Kane, S.; Liu, X.; Chen, J.; Ji, C.; Endler, E.; Li, R.; Liu, L.; et al. Lithium-ion battery fast charging: A review. eTransportation 2019, 1, 100011. [CrossRef]

17. Zhan, C.; Wu, T.; Lu, J.; Amine, K. Dissolution, migration, and deposition of transition metal ions in Li-ion batteries exemplified by Mn-based cathodes-A critical review. Energy Environ. Sci. 2018, 11, $243-257$. [CrossRef]

18. Yang, Z.; Wang, Y.; Chen, X.; Wu, H.; Zhang, Y. Mg 2+ and Ti 4+ Co-Doped Spinel LiMn $2 \mathrm{O} 4$ as Lithium-Ion Battery Cathode. Chemistry 2019, 4, 9583-9589. [CrossRef]

19. Kasnatscheew, J.; Streipert, B.; Röser, S.; Wagner, R.; Laskovic, I.C.; Winter, M. Determining oxidative stability of battery electrolytes: Validity of common electrochemical stability window (ESW) data and alternative strategies. Phys. Chem. Chem. Phys. 2017, 19, 16078-16086. [CrossRef]

20. Dou, S. Review, and prospects of Mn-based spinel compounds as cathode materials for lithium-ion batteries. Ionics 2015, 21, 3001-3030. [CrossRef]

21. Xu, G.; Liu, Z.; Zhang, C.; Cui, G.; Chen, L. Strategies for improving the cyclability and thermo-stability of LiMn2O4-based batteries at elevated temperatures. J. Mater. Chem. A 2015, 3, 4092-4123. [CrossRef]

22. Susanto, D.; Kim, H.; Kim, J.-Y.; Lim, S.; Yang, J.; Choi, S.A.; Chung, K.Y. Effect of (Mg, Al) double doping on the thermal decomposition of LiMn2O4 cathodes investigated by time-resolved X-ray diffraction. Curr. Appl. Phys. 2015, 15, S27-S31. [CrossRef]

23. Liu, Q.; Wang, S.; Tan, H.; Yang, Z.; Zeng, J. Preparation and Doping Mode of Doped LiMn2O4 for Li-Ion Batteries. Energies 2013, 6, 1718-1730. [CrossRef]

24. Zhao, H.; Li, F.; Liu, X.; Cheng, C.; Zhang, Z.; Wu, Y.; Xiong, W.; Chen, B. Effects of equimolar Mg (II) and $\mathrm{Si}$ (IV) co-doping on the electrochemical properties of spinel LiMn2-2xMgxSixO4 prepared by citric acid assisted sol-gel method. Electrochimica Acta 2015, 151, 263-269. [CrossRef]

25. Nayaka, G.P.; Pai, K.V.; Anjaneya, K.C.; Periasamy, P.; Tripathi, V.S.; Manjannaa, J. Structural, electrical, and electrochemical studies of LiNi0.4 M 0.1Mn1.5O4 (M = Co, Mg) solid solutions for lithium ion battery. Bull. Mater. Sci. 2016, 39, 1279-1284. [CrossRef]

26. Zhao, H.; Liu, X.; Cheng, C.; Li, Q.; Zhang, Z.; Wu, Y.; Chen, B.; Xiong, W. Synthesis and electrochemical characterizations of spinel LiMn1.94MO4 (M = Mn0.06, Mg0.06, Si0.06, (Mg0.03Si0.03)) compounds as cathode materials for lithium-ion batteries. J. Power Sources 2015, 282, 118-128. [CrossRef] 
27. Xiao, Z.H.; Cui, Q.-Q.; Li, X.-L.; Wang, H.-L.; Zhou, Q. Ionothermal synthesis for Mg-doped LiMn1.5Ni0.5O4 spinel with structural stability and high-rate performance. Ionics 2014, 21, 1261-1267. [CrossRef]

28. Wang, X.; Wang, J.; Wu, J.; Zhuang, X.; Ma, M.; Jiang, Z. Surface modification of Mg-doped spinel with different Li-containing manganese oxides. Ionics 2015, 21, 1851-1856. [CrossRef]

29. Wen, W.; Ju, B.; Wang, X.; Wu, C.; Shu, H.; Yang, X. Effects of magnesium and fluorine co-doping on the structural and electrochemical performance of the spinel LiMn2O4 cathode materials. Electrochimica Acta 2014, 147, 271-278. [CrossRef]

30. Zhang, H.; Liu, N.; Zhang, X.; Zhao, C.; Xu, Y. Microwave synthesis of LiMg0.05Mn1.95O4 and electrochemical performance at elevated temperature for lithium-ion batteries. J. Solid State Electrochem. 2013, 18, 569-575. [CrossRef]

31. Liu, M.; Huang, H.-T.; Lin, C.-M.; Chen, J.-M.; Liao, S.-C. Mg gradient-doped LiNi0.5Mn1.5O4 as the cathode material for Li-ion batteries. Electrochimica Acta 2014, 120, 133-139. [CrossRef]

32. Andre, D.; Kim, S.-J.; Lamp, P.; Lux, S.F.; Maglia, F.; Paschos, O.; Stiaszny, B. Future generations of cathode materials: An automotive industry perspective. J. Mater. Chem. A 2015, 3, 6709-6732. [CrossRef]

33. Massarotti, V.; Capsoni, D.; Bini, M. Stability of LiMn2O4 and new high temperature phases in air, $\mathrm{O}_{2}$ and $\mathrm{N}_{2}$. Solid State Commun. 2002, 122, 317-322. [CrossRef]

34. Molenda, M.; Dziembaj, R.; Podstawka, E.; Proniewicz, L. Changes in local structure of lithium manganese spinels (Li:Mn =1:2) characterised by XRD, DSC, TGA, IR, and Raman spectroscopy. J. Phys. Chem. Solids 2005, 66, 1761-1768. [CrossRef]

35. Amatucci, G.; Tarascon, J.-M. Optimization of Insertion Compounds Such as LiMn [sub 2] O [sub 4] for Li-Ion Batteries. J. Electrochem. Soc. 2002, 149, K31. [CrossRef]

36. Paulsen, J.M.; Dahn, J.R. Phase Diagram of Li-Mn-O Spinel in Air. Chem. Mater. 1999, 11, 3065-3079. [CrossRef]

37. Berbenni, V.; Marini, A. Thermoanalytical (TGA-DSC) and high temperature X-ray diffraction (HT-XRD) study of the thermal decomposition processes in Li2CO3-MnO mixtures. J. Anal. Appl. Pyrolysis 2002, 64, 43-58. [CrossRef]

38. Sun, Y.-K.; Oh, I.-H.; Kim, K.Y. Synthesis of Spinel LiMn2O4by the Sol-Gel Method for a Cathode-Active Material in Lithium Secondary Batteries. Ind. Eng. Chem. Res. 1997, 36, 4839-4846. [CrossRef]

39. Hon, Y.-M.; Fung, K.-Z.; Hon, M.H. Effect of Temperature and Atmosphere on Phase Stability and Morphology of LiMn2O4 Powder Synthesized by Citric Acid Gel Process. J. Ceram. Soc. Jpn. 2000, 108, 462-468. [CrossRef]

40. Zhao, M.S.; Song, X.P. Synthesizing kinetics and characteristics for spinel LiMn2O4 with the precursor using as lithium-ion battery cathode material. J. Power Sources 2007, 164, 822-828. [CrossRef]

41. Lin, J.; Yu, M.; Lin, C.; Liu, X. Multiform Oxide Optical Materials via the Versatile Pechini-Type Sol-Gel Process: Synthesis and Characteristics. J. Phys. Chem. C 2007, 111, 5835-5845. [CrossRef]

42. Dimesso, L. Pechini Processes: An Alternate Approach of the Sol-Gel Method, Preparation, Properties, and Applications. In Handbook of Sol-Gel Science and Technology; Springer Science and Business Media LLC: Berlin/Heidelberg, Germany, 2016; pp. 1-22.

43. Danks, A.E.; Hall, S.R.; Schnepp, Z. The evolution of 'sol-gel' chemistry as a technique for materials synthesis. Mater. Horizons 2016, 3, 91-112. [CrossRef]

44. Liu, W.; Farrington, G.C.; Chaput, F.; Dunn, B. Synthesis and Electrochemical Studies of Spinel Phase LiMn [sub 2] O [sub 4] Cathode Materials Prepared by the Pechini Process. J. Electrochem. Soc. 1996, 143, 879-884. [CrossRef]

45. Han, Y.-S.; Kim, H.-G. Synthesis of LiMn2O4 by modified Pechini method and characterization as a cathode for rechargeable Li/LiMn2O4 cells. J. Power Sources 2000, 88, 161-168. [CrossRef]

46. Son, J.; Kim, H.; Park, Y. New preparation method and electrochemical property of LiMn2O4 electrode. Electrochimica Acta 2004, 50, 453-459. [CrossRef]

47. Xiong, L.; Xu, Y.; Tao, T.; Goodenough, J.B. Synthesis, and electrochemical characterization of multi-cations doped spinel LiMn2O4 used for lithium ion batteries. J. Power Sources 2012, 199, 214-219. [CrossRef]

48. Amaral, F.A.D.; Santana, L.K.; Campos, I.O.; Fagundes, W.S.; Xavier, F.F.S.; Canobre, S.C. Pechini Synthesis of Nanostructured Li1.05M0.02Mn1.98O4 ( $\mathrm{M}=\mathrm{Al3}+$ or Ga3+). Mater. Res. 2015, 18, 250-259. [CrossRef]

49. Ptáček, P.; Opravil, T.; Šoukal, F. A Brief Introduction to the History of Chemical Kinetics. In Introducing the Effective Mass of Activated Complex and the Discussion on the Wave Function of this Instanton; IntechOpen: London, UK, 2018. 
50. Vyazovkin, S. Some Basics En Route to Isoconversional Methodology. In Isoconversional Kinetics of Thermally Stimulated Processes; Springer Science and Business Media LLC: Berlin/Heidelberg, Germany, 2015; pp. 1-25.

51. Šesták, J.; Berggren, G. Study of the kinetics of the mechanism of solid-state reactions at increasing temperatures. Thermochim. Acta 1971, 3,1-12. [CrossRef]

52. Šesták, J. Šesták-Berggren equation: Now questioned but formerly celebrated-What is right. J. Therm. Anal. Calorim. 2015, 127, 1117-1123. [CrossRef]

53. Khawam, A.; Flanagan, D.R. Solid-State Kinetic Models: Basics and Mathematical Fundamentals. J. Phys. Chem. B 2006, 110, 17315-17328. [CrossRef]

54. Vlaev, L.T.; Georgieva, V.; Tavlieva, M.P. On the Kinetic Mechanism of Non-Isothermal Degradation of Solids. In Reactions and Mechanisms in Thermal Analysis of Advanced Materials; Wiley: Hoboken, NJ, USA, 2015; pp. 547-578.

55. Hill, J. Principles and Practices of Thermal Analysis and Calorimetry. In Characterization of Materials; Wiley: Hoboken, NJ, USA, 2012.

56. Perejoón, A.; Saánchez-Jimeénez, P.E.; Criado, J.M.; Peérez-Maqueda, L.A. Kinetic Analysis of Complex Solid-State Reactions. A New Deconvolution Procedure. J. Phys. Chem. B 2011, 115, 1780-1791. [CrossRef]

57. Vyazovkin, S. Thermogravimetric Analysis. In Characterization of Materials; Wiley: Hoboken, NJ, USA, 2012.

58. Prime, R.B.; Bair, H.E.; Vyazovkin, S.; Gallagher, P.K.; Riga, A. Thermogravimetric Analysis (TGA). In Thermal Analysis of Polymers; Menczel, J.D., Prime, R.B., Eds.; John Wiley and Sons Inc.: Hoboken, NJ, USA, 2008.

59. van Werde, K.; Mondelaers, D.; Vanhoyland, G.; Nelis, D.; van Bael, M.K.; Mullens, J.; van Poucke, L.C.; van der Veken, B.; Desseyn, H.O. Thermal decomposition of the ammonium zinc acetate citrate precursor for aqueous chemical solution deposition of ZnO. J. Mater. Sci. 2002, 37, 81-88. [CrossRef]

60. Wyrzykowski, D.; Hebanowska, E.; Nowak-Wiczk, G.; Makowski, M.; Chmurzyński, L. Thermal behaviour of citric acid and isomeric aconitic acids. J. Therm. Anal. Calorim. 2010, 104, 731-735. [CrossRef]

61. Apelblat, A. Citric Acid; Springer International Publishing AG: Cham, Switzerland, 2014.

62. Predoana, L.; Jitianu, A.; Voicescu, M.; Apostol, N.G.; Zaharescu, M. Study of formation of $\mathrm{LiCoO}_{2}$ using a modified Pechini aqueous sol-gel process. J. Sol-Gel Sci. Technol. 2015, 74, 406-418. [CrossRef]

63. Allan, J.; Bonner, J.; Werninck, A.; Bowley, H.; Gerrard, D. Thermal studies on itaconic acid compounds of some transition metal ions. Thermochim. Acta 1987, 122, 295-303. [CrossRef]

64. Coats, A.W.; Redfern, J.P. Thermogravimetric analysis. A review. Anal. 1963, 88, 906. [CrossRef]

65. Sunde, T.O.L.; Grande, T.; Einarsrud, M.-A. Modified Pechini Synthesis of Oxide Powders and Thin Films. In Handbook of Sol-Gel Science and Technology; Springer Science and Business Media LLC: Berlin/Heidelberg, Germany, 2016; pp. 1-30.

66. Petrykin, V.; Kakihana, M. Chemistry and Applications of Polymeric Gel Precursors. In Handbook of Sol-Gel Science and Technology; Springer Science and Business Media LLC: Berlin/Heidelberg, Germany, 2018; pp. 81-112.

67. Földvári, M. Handbook of Thermogravimetric System of Minerals and Its Use in Geological Practice; Geological Institute of Hungary (Magyar Állami Földtani Intézet): Budapest, Hungary, 2011.

68. Liu, X.W.; Feng, Y.; Li, H.R.; Zhang, P.; Wang, P. Thermal decomposition kinetics of magnesite from thermogravimetric data. J. Therm. Anal. Calorim. 2011, 107, 407-412. [CrossRef]

69. Stern, K.H. High Temperature Properties and Thermal Decomposition of Inorganic Salts with Oxyanions. In High Temperature Properties and Thermal Decomposition of Inorganic Salts with Oxyanions; CRC Press: Boca Raton, FL, USA, 2000.

70. Beyer, H.; Meini, S.; Tsiouvaras, N.; Piana, M.; Gasteiger, H.A. Thermal and electrochemical decomposition of lithium peroxide in non-catalyzed carbon cathodes for Li-air batteries. Phys. Chem. Chem. Phys. 2013, 15, 11025. [CrossRef] [PubMed]

71. Thackeray, M.; Mansuetto, M.; Dees, D.; Vissers, D. The thermal stability of lithium-manganese-oxide spinel phases. Mater. Res. Bull. 1996, 31, 133-140. [CrossRef]

72. Thackeray, M.; Mansuetto, M.; Bates, J. Structural stability of LiMn2O4 electrodes for lithium batteries. J. Power Sources 1997, 68, 153-158. [CrossRef]

73. Luo, C.; Martin, M. Stability, and defect structure of spinels Li1 + x Mn2 - x O4 - $\delta$ : I. In situ investigations on the stability field of the spinel phase. J. Mater. Sci. 2007, 42, 1955-1964. [CrossRef]

74. Fedunik-Hofman, L.; Bayon, A.; Donne, S.W. Kinetics of Solid-Gas Reactions and Their Application to Carbonate Looping Systems. Energies 2019, 12, 2981. [CrossRef] 
75. Cai, J.; Wu, W.; Liu, R. Isoconversional Kinetic Analysis of Complex Solid-State Processes: Parallel and Successive Reactions. Ind. Eng. Chem. Res. 2012, 51, 16157-16161. [CrossRef]

76. Pomerantsev, A.L.; Kutsenova, A.V.; Rodionova, O.Y. Kinetic analysis of non-isothermal solid-state reactions: Multi-stage modeling without assumptions in the reaction mechanism. Phys. Chem. Chem. Phys. 2017, 19, 3606-3615. [CrossRef] [PubMed]

77. Opfermann, J. Kinetic Analysis Using Multivariate Non-linear Regression. I. Basic concepts. I. Basic concepts. J. Therm. Anal. Calorim. 2000, 60, 641-658. [CrossRef]

78. Nakano, M.; Wada, T.; Koga, N. Exothermic Behavior of Thermal Decomposition of Sodium Percarbonate: Kinetic Deconvolution of Successive Endothermic and Exothermic Processes. J. Phys. Chem. A 2015, 119, 9761-9769. [CrossRef] [PubMed]

79. Vlaev, L.; Nedelchev, N.; Gyurova, K.; Zagorcheva, M. A comparative study of non-isothermal kinetics of decomposition of calcium oxalate monohydrate. J. Anal. Appl. Pyrolysis 2008, 81, 253-262. [CrossRef]

80. Georgieva, V.; Vlaev, L.T.; Gyurova, K. Non-Isothermal Degradation Kinetics of $\mathrm{CaCO}_{3}$ from Different Origin. J. Chem. 2013, 1-12. [CrossRef]

81. Eyring, H. The Activated Complex and the Absolute Rate of Chemical Reactions. Chem. Rev. 1935, 17, 65-77. [CrossRef]

82. Ptáček, P.; Šoukal, F.; Opravil, T. Introduction to the Transition State Theory. In Introducing the Effective Mass of Activated Complex and the Discussion on the Wave Function of this Instanton; IntechOpen: London, UK, 2018.

83. Perez-Benito, J.F. Some Considerations on the Fundamentals of Chemical Kinetics: Steady State, Quasi-Equilibrium, and Transition State Theory. J. Chem. Educ. 2017, 94, 1238-1246. [CrossRef]

84. Hettema, H. Unity of Chemistry and Physics: The Theory of Absolute Reaction Rates; Springer Science and Business Media LLC: Berlin/Heidelberg, Germany, 2017; Volume 7, pp. 69-86.

85. Hashem, A.; Abdel-Ghany, A.; Abuzeid, H.M.; El-Tawil, R.; Indris, S.; Ehrenberg, H.; Mauger, A.; Julien, C.M. EDTA as chelating agent for sol-gel synthesis of spinel LiMn $2 \mathrm{O} 4$ cathode material for lithium batteries. J. Alloy. Compd. 2018, 737, 758-766. [CrossRef]

86. Bhuvaneswari, S.; Varadaraju, U.; Gopalan, R.; Prakash, R. Structural stability, and superior electrochemical performance of Sc-doped LiMn2O4 spinel as cathode for lithium ion batteries. Electrochimica Acta 2019, 301, 342-351. [CrossRef]

87. Subramania, A.; Angayarkanni, N.; Priya, A.R.S.; Gangadharan, R.; Vasudevan, T. Synthesis and characterization of LiMgyMn2-yO4 cathode materials by a modified Pechini process for lithium batteries. Bull. Mater. Sci. 2005, 28, 663-667. [CrossRef]

88. Hashem, A.; Abbas, S.M.; Hou, X.; Eid, A.; Abdel-Ghany, A.E. Facile one step synthesis method of spinel LiMn2O4 cathode material for lithium batteries. Heliyon 2019, 5, e02027. [CrossRef] [PubMed]

89. Zhao, H.; Li, D.; Wang, Y.; Li, F.; Wang, G.; Wu, T.; Wang, Z.; Li, Y.; Su, J. Sol-Gel Synthesis of Silicon-Doped Lithium Manganese Oxide with Enhanced Reversible Capacity and Cycling Stability. Materials 2018, 11, 1455. [CrossRef] [PubMed]

90. Yu, Z.-M.; Zhao, L.-C. Structure, and electrochemical properties of LiMn2O4. Trans. Nonferrous Met. Soc. China 2007, 17, 659-664. [CrossRef]

91. Douafer, S.; Lahmar, H.; Benamira, M.; Rekhila, G.; Trari, M. Physical and photoelectrochemical properties of the spinel LiMn $2 \mathrm{O} 4$ and its application in photocatalysis. J. Phys. Chem. Solids 2018, 118, 62-67. [CrossRef]

92. Chand, P.; Bansal, V.; Sukriti; Singh, V. Effect of $\mathrm{pH}$ values on structural, optical, electrical, and electrochemical properties of spinel LiMn2O4 cathode materials. J. Sci. Adv. Mater. Devices 2019, 4, 245-251. [CrossRef]

93. Jiang, C.; Tang, Z.; Wang, S.; Zhang, Z. A truncated octahedral spinel LiMn 2 O 4 as high-performance cathode material for ultrafast and long-life lithium-ion batteries. J. Power Sour. 2017, 357, 144-148. [CrossRef]

94. Kim, J.-S.; Kim, K.; Cho, W.; Shin, W.H.; Kanno, R.; Choi, J.W. A Truncated Manganese Spinel Cathode for Excellent Power and Lifetime in Lithium-Ion Batteries. Nano Lett. 2012, 12, 6358-6365. [CrossRef]

95. Zhou, S.; Mei, T.; Wang, X.; Qian, Y. Crystal structural design of exposed planes: Express channels, high-rate capability cathodes for lithium-ion batteries. Nanoscale 2018, 10, 17435-17455. [CrossRef]

(C) 2020 by the authors. Licensee MDPI, Basel, Switzerland. This article is an open access article distributed under the terms and conditions of the Creative Commons Attribution (CC BY) license (http://creativecommons.org/licenses/by/4.0/). 



\title{
Hole Transfer Layer Engineering for CdTe Nanocrystal Photovoltaics with Improved Efficiency
}

\author{
Yasi Jiang ${ }^{1,+}$, Yiyang Pan ${ }^{1,+}{ }^{\dagger}$, Wanhua $\mathrm{Wu}^{1,+}{ }^{+}$, Kaiying Luo ${ }^{1,+}$, Zhitao Rong ${ }^{1,+}{ }^{+}$, Sihang Xie ${ }^{1}$, \\ Wencai Zuo ${ }^{1}$, Jingya Yu ${ }^{1}$, Ruibo Zhang ${ }^{1}$, Donghuan Qin ${ }^{1,2, *}$, Wei Xu ${ }^{1,2}$, Dan Wang ${ }^{1,2}$ \\ and Lintao Hou ${ }^{3, *}$
}

1 School of Materials Science and Engineering, South China University of Technology, Guangzhou 510640, China; 201730321056@mail.scut.edu.cn (Y.J.); 201730321247@mail.scut.edu.cn (Y.P.);

201636291439@mail.scut.edu.cn (W.W.); msluoky@mail.scut.edu.cn (K.L.);

201720117942@mail.scut.edu.cn (Z.R.); 201730321308@mail.scut.edu.cn (S.X.);

201730321407@mail.scut.edu.cn (W.Z.); 201730303175@mail.scut.edu.cn (J.Y.);

201730321377@mail.scut.edu.cn (R.Z.); xuwei@scut.edu.cn (W.X.); wangdan@scut.edu.cn (D.W.)

2 State Key Laboratory of Luminescent Materials \& Devices, Institute of Polymer Optoelectronic Materials \& Devices, South China University of Technology, Guangzhou 510640, China

3 Siyuan Laboratory, Guangzhou Key Laboratory of Vacuum Coating Technologies and New Energy Materials, Guangdong Provincial Key Laboratory of Optical Fiber Sensing and Communications,

Department of Physics, Jinan University, Guangzhou 510632, China

* Correspondence: qindh@scut.edu.cn (D.Q.); thlt@jnu.edu.cn (L.H.);

Tel.: +86-020-8711-4346 (D.Q.); +86-020-8522-4386 (L.H.)

+ These authors contributed equally to this work.

Received: 17 June 2020; Accepted: 4 July 2020; Published: 10 July 2020

\begin{abstract}
Interface engineering has led to significant progress in solution-processed CdTe nanocrystal (NC) solar cells in recent years. High performance solar cells can be fabricated by introducing a hole transfer layer (HTL) between CdTe and a back contact electrode to reduce carrier recombination by forming interfacial dipole effect at the interface. Here, we report the usage of a commercial product 2,2',7,7'-tetrakis[N,N-di(4-methoxyphenyl)amino]-9,9'-spirobifluorene (Spiro) as a hole transfer layer to facilitate the hole collecting for CdTe nanocrystal solar cells. It is found that heat treatment on the hole transfer layer has significant influence on the $\mathrm{NC}$ solar cells performance. The $J_{\mathrm{sc}}, V_{\mathrm{oc}}$, and power conversion efficiency (PCE) of NC solar cells are simultaneously increased due to the decreased contact resistance and enhanced built-in electric field. We demonstrate solar cells that achieve a high PCE of $8.34 \%$ for solution-processed CdTe NC solar cells with an inverted structure by further optimizing the HTL annealing temperature, which is among the highest value in CdTe NC solar cells with the inverted structure.
\end{abstract}

Keywords: CdTe; nanocrystal; solar cells; Spiro

\section{Introduction}

Solution-processed nanocrystal (NC) solar cells have demonstrated as a candidate for low cost, environmentally friendly, and large scale "roll to roll" printing product due to their low raw material consumption and simple fabrication process [1-3]. Recently, intensive investigations have been focused on CdTe NC solar cells with an inverted structure [4,5]. Comparing to the conventional CdTe NC solar cells using indium tin oxide (ITO) as the anode, devices with an inverted structure have many advantages, such as long-term stability under ambient conditions by avoiding the usage of low work-function metal cathode on the top of the device and better photon absorption efficiency due to the small distance between the active layer and the illumination source $[6,7]$. Due to the 
high resistance and low doping concentration of CdTe NC thin film, it is difficult to obtain a low resistance contact between $\mathrm{CdTe}$ and the back contact electrode [8]. In order to fabricate efficient CdTe NC solar cells with an inverted structure, matching energy level between the CdTe NC and anode to reduce interfacial recombination is of essential importance to promote solar cell efficiency [9]. Introducing a thin hole transfer layer (HTL) between the CdTe NC and anode has been confirmed to be an effective way to reduce interfacial charge recombination and improve device performance [10]. It is well known that $\mathrm{Cu}$-doped interface layer has been applied successfully to $\mathrm{CdTe}$ thin film solar cells prepared by close-space sublimation (CSS) method [11,12]. Unfortunately, fabricating a homogeneous $\mathrm{Cu}$-doped layer on CdTe NC thin films remains a challenge, since $\mathrm{Cu}$ may diffuse quickly along the crystal boundaries of NCs and restrict further device performance improvement [13]. Yang et al. [14] investigated the application of commercially available poly-[3-(potassium-6-hexanoate)thiophene-2, 5-diy] (P3KT) as a HTL for aqueous processed CdTe NC solar cells with the configuration of $\mathrm{ITO} / \mathrm{SnO}_{2} / \mathrm{CdS} / \mathrm{CdTe} / \mathrm{P} 3 \mathrm{KT} / \mathrm{MoOx} / \mathrm{Au}$ and found that the insertion of P3KT optimized bandgap alignment and enhanced carrier collection efficiency. There were several reports about using triphenylamine type polymers such as poly(diphenylsilane-co-4-vinyl-triphenylamine) (Si-TPA) or poly(phenylphosphine-co-4-vinyl-triphenylamine) (P-TPA) as a HTL. In these reports, high power conversion efficiency (PCE) up to $9 \%$ is obtained, which is the highest value ever reported for CdTe NC solar cells with an inverted structure $[15,16]$. Researchers found that strong binding exists between $\mathrm{Cd}$ and $\mathrm{N}$ atoms and a dipole layer can thus be formed, which effectively decreases interfacial recombination and improves carrier collection efficiency.

In this paper, we develop a commercially available 2,2',7,7'-tetrakis[N,N-di(4-methoxyphenyl)amino] $-9,9^{\prime}$-spirobifluorene (Spiro) as the HTL for CdTe NC solar cells. Spiro has been widely and successfully applied in perovskite solar cells due to its matchable band alignment, good conductivity, and non-reactivity with active layers $[17,18]$. Furthermore, additives such as lithium bis(trifluoromethanesulfonyl) imide (TFSI-Li) [19], copper salts cuprous thiocyanate (CuPC) [20], or $\mathrm{Co}$ (III)-based complexes [21] can increase the conductance of Spiro and further improve device performance. In the case of CdTe NC solar cells, Yang et al. found that by introducing the Spiro HTL, an interfacial dipole layer was formed, which facilitated charge collection and improves open circuit voltage $\left(V_{\mathrm{oc}}\right) / \mathrm{PCE}$ compared to devices without Spiro [22]. Although improved performance (with PCE of 6.56\%) is obtained for the solar cell with the Spiro HTL in this case, the current density vs voltage $(J-V)$ curve shows roll-over phenomena, which imply that large contact resistance exists between the CdTe NC layer and HTL film.

Here, we further study the CdTe NC solar cells with the configuration of ITO/ZnO/CdS/CdSe/ $\mathrm{CdTe} / \mathrm{HTL} / \mathrm{Au}$ by using Spiro as an HTL. The usage of gradient electron transport layer modification in the cathode had been confirmed to decrease carrier recombination and improve the light harvesting efficiency in both short and long wavelength regions [23]. It was found that the annealing temperature on the HTL had a significant effect on the NC solar cells performance. The impact of HTL annealing temperature on the solar cell performance was studied by external quantum efficiency (EQE), $J-V$, capacitance-voltage $(C-V)$ analysis, and transient photovoltage (TPV) measurements. At an optimized annealing temperature, the solar cell with the Spiro HTL had an efficiency of $8.34 \%$, and the $V_{\mathrm{oc}}$, short circuit current density $\left(J_{\mathrm{sc}}\right)$, and fill factor $(\mathrm{FF})$ were $0.71 \mathrm{~V}, 23.11 \mathrm{~mA} / \mathrm{cm}^{2}$, and $50.83 \%$, respectively. On the other hand, the control device delivers an efficiency of $7.08 \%$, and the $V_{\mathrm{oc}}, J_{\mathrm{sc}}$, and FF of $0.65 \mathrm{~V}$, $21.91 \mathrm{~mA} / \mathrm{cm}^{2}$, and $49.71 \%$, respectively. Therefore, the NC device incorporating Spiro HTL shows significant and simultaneous improvements in $J_{\mathrm{sc}}, V_{\mathrm{oc}}$, and FF, which lead to $18 \%$ higher PCE than the device without HTL and 28\% higher PCE than the similar device reported before.

\section{Experiment}

CdS NCs, CdSe NCs, CdTe NCs, and ZnO precursors were prepared based on previous reported methods [15,24]. Spiro (CAS: 207739-72-8) was purchased from Derthon Optoelectronic Materials Science Technology Co., Ltd. (Shenzhen, China) and used as received. The CdTe NC solar cell with the 
$\mathrm{ITO} / \mathrm{ZnO} / \mathrm{CdSe} / \mathrm{CdTe} / \mathrm{Spiro} / \mathrm{Au}$ configuration was fabricated by layer-by-layer spin-coating solution process. In a typical process, as shown in Figure 1, the $\mathrm{Zn}^{2+}$ precursor solution was firstly deposited on ITO substrates by spin-casting and then annealed at $400{ }^{\circ} \mathrm{C}$ for $10 \mathrm{~min}$ to eliminate any organic impurities and form the $\mathrm{ZnO}$ layer. Then, one layer of CdS NCs, two layers of CdSe NCs, and five layers of CdTe NCs films were deposited on the $\mathrm{ZnO}$ film in sequence using a layer-by-layer solution process under ambient conditions, as reported in the literature $[16,25]$. To prepare solution for the fabrication of HTL, Spiro was dissolved in chlorobenzene with a concentration of $80 \mathrm{mg} \cdot \mathrm{mL}^{-1}$ while Li-TFSI was dissolved in acetonitrile with a concentration of $520 \mathrm{mg} \cdot \mathrm{mL}^{-1}$. Then, $1 \mathrm{~mL}$ of Spiro solution, $18 \mu \mathrm{L}$ of Li-TFSI solution, and $29 \mu \mathrm{L}$ of 4-tert-butylpyridine were mixed together to obtain the Li-doped Spiro precursor. Several drops of Li-doped Spiro precursor were then put on top of the $\mathrm{CdTe}$ NC thin film and spin-casted at $3000 \mathrm{rpm}$ for $20 \mathrm{~s}$. The above substrates were then annealed at $25 \sim 120{ }^{\circ} \mathrm{C}$ for $15 \mathrm{~min}$ under ambient conditions to improve conductivity and preserved in a desiccator for overnight oxidation of the Spiro [26]. Finally, a gold electrode $(80 \mathrm{~nm})$ was deposited via thermal evaporation through a shadow mask with an active area of $0.16 \mathrm{~cm}^{2}$.

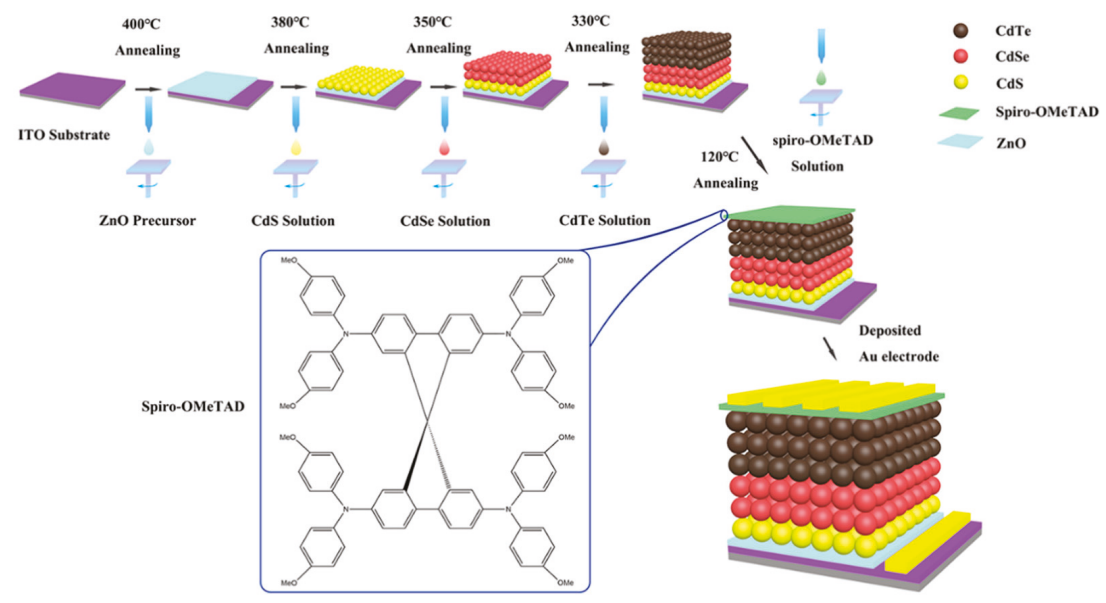

Figure 1. A schematic of the fabrication process of nanocrystal (NC) solar cells.

\section{Results and Discussion}

Small-molecule Spiro is widely used as the HTL in optoelectronic devices. The ultraviolet-visiblenear-infrared (UV-Vis-NIR) absorption spectrum of the Spiro in toluene is shown in Figure 2a. The optical bandgap of Spiro is $3.0 \mathrm{eV}$, calculated from its absorption onset of $412 \mathrm{~nm}$. The electrochemical behavior of the Spiro was investigated by cyclic voltammetry (CV) measurement, which is used to investigate the highest occupied molecular orbital (HOMO) and lowest occupied molecular orbital (LUMO) levels of Spiro. The CV characterization was performed in a solution of Bu4NPF6 (0.1 M) (with acetonitrile as solvent) at a scan rate of $50 \mathrm{mV} \cdot \mathrm{s}^{-1}$ at room temperature under argon. A drop of $1 \mathrm{mg} \cdot \mathrm{mL}^{-1}$ Spiro/toluene solution was put on the platinum electrode. After drying, the platinum electrode was immersed into the electrochemical cell and used as the working electrode. A Pt wire was used as the counter electrode, while a saturated calomel electrode was selected as the reference electrode. From the $C V$ curve shown in Figure $2 \mathrm{~b}$, the oxidation potential $\left(E_{\mathrm{ox}}\right)$ is located at $0.80 \mathrm{~V}$. Therefore, the $\mathrm{HOMO}$ of Spiro is $-5.20 \mathrm{eV}$ according to the empirical formula $E_{\mathrm{HOMO}}=-\left(E_{\mathrm{ox}}\right.$, onset +4.4$)$, which is confirmed in the literature [27]. The corresponding LUMO level of Spiro is $-2.2 \mathrm{eV}$ based on the optical bandgap value and HOMO value $(-5.2+3.0=-2.20 \mathrm{eV})$. In previous work [15], we found that the work function of CdTe NC thin film is $5.17 \mathrm{eV}$. Therefore, the Spiro will match well with the CdTe NC thin film, which is essential for decreasing energy loss and maximizing output voltage. 

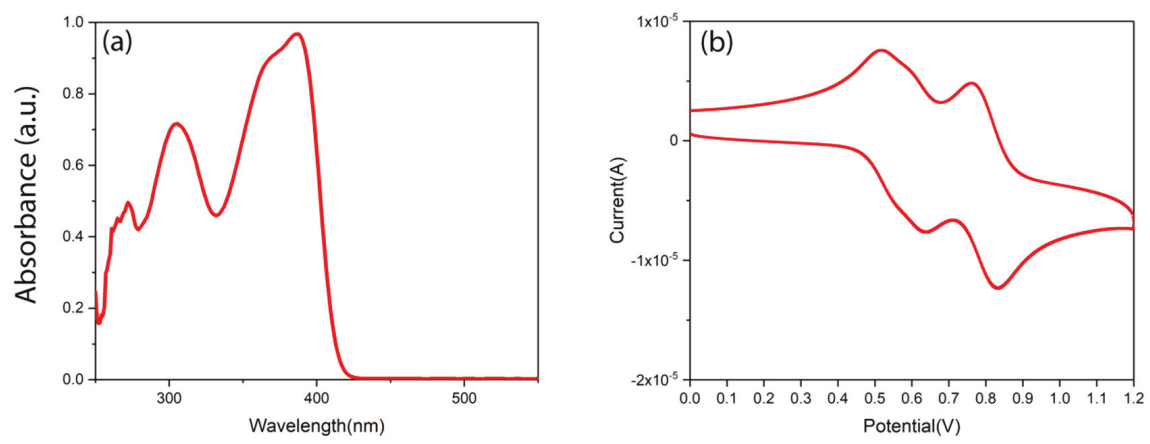

Figure 2. (a) Ultraviolet-visible (UV-Vis) spectrum of 2,2',7,7'-tetrakis[N,N-di(4-methoxyphenyl)amino] $-9,9^{\prime}$-spirobifluorene (Spiro) in chlorobenzene solution; (b) cyclic voltammetry curve of Spiro in acetonitrile solution.

Figure 3 shows the top view atomic Atomic force microscopy (AFM) images of as-deposited $\mathrm{ITO} / \mathrm{ZnO} / \mathrm{CdS} / \mathrm{CdSe} / \mathrm{CdTe} /$ Spiro (with/without) in a large area $(15 \mu \mathrm{m} \times 15 \mu \mathrm{m})$. Although the NC film was compact and flat (with a root mean square value of $7.12 \mathrm{~nm}$ ), there are still some distinct pinholes along with the continuous CdTe NC film, which may increase the leakage current due to the interface defects (Figure 3a). On the contrary, the NC thin film is covered almost entirely by the Spiro and it shows almost no pinholes in a large area. The whole film is much smoother and more homogeneous with a root mean square value of $4.21 \mathrm{~nm}$. Therefore, the introduction of Spiro HTL between the active layer and $\mathrm{Au}$ anode can form a passivation layer on the $\mathrm{CdTe} \mathrm{NC}$ layer, which is expected to decrease interface recombination and improve carrier collecting efficiencies.
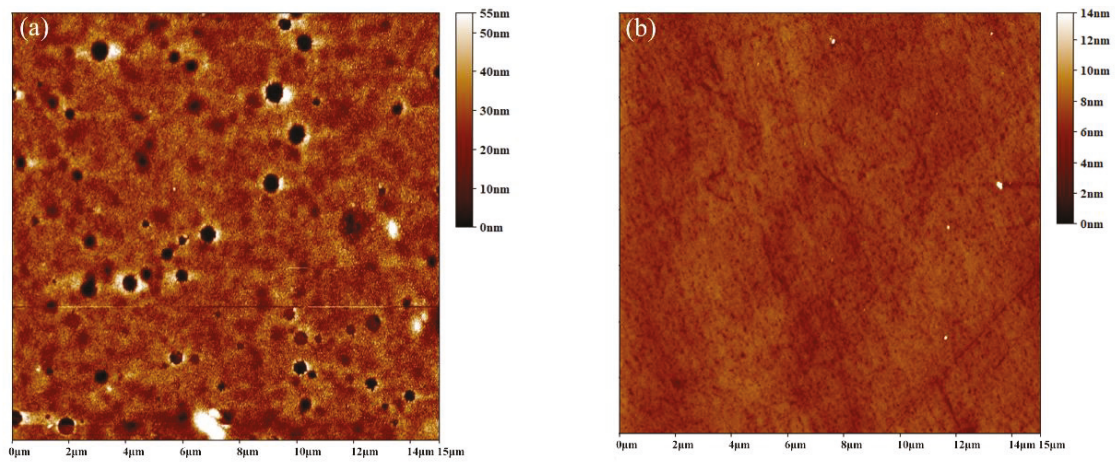

Figure 3. Atomic force microscopy (AFM) images of (a) indium tin oxide (ITO)/ZnO/CdS/CdTe and (b) ITO/ZnO/CdS/CdTe/Spiro thin films.

Figure 4a shows the schematic diagram of the NC solar cell with a bright-field (BF) transmission electron microscope (TEM) cross-sectional image of the actual device. The device includes a $40 \mathrm{~nm}$ $\mathrm{ZnO} / \mathrm{ITO}$ cathode, a gradient electron transport layer (30 nm CdS NC/60 nm CdSe), a 500 nm CdTe $\mathrm{NC}$ active layer, and a Spiro-OMe/Au anode. The CdSe $\mathrm{Te} 1-\mathrm{x}$ alloy layer is formed easily when growing and post-treating the CdTe layer as Se has a high miscibility with Te [25]. Therefore, there is no clear boundary between the CdSe NC and CdTe NC layer. The band alignment of the NC device is presented in Figure $4 \mathrm{~b}$. The valance band (VB) of CdTe NC is $5.3 \mathrm{eV}$, which is slightly higher than the HOMO of Spiro HTL (5.2 eV). As Spiro is $p$-type doping, holes can be collected by the anode while the electron can be reflected at the interface of NC/HTL $(-2.2 \mathrm{eV})$. To investigate the effect of 
Spiro HTL on device performance, solar cells with configurations of ITO/ZnO/CdS/CdSe/CdTe/Spiro (with/without)/Au were fabricated. The devices with the Spiro HTL are preserved in a desiccator for overnight oxidation of Spiro to improve conductivity, which were widely adopted for perovskite solar cells [27]. Figure 4c,d presents the $J-V$ curves of CdTe NC solar cells with/without HTL, while the insets show the performance parameters such as $V_{\mathrm{oc}}, J_{\mathrm{sc}}, \mathrm{FF}$, and PCE. The control device under optimized conditions (device structure: $\mathrm{ITO} / \mathrm{ZnO} / \mathrm{CdS} / \mathrm{CdSe} / \mathrm{CdTe} / \mathrm{Au}$ ) shows a $V_{\text {oc }}$ of $0.65 \mathrm{~V}$, a $J_{\text {sc }}$ of $21.91 \mathrm{~mA} \mathrm{~cm}^{-2}$, and a FF of $49.71 \%$, resulting in a PCE of $7.08 \%$, which is similar to the results reported in our previous works [16]. In the case of the NC solar cell with the Spiro HTL (device structure: $\mathrm{ITO} / \mathrm{ZnO} / \mathrm{CdS} / \mathrm{CdSe} / \mathrm{CdTe} / \mathrm{HTL} / \mathrm{Au}$ ), it shows a high $V_{\mathrm{oc}}$ of $0.69 \mathrm{~V}$, a very low $J_{\mathrm{sc}}$ of $14.55 \mathrm{~mA} \mathrm{~cm}^{-2}$, a low FF of $44.2 \%$, leading to a low PCE of $4.44 \%$. As a result, the device performance with HTL is significantly lower than the control device, which is quite different from the previous report [22]. We speculate that since the NC synthesis method and device structure as well as device fabrication process in our research are quite different from the previous report, the amount of interface defects at $\mathrm{CdTe} / \mathrm{HTL}$ might be at a high level in this device, resulting in large carrier recombination and poor device performance. It should be noted that the $J-V$ curve of NC device with HTL shows roll over phenomenon, which is similar to the ones reported by Yang et al. [22]. Large contact resistance at the interface of CdTe/HTL due to the weak interaction between the CdTe NCs and Spiro molecules might account for this phenomenon.

(a)
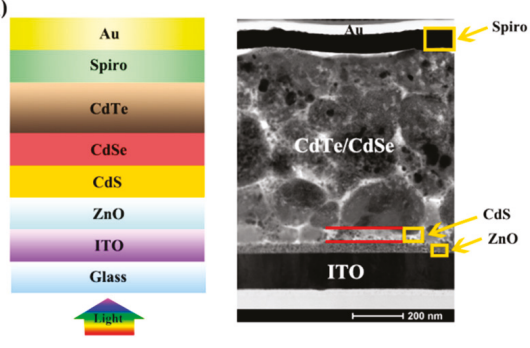

(c)

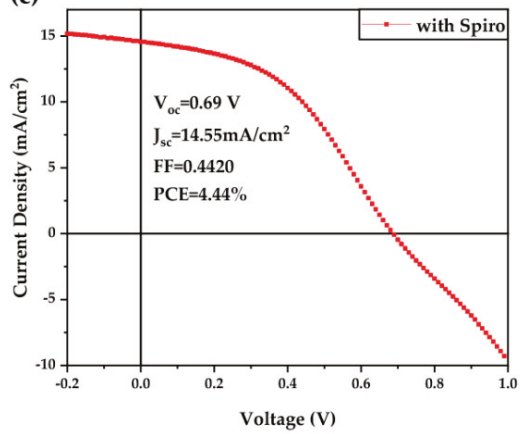

(b)

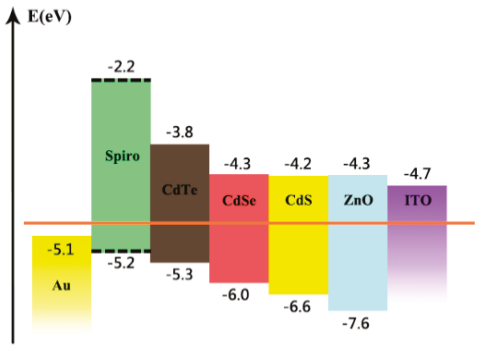

(d)

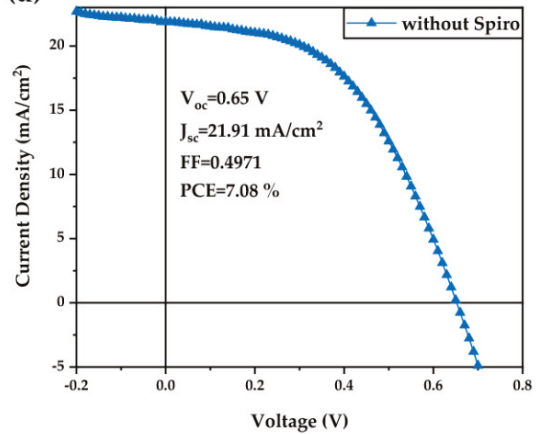

Figure 4. (a) The NC solar cell configuration and bright-field (BF) transmission electron microscope (TEM) cross-sectional image of the corresponding device; scale bar: $200 \mathrm{~nm}$; (b) band alignment of the NC solar cell with the Spiro hole transfer layer (HTL); (c) current density vs voltage $(J-V)$ curve of NC solar cells with the Spiro HTL (prepared at room ambient condition) and (d) $J-V$ curve of the control device (without using the Spiro HTL). 
It is well known that an appropriate annealing temperature is essential for improving the homogeneous morphology, increasing binding force between the HTL and CdTe NC film, eliminating interface defects, and optimizing carrier mobility of HTL. In previous reports [15,16], we found that heat treatment on HTL at around $120^{\circ} \mathrm{C}$ can significantly improve device performance by improving carrier collection efficiency and reducing contact resistance. Inspired by these successful practices, in order to overcome the drawback of contact resistance, the ITO/ZnO/CdS/CdSe/CdTe/HTL samples are heat-treated at different annealing temperatures from 25 to $180{ }^{\circ} \mathrm{C}$ for $10 \mathrm{~min}$ at ambient conditions. Then they are placed in a desiccator overnight before Au deposition. Figure 5a shows the PCE of NC solar cells with different HTL annealing temperatures, while the $J-V$ curves with different annealing temperatures are presented in Figure S1. The photovoltaic parameters are summarized in Table 1. It is found that PCE increases linearly as temperature increases from 50 to $120^{\circ} \mathrm{C}$, which is primarily ascribed to the increasement in $J_{\mathrm{sc}}$ from 13.04 to $\sim 23 \mathrm{~mA} / \mathrm{cm}^{2}$. Noted that the optimized annealing temperature is located between 110 and $120^{\circ} \mathrm{C}$. A PCE up to $8 \%$ is obtained in these cases, which shows almost two times higher than that of a device with $\mathrm{HTL}$ annealed at $50^{\circ} \mathrm{C}$. The $\mathrm{NC}$ device performance decays when the annealing temperature further increases and a PCE of only $1.27 \%$ is obtained at $180{ }^{\circ} \mathrm{C}$. In addition, $\mathrm{NC}$ devices with the Spiro HTL annealed at $110 \sim 130{ }^{\circ} \mathrm{C}$ show low series resistance $\left(R_{\mathrm{s}}\right.$, Table 1$)$ as a result of reduction in interfacial contact resistance (CdTe/HTL). From Figure 5b, one can see that the NC devices have very good repeatability. The 40 devices at least from eight individual batches are fabricated with PCE ranging from $7.6 \%$ to $8.4 \%$, producing an average value of about $8.2 \%$ (annealing temperature at 110 and $120^{\circ} \mathrm{C}$ ). More importantly, there is almost no roll over phenomenon on $J-V$ curves of devices annealed at temperature higher than $80^{\circ} \mathrm{C}$. Figure $5 \mathrm{c}, \mathrm{d}$ presents the $J-V$ and EQE curves of the champion and control devices. The champion device annealed at $120^{\circ} \mathrm{C}$ displays the following figures of merit: $J_{\mathrm{sc}}$ of $23.11 \mathrm{~mA} / \mathrm{cm}^{2}, V_{\mathrm{oc}}$ of $0.71 \mathrm{~V}$, FF of $50.83 \%$, and a high PCE of $8.34 \%$, which is among the highest PCE ever reported for CdTe NC solar cells with an inverted configuration. The PCE value obtained here shows a $28 \%$ improvement compared to previous report about CdTe NC solar cells with Spiro as HTL [22] (Table 1) and is 18\% higher than the control device. From Figure 5d, the EQE spectrum of device with the Spiro HTL shows a higher value than that of the control device from 600 to $900 \mathrm{~nm}$, which attributes to the reduction of interface recombination on $\mathrm{CdTe} /$ contact electrode and increase of effective carrier collection. By integrating the EQE curves, the calculated $J_{\mathrm{sc}}$ of $23.10 \mathrm{~mA} / \mathrm{cm}^{2}$ and $21.90 \mathrm{~mA} / \mathrm{cm}^{2}$ are predicted, which are consistent with the measured $J_{\mathrm{sc}}$ presented in the $J-V$ curves. The obvious improvement in performance of NC devices with Spiro HTL implies that Spiro is a good hole transfer material for CdTe NC solar cells. Among the devices with HTL, compared to the device without annealing, the device annealed at $\sim 120^{\circ} \mathrm{C}$ shows apparently higher PCE ( $8.34 \%$ vs. $4.44 \%$ ). This might be a result of more effective exciton separation and carrier collection due to the reinforcement of the $\mathrm{Cd}-\mathrm{N}$ bond and enhancement of the inner electric field by the formation of dipole layer (CdTe/HTL) when annealing at a relatively high temperature. To confirm this, the surface of ITO/ZnO/CdS/CdSe/CdTe/Spiro is characterized by X-ray photoelectron spectroscopy (XPS). From the narrow scan XPS of Cd 3d 3/2 and 5/2 spectrum for Spiro annealed at $120^{\circ} \mathrm{C}$ and $25^{\circ} \mathrm{C}$ (Figure S2 and Table S1), one can see that the binding energies of Cd 3d5/2 and Cd $3 \mathrm{~d} 3 / 2$ are $411.88 \mathrm{eV}$ and $405.08 \mathrm{eV}$, respectively, for the film annealed at $25^{\circ} \mathrm{C}$, while these values are $412.18 \mathrm{eV}$ and $405.38 \mathrm{eV}$ for Spiro annealed at $120^{\circ} \mathrm{C}$, respectively. Therefore, a higher $0.3 \mathrm{eV}$ value is obtained for Spiro annealed at $120^{\circ} \mathrm{C}$, which implies a strong $\mathrm{Cd}-\mathrm{N}$ bonding existence in this case, conforming to the results reported before [16]. Moreover, as shown in Figure S3a,b, compared to the HTL without annealing, the HTL annealed at $120^{\circ} \mathrm{C}$ presents a smoother surface (root mean square value of 2.56 vs. $4.49 \mathrm{~nm}$ ), which indicates less interface defects. The decrease in device performance at a relatively high annealing temperature $\left(>130^{\circ} \mathrm{C}\right)$ is likely to be a result of excess diffusion of Li into active layer and excess oxidation of Spiro at high temperature as the annealing treatment was carried out at ambient conditions. 
(a)

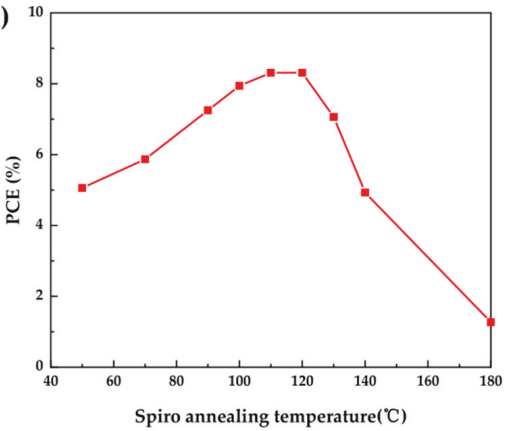

(c)

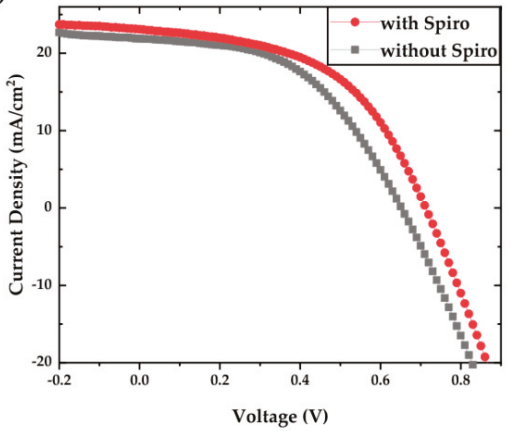

(b)

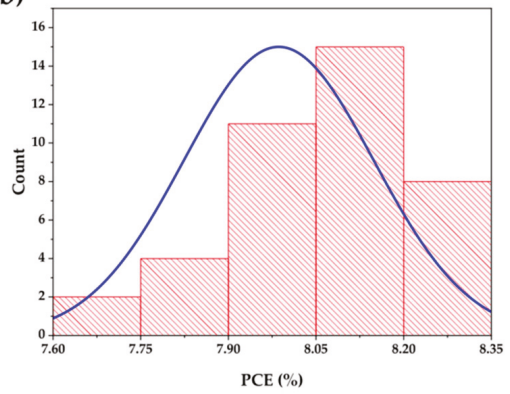

(d)

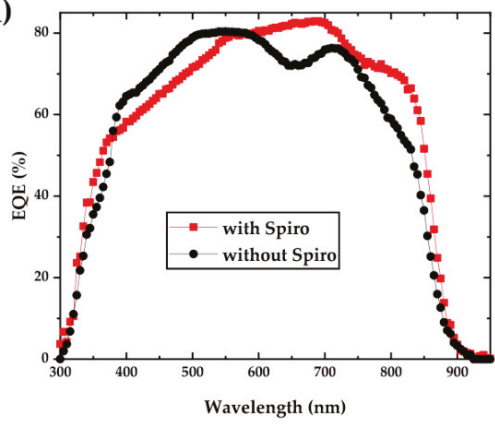

Figure 5. (a) The power conversion efficiency (PCE) of NC solar cells with different annealing temperatures; (b) the PCE distribution for NC solar cells with the Spiro HTL annealed at $120{ }^{\circ} \mathrm{C}$; (c) $J-V$ curves of champion and control devices and (d) the corresponding external quantum efficiency (EQE) spectra.

Table 1. Summarized performance of NC solar cells with the Spiro HTL annealed at different temperatures (Figure 5a) and Literature [22].

\begin{tabular}{|c|c|c|c|c|c|c|}
\hline $\begin{array}{l}\text { Spiro Annealing } \\
\text { Temperature }\left({ }^{\circ} \mathrm{C}\right)\end{array}$ & $\begin{array}{l}V_{\text {oc }} \\
\text { (V) }\end{array}$ & $\begin{array}{c}J_{\mathrm{sc}} \\
\left(\mathrm{mA} / \mathrm{cm}^{2}\right)\end{array}$ & FF (\%) & PCE (\%) & $\begin{array}{c}R_{S} \\
\left(\Omega \cdot \mathrm{cm}^{2}\right)\end{array}$ & $\begin{array}{c}R_{s h} \\
\left(\Omega \cdot \mathrm{cm}^{2}\right)\end{array}$ \\
\hline 50 & 0.70 & 13.04 & 55.43 & 5.06 & 13.7 & 239.5 \\
\hline 70 & 0.70 & 15.61 & 55.64 & 6.08 & 11.5 & 268.5 \\
\hline 90 & 0.66 & 21.26 & 51.67 & 7.25 & 9.5 & 455.0 \\
\hline 100 & 0.67 & 23.94 & 49.38 & 7.92 & 8.5 & 217.0 \\
\hline 110 & 0.70 & 23.75 & 50.11 & 8.33 & 8.8 & 235.3 \\
\hline 120 & 0.71 & 23.11 & 50.83 & 8.34 & 8.6 & 229.1 \\
\hline 130 & 0.69 & 18.41 & 55.66 & 7.07 & 9.9 & 316.8 \\
\hline 140 & 0.69 & 12.19 & 58.61 & 4.93 & 13.0 & 394.4 \\
\hline 180 & 0.61 & 5.09 & 40.90 & 1.27 & 46.3 & 273.0 \\
\hline Literature [22] & 0.71 & 18.78 & 49.20 & 6.56 & - & - \\
\hline Controlled device & 0.65 & 21.90 & 49.71 & 7.08 & 10.2 & 291.6 \\
\hline
\end{tabular}

The $V_{\text {oc }}$ of CdTe NC solar cells is relatively proportional to the built-in potential $\left(V_{\mathrm{bi}}\right)$ generated from the $p$-type $\mathrm{CdTe}_{\mathrm{x}} \mathrm{Se}_{1-\mathrm{x}}$ alloy and $n$-type CdS NCs. With the appearance of Spiro-OMe HTL, a positive potential between CdTe and HTL is created as a result of the formation of the Cd-N bond, as shown in Figure 6a. It reinforces the $V_{\mathrm{bi}}$ and usually results in a high $V_{\mathrm{oc}}$ of the device, like in this case. To provide a solid support for this hypothesis, $C-V$ analysis with increasing bias voltage 
at a constant frequency of $1000 \mathrm{~Hz}$ was carried out to measure the built-in field of the NC solar cells with/without HTL. Figure 6a shows the plots of $C^{-2}$ with bias voltage $(V)$. Based on the Mott-Schottky equation [28], the relationship between the capacitance $\left(C^{-2}\right)$ and applied voltage $(V)$ is expressed as follows:

$$
C^{-2}=\frac{2}{A^{2} q \varepsilon_{0} \varepsilon N_{\mathrm{A}}}\left(V_{\mathrm{bi}}-V\right)
$$

where $A$ is the active area of NC solar cells, $V_{\mathrm{bi}}$ the built-in potential, $q$ is the elementary charge, $\varepsilon$ is the relative dielectric constant (10.6 for CdTe), $\varepsilon_{0}$ is the permittivity of vacuum, and $N_{\mathrm{A}}$ is the net acceptor concentration in an active layer. The value of $V_{\mathrm{bi}}$ is obtained by fitting a line at a forward bias from the slope and the extrapolated intersection with the $\mathrm{x}$-axis. The $V_{\mathrm{bi}}$ for NC solar cells with/without HTL is $0.72 \mathrm{~V}$ and $0.65 \mathrm{~V}$, respectively, which agrees well with their $V_{\mathrm{oc}}$ values obtained from the $J-V$ curves. Like the TPA and TPP polymer, there are many amine groups that exist in the Spiro molecular framework. The $\mathrm{Cd}-\mathrm{N}$ bond is formed during the annealing process and a dipole layer can be formed at the CdTe/HTL interface. Similar results have been found in the case of $\mathrm{ZnO} /$ oligophenylene interface with a phosphonate-based self-assembled monolayer [29]. Therefore, the direction of the dipole moment is the same as the $V_{\text {bi }}$ generated from the active layer, which will enhance $V_{\text {bi }}$ and improve holes transport as well as lower the electron/hole recombination at the CdTe/Au interface, resulting in higher $V_{\mathrm{oc}}$ in the solar cells with HTL.

(a)

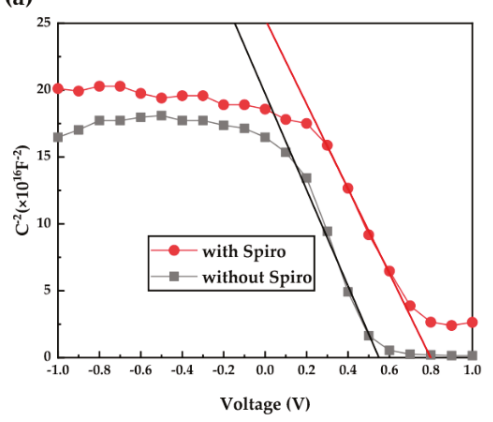

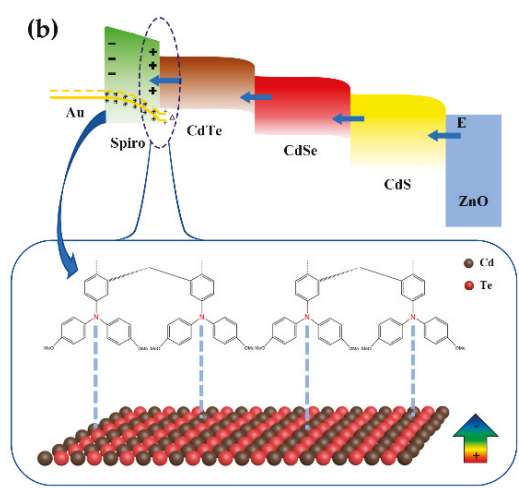

Figure 6. (a) Mott-Schottky capacitance-voltage $(C-V)$ curves of NC solar cells with/without Spiro; (b) a schematic of interfacial dipole and electric field of the NC solar cell with the Spiro HTL.

Compared to the control device, the improvement in NC solar cells with HTL is mainly attributed to the increase in $J_{\mathrm{sc}}$ and $V_{\mathrm{oc}}$. To further investigate the effect of HTL on the recombination process of NC solar cells, we measured the $J-V$ curves under dark. From the dark $J-V$ curves (Figure 7a), one can observe that the reverse current in the NC solar cell with HTL was significantly lower than that of the control device. Lower leakage current obtained in the device with HTL implies that the presence of HTL between the CdTe NC layer and Au anode leads to the passivation of interface defects and reduction of carriers' recombination, resulting in a significant improvement in $J_{\mathrm{sc}}$ and device performance. Figure $6 \mathrm{~b}$ shows the interfacial dipole and electric field in the NC solar cells with Spiro as an HTL. The formation of the dipole layer with electric dipole moment points toward the anode. Certainly, the conductivity, mobility of Spiro, and the diffusion of Li into CdTe NC film also affect the device performance. A systematic study of the effects of these factors on the device performance is still ongoing and will be reported in our following work. Here we present the TPV measurement to investigate the charge recombination in NC solar cells with/without the Spiro HTL. In the TPV measurement, the NC solar cells are placed under a white light bias and additional amounts of charges are generated by applying another weak laser pulse. Figure $7 \mathrm{~b}$ shows the charge recombination of NC 
devices with/without HTL, which are characterized by tracking the transient voltage associated with the perturbations in charge population. The charge recombination time for the NC device with Spiro HTL is $1.87 \mu \mathrm{s}$, while this value of the control device without the Spiro HTL is $1.12 \mu \mathrm{s}$. In other words, compared to the control device, a low charge recombination rate exists in the device with Spiro HTL, which is conformed to the higher $J_{\mathrm{sc}}$ and FF obtained in the device with HTL.

(a)

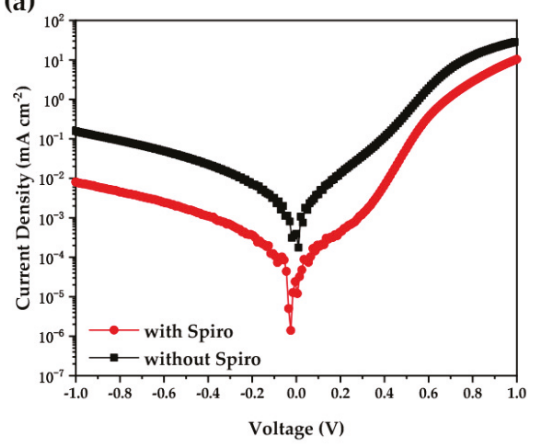

(b)

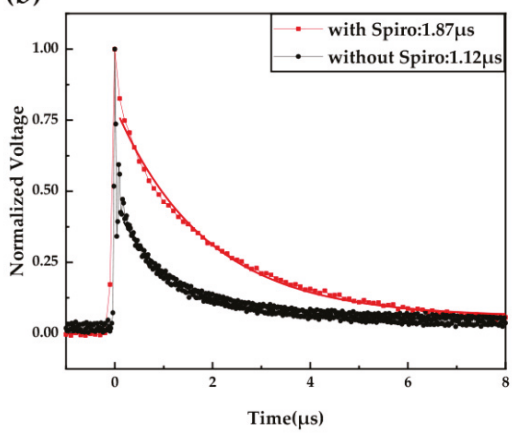

Figure 7. (a) $J-V$ curves under dark and (b) transient photovoltage (TPV) measurements of the champion and control devices.

In conclusion, we developed Spiro as the HTL for solution-processed CdTe NC solar cells. It was found that by performing annealing treatment after the deposition of HTL, the improvements in hole mobility and conductivity can be obtained in NC solar cells with Spiro HTL. Simultaneous improvements in $V_{\mathrm{oc}}, J_{\mathrm{sc}}$, and FF for CdTe NC solar cells are achieved when the annealing temperature is located among the range of 100 to $130{ }^{\circ} \mathrm{C}$. At an optimized annealing temperature of $120{ }^{\circ} \mathrm{C}$, a champion device with a high PCE of $8.34 \%$ was obtained, which shows a $28 \%$ higher PCE than the NC device with Spiro HTL reported before. The introduction of Spiro can enhance built-in potential across the solar cell owing to interface dipole effect and decrease interface recombination due to increase in $J_{\mathrm{sc}}$. The research reported here provides a versatile method to further improve CdTe NC solar cells with efficiency towards $10 \%$ from various design and material systems.

Supplementary Materials: The following are available online at http://www.mdpi.com/2079-4991/10/7/1348/s1, Figure S1: $J-V$ curves of NC solar cells with HTL annealed at different temperatures; Figure S2: The narrow XPS spectra of Cd3d for ITO/ZnO/CdS/CdSe/CdTe/Spiro with different annealing temperature; Table S1: Summarized XPS values of Cd3d with HTL annealing at different temperatures (Figure S2); Figure S3: AFM images of HTL (a) without annealing $\left(25^{\circ} \mathrm{C}\right)$ and (b) with annealing at $120^{\circ} \mathrm{C}$.

Author Contributions: D.Q., Y.J., and Y.P. conceived and designed the experiments; Y.J., Y.P., W.W., K.L., Z.R., S.X., W.Z., J.Y., and R.Z. conducted the experiments; Y.J. and Y.P. analyzed the data; D.Q., W.X., D.W., and L.H. contributed reagents/materials/analysis tools; D.Q., Y.J., and Y.P. compiled the paper. All authors have read and agreed to the published version of the manuscript.

Funding: This research received no external funding.

Acknowledgments: We thank the financial support of the National Natural Science Foundation of China (No. 21875075, 61774077, 61274062, 61775061), Guangdong Natural Science Fund (No. 2018A0303130041), Guangzhou Science and Technology Plan Project (No. 201804010295, 2018A0303130211), National Undergraduate Innovative and Entrepreneurial Training Program (No. 201910561006), the Key Projects of Joint Fund of Basic and Applied Basic Research Fund of Guangdong Province (2019B1515120073), the Research and Development Program in Key Areas of Guangdong Province (2019B090921002 and 2019B010132004), and the Fundamental Research Funds for the Central Universities for financial support.

Conflicts of Interest: The authors declare no conflict of interest. 


\section{References}

1. Choi, J.; Choi, M.J.; Kim, J.; Dinic, F.; Todorovic, P.; Sun, B.; Wei, M.; Baek, S.W.; Hoogland, S.; Garcia de Arquer, F.P.; et al. Stabilizing Surface Passivation Enables Stable Operation of Colloidal Quantum Dot Photovoltaic Devices at Maximum Power Point in an Air Ambient. Adv. Mater. 2020, 32, 1906497. [CrossRef] [PubMed]

2. Kagan, C.R.; Lifshitz, E.; Sargent, E.H.; Talapin, D.V. Building devices from colloidal quantum dots. Science 2016, 353, 5523. [CrossRef] [PubMed]

3. Luo, K.; Wu, W.; Xie, S.; Jiang, Y.; Liao, S.; Qin, D. Building Solar Cells from Nanocrystal Inks. Appl. Sci. 2019, 9, 1885. [CrossRef]

4. Yao, S.; Liu, L.; Zeng, Q.; Du, X.; Im, C.; Liu, Y.; Zhang, H.; Yang, B.; Cui, T.; Tian, W. Chloride treatment for highly efficient aqueous-processed CdTe nanocrystal-based hybrid solar cells. J. Mater. Chem. C 2018, 6, 11156-11161. [CrossRef]

5. Chen, Z.; Du, X.; Zeng, Q.; Yang, B. Recent development and understanding of polymer-nanocrystal hybrid solar cells. Mater. Chem. Front. 2017, 1, 1502-1513. [CrossRef]

6. Liu, H.; Tian, Y.; Zhang, Y.; Gao, K.; Lu, K.; Wu, R.; Qin, D.; Wu, H.; Peng, Z.; Hou, L.; et al. Solution processed $\mathrm{CdTe} / \mathrm{CdSe}$ nanocrystal solar cells with more than $5.5 \%$ efficiency by using an inverted device structure. J. Mater. Chem. C 2015, 3, 4227-4234. [CrossRef]

7. Chen, N.-N.; Jin, G.; Wang, L.-J.; Sun, H.-N.; Zeng, Q.-S.; Yang, B.; Sun, H.-Z. Highly Efficient Aqueous-Processed Hybrid Solar Cells: Control Depletion Region and Improve Carrier Extraction. Adv. Energy Mater. 2019, 9, 1803849. [CrossRef]

8. Kumar, S.G.; Rao, K.S.R.K. Physics and chemistry of CdTe/CdS thin film heterojunction photovoltaic devices: Fundamental and critical aspects. Energy Environ. Sci. 2014, 7, 45-102. [CrossRef]

9. Ferekides, C.S.; Balasubramanian, U.; Mamazza, R.; Viswanathan, V.; Zhao, H.; Morel, D.L. CdTe thin film solar cells: Device and technology issues. Sol. Energy 2004, 77, 823-830. [CrossRef]

10. Zhao, Y.; Zeng, Q.; Liu, X.; Jiao, S.; Pang, G.; Du, X.; Zhang, K.; Yang, B. Highly efficient aqueous-processed polymer/nanocrystal hybrid solar cells with an aqueous-processed $\mathrm{TiO}_{2}$ electron extraction layer. J. Mater. Chem. A 2016, 4, 11738-11746. [CrossRef]

11. Bao, Z.; Yang, X.; Li, B.; Luo, R.; Liu, B.; Tang, P.; Zhang, J.; Wu, L.; Li, W.; Feng, L. The study of CdSe thin film prepared by pulsed laser deposition for CdSe/CdTe solar cell. J. Mater. Sci. Mater. Electron. 2016, 27, 7233-7239. [CrossRef]

12. Paudel, N.R.; Yan, Y. Enhancing the photo-currents of CdTe thin-film solar cells in both short and long wavelength regions. Appl. Phys. Lett. 2014, 105, 183510. [CrossRef]

13. Chen, B.; Liu, J.; Cai, Z.; Xu, A.; Liu, X.; Rong, Z.; Qin, D.; Xu, W.; Hou, L.; Liang, Q. The Effects of ZnTe:Cu Back Contact on the Performance of CdTe Nanocrystal Solar Cells with Inverted Structure. Nanomaterials 2019, 9, 626. [CrossRef]

14. Zeng, Q.; Hu, L.; Cui, J.; Feng, T.; Du, X.; Jin, G.; Liu, F.; Ji, T.; Li, F.; Zhang, H.; et al. High-Efficiency Aqueous-Processed Polymer/CdTe Nanocrystals Planar Heterojunction Solar Cells with Optimized Band Alignment and Reduced Interfacial Charge Recombination. ACS Appl. Mater. Interfaces 2017, 9, 31345-31351. [CrossRef]

15. Rong, Z.; Guo, X.; Lian, S.; Liu, S.; Qin, D.; Mo, Y.; Xu, W.; Wu, H.; Zhao, H.; Hou, L. Interface Engineering for Both Cathode and Anode Enables Low-Cost Highly Efficient Solution-Processed CdTe Nanocrystal Solar Cells. Adv. Funct. Mater. 2019, 29, 1904018. [CrossRef]

16. Guo, X.; Tan, Q.; Liu, S.; Qin, D.; Mo, Y.; Hou, L.; Liu, A.; Wu, H.; Ma, Y. High-efficiency solution-processed CdTe nanocrystal solar cells incorporating a novel crosslinkable conjugated polymer as the hole transport layer. Nano Energy 2018, 46, 150-157. [CrossRef]

17. Hawash, Z.; Ono, L.K.; Qi, Y. Recent Advances in Spiro-MeOTAD Hole Transport Material and Its Applications in Organic-Inorganic Halide Perovskite Solar Cells. Adv. Mater. Interfaces 2018, 5, 1700623. [CrossRef]

18. Rong, Y.; Hu, Y.; Mei, A.; Tan, H.; Saidaminov, M.I.; Seok, S.I.; McGehee, M.D.; Sargent, E.H.; Han, H. Challenges for commercializing perovskite solar cells. Science 2018, 361, 8235. [CrossRef]

19. Burschka, J.; Dualeh, A.; Kessler, F.; Baranoff, E.; Cevey-Ha, N.-L.; Yi, C.; Nazeeruddin, M.K.; Graetzel, M. Tris(2-(1H-pyrazol-1-yl)pyridine)cobalt(III) as p-Type Dopant for Organic Semiconductors and Its Application in Highly Efficient Solid-State Dye-Sensitized Solar Cells. J. Am. Chem. Soc. 2011, 133, 18042-18045. [CrossRef] 
20. Li, M.; Wang, Z.-K.; Yang, Y.-G.; Hu, Y.; Feng, S.-L.; Wang, J.-M.; Gao, X.-Y.; Liao, L.-S. Copper Salts Doped Spiro for High-Performance Perovskite Solar Cells. Adv. Energy Mater. 2016, 6, 1601156. [CrossRef]

21. Noh, J.H.; Jeon, N.J.; Choi, Y.C.; Nazeeruddin, M.K.; Graetzel, M.; Seok, S.I. Nanostructured $\mathrm{TiO}_{2} / \mathrm{CH}_{3} \mathrm{NH}_{3} \mathrm{PbI}_{3}$ heterojunction solar cells employing spiro-OMeTAD/Co-complex as hole-transporting material. J. Mater. Chem. A 2013, 1, 11842-11847. [CrossRef]

22. Du, X.; Chen, Z.; Liu, F.; Zeng, Q.; Jin, G.; Li, F.; Yao, D.; Yang, B. Improvement in Open-Circuit Voltage of Thin Film Solar Cells from Aqueous Nanocrystals by Interface Engineering. ACS Appl. Mater. Interfaces 2016, 8, 900-907. [CrossRef]

23. Wen, S.Y.; Li, M.Z.; Yang, J.Y.; Mei, X.L.; Wu, B.; Liu, X.L.; Heng, J.X.; Qin, D.H.; Hou, L.T.; Xu, W.; et al. Rationally Controlled Synthesis of CdSexTe1-x Alloy Nanocrystals and Their Application in Efficient Graded Bandgap Solar Cells. Nanomaterials 2017, 7, 380. [CrossRef] [PubMed]

24. Li, M.; Liu, X.; Wen, S.; Liu, S.; Heng, J.; Qin, D.; Hou, L.; Wu, H.; Xu, W.; Huang, W. CdTe Nanocrystal Hetero-Junction Solar Cells with High Open Circuit Voltage Based on Sb-doped $\mathrm{TiO}_{2}$ Electron Acceptor Materials. Nanomaterials 2017, 7, 101. [CrossRef]

25. Liu, S.; Liu, W.; Heng, J.; Zhou, W.; Chen, Y.; Wen, S.; Qin, D.; Hou, L.; Wang, D.; Xu, H. Solution-Processed Efficient Nanocrystal Solar Cells Based on CdTe and CdS Nanocrystals. Coatings 2018, 8, 26. [CrossRef]

26. Yang, D.; Yang, R.; Wang, K.; Wu, C.; Zhu, X.; Feng, J.; Ren, X.; Fang, G.; Priya, S.; Liu, S. High efficiency planar-type perovskite solar cells with negligible hysteresis using EDTA-complexed $\mathrm{SnO}_{2}$. Nat. Commun. 2018, 9, 3239. [CrossRef]

27. Jeon, N.J.; Lee, J.; Noh, J.H.; Nazeeruddin, M.K.; Grätzel, M.; Seok, S.I. Efficient Inorganic-Organic Hybrid Perovskite Solar Cells Based on Pyrene Arylamine Derivatives as Hole-Transporting Materials. J. Am. Chem. Soc. 2013, 135, 19087-19090. [CrossRef] [PubMed]

28. Zhu, J.; Yang, Y.; Gao, Y.; Qin, D.; Wu, H.; Hou, L.; Huang, W. Enhancement of open-circuit voltage and the fill factor in CdTe nanocrystal solar cells by using interface materials. Nanotechnology 2014, 25, 365203. [CrossRef]

29. Timpel, M.; Nardi, M.V.; Ligorio, G.; Wegner, B.; Patzel, M.; Kobin, B.; Hecht, S.; Koch, N. Energy-Level Engineering at $\mathrm{ZnO} /$ Oligophenylene Interfaces with Phosphonate-Based Self-Assembled Monolayers. ACS Appl. Mater. Interfaces 2015, 7, 11900-11907. [CrossRef]

(C) 2020 by the authors. Licensee MDPI, Basel, Switzerland. This article is an open access article distributed under the terms and conditions of the Creative Commons Attribution (CC BY) license (http://creativecommons.org/licenses/by/4.0/). 

Article

\title{
$\mathrm{W}_{2} \mathrm{C} / \mathrm{WS}_{2}$ Alloy Nanoflowers as Anode Materials for Lithium-Ion Storage
}

\author{
Thang Phan Nguyen and Il Tae Kim* \\ Department of Chemical and Biological Engineering, Gachon University, Seongnam-si, Gyeonggi-do 13120, \\ Korea; phanthang87@gmail.com \\ * Correspondence: itkim@gachon.ac.kr
}

Received: 20 June 2020; Accepted: 6 July 2020; Published: 9 July 2020

\begin{abstract}
Recently, composites of MXenes and two-dimensional transition metal dichalcogenides have emerged as promising materials for energy storage applications. In this study, $\mathrm{W}_{2} \mathrm{C} / \mathrm{WS}_{2}$ alloy nanoflowers (NFs) were prepared by a facile hydrothermal method. The alloy NFs showed a particle size of $200 \mathrm{~nm}-1 \mu \mathrm{m}$, which could be controlled. The electrochemical performance of the as-prepared alloy NFs was investigated to evaluate their potential for application as lithium-ion battery (LIB) anodes. The incorporation of $\mathrm{W}_{2} \mathrm{C}$ in the $\mathrm{WS}_{2} \mathrm{NFs}$ improved their electronic properties. Among them, the $\mathrm{W}_{2} \mathrm{C} / \mathrm{WS}_{2}$ 4h $\mathrm{NF}$ electrode showed the best electrochemical performance with an initial discharge capacity of $1040 \mathrm{mAh} \mathrm{g}^{-1}$ and excellent cyclability corresponding to a reversible capacity of $500 \mathrm{mAh}$ $\mathrm{g}^{-1}$ after 100 cycles compared to that of the pure $\mathrm{WS}_{2} \mathrm{NF}$ electrode. Therefore, the incorporation of $\mathrm{W}_{2} \mathrm{C}$ is a promising approach to improve the performance of LIB anode materials.
\end{abstract}

Keywords: $\mathrm{W}_{2} \mathrm{C}$; $\mathrm{WS}_{2}$; hydrothermal; nanoflowers; lithium-ion batteries

\section{Introduction}

Two-dimensional (2D) materials such as graphene and transition metal chalcogenides show great potential for energy storage and conversion applications owing to their large surface area, high conductivity, and good physical and chemical stability [1-12]. Among these 2D materials, MXenes, which have been discovered recently, have been extensively investigated for energy storage applications. It should be noted that MXenes are the transition metal carbides/nitride, which have graphene-like structure, possessing many advantages of 2D materials such as high conductivity, flexibility, easy processing, and so on [13]. Mashtalir et al. synthesized intercalated $\mathrm{Ti}_{3} \mathrm{C}_{2}$ flakes with high stability and the charging rate for application as an anode material for lithium-ion batteries (LIBs) [14]. Naguib et al. prepared niobium and vanadium carbide LIB anodes with high rate capacity [15]. The MXene anodes exhibited excellent electrochemical performance at high currents because of their low diffusion barrier [16]. In addition, $\mathrm{Fe}_{3} \mathrm{O}_{4} @ \mathrm{Ti}_{2} \mathrm{C}_{3} \mathrm{LIB}$ anodes exhibited an ultrahigh capacity of approximately $747 \mathrm{mAh} \mathrm{g}^{-1}$ at $1 \mathrm{C}$ for 1000 cycles. Moreover, these materials exhibited a capacity of approximately $278 \mathrm{mAh} \mathrm{g}^{-1}$ at the high rate of $5 \mathrm{C}$ [17]. Zhang et al. have demonstrated the use of MXenes as conductive binders for viscous aqueous inks of silicon materials, which were used as high-capacity anode materials for LIBs [18]. In these materials, MXenes not only acted as a conductive network for Si particles, but also improved the mechanical stability of the material.

Tungsten metal compounds such as oxides, chalcogenides, and carbides are used in a wide range of applications such as catalysis, energy conversion, and energy storage [19-27]. Feng et al. prepared $\mathrm{WS}_{2}$ nanoflakes with a high reversible capacity of $680 \mathrm{mAh} \mathrm{g}^{-1}$ for 20 cycles as anode materials for LIBs [27]. Srinivaas et al. have prepared highly rich $1 \mathrm{~T} \mathrm{WS}_{2}$ phase in few layered nanoflowers (NFs) with stable electrochemical performance and a high initial capacity of approximately $890 \mathrm{mAh} \mathrm{g}^{-1}$ as anode materials for LIBs [28]. $\mathrm{W}_{2} \mathrm{C}$ is a good catalyst. When grown on carbon nanotubes, it exhibits 
high photo/electrocatalytic performance for the hydrogen evolution reaction [26,29]. Simulation results have shown that $\mathrm{W}_{2} \mathrm{C}$ can exhibit an ultra-fast loading of lithium ions owing to its low diffusion barrier of about $0.045-0.13 \mathrm{eV}$ [30]. Thus, the combination of $\mathrm{WS}_{2}$ and $\mathrm{W}_{2} \mathrm{C}$ is expected to yield a promising LIB anode material.

In this study, we prepared a $\mathrm{W}_{2} \mathrm{C} / \mathrm{WS}_{2}$ NF composite via a facile hydrothermal process. By controlling the reaction time, alloy NFs with different sizes could be prepared. The structures, chemical compositions, and binding states of the as-prepared NFs were investigated. Finally, the potential of the $\mathrm{W}_{2} \mathrm{C} / \mathrm{WS}_{2} \mathrm{NFs}$ for LIB anode applications was investigated. The NFs showed promising electrochemical performance and excellent Li storage.

\section{Materials and Methods}

\subsection{Chemical Materials}

Tungsten (VI) chloride $\left(\mathrm{WCl}_{6}, 99.9 \%\right.$ trace metals basis, Sigma-Aldrich Inc., St. Louis, MO, USA), thioacetamide $\left(\mathrm{C}_{2} \mathrm{H}_{5} \mathrm{NS}, 99 \%\right.$, Sigma-Aldrich, Sigma-Aldrich Inc., St. Louis, MO, USA),

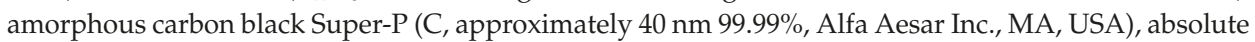
ethanol $\left(\mathrm{C}_{2} \mathrm{H}_{5} \mathrm{OH}\right.$, Alpha Aesar Inc., MA, USA), and polyvinylidene fluoride (PVDF, 534,000 $\mathrm{M}_{\mathrm{W}}$, Sigma-Aldrich, Sigma-Aldrich Inc., St. Louis, MO, USA) were used as received without any treatment.

\subsection{Synthesis of $\mathrm{W}_{2} \mathrm{C} / W S_{2} \mathrm{NFs}$}

The $\mathrm{W}_{2} \mathrm{C} / \mathrm{WS}_{2}$ alloy NFs were prepared according to a previously reported procedure [31]. Briefly, $0.6 \mathrm{~g}$ of $\mathrm{WCl}_{6}$ was dispersed as the $\mathrm{W}$ source in a $20 \mathrm{~mL}$ tube with $4 \mathrm{~mL}$ of absolute ethanol. For the sulfur and carbon source, $1.2 \mathrm{~g}$ of thioacetamide was dispersed in $4 \mathrm{~mL}$ of absolute ethanol under stirring. Then, the $\mathrm{WCl}_{6}$ solution was quickly added to the thioacetamide solution, and the resulting solution was stirred for $5 \mathrm{~min}$. Then, $30 \mathrm{~mL}$ of deionized (DI) water was added, and the solution was stirred for $1 \mathrm{~h}$. Then, the reaction mixture was transferred to a $50 \mathrm{~mL}$ polypropylene-lined autoclave and heated in an oven at $250{ }^{\circ} \mathrm{C}$ for 2,4 , and $12 \mathrm{~h}$ to obtain the $\mathrm{W}_{2} \mathrm{C} / \mathrm{WS}_{2} \_2 \mathrm{~h}, \mathrm{~W}_{2} \mathrm{C} / \mathrm{WS}_{2} \_\mathrm{h}$, and $\mathrm{W}_{2} \mathrm{C} / \mathrm{WS}_{2}{ }_{1} 12 \mathrm{~h}$ precipitates, respectively. These precipitates were washed four times with ethanol and DI water and were then dried in an oven at $60^{\circ} \mathrm{C}$ to obtain the $\mathrm{W}_{2} \mathrm{C} / \mathrm{WS}_{2}$ powders.

\subsection{Characterization}

X-ray diffraction (XRD) (D/MAX-2200 Rigaku, Tokyo, Japan) was used to analyze the structure of the samples. The XRD patterns of the samples were recorded over the $2 \theta$ range of $5-70^{\circ}$. The morphologies, structures, and sizes of the samples were investigated by scanning electron microscopy (SEM) (Hitachi S4700, Tokyo, Japan) and transmission electron microscopy (TEM) (TECNAI G2F30, FEI corp., OR, USA). The Raman spectra of the samples were acquired using a Raman spectrometer (Lab RAM HR, Horiba JobinYvon, Horiba Ltd., Kyoto, Japan, $532 \mathrm{~nm}$ laser excitation). X-ray photoelectron spectroscopy (XPS) (Axis Ultra DLD, Kratos Analytical Ltd, Kyoto, Japan) under a high vacuum of $1.6 \times 10^{-10}$ mbar with a monochromatic $\mathrm{Al} \mathrm{K} \alpha$ line was used to investigate the chemical compositions and atomic binding of the samples.

\subsection{Electrochemical Measurements}

The LIBs were assembled using coin-type cells (CR 2032, Rotech Inc., Gwangju, Korea). The working electrode was prepared by casting a slurry of $70 \%$ active material $\left(\mathrm{W}_{2} \mathrm{C} / \mathrm{WS}_{2}\right.$ alloy $\mathrm{NFs}$ ), 15\% conductive carbon black (Super-P), and 15\% PVDF in N-methyl-2-pyrrolidinone on a copper foil by doctor blading. After drying in a vacuum oven at $70^{\circ} \mathrm{C}$ for $12 \mathrm{~h}$, the electrodes were punched into circular discs with a diameter of $12 \mathrm{~mm}$. The battery half-cell structures were assembled under an $\mathrm{Ar}_{2}$ atmosphere in a glovebox. A lithium foil, polyethylene, and $1 \mathrm{M} \mathrm{LiPF}_{6}$ in ethylene carbonate/diethylene carbonate (1:1 in volume) were employed as the reference electrode, separator, and electrolyte, respectively. Galvanostatic electrochemical charge-discharge measurements were 
carried out using a battery cycle tester (WBCS3000, WonAtech, Seocho-gu, Seoul) over the voltage range of $0.1-3.0 \mathrm{~V}$ versus $\mathrm{Li} / \mathrm{Li}^{+}$. Cyclic voltammetry $(\mathrm{CV})$ tests were carried out using ZIVE MP1 (WonAtech, Seocho-gu, Seoul) over the voltage range of $0.1-3.0 \mathrm{~V}$ at a scanning rate of $0.1 \mathrm{mV} \mathrm{s}^{-1}$. Electrochemical impedance spectroscopic (EIS) measurements were carried out using a ZIVE MP1 (WonAtech, Seocho-gu, Seoul) over the frequency range of $100 \mathrm{kHz}-0.1 \mathrm{~Hz}$.

\section{Results}

For the synthesis of the $\mathrm{W}_{2} \mathrm{C} / \mathrm{WS}_{2} \mathrm{NFs}$, the $\mathrm{WCl}_{6}$ precursor was pre-mixed with absolute ethanol $\left(\mathrm{WCl}_{6}+\mathrm{xC}_{2} \mathrm{H}_{5} \mathrm{OH} \rightarrow \mathrm{WCl}_{6-\mathrm{x}}\left(\mathrm{OC}_{2} \mathrm{H}_{5}\right)_{\mathrm{x}}+\mathrm{xHCl}\right)$ before mixing with thioacetamide to prevent its unexpected reaction with moisture $\left(\mathrm{WCl}_{6}+\mathrm{xH}_{2} \mathrm{O} \rightarrow \mathrm{WCl}_{6-\mathrm{x}}(\mathrm{OH})_{\mathrm{x}}+\mathrm{xHCl}\right)$ [31,32]. The hydrolysis of thioacetamide produced hydrosulfide, acetic acid, and ammonia $\left(2 \mathrm{C}_{3} \mathrm{H}_{5} \mathrm{NS}+6 \mathrm{H}_{2} \mathrm{O} \rightarrow 2 \mathrm{H}_{2} \mathrm{~S}+\right.$ $\left.3 \mathrm{CH}_{3} \mathrm{COOH}+2 \mathrm{NH}_{3}\right)$. The introduction of hydrosulfide, acetic acid, and ethanol, respectively, acted as the sulfur and carbon sources for the formation of the $\mathrm{W}_{2} \mathrm{C} / \mathrm{WS}_{2}$ alloys. Figure $1 \mathrm{a}-\mathrm{c}$ show the SEM images of the $\mathrm{W}_{2} \mathrm{C} / \mathrm{WS}_{2}{ }_{2} \mathrm{~h}, \mathrm{~W}_{2} \mathrm{C} / \mathrm{WS}_{2}{ }_{-} 4 \mathrm{~h}$, and $\mathrm{W}_{2} \mathrm{C} / \mathrm{WS}_{2} \_12 \mathrm{hNFs}$, respectively. The particle sizes of the $\mathrm{W}_{2} \mathrm{C} / \mathrm{WS}_{2} \_2 \mathrm{~h}, \mathrm{~W}_{2} \mathrm{C} / \mathrm{WS}_{2} \_\mathrm{h}$, and $\mathrm{W}_{2} \mathrm{C} / \mathrm{WS}_{2} \_12 \mathrm{~h} \mathrm{NFs}$ were 200,400 , and $1000 \mathrm{~nm}$, respectively. The NFs showed a highly uniform structure, indicating that the synthesis procedure was highly reproducible. Each NF consisted of several leaves of $\mathrm{W}_{2} \mathrm{C}$ nanosheets and $\mathrm{WS}_{2}$ nanocrystals. Meanwhile, the $\mathrm{WS}_{2}$ NFs synthesized without ethanol showed a complex structure because of the non-uniform dispersion of W (Figure 1d).

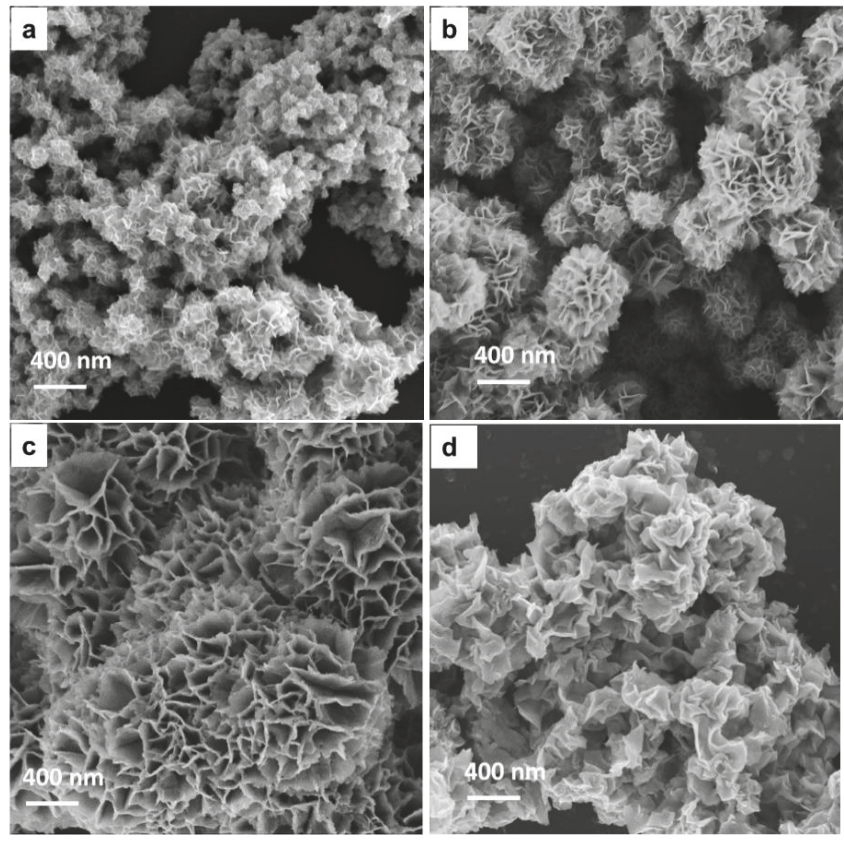

Figure 1. SEM images of the (a) $\mathrm{W}_{2} \mathrm{C} / \mathrm{WS}_{2} \_2 \mathrm{~h},(\mathbf{b}) \mathrm{W}_{2} \mathrm{C} / \mathrm{WS}_{2} \_\mathrm{h},(\mathbf{c}) \mathrm{W}_{2} \mathrm{C} / \mathrm{WS}_{2}{ }_{2} 12 \mathrm{~h}$, and (d) $\mathrm{WS}_{2} \mathrm{NFs}$.

To further examine the structure of the $\mathrm{W}_{2} \mathrm{C} / \mathrm{WS}_{2} \mathrm{NFs}$, powder $\mathrm{XRD}$ measurements were carried out over the $2 \theta$ range of $5-70^{\circ}$ (Figure $2 \mathrm{a}$ ). The XRD peaks of all the samples could be indexed to the hexagonal structure of $\mathrm{W}_{2} \mathrm{C}$ and $\mathrm{WS}_{2}$ [32-35]. It should be noted that the $\mathrm{W}_{2} \mathrm{C} / \mathrm{WS}_{2}$ 2 $2 \mathrm{~h}$ sample showed weak $\mathrm{WS}_{2}$ peaks. Moreover, this sample showed broad $\mathrm{W}_{2} \mathrm{C}$ peaks, indicating the small crystallite size of $\mathrm{W}_{2} \mathrm{C}$. The $\mathrm{W}_{2} \mathrm{C} / \mathrm{WS}_{2}{ }_{4} 4 \mathrm{~h}$ and $\mathrm{W}_{2} \mathrm{C} / \mathrm{WS}_{2} \_12 \mathrm{~h}$ samples showed clear $\mathrm{W}_{2} \mathrm{C}$ and $\mathrm{WS}_{2}$ peaks, indicating the co-existence of these hexagonal-structured materials. For comparison, a $\mathrm{WS}_{2}$ 
sample was prepared using the same procedure as that used for preparing the $\mathrm{W}_{2} \mathrm{C} / \mathrm{WS}_{2} \mathrm{NFs}$ but without the addition of ethanol. This sample showed peaks corresponding to $\mathrm{WS}_{2}$ only. Therefore, the addition of ethanol during the synthesis not only prevented the oxidation of $\mathrm{WCl}_{6}$ but also contributed to the formation of carbide from the thioacetamide source. The structures of $\mathrm{W}_{2} \mathrm{C}$ and $\mathrm{WS}_{2}$ in the alloy NFs were examined by Raman spectroscopy (Figure 2b). The samples for Raman spectroscopy measurements were prepared on $\mathrm{SiO}_{2} / \mathrm{Si}$ substrates, and a 532-nm wavelength laser source was used. The samples showed two peaks at 351.5 and $415.2 \mathrm{~cm}^{-1}$ corresponding to the in-plane mode vibration $\mathrm{E}_{2 \mathrm{~g}}^{1}$ and out-plane mode vibration $\mathrm{A}_{1 \mathrm{~g}}$ of $\mathrm{WS}_{2}$, respectively [2,36]. Moreover, the peaks detected at 700 and $805 \mathrm{~cm}^{-1}$ can be attributed to the stretching modes of $\mathrm{W}-\mathrm{C}[26,37]$. The D- and G-bands corresponding to the $\mathrm{sp}^{3}$ and $\mathrm{sp}^{2}$ carbon atoms in $\mathrm{W}_{2} \mathrm{C}$ were observed at $1200-1700 \mathrm{~cm}^{-1}$. These results indicate the co-existence of $\mathrm{W}_{2} \mathrm{C}$ and $\mathrm{WS}_{2}$ in the alloy NFs.
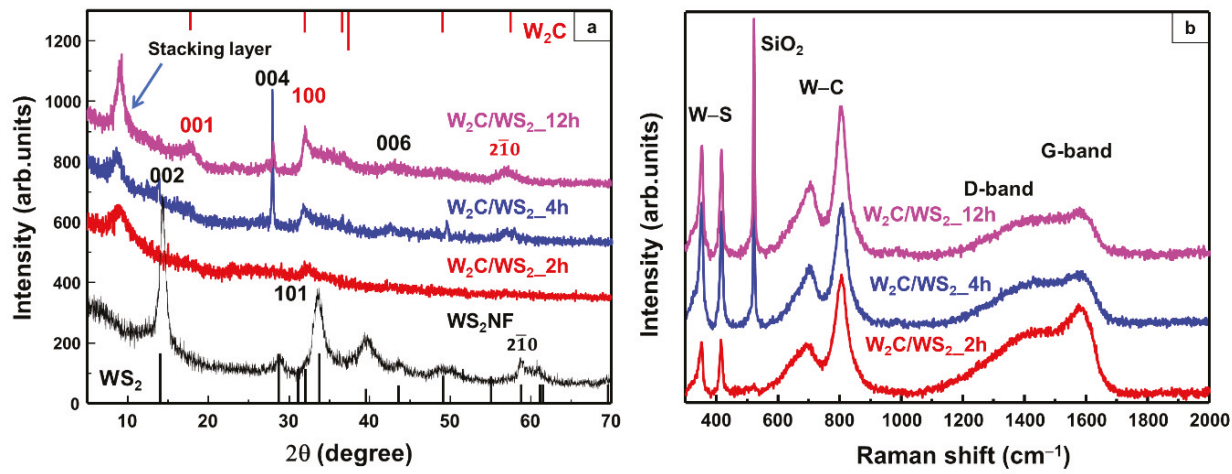

Figure 2. (a) X-ray diffraction (XRD) patterns and (b) Raman spectra of the $\mathrm{W}_{2} \mathrm{C} / \mathrm{WS}_{2}$ alloy nanoflowers (NFs) synthesized by heating at $250{ }^{\circ} \mathrm{C}$ for 2,4 , and $12 \mathrm{~h}$.

The structure of the $\mathrm{W}_{2} \mathrm{C} / \mathrm{WS}_{2}$ alloy NFs was further examined using TEM. As can be observed from Figure 3a, the samples showed a uniform NF structure with many leaves. Some Moiré patterns with a size of about $0.9-1.0 \mathrm{~nm}$ could be observed in the TEM images of the samples (Figure 3b). This can be attributed to the formation of the $\mathrm{W}_{2} \mathrm{C} / \mathrm{WS}_{2}$ interlayer spacing [31]. The lattice spacings of $\mathrm{W}_{2} \mathrm{C}$ and $\mathrm{WS}_{2}$ in the samples were also measured from their high-resolution TEM (HRTEM) image shown in Figure 3c. The distance spacings of the $\mathrm{WS}_{2}(100)$ and $\mathrm{W}_{2} \mathrm{C}(101)$ planes were measured to be 0.27 and $0.23 \mathrm{~nm}$, respectively. These spacings are characteristic of these materials. Moreover, the selected-area electron diffraction (SAED) pattern shown in Figure $3 \mathrm{~d}$ indicates that $\mathrm{W}_{2} \mathrm{C} / \mathrm{WS}_{2}$ alloy NFs with a highly crystalline hexagonal structure were successfully fabricated.

The chemical compositions and atomic binding energies of the $\mathrm{W}_{2} \mathrm{C} / \mathrm{WS}_{2}$ alloys were analyzed by XPS (Figure 4a-d). The survey scan XPS profiles of the alloys showed clear and sharp peaks corresponding to $\mathrm{W}, \mathrm{S}, \mathrm{O}, \mathrm{C}$, and $\mathrm{Si}$ (from substrate) (Figure 4a). No impurity peak was detected, indicating the high purity of the $\mathrm{W}_{2} \mathrm{C} / \mathrm{WS}_{2}$ alloys. The high-resolution $\mathrm{W} 4 \mathrm{f}, \mathrm{S} 2 \mathrm{p}$, and $\mathrm{C} 1 \mathrm{~s}$ spectra of the alloys are shown in Figure $4 \mathrm{~b}-\mathrm{d}$, respectively. The $\mathrm{W}$ 4f peak consisted of doublet peaks corresponding to the $\mathrm{W}-\mathrm{C}, \mathrm{W}-\mathrm{S}$, and $\mathrm{W}-\mathrm{O}$ bonds. The contribution of $\mathrm{W}-\mathrm{O}$ bonding can be attributed to the slight oxidation on the surface of the alloys, which always occurs during the preparation or natural oxidation of a material in air [29]. The W 4f7/2 and W 4f5/2 peaks of the $\mathrm{W}-\mathrm{C}$ doublet were observed at 31.9 and $34.1 \mathrm{eV}$, respectively, while those of the $\mathrm{W}-\mathrm{S}$ doublet were observed at 32.4 and $34.6 \mathrm{eV}$, respectively. The $\mathrm{W} 4 \mathrm{f} 7 / 2$ and $\mathrm{W} 4 \mathrm{f} 5 / 2$ peaks of the $\mathrm{W}-\mathrm{O}$ doublet were observed at 36.0 and $38.2 \mathrm{eV}$, respectively. The $S 2 p$ peak of the samples could be deconvoluted into the $S 2 p 3 / 2$ and $S$ 2p1/2 peaks, which were observed at 161.4 and $162.6 \mathrm{eV}$, respectively. Furthermore, the slight oxidation of the surface of the alloys during the preparation resulted in the appearance of the $\mathrm{S}-\mathrm{O}$ bond peak at about $169 \mathrm{eV}$. Finally, the $\mathrm{C} 1$ s peak of the samples could be deconvoluted into those corresponding to $\mathrm{C}-\mathrm{W}$ bonding at 
$284.7 \mathrm{eV}, \mathrm{C}-\mathrm{O}$ bonding at $286.2 \mathrm{eV}$, and $\mathrm{C}-\mathrm{OH}$ bonding at $288.5 \mathrm{eV}$. This is consistent with the binding energy of $\mathrm{C}$ in carbide compounds [38].

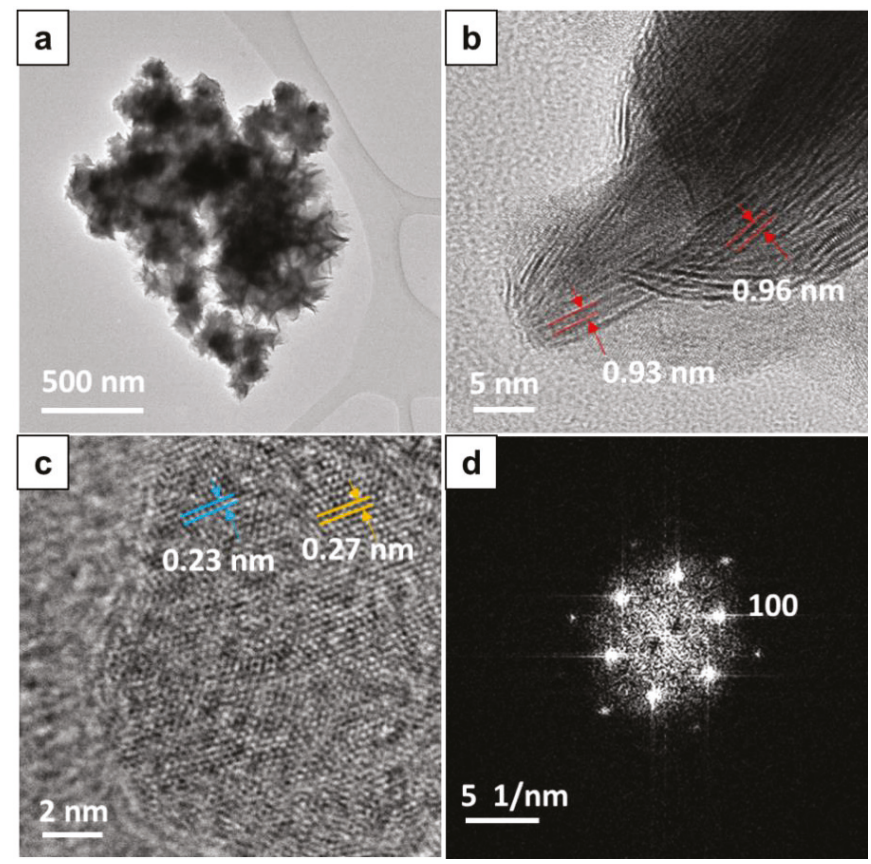

Figure 3. (a) TEM image; (b,c) HRTEM image and (d) selected-area electron diffraction (SAED) pattern of the $\mathrm{W}_{2} \mathrm{C} / \mathrm{WS}_{2}$ 4h NF sample.
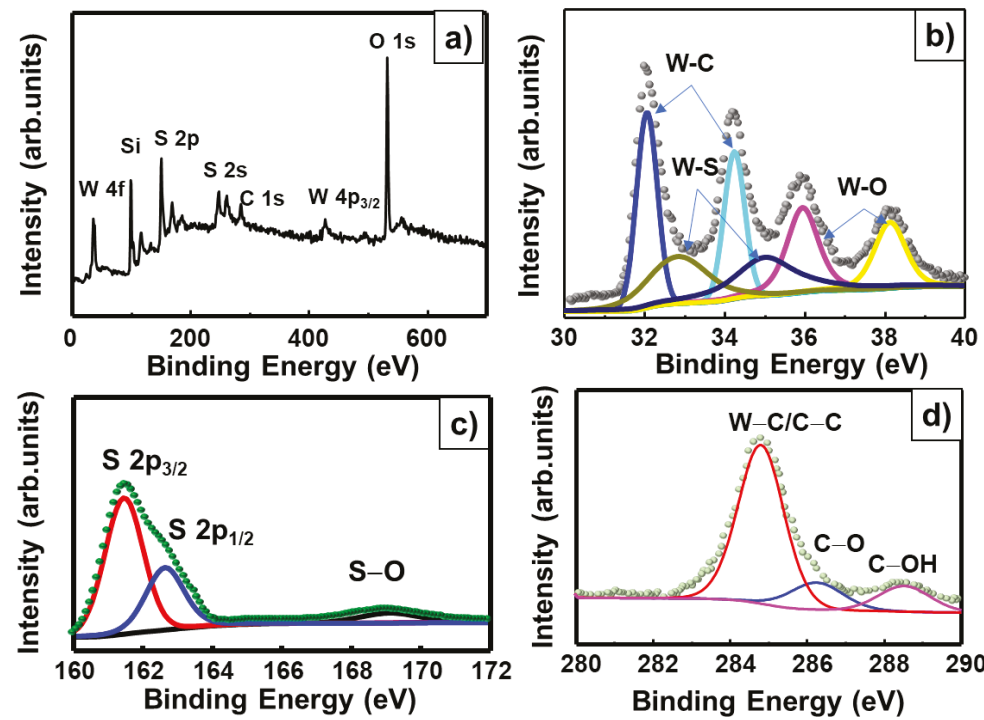

Figure 4. XPS profiles of the $\mathrm{W}_{2} \mathrm{C} / \mathrm{WS}_{2}{ }_{4} 4 \mathrm{~h} \mathrm{NF}$ sample with (a) survey scan spectrum and high-resolution (b) W 4f, (c) S 2p, and (d) C 1s spectra. 
To evaluate the electrochemical performance of the alloys for application as LIB anode materials, their CV tests were carried out for three cycles over the voltage range of 0.1-3.0 V (Figure 5a-d). In the first cycle, the as-prepared $\mathrm{WS}_{2} \mathrm{NFs}$ showed lithiation at $0.5,1.2$, and $1.4 \mathrm{~V}$ attributing to the reduction of $\mathrm{WS}_{2}$ to $\mathrm{Li}_{2} \mathrm{~S}$ through multiple steps, including the formation of $\mathrm{Li}_{x} \mathrm{WS}_{2}$ and $\mathrm{Li}_{2} \mathrm{~S}$ [28]. The peak observed at $0.5 \mathrm{~V}$ corresponds to the conversion reaction $\left(4 \mathrm{Li}^{+}+\mathrm{WS}_{2}+4 \mathrm{e}^{-} \rightarrow 2 \mathrm{Li}_{2} \mathrm{~S}+\mathrm{W}\right)$ as well as the decomposition of the non-aqueous electrolyte to form the solid electrolyte interface (SEI) layer $[28,39]$. In the second cycle, the peak at $0.5 \mathrm{~V}$ disappeared because of the formation of the SEI and gel-like polymeric layers by the dissolution of $\mathrm{Li}_{2} \mathrm{~S}$ into the electrolyte, leading to its degradation [40]. The peaks at 1.2 and $1.4 \mathrm{~V}$ shifted to $1.27 \mathrm{~V}$. An additional peak was observed at $1.9 \mathrm{~V}$, indicating the insertion of $\mathrm{Li}$ into $\mathrm{Li}_{\mathrm{x}} \mathrm{WS}_{2}$ [28]. Figure $5 \mathrm{~b}-\mathrm{d}$ show the cyclic voltammograms of the $\mathrm{W}_{2} \mathrm{C} / \mathrm{WS}_{2}{ }_{2} \mathrm{~h}$, $\mathrm{W}_{2} \mathrm{C} / \mathrm{WS}_{2} \_\mathrm{h}$, and $\mathrm{W}_{2} \mathrm{C} / \mathrm{WS}_{2} \_12 \mathrm{~h}$ samples, respectively. In the first cycle, the $\mathrm{W}_{2} \mathrm{C} / \mathrm{WS}_{2}{ }_{2} \mathrm{~h}$ sample showed a small peak at about $1.1 \mathrm{~V}$. In the second and third cycles, the sample showed reduction peaks at 1.25 and $1.9 \mathrm{~V}$ attributing to the multi-step lithiation of $\mathrm{WS}_{2}$. Interestingly, the $\mathrm{W}_{2} \mathrm{C} / \mathrm{WS}_{2}$ - 4 h and $\mathrm{W}_{2} \mathrm{C} / \mathrm{WS}_{2}{ }_{1} 12 \mathrm{~h}$ samples with large NFs showed only a broad peak at $1.3-1.5 \mathrm{~V}$ in the first discharge cycle. This phenomenon can be attributed to the change in the work function of $\mathrm{WS}_{2}$ by the addition of $\mathrm{W}_{2} \mathrm{C}$ [31]. The changes in the work function of the alloys corresponded to the changes in their reduction potentials. The work function of the $\mathrm{W}_{2} \mathrm{C} / \mathrm{WS}_{2} \mathrm{NFs}$ increased from 4.31 to $4.7 \mathrm{eV}$ with an increase in the reaction time from 2 to $12 \mathrm{~h}$. The work function of the pure $\mathrm{WS}_{2}$ sample was $4.95 \mathrm{eV}$. The bare $\mathrm{WS}_{2}$ electrode showed lithiation peaks at 1.4 and $1.9 \mathrm{~V}$. On the other hand, the $\mathrm{W}_{2} \mathrm{C} / \mathrm{WS}_{2}{ }_{2} \mathrm{~h}$ and $\mathrm{W}_{2} \mathrm{C} / \mathrm{WS}_{2}$-4h electrodes showed lithiation peaks at lower potentials at around 1.2-1.5 V. These samples did not show any lithiation peak at $1.9 \mathrm{~V}$. Hence, it can be stated that the decrease in the work function resulted in a decrease in the lithiation potential of the samples. As shown by the XRD patterns, the $\mathrm{W}_{2} \mathrm{C} / \mathrm{WS}_{2}{ }_{2} \mathrm{~h}$ sample showed broader $\mathrm{W}_{2} \mathrm{C}$ peaks than the other samples, indicating that the $\mathrm{W}_{2} \mathrm{C}$ crystallite size of this sample was smaller than those of the other samples. Therefore, the change in the second lithiation potential of the $\mathrm{W}_{2} \mathrm{C} / \mathrm{WS}_{2} \_2 \mathrm{~h}$ electrode was comparable to the initial potential of the $\mathrm{WS}_{2}$ electrode because of the instability of its smaller $\mathrm{W}_{2} \mathrm{C}$ crystals. The $\mathrm{W}_{2} \mathrm{C} / \mathrm{WS}_{2} \mathrm{H}_{-} \mathrm{h}$ and $\mathrm{W}_{2} \mathrm{C} / \mathrm{WS}_{2}{ }_{1} 12 \mathrm{~h}$ electrodes only showed reduction peaks at about $1.2-1.5 \mathrm{~V}$. This indicates that with an increase in the reaction time, the bonding between $\mathrm{W}_{2} \mathrm{C}$ and $\mathrm{WS}_{2}$ became stronger. The $\mathrm{W}_{2} \mathrm{C} / \mathrm{WS}_{2}$ and $\mathrm{WS}_{2} \mathrm{NFs}$ showed similar oxidation peaks because of the restoration of the $\mathrm{WS}_{2}$ structure at about 1.7-1.9 $\mathrm{V}$ and the oxidation of $\mathrm{Li}_{2} \mathrm{~S}\left(\mathrm{Li}_{2} \mathrm{~S} \rightarrow 2 \mathrm{Li}+\mathrm{S}\right)$ at about 2.3-2.5 V [39]. The $\mathrm{W}_{2} \mathrm{C} / \mathrm{WS}_{2} \mathrm{NFs}$ showed an oxidation peak at approximately $1.2 \mathrm{~V}$, which was attributed to the delithiation of $\mathrm{W}_{2} \mathrm{C}$.

The initial discharge and charge voltage profiles of the $\mathrm{W}_{2} \mathrm{C} / \mathrm{WS}_{2}$ and $\mathrm{WS}_{2} \mathrm{NFs}$ were obtained over the voltage range of $0.1-3.0 \mathrm{~V}$ at a scan rate of $100 \mathrm{~mA} \mathrm{~g}^{-1}$, as shown in Figure 6a. The $\mathrm{WS}_{2} \mathrm{NFs}_{\text {showed }}$ the charge and discharge capacities of 504.0 and $656.6 \mathrm{mAh} \mathrm{g}^{-1}$, respectively. The $\mathrm{W}_{2} \mathrm{C} / \mathrm{WS}_{2}{ }_{2} 2 \mathrm{~h}$, $\mathrm{W}_{2} \mathrm{C} / \mathrm{WS}_{2} \_\mathrm{h}$, and $\mathrm{W}_{2} \mathrm{C} / \mathrm{WS}_{2}{ }_{1} 12 \mathrm{~h}$ NFs showed the charge and discharge capacities of 595.2 and 935.2 $\mathrm{mAh} \mathrm{g}^{-1}, 751.8$ and $1040.5 \mathrm{mAh} \mathrm{g}^{-1}, 717.7$ and $953.5 \mathrm{mAh} \mathrm{g}^{-1}$, respectively. It has been reported that carbide materials are promising candidates for energy storage applications [41]. In this study, the addition of $\mathrm{W}_{2} \mathrm{C}$ to the $\mathrm{WS}_{2} \mathrm{NF}$ sample improved its storage capacity. The cyclic performances of the $\mathrm{W}_{2} \mathrm{C} / \mathrm{WS}_{2}$ and $\mathrm{WS}_{2} \mathrm{NFs}$ were evaluated over 100 cycles, as shown in Figure $6 \mathrm{~b}$. The alloys NF electrodes exhibited different electrochemical properties depending on the reaction time. For instance, after 10 cycles, the capacities of the $\mathrm{W}_{2} \mathrm{C} / \mathrm{WS}_{2}{ }_{2} \mathrm{~h}$ and $\mathrm{W}_{2} \mathrm{C} / \mathrm{WS}_{2} \_12 \mathrm{~h}$ electrodes decayed rapidly by about $55 \%$. After 30-40 cycles, the samples showed low stable capacities of 100-200 $\mathrm{mAh} \mathrm{g}^{-1}$ with a high Coulombic efficiency of approximately $95-99 \%$. On the other hand, the $\mathrm{W}_{2} \mathrm{C} / \mathrm{WS}_{2} \_4$ h electrode showed excellent cyclic stability with a high capacity of $500 \mathrm{mAh} \mathrm{g}^{-1}$ after 100 cycles as compared to the other electrodes. The reasons why the $\mathrm{W}_{2} \mathrm{C} / \mathrm{WS}_{2}$ - 4 h electrode demonstrated the best performance are the stable binding of $\mathrm{W}_{2} \mathrm{C}$ to $\mathrm{WS}_{2}$ and the lowering of reduction potential in addition to the low resistance (discussed later). This sample showed a Coulombic efficiency of 97-98\%. Meanwhile, the $\mathrm{WS}_{2}$ NFs showed a Coulombic efficiency of $93-94 \%$ and a continuous decrease in the cyclic capacity to approximately $145 \mathrm{mAh} \mathrm{g}^{-1}$ during the 100 th cycle. 

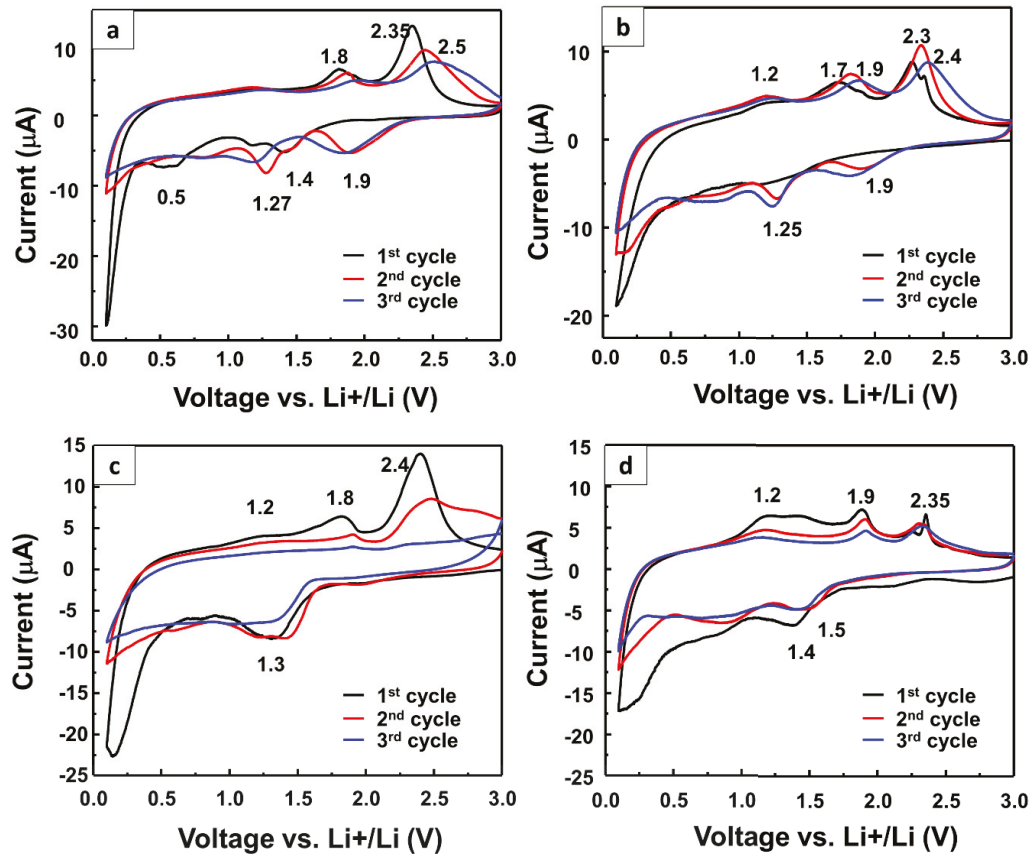

Figure 5. Cyclic voltammograms of the (a) as-prepared $\mathrm{WS}_{2} \mathrm{NF},(\mathbf{b}) \mathrm{W}_{2} \mathrm{C} / \mathrm{WS}_{2}{ }_{2} 2 \mathrm{~h} \mathrm{NF},(\mathbf{c}) \mathrm{W}_{2} \mathrm{C} / \mathrm{WS}_{2}$ 4h $\mathrm{NF}$, and (d) $\mathrm{W}_{2} \mathrm{C} / \mathrm{WS}_{2}{ }_{1} 12 \mathrm{~h}$ NF electrodes.
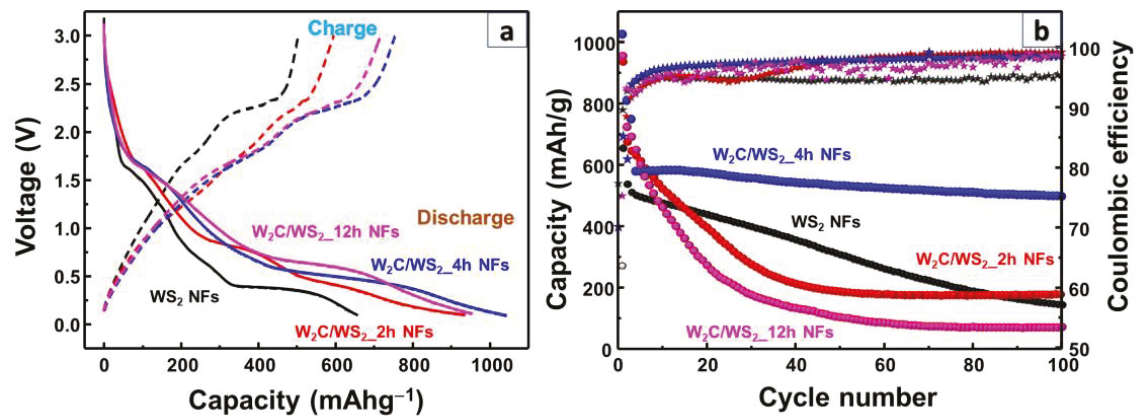

Figure 6. (a) Initial voltage profiles and (b) cyclic performance of the as-prepared $\mathrm{WS}_{2} \mathrm{NF}, \mathrm{W}_{2} \mathrm{C} / \mathrm{WS}_{2}{ }_{2} \mathrm{~h}$ $\mathrm{NF}, \mathrm{W}_{2} \mathrm{C} / \mathrm{WS}_{2}{ }_{4} 4 \mathrm{~h} \mathrm{NF}$, and $\mathrm{W}_{2} \mathrm{C} / \mathrm{WS}_{2}{ }_{1} 12 \mathrm{~h}$ NF electrodes over 100 cycles.

To further investigate the performance of the NFs, their EIS measurements were carried out over the frequency range of $100 \mathrm{kHz}-0.1 \mathrm{~Hz}$ at a voltage of $3.0 \mathrm{~V}$. Figure 7 shows the Nyquist plots of the $\mathrm{WS}_{2}$ and $\mathrm{W}_{2} \mathrm{C} / \mathrm{WS}_{2} \mathrm{NF}$ electrodes with the equivalent circuit as an inset containing the constant phase elements $(C P E 1,2)$, series resistance $\left(R_{s}\right)$, charge transfer resistance $\left(R_{\mathrm{ct}}\right)$, solid electrolyte resistance $\left(\mathrm{R}_{\mathrm{SEI}}\right)$, and diffusion Warburg element $(\mathrm{W})$. The semicircular arc corresponds to their charge transfer resistances between the interface of electrode and electrolyte [42]. The resistance values are summarized in Table 1. The $\mathrm{WS}_{2} \mathrm{NF}$ anode showed the highest charge transfer resistance among all the anodes investigated. The charge transfer resistance of the $\mathrm{WS}_{2} \mathrm{NFs}$ decreased with the addition of $\mathrm{W}_{2} \mathrm{C}$ in the case of the $\mathrm{W}_{2} \mathrm{C} / \mathrm{WS}_{2}{ }_{2} \mathrm{~h}$ and $\mathrm{W}_{2} \mathrm{C} / \mathrm{WS}_{2} \_$h electrodes. However, it increased again for the $\mathrm{W}_{2} \mathrm{C} / \mathrm{WS}_{2}{ }_{2} 12 \mathrm{~h}$ electrode. The difference in the performance of the as-prepared $\mathrm{W}_{2} \mathrm{C} / \mathrm{WS}_{2}$ electrodes 
could be due to the different amount of $\mathrm{W}_{2} \mathrm{C}$ in the alloys. As shown by the Raman spectrum in Figure $2 b$, the peak intensities of the D- and G-band from the carbon atoms in $\mathrm{W}_{2} \mathrm{C}$ decreased when the reaction time increased, illustrating an increase in the amount of $\mathrm{WS}_{2}$. In the case of the $\mathrm{W}_{2} \mathrm{C} / \mathrm{WS}_{2}{ }_{1} 12 \mathrm{~h}$ sample, it could have an excess amount of $\mathrm{H}_{2} \mathrm{~S}$ at $250{ }^{\circ} \mathrm{C}$, and the applied high pressure sulfurized the weak bonding of $\mathrm{W}-\mathrm{C}$, leading to the lower amount of $\mathrm{C}$, which was confirmed by Raman spectra representing the decrease of the D-band and G-band. Moreover, the flower size of the $\mathrm{W}_{2} \mathrm{C} / \mathrm{WS}_{2}{ }_{-} 12 \mathrm{~h}$ sample is about $1 \mu \mathrm{m}$, which is even bigger than the random size of $\mathrm{WS}_{2} \mathrm{NFs}$. It should be noted that the increase in size could lead to the decrease in the conductivity [28]. When the amount and size of $\mathrm{WS}_{2}$ increase, the resistance of the electrodes increases, as discussed in the EIS results. Specifically, the $\mathrm{W}_{2} \mathrm{C} / \mathrm{WS}_{2} \_2 \mathrm{~h}$ and $4 \mathrm{~h}$ electrodes showed lower resistances compared to that of the $\mathrm{W}_{2} \mathrm{C} / \mathrm{WS}_{2}{ }_{1} 12 \mathrm{~h}$ electrode. Even though the $\mathrm{W}_{2} \mathrm{C} / \mathrm{WS}_{2} \_$h electrode showed the lowest resistance value, the cycling performance was not stable due to the weak binding of the $\mathrm{W}_{2} \mathrm{C}$ crystal to $\mathrm{WS}_{2}$, leading to the gradual capacity decay, as discussed earlier. Thus, it can be concluded that the control of reaction time for the preparation of $\mathrm{W}_{2} \mathrm{C} / \mathrm{WS}_{2}$ electrodes is crucial to optimize the overall electrochemical properties, where the $\mathrm{W}_{2} \mathrm{C} / \mathrm{WS}_{2} 4 \mathrm{~h}$ alloy is the best electrode. Computational calculations have revealed that $\mathrm{W}_{2} \mathrm{C}$ materials are promising candidates for Li storage applications [30]. Li ions tend to adsorb on $\mathrm{W}_{2} \mathrm{C}$ materials to form a metal cluster. Moreover, MXenes nanosheets materials exhibit high conductivity [43]. In this study, the addition of $\mathrm{W}_{2} \mathrm{C}$ reduced the charge transfer resistance of the $\mathrm{WS}_{2} \mathrm{NFs}$, and the resulting $\mathrm{W}_{2} \mathrm{C} / \mathrm{WS}_{2}$ alloy NFs showed high storage capacity and stability for LIB applications.

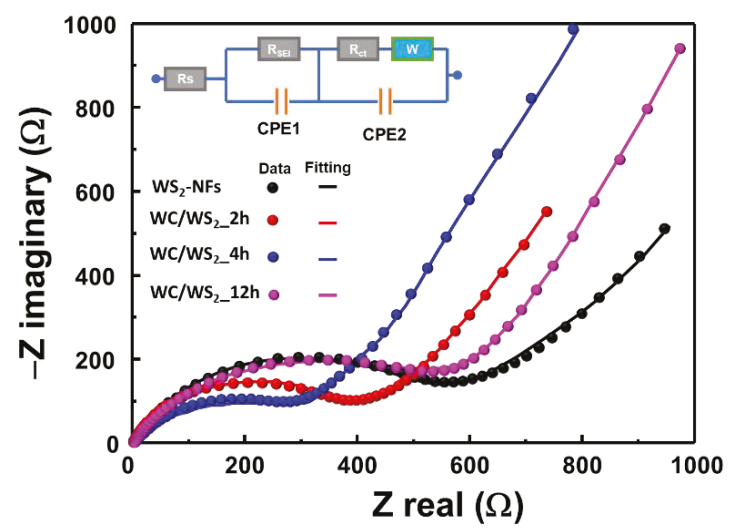

Figure 7. Nyquist plots of the as-prepared $\mathrm{WS}_{2} \mathrm{NF}, \mathrm{W}_{2} \mathrm{C} / \mathrm{WS}_{2}{ }_{2} \mathrm{~h} \mathrm{NF}, \mathrm{W}_{2} \mathrm{C} / \mathrm{WS}_{2} \_4 \mathrm{~h} \mathrm{NF}$, and $\mathrm{W}_{2} \mathrm{C} / \mathrm{WS}_{2} \_12 \mathrm{~h}$ NF electrodes with inset equivalent circuit.

Table 1. Comparison of resistance values extracted from equivalent circuit for the electrochemical impedance spectroscopic (EIS) measurement.

\begin{tabular}{cccc}
\hline Sample & $\mathbf{R}_{\mathbf{s}}$ & $\mathbf{R}_{\text {ct }}$ & $\mathbf{R}_{\text {SEI }}$ \\
\hline WS $_{2}$ NFs & 2.12 & 627 & 430 \\
WC/WS $_{2}$ 2h & 3.04 & 381 & 367 \\
WC/WS 2 4h & 1.24 & 312 & 350 \\
WC/WS $12 \mathrm{~h}$ & 5.41 & 620 & 422 \\
\hline
\end{tabular}

\section{Conclusions}

$\mathrm{W}_{2} \mathrm{C} / \mathrm{WS}_{2} \mathrm{NFs}$ were successfully fabricated via a facile hydrothermal method at low temperature. The particle size of the NFs could be controlled $(200 \mathrm{~nm}-1 \mu \mathrm{m})$. The obtained NFs exhibited high purity and well-defined hexagonal structures of $\mathrm{W}_{2} \mathrm{C}$ and $\mathrm{WS}_{2}$. The NF alloys were employed as anode materials for LIBs. The $\mathrm{W}_{2} \mathrm{C} / \mathrm{WS}_{2}$ 4h sample showed a high initial discharge capacity of $1040 \mathrm{mAh} \mathrm{g}^{-1}$. 
The alloy electrodes showed a low charge transfer resistance of $200-600 \Omega$, indicating that the $\mathrm{W}_{2} \mathrm{C} / \mathrm{WS}_{2}$ alloy electrodes were highly conductive as compared to the $\mathrm{WS}_{2} \mathrm{NF}$ electrode. Among all the electrodes investigated, the $\mathrm{W}_{2} \mathrm{C} / \mathrm{WS}_{2} \_$h electrode exhibited the highest stable capacity of up to approximately $500 \mathrm{mAh} \mathrm{g}^{-1}$ over 100 cycles, which could be attributed to the optimized $\mathrm{W}_{2} \mathrm{C}$ in $\mathrm{WS}_{2}$ $\mathrm{NFs}$, Therefore, the $\mathrm{W}_{2} \mathrm{C} / \mathrm{WS}_{2}$ alloy NFs prepared in this study showed a potential for energy storage and conversion applications.

Author Contributions: Conceptualization, T.P.N.; methodology, T.P.N.; validation, T.P.N.; writing-review and editing, T.P.N. and I.T.K.; visualization, T.P.N.; project administration, I.T.K.; funding acquisition, I.T.K. All authors have read and agreed to the published version of the manuscript.

Funding: This work was supported by the Korea Electric Power Corporation (grant number: R18XA02). This research was supported by the Basic Science Research Capacity Enhancement Project of Korea Basic Science Institute (National research Facilities and Equipment Center) and was funded by the Ministry of Education. (2019R1A6C1010016).

Conflicts of Interest: The authors declare no conflict of interest.

\section{References}

1. Xu, M.; Liang, T.; Shi, M.; Chen, H. Graphene-Like Two-Dimensional Materials. Chem. Rev. 2013, 113, 3766-3798. [CrossRef] [PubMed]

2. Matte, H.S.; Gomathi, A.; Manna, A.K.; Late, D.J.; Datta, R.; Pati, S.K.; Rao, C.N. $\mathrm{MoS}_{2}$ and $\mathrm{WS}_{2}$ analogues of graphene. Angew. Chem. Int. Ed. Engl. 2010, 49, 4059-4062. [CrossRef]

3. Kolobov, A.V.; Tominaga, J. Two-Dimensional Transition-Metal. Dichalcogenides; Springer International Publishing: Cham, Switzerland, 2016.

4. Kalambate, P.K.; Gadhari, N.S.; Li, X.; Rao, Z.; Navale, S.T.; Shen, Y.; Patil, V.R.; Huang, Y. Recent advances in MXene-based electrochemical sensors and biosensors. TrAC Trends Anal. Chem. 2019, 120, 115643. [CrossRef]

5. Naguib, M.; Mochalin, V.N.; Barsoum, M.W.; Gogotsi, Y. 25th Anniversary Article: MXenes: A New Family of Two-Dimensional Materials. Adv. Mater. 2014, 26, 992-1005. [CrossRef]

6. Nguyen, T.P.; Tuan Nguyen, D.M.; Tran, D.L.; Le, H.K.; Vo, D.-V.N.; Lam, S.S.; Varma, R.S.; Shokouhimehr, M.; Nguyen, C.C.; Le, Q.V. MXenes: Applications in electrocatalytic, photocatalytic hydrogen evolution reaction and $\mathrm{CO}_{2}$ reduction. Mol. Catal. 2020, 486, 110850. [CrossRef]

7. Gatensby, R.; McEvoy, N.; Lee, K.; Hallam, T.; Berner, N.C.; Rezvani, E.; Winters, S.; O’Brien, M.; Duesberg, G.S. Controlled synthesis of transition metal dichalcogenide thin films for electronic applications. Appl. Surf. Sci. 2014, 297, 139-146. [CrossRef]

8. $\quad$ Phung, V.-D.; Jung, W.-S.; Kim, J.-H.; Lee, S.-W. Gold nanostructures electrodeposited on graphene oxide-modified indium tin oxide glass as a surface-enhanced Raman scattering-active substrate for ultrasensitive detection of dopamine neurotransmitter. Jpn. J. Appl. Phys. 2018, 57, 08PF02. [CrossRef]

9. Nguyen, Q.H.; Hur, J. $\mathrm{MoS}_{2}-\mathrm{C}-\mathrm{TiC}$ Nanocomposites as New Anode Materials for High-Performance Lithium-Ion Batteries. J. Nanosci. Nanotechnol. 2019, 19, 996-1000. [CrossRef]

10. Nguyen, Q.H.; Nguyen, Q.H.; Hur, J. High-Performance $\mathrm{ZnTe}-\mathrm{TiO}_{2}-\mathrm{C}$ nanocomposite with half-cell and full-cell applications as promising anode material for Li-Ion batteries. Appl. Surf. Sci. 2020, 509, 144718. [CrossRef]

11. Liu, N.; Choi, W.; Kim, H.; Jung, C.; Kim, J.; Choo, S.H.; Kwon, Y.; An, B.-S.; Hong, S.; So, S.; et al. Rapid and mass-producible synthesis of high-crystallinity $\mathrm{MoSe}_{2}$ nanosheets by ampoule-loaded chemical vapor deposition. Nanoscale 2020, 12, 6991-6999. [CrossRef] [PubMed]

12. Tran, A.-V.; Shim, K.; Vo Thi, T.-T.; Kook, J.-K.; An, S.S.A.; Lee, S.-W. Targeted and controlled drug delivery by multifunctional mesoporous silica nanoparticles with internal fluorescent conjugates and external polydopamine and graphene oxide layers. Acta Biomater. 2018, 74, 397-413. [CrossRef] [PubMed]

13. Naguib, M.; Kurtoglu, M.; Presser, V.; Lu, J.; Niu, J.; Heon, M.; Hultman, L.; Gogotsi, Y.; Barsoum, M.W. Two-Dimensional Nanocrystals Produced by Exfoliation of $\mathrm{Ti}_{3} \mathrm{AlC}_{2}$. Adv. Mater. 2011, 23, 4248-4253. [CrossRef] [PubMed]

14. Mashtalir, O.; Naguib, M.; Mochalin, V.N.; Dall'Agnese, Y.; Heon, M.; Barsoum, M.W.; Gogotsi, Y. Intercalation and delamination of layered carbides and carbonitrides. Nat. Commun. 2013, 4, 1-7. [CrossRef] [PubMed] 
15. Naguib, M.; Halim, J.; Lu, J.; Cook, K.M.; Hultman, L.; Gogotsi, Y.; Barsoum, M.W. New Two-Dimensional Niobium and Vanadium Carbides as Promising Materials for Li-Ion Batteries. J. Am. Chem. Soc. 2013, 135, 15966-15969. [CrossRef]

16. Tang, Q.; Zhou, Z.; Shen, P. Are MXenes Promising Anode Materials for Li Ion Batteries? Computational Studies on Electronic Properties and Li Storage Capability of $\mathrm{Ti}_{3} \mathrm{C}_{2}$ and $\mathrm{Ti}_{3} \mathrm{C}_{2} \mathrm{X}_{2}(\mathrm{X}=\mathrm{F}, \mathrm{OH})$ Monolayer. J. Am. Chem. Soc. 2012, 134, 16909-16916. [CrossRef]

17. Wang, Y.; Li, Y.; Qiu, Z.; Wu, X.; Zhou, P.; Zhou, T.; Zhao, J.; Miao, Z.; Zhou, J.; Zhuo, S. $\mathrm{Fe}_{3} \mathrm{O}_{4} @ \mathrm{Ti}_{3} \mathrm{C}_{2} \mathrm{MXene}$ hybrids with ultrahigh volumetric capacity as an anode material for lithium-ion batteries. J. Mater. Chem. A 2018, 6, 11189-11197. [CrossRef]

18. Zhang, C.; Park, S.-H.; Seral-Ascaso, A.; Barwich, S.; McEvoy, N.; Boland, C.S.; Coleman, J.N.; Gogotsi, Y.; Nicolosi, V. High capacity silicon anodes enabled by MXene viscous aqueous ink. Nat. Commun. 2019, 10, 1-9. [CrossRef]

19. Nayak, A.K.; Pradhan, D. Microwave-Assisted Greener Synthesis of Defect-Rich Tungsten Oxide Nanowires with Enhanced Photocatalytic and Photoelectrochemical Performance. J. Phys. Chem. C 2018, 122, 3183-3193. [CrossRef]

20. Meyer, J.; Hamwi, S.; Kröger, M.; Kowalsky, W.; Riedl, T.; Kahn, A. Transition Metal Oxides for Organic Electronics: Energetics, Device Physics and Applications. Adv. Mater. 2012, 24, 5408-5427. [CrossRef]

21. Emin, S.; Altinkaya, C.; Semerci, A.; Okuyucu, H.; Yildiz, A.; Stefanov, P. Tungsten carbide electrocatalysts prepared from metallic tungsten nanoparticles for efficient hydrogen evolution. Appl. Catal. B 2018, 236, 147-153. [CrossRef]

22. Choi, H.; Kim, B.; Ko, M.J.; Lee, D.-K.; Kim, H.; Kim, S.H.; Kim, K. Solution processed $\mathrm{WO}_{3}$ layer for the replacement of PEDOT:PSS layer in organic photovoltaic cells. Org. Electron. 2012, 13, 959-968. [CrossRef]

23. Li, W.-J.; Fu, Z.-W. Nanostructured $\mathrm{WO}_{3}$ thin film as a new anode material for lithium-ion batteries. Appl. Surf. Sci. 2010, 256, 2447-2452. [CrossRef]

24. Chen, T.-Y.; Chang, Y.-H.; Hsu, C.-L.; Wei, K.-H.; Chiang, C.-Y.; Li, L.-J. Comparative study on MoS $_{2}$ and WS2 for electrocatalytic water splitting. Int. J. Hydrogen Energy 2013, 38, 12302-12309. [CrossRef]

25. Lukowski, M.A.; Daniel, A.S.; English, C.R.; Meng, F.; Forticaux, A.; Hamers, R.J.; Jin, S. Highly active hydrogen evolution catalysis from metallic $\mathrm{WS}_{2}$ nanosheets. Energy Environ. Sci. 2014, 7, 2608-2613. [CrossRef]

26. Chen, Z.; Gong, W.; Cong, S.; Wang, Z.; Song, G.; Pan, T.; Tang, X.; Chen, J.; Lu, W.; Zhao, Z. Eutectoid-Structured $\mathrm{WC} / \mathrm{W}_{2} \mathrm{C}$ heterostructures: A new platform for long-term alkaline hydrogen evolution reaction at low overpotentials. Nano Energy 2020, 68, 104335. [CrossRef]

27. Feng, C.; Huang, L.; Guo, Z.; Liu, H. Synthesis of tungsten disulfide $\left(\mathrm{WS}_{2}\right)$ nanoflakes for lithium ion battery application. Electrochem. Commun. 2007, 9, 119-122. [CrossRef]

28. Srinivaas, M.; Wu, C.-Y.; Duh, J.-G.; Wu, J.M. Highly Rich 1T Metallic Phase of Few-Layered WS 2 Nanoflowers for Enhanced Storage of Lithium-Ion Batteries. ACS Sustain. Chem. Eng. 2019, 7, 10363-10370. [CrossRef]

29. Gong, Q.; Wang, Y.; Hu, Q.; Zhou, J.; Feng, R.; Duchesne, P.N.; Zhang, P.; Chen, F.; Han, N.; Li, Y.; et al. Ultrasmall and phase-pure $\mathrm{W}_{2} \mathrm{C}$ nanoparticles for efficient electrocatalytic and photoelectrochemical hydrogen evolution. Nat. Commun. 2016, 7, 1-8. [CrossRef]

30. Zhang, Y. First principles prediction of two-dimensional tungsten carbide $\left(\mathrm{W}_{2} \mathrm{C}\right)$ monolayer and its Li storage capability. Comput. Condens. Matter 2017, 10, 35-38. [CrossRef]

31. Nguyen, T.P.; Choi, K.S.; Kim, S.Y.; Lee, T.H.; Jang, H.W.; Van Le, Q.; Kim, I.T. Strategy for controlling the morphology and work function of $\mathrm{W}_{2} \mathrm{C} / \mathrm{WS}_{2}$ nanoflowers. J. Alloys Compd. 2020, 829, 154582. [CrossRef]

32. Nguyen, T.P.; Kim, S.Y.; Lee, T.H.; Jang, H.W.; Le, Q.V.; Kim, I.T. Facile synthesis of $\mathrm{W}_{2} \mathrm{C@WS}_{2}$ alloy nanoflowers and their hydrogen generation performance. Appl. Surf. Sci. 2020, 504, 144389. [CrossRef]

33. Rout, C.S.; Joshi, P.D.; Kashid, R.V.; Joag, D.S.; More, M.A.; Simbeck, A.J.; Washington, M.; Nayak, S.K.; Late, D.J. Superior field emission properties of layered $W_{2}$-RGO nanocomposites. Sci. Rep. 2013, 3, 1-8. [CrossRef] [PubMed]

34. Kurlov, A.S.; Gusev, A.I. Tungsten carbides and W-C phase diagram. Inorg. Mater. 2006, 42, $121-127$. [CrossRef]

35. Litasov, K.D.; Shatskiy, A.; Fei, Y.W.; Suzuki, A.; Ohtani, E.; Funakoshi, K. Pressure-Volume-Temperature equation of state of tungsten carbide to $32 \mathrm{GPa}$ and 1673 K. J. Appl. Phys. 2010, 108, 053513. [CrossRef] 
36. Molina-Sánchez, A.; Wirtz, L. Phonons in single-layer and few-layer $\mathrm{MoS}_{2}$ and $\mathrm{WS}_{2}$. Phys. Rev. B 2011, 84, 155413. [CrossRef]

37. Yan, Y.; Xia, B.; Qi, X.; Wang, H.; Xu, R.; Wang, J.-Y.; Zhang, H.; Wang, X. Nano-Tungsten carbide decorated graphene as co-catalysts for enhanced hydrogen evolution on molybdenum disulfide. Chem. Commun. 2013, 49, 4884-4886. [CrossRef] [PubMed]

38. Cheng, Y.; Pang, K.; Wu, X.; Zhang, Z.; Xu, X.; Ren, J.; Huang, W.; Song, R. In Situ Hydrothermal Synthesis $\mathrm{MoS}_{2} /$ Guar Gum Carbon Nanoflowers as Advanced Electrocatalysts for Electrocatalytic Hydrogen Evolution. ACS Sustain. Chem. Eng. 2018, 6, 8688-8696. [CrossRef]

39. Shiva, K.; Ramakrishna Matte, H.S.S.; Rajendra, H.B.; Bhattacharyya, A.J.; Rao, C.N.R. Employing synergistic interactions between few-layer $\mathrm{WS}_{2}$ and reduced graphene oxide to improve lithium storage, cyclability and rate capability of Li-ion batteries. Nano Energy 2013, 2, 787-793. [CrossRef]

40. Mak, K.F.; He, K.; Lee, C.; Lee, G.H.; Hone, J.; Heinz, T.F.; Shan, J. Tightly bound trions inmonolayer MoS2. Nat. Mater. 2013, 12, 207-211. [CrossRef]

41. Zhang, C.; Ma, Y.; Zhang, X.; Abdolhosseinzadeh, S.; Sheng, H.; Lan, W.; Pakdel, A.; Heier, J.; Nüesch, F. Two-Dimensional Transition Metal Carbides and Nitrides (MXenes): Synthesis, Properties, and Electrochemical Energy Storage Applications. Energy Environ. Mater. 2020, 3, 29-55. [CrossRef]

42. Moya, A.A. Identification of characteristic time constants in the initial dynamic response of electric double layer capacitors from high-frequency electrochemical impedance. J. Power Sour. 2018, 397, 124-133. [CrossRef]

43. Samad, A.; Shafique, A.; Kim, H.J.; Shin, Y.-H. Superionic and electronic conductivity in monolayer $\mathrm{W}_{2} \mathrm{C}$ : Ab initio predictions. J. Mater. Chem. A 2017, 5, 11094-11099. [CrossRef]

(C) 2020 by the authors. Licensee MDPI, Basel, Switzerland. This article is an open access article distributed under the terms and conditions of the Creative Commons Attribution (CC BY) license (http://creativecommons.org/licenses/by/4.0/). 

Article

\title{
Noble Metal Nanoparticles Incorporated Siliceous TUD-1 Mesoporous Nano-Catalyst for Low-Temperature Oxidation of Carbon Monoxide
}

\author{
Badria M. Al-Shehri ${ }^{1,2}$, Mohd Shkir ${ }^{3}$, A. S. Khder ${ }^{2}$, Ajeet Kaushik ${ }^{4, *}$ \\ and Mohamed S. Hamdy ${ }^{1, *}$ \\ 1 Catalysis Research Group (CRG), Department of Chemistry, College of Science, King Khalid University, \\ P.O. Box 9004, Abha 61413, Saudi Arabia; balshehre@kku.edu.sa \\ 2 Chemistry Department, College of Science, Umm Al-Qura University, Makkah 21421, Saudi Arabia; \\ askhder@gmail.com \\ 3 Advanced Functional Materials and Optoelectronics Laboratory (AFMOL), Department of Physics, \\ College of Science, King Khalid University, Abha 61413, Saudi Arabia; shkirphysics@gmail.com \\ 4 NanoBioTech Laboratory, Department of Natural Sciences, Division of Sciences, Art and Mathematics, \\ Florida Polytechnic University, Lakeland, FL 33805, USA \\ * Correspondence: akaushik@floridapoly.edu (A.K.); m.s.hamdy@gmail.com (M.S.H.); \\ Tel.: +966-1724-18892 (M.S.H.)
}

Received: 26 April 2020; Accepted: 7 May 2020; Published: 30 May 2020

\begin{abstract}
This report, for the first time, demonstrated the low-temperature oxidation of carbon monoxide (CO) using nano-catalysts consisting of noble metal nanoparticles incorporated in TUD-1 mesoporous silica nano-structures synthesized via a one-pot surfactant-free sol-gel synthesis methodology. Herein, we investigated a nano-catalyst, represented as M-TUD-1 ( $M=R h, P d$, $\mathrm{Pt}$ and $\mathrm{Au}$ ), which was prepared using a constant $\mathrm{Si} / \mathrm{M}$ ratio of 100 . The outcome of the analytical studies confirmed the formation of a nano-catalyst ranging from 5 to $10 \mathrm{~nm}$ wherein noble metal nanoparticles were distributed uniformly onto the mesopores of TUD-1. The catalytic performance of M-TUD-1 catalysts was examined in the environmentally impacted $\mathrm{CO}$ oxidation reaction to $\mathrm{CO}_{2}$. The catalytic performance of Au-TUD-1 benchmarked other M-TUD-1 catalysts and a total conversion of $\mathrm{CO}$ was obtained at $303 \mathrm{~K}$. The activity of the other nano-catalysts was obtained as Pt-TUD-1 > Pd-TUD-1 > Rh-TUD-1, with a total CO conversion at temperatures of 308, 328 and $348 \mathrm{~K}$, respectively. The Au-TUD-1 exhibited a high stability and reusability as indicated by the observed high activity after ten continuous runs without any treatment. The outcomes of this research suggested that M-TUD-1 are promising nano-catalysts for the removal of the toxic CO gas and can also potentially be useful to protect the environment where a long-life time, cost-effectiveness and industrial scaling-up are the key approaches.
\end{abstract}

Keywords: nano-catalyst; noble metals; TUD-1; mesoporous silica; CO-oxidation; air purification

\section{Introduction}

The emission of carbon monoxide (CO) from several industrial applications and automobiles into atmosphere has been considered as one of the harmful environmental pollutions which indirectly affect global warming [1]. Due to continuous emission mainly via automobiles, in developed countries, the CO concentration has already reached an alarming level of about $65 \%$ [2]. Almost $90 \%$ of such emission is emitted during the cold step $[3,4]$. This means that the CO oxidation reaction can be a crucial step to minimize the emission of $\mathrm{CO}$ in the air and can therefore reduce the environmental pollutions. As one of the efficient solutions, several catalytic systems investigated to date for $\mathrm{CO}$ oxidation have been based on smart functional materials [5]. The observed significant outcomes have incited scientists to 
focus on design and develop novel nano-catalysts based on transition metals with half-filled d-orbital as the catalyst. This is due to their high activity on these nano-systems which are produced from their surface propensity to forming oxygen active species over the metal surface [6-8]. Considering this, noble metal-based nano-catalysts such as $\mathrm{Au}, \mathrm{Pt}, \mathrm{Pd}, \mathrm{Rh}, \mathrm{Ru}$ and $\mathrm{Ag}$ are being very effective to catalyze the $\mathrm{CO}$ oxidation reaction. However, the requirement of high temperature and pressure to achieve a better performance was a major concern in exploring them for wider applications $[9,10]$. Furthermore, the high price of noble metals also limited their utilization for $\mathrm{CO}$ oxidation applications if important commercial scale, such as for automobiles, is a point of focus. Thus, investigating noble metals (as dopants) supported that the transition metal-based nano-catalysis to be one of the best ways to overcome the challenges of high cost and tough operational parameters [11]. In addition, this new direction of developing nano-catalysts can lead to achieving a high activity in $\mathrm{CO}$ oxidation at a mild condition [12]. The quality of support toward CO oxidation was found to be dependent on various salient features such as porosity, productivity, selectivity and production cost along with reaction time, temperature and pressure [13,14]. Considering all of these aspects, developing noble metal-supported transition metals (metal oxides) such as [15,16] zeolite- [17] and clay-based [18] nano-catalysts will be of high significance to achieve $\mathrm{CO}$ oxidation in a controlled manner.

Reports have suggested that one of the effective supports recommended to accommodate noble metal nanoparticles with reference to catalytic activity is mesoporous silica. For example, silver (Ag) nanoparticles were doped in mesoporous silica materials of different morphology such as KCC-1, SBA-15, and MCM-41, to fabricate Ag/KCC-1. This nano-catalytic system exhibited the enhanced activity as noted in $[19,20]$ as an indication of the influence of support on the catalytic activity of the $\mathrm{Ag}$ nanoparticles. In another study, the distribution degree of ruthenium $(\mathrm{Ru})$ nanoparticles into different types (1D, 2D, 3D) of mesoporous silica, to fabricate Ru/SBA-15, Ru/KIT-6, Ru/MCM-41 and $\mathrm{Ru} / \mathrm{MCM}-48$ catalytic systems, was conducted to explore variation in CO oxidation [21]. In support of the above hypothesis, several researchers have also explored the effect of the active site available during the oxidation phenomena. For example, Ratnasamy et al. [22] incorporated gold (Au) and platinum ( $\mathrm{Pt}$ ) nanoparticles into MCM-41 mesoporous silica with different ratios for CO preferential oxidation, as the total $\mathrm{CO}$ conversion was at $80^{\circ} \mathrm{C}$. In addition, $\mathrm{Ag}$, Pt and Rh were loaded into SBA-15 to investigate the activity and selectivity of the catalysts towards $\mathrm{CO}$ oxidation $[23,24]$.

Considering the challenges and possible alternatives, this research, for the first time, demonstrated the influence of a 3D-type of mesoporous silica i.e., TUD-1 nanostructures doped with various noble metal nanoparticles $(\mathrm{Au}, \mathrm{Ru}, \mathrm{Au}$, and $\mathrm{Pt})$, on $\mathrm{CO}$ conversion to $\mathrm{CO}_{2}$ at a low temperature. These four nano-catalyst systems were synthesized via incorporating the selected noble metals into a TUD-1 framework using a one-step sol-gel technique. The developed nano-catalysts were chemically and physically characterized, the catalytic activity of the prepared catalysts was evaluated in CO oxidation reaction and the stability of the best performing catalyst was also investigated.

\section{Experiment}

\subsection{The Catalysts Synthesis}

Four catalysts were synthesized by a one-pot surfactant-free sol-gel method which was reported earlier in [25], with a Si/M fixed ratio equal to $100(\mathrm{M}=\mathrm{Rh}, \mathrm{Pd}, \mathrm{Pt}$ and $\mathrm{Au})$. In typical procedure and based on the molar oxide ratio of $1 \mathrm{SiO}_{2}: 0.01 \mathrm{MO}_{\mathrm{x}}: 0.5 \mathrm{TEAOH}: 1 \mathrm{TEA}: 15 \mathrm{H}_{2} \mathrm{O}$, a mixture of triethanolamine (TEA, 97\%, ACROS, Geel, Belgium) and noble metal solution $\left(\mathrm{Rh}\left(\mathrm{NO}_{3}\right)_{2} \cdot 6 \mathrm{H}_{2} \mathrm{O}, \mathrm{Pd}\left(\mathrm{NO}_{3}\right)_{2} \cdot 6 \mathrm{H}_{2} \mathrm{O}\right.$, $\mathrm{Pt}\left(\mathrm{NO}_{3}\right)_{2} \cdot 6 \mathrm{H}_{2} \mathrm{O}$, or $\mathrm{HAuCl}_{4} \cdot \mathrm{XH}_{2} \mathrm{O}$, Sigma Aldrich, St. Louis, MO, USA) was slowly added under vigorous stirring of tetraethylorthosilicate (TEOS, $+98 \%$, ACROS, Geel, Belgium). After stirring for a few minutes, tetraethylammonium hydroxide (TEAOH, 35\%, ACROS, Geel, Belgium) was added and the overall resultant mixture was kept under vigorous stirring for 2-24 $\mathrm{h}$ at ambient conditions until the gelation was achieved. The formed gel was dried overnight at $371 \mathrm{~K}$, and then hydrothermally treated in stainless autoclaves for four hours at $451 \mathrm{~K}$. Finally, the produced powders were calcinated 
for ten hours at $873 \mathrm{~K}$ with a programed heating of $1 \mathrm{~K} / \mathrm{min}$. The final solid powders were grinded, sieved and stored in clean desiccator.

\subsection{The Catalysts Characterizations}

The four factionalized Rh-TUD-1, Pd-TUD-1, Pt-TUD-1 and Au-TUD-1 nano-systems were characterized using a set of elemental and quantitative tools. The amount of metals was measured by a inductively coupled plasma (ICP-OES) analysis of Thermo scientific (Waltham, MA, USA), ICAP 7000 series, part No: 1340910, Qtegra Software (1.3.882.20), (Waltham, MA, USA). The degree of crystallinity was determined using powder X-ray diffraction (XRD) patterns which were recorded on a Schimadzu 6000 DX diffractometer (Shimadzu Corporation, Kyoto, Japan) equipped with a graphite monochromator using $\mathrm{Cu} \mathrm{K} \alpha(\lambda=0.1541 \mathrm{~nm})$. The Nitrogen adsorption-desorption isotherms were recorded on a QuantaChrome Autosorb-6B at $77 \mathrm{~K}$ (Quantachrome Instruments, Boynton Beach, FL, USA). The pore size distribution was calculated from the adsorption branch using the Barret-Joyner-Halenda (BJH) model. The Brunauer-Emmett-Teller (BET) method was used to calculate the surface area of the samples, whereas the mesopore volume and external surface area were calculated using the $\tau$ - plot method. Scanning electron microscopy (SEM, Jeol Model 6360 LVSEM, JEOL Inc., Peabody, MA, USA) was used to investigate the morphological structure, and the micrographs were obtained after coating the samples with gold to avoid charging affects and to enhance contrast. Moreover, the SEM was equipped with an energy dispersive Xray (EDX, Jeol Model 6360 LVSEM, JEOL Inc., Peabody, MA, USA), which was used for qualitative and semi-quantitative elemental analysis. High-resolution transmission electron microscopy (HR-TEM) was carried out on a Philips CM30UT electron microscope (Philips Electronics, Eindhoven, The Netherlands) with a field emission gun as the source of electrons, and was operated at $300 \mathrm{kV}$. Finally, the chemical state of the metals and the surface composition of materials were analyzed by a X-ray photoelectron spectroscopy (XPS) PHI 5400 ESCA (ULVAC-PHI, Inc., Kanagawa, Japan) equipped with a dual Mg/Al anode X-ray source, a hemispherical capacitor analyzer and a $5 \mathrm{keV}$ ion gun. All measurements were carried out at room temperature.

\subsection{Catalytic Activity Investigation}

The catalytic oxidation of $\mathrm{CO}$ was carried out in a fixed bed reactor. In this system, there were three units, the first was the mixing and feed unit which was responsible for the gases mixing, the second unit was the reactor unit which contained the fixed-bed quartz tube, while the third unit was the analysis unit which contained the gas chromatograph (GC) equipped with a thermal conductivity detector (TCD). According to the classical procedure of the experiment, $50 \mathrm{mg}$ of the prepared catalyst, with a particle size between 180 and $315 \mu \mathrm{m}$ to minimize the mass transfer limitation, was loaded into the middle of a quartz tube without dilution and with a space velocity (GHSV) of $36,000 \mathrm{~h}^{-1}$ at 3 mbar. A pre-treating process for the catalyst was necessary to clean the surface and to activate the catalyst, which was performed by heating the reactor to $673 \mathrm{~K}$ for $1 \mathrm{~h}$ and then cool it back to the initial temperature. Then, a mixture of $1 \% \mathrm{CO}$ and $\mathrm{O}_{2}$ (both balanced with $\mathrm{N}_{2}$ gas) was feeding into the reactor with a pressure of $4.5 \mathrm{mbar}$. The temperature program was adjusted to start heating from room temperature to $673 \mathrm{~K}$ with a heating ramp of $1 \mathrm{~K} / \mathrm{min}$. Finally, the concentrations of the gas mixture i.e., $\mathrm{CO}, \mathrm{CO}_{2}, \mathrm{O}_{2}$ and $\mathrm{N}_{2}$, were analyzed online by gas chromatograph (Chrompack CP9001, Varian, Middelburg, The Netherlands) equipped with a TCD detector by using the Poraplot $\mathrm{Q}$ column.

\section{Results and Discussion}

\subsection{Compositional Analysis}

The ICP elemental analyses were performed to quantitatively determine the amount of noble metal in each sample. Rh-TUD-1 showed the maximum ions incorporation (98.8\%), while Au-TUD-1 exhibited the lowest ions incorporation with a percentage of $93.4 \%$. The obtained results are listed 
in Table 1 and it showed that more than $93 \%$ of all the added noble metal ions in the synthesis mixture were found in the final solid product.

Table 1. The elemental analysis and the texture properties of the prepared M-TUD-1 samples as obtained from the ICP and $\mathrm{N}_{2}$ sorption measurements, respectively.

\begin{tabular}{cccccc}
\hline \multirow{2}{*}{ Sample } & \multicolumn{2}{c}{ Si/M Ratio } & \multicolumn{3}{c}{ Texture Properties } \\
\cline { 2 - 6 } & Synthesis Mixture & Final Product & Surface Area $\left(\mathbf{m}^{2} / \mathbf{g}\right)$ & Pore Volume $\left(\mathbf{c m}^{3} / \mathbf{g}\right)$ & Pore Size $(\mathbf{n m})$ \\
\hline TUD-1 & $\infty$ & $\infty$ & 655.2 & 1.710 & 4.5 \\
\hline Pt-TUD-1 & 100 & 101.41 & 710.6 & 1.165 & 4.6 \\
\hline Rh-TUD-1 & 100 & 101.21 & 685.9 & 0.804 & 5.9 \\
\hline Au-TUD-1 & 100 & 107.06 & 644.1 & 0.970 & 7.5 \\
\hline Pd-TUD-1 & 100 & 103.62 & 622.3 & 1.291 & 6.8 \\
\hline
\end{tabular}

The textural properties of the TUD-1 and M-TUD-1 catalysts were determined using a $\mathrm{N}_{2}$ physisorption analysis approach and the outcomes are summarized in Table 1. All the prepared samples exhibited a high specific surface area of more than $>620 \mathrm{~m}^{2} / \mathrm{g}$. The Pt-TUD- 1 exhibited the highest surface area $\left(710 \mathrm{~m}^{2} / \mathrm{g}\right)$, while the Pd-TUD-1 showed the minimal surface area $\left(622.3 \mathrm{~m}^{2} / \mathrm{g}\right)$. The reason for the difference of surface area could be related to the size and distribution of the nanoparticles present inside the pores of TUD-1. Moreover, the pore volumes of all four M-TUD-1 samples were less than that of the neat TUD-1 sample, which gave an indication of the presence of noble metal nanoparticles inside the mesopores of TUD-1. On the other hand, the pore size of the entire M-TUD-1 samples were larger than that of the TUD-1 as an indication of the expansion of the pores during the synthesis to accommodate the formed noble metal nanoparticles.

Moreover, the $\mathrm{N}_{2}$ sorption isotherms of the prepared catalysts were compared with reference to TUD-1 as shown in Figure 1A. The M-TUD-1 samples displayed a typical IV isotherm with $\mathrm{H}_{2}$-hysteresis loop, which was very similar to that of the TUD-1 isotherm which suggested that the prepared nano-catalysts belonged to the mesoporous category as per the approved IUPAC concept [26]. The corresponding pore size distribution (Figure 1B) showed a narrow and non-uniformed pore size as well as shape distribution signals in the range of 4.6 to $7.5 \mathrm{~nm}$. Moreover, it is worth noting that the pore diameter of these catalysts belonged to the mesopore category $(2-50 \mathrm{~nm})$ [27].
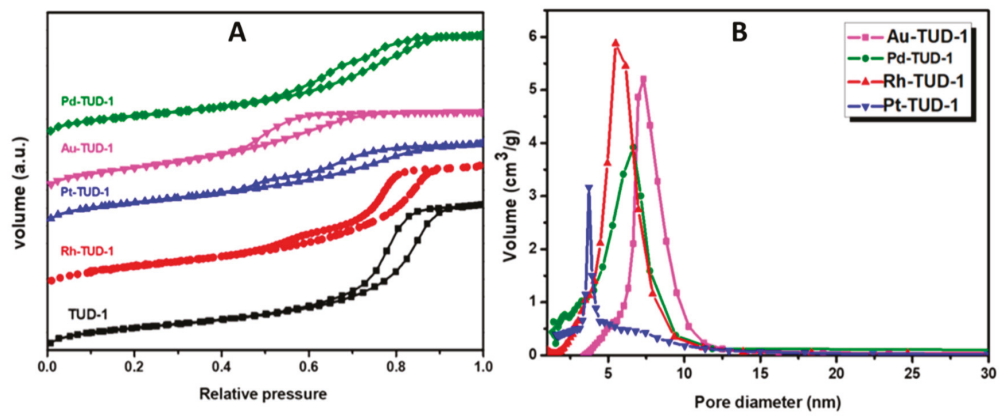

Figure 1. (A) $\mathrm{N}_{2}$ sorption isotherms of the four investigated M-TUD-1 catalysts as obtained from a QuantaChrome Autosorb-6B at $77 \mathrm{~K}$. (B) The corresponding pore size distribution as calculated from the adsorption branch using the Barret-Joyner-Halenda (BJH) model.

To investigate the crystallinity of all four M-TUD-1 nano-catalysts, the XRD patterns were recorded and compared (as presented in Figure 2A) with the TUD-1 material as a reference. The TUD- 1 and the M-TUD-1 catalysts exhibited a broad diffraction peak ranging from $20^{\circ}$ to $30^{\circ}$ which indicated the formation of amorphous matrices of silicates according to previous reports [28]. This indicated that the framework of the TUD-1 did not significantly changed after the incorporation of the noble 
metal nanoparticles. In M-TUD-1, new additional sharp peaks appeared, which typically referred to the face-centered cubic (fcc) crystalline skeleton of the (111), (200), and (220) planes [29,30]. In these diffraction patterns, the (111) plane referred to the strongest diffraction peaks at $41.07^{\circ}, 40.05^{\circ}, 40.0^{\circ}$ and $38.33^{\circ}$ for $\mathrm{Rh}, \mathrm{Pd}, \mathrm{Pt}$ and $\mathrm{Au}$, respectively [31]. However, the second diffraction peaks at $47.95^{\circ}, 44.58^{\circ}$, $46.03^{\circ}$ and $44.8^{\circ}$ were assigned to the (200) plane of noble metals with the same order. Finally, weak diffraction peaks around $70.14^{\circ}, 68.47^{\circ}, 67.54^{\circ}$ and $65.01^{\circ}$ were identified as the (220) plane of $\mathrm{M}=\mathrm{Rh}$, $\mathrm{Pd}, \mathrm{Pt}$ and $\mathrm{Au}$, respectively [32,33].

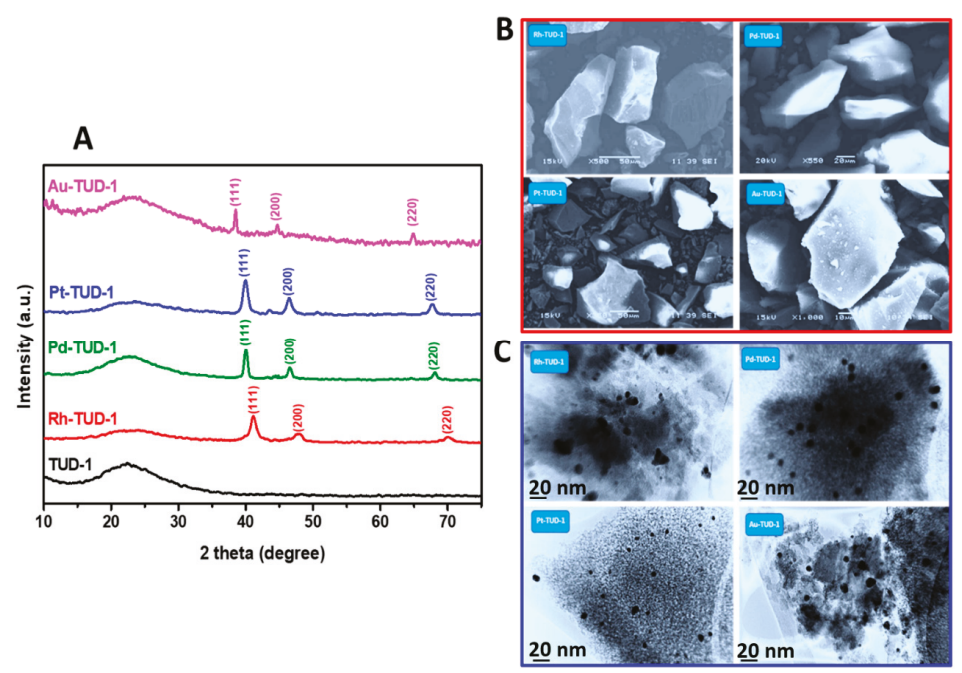

Figure 2. (A) XRD patterns of the four prepared M-TUD-1 $(\mathrm{M}=\mathrm{Au}, \mathrm{Pt}, \mathrm{Pd}$ and $\mathrm{Ru})$ samples compared with that of the TUD-1, (B) the SEM micrographs and (C) the high-resolution transmission electron microscopy (HR-TEM) micrographs of the M-TUD-1 (Rh, Pd, Pt and Au) samples.

Figure 2B shows the SEM micrographs of the four M-TUD-1 nano-catalysts. All the nano-catalyst particles exhibited the irregular shape, which is a characteristic of amorphous TUD-1 mesoporous material. Furthermore, no bulky or separating crystals were observed which can be indicative of the total incorporation of noble metals into the TUD-1 framework. The size and the distribution of the noble metal nanoparticles were determined through the HR-TEM technique as illustrated in Figure 2C. The four micrographs exhibited a worm-like porous network of the TUD-1, and the well distributed noble metal nanoparticles are clearly visible. The average size of nanocrystals was almost in the range of 5 to $10 \mathrm{~nm}$. More importantly, the obtained micrographs did not show any nanoparticle aggregation or bulky phase as an indication of the high validity of the synthesis procedure to prepare such types of catalytic structures.

Moreover, the elemental mapping analysis of the four M-TUD-1 nano-catalysts was explored using EDS as presented in Figure 3. A uniform distribution of the incorporated noble metals ( $\mathrm{Rh}, \mathrm{Pd}$, $\mathrm{Pt}$ and $\mathrm{Au}$ ) was observed in all the nano-catalyst samples. Moreover, the EDX outcomes confirmed the presence of $\mathrm{Si}, \mathrm{O}$, in addition to the incorporated noble metal ( $\mathrm{Rh}, \mathrm{Pd}, \mathrm{Pt}$ or $\mathrm{Au}$ ) only without strange ions which was evidence of the high purity of the prepared samples.

The chemical states of the surface elements in addition to the chemical compositions of the catalysts were investigated by using the XPS technique. The obtained results are presented in Figure 4 and the corresponding binding energies are listed in Table 2. For all the samples, the two peaks which were located at values of about $103.85 \mathrm{eV}$ and $533.01 \mathrm{eV}$ were attributed to $\mathrm{Si} 2 \mathrm{p}$ and O 1s, respectively, according to the previous reports [34,35]. The XPS profile of Rh-TUD-1 showed the binding energies of $R h 3 d_{5 / 2}$ and $R h 3 d_{3 / 2}$ around $307.6 \mathrm{eV}$ and $311.8 \mathrm{eV}$, respectively, which could be assigned to the 
presence of $\mathrm{Rh}^{0}$ as a metallic nanoparticle on the mesoporous surface of the Rh-TUD-1 catalyst [36,37]. Additionally, in the spectrum of Pd-TUD-1, two peaks centered at $340 \mathrm{eV}$ and $335.7 \mathrm{eV}$ which could be assigned to $\mathrm{Pd} 3 \mathrm{~d}_{5 / 2}$ and $\mathrm{Pd} 3 \mathrm{~d}_{3 / 2}$ in the $\mathrm{Pd}^{0}$ state [38]. Furthermore, in the XPS spectrum of Pt-TUD-1, two main peaks located around $71.76 \mathrm{eV}$ and $74.97 \mathrm{eV}$ of $\mathrm{Pt} 4 \mathrm{f}_{7 / 2}$ and $\mathrm{Pt} 4 \mathrm{f}_{5 / 2}$ were clearly visible, which could be assigned to zero-valent platinum [39]. Finally, as can be seen in the XPS spectrum of Au-TUD-1, it can be observed that the peaks of $\mathrm{Au} 4 \mathrm{f}_{7 / 2}$ and $\mathrm{Au} 4 \mathrm{f}_{5 / 2}$ were located at $84.42 \mathrm{eV}$ and $88.04 \mathrm{eV}$, which corresponds to $\mathrm{Au}^{0}$ state as reported previously [40].
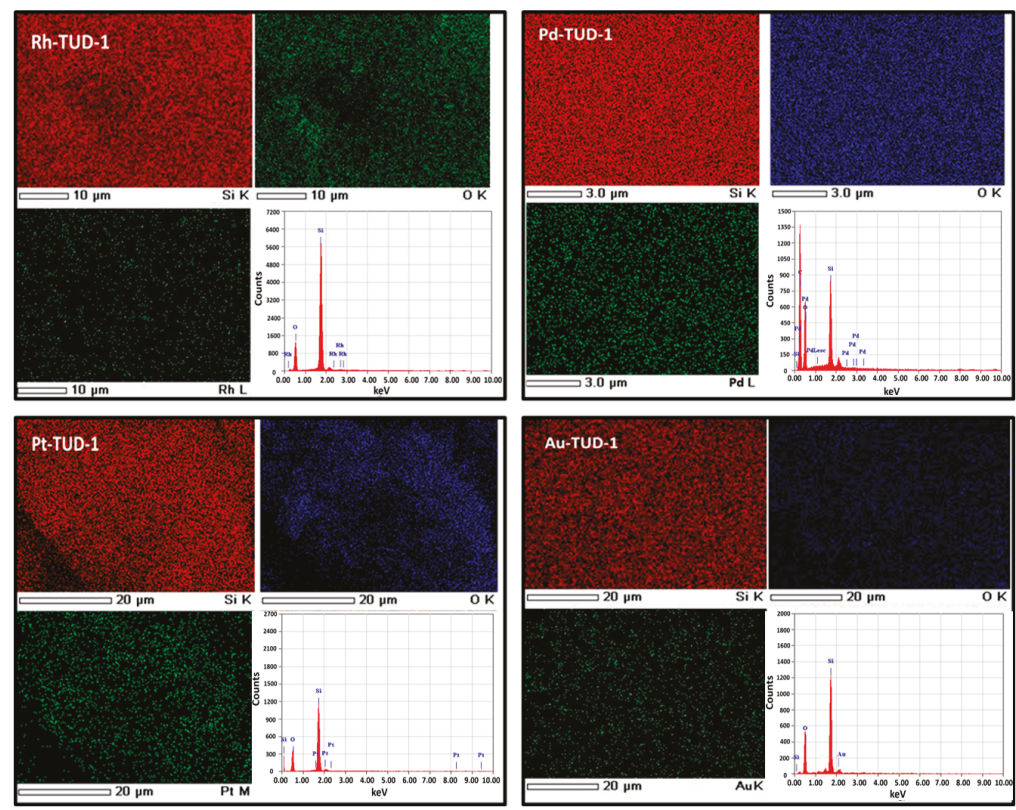

Figure 3. The elemental mapping and the energy dispersive Xray (EDX) spectroscopic analysis of the M-TUD-1 (Rh, Pd, Pt and Au) samples.
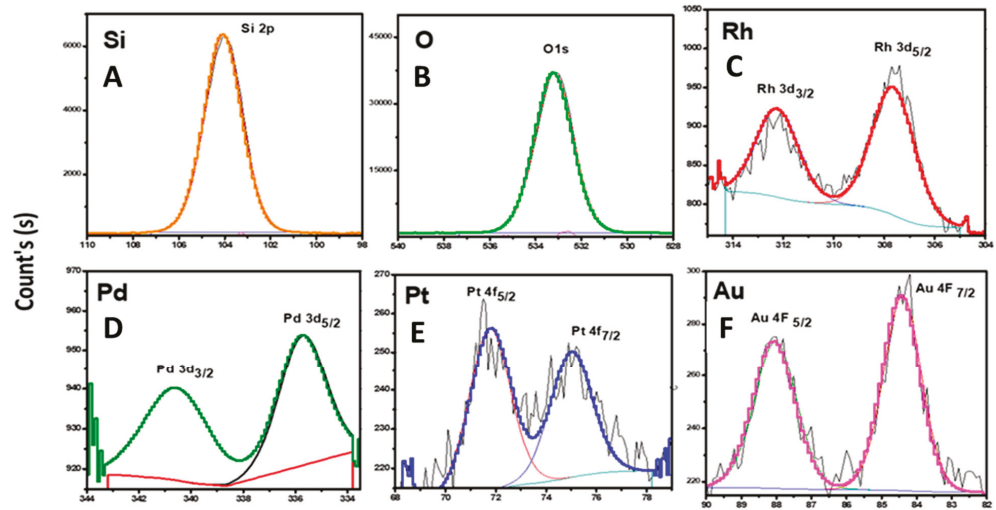

Binding energy (eV)

Figure 4. X-ray photoelectron spectroscopy (XPS) profiles of Si 2p (A), O 1s (B), Rh 3d (C), Pd 3d (D) Pt $4 \mathrm{f}(\mathrm{E})$ and of $\mathrm{Au} 4 \mathrm{f}(\mathrm{F})$ over the M-TUD-1 (where $\mathrm{M}=\mathrm{Rh}, \mathrm{Pd}, \mathrm{Pt}, \mathrm{Au})$ catalysts. 
Table 2. The binding energy of the Si 2p, O 1s, Rh 3d, Pd 3d, Pt 4f and the Au 4f photoelectrons of the catalysts (experimental error $= \pm 0.5 \mathrm{eV})$.

\begin{tabular}{|c|c|c|c|c|}
\hline \multirow{2}{*}{ Peaks of XPS Spectrum } & \multicolumn{4}{|c|}{ Binding Energy $(\mathrm{eV})$} \\
\hline & Rh-TUD-1 & Pd-TUD-1 & Pt-TUD-1 & Au-TUD-1 \\
\hline $\mathrm{Si} 2 \mathrm{p}$ & 102.9 & 102.73 & 102.8 & 102.76 \\
\hline $\mathrm{O} 1 \mathrm{~s}$ & 531.9 & 531.93 & 531.97 & 530.68 \\
\hline $\operatorname{Rh} 3 \mathrm{~d}$ & $\begin{array}{l}5 / 2=307.6 \\
3 / 2=311.8\end{array}$ & - & - & - \\
\hline $\operatorname{Pd} 3 \mathrm{~d}$ & - & $\begin{array}{c}5 / 2=335.7 \\
3 / 2=340\end{array}$ & - & - \\
\hline $\mathrm{Pt} 4 \mathrm{f}$ & - & - & $\begin{array}{l}5 / 2=71.76 \\
7 / 2=74.97\end{array}$ & - \\
\hline $\mathrm{Au} 4 \mathrm{f}$ & - & - & - & $\begin{array}{l}5 / 2=84.42 \\
7 / 2=88.04\end{array}$ \\
\hline
\end{tabular}

\subsection{Catalytic Performance toward CO Oxidation}

The results of the $\mathrm{CO}$ oxidation reactions which were catalyzed by the different noble metals incorporated the TUD-1 mesoporous material as presented in Figure 5A. The obtained results showed that Au-TUD-1 exhibited the highest activity, in which a $100 \%$ conversion of $\mathrm{CO}$ was obtained at $303 \mathrm{~K}$. On the other hand, Pt-TUD-1 exhibited a 100\% conversion within $318 \mathrm{~K}$, and Pd-TUD-1 also converted $100 \%$ of CO at $328 \mathrm{~K}$, while Rh-TUD- 1 converted $100 \%$ of CO at $348 \mathrm{~K}$. The activity could be set in the order of $\mathrm{Au}>\mathrm{Pt}>\mathrm{Pd}>\mathrm{Rh}$, which was the same trend obtained by Santos et al. [41]. Therefore, the best performing catalyst, Au-TUD-1, was chosen for further investigations.
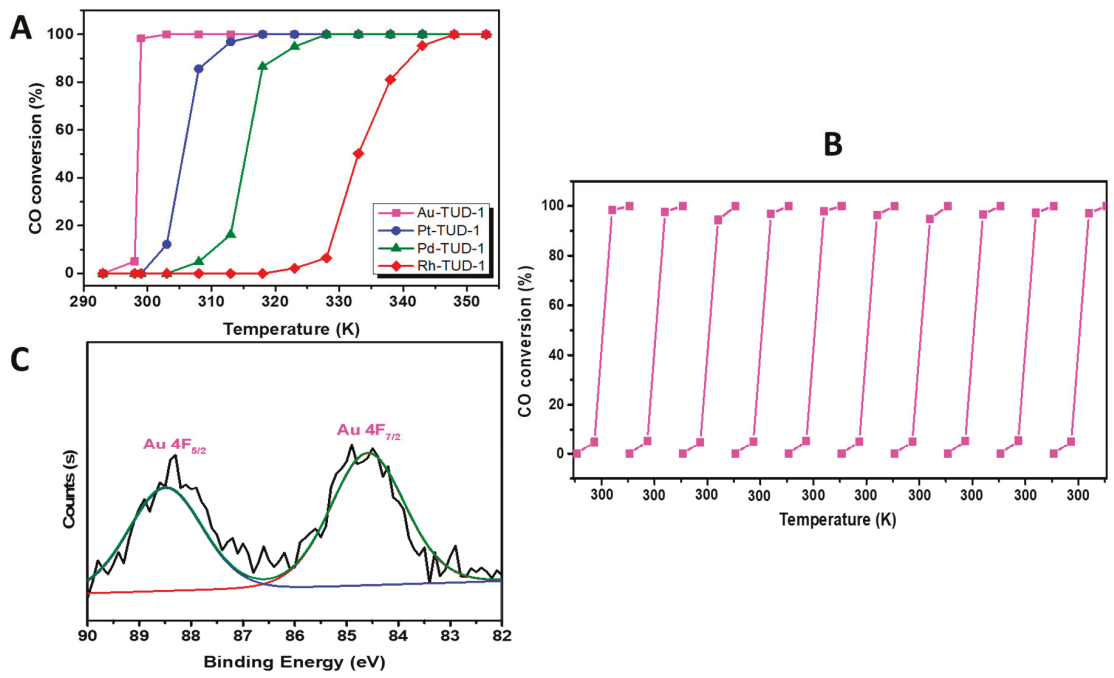

Figure 5. (A) The conversion of carbon monoxide (CO) in the presence of $\mathrm{O}_{2}$ as a function of the applied temperature over the four investigated M-TUD-1 catalysts. (B) The performance of the Au-TUD-1 catalyst in 10 consecutive runs represented in the CO conversion \% as a function of the applied temperature and $(\mathbf{C})$ the XPS of the Au-TUD-1 catalyst sample after ten consecutive runs.

The reusability of the Au-TUD-1 sample was evaluated via activating ten consecutive reactions without treatment and the observed results are presented in Figure 5B. This nano-catalyst sample exhibited a high reusability property and maintained almost the same activity in the consecutive reactions, and 100\% conversion of CO was obtained in the range of $303-305 \mathrm{~K}$ in all of the reactions. 
This result did not only show the high efficiency of Au-TUD-1, but also the good possibility of using it in many consecutive reactions without treatment.

In order to investigate the stability of the Au-TUD-1 sample, an additional XPS study was conducted for the sample which was used in the consecutive reactions. The obtained XPS is presented in Figure 5C. Two peaks were obtained at binding energies of $84.42 \mathrm{eV}$ and $88.04 \mathrm{eV}$ which assigned the $\mathrm{Au} 4 \mathrm{f}_{7 / 2}$ and $\mathrm{Au} 4 \mathrm{f}_{5 / 2}$, which could be indicative of the presence of $\mathrm{Au}^{0}$ nanoparticles in the silica matrix. By comparing the fresh XPS results (presented in Figure 4) and the XPS for the used sample, neither the positions nor the intensity of the peaks were changed which was an indication for the high stability of the oxidation state of gold nanoparticles.

\subsection{Proposed Mechanism}

The mechanism of $\mathrm{CO}$ oxidation using molecular oxygen over noble metals involves several steps supported by the literature [42-44]. In general, M-TUD1-assisted CO oxidation is a three-step procedure (as illustrated in Figure 6A), as follows: (i) CO adsorption, (ii) $\mathrm{O}_{2}$ activation and (iii) $\mathrm{CO}$ oxidation. In brief, the first step included the direct and immediate adsorption of the $\mathrm{CO}$ gas molecules on the $\mathrm{M}^{0}$ active sites $[42,43]$. This was a chemisorption process which involved a strong chemical bond formed between the metal surface and the $\mathrm{CO}$ molecules. The second step was the activation of the $\mathrm{O}_{2}$ molecules, which took place through the formation of oxygen vacancies in the rich surface of the nano-catalyst, which accelerates the formation of the metal- $\mathrm{O}_{2}$ molecule. The key factor at this step was the requirement energy to dissociate the adsorbed oxygen molecules. Finally, as the third step, the $\mathrm{CO}_{2}$ formation took place as oxygen migration adsorbed by the $\mathrm{CO}$ molecule on the dual- or active-site of the catalyst (surface oxygen vacancies and nanoparticles of noble metals).
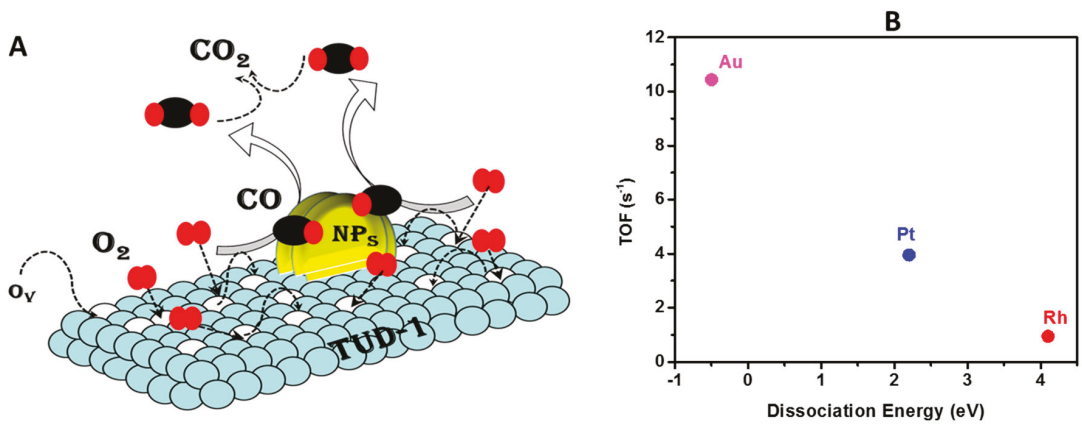

Figure 6. (A) The proposed mechanism for CO oxidation over M-TUD-1 and (B) the obtained turn over frequency (TOF) as a function of the dissociation energy of the oxygen molecules over the applied noble metal nanoparticles.

\subsection{The Differences in Activity}

Based on the outcomes of the analytical studies, it was observed that there were significant differences in the efficiency of the four investigated noble metals toward CO oxidation. Although the largest surface area was for Pt-TUD-1 followed by Rh-TUD-1 and then Au-TUD-1, and finally, Pd-TUD-1, it was Au-TUD-1 that exhibited the highest activity. So, the surface area was not the only key factor for explaining such activity difference as reported in many previous articles [45-47]. On the other hand, the obtained activity difference would be explained by the distribution degree of the metal nanoparticles and their average size, but all the prepared catalysts exhibited almost the same trend in particle size and the same well distributed nanoparticles. Therefore, the metal distribution and the particle size were not the critical points in explaining the activity difference.

Hence, the obtained activity difference must have been related to the metals themselves and their chemical properties. The key factor was most likely the activation energy of each metal as a function 
of oxygen chemisorption dissociation where the activation and migration facilities of oxygen species were conductive to the formation of abundant surface oxygen vacancies and played a significant role in the $\mathrm{CO}$ oxidation reaction at a lower temperature. Considering the dissociative adsorption of oxygen which is illustrated in Figure $6 \mathrm{~B}$, the specific activities at $175{ }^{\circ} \mathrm{C}$ of the $\mathrm{CO}$ reaction for the different prepared catalysts were in agreement with the obtained activity trend, where the Au-TUD-1 nanoparticles had the lowest value of activation energy required for oxygen gas dissociation with the highest TOF, followed by Pt-TUD-1, and the highest value of activation energy being in Rh-TUD-1. The obtained activity trend and the possible explanation were in good agreement with the research outcomes of Santos et al. [43].

\subsection{Comparison with Other Supports}

As observed, amongst several noble metals, Au nanoparticles were very active in the $\mathrm{CO}$ oxidation [45-55]. Several of evidenced noble metals were explored to support the claim, with reference to Au nanoparticles, that some of them were inert and did not participate in one way or another in the chemical reaction, e.g., silica [54,55], while some participated in the reaction such as $\mathrm{Al}_{2} \mathrm{O}_{3}$ in [51]. A comparison between the different materials which were used to support the Au nanoparticles in the CO oxidation reaction are listed in Table 3.

Table 3. A comparison between the different materials which supported the Au nanoparticles in the $\mathrm{CO}$ oxidation and the obtained activity.

\begin{tabular}{|c|c|c|c|c|}
\hline Ref. & Au Support & Au Loading \% & Au Nanosize (nm) & Temperature (K) \\
\hline Current work & TUD-1 & 0.94 & $5-10 \mathrm{~nm}$ & $303 \mathrm{~K}$ \\
\hline$[45]$ & $\alpha-\mathrm{FeOOH}$ & 0.92 & $30 \mathrm{~nm}$ & $507 \mathrm{~K}$ \\
\hline$[46]$ & mesoporous $\mathrm{Fe}_{2} \mathrm{O}_{3}$ & 7.9 & $3-10 \mathrm{~nm}$ & $523 \mathrm{~K}$ \\
\hline [47] & $\mathrm{MnO}_{2}$ & 1.0 & $1-3 \mathrm{~nm}$ & $321 \mathrm{~K}$ \\
\hline$[48]$ & $\mathrm{CeO}_{2} / \mathrm{Al}_{2} \mathrm{O}_{3}$ & 1.6 & $2-3 \mathrm{~nm}$ & $322 \mathrm{~K}$ \\
\hline [49] & $\mathrm{CuO}$ & 1.0 & $4-8 \mathrm{~nm}$ & $353 \mathrm{~K}$ \\
\hline [50] & $\mathrm{CeO}_{2}$ & 1.0 & $5-10 \mathrm{~nm}$ & $393 \mathrm{~K}$ \\
\hline [51] & $\mathrm{Ni} / \mathrm{Al}_{2} \mathrm{O}_{3}$ & 1.0 & $2.4-3.5 \mathrm{~nm}$ & $293 \mathrm{~K}$ \\
\hline$[52]$ & $\mathrm{FeO}_{\mathrm{x}} / \mathrm{TiO}_{2}$ & 1.0 & $5 \mathrm{~nm}$ & $373 \mathrm{~K}$ \\
\hline [53] & $\mathrm{Mn}_{3} \mathrm{O}_{4}$ & 4.0 & $30-40 \mathrm{~nm}$ & $371 \mathrm{~K}$ \\
\hline$[54]$ & SBA-15 & 4.8 & $10-50 \mathrm{~nm}$ & $433 \mathrm{~K}$ \\
\hline$[55]$ & MCM-41 & 4 & $5.1-6.9 \mathrm{~nm}$ & $454 \mathrm{~K}$ \\
\hline
\end{tabular}

Based on the results listed in Table 3, the Au-TUD-1 exhibited high activity, not only more than other mesoporous silica materials such as MCM-41 and SBA-15, but also more than the other supporting materials such as $\mathrm{CeO}_{2}, \mathrm{CuO}$ and $\mathrm{MnO}_{2}$. The TUD-1 mesoporous material, with its uniform pore system and interconnectivity pores, offers excellent accessibility for reactants and products to reach or leave the $\mathrm{Au}^{0}$ active sites which makes the reaction proceed faster than for other mesoporous materials. Few studies were also reported to show the advantages of using TUD-1 as a support for different active sites, such as copper in phenol hydroxylation [56], vanadium in the epoxidation of trans-stilbene [57] and indium in Baeyer-Villiger oxidation [58]. Therefore, Au-TUD-1 was considered a promising catalyst for $\mathrm{CO}$ oxidation, and further developments were carried out to reach the conversion temperature below the room temperature and to compare it with other Au catalysts $[59,60]$, which will be reported shortly.

\section{Conclusions and Viewpoint}

In summary, the design and development of a class of nano-catalysts including noble metal nanoparticles supporting mesoporous silica nano-catalysts using an easy and scalable method was 
demonstrated in this research. The catalytic performance of these nano-catalysts was evaluated using $\mathrm{CO}$ oxidation at a low temperature, as a model system. We observed that the $\mathrm{M}^{0}$ nanoparticles of $(\mathrm{Rh}, \mathrm{Pd}, \mathrm{Pt}$ or $\mathrm{Au}$ ) with an average size of $5-10 \mathrm{~nm}$ were successfully incorporated into the siliceous TUD-1 mesoporous material by a one-step sol-gel surfactant-free procedure. The outcomes of analytical studies confirmed the formation of noble metal nanoparticles with the same loading (around 1\%) and a high distribution into 3D-silica framework. Based on the obtained catalytic activities toward CO oxidation, the Au-TUD-1 catalyst exhibited the best catalytic performance for the oxidation of $\mathrm{CO}$ at room temperature followed by Pt-TUD-1 and then Pd-TUD-1, whereas Rh-TUD-1 exhibited the lowest activity at a higher temperature. The observed reusability of Au-TUD-1 projected this nano-catalyst's useful for ten consecutive catalytic reactions without compromising its activity.

The herein developed nano-catalysts based on metallic nanoparticles are cost-effective and exhibit fascinating catalytic activity. These salient features project these nano-catalysts as desired materials with promising applications in air purification, respiratory/escape masks for removing gases, refuge chambers, devices for self-rescue breathing and several others to protect from harmful gases present in the environment. Such nano-catalysts are also suitable to design and develop filters or cartridges for the trapping of harmful particles of chemicals, substances and gases in the atmosphere where the living breath to live, work, or survive.

Author Contributions: Conceptualization, B.M.A.-S. and M.S.; methodology, B.M.A.-S. and M.S.H.; writing — original draft preparation, A.K. and A.S.K.; writing—review and editing, M.S.H.; funding acquisition. All authors have read and agreed to the published version of the manuscript.

Funding: This research was funded by the Deanship of Scientific Research at King Khalid University, Saudi Arabia grant number (G.R.P-98-41).

Acknowledgments: The authors sincerely acknowledge the Deanship of Scientific Research at King Khalid University, Saudi Arabia, for grant number (G.R.P-98-41).

Conflicts of Interest: On behalf of all authors, the corresponding author states that there is no conflict of interest.

\section{References}

1. Kaneti, Y.V.; Tanaka, S.; Jikihara, Y.; Nakayama, T.; Bando, Y.; Haruta, M.; Yamauchi, Y. Room temperature carbon monoxide oxidation based on two-dimensional gold-loaded mesoporous iron oxide nanoflakes. Chem. Comm. 2018, 54, 8514-8517. [CrossRef]

2. Zhang, X.; Yang, Y.; Song, L.; Wang, Y.; He, C.; Wang, Z.; Cui, L. High and stable catalytic activity of $\mathrm{Ag} / \mathrm{Fe}_{2} \mathrm{O}_{3}$ catalysts derived from MOFs for CO oxidation. Mol. Catal. 2018, 447, 80-89. [CrossRef]

3. Rijkeboer, R.C. Catalysts on cars- practical experience. Catal. Today 1991, 11, 141-150. [CrossRef]

4. Lenaers, G. On-board real-life emission measurements on a 3-way catalyst gasoline car in motor way-, rural-and city traffic and on two Euro-1 diesel city buses. Sci. Total Environ. 1996, 189, 139-147. [CrossRef]

5. Mizuno, N. (Ed.) Modern Heterogeneous Oxidation Catalysis: Design, Reactions and Characterization; John Wiley \& Sons: Weinheim, Germany, 2009.

6. Pillay, D.; Hwang, G.S. $\mathrm{O}_{2}$-coverage-dependent $\mathrm{CO}$ oxidation on reduced $\mathrm{TiO}_{2}$ (110): A first principles study. J. Chem. Phys. 2006, 125, 1447066. [CrossRef] [PubMed]

7. Liu, W.; Flytzani-Stephanopoulos, M. Transition metal-promoted oxidation catalysis by fluorite oxides: A study of $\mathrm{CO}$ oxidation over $\mathrm{Cu} \mathrm{CeO}_{2}$. Chem. Eng. J. Bio chem. Eng. J. 1996, 64, 283-294. [CrossRef]

8. Eichler, A. CO oxidation on transition metal surfaces: Reaction rates from first principles. Surf. Sci. 2002, 498, 314-320. [CrossRef]

9. Yao, Y.F.Y. Oxidation of alkanes over noble metal catalysts. Ind. Eng. Chem. Prod. Res. Dev. 1980, 19, $293-298$. [CrossRef]

10. Oh, S.H.; Hoflund, G.B. Low-temperature catalytic carbon monoxide oxidation over hydrous and anhydrous palladium oxide powders. J. Catal. 2007, 245, 35-44. [CrossRef]

11. Xanthopoulou, G.G.; Novikov, A.V.; Knysh, Y.A.; Amosov, A.P. Nanocatalysts for low-temperature oxidation of CO. Eurasian Chemico Technol. J. 2015, 17, 17-31. [CrossRef]

12. Gélin, P.; Primet, M. Complete oxidation of methane at low temperature over noble metal-based catalysts: A review. Appl. Catal. B 2002, 39, 1-37. [CrossRef] 
13. Ratnasamy, P.; Srinivas, D.; Satyanarayana, C.V.V.; Manikandan, P.; Kumaran, R.S.; Sachin, M.; Shetti, V.N. Influence of the support on the preferential oxidation of $\mathrm{CO}$ in hydrogen-rich steam reformates over the $\mathrm{CuO}-\mathrm{CeO}_{2}-\mathrm{ZrO}_{2}$ system. J. Catal. 2004, 221, 455-465. [CrossRef]

14. Suchorski, Y.; Kozlov, S.M.; Bespalov, I.; Datler, M.; Vogel, D.; Budinska, Z.; Rupprechter, G. The role of metal/oxide interfaces for long-range metal particle activation during CO oxidation. Nat. Mater. 2018, 17, 519. [CrossRef] [PubMed]

15. Palomino, R.M.; Gutiérrez, R.A.; Liu, Z.; Tenney, S.; Grinter, D.C.; Crumlin, E.; Senanayake, S.D.D. Invrse Catalysts for CO Oxidation: Enhanced Oxide-Metal Interactions in $\mathrm{MgO} / \mathrm{Au}$ (111), $\mathrm{CeO}_{2} / \mathrm{Au}$ (111), and $\mathrm{TiO}_{2} / \mathrm{Au}$ (111). ACS Sustain. Chem. Eng. 2017, 5, 10783-10791. [CrossRef]

16. Cui, Y.; Xu, L.; Chen, M.; Lv, C.; Lian, X.; Wu, C.E.; Hu, X. CO Oxidation over Metal Oxide $\left(\mathrm{La}_{2} \mathrm{O}_{3}\right.$, $\mathrm{Fe}_{2} \mathrm{O}_{3}, \mathrm{PrO}_{2}, \mathrm{Sm}_{2} \mathrm{O}_{3}$, and $\mathrm{MnO}_{2}$ ) Doped CuO-Based Catalysts Supported on Mesoporous $\mathrm{Ce}_{0.8} \mathrm{Zr}_{0.2} \mathrm{O}_{2}$ with Intensified Low-Temperature Activity. Catalysts 2019, 9, 724. [CrossRef]

17. Kolobova, E.; Pestryakov, A.; Mamontov, G.; Kotolevich, Y.; Bogdanchikova, N.; Farias, M.; Corberan, V.C. Low-temperature $\mathrm{CO}$ oxidation on $\mathrm{Ag} / \mathrm{ZSM}-5$ catalysts: Influence of $\mathrm{Si} / \mathrm{Al}$ ratio and redox pretreatments on formation of silver active sites. Fuel 2017, 188, 121-131. [CrossRef]

18. Wang, Y.; Li, X.; Lv, T.; Wu, R.; Zhao, Y. Effect of precipitants on the catalytic performance of Pd-Cu/attapulgite clay catalyst for $\mathrm{CO}$ oxidation at room temperature and in humid circumstances. React. Kinet. Mech. Cat. 2018, 124, 203-216. [CrossRef]

19. Al-Shehri, B.M.; el Rahman, S.K.A.; Ashour, S.S.; Hamdy, M.S. A review: The utilization of mesoporous materials in wastewater treatment. Mater. Res. Exp. 2019, 6, 122002. [CrossRef]

20. Xu, J.; Zhang, J.; Peng, H.; Xu, X.; Liu, W.; Wang, Z.; Wang, X. Ag supported on meso-structured $\mathrm{SiO}_{2}$ with different morphologies for $\mathrm{CO}$ oxidation: On the inherent factors influencing the activity of Ag catalysts. Microporous Mesoporous Mater. 2017, 242, 90-98. [CrossRef]

21. Wang, L.; Chen, J.; Patel, A.; Rudolph, V.; Zhu, Z. Catalytic performance of Ru nanoparticles supported on different mesoporous silicas for preferential oxidation of $\mathrm{CO}$ in $\mathrm{H}_{2}$-rich atmosphere. Appl. Catal. A Gen. 2012, 447, 200-209. [CrossRef]

22. Chilukuri, S.; Joseph, T.; Malwadkar, S.; Damle, C.Y.; Halligudi, S.B.; Rao, B.S.; Sastry, M.; Ratnasamy, P. $\mathrm{Au}$ and $\mathrm{Au}-\mathrm{Pt}$ bimetallic nanoparticles in MCM-41 materials: Applications in co preferential oxidation. Stud. Surf. Sci. Catal. 2003, 146, 573-576. [CrossRef]

23. Zhang, X.; Dong, H.; Wang, Y.; Liu, N.; Zuo, Y.; Cui, L. Study of catalytic activity at the Ag/Al-SBA-15 catalysts for CO oxidation and selective CO oxidation. Chem. Eng. J. 2016, 283, 1097-1107. [CrossRef]

24. Krishnan, C.K.; Nakamura, K.; Hirata, H.; Ogura, M. Pt/CeO $-\mathrm{ZrO}_{2}$ present in the mesopores of SBA-15-A better catalyst for CO oxidation. Phys. Chem. Chem. Phys. 2010, 12, 7513-7520. [CrossRef]

25. Al-Shehri, B.M.; Altass, H.M.; Ashour, S.S.; Shkir, M.; el Rahman, S.K.A.; Hamdy, M.S. Enhancement the photocatalytic performance of semiconductors through composite formation with Eu-TUD-1. Optik 2020, 202, 163522. [CrossRef]

26. Sing, K.; Everett, D.; Haul, R.; Moscou, L.; Pierotti, R.; Rouquerol, J.; Siemieniewska, T. International union of pure commission on colloid and surface chemistry including catalysis reporting physisorption data for gas/solid systems with special reference to the determination of surface area and porosity. Pure Appl. Chem. 1985, 57, 603-619. [CrossRef]

27. Mubarak, A.T.; Alhanash, A.M.; Benaissa, M.; Hegazy, H.H.; Hamdy, M.S. In-situ activation of Pd-TUD-1 during the selective reduction of 1,5-cyclooctadiene. Microporous Mesoporous Mater. 2019, 278, 225-231. [CrossRef]

28. Al-Shehri, B.M.; Khder, A.R.; Ashour, S.S.; Alhanash, A.M.; Shkir, M.; Hamdy, M.S. Effect of europium loading on the photoluminescence property of europium incorporated 3D-Mesoporous silica. J. Non Cryst. Solids 2019, 515, 68-74. [CrossRef]

29. Verma, S.; Baig, R.N.; Nadagouda, M.N.; Varma, R.S. Photocatalytic CH activation and oxidative esterification using Pd@g- $\mathrm{C}_{3} \mathrm{~N}_{4}$. Catal. Today 2018, 309, 248-252. [CrossRef]

30. Lin, X.J.; Sun, T.Q.; Yang, L.P.; Sun, Y.G.; Bin, D.S.; Duan, S.Y.; Cao, A.M. A facile synthetic strategy for the creation of hollow noble metal/transition metal oxide nanocomposites. Chem. Commun. 2019, 5, 1076-1079. [CrossRef] 
31. Yildiz, Y.; Okyay, T.O.; Sen, B.; Gezer, B.; Kuzu, S.; Savk, A.; Sen, F. Highly monodisperse Pt/Rh nanoparticles confined in the graphene oxide for highly efficient and reusable sorbents for methylene blue removal from aqueous solutions. ChemistrySelect 2017, 2, 697-701. [CrossRef]

32. Kumari, M.M.; Jacob, J.; Philip, D. Green synthesis and applications of Au-Ag bimetallic nanoparticles. Spectrochim. Acta A Mol. Biomol. Spectro. 2015, 137, 185-192. [CrossRef] [PubMed]

33. Varga, E.; Pusztai, P.; Óvári, L.; Oszkó, A.; Erdőhelyi, A.; Papp, C.; Kiss, J. Probing the interaction of Rh, Co and bimetallic Rh-Co nanoparticles with the $\mathrm{CeO}_{2}$ support: Catalytic materials for alternative energy generation. Phys. Chem. Chem. Phys. 2015, 17, 27154-27166. [CrossRef] [PubMed]

34. Grunthaner, F.J.; Grunthaner, P.J.; Vasquez, R.P.; Lewis, B.; Maserjian, J.; Madhukar, A. Local atomic and electronic structure of oxide/GaAs and $\mathrm{SiO}_{2} / \mathrm{Si}$ interfaces using high-resolution XPS. J. Vac. Sci. Technol. 1979, 16, 1443-1453. [CrossRef]

35. López, G.P.; Castner, D.G.; Ratner, B.D. XPS O 1s binding energies for polymers containing hydroxyl, ether, ketone and ester groups. Surf. Interface Anal. 1991, 17, 267-272. [CrossRef]

36. Su, P.; Chen, Y.; Liu, X.; Chuai, H.; Liu, H.; Zhu, B.; Huang, W. Preparation and Characterization of $\mathrm{Rh} / \mathrm{MgSNTs}$ Catalyst for Hydroformylation of Vinyl Acetate: The $\mathrm{Rh}^{0}$ was obtained by calcination. Catalysts 2019, 9, 215. [CrossRef]

37. Simagina, V.I.; Storozhenko, P.A.; Netskina, O.V.; Komova, O.V.; Odegova, G.V.; Larichev, Y.V.; Ishchenko, A.V.; Ozerova, A.M. Development of catalysts for hydrogen generation from hydride compounds. Catalysts Today 2008, 138, 253-259. [CrossRef]

38. Brun, M.; Berthet, A.; Bertolini, J.C. XPS, AES and Auger parameter of Pd and PdO. J. Electron Spectrosc. 1999, 104, 55-60. [CrossRef]

39. Arico, A.S.; Shukla, A.K.; Kim, H.; Park, S.; Min, M.; Antonucci, V. An XPS study on oxidation states of Pt and its alloys with $\mathrm{Co}$ and $\mathrm{Cr}$ and its relevance to electroreduction of oxygen. Appl. Surf. Sci. 2001, 172, 33-40. [CrossRef]

40. Tunc, I.; Suzer, S.; Correa-Duarte, M.A.; Liz-Marzan, L.M. XPS characterization of Au (core)/SiO 2 (shell) nanoparticles. J. Phys. Chem. B 2005, 109, 7597-7600. [CrossRef]

41. Santos, V.P.; Carabineiro, S.A.; Tavares, P.B.; Pereira, M.F.; Órfão, J.J.; Figueiredo, J.L. Oxidation of CO, ethanol and toluene over $\mathrm{TiO}_{2}$ supported noble metal catalysts. Appl. Catal. B 2010, 99, 198-205. [CrossRef]

42. Schryer, D.R.; Upchurch, B.T.; Sidney, B.D.; Brown, K.G.; Hoflund, G.B.; Herz, R.K. A proposed mechanism for Pt/SnO sub x-catalyzed CO oxidation. J. Catal. 1991, 130. [CrossRef]

43. Han, Q.; Zhang, D.; Guo, J.; Zhu, B.; Huang, W.; Zhang, S. Improved Catalytic Performance of $\mathrm{Au} / \alpha-\mathrm{Fe}_{2} \mathrm{O}_{3}$-Like-Worm Catalyst for Low Temperature CO Oxidation. Nanomaterials 2019, 9, 1118. [CrossRef] [PubMed]

44. Hu, Z.P.; Zhao, H.; Gao, Z.M.; Yuan, Z.Y. High-surface-area activated red mud supported $\mathrm{Co}_{3} \mathrm{O}_{4}$ catalysts for efficient catalytic oxidation of CO. RSC Adv. 2016, 6, 94748-94755. [CrossRef]

45. Altass, H.M.; Khder, A.E.R.S. Catalytic oxidation of carbon monoxide over of gold-supported iron oxide catalyst. Mater. Res. Innov. 2018, 22, 107-114. [CrossRef]

46. Tanaka, S.; Lin, J.; Kaneti, Y.V.; Yusa, S.I.; Jikihara, Y.; Nakayama, T.; Yamauchi, Y. Gold nanoparticles supported on mesoporous iron oxide for enhanced CO oxidation reaction. Nanoscale 2018, 10, 4779-4785. [CrossRef]

47. Gu, D.; Tseng, J.C.; Weidenthaler, C.; Bongard, H.J.; Spliethoff, B.; Schmidt, W.; Schu'th, F. Gold on different manganese oxides: Ultra-low-temperature $\mathrm{CO}$ oxidation over colloidal gold supported on bulk- $\mathrm{MnO}_{2}$ nanomaterials. J. Am. Chem. Soc. 2016, 138, 9572-9580. [CrossRef]

48. Li, Z.; Wang, H.; Zhao, W.; Xu, X.; Jin, Q.; Qi, J.; Wang, D. Enhanced catalytic activity of Au-CeO $\mathrm{O}_{2} / \mathrm{Al}_{2} \mathrm{O}_{3}$ monolith for low-temperature CO oxidation. Catal. Commun. 2019, 129, 105729. [CrossRef]

49. Dong, F.; Guo, Y.; Zhang, D.; Zhu, B.; Huang, W.; Zhang, S. Gold Nanoparticles Supported on Urchin-Like CuO: Synthesis, Characterization, and Their Catalytic Performance for CO Oxidation. Nanomaterials 2020, 10, 67. [CrossRef]

50. Fiorenza, R.; Spitaleri, L.; Gulino, A.; Sciré, S. High-Performing Au-Ag Bimetallic Catalysts Supported on Macro-Mesoporous $\mathrm{CeO}_{2}$ for Preferential Oxidation of $\mathrm{CO}$ in $\mathrm{H}_{2}$-Rich Gases. Catalysts 2020, 10, 49. [CrossRef]

51. Lu, R.; He, L.; Wang, Y.; Gao, X.Q.; Li, W.C. Promotion effects of nickel-doped $\mathrm{Al}_{2} \mathrm{O}_{3}$-nanosheet-supported Au catalysts for CO oxidation. Chin. J. Catal. 2020, 41, 350-356. [CrossRef] 
52. Portillo-Vélez, N.S.; Zanella, R. Comparative study of transition metal (Mn, Fe or Co) catalysts supported on titania: Effect of Au nanoparticle's addition towards CO oxidation and soot combustion reactions. Chem. Eng. J. 2019, 385, 123848. [CrossRef]

53. Morad, M.; Karim, M.A.; Altass, H.M.; Khder, A.E.R.S. Microwave-Assisted Synthesis of Gold Nanoparticles Supported on $\mathrm{Mn}_{3} \mathrm{O}_{4}$ Catalyst for Low Temperature CO Oxidation. Environ. Technol. 2019, 1-29. [CrossRef] [PubMed]

54. Yang, C.M.; Kalwei, M.; Schüth, F.; Chao, K.J. Gold nanoparticles in SBA-15 showing catalytic activity in CO oxidation. Appl. Catal. A Gen. 2003, 254, 289-296. [CrossRef]

55. Wu, H.; Pantaleo, G.; Venezia, A.; Liotta, L. Mesoporous silica-based gold catalysts: Novel synthesis and Application in Catalytic Oxidation of CO and Volatile Organic Compounds (VOCs). Catalysts 2013, 3, 774-793. [CrossRef]

56. Pachamuthu, M.P.; Srinivasan, V.V.; Maheswari, R.; Shanthi, K.; Ramanathan, A. The impact of the copper source on the synthesis of meso-structured CuTUD-1: A promising catalyst for phenol hydroxylation. Catal. Sci. Technol. 2013, 12, 3335-3342. [CrossRef]

57. Kumar, R.; Das, P.P.; Al-Fatesh, A.S.; Fakeeha, A.H.; Pandey, J.K.; Chowdhury, B. Highly active InO KTUD-1 $^{-}$ catalyst towards Baeyer-Villiger oxidation of cyclohexanone using molecular oxygen and benzaldehyde. Catal. Commun. 2016, 74, 80-84. [CrossRef]

58. Manjunathan, P.; Vijaykumar, S.M.; Prakash, C.; Atul, B.K.; Shubhangi, B.U.; Raman, R.; Ganapati, V.S. Mesoporous tin oxide: An efficient catalyst with versatile applications in acid and oxidation catalysis. Catal. Today 2018, 309, 61-76. [CrossRef]

59. Fujita, T.; Ishida, T.; Shibamoto, K.; Honma, T.; Ohashi, H.; Murayama, T.; Haruta, M. CO Oxidation over $\mathrm{Au} / \mathrm{ZnO}$ : Unprecedented Change of the Reaction Mechanism at Low Temperature Caused by a Different $\mathrm{O}_{2}$ Activation Process. ACS Catal. 2019, 9, 8364-8372. [CrossRef]

60. Camposeco, R.; Castillo, S.; Hinojosa-Reyes, M.; Nava, N.; Zanella, R. Efficient CO (carbon monoxide) oxidation using gold catalysts supported on $\mathrm{WO}_{3}$ /titanate protonated nanotubes. Mater. Res. Bull. 2019, 115, 247-256. [CrossRef]

(C) 2020 by the authors. Licensee MDPI, Basel, Switzerland. This article is an open access article distributed under the terms and conditions of the Creative Commons Attribution (CC BY) license (http://creativecommons.org/licenses/by/4.0/). 



\title{
$\mathrm{TiO}_{2}$ Nanotube Layers Decorated with $\mathrm{Al}_{2} \mathrm{O}_{3} / \mathrm{MoS}_{2} / \mathrm{Al}_{2} \mathrm{O}_{3}$ as Anode for Li-ion Microbatteries with Enhanced Cycling Stability
}

\author{
Alexander Teklit Tesfaye ${ }^{1}$, Hanna Sopha ${ }^{2,3}$, Angela Ayobi ${ }^{1}$, Raul Zazpe ${ }^{2,3}$, \\ Jhonatan Rodriguez-Pereira ${ }^{2}$, Jan Michalicka ${ }^{3}$, Ludek Hromadko ${ }^{2,3}$, Siowwoon Ng $^{3}$, \\ Zdenek Spotz $^{3}$, Jan Prikryl ${ }^{2}$, Jan M. Macak ${ }^{2,3}$ and Thierry Djenizian ${ }^{1,4, *}$ \\ 1 Mines Saint-Etienne, Center of Microelectronics in Provence, Flexible Electronics Department, \\ 13541 Gardanne, France; alexanderteklit@gmail.com (A.T.T.); angieayobi@gmail.com (A.A.) \\ 2 Center of Materials and Nanotechnologies, Faculty of Chemical Technology, University of Pardubice, \\ Nam. Cs. Legii 565, 53002 Pardubice, Czech Republic; HannaIngrid.Sopha@upce.cz (H.S.); \\ Raul.Zazpe@upce.cz (R.Z.); Jhonatan.RodriguezPereira@upce.cz (J.R.-P.); Ludek.Hromadko@upce.cz (L.H.); \\ Jan.Prikryl@upce.cz (J.P.); Jan.Macak@upce.cz (J.M.M.) \\ 3 Central European Institute of Technology, Brno University of Technology, Purkyňova 123, \\ 61200 Brno, Czech Republic; jan.michalicka@ceitec.vutbr.cz (J.M.); SiowWoon.Ng@ceitec.vutbr.cz (S.N.); \\ Zdenek.Spotz@ceitec.vutbr.cz (Z.S.) \\ 4 Al-Farabi Kazakh National University, Center of Physical-Chemical Methods of Research and Analysis, \\ 96A. Tole bi str., 050012 Almaty, Kazakhstan \\ * Correspondence: thierry.djenizian@emse.fr
}

Received: 16 April 2020; Accepted: 12 May 2020; Published: 17 May 2020

\begin{abstract}
TiO}_{2}$ nanotube layers (TNTs) decorated with $\mathrm{Al}_{2} \mathrm{O}_{3} / \mathrm{MoS}_{2} / \mathrm{Al}_{2} \mathrm{O}_{3}$ are investigated as a negative electrode for $3 \mathrm{D} \mathrm{Li}$-ion microbatteries. Homogenous nanosheets decoration of $\mathrm{MoS}_{2}$, sandwiched between $\mathrm{Al}_{2} \mathrm{O}_{3}$ coatings within self-supporting TNTs was carried out using atomic layer deposition (ALD) process. The structure, morphology, and electrochemical performance of the $\mathrm{Al}_{2} \mathrm{O}_{3} / \mathrm{MoS}_{2} / \mathrm{Al}_{2} \mathrm{O}_{3}$-decorated TNTs were studied using scanning transmission electron microscopy, energy dispersive $\mathrm{X}$-ray spectroscopy, $\mathrm{X}$-ray photoelectron spectroscopy, and chronopotentiometry. $\mathrm{Al}_{2} \mathrm{O}_{3} / \mathrm{MoS}_{2} / \mathrm{Al}_{2} \mathrm{O}_{3}$-decorated TNTs deliver an areal capacity almost three times higher than that obtained for $\mathrm{MoS}_{2}$-decorated TNTs and as-prepared TNTs after 100 cycles at 1C. Moreover, stable and high discharge capacity $\left(414 \mu \mathrm{Ah} \mathrm{cm}^{-2}\right)$ has been obtained after 200 cycles even at very fast kinetics (3C).
\end{abstract}

Keywords: $\mathrm{TiO}_{2}$ nanotube; $\mathrm{MoS}_{2} ; \mathrm{Al}_{2} \mathrm{O}_{3}$; atomic layer deposition; Li-ion microbatteries

\section{Introduction}

Nowadays, microelectrochemical systems are key devices for providing power for micro/nanoelectromechanical devices (M/NEMS) in the fields of bio/medical engineering, aerospace, and intelligent sensors [1-3]. The microelectrochemical systems can be classified based on their power source as rechargeable Li-ion microbatteries ( $\mu$ LIBs) [4-6], microsupercapacitors [7], microfuel cells [8], and microthermoelectric batteries [9]. The two main requirements for selecting power sources for M/NEMS devices are high energy/power densities and long lifetime [10,11]. Planar 2D $\mu$ LIBs energy and power densities have an intrinsically inverse correlation, i.e., microbatteries with thick electrodes deliver a high-energy and a low-power density, while the reverse is true for thin electrodes [12]. Hence, the development of 3D $\mu$ LIBs forms a viable alternative to planar $2 \mathrm{D} \mu \mathrm{LIBs}$ to overcome the tradeoff between power and energy $[13,14]$. Nanomaterials such as nanopillars, nanorods, nanowires, 
and nanotubes are widely explored as potential electrode materials for 3D $\mu$ LIBs due to their short ion diffusion distances, high aspect ratio, and small foot print [15-18].

Self-supported $\mathrm{TiO}_{2}$ nanotube (TNT) layers have been extensively explored as anodes for 2D/3D $\mu$ LIBs due to their unique one-dimensional architecture, high self-ordering degree, short $\mathrm{Li}^{+}$ diffusion distance, fast electron transport, safety (high lithiation potential $\sim 1.7 \mathrm{~V} \mathrm{vs.} \mathrm{Li} / \mathrm{Li}^{+}$), low self-discharge rate, and nontoxic nature [18-22]. However, their low theoretical capacity $\left(168 \mathrm{mAh} \mathrm{g}^{-1}\right)$ and poor electronic conductivity pose a major obstacle for practical application $[20,23,24]$.

To overcome these problems, surface modification of the TNT layers by coating, decorating, and doping with various materials have been extensively explored [6,25-38]. Because of the low volumetric expansion and high porosity, the surface modified TNT layers deliver high capacity, while keeping the mechanical stability of the nanostructured electrode. In our recent work, we showed, for the first time, TNT layers homogenously decorated with ultrathin $\mathrm{MoS}_{2}$ nanosheets using atomic layer deposition (ALD) process that can be used as anode for 3D $\mu$ LIBs [6]. The $\mathrm{MoS}_{2}$-decorated TNT layers deliver superior electrochemical performance in comparison to their pristine counterparts. However, the capacity fades continuously during cycling due to the formation of thick solid electrolyte interphase (SEI) on the surface of the electrode and the loss of active material [6].

In the present study, we report the remarkable electrochemical properties obtained for the reversible insertion of $\mathrm{Li}$ ions in $\mathrm{Al}_{2} \mathrm{O}_{3} / \mathrm{MoS}_{2} / \mathrm{Al}_{2} \mathrm{O}_{3}$-decorated TNT layers. The capacity fading is strongly attenuated by protecting the $\mathrm{MoS}_{2}$ nanosheets with $\mathrm{Al}_{2} \mathrm{O}_{3}$ sandwich coating, produced before and also after the $\mathrm{MoS}_{2}$ ALD process. The 3D multilayers deliver excellent areal capacities with good stability up to 200 cycles even at very fast kinetics, making the $\mathrm{Al}_{2} \mathrm{O}_{3} / \mathrm{MoS}_{2} / \mathrm{Al}_{2} \mathrm{O}_{3}$-decorated TNT layers a potential candidate as a negative electrode for high performance $\mu \mathrm{LIBs}$.

\section{Materials and Methods}

\subsection{Synthesis of TNTs and ALD-Decorated TNTS}

Self-organized TNT layers with a thickness of $\sim 20 \mu \mathrm{m}$ and an inner diameter of $\sim 110 \mathrm{~nm}$ were produced via anodization of thin Ti foils (127 $\mu \mathrm{m}$ thick, Sigma-Aldrich) according to the previous published work [39]. In brief, the Ti foils were anodized in an ethylene glycol-based electrolyte containing $\mathrm{NH}_{4} \mathrm{~F}(170 \mathrm{~mm})$ and $1.5 \mathrm{vol} \% \mathrm{H}_{2} \mathrm{O}$ at $60 \mathrm{~V}$ for $4 \mathrm{~h}$. Prior to anodization the Ti foils were degreased by sonication in isopropanol and acetone for $60 \mathrm{~s}$, respectively, and dried in air. The anodization setup consisted of a high-voltage potentiostat (PGU-200 V; Elektroniklabor GmbH) in a two-electrode configuration, with a Pt foil as a counter electrode and the Ti foil as a working electrode. After anodization, the TNT layers were sonicated in isopropanol for $5 \mathrm{~min}$ and dried in air. Before further use, the TNT layers were annealed in air in a muffle oven at $400{ }^{\circ} \mathrm{C}$ for $1 \mathrm{~h}$ to obtain crystalline anatase phase.

The samples were coated using atomic layer deposition (ALD) (Beneq TFS-200) with 15 cycles $\mathrm{MoS}_{2}$ (henceforth named as $\mathrm{MoS}_{2}$-TNTs) or with a three-layer coating consisting of 9 cycles $\mathrm{Al}_{2} \mathrm{O}_{3}-15$ cycles $\mathrm{MoS}_{2}-9$ cycles $\mathrm{Al}_{2} \mathrm{O}_{3}$ (henceforth referred as $\mathrm{Al}_{2} \mathrm{O}_{3} / \mathrm{MoS}_{2} / \mathrm{Al}_{2} \mathrm{O}_{3}$-TNTs). The coating of $\mathrm{MoS}_{2}$ was carried out as described in our previous work with bis(t-butylimido)bis(dimethylamino) molybdenum (Strem, 98\%) and hydrogen sulfide (99.5\%) as molybdenum and sulphur precursors, respectively [6]. The $\mathrm{MoS}_{2}$ was deposited within the TNT layers by applying 15 ALD cycles at a temperature of $275{ }^{\circ} \mathrm{C}$ with $\mathrm{N}_{2}(99.9999 \%)$ as carrier gas at a flow rate of 500 standard cubic centimeters per min (sccm). The molybdenum precursor was heated up to $75{ }^{\circ} \mathrm{C}$ to increase its vapor pressure. Under these deposition conditions, one growth ALD cycle was defined by the following sequence: Bis(t-butylimido)bis(dimethylamino) molybdenum pulse (4 s)—Bis(t-butylimido)bis (dimethylamino) molybdenum exposure (45 s) $-\mathrm{N}_{2}$ purge $(90 \mathrm{~s})-\mathrm{H}_{2} \mathrm{~S}$ pulse $(2.5 \mathrm{~s})-\mathrm{H}_{2} \mathrm{~S}$ exposure $(45 \mathrm{~s})-\mathrm{N}_{2}$ purge $(90 \mathrm{~s})$.

The coating of $\mathrm{Al}_{2} \mathrm{O}_{3}$ on the TNT layers was prepared using trimethylaluminum (TMA, Strem, $99.999+\%)$ and deionized water $(18 \mathrm{M} \Omega)$ as aluminum and oxygen precursors, respectively $[29,39]$. Under these conditions, one $\mathrm{ALD} \mathrm{Al}_{2} \mathrm{O}_{3}$ growth cycle was defined by the following sequence: 
TMA pulse (500 ms) - TMA exposure (5 s) - $\mathrm{N}_{2}$ purge $(10 \mathrm{~s})-\mathrm{H}_{2} \mathrm{O}$ pulse $(500 \mathrm{~ms})-\mathrm{H}_{2} \mathrm{O}$ exposure $(5 \mathrm{~s})-\mathrm{N}_{2}$ purge $(10 \mathrm{~s})$. All processes were carried out at a temperature of $150{ }^{\circ} \mathrm{C}$, using $\mathrm{N}_{2}(99.9999 \%)$ as the carrier gas, at a flow rate of $400 \mathrm{sccm}$. The ALD process of 9 cycles $\mathrm{Al}_{2} \mathrm{O}_{3}$ corresponds to a nominal thickness of $1 \mathrm{~nm} \mathrm{Al}_{2} \mathrm{O}_{3}$, as shown in our previous work [29].

\subsection{Materials Characterization}

The morphology and chemical composition of the fresh and cycled electrodes were characterized by a field emission electron microscope (FE-SEM JEOL JSM 7500F, JEOL, Tokyo, Japan) and a transmission electron microscope (Titan Themis 60-300, Thermo Fisher Scientific, Eindhoven, Netherlands) operated at $300 \mathrm{keV}$ and equipped with a high angle annular dark field detector for scanning transmission electron microscopy (STEM-HAADF) and Super-X energy dispersive X-ray (EDX) spectrometer with $4 \times 30 \mathrm{~mm}^{2}$ windowless silicon drift detectors. All the EDX elemental maps are shown in net intensities, which represent the count intensities according to the background corrected and fitted model performed by Velox 2.9 software. Cross section views were obtained from mechanical bended TNTs. Dimensions of the layers were measured and statistically evaluated using proprietary Nanomeasure software.

The surface chemical state of $\mathrm{MoS}_{2}$ was monitored by X-ray photoelectron spectroscopy (XPS) (ESCA2SR, Scienta-Omicron, Taunusstein, Germany) using a monochromatic Al K $\alpha$ (1486.7 eV) X-ray source operated with $250 \mathrm{~W}$ and $12.5 \mathrm{kV}$. The binding energy scale was referenced to adventitious carbon $(284.8 \mathrm{eV})$.

\subsection{Electrochemical Characterization}

The electrochemical performance tests were performed using standard two-electrode Swagelok cells that were assembled in a glovebox filled with high purity argon (Ar). The half-cells consist of as-prepared TNTs, $\mathrm{MoS}_{2}$-TNTs, or $\mathrm{Al}_{2} \mathrm{O}_{3} / \mathrm{MoS}_{2} / \mathrm{Al}_{2} \mathrm{O}_{3}$-TNTs as the working electrode and Li foil (1 mm in thickness and $9 \mathrm{~mm}$ in diameter) as the reference electrode. The two electrodes were separated by a Whatman glass microfiber soaked in organic liquid electrolyte solution $(0.35 \mathrm{~mL})$ composed of $1 \mathrm{M}$ $\mathrm{LiPF}_{6}$ dissolved in a 1:1 vol.\% mixture of ethylene carbonate (EC) and dimethyl carbonate (DMC).

The electrochemical performance tests (cyclic voltammetry, $\mathrm{CV}$, galvanostatic charge-discharge) were performed using a VMP3 potentiostat (Bio Logic, France). The CV curves were recorded in a potential window of $0.01-3 \mathrm{~V}$ at a scan rate of $1 \mathrm{mV} \mathrm{s}^{-1}$. Galvanostatic tests were performed at multiple C-rate in the potential window of 0.01-3 V. The current was applied based on TNTs assuming a porosity of $70.5 \%$. The porosity calculation is based on the amount of the TNTs per $\mathrm{cm}^{2}$ and should be noted that it is only an estimated value (see supplementary materials for the calculations). $\mathrm{C} / \mathrm{n}$ means the battery is fully charged or discharged up to its total storage capacity in $\mathrm{n}$ hours (for this work $1 C=340 \mu \mathrm{A} \mathrm{cm}^{-2}$ ). As the surface area of the as-prepared and ALD-decorated TNTs are macroscopic $\left(0.82 \mathrm{~cm}^{2}\right)$, the obtained capacities are given in areal capacities $\left(\mathrm{mAh} \mathrm{cm} \mathrm{cm}^{-2}\right)$.

\section{Results and Discussion}

The highly ordered TNT layers were $20 \mu \mathrm{m}$ thick, and the nanotubes had an inner diameter of $\sim 110 \mathrm{~nm}$ resulting in an aspect ratio of 180, as shown in our previous publication [6]. As the amount of $\mathrm{MoS}_{2}$ decorated on the TNT layers by 15 ALD cycles is very low, it was not possible to visualize it by using SEM. However, as proved previously by STEM-EDX, already 2 ALD cycles of $\mathrm{MoS}_{2}$ led to a decoration of the TNT layers with small $\mathrm{MoS}_{2}$ sheets [6].

Figure 1 shows a STEM-HAADF image of the edge of TNT decorated with 9 cycles $\mathrm{Al}_{2} \mathrm{O}_{3}-15$ cycles $\mathrm{MoS}_{2}-9$ cycles $\mathrm{Al}_{2} \mathrm{O}_{3}$ and the corresponding EDX maps (see Figure S1a for the EDX spectrum). These maps reveal a homogenous distribution of Mo and $\mathrm{S}$ as well as of $\mathrm{Al}$ on the TNT wall. In comparison with our previous publication, the $\mathrm{MoS}_{2}$ nanosheets appear smaller [6]. This can be explained by the different chemical nature of the surfaces that $\mathrm{MoS}_{2}$ was deposited on: herein, the $\mathrm{MoS}_{2}$ was deposited on the $\mathrm{Al}_{2} \mathrm{O}_{3}$ layer, while in our previous publication the $\mathrm{MoS}_{2}$ was deposited directly 
on the TNT walls [6]. The initial ALD growth of $\mathrm{MoS}_{2}$ is different on different surfaces, and, thus, $\mathrm{MoS}_{2}$ nanosheets observed herein are smaller than if they are directly grown on $\mathrm{TiO}_{2}$.

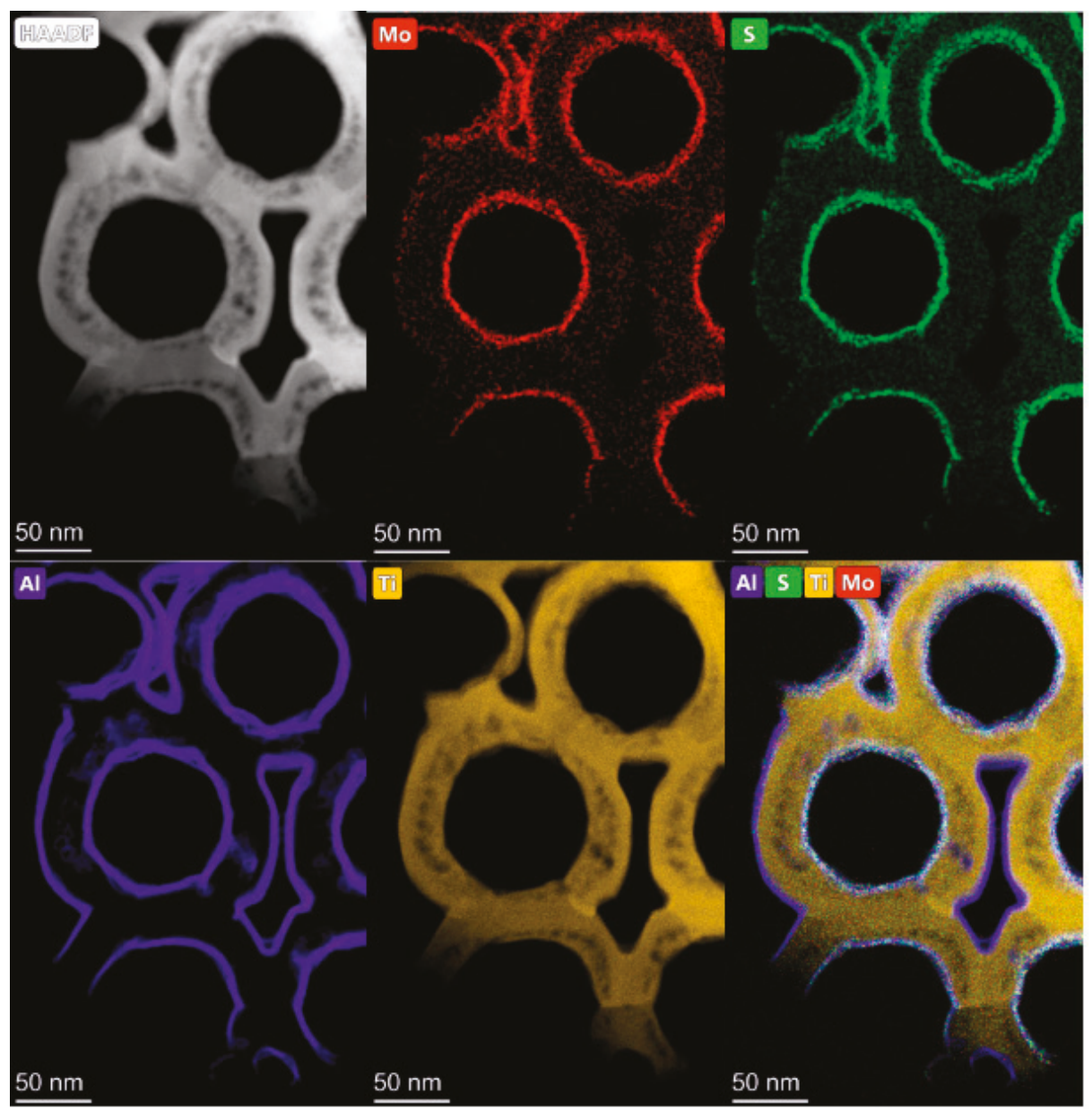

Figure 1. STEM-HAADF image in high magnification and the STEM EDX elemental maps showing the distribution of $\mathrm{Mo}, \mathrm{S}$, and $\mathrm{Al}$ on the surface of the $\mathrm{TiO}_{2}$ nanotube layers (TNTs).

XPS survey spectra of TNT layers decorated with 15 cycles $\mathrm{MoS}_{2}$ and with 9 cycles $\mathrm{Al}_{2} \mathrm{O}_{3}-15$ cycles $\mathrm{MoS}_{2}-9$ cycles $\mathrm{Al}_{2} \mathrm{O}_{3}$ are shown in Figure 2a. For 15 cycles $\mathrm{MoS}_{2}$ sample, Ti 2p and $\mathrm{O}$ 1s signals stem from the underlying TNT layer. In the case of the sandwich sample it is observed that the intensity of the $\mathrm{O} 1 \mathrm{~s}$ signal increases and the Ti $2 \mathrm{p}$ decreases, due to the presence of the $\mathrm{Al}_{2} \mathrm{O}_{3}$ layers; therefore most of the $\mathrm{O} 1 \mathrm{~s}$ comes from the $\mathrm{Al}_{2} \mathrm{O}_{3}$. The $\mathrm{C}$ species detected on both TNT layers are related to adventitious carbon. Figure $2 \mathrm{~b}$ shows the corresponding Mo $3 \mathrm{~d}$ high-resolution spectra (HR) along with the $\mathrm{S} 2 \mathrm{~s}$ signal. As can be seen, the HR signals on both samples are relatively broad. This can be explained by the very thin $\mathrm{MoS}_{2}$ decoration as on the $\mathrm{TiO}_{2} / \mathrm{MoS}_{2}$ interface, as well as on the $\mathrm{Al}_{2} \mathrm{O}_{3} / \mathrm{MoS}_{2}$ some Mo-O bonds might be built. When higher ALD MoS 2 cycle numbers were applied (results not shown), the signals became narrower due to thicker $\mathrm{MoS}_{2}$ nanosheet decorations, and the XPS spectra showed pure $\mathrm{MoS}_{2}$ [6]. Considering this, Mo $3 \mathrm{~d} \mathrm{HR}$ spectra of both samples show their corresponding

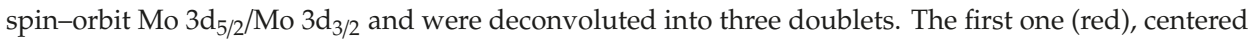


at $229.0 / 232.1 \mathrm{eV}$, is assigned to $\mathrm{Mo}^{4+}$ belonging to the $\mathrm{MoS}_{2}$ lattice $[40,41]$. The second one (blue), located at $\sim 229.9 / 233.0 \mathrm{eV}$, is attributed to Mo bonded with oxygen to form $\mathrm{MoO}_{2}$ [42]. The last doublet (orange) at $\sim 232.5 / 235.6 \mathrm{eV}$ corresponds to $\mathrm{MoO}_{3}[43,44]$. It is notable that in the sandwich sample the signals corresponding to $\mathrm{MoS}_{2}$ decrease, while molybdenum oxide signals increase. This could be due to the interaction of $\mathrm{MoS}_{2}$ with the water used as a precursor for the synthesis of $\mathrm{Al}_{2} \mathrm{O}_{3}$. Besides, $\mathrm{S} 2 \mathrm{~s}$ peaks of the 15 cycles $\mathrm{MoS}_{2}$ sample, centered at $226.6\left(\mathrm{MoS}_{2}\right)$ (dark cyan) and $229.5 \mathrm{eV}$ ( $\mathrm{SH}$-thiol groups) (purple), respectively, and S 2s peaks of the sandwich sample, located at $226.8\left(\mathrm{MoS}_{2}\right)($ dark cyan) and $234.2\left(\mathrm{SO}_{4}{ }^{2-}\right)$ (green), respectively, agree well with the chemical species observed in S 2p. In Figure 2c, the deconvoluted HR S 2p spectra of both samples confirm the presence of $\mathrm{MoS}_{2}$ with the doublet $S 2 \mathrm{p}_{3 / 2} / \mathrm{S} 2 \mathrm{p}_{1 / 2}$ (dark cyan), centered at $\sim 161.9 / 163.1 \mathrm{eV}$, which corresponds to the $\mathrm{S}^{2-}$ state from the $\mathrm{MoS}_{2}$ lattice [45]. However, each sample presented two different additional chemical species. 15 cycles $\mathrm{MoS}_{2}$ sample show another doublet (purple) at 163.6/164.8 eV attributed to SH that remained on the surface after the $\mathrm{MoS}_{2}$ deposition [46]. The sandwich sample displayed its doublet (green) at $\sim 167.8 / 169.0 \mathrm{eV}$, assigned to $\mathrm{SO}_{4}{ }^{2-}$ (sulfate) [46], possibly due to the interaction of sulfur with the water used in $\mathrm{Al}_{2} \mathrm{O}_{3}$ synthesis.
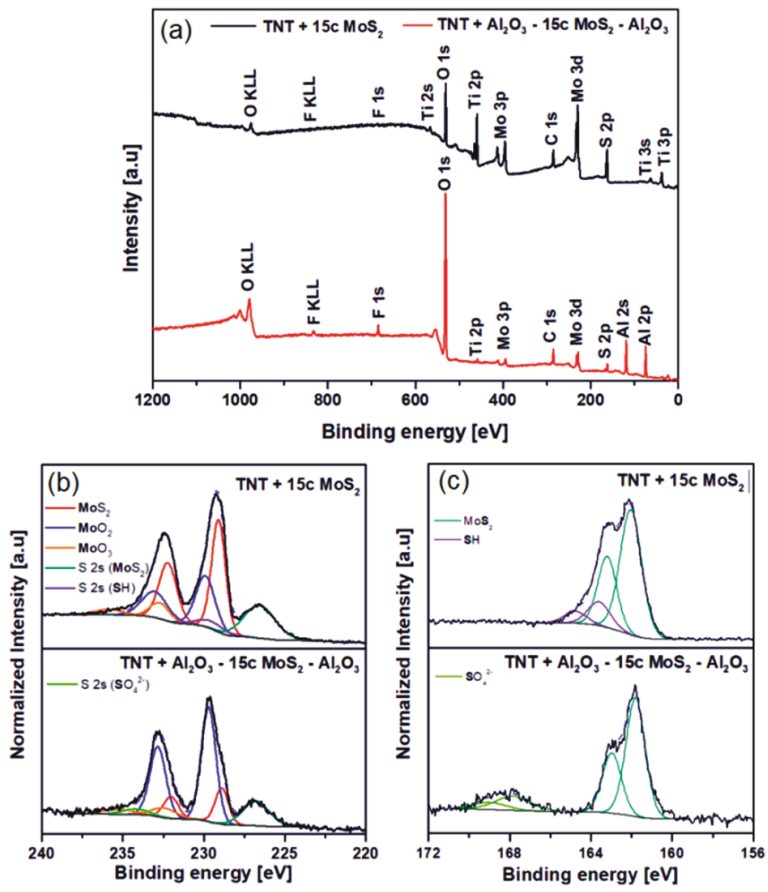

Figure 2. (a) X-ray photoelectron spectroscopy (XPS) survey spectra, (b) Mo 3d high resolution spectra and (c) S 2p high resolution spectra for TNT layers decorated with 15 cycles $\mathrm{MoS}_{2}$ and with 9 cycles $\mathrm{Al}_{2} \mathrm{O}_{3}-15$ cycles $\mathrm{MoS}_{2} \longrightarrow 9$ cycles $\mathrm{Al}_{2} \mathrm{O}_{3}$.

Figure 3a-c shows the cyclic voltammetry curves obtained for as-prepared TNTs, $\mathrm{MoS}_{2}-\mathrm{TNTs}$ and $\mathrm{Al}_{2} \mathrm{O}_{3} / \mathrm{MoS}_{2} / \mathrm{Al}_{2} \mathrm{O}_{3}$-TNTs recorded at a scan rate of $1 \mathrm{mV} \mathrm{s}^{-1}$ in the potential window of $0.01-3 \mathrm{~V}$ vs. $\mathrm{Li} / \mathrm{Li}^{+}$. All the $\mathrm{CV}$ curves obtained exhibit a cathodic peak at $1.7 \mathrm{~V} \mathrm{vs.} \mathrm{Li} / \mathrm{Li}^{+}$and anodic peak at $2.2 \mathrm{~V}$ vs. $\mathrm{Li} / \mathrm{Li}^{+}$associated to the reversible insertion/extraction of $\mathrm{Li}^{+}$into/from anatase according to Equation (1) $[5,18,47,48]$. However, the first insertion peak for $\mathrm{Al}_{2} \mathrm{O}_{3} / \mathrm{MoS}_{2} / \mathrm{Al}_{2} \mathrm{O}_{3}-\mathrm{TNTs}$ is shallow and shifts to the lower potential because of the $\mathrm{Al}_{2} \mathrm{O}_{3}$ insulating coating which slows down 
the Li-diffusion [29]. This behavior is not observed in the subsequent cycles due to the formation of a conductive Al-O-Li phase.

$$
\mathrm{TiO}_{2}+\mathrm{xLi}^{+}+\mathrm{xe}^{-} \rightleftharpoons \mathrm{Li}_{\mathrm{x}} \mathrm{TiO}_{2} \quad 0 \leq \mathrm{x} \leq 1,
$$
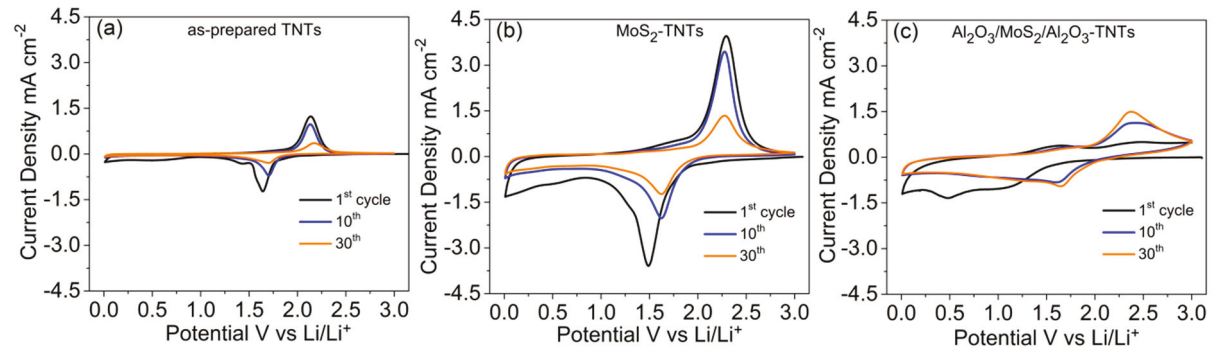

Figure 3. Cyclic voltammograms of (a) as-prepared TNTs, (b) $\mathrm{MoS}_{2}$-TNTs and (c) $\mathrm{Al}_{2} \mathrm{O}_{3} / \mathrm{MoS}_{2}$ / $\mathrm{Al}_{2} \mathrm{O}_{3}$-TNTs recorded at a scan rate of $1 \mathrm{mV} \mathrm{s}^{-1}$

In comparison to as-prepared TNTs, the CV curves show additional peaks for the $\mathrm{MoS}_{2}$-TNTs (Figure 3b) and $\mathrm{Al}_{2} \mathrm{O}_{3} / \mathrm{MoS}_{2} / \mathrm{Al}_{2} \mathrm{O}_{3}$-TNTs (Figure $3 \mathrm{c}$ ). These peaks are attributed to the multistep reaction of $\mathrm{Li}^{+}$with $\mathrm{MoS}_{2}$. During the first discharge (lithiation), the two cathodic peaks at $1.25-1.75 \mathrm{~V}$ and $0.5 \mathrm{~V}$ vs. $\mathrm{Li} / \mathrm{Li}^{+}$are attributed to phase transformation of $\mathrm{MoS}_{2}$ in to $\mathrm{Li}_{\mathrm{x}} \mathrm{MoS}_{2}$ and the subsequent complete reduction of $\mathrm{Mo}^{4+}$ to $\mathrm{Mo}^{0}$ and $\mathrm{Li}_{2} \mathrm{~S}$, respectively, according to Equations $(2)$ and $(3)[49,50]$. Upon the charge (delithiation) process, the shallow peak at $1.9 \mathrm{vs}$. $\mathrm{Li} / \mathrm{Li}^{+}$associated with retrieval of $\mathrm{Li}_{x} \mathrm{MoS}_{2}$ from Mo is dwarfed by the broader and more prominent peak at 2-2.75 V vs. $\mathrm{Li} / \mathrm{Li}^{+}$, which correspond to the oxidation of $\mathrm{Li}_{2} \mathrm{~S}$ to $\mathrm{S}$ according to Equations (3) and (4), respectively $[49,50]$. This phenomenon is more pronounced for $\mathrm{MoS}_{2}$-TNTs because of the absence of the protective $\mathrm{Al}_{2} \mathrm{O}_{3}$-coating layer.

$$
\begin{gathered}
\mathrm{MoS}_{2}+x \mathrm{Li}^{+}+x \mathrm{e}^{-} \rightarrow \mathrm{Li}_{x} \mathrm{MoS}_{2} \\
\mathrm{Li}_{x} \mathrm{MoS}_{2}+(4-x) \mathrm{Li}^{+}+(4-x) \mathrm{e}^{-} \rightleftharpoons \mathrm{Mo}+2 \mathrm{Li}_{2} \mathrm{~S} \\
\mathrm{Li}_{2} \mathrm{~S} \rightleftharpoons 2 \mathrm{Li}^{+}+\mathrm{S}+2 \mathrm{e}^{-}
\end{gathered}
$$

Compared to the $C V$ curves of as-prepared TNTs and $\mathrm{Al}_{2} \mathrm{O}_{3} / \mathrm{MoS}_{2} / \mathrm{Al}_{2} \mathrm{O}_{3}$-TNTs, the $\mathrm{MoS}_{2}-\mathrm{TNT}$ shows broader peaks and larger surface area under the CV curve. This is attributed to the $\mathrm{MoS}_{2}$-decoration contributing to the total capacity and modification of the electrode structure. However, the peak intensity and area under the CV curve diminish with cycling. In our previous work, we reported that electrochemical performance of $\mathrm{MoS}_{2}$-TNTs is affected by the dissolution of $\mathrm{S}$ combined to the formation and growth of a SEI layer [6]. In contrast, reversible and stable CV curves are obtained for $\mathrm{Al}_{2} \mathrm{O}_{3} / \mathrm{MoS}_{2} / \mathrm{Al}_{2} \mathrm{O}_{3}$-TNTs owing to the ALD-deposited $\mathrm{Al}_{2} \mathrm{O}_{3}$ thin layers. The surface modification results in the improved stability of the electrode by limiting the $\mathrm{S}$ dissolution and the growth of the SEI layer through the formation of a stable Al-O-Li composite [29].

The electrochemical performance was evaluated through the examination of the charge/discharge profiles obtained by galvanostatic cycling tests. Figure $4 \mathrm{a}-\mathrm{c}$, shows the galvanostatic charge/discharge profiles for as-prepared TNTs, $\mathrm{MoS}_{2}$-TNTs, and $\mathrm{Al}_{2} \mathrm{O}_{3} / \mathrm{MoS}_{2} / \mathrm{Al}_{2} \mathrm{O}_{3}$-TNTs at a current density of $340 \mu \mathrm{A} \mathrm{cm}{ }^{-2}(1 \mathrm{C})$ in the potential window of $0.01-3 \mathrm{~V} \mathrm{vs}$. $\mathrm{Li} / \mathrm{Li}^{+}$. The charge/discharge profiles are in agreement with the electrochemical behaviors observed from the CV plots. For as-prepared TNTs and $\mathrm{MoS}_{2}$-TNTs, the obtained capacity fades with cycle number unlike to the $\mathrm{Al}_{2} \mathrm{O}_{3} / \mathrm{MoS}_{2} / \mathrm{Al}_{2} \mathrm{O}_{3}$-TNTs. This is attributed to the beneficial effects of the $\mathrm{Al}_{2} \mathrm{O}_{3}$-coating on the TNTs, which are in agreement with works reported in the literature [25,29,51,52]. 

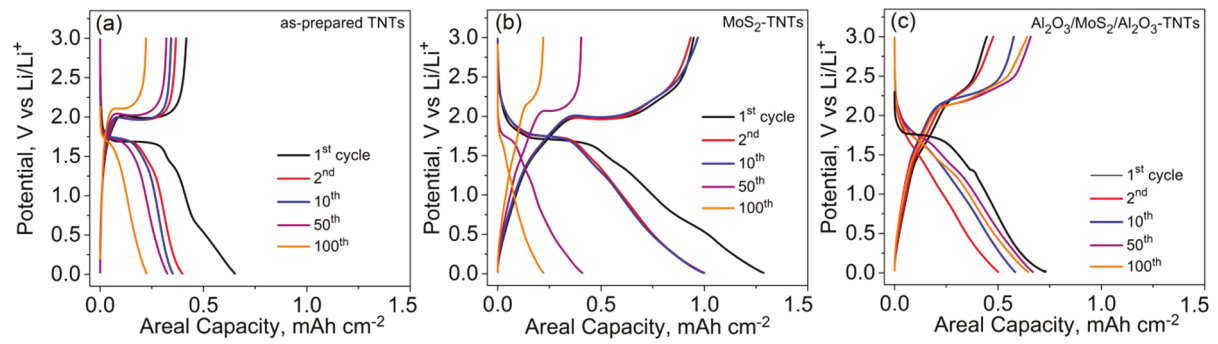

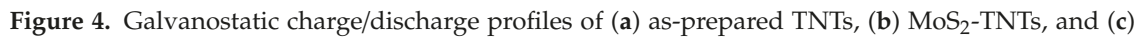
$\mathrm{Al}_{2} \mathrm{O}_{3} / \mathrm{MoS}_{2} / \mathrm{Al}_{2} \mathrm{O}_{3}$-TNTs at $1 \mathrm{C}$.

Figure 5 a shows the discharge capacity vs. cycle number for as-prepared TNTs, $\mathrm{MoS}_{2}$-TNTs, and $\mathrm{Al}_{2} \mathrm{O}_{3} / \mathrm{MoS}_{2} / \mathrm{Al}_{2} \mathrm{O}_{3}$-TNTs cycled at $1 \mathrm{C}$. The first cycle delivers a discharge capacity of $652 \mu \mathrm{Ah} \mathrm{cm}^{-2}$, $1286 \mu \mathrm{Ah} \mathrm{cm}^{-2}$, and $729 \mu \mathrm{Ah} \mathrm{cm}{ }^{-2}$ for the as-prepared TNTs, $\mathrm{MoS}_{2}-\mathrm{TNTs}$, and $\mathrm{Al}_{2} \mathrm{O}_{3} / \mathrm{MoS}_{2} / \mathrm{Al}_{2} \mathrm{O}_{3}$-TNTs, respectively. The higher capacity obtained for the decorated-TNT electrodes are attributed to the contribution of $\mathrm{MoS}_{2}$ coating. The irreversible capacity observed after the first cycle is attributed to the side reactions of $\mathrm{Li}^{+}$with water molecule traces and the structural defects of the TNTs, and additionally, the dissolution of $\mathrm{S}$ and the formation of the SEI layer in the case of $\mathrm{MoS}_{2}$-TNTs $[6,53,54]$. It is clearly apparent that the $\mathrm{Al}_{2} \mathrm{O}_{3} / \mathrm{MoS}_{2} / \mathrm{Al}_{2} \mathrm{O}_{3}$-TNTs have superior cyclability than as-prepared TNTs and $\mathrm{MoS}_{2}$-TNTs with a reversible capacity of $640 \mu \mathrm{Ah} \mathrm{cm} \mathrm{cm}^{-2}$ obtained, whereas only $222 \mu \mathrm{Ah} \mathrm{cm}^{-2}$ and $220 \mu \mathrm{Ah} \mathrm{cm}^{-2}$ was retained after 100 cycles for the as-prepared TNTs and $\mathrm{MoS}_{2}$-TNTs, respectively. It is remarkable that the areal capacities increase with the number of cycles. This is attributed to the formation of microcracks as the result of $\mathrm{Li}^{+}$reaction with $\mathrm{MoS}_{2}$, which expose additional pore channels. In addition, the presence of $\mathrm{Al}_{2} \mathrm{O}_{3}$ decoration bestows the TNT electrodes with enhanced chemical properties. Figure $5 \mathrm{~b}$ shows the coulombic efficiency (CE) at $1 \mathrm{C}$ for 100 cycles. The $\mathrm{CE}$ obtained for $\mathrm{Al}_{2} \mathrm{O}_{3} / \mathrm{MoS}_{2} / \mathrm{Al}_{2} \mathrm{O}_{3}$-TNTs at the first cycle was $62 \%$ and reached more than $99 \%$ just after three cycles. In comparison, as-prepared TNTs and $\mathrm{MoS}_{2}$-TNTs have a first cycle CE of $64 \%$ and $74 \%$ and reaching the $98 \%$ only after 15 and 85 cycles, respectively. These values indicate relatively more stable SEI formation on the surface of the $\mathrm{Al}_{2} \mathrm{O}_{3}$-coated electrode even after long-term cycling. It is remarkable that the beneficial effect of the $\mathrm{Al}_{2} \mathrm{O}_{3}$ coating is also evidenced at very fast kinetics $(3 \mathrm{C})$ over 200 cycles as shown in Figure 5c. Indeed, the $\mathrm{Al}_{2} \mathrm{O}_{3} / \mathrm{MoS}_{2} / \mathrm{Al}_{2} \mathrm{O}_{3}$-TNT electrode is able to maintain a capacity of $414 \mu \mathrm{Ah} \mathrm{cm}{ }^{-2}$, whereas the as-prepared TNTs and $\mathrm{MoS}_{2}$-TNTs retain only $130 \mu \mathrm{Ah} \mathrm{cm}^{-2}$ and $195 \mu \mathrm{Ah} \mathrm{cm}^{-2}$, respectively. The main electrochemical results of the as-prepared and ALD-decorated TNTs in comparison with literature are shown in Table 1. 

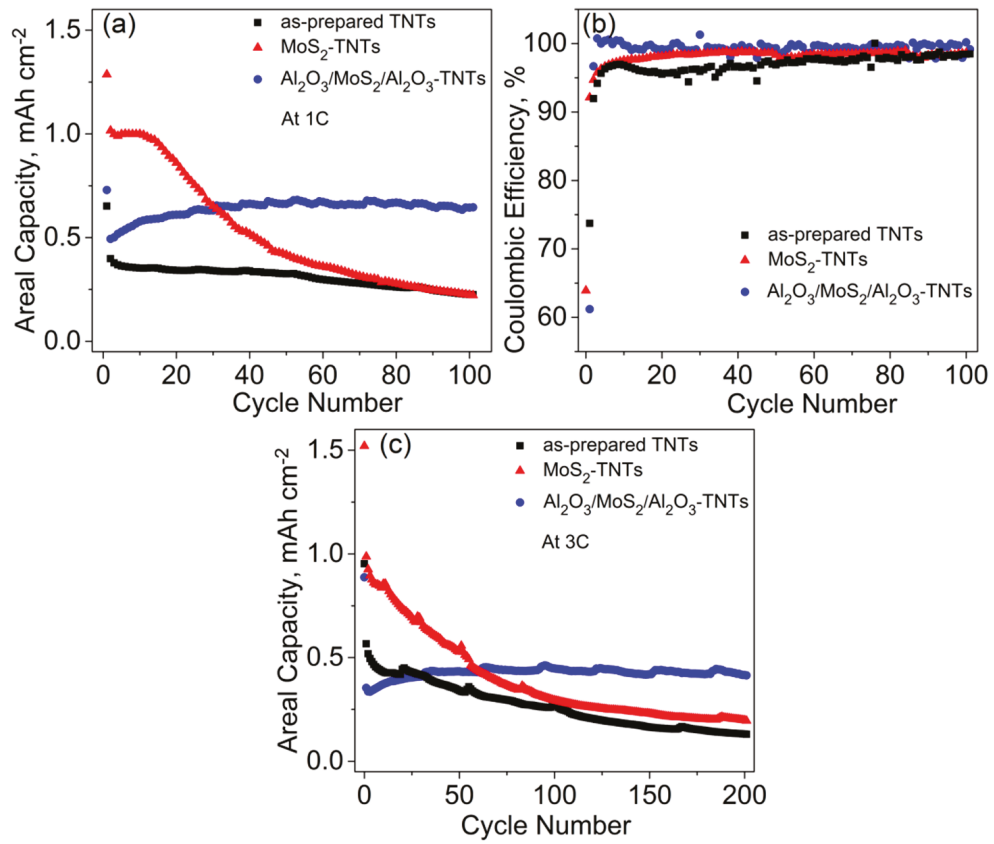

Figure 5. Long-term cycling tests of as-prepared TNTs, $\mathrm{MoS}_{2}$-TNTs, and $\mathrm{Al}_{2} \mathrm{O}_{3} / \mathrm{MoS}_{2} / \mathrm{Al}_{2} \mathrm{O}_{3}-\mathrm{TNTs}$ : (a) at $1 \mathrm{C}$ for 100 cycles, and (b) the corresponding coulombic efficiency vs. cycle number and (c) at $3 \mathrm{C}$ for 200 cycles.

Table 1. Comparison of the electrochemical performance of as-prepared and atomic layer deposition (ALD)-decorated TNTs with TNTs coated with various materials.

\begin{tabular}{|c|c|c|c|}
\hline Working Electrode & $\begin{array}{l}\text { First Discharge Capacity } \\
\left(\mu \mathrm{Ah} \mathrm{cm}^{-2}\right) \text { at C-Rate }\end{array}$ & $\begin{array}{c}\text { Discharge Capacity after (n) } \\
\text { Cycle }\left(\mu \mathrm{Ah} \mathrm{cm}^{-2}\right)\end{array}$ & $\begin{array}{l}\text { Coulombic Efficiency } \\
(\%) \text { after (n) Cycles }\end{array}$ \\
\hline \multirow{2}{*}{ as-prepared TNTs } & 1C-652 & $222(100)$ & $\sim 98 \%(100)$ \\
\hline & $3 C-952$ & $130(200)$ & 98\% (200) \\
\hline \multirow{2}{*}{$\mathrm{MoS}_{2}$-TNTs } & $1 C-1286$ & $220(100)$ & ح9\% (100) \\
\hline & 3C-1520 & $195(200)$ & 98\% (200) \\
\hline \multirow{2}{*}{$\mathrm{Al}_{2} \mathrm{O}_{3} / \mathrm{MoS}_{2} / \mathrm{Al}_{2} \mathrm{O}_{3}$-TNTs } & $1 C-729$ & 640 (100) & $>99 \%(100)$ \\
\hline & $3 C-887$ & $414(200)$ & $>99 \%$ (200) \\
\hline $\mathrm{SnO}_{2} @ \mathrm{TNTs}$ [55] & 2C-469.8 & $113(50)$ & $>94 \%(50)$ \\
\hline $\mathrm{Co}_{3} \mathrm{O}_{4} @$ TNTs [56] & $1 C-200$ & $103(25)$ & NA \\
\hline 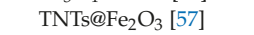 & $100 \mathrm{~mA} \mathrm{~cm}^{-2}-570$ & $680(50)$ & $100 \%(50)$ \\
\hline
\end{tabular}

Post-mortem analysis was carried out to provide further evidence for the positive contribution of the $\mathrm{Al}_{2} \mathrm{O}_{3}$ decoration on the electrochemical properties. Figure $6 \mathrm{a}-\mathrm{c}$ shows the SEM images of the as-prepared TNTs, $\mathrm{MoS}_{2}$-TNTs, and $\mathrm{Al}_{2} \mathrm{O}_{3} / \mathrm{MoS}_{2} / \mathrm{Al}_{2} \mathrm{O}_{3}$-TNTs after 200 charge/discharge cycles at $3 \mathrm{C}$, respectively. A very thick (ca. $6 \mu \mathrm{m}$ ) and rough SEI layer has been grown on $\mathrm{MoS}_{2}-\mathrm{TNTs}_{\mathrm{s}}$ (Figure 6b) in comparison to as-prepared TNTs that is around $2 \mu \mathrm{m}$ thick (Figure 6a). Similar behavior was observed from our previous work on $\mathrm{MoS}_{2}$-coated TNTs [6]. In contrary, the SEI formed on $\mathrm{Al}_{2} \mathrm{O}_{3} / \mathrm{MoS}_{2} / \mathrm{Al}_{2} \mathrm{O}_{3}$-TNTs is much thinner (ca. $1 \mu \mathrm{m}$ ) and smoother (Figure 6c) confirming the benefit of $\mathrm{Al}_{2} \mathrm{O}_{3}$ coatings. This effect is further evidenced by STEM-EDX elemental maps given in Figure $6 \mathrm{~d}$ showing the homogenous distribution of Mo, S, and $\mathrm{Al}$ on the TNT walls after electrochemical tests (see Figure S1b for the EDX spectrum). 


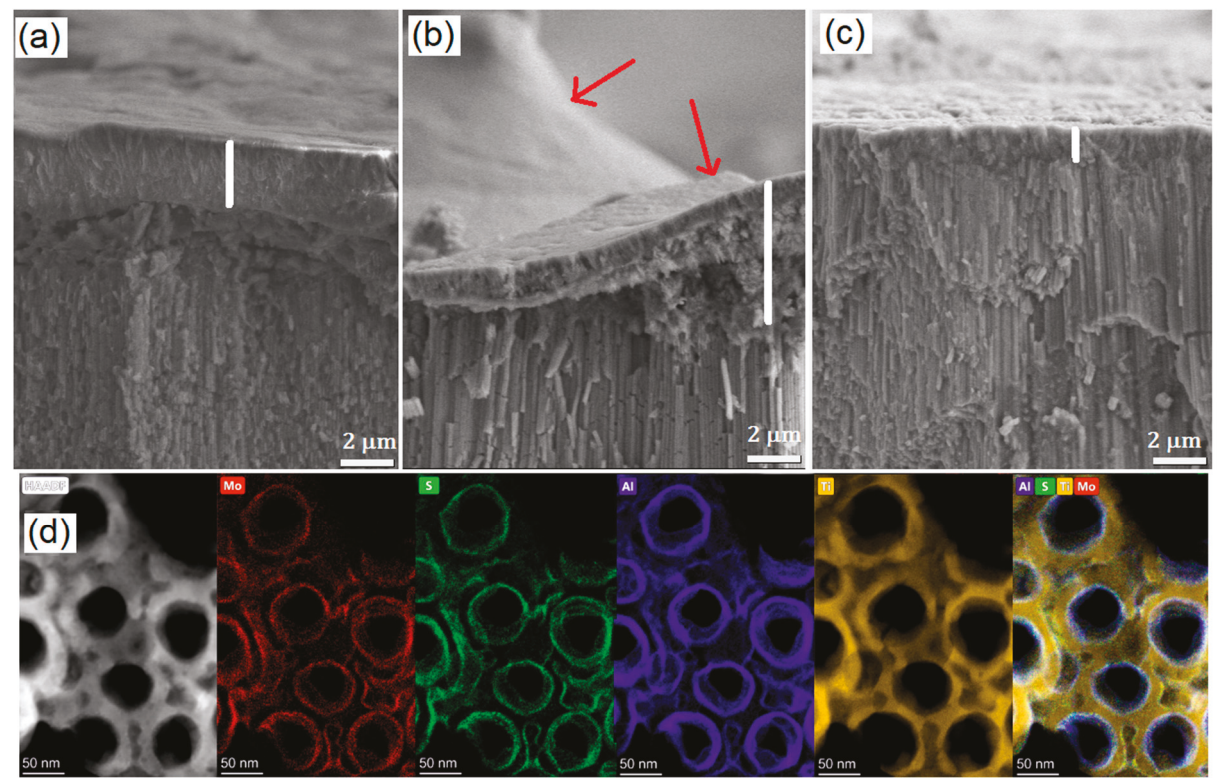

Figure 6. Cross sectional SEM images of (a) as-prepared TNTs, (b) MoS 2 -TNTs, and (c) $\mathrm{Al}_{2} \mathrm{O}_{3} / \mathrm{MoS}_{2} / \mathrm{Al}_{2} \mathrm{O}_{3}$-TNTs after 200 cycles at 3C. Solid electrolyte interphase (SEI) layer thickness and surface roughness is indicated by a white line and red arrows. (d) High magnification STEM HAADF image and the STEM-EDX elemental maps showing the distribution of $\mathrm{Mo}, \mathrm{S}$, and $\mathrm{Al}$ on the surface of the TNT for $\mathrm{Al}_{2} \mathrm{O}_{3} / \mathrm{MoS}_{2} / \mathrm{Al}_{2} \mathrm{O}_{3}$-TNTs.

\section{Conclusions}

In this work, enhanced electrochemical performance of TNT was achieved by decorating the surface with nanosheets of $\mathrm{MoS}_{2}$, sandwiched between $\mathrm{Al}_{2} \mathrm{O}_{3}$ coatings. ALD technique was used to homogenously deposit the $\mathrm{MoS}_{2}$ nanosheets and the $\mathrm{Al}_{2} \mathrm{O}_{3}$ layers on the self-supporting TNT layers. The excellent capacity and stability of $\mathrm{Al}_{2} \mathrm{O}_{3} / \mathrm{MoS}_{2} / \mathrm{Al}_{2} \mathrm{O}_{3}$-decorated TNT is attributed to the mechanical and structural stability imported by $\mathrm{Al}_{2} \mathrm{O}_{3}$ decoration. The $\mathrm{Al}_{2} \mathrm{O}_{3}$ limits the formation and growth of SEI layer and loss of active material during cycling. As a result, the $\mathrm{Al}_{2} \mathrm{O}_{3} / \mathrm{MoS}_{2} / \mathrm{Al}_{2} \mathrm{O}_{3}$-decorated TNT deliver an areal capacity almost three times higher than that obtained for $\mathrm{MoS}_{2}$-decorated TNT and as-prepared TNTs after 100 cycles at 1C.

Supplementary Materials: The following are available online at http://www.mdpi.com/2079-4991/10/5/953/s1. Calculation to determine the porosity of TNTs and Figure S1: EDX spectrum of $\mathrm{Al}_{2} \mathrm{O}_{3} / \mathrm{MoS}_{2} / \mathrm{Al}_{2} \mathrm{O}_{3}-\mathrm{TNTs}$ (a) before and (b) after 100 galvanostatic cycles.

Author Contributions: Conceptualization, T.D. and J.M.M.; methodology, A.T.T., H.S., A.A., R.Z., J.R.-P., J.M., L.H., S.N., Z.S., and J.P.; formal analysis, A.T.T. and H.S.; writing-original draft preparation, A.T.T. and H.S.; writing - review and editing, J.M.M. and T.D.; supervision, T.D. and J.M.M.; funding acquisition, J.M.M. and T.D. All authors have read and agreed to the published version of the manuscript.

Funding: This research was funded by the European Research Council (project 638857) and Ministry of Youth, Education and Sports of the Czech Republic (LM2015082, LQ1601, CZ.02.1.01/0.0/0.0/16_013/0001829).

Acknowledgments: CzechNanoLab project LM2018110 funded by MEYS CR is gratefully acknowledged for the financial support of the TEM measurements at CEITEC Nano Research Infrastructure.

Conflicts of Interest: The authors declare no conflict of interest. 


\section{References}

1. Ferrari, S.; Loveridge, M.; Beattie, S.D.; Jahn, M.; Dashwood, R.J.; Bhagat, R. Latest advances in the manufacturing of 3D rechargeable lithium microbatteries. J. Power Sources 2015, 286, 25-46. [CrossRef]

2. Nasreldin, M.; Delattre, R.; Ramuz, M.; Lahuec, C.; Djenizian, T.; de Bougrenet de la Tocnaye, J.-L. Flexible micro-battery for powering smart contact lens. Sensors 2019, 19, 2062. [CrossRef] [PubMed]

3. Wang, Y.; Liu, B.; Li, Q.; Cartmell, S.; Ferrara, S.; Deng, Z.D.; Xiao, J. Lithium and lithium ion batteries for applications in microelectronic devices: A review. J. Power Sources 2015, 286, 330-345. [CrossRef]

4. Oudenhoven, J.F.M.; Baggetto, L.; Notten, P.H.L. All-Solid-State Lithium-Ion Microbatteries: A Review of Various Three-Dimensional Concepts. Adv. Energy Mater. 2011, 1, 10-33. [CrossRef]

5. Tesfaye, A.T.; Mashtalir, O.; Naguib, M.; Barsoum, M.W.; Gogotsi, Y.; Djenizian, T. Anodized $\mathrm{Ti}_{3} \mathrm{SiC}_{2}$ as an anode material for Li-ion microbatteries. Acs Appl. Mater. Interfaces 2016, 8, 16670-16676. [CrossRef]

6. Sopha, H.; Tesfaye, A.T.; Zazpe, R.; Michalicka, J.; Dvorak, F.; Hromadko, L.; Krbal, M.; Prikryl, J.; Djenizian, T.; Macak, J.M. ALD growth of $\mathrm{MoS}_{2}$ nanosheets on $\mathrm{TiO}_{2}$ nanotube supports. FlatChem 2019, 17, 100130. [CrossRef]

7. Zhang, H.; Cao, Y.; Chee, M.O.L.; Dong, P.; Ye, M.; Shen, J. Recent advances in micro-supercapacitors. Nanoscale 2019, 11, 5807-5821. [CrossRef]

8. Kundu, A.; Jang, J.H.; Gil, J.H.; Jung, C.R.; Lee, H.R.; Kim, S.H.; Ku, B.; Oh, Y.S. Micro-fuel cells-Current development and applications. J. Power Sources 2007, 170, 67-78. [CrossRef]

9. Yang, Y.; Pradel, K.C.; Jing, Q.; Wu, J.M.; Zhang, F.; Zhou, Y.; Zhang, Y.; Wang, Z.L. Thermoelectric Nanogenerators Based on Single Sb-Doped ZnO Micro/Nanobelts. Acs Nano 2012, 6, 6984-6989. [CrossRef]

10. Pikul, J.H.; Zhang, H.G.; Cho, J.; Braun, P.V.; King, W.P. High-power lithium ion microbatteries from interdigitated three-dimensional bicontinuous nanoporous electrodes. Nat. Commun. 2013, 4, 1732. [CrossRef]

11. Li, W.; Christiansen, T.L.; Li, C.; Zhou, Y.; Fei, H.; Mamakhel, A.; Iversen, B.B.; Watkins, J.J. High-power lithium-ion microbatteries from imprinted 3D electrodes of sub-10 $\mathrm{nm} \mathrm{LiMn} 2 \mathrm{O}_{4} / \mathrm{Li}_{4} \mathrm{Ti}_{5} \mathrm{O}_{12}$ nanocrystals and a copolymer gel electrolyte. Nano Energy 2018, 52, 431-440. [CrossRef]

12. Yue, C.; Li, J.; Lin, L. Fabrication of Si-based three-dimensional microbatteries: A review. Front. Mech. Eng. 2017, 12, 459-476. [CrossRef]

13. Long, J.W.; Dunn, B.; Rolison, D.R.; White, H.S. Three-dimensional battery architectures. Chem. Rev. 2004, 104, 4463-4492. [CrossRef] [PubMed]

14. Hur, J.I.; Smith, L.C.; Dunn, B. High Areal Energy Density 3D Lithium-Ion Microbatteries. Joule 2018, 2, 1187-1201. [CrossRef]

15. Zeng, W.; Zheng, F.; Li, R.; Zhan, Y.; Li, Y.; Liu, J. Template synthesis of $\mathrm{SnO}_{2} / \alpha-\mathrm{Fe}_{2} \mathrm{O}_{3}$ nanotube array for 3D lithium ion battery anode with large areal capacity. Nanoscale 2012, 4, 2760-2765. [CrossRef] [PubMed]

16. Shaijumon, M.M.; Perre, E.; Daffos, B.; Taberna, P.L.; Tarascon, J.M.; Simon, P. Nanoarchitectured 3D cathodes for Li-Ion microbatteries. Adv. Mater. 2010, 22, 4978-4981. [CrossRef] [PubMed]

17. Wei, W.; Oltean, G.; Tai, C.-W.; Edstrom, K.; Bjorefors, F.; Nyholm, L. High Energy and Power Density $\mathrm{TiO}_{2}$ Nanotube Electrodes for 3D Li-ion Microbatteries. J. Mater. Chem. A 2013, 1, 8160-8169. [CrossRef]

18. Ellis, B.L.; Knauth, P.; Djenizian, T. Three-Dimensional Self-Supported Metal Oxides for Advanced Energy Storage. Adv. Mater. 2014, 26, 3368-3397. [CrossRef]

19. Su, X.; Wu, Q.; Zhan, X.; Wu, J.; Wei, S.; Guo, Z. Advanced titania nanostructures and composites for lithium ion battery. J. Mater. Sci. 2012, 47, 2519-2534. [CrossRef]

20. Chen, Z.; Belharouak, I.; Sun, Y.K.; Amine, K. Titanium-based anode materials for safe lithium-ion batteries. Adv. Funct. Mater. 2013, 23, 959-969. [CrossRef]

21. Ortiz, G.F.; Hanzu, I.; Djenizian, T.; Lavela, P.; Tirado, J.L.; Knauth, P. Alternative Li-ion battery electrode based on self-organized titania nanotubes. Chem. Mater. 2009, 21, 63-67. [CrossRef]

22. Vacandio, F.; Fraoucene, H.; Sugiawati, V.A.; Eyraud, M.; Hatem, D.; Belkaid, M.S.; Pasquinelli, M.;

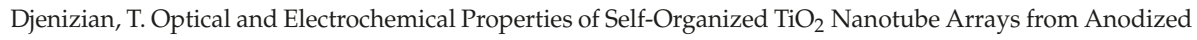
Ti-6Al-4V Alloy. Front. Chem. 2019, 7, 66.

23. Myung, S.T.; Takahashi, N.; Komaba, S.; Yoon, C.S.; Sun, Y.K.; Amine, K.; Yashiro, H. Nanostructured $\mathrm{TiO}_{2}$ and Its Application in Lithium-Ion Storage. Adv. Funct. Mater. 2011, 21, 3231-3241. [CrossRef] 
24. Borghols, W.; Lützenkirchen-Hecht, D.; Haake, U.; Van Eck, E.; Mulder, F.; Wagemaker, M. The electronic structure and ionic diffusion of nanoscale $\mathrm{LiTiO}_{2}$ anatase. Phys. Chem. Chem. Phys. 2009, 11, 5742-5748. [CrossRef] [PubMed]

25. Dvorak, F.; Zazpe, R.; Krbal, M.; Sopha, H.; Prikryl, J.; Ng, S.; Hromadko, L.; Bures, F.; Macak, J.M. One-dimensional anodic $\mathrm{TiO}_{2}$ nanotubes coated by atomic layer deposition: Towards advanced applications. Appl. Mater. Today 2019, 14, 1-20. [CrossRef]

26. Salian, G.D.; Krbal, M.; Sopha, H.; Lebouin, C.; Coulet, M.-V.; Michalicka, J.; Hromadko, L.; Tesfaye, A.T.; Macak, J.M.; Djenizian, T. Self-supported sulphurized $\mathrm{TiO}_{2}$ nanotube layers as positive electrodes for lithium microbatteries. Appl. Mater. Today 2019, 16, 257-264. [CrossRef]

27. Lu, Z.; Yip, C.T.; Wang, L.; Huang, H.; Zhou, L. Hydrogenated $\mathrm{TiO}_{2}$ nanotube arrays as high-rate anodes for lithium-ion microbatteries. ChemPlusChem 2012, 77, 991-1000. [CrossRef]

28. Salian, G.D.; Koo, B.M.; Lefevre, C.; Cottineau, T.; Lebouin, C.; Tesfaye, A.T.; Knauth, P.; Keller, V.; Djenizian, T. Niobium Alloying of Self-Organized $\mathrm{TiO}_{2}$ Nanotubes as an Anode for Lithium-Ion Microbatteries. Adv. Mater. Technol. 2018, 3, 1700274. [CrossRef]

29. Sopha, H.; Salian, G.D.; Zazpe, R.; Prikryl, J.; Hromadko, L.; Djenizian, T.; Macak, J.M. ALD Al2O3-Coated $\mathrm{TiO}_{2}$ Nanotube Layers as Anodes for Lithium-Ion Batteries. Acs Omega 2017, 2, 2749-2756. [CrossRef]

30. Kyeremateng, N.A.; Vacandio, F.; Sougrati, M.-T.; Martinez, H.; Jumas, J.-C.; Knauth, P.; Djenizian, T. Effect of $\mathrm{Sn}$-doping on the electrochemical behaviour of $\mathrm{TiO}_{2}$ nanotubes as potential negative electrode materials for 3D Li-ion micro batteries. J. Power Sources 2013, 224, 269-277. [CrossRef]

31. Zhu, Q.; $\mathrm{Hu}, \mathrm{H}$.; Li, G.; Zhu, C.; Yu, Y. $\mathrm{TiO}_{2}$ nanotube arrays grafted with $\mathrm{MnO}_{2}$ nanosheets as high-performance anode for lithium ion battery. Electrochim. Acta 2015, 156, 252-260. [CrossRef]

32. Gao, L.; Hu, H.; Li, G.; Zhu, Q.; Yu, Y. Hierarchical 3D $\mathrm{TiO}_{2} @ \mathrm{Fe}_{2} \mathrm{O}_{3}$ nanoframework arrays as high-performance anode materials. Nanoscale 2014, 6, 6463-6467. [CrossRef] [PubMed]

33. Brumbarov, J.; Kunze-Liebhäuser, J. Silicon on conductive self-organized $\mathrm{TiO}_{2}$ nanotubes-A high capacity anode material for Li-ion batteries. J. Power Sources 2014, 258, 129-133. [CrossRef]

34. Madian, M.; Giebeler, L.; Klose, M.; Jaumann, T.; Uhlemann, M.; Gebert, A.; Oswald, S.; Ismail, N.; Eychmüller, A.; Eckert, J. Self-Organized $\mathrm{TiO}_{2} / \mathrm{CoO}$ Nanotubes as Potential Anode Materials for Lithium Ion Batteries. Acs Sustain. Chem. Eng. 2015, 3, 909-919. [CrossRef]

35. Yiping, T.; Xiaoxu, T.; Guangya, H.; Guoqu, Z. Nanocrystalline $\mathrm{Li}_{4} \mathrm{Ti}_{5} \mathrm{O}_{12}$-coated $\mathrm{TiO}_{2}$ nanotube arrays as three-dimensional anode for lithium-ion batteries. Electrochim. Acta 2014, 117, 172-178. [CrossRef]

36. Sugiawati, V.A.; Vacandio, F.; Galeyeva, A.; Kurbatov, A.P.; Djenizian, T. Enhanced Electrochemical Performance of Electropolymerized Self-Organized $\mathrm{TiO}_{2}$ Nanotubes Fabricated by Anodization of Ti Grid. Front. Phys. 2019, 7, 179. [CrossRef]

37. Plylahan, N.; Kyeremateng, N.A.; Eyraud, M.; Dumur, F.; Martinez, H.; Santinacci, L.; Knauth, P.; Djenizian, T. Highly conformal electrodeposition of copolymer electrolytes into titania nanotubes for 3D Li-ion batteries. Nanoscale Res. Lett. 2012, 7, 349. [CrossRef]

38. Kyeremateng, N.A.; Dumur, F.; Knauth, P.; Pecquenard, B.; Djenizian, T. Electrodeposited copolymer electrolyte into nanostructured titania electrodes for 3D Li-ion microbatteries. C. R. Chim. 2013, 16, 80-88. [CrossRef]

39. Zazpe, R.; Knaut, M.; Sopha, H.; Hromadko, L.; Albert, M.; Prikryl, J.; Gartnerova, V.; Bartha, J.W.; Macak, J.M. Atomic layer deposition for coating of high aspect ratio $\mathrm{TiO}_{2}$ nanotube layers. Langmuir 2016, 32, 10551-10558. [CrossRef]

40. Stevens, G.; Edmonds, T. Catalytic activity of the basal and edge planes of molybdenum disulphide. J. Less Common Met 1977, 54, 321-330. [CrossRef]

41. Ganta, D.; Sinha, S.; Haasch, R.T. 2-D material molybdenum disulfide analyzed by XPS. Surf. Sci. Spectra 2014, 21, 19-27. [CrossRef]

42. Benoist, L.; Gonbeau, D.; Pfister-Guillouzo, G.; Schmidt, E.; Meunier, G.; Levasseur, A. XPS analysis of lithium intercalation in thin films of molybdenum oxysulphides. Surf Interface Anal 1994, 22, 206-210. [CrossRef]

43. Hopfengärtner, G.; Borgmann, D.; Rademacher, I.; Wedler, G.; Hums, E.; Spitznagel, G. XPS studies of oxidic model catalysts: Internal standards and oxidation numbers. J Electron Spectros Relat Phenom. 1993, 63, 91-116. [CrossRef]

44. Patterson, T.A.; Carver, J.C.; Leyden, D.E.; Hercules, D.M. A surface study of cobalt-molybdena-alumina catalysts using x-ray photoelectron spectroscopy. J. Phys. Chem. 1976, 80, 1700-1708. [CrossRef] 
45. Alstrup, I.; Chorkendorff, I.; Candia, R.; Clausen, B.S.; Topsøe, H. A combined X-Ray photoelectron and Mössbauer emission spectroscopy study of the state of cobalt in sulfided, supported, and unsupported Co Mo catalysts. J. Catal. 1982, 77, 397-409. [CrossRef]

46. Moulder, J.F.; Stickle, W.F.; Sobol, P.E.; Bomben, K.D. Handbook of X-ray Photoelectron Spectroscopy: A Reference Book of Standard Spectra for Identification and Interpretation of XPS Data, Perkin Elmer Corp., Physical Electronics Division: EdenPrairie, MN, USA, 1995.

47. Van de Krol, R.; Goossens, A.; Schoonman, J. Spatial extent of lithium intercalation in anatase $\mathrm{TiO}_{2}$. J. Phys. Chem. B 1999, 103, 7151-7159. [CrossRef]

48. Tesfaye, A.T.; Gogotsi, Y.; Djenizian, T. Tailoring the morphological properties of anodized $\mathrm{Ti}_{3} \mathrm{SiC}_{2}$ for better power density of Li-ion microbatteries. Electrochem. Commun. 2017, 81, 29-33. [CrossRef]

49. Wu, C.-Y.; Chang, W.-E.; Sun, Y.-G.; Wu, J.-M.; Duh, J.-G. Three-dimensional S-MoS $\mathrm{M}_{2} \alpha-\mathrm{Fe}_{2} \mathrm{O}_{3}$ nanoparticles composites as lithium-ion battery anodes for enhanced electrochemical performance. Mater. Chem. Phys. 2018, 219, 311-317. [CrossRef]

50. Wang, L.; Zhang, Q.; Zhu, J.; Duan, X.; Xu, Z.; Liu, Y.; Yang, H.; Lu, B. Nature of extra capacity in MoS2 electrodes: Molybdenum atoms accommodate with lithium. Energy Storage Mater. 2019, 16, 37-45. [CrossRef]

51. Balach, J.; Jaumann, T.; Giebeler, L. Nanosized Li2S-based cathodes derived from $\mathrm{MoS}_{2}$ for high-energy density Li-S cells and $\mathrm{Si}-\mathrm{Li}_{2} \mathrm{~S}$ full cells in carbonate-based electrolyte. Energy Storage Mater. 2017, 8, $209-216$. [CrossRef]

52. Lindström, H.; Södergren, S.; Solbrand, A.; Rensmo, H.; Hjelm, J.; Hagfeldt, A.; Lindquist, S.-E. Li+ ion insertion in $\mathrm{TiO}_{2}$ (anatase). 2. Voltammetry on nanoporous films. J. Phys. Chem. B 1997, 101, 7717-7722. [CrossRef]

53. Lipson, A.L.; Puntambekar, K.; Comstock, D.J.; Meng, X.; Geier, M.L.; Elam, J.W.; Hersam, M.C. Nanoscale investigation of solid electrolyte interphase inhibition on Li-ion battery $\mathrm{MnO}$ electrodes via atomic layer deposition of $\mathrm{Al}_{2} \mathrm{O}_{3}$. Chem. Mater. 2014, 26, 935-940. [CrossRef]

54. Plylahan, N.; Letiche, M.; Barr, M.K.S.; Ellis, B.; Maria, S.; Phan, T.N.; Bloch, E.; Knauth, P.; Djenizian, T. High energy and power density $\mathrm{TiO}_{2}$ nanotube electrodes for single and complete lithium-ion batteries. J. Power Sources 2015, 273, 1182-1188. [CrossRef]

55. Wu, X.; Zhang, S.; Wang, L.; Du, Z.; Fang, H.; Ling, Y.; Huang, Z. Coaxial $\mathrm{SnO}_{2} @ \mathrm{TiO}_{2}$ nanotube hybrids: From robust assembly strategies to potential application in Li+ storage. J. Mater. Chem. 2012, 22, 11151-11158. [CrossRef]

56. Kyeremateng, N.A.; Lebouin, C.; Knauth, P.; Djenizian, T. The electrochemical behaviour of $\mathrm{TiO}_{2}$ nanotubes with $\mathrm{Co}_{3} \mathrm{O}_{4}$ or $\mathrm{NiO}$ submicron particles: Composite anode materials for $\mathrm{Li}$-ion micro batteries. Electrochim. Acta 2013, 88, 814-820. [CrossRef]

57. Yu, L.; Wang, Z.; Zhang, L.; Wu, H.B.; Lou, X.W.D. $\mathrm{TiO}_{2}$ nanotube arrays grafted with $\mathrm{Fe}_{2} \mathrm{O}_{3}$ hollow nanorods as integrated electrodes for lithium-ion batteries. J. Mater. Chem. A 2013, 1, 122-127. [CrossRef]

(C) 2020 by the authors. Licensee MDPI, Basel, Switzerland. This article is an open access article distributed under the terms and conditions of the Creative Commons Attribution (CC BY) license (http://creativecommons.org/licenses/by/4.0/). 
Article

\title{
Graphitic Carbon Nitride Doped Copper-Manganese Alloy as High-Performance Electrode Material in Supercapacitor for Energy Storage
}

\author{
Samarjeet Singh Siwal ${ }^{1, *}$, Qibo Zhang ${ }^{1,2, *}$, Changbin Sun ${ }^{1}$ and Vijay Kumar Thakur ${ }^{3,4, *}$ \\ 1 Key Laboratory of Ionic Liquids Metallurgy, Faculty of Metallurgical and Energy Engineering, Kunming \\ University of Science and Technology, Kunming 650093, China; changbin_sun@163.com \\ 2 State Key Laboratory of Complex Nonferrous Metal Resources Cleaning Utilization in Yunnan Province, \\ Kunming 650093, China \\ 3 Enhanced Composites and Structures Center, School of Aerospace, Transport and Manufacturing, \\ Cranfield University, Bedfordshire MK43 0AL, UK \\ 4 Department of Mechanical Engineering, School of Engineering, Shiv Nadar University, \\ Uttar Pradesh 201314, India \\ * Correspondence: samarjeet6j1@gmail.com (S.S.S.); qibozhang@kust.edu.cn (Q.Z.); \\ Vijay.Vumar@cranfield.ac.uk (V.K.T.)
}

Received: 9 November 2019; Accepted: 16 December 2019; Published: 18 December 2019

\begin{abstract}
Here, we report the synthesis of copper-manganese alloy $\left(\mathrm{CuMnO}_{2}\right)$ using graphitic carbon nitride $(\mathrm{gCN})$ as a novel support material. The successful formation of $\mathrm{CuMnO}_{2}-\mathrm{gCN}$ was confirmed through spectroscopic, optical, and other characterization techniques. We have applied this catalyst as the energy storage material in the alkaline media and it has shown good catalytic behavior in supercapacitor applications. The $\mathrm{CuMnO}_{2}-\mathrm{gCN}$ demonstrates outstanding electrocapacitive performance, having high capacitance $\left(817.85 \mathrm{~A} \cdot \mathrm{g}^{-1}\right.$ ) and well-cycling stability (1000 cycles) when used as a working electrode material for supercapacitor applications. For comparison, we have also used the $\mathrm{gCN}$ and $\mathrm{Cu}_{2} \mathrm{O}-\mathrm{gCN}$ for supercapacitor applications. This study proposes a simple path for the extensive construction of self-attaining double metal alloy with control size and uniformity in high-performance energy-storing materials.
\end{abstract}

Keywords: copper-manganese alloy; energy storage; supercapacitor; graphitic carbon nitride

\section{Introduction}

Currently, there is a great thrust on the usage of two-dimensional (2D) graphitic carbon nanomaterials for energy storage owing to their novel electronic and other characteristics [1-3]. The faradic response within 2D graphitic carbon also advances their electrochemical energy storing activity and, for this, the overview of heteroatoms, for example, nitrogen, must be confirmed as a capable method [4-7]. Owing to the enhanced feasting of universal energy sources, significant efforts have been dedicated to the advancement of feasible energy renovation/storage strategies [8-11]. Indeed, the growth of environmentally-friendly energy renovation/storing strategies has developed significant worries that require sufficient explanation to preserve the feasibility of our atmosphere. In this direction, supercapacitor denotes a novel type of energy storing strategy among economical capacitors, as well as for chargeable batteries, which carries high power density along with an extensive lifecycle $[12,13]$. However, its small energy density $\left(<10 \mathrm{Wh} \cdot \mathrm{kg}^{-1}\right)$ significantly limits its real-world use [14].

The notable mechanical and chemical characteristics including thermal flexibility of carbon nitrides linked by their surface and intralayer chemical reactivity have led to the opportunities for elaborating carbon nitride substances for catalysis uses, either intrinsically or while adorned by metal/metal oxide 
nanoparticles (NPs). Graphitic carbon nitride ( $\mathrm{gCN}$ ) substances have been revealed to act as metal-free heterogeneous reactants, relying on the inherent Brønsted acid and Lewis base functionalities that give catalytically active positions $[15,16]$. Among several allotropes of carbon nitride, $\mathrm{gCN}$ is the most studied because it has semiconductor behavior with a bandgap of $2.7 \mathrm{eV}$ [17]. Thin films of gCN shaped throughs-triazine/heptazine have been compared with hydrogen bonding to form a structure parallel to the graphite [18]. gCN holds outstanding characteristics, for example, long thermal steadiness able near $600{ }^{\circ} \mathrm{C}$ in air, defiance towards numerous chemicals, high $\mathrm{N}_{2}$ contented, ecologically benevolent properties, and so on. While unpackaged gCN shows more theoretic $\mathrm{N}_{2}$ contented ( $\mathrm{C} / \mathrm{N}$ proportion is 0.75$)$, it is exciting for manufacturing $\mathrm{gCN}$ by perfect stoichiometry via physical/chemical approaches as the development of the $\mathrm{C}-\mathrm{N}$ chain is thermodynamically unfavorable, then polycondensation of the pioneer's issues $\mathrm{N}_{2}$ particle in its place of establishing the $\mathrm{C}-\mathrm{N}$ bond [14]. Furthermore, the intrinsic small surface area and the nonporous behavior of bulk gCN have restricted their use within electrocatalysis, energy-storing, chemisorption, and so on [19]. Towards mitigation of these issues, Vinu et al. [20] adopted a rigid pattern process that effectively produced permeable, more surface area of gCN. Consequently, owing to the achieved high surface area, permeable gCN was exposed to show virtuous catalytic movement, power, and gas storing ability [21]. By the way, transition metal sulfides (TMSs), particularly, manganese sulfides (MnS), have been well-thought-out as probable substantial materials aimed at supercapacitor (SC) applications [22]. gCN-doped MnS has accomplished characteristics, for example, higher theoretic specific capacitance $\left(463.32 \mathrm{~F} \cdot \mathrm{g}^{-1}\right)$, high durability, low price, profuse, and ecological flora [23]. Mesoporous gCN substances exhibit the maximum specific capacitance around $286 \mathrm{~F} \cdot \mathrm{g}^{-1}$ and a current density of $0.75 \mathrm{~A} \cdot \mathrm{g}^{-1}$ [24]. Further, Xiaoyang et al. [25] have reported their study on $\mathrm{NiMoO}_{4}$ films that were grown on $\mathrm{gCN}$ employing a facile chemical precipitation protocol that shows a significant specific capacitance of $1275 \mathrm{~F}^{-1} \mathrm{~g}^{-1}$ on $0.25 \mathrm{~A} \cdot \mathrm{g}^{-1}$ owing to the interconnected composition as well as appearance of $\mathrm{N}$ with the inclusion of $\mathrm{gCN}$.

Numerous nanostructured resources comprising metal alloys, metal oxides, and metal hydroxides [26-29] are being extensively employed within electrochemical SCs owing to their lower price, natural profusion, and outstanding charge storing aptitude [30]. The use of transition metal oxides (e.g., $\mathrm{Co}_{3} \mathrm{O}_{4}, \mathrm{MnO}_{2}$, and $\mathrm{CuO}$ ) is an economical approach to advance catalytic converters with improved surface area, permeability, activity, and durability to name a few [31]. In our present work, we have synthesized gCN doped copper (I) oxide nanoparticle and manganese-copper alloys with exceptional surface area and homogenous distribution of $\mathrm{CuMnO}_{2}$ for exposing more active sites. The different analyses and catalytic performances show the better utility of this material for SC applications. From the different characterizations, the formation of $\mathrm{Cu}_{2} \mathrm{O}-\mathrm{gCN}$ and $\mathrm{CuMnO}_{2}-\mathrm{gCN}$ with the porous structure was confirmed. For comparison, we have studied the $\mathrm{gCN}$ and $\mathrm{Cu}_{2} \mathrm{O}-\mathrm{gCN}$ nanoparticles and found a massive improvement in the catalytic performance after introducing the $\mathrm{Mn}$ to the system. This is the facile route to synthesize the energy storage materials at room temperature without any specific equipment with excellent stability and charge storage capability. The $\mathrm{CuMnO}_{2}-\mathrm{gCN}$ manifests excellent electrocapacitive performance with high capacitance $\left(817.85 \mathrm{~A} \cdot \mathrm{g}^{-1}\right)$ and well-cycling stability (1000 cycles) used as working electrode material for supercapacitor applications.

\section{Materials and Methods}

\subsection{Wide-Ranging Process for the Synthesis of $g \mathrm{CN}, \mathrm{Cu}{ }_{2} \mathrm{O}-g \mathrm{CN}$, and $\mathrm{CuMnO} \mathrm{O}_{2}-g \mathrm{CN}$}

In representative operation, $20 \mathrm{~g}$ of urea was retained under a closed porcelain vessel at $60{ }^{\circ} \mathrm{C}$ following atmospheric condition for $4 \mathrm{~h}$. Afterward, this precursor was shifted in a muffle kiln for $4 \mathrm{~h}$ at $450{ }^{\circ} \mathrm{C}$ [32-34]. The pale-yellow-stock material $\mathrm{gCN}$ was rinsed numerous times using deionized water to eliminate the remaining alkaline sorts over the specimen exterior and again dried at $60^{\circ} \mathrm{C}$ for $24 \mathrm{~h}$. In the subsequent step, the collected material was dispersed in $100 \mathrm{~mL}$ of water in a $250 \mathrm{~mL}$ conical flask. The $\mathrm{Cu}_{2} \mathrm{O}-\mathrm{gCN}$ was amalgamated using a single-step borohydride reduction method at 
room temperature. An aqueous suspension of copper sulphate pentahydrate $\left(10^{-1} \mathrm{~mol} \cdot \mathrm{dm}^{-3}\right)$ was annexed dropwise ( $5 \mathrm{wt} \%$ loading of $\mathrm{Cu}$ ) to the round-bottom container. Subsequently, $5 \mathrm{~mL}$ of $\mathrm{NaBH}_{4}\left(10^{-2} \mathrm{~mol} \cdot \mathrm{dm}^{-3}\right)$ solution was added gradually, aiming at the reduction of the Cu salt. Lastly, the substance was penetrated, rinsed through water, and then dried. Similarly, $\mathrm{CuMnO}_{2}(5.0 \mathrm{~mol} \%$ of $\mathrm{Cu}$ and $\mathrm{Mn}$ loading) was also synthesized employing the lineages of $\mathrm{CuSO}_{4} \cdot 5 \mathrm{H}_{2} \mathrm{O}$ and $\mathrm{KMnO}_{4}$ powder. Lastly, the material was separated, rinsed with water numerous times, and dried at $70{ }^{\circ} \mathrm{C}$ for $24 \mathrm{~h}$ following vacuum condition.

\subsection{Electrode Modification}

The anode electrodes were fabricated through drop-casting gCN, $\mathrm{Cu}_{2} \mathrm{O}-\mathrm{gCN}$, and $\mathrm{CuMnO}_{2}-\mathrm{gCN}$ over a glassy carbon electrode (GCE). Before deposition, the GCE was swept via sonicating in ethanol around 2 min then washing successively by acetone along with deionized water. During drop-casting, the substance suspension was fabricated through scattering $2 \mathrm{mg}$ of $\mathrm{gCN}, \mathrm{Cu}_{2} \mathrm{O}-\mathrm{gCN}$ and $\mathrm{CuMnO}_{2}-\mathrm{gCN}$ powder individually within $1 \mathrm{~mL}$ of $4: 1 \mathrm{v} / v$ ethyl acetate/5\% Nafion through sonication after drop-casted upon a GCE by a catalyst packing of $0.2 \mathrm{mg} \cdot \mathrm{cm}^{-2}$ then leave at room temperature for $2 \mathrm{~h}$. The coating width was examined by changing the deposition period.

\subsection{Electrochemical Experiments}

Electrochemical study was carried out using a Shanghai Chenhua 760 E potentiostat within a single-cell three-electrode system in a $0.5 \mathrm{~mol} \cdot \mathrm{dm}^{-3} \mathrm{KOH}$ solution. The electrochemical containers were cleaned by aqua regia and then millipore water before further analyses. Glassy carbon, $\mathrm{Pt}$ column, and $\mathrm{Hg} / \mathrm{HgO}^{+}\left(3.0 \mathrm{~mol} \cdot \mathrm{dm}^{-3} \mathrm{KOH}\right)$ were adopted as the working, counter, and reference electrodes, respectively. The charging-discharging of the catalyst was measured utilizing chronopotentiometry at various current densities. In addition, electrochemical impedance spectroscopy (EIS) analyses were conducted in the frequency range from $3 \mathrm{MHz}$ to $10 \mathrm{~Hz}$.

Specific capacitance $\left(C_{S}\right)$, power density $(P)$, plus energy density $(E)$ are received from the galvanostatic discharge arcs conferred by the subsequent equations [35]:

$$
\begin{gathered}
C_{s}=\frac{I \Delta t}{m \Delta V}\left(F \cdot g^{-1}\right) \\
E=\frac{0.5 C_{S} \Delta V^{2}}{3.6}\left(W h \cdot \mathrm{kg}^{-1}\right), \\
P=\frac{3600 E}{\Delta t}\left(F \cdot g^{-1}\right) .
\end{gathered}
$$

Here, I represents the discharge current, $\Delta t$ displays the complete discharge period, and $\Delta V$ is the potential period of complete discharge.

\subsection{Characterization}

The X-ray diffraction (XRD) pattern was carried out on a Rigaku X-ray diffractometer (MinifexII Desktop) with $\mathrm{Cu} K \alpha$ radiation (Rigaku Corporation, Tokyo, Japan). Field-emission scanning electron microscopy (FESEM; Nova 400 Nano-SEM, Nova High-Technologies Corporation, Abingdon, UK) was carried out at an expedited voltage of $15 \mathrm{kV}$. Transmission electron microscopy (TEM) analyses were conducted at $200 \mathrm{kV}$ applying Tecnai G2 TF30 (JEOL, Tokyo, Japan) transmission microscopy. X-ray photoelectron spectroscopy (XPS) data were collected by a PHI 550 (Thermo Fisher Scientific, Waltham, MA, USA) spectrometer employing a monochromatic Al-K $\alpha(1486.6 \mathrm{eV})$ radiation origin and a hemispheric detector including an energy resolution of $0.1 \mathrm{eV}$. Materials surface area and pore size spreading of the specimens were estimated by $\mathrm{N}_{2}$ adsorption-desorption depending upon the Brauner-Emmet-Teller (BET) plus Barrett-Joyner-Halenda (BJH) (Quantachrome Instrument, Boynton Beach, FL, USA) method (Belsorp-BELMAX). 


\section{Results and Discussion}

\subsection{Morphological and Structural Analysis}

The schematic representation of the catalyst synthesis is shown in Figure 1A. The characteristics of a crystallographic assembly of gCN nanosheets, $\mathrm{Cu}_{2} \mathrm{O}-\mathrm{gCN}$, and $\mathrm{CuMnO}_{2}-\mathrm{gCN}$ nanohybrids with the varied quantity of gCN are shown in Figure $1 \mathrm{~B}$. The gCN nanosheets generally showed a very weak peak on $13.1^{\circ}(100)$, then an additional separate peak on $27.5^{\circ}$ indexed towards (002) planes of hexagonal graphitic carbon assembly, assigned towards the inter-film filling and interplanar assembling peaks of the aromatic structure, correspondingly [36]. Meanwhile, the peaks at $13.1^{\circ}, 27.7^{\circ}, 36.4^{\circ}, 42.3^{\circ}$, $61.3^{\circ}, 73.5^{\circ}$ and $77.3^{\circ}$ are indexed as (100), (002), (111), (200), (220), (311), and (222), respectively, and the characteristic diffractions of the hydrotalcite crystalline assembly of $\mathrm{Cu}_{2} \mathrm{O}-\mathrm{gCN}$ nanohybrids $[37,38]$. The peak intensity on $27.5^{\circ}$ elevated deprived of upsetting the location of the peak of $\mathrm{Cu}_{2} \mathrm{O}-\mathrm{gCN}$ by mounting the weight of gCN nanofilms upon $\mathrm{Cu}$. It intended that the crystal development of gCN nanofilms did not hinder the crystal growing of $\mathrm{Cu}_{2} \mathrm{O}-\mathrm{gCN}$. While we introduced the $\mathrm{Mn}$ to the above system, the nature of the material changed from the crystalline to amorphous and the peaks corresponding to the $\mathrm{Cu}_{2} \mathrm{O}$ gone in the final $\mathrm{CuMnO}_{2}-\mathrm{gCN}$ product. The High-resolution Transmission Electron Microscopy (HRTEM) and fast Fourier transform (FFT) studies also confirm the amorphous nature of the $\mathrm{CuMnO}_{2}-\mathrm{gCN}$ material. Hereafter, the recommended two dissimilar paths for the development of $\mathrm{CuMnO}_{2}$ are as follows [39]:

(a) First step:

$$
\frac{1}{(3-x)} \mathrm{Cu}_{x} \mathrm{Mn}_{3-x} \mathrm{O}_{4}+\frac{(3-2 x)}{3-x} \mathrm{CuO} \rightarrow \frac{1}{2(3-x)} \mathrm{O}_{2}+\mathrm{CuMnO}_{2}(x=1)
$$

(b) Second step:

$$
\begin{gathered}
2 \mathrm{CuO} \rightarrow \mathrm{Cu}_{2} \mathrm{O}+\frac{1}{2} \mathrm{O}_{2} \\
\mathrm{Mn}_{2} \mathrm{O}_{3}+\mathrm{Cu}_{2} \mathrm{O}
\end{gathered}
$$

(A)
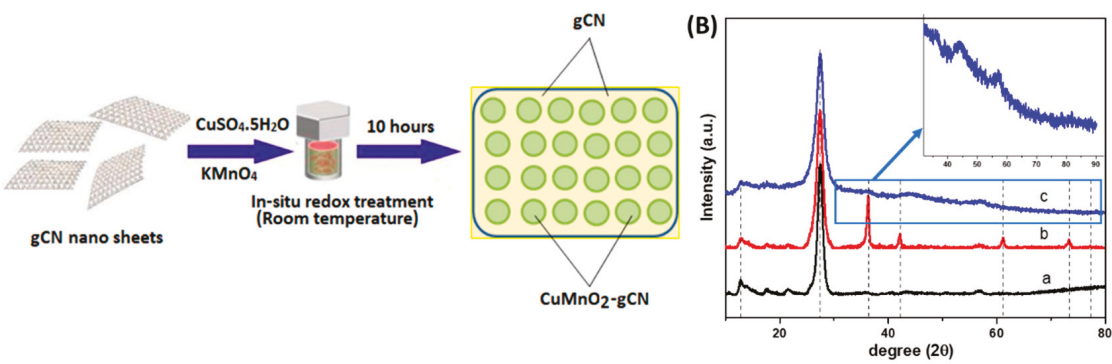

Figure 1. (A) Schematic representation of the catalyst synthesis. (B) X-ray diffraction (XRD) pattern of (a) graphitic carbon nitride $(\mathrm{gCN}),(\mathbf{b}) \mathrm{Cu}_{2} \mathrm{O}-\mathrm{gCN}$, and (c) $\mathrm{CuMnO}_{2}-\mathrm{gCN}$.

Equations (5) and (6) give the final reaction:

$$
2 \mathrm{CuO}+\mathrm{Mn}_{2} \mathrm{O}_{3} \rightarrow 2 \mathrm{CuMnO}_{2}+\frac{1}{2} \mathrm{O}_{2}
$$

The morphology and corresponding energy-dispersive X-ray spectrum (EDX) element mapping of gCN sheets, which are employed as a precursor to construct $\mathrm{Cu}_{2} \mathrm{O}-\mathrm{gCN}$ compounds, is shown in Figure S1. The gCN films can be identified obviously on the exterior of the sphere-shaped aggregates, which specifies the development of $\mathrm{Cu}_{2} \mathrm{O}-\mathrm{gCN}$ composites (Figure S2). As reported, the formation 
of $\mathrm{Cu}_{2} \mathrm{O}-\mathrm{gCN}$ aggregates is an outcome of the robust attraction among the $\mathrm{MO}_{\mathrm{x}}$ and the abundant active groups of gCN [40]. The intimate contact between the gCN sheet and $\mathrm{Cu}_{2} \mathrm{O}$ microspheres was further confirmed by TEM, Scanning transmission electron microscope-High-angle annular dark-field (STEM-HAADF), and HRTEM images, as shown in Figure S3a-c. The TEM image (Figure 2a) of the $\mathrm{CuMnO}_{2}-\mathrm{gCN}$ complex displays that nanoparticles are perceived with a large size spreading, changing from 8 to $15 \mathrm{~nm}$, on the gCN doped composite. Furthermore, the HAADF-STEM and its corresponding Energy-dispersive X-ray spectroscopy (EDS) element mapping images (Figure 2b) indicate the homogeneous distribution of $\mathrm{N}, \mathrm{C}, \mathrm{O}, \mathrm{Mn}$, and the doped $\mathrm{Cu}$ atoms in the whole materials [41]. The HRTEM images (Figure 2c) reveal no clear lattice fringes in the $\mathrm{CuMnO}_{2}-\mathrm{gCN}$, emphasizing their amorphous structure, which is consistent with the results of the corresponding fast Fourier transform (FFT) pattern and the above XRD analysis.

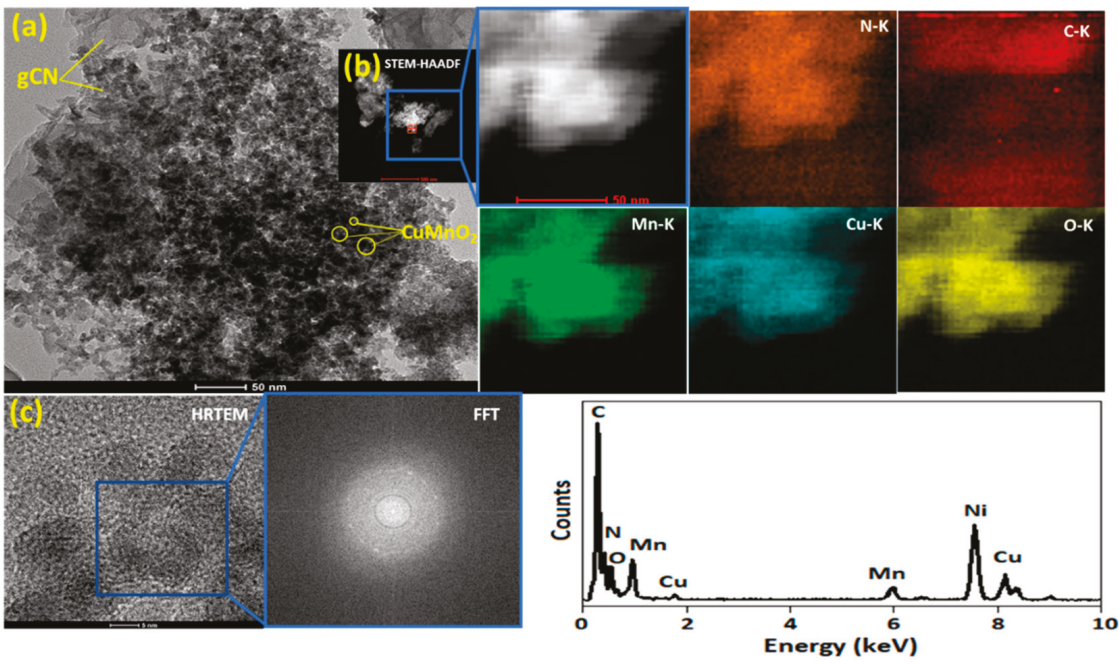

Figure 2. (a) Transmission electron microscopy (TEM), (b) STEM-HAADF images of $\mathrm{CuMnO}_{2}$-gCN and corresponding EDX elemental mapping of the selected area in $(\mathbf{b}, \mathbf{c})$ HRTEM image of $\mathrm{CuMnO}_{2}-\mathrm{gCN}$ and corresponding fast Fourier transform (FFT) pattern of the selected area.

The SEM images for the $\mathrm{CuMnO}_{2}$-gCN material conferred the appearance of gCN nanofilms and $\mathrm{CuMnO}_{2}$ nanoplates dispersed at the exterior of gCN by compact bits of comparable sizes and frames; the bit size is $0.5-2 \mu \mathrm{m}$ (Figure 3a,b). As shown in Figure 3b, the docility of gCN observed from some points that are not incorporated through the nanoplates. The nanoplates exhibit comparable pattern and width essentially revealed in Figure 3a, describing that the addition of gCN does not influence the completion of $\mathrm{CuMnO}_{2}$ nanoplates. The disclosed compound of gCN nanofilms and $\mathrm{CuMnO}_{2}$ nanoplates could improve the surface area associated with $\mathrm{Cu}_{2} \mathrm{O}-\mathrm{gCN}$ nanoplates (Figure S2). The EDS investigation (Figure 3c) explains that the resulting oxide comprises $\mathrm{Cu}, \mathrm{Mn}, \mathrm{C}, \mathrm{N}$, and O near stoichiometric proportions, recommending that the manufactured nanostructures are composed of absolute crednerite $\mathrm{CuMnO}_{2}$-gCN.

The introduction of carbon atoms into the composition of $\mathrm{CN}$ was additionally investigated by X-ray photoelectron spectroscopy (XPS). XPS core level spectra recommend that the bonding arrangement among carbon and $\mathrm{N}_{2}$ atoms toward the existing specimen is next to that of the gCN construction [42]. The C1s' high-resolution XPS spectra (Figure 4a) of gCN display two main peaks at $284.9 \mathrm{eV}$ and $288.2 \mathrm{eV}$, which might be attributed to defect-encompassing $\mathrm{sp}^{2}$-hybridized carbon particles [43,44]. The N1s' high-resolution spectrum (Figure 4b) is deconvoluted within three peaks including binding energies about 400.9, 399.7, and $398.6 \mathrm{eV}$, which are associated with $\mathrm{C}-\mathrm{N}-\mathrm{H}$, 
$\mathrm{N}-(\mathrm{C})_{3}$, and $\mathrm{C}-\mathrm{N}=\mathrm{C}$ components, correspondingly [45,46]. Furthermore, the close-fitting O1s' spectra (Figure 4c) is categorized through three bands: two on 532.3 and $531.3 \mathrm{eV}$, owing to the fascination of oxygen and water particles upon the compound exterior, and then one at $530.4 \mathrm{eV}$, which resembles the $\mathrm{O}^{2-}$ band by $\mathrm{Cu}$ and $\mathrm{Mn}[47]$.

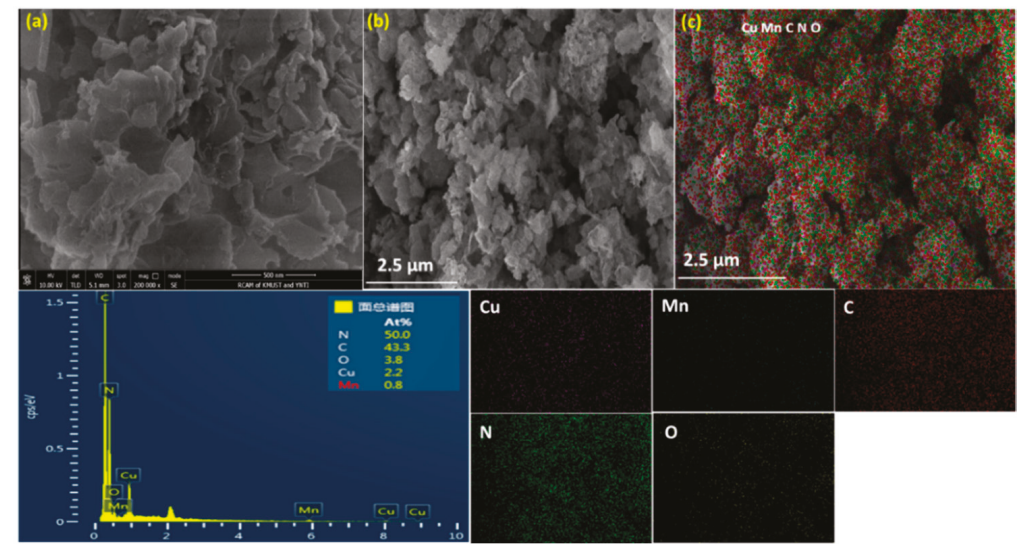

Figure 3. (a,b) Scanning electron microscopy (SEM) images and (c) corresponding EDS elemental mapping of $\mathrm{CuMnO}_{2}$-gCN.
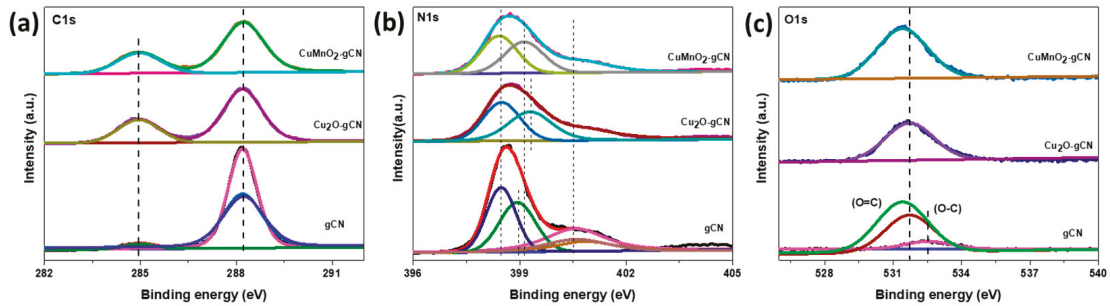

(d)
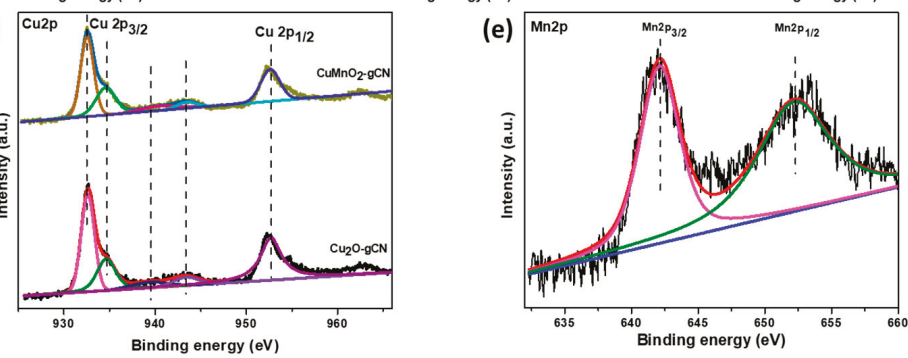

Figure 4. High-resolution X-ray photoelectron spectroscopy (XPS) spectra of (a) C1s, (b) N1s, (c) O1s, (d) $\mathrm{Cu} 2 \mathrm{p}$, and (e) $\mathrm{Mn} 2 \mathrm{p}$ for gCN, $\mathrm{Cu}_{2} \mathrm{O}-\mathrm{gCN}$, and $\mathrm{CuMnO}_{2}-\mathrm{gCN}$.

The XPS results disclose the existence of $\mathrm{Cu}_{2} \mathrm{O}$ nanocrystals, as revealed via the $\mathrm{Cu} 2 \mathrm{p}_{3 / 2}$ peaks in Figure $4 \mathrm{~d} . \mathrm{Cu}^{+}$has a solitary peak at $932.2 \mathrm{eV}$ with a full width half maximum (fwhm) of $(1.64 \pm$ $0.2 \mathrm{eV})[48,49]$ and shakeup satellites at $\sim 939.35$ and $\sim 943.36 \mathrm{eV}$ at higher binding energies. The $\mathrm{Cu}$ $2 \mathrm{p}_{3 / 2}$ aimed at the $\mathrm{Cu}_{2} \mathrm{O}-\mathrm{gCN}$ and $\mathrm{CuMnO}_{2}$ composites were described at $\sim 932.6 \mathrm{eV}$ and $\sim 932.5 \mathrm{eV}$, correspondingly [50]. Inside the $\mathrm{Cu}$ spectra, two main peaks on $\sim 932.6 \mathrm{eV}\left(\mathrm{Cu} 2 \mathrm{p}_{3 / 2}\right)$ and then $\sim 952.8$ $\mathrm{eV}\left(\mathrm{Cu} 2 \mathrm{p}_{1 / 2}\right)$ by a splitting energy of $20.2 \mathrm{eV}$ verify the monovalent state of $\mathrm{Cu}$ ion [51,52]. The XPS study spectra of the $\mathrm{CuMnO}_{2}-\mathrm{gCN}$ (Figure S4) approve the presence of $\mathrm{C}, \mathrm{Mn}, \mathrm{Cu}, \mathrm{N}$, and O. Figure 4e displays the high-resolution XPS spectrum of $\mathrm{Mn} 2 \mathrm{p}$ for $\mathrm{Cu}_{2} \mathrm{O}-\mathrm{gCN}$ and $\mathrm{CuMnO}_{2}-\mathrm{gCN}$. Within the $\mathrm{Mn}$ 
spectra, intense peaks at $642.1 \mathrm{eV}\left(\mathrm{Mn} 2 \mathrm{p}_{3 / 2}\right)$ and $653.5 \mathrm{eV}\left(\mathrm{Mn} 2 \mathrm{p}_{1 / 2}\right)$ by a splitting energy of $11.4 \mathrm{eV}$ recognize the $\mathrm{Mn}^{3+}$ valance in the nanocomposite $[41,53]$. Two major peaks accredited towards $\mathrm{Mn}$ $2 \mathrm{p}_{3 / 2}$ and $\mathrm{Mn} 2 \mathrm{p}_{1 / 2}$ may be detected in mesoporous $\mathrm{MnO}_{2}$. After a peak-fitting deconvolution, the $\mathrm{Mn}$ $2 \mathrm{p}_{3 / 2}$ of mesoporous $\mathrm{MnO}_{2}$ can be defined one peak with $\mathrm{Mn}^{4+} \sim 642.1$, and the conforming peaks of mesoporous $\mathrm{MnO}_{2}$ in $\mathrm{Mn} 2 \mathrm{p}_{1 / 2}$ can also be defined as one peak with $\mathrm{Mn}^{4+} \sim 653.5$, demonstrating that $\mathrm{Mn}^{4+}$ is the key valence state of $\mathrm{Mn}$ in $\mathrm{MnO}_{2}$ [54].

Figure 5 shows the nitrogen adsorption and desorption isotherm for all the samples, gCN (A), $\mathrm{Cu}_{2} \mathrm{O}-\mathrm{gCN}(\mathrm{B})$, and $\mathrm{CuMnO}_{2}-\mathrm{gCN}(\mathrm{C})$. These ingredients showed type IV isotherm through the hysteresis loop, which is an asset of the mesoporous substances [55]. The BET surface area experiments approve the augmented surface area of $\mathrm{CuMnO}_{2}-\mathrm{gCN}\left(82.29 \mathrm{~m}^{2} \cdot \mathrm{g}^{-1}\right)$ compared with $\mathrm{Cu}_{2} \mathrm{O}-\mathrm{gCN}$ $\left(65.95 \mathrm{~m}^{2} \cdot \mathrm{g}^{-1}\right)$ and $\mathrm{gCN}\left(63.16 \mathrm{~m}^{2} \cdot \mathrm{g}^{-1}\right)$, owing to the combination of $\mathrm{Mn}$ in the electrode material structure and the development of subordinate pores between $\mathrm{gCN}$ and $\mathrm{CuMnO}_{2}$. The improvement of surface area may deliver a higher amount of active positions, anticipated electrical linking for the profligate rate of a redox reaction, including charge transfer that could efficiently improve the energy storing capability. This remark is in acceptable agreement through the result of BJH pore size delivery (inset of Figure 5A-C), at which the maximum size of the $\mathrm{CuMnO}_{2}-\mathrm{gCN}$ nanocomposite is $12.5 \mathrm{~nm}$, which can originate from the space among the $\mathrm{CuMnO}_{2}$ nanoplates plus gCN in addition to the nanosheets themselves. The isotherm was adapted to investigate the pore size distribution of the material by applying the Barrett-Joyner-Halenda (BJH) methods. The calculated BJH adsorption cumulative sizes of pores of the synthesized $\mathrm{CuMnO}_{2}-\mathrm{gCN}$ with a wide distribution of the pore radius of the material were noticed in Figure $5 \mathrm{C}$ along with the pore volume of $0.429886 \mathrm{~cm}^{3} \cdot \mathrm{g}^{-1}$.
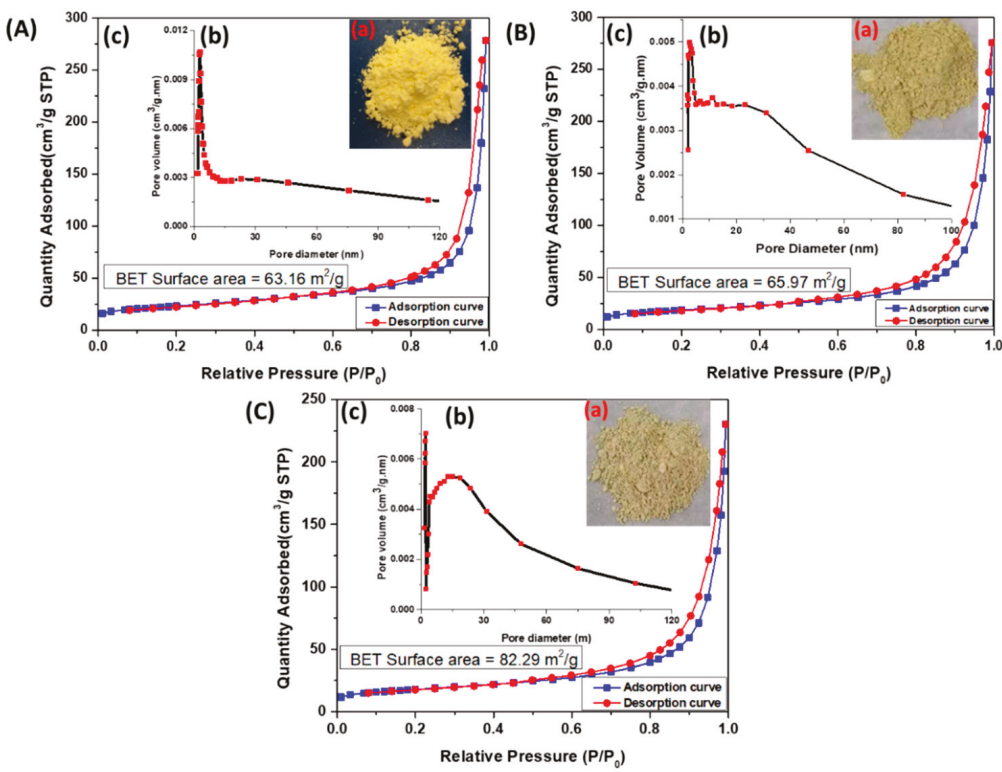

Figure 5. (A-C) The optical images (a,b) pore size distribution, and (c) nitrogen adsorption and desorption isotherms of $\mathrm{gCN}, \mathrm{Cu}_{2} \mathrm{O}-\mathrm{gCN}$, and $\mathrm{CuMnO}_{2}-\mathrm{gCN}$, respectively. BET, Brauner-Emmet-Teller.

\subsection{Electrochemical Studies}

In the current study, we report the super-capacitive activity of the manufactured gCN and $\mathrm{Cu}_{2} \mathrm{O}-\mathrm{gCN}$, as a base substantial, in rapports of specific capacitance, energy and power densities, and electrochemical steadiness. Cyclic voltammetry (CV) and galvanostatic charge/discharge (GCD) analysis were initially done for explaining the electrochemical activity of the modified working 
GCE in a three-electrode scheme in a $0.5 \mathrm{~mol} \cdot \mathrm{dm}^{-3} \mathrm{KOH}$ solution. Figure 6 a (inset figure) presents the comparison of $\mathrm{CV}$ study of the $\mathrm{gCN}, \mathrm{Cu}_{2} \mathrm{O}-\mathrm{gCN}$, and $\mathrm{CuMnO}_{2}-\mathrm{gCN}$ materials at a scan rate of $20 \mathrm{mV} \cdot \mathrm{s}^{-1}$ within a voltage range of -0.25 to $0.3 \mathrm{~V}$ and the highest current density value of 0.41 and $0.10 \mathrm{~A} \cdot \mathrm{g}^{-1}$, correspondingly, was attained at $0.3 \mathrm{~V}$. We optimized and chose this potential window for our experiment because, beyond this potential value, the current density was not stable for the repetitive number of cycles. To see the synergetic effect and to increase the conductivity of the $\mathrm{Cu}_{2} \mathrm{O}-\mathrm{gCN}$, we synthesized the $\mathrm{CuMnO}_{2}-\mathrm{gCN}$. Figure 6a (main panel) demonstrates the voltammogram of the $\mathrm{CuMnO}_{2}$-gCN modified working electrode in $0.5 \mathrm{~mol} \cdot \mathrm{dm}^{-3} \mathrm{KOH}$ at a potential sweep rate of $20 \mathrm{mV} \cdot \mathrm{s}^{-1}$, and a considerable enhancement on the current performance, $3.21 \mathrm{~A} \cdot \mathrm{g}^{-1}$, was observed. The extraordinary growth in the connected $\mathrm{CV}$ area of the $\mathrm{CuMnO}_{2}-\mathrm{gCN}$ material in comparison with the $\mathrm{Cu}_{2} \mathrm{O}-\mathrm{gCN}$ modified material is attributed to the combination of the high exterior area and electrochemical response of $\mathrm{gCN}$. This suggests the higher charge storage aptitude and extensive development of the activity. The integral area should be distinguished, below which the $\mathrm{CV}$ curves of plain gCN incorporated GCE are lesser than those of the $\mathrm{Cu}_{2} \mathrm{O}-\mathrm{gCN}$ and $\mathrm{CuMnO}_{2}-\mathrm{gCN}$ materials; exposing the insignificant influence of capacitance of the gCN supported material in entire specific capacitance (inset Figure 6a). The synergetic impact within the current density value of the $\mathrm{CuMnO}_{2}-\mathrm{gCN}$ incorporated electrode could be owing to the invention of the electronic and structural heterogeneity of the material. Now, the $\mathrm{CuMnO}_{2}-\mathrm{gCN}$ alloy has been adopted as the working substance for the remaining studies and constant enhancement of the current density conditions, as shown by the $\mathrm{CV}$, has been marked with progressing scan rate from 20 to $400 \mathrm{mV} \cdot \mathrm{s}^{-1}$, curves (a-h), sequentially (Figure $6 \mathrm{~b}$ ). The $C_{S}$ drops as the scan rate raises, which indicates the limited approachability of ions into the central section at a small-time range [56].
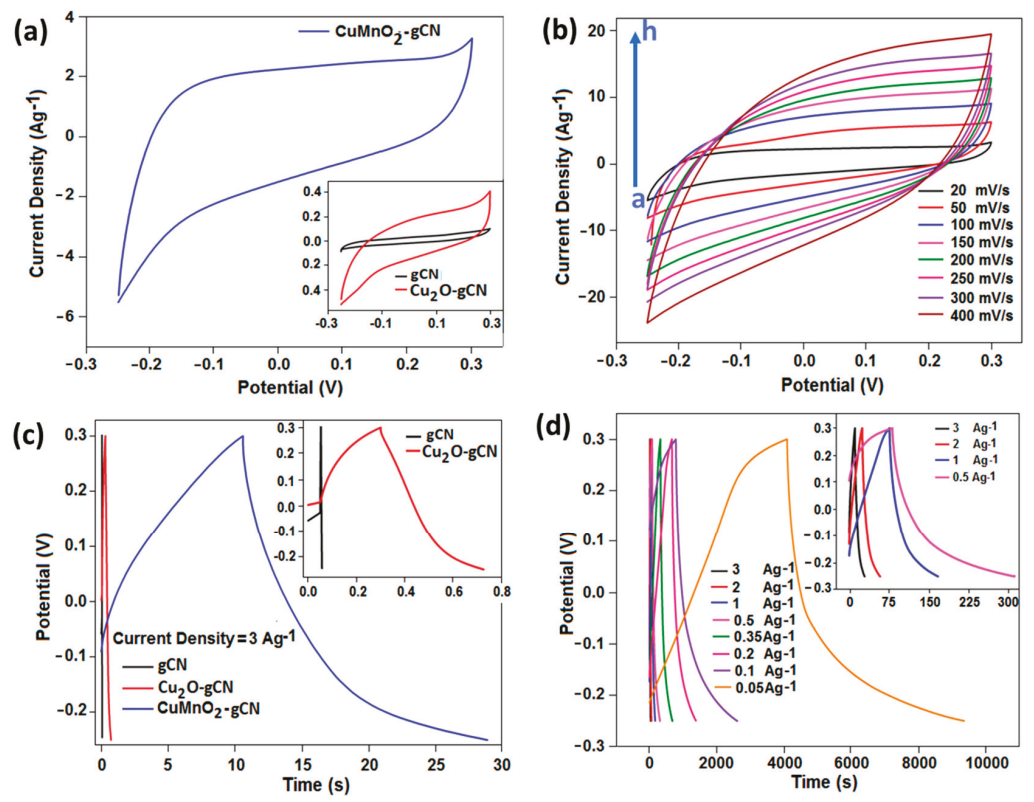

Figure 6. (a) Cyclic voltammetry (CV) curves of $\mathrm{CuMnO}_{2}-\mathrm{gCN}$ and inset figure for $\mathrm{gCN}$ and $\mathrm{Cu}_{2} \mathrm{O}-\mathrm{gCN}$ study at scan rate of $20 \mathrm{mV} \cdot \mathrm{s}^{-1}$ in $0.5 \mathrm{~mol} \cdot \mathrm{dm}^{-3} \mathrm{KOH}$. (b) The scan rate study of $\mathrm{CuMnO}_{2}-\mathrm{gCN}$. (c) Galvanostatic charge-discharge (GCD) curves of $\mathrm{gCN}, \mathrm{Cu}_{2} \mathrm{O}-\mathrm{gCN}$, and $\mathrm{CuMnO}_{2}-\mathrm{gCN}$ (the current density is $3 \mathrm{~A} \cdot \mathrm{g}^{-1}$ ). (d) GCD studies at diverse current densities of $\mathrm{CuMnO}_{2}$-gCN (whole study carried out in $\left.0.5 \mathrm{~mol} \cdot \mathrm{dm}^{-3} \mathrm{KOH}\right)$. 
The outstanding capacitive activity of the synthesized electrode substances was also confirmed from GCD measurements (Figure 6c). The GCD measurements for the $\mathrm{gCN}, \mathrm{Cu}_{2} \mathrm{O}-\mathrm{gCN}$, and $\mathrm{CuMnO}_{2}$-gCN composite incorporated electrodes, studied within the potential range from $-0.25 \mathrm{~V}$ to $0.3 \mathrm{~V}$, applying at a constant current density of $3.0 \mathrm{~A} \cdot \mathrm{g}^{-1}$ in $0.5 \mathrm{~mol} \cdot \mathrm{dm}^{-3} \mathrm{KOH}$. The $C_{S}$ values, gained from charge-discharge studies, of the corresponding composites were $0.8,3.45$, and $100.25 \mathrm{~F} \cdot \mathrm{g}^{-1}$, respectively, for the fixed current density of $3.0 \mathrm{~A} \cdot \mathrm{g}^{-1}$. Figure $6 \mathrm{~d}$ exhibits the GCD cycles for the $\mathrm{CuMnO}_{2}-\mathrm{gCN}$ material incorporated electrodes, by applying a different current density value from 3.0 to $0.05 \mathrm{~A} \cdot \mathrm{g}^{-1}$ in $0.5 \mathrm{~mol} \cdot \mathrm{dm}^{-3} \mathrm{KOH}$. The $C_{S}$ data, found from charge-discharge studies, of the corresponding substantial were 100.25, 123.27, 165.58, 209.09, 225.32, 261.34, 332.09, 480.49, and $817.85 \mathrm{~F} \cdot \mathrm{g}^{-1}$ for the current density value of $3.0,2.0,1.0,0.5,0.35,0.2,0.1,0.05$, and $0.025 \mathrm{~A} \cdot \mathrm{g}^{-1}$, correspondingly. An extensive discharge period resembles a higher capacitance of the $\mathrm{CuMnO}_{2}-\mathrm{gCN}$ modified GCE, owing to a combing impact among gCN and $\mathrm{CuMnO}_{2}$ and an improved efficient surface area essentially aimed at ion exchange. To analyse the reliability and storage capacitance of the synthesized material, we used $\mathrm{CuMnO}_{2}-\mathrm{gCN}$ modified anode electrode in alkaline media at a fixed potential sweep rate and observed a considerable enhancement on the current performance. An extensive discharge period resembles a higher capacitance of the $\mathrm{CuMnO}_{2}-\mathrm{gCN}$ modified GCE, owing to a combing impact among gCN and $\mathrm{CuMnO}_{2}$ and an improved efficient surface area essentially aimed at ion exchange. From the GCD and CV studies, it was observed and confirmed that the durability and storage capability of our material has the potential for supercapacitor applications.

The graphical illustration, bar-chart (Figure 7a), denotes the current density vulnerability on the $C_{S}$ data. By varying the current density values from 0.025 to $3 \mathrm{~A} \cdot \mathrm{g}^{-1}$, the highest specific capacitance was attained while the experiment was carried out under the lowest input current density. For the energy storage application, the stability of the material is a significant restriction for the durability of the anode substance. We employed the GCD analysis to assess the stability of the $\mathrm{CuMnO}_{2}-\mathrm{gCN}$ anode material up to 1000 cycles. Figure $7 \mathrm{~b}$ exhibits that $\mathrm{CuMnO}_{2}-\mathrm{gCN}$ anode material displayed higher rate steadiness around 91\% of its initial capacitance after 1000 cycles, charging and discharging, and shows the high durability of the composite. The higher rate competence of the $\mathrm{CuMnO}_{2}-\mathrm{gCN}$ anode is accredited to the quicker diffusion extent of the ions, and the higher exterior area, including the increased electrochemical response.

Figure $7 \mathrm{c}$ displays the graphical illustration of the energy and power density of the material versus current density. With a reduction in the current density conditions, the energy density rises and the power density decreases. The nonlinear characteristics of the curve (energy versus current density) change with time, a variable factor that varies with the current value in comparison with the energy density. Electrochemical impedance spectroscopy (EIS) investigation was conducted to identify the electrical features of all the incorporated substances. The EIS study was carried out to determine the kinetic criterion of the $\mathrm{gCN}, \mathrm{Cu}_{2} \mathrm{O}-\mathrm{gCN}$, and $\mathrm{CuMnO}_{2}-\mathrm{gCN}$ incorporated materials on a frequency scale from $3 \mathrm{MHz}$ to $10 \mathrm{~Hz}$ at open-circuit voltages (Figure 7d). The Nyquist designs of the three-electrode elements are made of the slanted semicircles within the high-frequency range and vertical shapes during the low-frequency section, which represents frontier charge-transfer resistance $\left(\mathrm{R}_{\mathrm{ct}}\right)$ and dissemination resistance into the electroactive substance, sequentially $[57,58]$. The $R_{\mathrm{ct}}$ outcome is $86.9,90.1$, and $22.9 \Omega$ aimed at the $\mathrm{gCN}, \mathrm{CuO}_{2}-\mathrm{gCN}$, and $\mathrm{CuMnO}_{2}-\mathrm{gCN}$ materials, sequentially. The $\mathrm{CuMnO}_{2}-\mathrm{gCN}$ electrode shows a more perpendicular line $\left(50^{\circ}\right)$ compared with the $\mathrm{Cu}_{2} \mathrm{O}-\mathrm{gCN}\left(35^{\circ}\right)$ and gCN electrode $\left(25^{\circ}\right)$; representing the lower dispersion resistance with more distinct capacitive performance. The operative assistance of gCN nanosheets as per the conductive outline within the $\mathrm{CuMnO}_{2}-\mathrm{gCN}$ nanocomposite is the looming reason for electrochemical activity development. The outcome specifies that the compound of $\mathrm{CuMnO}_{2}$-gCN structure has more ability to store the energy as compared with other base materials. 
(a)

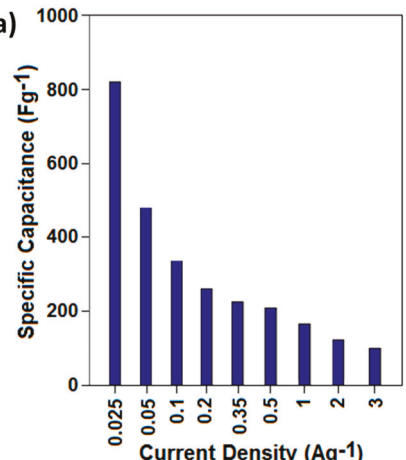

(d)

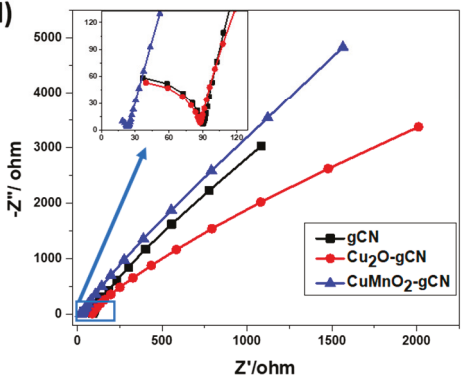

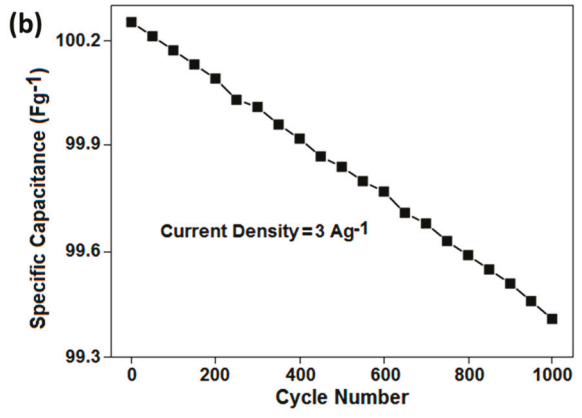

(c)

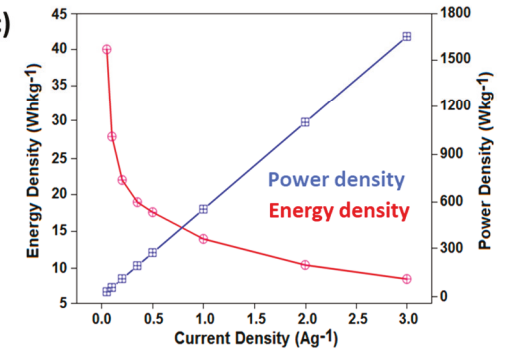

Figure 7. (a) Calculated specific capacitance of the $\mathrm{CuMnO}_{2}-\mathrm{gCN}$ sample. (b) Cycling stability performance of $\mathrm{CuMnO}_{2}-\mathrm{gCN}$ (the current density is $3 \mathrm{~A} \cdot \mathrm{g}^{-1}$ ). (c) The graphical relation between the energy density and power density as the function of current density for $\mathrm{CuMnO}_{2}-\mathrm{gCN}$ material, in the potential range of 3.0-0.1 V. (d) Nyquist plots of gCN, $\mathrm{Cu}_{2} \mathrm{O}-\mathrm{gCN}$, and $\mathrm{CuMnO}_{2}-\mathrm{gCN}$ in a frequency range of $3 \mathrm{MHz}-10 \mathrm{~Hz}$ under an open circuit condition.

\section{Conclusions}

In this report, we reveal the synthesis of novel anode material for energy storage applications. We used a facile route to synthesize the copper-manganese alloy of diverse stoichiometric configurations that were supported on gCN nanosheets. The $\mathrm{CuMnO}_{2}-\mathrm{gCN}$ modified GCE reveals a better electrochemical response compared with the $\mathrm{Cu}_{2} \mathrm{O}-\mathrm{gCN}$ electrode. The $\mathrm{CuMnO}_{2}-\mathrm{gCN}$ material exhibits a high specific capacitance $\left(817.85 \mathrm{~F} \cdot \mathrm{g}^{-1}\right.$ at $0.025 \mathrm{~A} \cdot \mathrm{g}^{-1}$ ) and great cycling stability (retention of $91 \%$ up to 1000 cycles). On the basis of the current results, the $\mathrm{CuMnO}_{2}$-gCN composite offers a piece of compelling evidence as a potential electrode material for use in progressive energy storage devices. SCs' discovery in advance energy purposes vast energy capability including equipment by comparatively less time plus higher endurance. Recently, the integration of carbons including metal oxides/alloy to develop hybrid SCs can be described as a potential substitute for energy-related purposes.

Supplementary Materials: The following are available online at https://www.mdpi.com/2079-4991/10/1/2/s1, Figure S1: (a,b) SEM images and (c) corresponding EDX elemental mapping of gCN; Figure S2: (a,b) SEM images and (c) corresponding EDX elemental mapping of $\mathrm{Cu}_{2} \mathrm{O}-\mathrm{gCN}$; Figure S3: TEM image of $\mathrm{Cu}_{2} \mathrm{O}-\mathrm{gCN}$ (a), (b) STEM-HAADF images of $\mathrm{Cu}_{2} \mathrm{O}-\mathrm{gCN}$ and corresponding EDX elemental mapping of the selected area, and (c) HRTEM image of $\mathrm{Cu}_{2} \mathrm{O}-\mathrm{gCN}$ and corresponding FFT image of selected area in (c); Figure S4: XPS survey spectrum of $\mathrm{CuMnO}_{2}$-gCN nanocomposite.

Author Contributions: Synthesis and experimental design, S.S.S.; Sample characterization, S.S.S. and C.S.; Concentration analysis, S.S.S. and C.S.; Supervision, Q.Z. and V.K.T.; Writing-original draft, S.S.S.; Writing - review \& editing, S.S.S., Q.Z., and V.K.T.; Funding acquisition, S.S.S. and Q.Z. All authors have read and agreed to the published version of the manuscript. 
Funding: This research work was funded by financial support from the National Natural Science Foundation of China (21962008, 51464028), Candidate Talents Training Fund of Yunnan Province (2017PY269SQ, 2018HB007), and Yunnan Ten Thousand Talents Plan Young \& Elite Talents Project (YNWR-QNBJ-2018-346).

Acknowledgments: We are grateful for the financial support from the National Natural Science Foundation of China, Candidate Talents Training Fund of Yunnan Province, and Yunnan Ten Thousand Talents Plan Young \& Elite Talents Project.

Conflicts of Interest: The authors declare no conflict of interest.

\section{References}

1. Kong, L.; Chen, Q.; Shen, X.; Xia, C.; Ji, Z.; Zhu, J. Ionic liquid templated porous boron-doped graphitic carbon nitride nanosheet electrode for high-performance supercapacitor. Electrochim. Acta 2017, 245, 249-258. [CrossRef]

2. Xie, G.; Zhang, K.; Guo, B.; Liu, Q.; Fang, L.; Gong, J.R. Graphene-based materials for hydrogen generation from light-driven water splitting. Adv. Mater. 2013, 25, 3820-3839. [CrossRef] [PubMed]

3. Ling, Z.; Wang, Z.; Zhang, M.; Yu, C.; Wang, G.; Dong, Y.; Liu, S.; Wang, Y.; Qiu, J. Sustainable synthesis and assembly of biomass-derived $\mathrm{B} / \mathrm{N}$ co-doped carbon nanosheets with ultrahigh aspect ratio for high-performance supercapacitors. Adv. Funct. Mater. 2016, 26, 111-119. [CrossRef]

4. Kong, L.; Chen, Q.; Shen, X.; Xu, Z.; Xu, C.; Ji, Z.; Zhu, J. MOF derived nitrogen-doped carbon polyhedrons decorated on graphitic carbon nitride sheets with enhanced electrochemical capacitive energy storage performance. Electrochim. Acta 2018, 265, 651-661. [CrossRef]

5. Jeong, H.M.; Lee, J.W.; Shin, W.H.; Choi, Y.J.; Shin, H.J.; Kang, J.K.; Choi, J.W. Nitrogen-doped graphene for high-performance ultracapacitors and the importance of nitrogen-doped sites at basal planes. Nano Lett. 2011, 11, 2472-2477. [CrossRef] [PubMed]

6. Wu, Z.-S.; Winter, A.; Chen, L.; Sun, Y.; Turchanin, A.; Feng, X.; Müllen, K. Three-dimensional nitrogen and boron co-doped graphene for high-performance all-solid-state supercapacitors. Adv. Mater. 2012, 24, 5130-5135. [CrossRef] [PubMed]

7. Han, J.; Zhang, L.L.; Lee, S.; Oh, J.; Lee, K.-S.; Potts, J.R.; Ji, J.; Zhao, X.; Ruoff, R.S.; Park, S. Generation of B-doped graphene nanoplatelets using a solution process and their supercapacitor applications. ACS Nano 2013, 7, 19-26. [CrossRef]

8. Kong, L.; Chen, Q.; Shen, X.; Zhu, G.; Zhu, J. Ionic liquid directed construction of foam-like mesoporous boron-doped graphitic carbon nitride electrode for high-performance supercapacitor. J. Colloid Interface Sci. 2018, 532, 261-271. [CrossRef]

9. Winter, M.; Brodd, R.J. What are batteries, fuel cells, and supercapacitors? Chem. Rev. 2004, 104, 4245-4270. [CrossRef] [PubMed]

10. Salunkhe, R.R.; Lee, Y.H.; Chang, K.H.; Li, J.M.; Simon, P.; Tang, J.; Torad, N.L.; Hu, C.C.; Yamauchi, Y. Nanoarchitectured graphene-based supercapacitors for next-generation energy-storage applications. Chem. Eur. J. 2014, 20, 13838-13852. [CrossRef]

11. Tyagi, A.; Joshi, M.C.; Shah, A.; Thakur, V.K.; Gupta, R.K. Hydrothermally tailored three-dimensional Ni-V layered double hydroxide nanosheets as high-performance hybrid supercapacitor applications. ACS Omega 2019, 4, 3257-3267. [CrossRef] [PubMed]

12. Simon, P.; Gogotsi, Y. Materials for electrochemical capacitors. Nat. Mater. 2008, 7, 845. [CrossRef]

13. Liu, C.; Li, F.; Ma, L.P.; Cheng, H.M. Advanced materials for energy storage. Adv. Mater. 2010, 22, $28-62$. [CrossRef] [PubMed]

14. Zhai, Y.; Dou, Y.; Zhao, D.; Fulvio, P.F.; Mayes, R.T.; Dai, S. Carbon materials for chemical capacitive energy storage. Adv. Mater. 2011, 23, 4828-4850. [CrossRef] [PubMed]

15. Kessler, F.K.; Zheng, Y.; Schwarz, D.; Merschjann, C.; Schnick, W.; Wang, X.; Bojdys, M.J. Functional carbon nitride materials-Design strategies for electrochemical devices. Nat. Rev. Mater. 2017, 2, 17030. [CrossRef]

16. Miller, T.S.; Jorge, A.B.; Suter, T.M.; Sella, A.; Corà, F.; McMillan, P.F. Carbon nitrides: Synthesis and characterization of a new class of functional materials. Phys. Chem. Chem. Phys. 2017, 19, 15613-15638. [CrossRef] 
17. Thomas, A.; Fischer, A.; Goettmann, F.; Antonietti, M.; Müller, J.-O.; Schlögl, R.; Carlsson, J.M. Graphitic carbon nitride materials: Variation of structure and morphology and their use as metal-free catalysts. J. Mater. Chem. 2008, 18, 4893-4908. [CrossRef]

18. Lakhi, K.S.; Park, D.H.; Al-Bahily, K.; Cha, W.; Viswanathan, B.; Choy, J.H.; Vinu, A. Mesoporous carbon nitrides: Synthesis, functionalization, and applications. Chem. Soc. Rev. 2017, 46, 72-101. [CrossRef]

19. Zheng, Y.; Liu, J.; Liang, J.; Jaroniec, M.; Qiao, S.Z. Graphitic carbon nitride materials: Controllable synthesis and applications in fuel cells and photocatalysis. Energy Environ. Sci. 2012, 5, 6717-6731. [CrossRef]

20. Vinu, A.; Ariga, K.; Mori, T.; Nakanishi, T.; Hishita, S.; Golberg, D.; Bando, Y. Preparation and characterization of well-ordered hexagonal mesoporous carbon nitride. Adv. Mater. 2005, 17, 1648-1652. [CrossRef]

21. Idris, M.B.; Devaraj, S. Tuning the chemical composition, textural and capacitance properties of mesoporous graphitic carbon nitride. Electrochim. Acta 2019, 303, 219-230. [CrossRef]

22. Mohamed, S.G.; Attia, S.Y.; Barakat, Y.F.; Hassan, H.H.; Zoubi, W.A. Hydrothermal synthesis of $\alpha$-MnS Nanoflakes@Nitrogen and sulfur co-doped rGO for high-performance hybrid supercapacitor. ChemistrySelect 2018, 3, 6061-6072. [CrossRef]

23. Ragupathi, V.; Panigrahi, P.; Subramaniam, N.G. g- $\mathrm{C}_{3} \mathrm{~N}_{4}$ doped MnS as high performance electrode material for supercapacitor application. Mater. Lett. 2019, 246, 88-91. [CrossRef]

24. Idris, M.B.; Devaraj, S. Mesoporous graphitic carbon nitride synthesized using biotemplate as a high-performance electrode material for supercapacitor and electrocatalyst for hydrogen evolution reaction in acidic medium. J. Energy Storage 2019, 26, 101032. [CrossRef]

25. Xu, X.; Liu, Q.; Wei, T.; Zhao, Y.; Zhang, X. Enhanced energy storage activity of $\mathrm{NiMoO}_{4}$ modified by graphitic carbon nitride. J. Mater. Sci. Mater. Electron. 2019, 30, 5109-5119. [CrossRef]

26. Ke, Q.; Liao, Y.; Yao, S.; Song, L.; Xiong, X. A three-dimensional $\mathrm{TiO}_{2}$ /graphene porous composite with nano-carbon deposition for supercapacitor. J. Mater. Sci. 2016, 51, 2008-2016. [CrossRef]

27. Li, Q.; Zheng, S.; Xu, Y.; Xue, H.; Pang, H. Ruthenium based materials as electrode materials for supercapacitors. Chem. Eng. J. 2018, 333, 505-518. [CrossRef]

28. Prasanna, K.; Santhoshkumar, P.; Jo, Y.N.; Sivagami, I.N.; Kang, S.H.; Joe, Y.C.; Lee, C.W. Highly porous $\mathrm{CeO}_{2}$ nanostructures prepared via combustion synthesis for supercapacitor applications. Appl. Surf. Sci. 2018, 449, 454-460. [CrossRef]

29. Chen, R.; Puri, I.K.; Zhitomirsky, I. High areal capacitance of FeOOH-carbon nanotube negative electrodes for asymmetric supercapacitors. Ceram. Int. 2018, 44, 18007-18015. [CrossRef]

30. Ensafi, A.A.; Abarghoui, M.M.; Rezaei, B. Graphitic carbon nitride nanosheets coated with $\mathrm{Ni}_{2} \mathrm{CoS}_{4}$ nanoparticles as a high-rate electrode material for supercapacitor application. Ceram. Int. 2019, 45, 8518-8524. [CrossRef]

31. Song, W.; Poyraz, A.S.; Meng, Y.; Ren, Z.; Chen, S.-Y.; Suib, S.L. Mesoporous $\mathrm{Co}_{3} \mathrm{O}_{4}$ with controlled porosity: Inverse micelle synthesis and high-performance catalytic $\mathrm{CO}$ oxidation at $-60^{\circ} \mathrm{C}$. Chem. Mater. 2014, 26, 4629-4639. [CrossRef]

32. Siwal, S.; Devi, N.; Perla, V.K.; Ghosh, S.K.; Mallick, K. Promotional role of gold in electrochemical methanol oxidation. Catal. Struct. React. 2019, 5, 1-9. [CrossRef]

33. Siwal, S.; Devi, N.; Perla, V.; Barik, R.; Ghosh, S.; Mallick, K. The influencing role of oxophilicity and surface area of the catalyst for electrochemical methanol oxidation reaction: A case study. Mater. Res. Innov. 2018, 23, 440-447. [CrossRef]

34. Siwal, S.S.; Thakur, S.; Zhang, Q.B.; Thakur, V.K. Electrocatalysts for electrooxidation of direct alcohol fuel cell: Chemistry and applications. Mater. Today Chem. 2019, 14, 100182. [CrossRef]

35. Bahmani, F.; Kazemi, S.H.; Wu, Y.; Liu, L.; Xu, Y.; Lei, Y. CuMnO ${ }_{2}$-reduced graphene oxide nanocomposite as a free-standing electrode for high-performance supercapacitors. Chem. Eng. J. 2019, 375, 121966. [CrossRef]

36. Shakeel, M.; Arif, M.; Yasin, G.; Li, B.; Khan, H.D. Layered by layered Ni-Mn-LDH/g-C ${ }_{3} \mathrm{~N}_{4}$ nanohybrid for multi-purpose photo/electrocatalysis: Morphology controlled strategy for effective charge carriers separation. Appl. Catal. B Environ. 2019, 242, 485-498. [CrossRef]

37. Meghana, S.; Kabra, P.; Chakraborty, S.; Padmavathy, N. Understanding the pathway of antibacterial activity of copper oxide nanoparticles. RSC Adv. 2015, 5, 12293-12299. [CrossRef]

38. An, X.; Li, K.; Tang, J. Cu $\mathrm{Cu}_{2} \mathrm{O} /$ Reduced graphene oxide composites for the photocatalytic conversion of $\mathrm{CO}_{2}$. ChemSusChem 2014, 7, 1086-1093. [CrossRef] 
39. Benreguia, N.; Barnabé, A.; Trari, M. Preparation and characterization of the semiconductor $\mathrm{CuMnO}_{2}$ by sol-gel route. Mater. Sci. Semicond. Process. 2016, 56, 14-19. [CrossRef]

40. Chang, P.Y.; Tseng, I.H. Photocatalytic conversion of gas phase carbon dioxide by graphitic carbon nitride decorated with cuprous oxide with various morphologies. J. CO2 Util. 2018, 26, 511-521. [CrossRef]

41. Wang, L.; Arif, M.; Duan, G.; Chen, S.; Liu, X. A high performance quasi-solid-state supercapacitor based on $\mathrm{CuMnO}_{2}$ nanoparticles. J. Power Sources 2017, 355, 53-61. [CrossRef]

42. Ramesh, K.; Prashantha, M.; Reddy, N.K.; Gopal, E.S. Synthesis of nano structured carbon nitride by pyrolysis assisted chemical vapour deposition. Integr. Ferroelectr. 2010, 117, 40-48. [CrossRef]

43. Niu, P.; Qiao, M.; Li, Y.; Huang, L.; Zhai, T. Distinctive defects engineering in graphitic carbon nitride for greatly extended visible light photocatalytic hydrogen evolution. Nano Energy 2018, 44, 73-81. [CrossRef]

44. Liang, Q.; Li, Z.; Huang, Z.-H.; Kang, F.; Yang, Q.H. Holey graphitic carbon nitride nanosheets with carbon vacancies for highly improved photocatalytic hydrogen production. Adv. Funct. Mater. 2015, 25, 6885-6892. [CrossRef]

45. Liu, S.; Dong, Y.; Wang, Z.; Huang, H.; Zhao, Z.; Qiu, J. Towards efficient electrocatalysts for oxygen reduction by doping cobalt into graphene-supported graphitic carbon nitride. J. Mater. Chem. A 2015, 3, 19657-19661. [CrossRef]

46. Kim, H.; Gim, S.; Jeon, T.H.; Kim, H.; Choi, W. Distorted carbon nitride structure with substituted benzene moieties for enhanced visible light photocatalytic activities. ACS Appl. Mater. Interfaces 2017, 9, 40360-40368. [CrossRef]

47. Huang, M.; Zhang, Y.; Li, F.; Wang, Z.; Alamusi Hu, N.; Wen, Z.; Liu, Q. Merging of Kirkendall Growth and Ostwald Ripening: $\mathrm{CuO} @ \mathrm{MnO}_{2}$ core-shell architectures for asymmetric supercapacitors. Sci. Rep. 2014, 4, 4518. [CrossRef]

48. Chusuei, C.C.; Brookshier, M.A.; Goodman, D.W. Correlation of relative X-ray photoelectron spectroscopy shake-up intensity with $\mathrm{CuO}$ particle size. Langmuir 1999, 15, 2806-2808. [CrossRef]

49. Wu, C.K.; Yin, M.; O’Brien, S.; Koberstein, J.T. Quantitative analysis of copper oxide nanoparticle composition and structure by X-ray photoelectron spectroscopy. Chem. Mater. 2006, 18, 6054-6058. [CrossRef]

50. Han, S.; Hu, X.; Yang, W.; Qian, Q.; Fang, X.; Zhu, Y. Constructing the band alignment of graphitic carbon nitride $\left(\mathrm{g}-\mathrm{C}_{3} \mathrm{~N}_{4}\right) / \operatorname{Copper}(\mathrm{I})$ oxide $\left(\mathrm{Cu}_{2} \mathrm{O}\right)$ composites by adjusting the contact facet for superior photocatalytic activity. ACS Appl. Energy Mater. 2019, 2, 1803-1811. [CrossRef]

51. Park, H.; Kwon, J.; Choi, H.; Shin, D.; Song, T.; Lou, X.W.D. Unusual $\mathrm{Na}^{+}$ion intercalation/deintercalation in metal-rich $\mathrm{Cu}_{1.8} \mathrm{~S}$ for Na-ion batteries. ACS Nano 2018, 12, 2827-2837. [CrossRef] [PubMed]

52. Ye, M.; Wen, X.; Zhang, N.; Guo, W.; Liu, X.; Lin, C. In situ growth of CuS and $\mathrm{Cu}_{1.8} \mathrm{~S}$ nanosheet arrays as efficient counter electrodes for quantum dot-sensitized solar cells. J. Mater. Chem. A 2015, 3, 9595-9600. [CrossRef]

53. Lei, K.; Han, X.; Hu, Y.; Liu, X.; Cong, L.; Cheng, F.; Chen, J. Chemical etching of manganese oxides for electrocatalytic oxygen reduction reaction. Chem. Commun. 2015, 51, 11599-11602. [CrossRef] [PubMed]

54. Zhan, S.; Zhu, D.; Qiu, M.; Yu, H.; Li, Y. Highly efficient removal of NO with ordered mesoporous manganese oxide at low temperature. RSC Adv. 2015, 5, 29353-29361. [CrossRef]

55. Kaverlavani, S.K.; Moosavifard, S.E.; Bakouei, A. Designing graphene-wrapped nanoporous $\mathrm{CuCo}_{2} \mathrm{O}_{4}$ hollow spheres electrodes for high-performance asymmetric supercapacitors. J. Mater. Chem. A 2017, 5, 14301-14309. [CrossRef]

56. Shen, L.; Du, L.; Tan, S.; Zang, Z.; Zhao, C.; Mai, W. Flexible electrochromic supercapacitor hybrid electrodes based on tungsten oxide films and silver nanowires. Chem. Commun. 2016, 52, 6296-6299. [CrossRef]

57. Chavan, H.S.; Hou, B.; Ahmed, A.T.A.; Jo, Y.; Cho, S.; Kim, J.; Pawar, S.M.; Cha, S.; Inamdar, A.I.; Im, H.; et al. Nanoflake $\mathrm{NiMoO}_{4}$ based smart supercapacitor for intelligent power balance monitoring. Sol. Energy Mater. Sol. Cells 2018, 185, 166-173. [CrossRef]

58. Guo, X.; Zheng, T.; Ji, G.; Hu, N.; Xu, C.; Zhang, Y. Core/shell design of efficient electrocatalysts based on $\mathrm{NiCO}_{2} \mathrm{O}_{4}$ nanowires and NiMn LDH nanosheets for rechargeable zinc-air batteries. J. Mater. Chem. A 2018, 6, 10243-10252. [CrossRef]

(C) 2019 by the authors. Licensee MDPI, Basel, Switzerland. This article is an open access article distributed under the terms and conditions of the Creative Commons Attribution (CC BY) license (http://creativecommons.org/licenses/by/4.0/). 

Article

\title{
Fluoride-Ion Batteries: On the Electrochemical Stability of Nanocrystalline $\mathrm{La}_{0.9} \mathrm{Ba}_{0.1} \mathrm{~F}_{2.9}$ against Metal Electrodes
}

\author{
Maria Gombotz ${ }^{1, *}$, Veronika Pregartner ${ }^{1}$, Ilie Hanzu ${ }^{1,2, *}$ and H. Martin R. Wilkening ${ }^{1,2}$ \\ 1 Institute for Chemistry and Technology of Materials, Technical Universtiy of Graz, Graz 8010, Austria; \\ veronika.pregartner@tugraz.at (V.P.); wilkening@tugraz.at (H.M.R.W.) \\ 2 ALISTORE-European Research Institute, CNRS FR3104, Hub de l'Energie, Rue Baudelocque, \\ 80039 Amiens, France \\ * Correspondence: gombotz@tugraz.at (M.G.); hanzu@tugraz.at (I.H.)
}

Received: 27 September 2019; Accepted: 23 October 2019; Published: 25 October 2019

\begin{abstract}
Over the past years, ceramic fluorine ion conductors with high ionic conductivity have stepped into the limelight of materials research, as they may act as solid-state electrolytes in fluorine-ion batteries (FIBs). A factor of utmost importance, which has been left aside so far, is the electrochemical stability of these conductors with respect to both the voltage window and the active materials used. The compatibility with different current collector materials is important as well. In the course of this study, tysonite-type $\mathrm{La}_{0.9} \mathrm{Ba}_{0.1} \mathrm{~F}_{2.9}$, which is one of the most important electrolyte in first-generation FIBs, was chosen as model substance to study its electrochemical stability against a series of metal electrodes viz. $\mathrm{Pt}, \mathrm{Au}, \mathrm{Ni}, \mathrm{Cu}$ and $\mathrm{Ag}$. To test anodic or cathodic degradation processes we carried out cyclic voltammetry (CV) measurements using a two-electrode set-up. We covered a voltage window ranging from -1 to $4 \mathrm{~V}$, which is typical for FIBs, and investigated the change of the response of the CVs as a function of scan rate $(2 \mathrm{mV} / \mathrm{s}$ to $0.1 \mathrm{~V} / \mathrm{s})$. It turned out that $\mathrm{Cu}$ is unstable in combination with $\mathrm{La}_{0.9} \mathrm{Ba}_{0.1} \mathrm{~F}_{2.9}$, even before voltage was applied. The cells with $\mathrm{Au}$ and Pt electrodes show reactions during the CV scans; in the case of $\mathrm{Au}$ the irreversible changes seen in $\mathrm{CV}$ are accompanied by a change in color of the electrode as investigated by light microscopy. Ag and $\mathrm{Ni}$ electrodes seem to suffer from contact issues which, most likely, also originate from side reactions with the electrode material. The experiments show that the choice of current collectors in future FIBs will become an important topic if we are to develop long-lasting FIBs. Most likely, protecting layers between the composite electrode material and the metal current collector have to be developed to prevent any interdiffusion or electrochemical degradation processes.
\end{abstract}

Keywords: solid fluoride electrolytes; ceramics; $\mathrm{LaF}_{3}$; fluorine-ion batteries; metal current collectors; electrochemical stability; cyclic voltammetry

\section{Introduction}

Lithium-ion batteries are by far the most widely used electrochemical energy storage systems. Since this battery technology starts to suffer from several issues, such as the exploitation of cobalt or nickel mines [1] in geopolitical disputed regions, alternative systems gain more and more importance. One of these alternate post-lithium systems, besides the development of sodium-ion batteries [2], relies on fluorine anions as the electrochemically active species.

The first explicit reference of a highly conducting F-bearing solid-state electrolyte, namely $\mathrm{PbF}_{2}$, was already in 1834 by Michael Faraday [3,4], who discovered ionic conduction in $\mathrm{AgI}$ and $\mathrm{PbF}_{2}$, see refs. [5,6] for an overview. In 1921, Carl Tubandt measured transference numbers of a series of solid electrolytes including $\mathrm{PbF}_{2}$ [7]. It then took several decades until 1971 when Baukal [8] 
and 1976 when Kennedy et al. [9] and Schoonman [10] constructed the first fluoride thin-film galvanic cells, see also refs. [11,12]. In 2011 Reddy et al. [13] revived the topic with a closer investigation of possible cathode materials [14-16], whereby $\mathrm{La}_{0.9} \mathrm{Ba}_{0.1} \mathrm{~F}_{2.9}$, see also ref. [17], was chosen as solid state electrolyte due to its high conductivity of $2.8 \times 10^{-4} \mathrm{~S} \mathrm{~cm}^{-1}$ at $160{ }^{\circ} \mathrm{C}$. Also polymer matrix [18] and liquid electrolytes [19] were investigated. Recently, several studies concerning various anode [20,21] and cathode materials [22] appeared; their suitability and performance have always been investigated in combination with $\mathrm{La}_{0.9} \mathrm{Ba}_{0.1} \mathrm{~F}_{2.9}$ as the ceramic electrolyte of choice. To the best of our knowledge, no detailed studies concerning the electrochemical stability of solid-state fluoride electrolytes against metallic current collectors have been reported yet, neither of $\mathrm{La}_{0.9} \mathrm{Ba}_{0.1} \mathrm{~F}_{2.9}$ nor of other $\mathrm{F}^{-}$conductors such as $\mathrm{Ba}_{0.7} \mathrm{Sb}_{0.3} \mathrm{~F}_{2.3}$, which is not stable against $\mathrm{Ce}$ as anode material [23], $\mathrm{Ce}_{1-x} \mathrm{Sr}_{x} \mathrm{~F}_{3-x}(0 \leq x<0.15)$ [24] or $\mathrm{Sm}_{1-x} \mathrm{Ca}_{x} \mathrm{~F}_{3-x}(0.05 \leq x<0.15)$ [25]. Since a solid-state electrode must also contain a certain amount of (solid) electrolyte, it is important and meaningful to evaluate the stability of the electrolyte with respect to the current collector material.

In the course of this study, the electrochemical stability of nanocrystalline $\mathrm{La}_{0.9} \mathrm{Ba}_{0.1} \mathrm{~F}_{2.9}$, synthesized following a mechanochemical route, was examined by cyclic voltammetry (CV). Prior to our stability tests we checked the purity of the tysonite phase via X-ray powder diffraction and carried out electrochemical impedance spectroscopy (EIS) to determine its F ionic conductivity. The crystal structure of $\mathrm{La}_{0.9} \mathrm{Ba}_{0.1} \mathrm{~F}_{2.9}$ is illustrated in Figure 1. Here, we investigated the electrochemical stability of $\mathrm{La}_{0.9} \mathrm{Ba}_{0.1} \mathrm{~F}_{2.9}$ in combination with various metal electrodes namely $\mathrm{Cu}, \mathrm{Ag}$, $\mathrm{Au}, \mathrm{Pt}$ and $\mathrm{Ni}$, which were applied to the compacted electrolyte pellets by direct current sputtering.

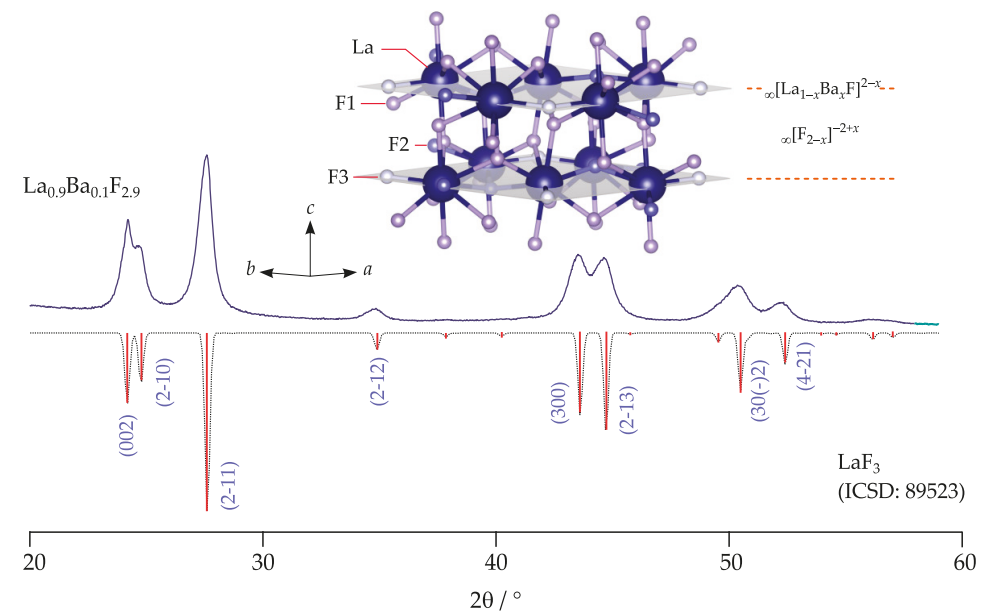

Figure 1. X-ray powder diffractogram of mechanosynthesized, nanocrystalline $\mathrm{La}_{0.9} \mathrm{Ba}_{0.1} \mathrm{~F}_{2.9}$; the pattern was recorded at room temperature and ambient atmosphere. It is compared to that of $\mathrm{LaF}_{3}$, which serves as a reference (ICSD: 89523, $P \overline{3} c 1$ ); $\mathrm{LaF}_{3}$ crystallizes with the well-known tysonite structure providing three different F sites labeled F1 (12g), F2 (4d) and F3 (2a). Each site is fully occupied by fluorine anions. $\mathrm{F} 1$ anions reside in the ${ }_{\infty}\left[\mathrm{F}_{2-x}\right]^{-2+x}$ interslabs and are located in distorted $\mathrm{La}_{4}$ tetrahedra.

Usually, electrochemical stability of electrolytes is tested via CV in a three electrode set-up. As fluorine is not solid at ambient conditions, it cannot easily serve as a reference electrode, which makes the interpretation of the CV results obtained from a two electrode set-up, as applied here, rather difficult [26]. We also varied the size of the working electrode (WE); diameters were varied from 2.5 to $8 \mathrm{~mm}$, to find out whether it has any influence on the results. Our CV measurements cover a voltage window from -1 to $4 \mathrm{~V}$. This voltage window is similar to that used in earlier reports ( 1 to $3.5 \mathrm{~V}$ [13] and 0 to $3.5 \mathrm{~V}$ [22]). Compared to a recently published study [27] on $\mathrm{La}_{0.9} \mathrm{Ba}_{0.1} \mathrm{~F}_{2.9}$, 
where we carried out CV at a rate of $100 \mathrm{mV} / \mathrm{S}$, here we reduced the scan rate to $2 \mathrm{mV} / \mathrm{s}$. Screening of five different metal electrode materials offers a quite diverse picture and highlights the reactivity of fluorine-containing electrolytes, as in none of the electrolyte/electrode configurations a stable electrochemical state could be achieved under the conditions mentioned above.

\section{Materials and Methods}

\subsection{Mechanochemical Synthesis}

Nanostructured $\mathrm{La}_{0.9} \mathrm{Ba}_{0.1} \mathrm{~F}_{2.9}$ was mechanosynthesized with the help of a high-energy planetary mill (Fritsch Pulverisette 7 Premium line, Fritsch GmbH, Idar-Oberstein, DE). For this purpose, stoichiometric amounts of the educts viz. $\mathrm{LaF}_{3}$ (99.99\%, Alfa Aesar, Kandel, DE) and $\mathrm{BaF}_{2}(99.99 \%$, Sigma Aldrich, Darmstadt, DE) were loaded into a $\mathrm{ZrO}_{2}$ milling beaker with a volume of $45 \mathrm{~mL}$. We added 180 balls made of the same material; the diameter of each milling ball was $5 \mathrm{~mm}$. The milling procedure was carried out at a rotation speed of $600 \mathrm{rpm}$; the mixture was milled for $10 \mathrm{~h}$ whereby 15 min milling was followed by a break of $15 \mathrm{~min}$ to allow cooling of the mixture and the beaker. Loading as well as unloading of the beakers was strictly carried out under inert atmosphere; we used an Ar-filled glovebox $\left(\mathrm{O}_{2}, \mathrm{H}_{2} \mathrm{O}<0.5 \mathrm{ppm}\right)$ to avoid any contamination by water vapor or moisture.

\subsection{X-Ray Powder Diffraction}

The powdered sample was analyzed by X-ray powder diffraction (XRPD) to ensure that the educts have fully been transformed to $\mathrm{La}_{0.9} \mathrm{Ba}_{0.1} \mathrm{~F}_{2.9}$ crystallizing, as $\mathrm{LaF}_{3}$ does, in the tysonite phase. Diffractogramms were recorded with a Bruker D8 Advance diffractometer operating with Bragg Brentano geometry and $\mathrm{CuK} \alpha$ radiation $(1.5406 \AA)$. XRPD reflections were recorded over a $2 \theta$ range of 10 to $100^{\circ} 2 \theta$ (stepsize $0.02^{\circ} 2 \theta, 1 \mathrm{~s}$ measuring time per step). With the aid of the program $X$-PertHighScorePlus (PANalytical, Malvern, UK) we analyzed the diffractogramms according to the refinement procedure introduced by Rietveld.

\subsection{Broadband Impedance Spectroscopy}

The ionic conductivity of the as-prepared $\mathrm{La}_{0.9} \mathrm{Ba}_{0.1} \mathrm{~F}_{2.9}$ was checked by solid-state impedance spectroscopy. Hence, the powder samples were pressed to cylindrical pellets with a diameter of $5 \mathrm{~mm}$ and a thickness of ca. $1 \mathrm{~mm}$; we used a press of P. O. Weber and applied a uniaxial force of $0.5 \mathrm{t}$. Ion blocking Pt electrodes with a thickness of $100 \mathrm{~nm}$ were applied on both sides of the pellet by sputtering (Leica sputter device (EM SCD050, Leica Microsystems, Wetzlar, DE)). Impedance data were recorded with a Novocontrol Concept 80 broadband spectrometer in combination with an active BDS 1200 cell [28] and a ZGS interface (Novocontrol). Impedance data were recorded over a frequency range from $10^{-2} \mathrm{~Hz}$ to $10^{7} \mathrm{~Hz}$ at temperatures ranging from 20 to $200{ }^{\circ} \mathrm{C}$. A QUATRO cryo-system (Novocontrol, Montabaur, DE) controlled the temperature of all measurements, which were carried out under a constant flow of dry, freshly evaporated $\mathrm{N}_{2}$ gas.

\subsection{Cyclic Voltammetry}

For all-solid-state cyclic voltammetry measurements approximately $120 \mathrm{mg}$ of the sample powder were pressed into cylindrical pellets with a diameter of $8 \mathrm{~mm}$. After uni-axial pressing $(0.4 \mathrm{t})$ the thickness of the pellets ranged from 0.9 to $1 \mathrm{~mm}$. As reference and counter electrode (CE) different materials of high purity $(\mathrm{Au}, \mathrm{Ag}, \mathrm{Cu}, \mathrm{Pt}, \mathrm{Ni})$ were sputtered on one complete side of the pellets. We studied pellets equipped with sputtered working electrodes (Leica, EM SCD050) of the following diameters $d: 2.5,4,6$ and $8 \mathrm{~mm}$. Again, all preparation steps were carried out in a glovebox filled with $\operatorname{Ar}\left(\mathrm{H}_{2} \mathrm{O}, \mathrm{O}_{2}<0.5 \mathrm{ppm}\right)$. The sample chamber of the sputter device was purged with Ar 5.0 for five times before the sputter process was started to avoid any contamination with moisture or $\mathrm{O}_{2}$. Cyclic voltammetry was performed with a Parstat MC potentiostat (Princeton Applied Research) equipped with a low-current option. We carried out all measurements at a temperature of $200{ }^{\circ} \mathrm{C}$ in a cell, 
which was continuously purged with $\mathrm{N}_{2}$. Scanning rates ranged from 0.002 to $0.1 \mathrm{~V} / \mathrm{s}$ whereby the voltage was varied from $-1 \mathrm{~V}$ to $4 \mathrm{~V}$. A schematic drawing of the cell set-up is shown in Figure A1.

\subsection{Scanning Electron Microscopy}

The surface of the pellets ( $\mathrm{Ag}$ and $\mathrm{Au}$ as electrode, working electrode $d=2.5 \mathrm{~mm}$ ) before and after $\mathrm{CV}$ were investigated by digital light microscopy (Di-Li Digital-Mikroskop, TCapture) and by scanning electron microscopy (SEM, VEGA3 TESCAN), in both the secondary electron (SE) and backscattered electron (BSE) mode. SEM was combined with energy dispersive X-ray spectroscopy (EDX) to analyze the elemental distribution at the electrode/electrolyte interface. IGOR Pro (Wavemetrics) software was used for data analysis.

\section{Results and Discussion}

The phase purity of the mechanosynthesized $\mathrm{La}_{0.9} \mathrm{Ba}_{0.1} \mathrm{~F}_{2.9}$ sample was verified by XRPD. The diffractogram, which is depicted in Figure 1, is composed of broad reflections due to the small grain size obtained after the milling process. According to Scherrer's equation we estimate that the mean crystallite diameter is in the order of 10 to $20 \mathrm{~nm}$; a similar result has been reported recently for the same material [27]. XRPD reveals that the solid solution crystallizes with the tysonite structure of $\mathrm{LaF}_{3}$ (ICSD: 89523). Lattice constants, slightly deviating from that of Ba-free $\mathrm{LaF}_{3}$, point to successful incorporation of the $\mathrm{Ba}^{2+}$ ions. Conductivity spectroscopy revealed that, as expected for the electrolyte $\mathrm{La}_{0.9} \mathrm{Ba}_{0.1} \mathrm{~F}_{2.9}$, the ionic conductivity at a temperature of $200^{\circ} \mathrm{C}$ was $\sigma^{\prime}(v \rightarrow 0) \equiv \sigma_{\mathrm{DC}}=2.36 \times 10^{-4} \mathrm{~S} / \mathrm{cm}$. This value can be directly read off from the conductivity isotherms, which are shown in Figure 2 alongside with the Arrhenius plot of $\sigma_{\mathrm{DC}} T$ vs. 1000/T. For selected temperatures, viz. for 20,100 and $200{ }^{\circ} \mathrm{C}$ the data are also shown using the representation according to Nyquist [29]. The conductivity isotherms shown here perfectly agree with those published earlier by our group, see Breuer et al. [27]. For a general discussion and interpretation of conductivity data we refer to the literature [29-31].

To evaluate the compatibility of the electrolyte with a range of current collector materials, the various metals were applied on both sides of the cylindrical pellets by sputtering. As the reaction of interest is supposed to occur at the working electrode, we took into account that the current flow at the working electrode should, in principle, never be limited by the current flow passing through the reference/counter electrode. In classical liquid-based electrochemistry, this condition is achieved by using a counter electrode with a much larger surface than that of the working electrode. This condition is much more difficult to achieve in the solid state. However, here we investigated the influence of the size of the working electrode and varied it from 2.5, 4, 6 to $8 \mathrm{~mm}$; the latter diameter corresponds to the full size of the surface of the pellet.

Except for $\mathrm{Cu}$, all electrode materials were sputtered with success and did not show any direct reaction with the electrolyte. However, in the case of the $\mathrm{Cu}$ electrode we noticed a silver colored surface directly after the sputtering process. Irrespective of this change in color, we took a pellet with a working electrode of $2.5 \mathrm{~mm}$ in diameter, which was subjected to CV. CV measurements resulted in a noisy signal due to contact problems, as it is shown in Figure A2a. At a potential $E$ larger than $2 \mathrm{~V}$ we notice electrochemical reactions, at least at very low scan rates of $2 \mathrm{mV} / \mathrm{s}$. The corresponding maximum current amplitude is relatively small and turned out to be in the order of $0.6 \mu \mathrm{A}$ at $E=4 \mathrm{~V}$. Additionally, inspection by light microscopy revealed a diffuse region with coppery color between the actual electrode and pure $\mathrm{La}_{0.9} \mathrm{Ba}_{0.1} \mathrm{~F}_{2.9}$, see Figure A2b. 
a

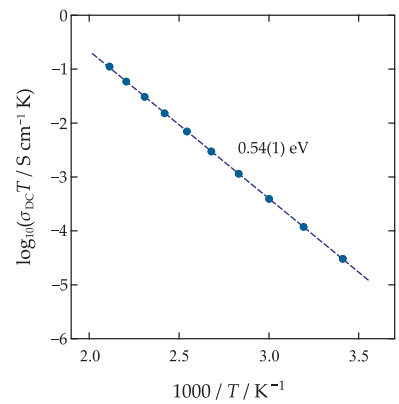

b

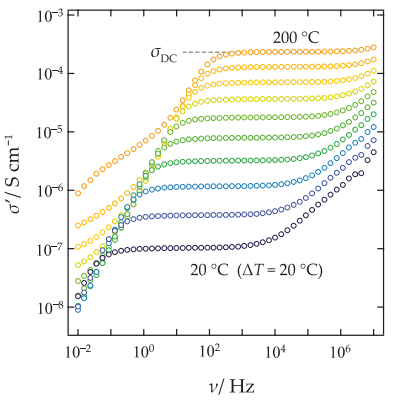

c

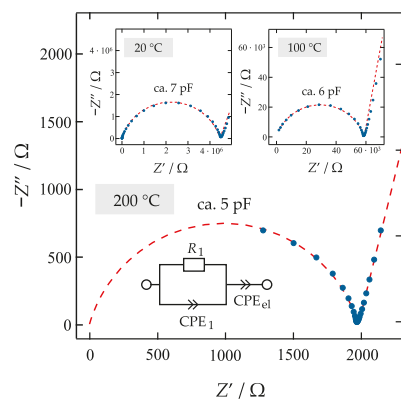

Figure 2. (a) Arrhenius Plot of the ionic conductivity $\sigma_{\mathrm{DC}}$ multiplied with absolute temperature $T$ vs. $1000 / T$ of nanocrystalline $\mathrm{La}_{0.9} \mathrm{Ba}_{0.1} \mathrm{~F}_{2.9}$ that was prepared by a mechanochemical approach. (b) Conductivity isotherms of $\mathrm{La}_{0.9} \mathrm{Ba}_{0.1} \mathrm{~F}_{2.9}$ starting from $20^{\circ} \mathrm{C}$ and ending at $200{ }^{\circ} \mathrm{C}$, which was the highest temperature where we measured conductivities. (c) Nyquist representation of the complex impedance data of $\mathrm{La}_{0.9} \mathrm{Ba}_{0.1} \mathrm{~F}_{2.9}$; the curve refers to a temperature of $200^{\circ} \mathrm{C}$ and shows the imaginary part of the complex impedance $-Z^{\prime \prime}$ plotted vs. the real part $Z^{\prime}$. The inset shows additionally the Nyquist representation at temperatures of $20^{\circ} \mathrm{C}$ and $100^{\circ} \mathrm{C}$. The spike at low frequencies represents electrode polarization effects originating from the ion-blocking electrodes used. The whole location curve was parameterized with the equivalent circuit shown in the inset. It consists of a resistor $R_{1}$ connected in parallel to a constant phase element (CPE); this $R_{1}-\mathrm{CPE}_{1}$ element represents the overall (bulk) semicircle and leads to an associated capacitance $C[32,33]$ of $\sim 5 \mathrm{pF}$, which is a typical value for electrical relaxation taking place in the interior regions of the grains [29]. Another CPE element, connected in series, was used to approximate electrode polarization.

Similar results were found for the Ag electrode. From visual inspection the electrode appeared to have not reacted with the electrolyte; $\mathrm{CV}$, however, points to irreversible changes, as is documented in Figure A2c. During cycling the electrode also suffered from contact issues and changed color from silvery to orange. Below $E=4 \mathrm{~V}$ the current amplitude did not exceed values above $5 \mu \mathrm{A}$; thus larger as in the case of the $\mathrm{Cu}$ electrode. Hence, we investigated the electrode and the surface of the electrolyte via light microscopy, SEM and EDX line scanning (see Figure 3). Changes in color at the $\mathrm{Ag} \mid \mathrm{La}_{0.9} \mathrm{Ba}_{0.1} \mathrm{~F}_{2.9}$ interface are clearly visible in Figure 3, which shows SEM images of the surface before (Figure 3a) and after cycling (Figure 3d). SEM images taken in SE mode, see (Figure 3b) and (Figure 3e), indicate that the original clear border between the electrode and the ternary fluoride $\mathrm{La}_{0.9} \mathrm{Ba}_{0.1} \mathrm{~F}_{2.9}$ became more diffuse. Presumably, migration of Ag is responsible for this observation. To prove this assumption EDX linescans across the interface (as indicated by the horizontal bars in (Figure 3b) and (Figure 3e)) were performed. The results from before (Figure 3c) and after CV (Figure 3f) indeed reveal a trend in Ag distribution. While the concentration of Ag on the reference surface falls away sharply at the $\mathrm{Ag} \mid \mathrm{La}_{0.9} \mathrm{Ba}_{0.1} \mathrm{~F}_{2.9}$ interface, after the $\mathrm{CV}$ measurements it does not. Therefore, we conclude that Ag migrates in the material, visibly over the surface during cycling. Ag migration leads to irreversible changes at this interface. 
a

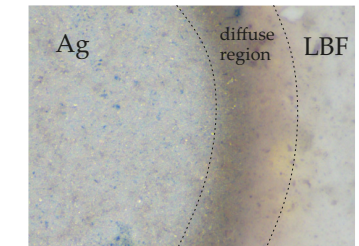

d

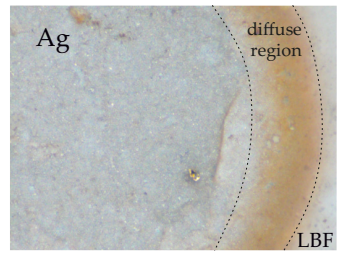

b

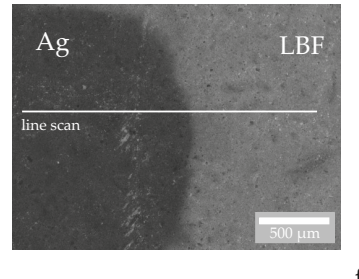

e

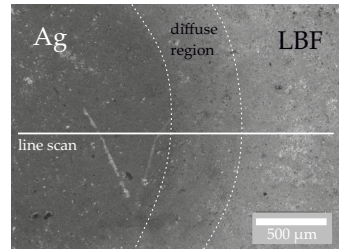

C

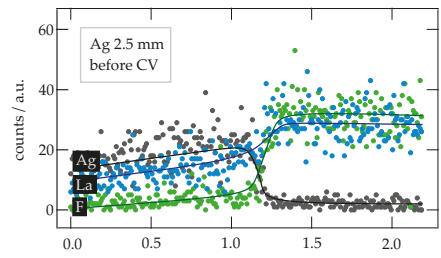

f

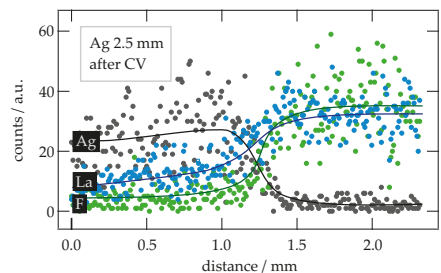

Figure 3. (a) Images acquired by digital light microscopy of a sample pellet with Ag as working electrode $(d=2.5 \mathrm{~mm}$ ) before the cyclic voltammetry $(\mathrm{CV})$ measurements have been carried out. (b) SEM image (secondary electron (SE) detector) of this pellet before CV. The horizontal line indicates the run of the energy dispersive X-ray spectroscopy (EDX) line scan. (c) EDX line scan across the surface of the pellet, as depicted in (b), for the elements F, Ag and La. The lines are only a guide for the eye. (d) Image obtained via digital light microscopy of a sample pellet with Ag working electrode after CV. (e) SEM image (SE detector) of the sample pellet with Ag as working electrode, the image was taken after the CV measurements. The horizontal line indicates the run of the (EDX) line scan. (f) EDX line scan across the surface of the pellet, as depicted in (b), for the elements F, Ag and La, respectively The lines are drawn to guide the eye.

In Figure 4a,b CVs of the symmetrical cell $\mathrm{Au}\left|\mathrm{La}_{0.9} \mathrm{Ba}_{0.1} \mathrm{~F}_{2.9}\right| \mathrm{Au}$, recorded in a voltage window of -1 to $4 \mathrm{~V}$ and scan rates ranging from $2 \mathrm{mV} / \mathrm{s}$ to $0.1 \mathrm{~V} / \mathrm{s}$, are shown. The corresponding images from light microscopy are depicted in Figure 5. In the cyclic voltamogram with the WE having a size of $2.5 \mathrm{~mm}$, see (a), distinct anodic and cathodic peaks are visible at a scan rate of $2 \mathrm{mV} / \mathrm{s}$. Two anodic peaks (positive direction of scanning) are clearly visible and also two less apparent cathodic peaks show up in the negative direction of scanning. The main anodic peak at $E=3 \mathrm{~V}$, whose counterpart is visible at a faster scan rate of $10 \mathrm{mV} / \mathrm{s}$ at ca. $E=0.6 \mathrm{~V}$. Most likely, these peaks reveal the formation (and decomposition) of $\mathrm{AuF}_{3}$ at the $\mathrm{Au} \mid \mathrm{La}_{0.9} \mathrm{Ba}_{0.1} \mathrm{~F}_{2.9}$ interfaces. With increasing cycling, i.e., with increasing Au interdiffusion (see below), the shape of the CVs changes. At scan rates of 50 and $100 \mathrm{mV} / \mathrm{s}$ anodic and cathodic peaks at lower voltages appear indicating the irreversibly change of the interface on its electrochemical behavior. The maximum current amplitude that is reached at a scan rate of $100 \mathrm{mV} / \mathrm{s}$ is approximately $8 \mu \mathrm{A}$ at ca. $E=2.1 \mathrm{~V}$.

The first cycle of a pellet with a diameter of the working electrode of $8 \mathrm{~mm}$ is depicted in Figure 4f. When compared with the CV recorded using a disc with $d=2.5 \mathrm{~mm}$, similarities can be seen. Again, two peaks in the positive direction occur. In contrast, no cathodic peaks are visible in this case. This trend continues when going to higher scan rates, see Figure 4e,f, as the curves do not reveal any peaks at $E$ lower than $2 \mathrm{~V}$ but current responses as high as $3 \mu \mathrm{A}$ when $E$ reaches $3.5 \mathrm{~V}$. CV's for WE diameters of 4 and $6 \mathrm{~mm}$ are shown for the sake of brevity in the Appendix A, see Figure A3a,d, as no major differences compared to a WE diameter of $2.5 \mathrm{~mm}$ are recognizable. If we take for example a look on Figure 4, where Au is used as electrode material, a small scan rate results in a small current for a WE diameter of $2.5 \mathrm{~mm}$ and the current is increasing with the scan rate. The opposite trend is, however, visible for a WE diameter of $8 \mathrm{~mm}$; the corresponding current is decreasing with the scan rate. The difference in behavior between the $2.5 \mathrm{~mm} \mathrm{WE}$ and the $8 \mathrm{~mm} \mathrm{WE}$ can be traced back to the influence of the $\mathrm{CE}$. As mentioned in the experimental section, the $\mathrm{CE}$ electrode is covering one entire 
side of the pellet ( $8 \mathrm{~mm}$ in diameter) and only the diameter of the WE is varied. For a $2.5 \mathrm{~mm} \mathrm{WE}$ with an $8 \mathrm{~mm} \mathrm{CE}$ the ratio between the surface areas is higher than 1:10. A large surface area of the $\mathrm{CE}$ with respect to the WE is necessary whenever a 2-electrode cell configurations is used to ensure that the current through the cell is limited by the WE, then the influence of the CE would be small. This is, however, not the case when $8 \mathrm{~mm}$ working electrodes are used, the WE:CE surface area ratio is 1:1. Thus, in this case, the CE would show a significant influence on the current response of the cell, as seen in Figure 4.

a
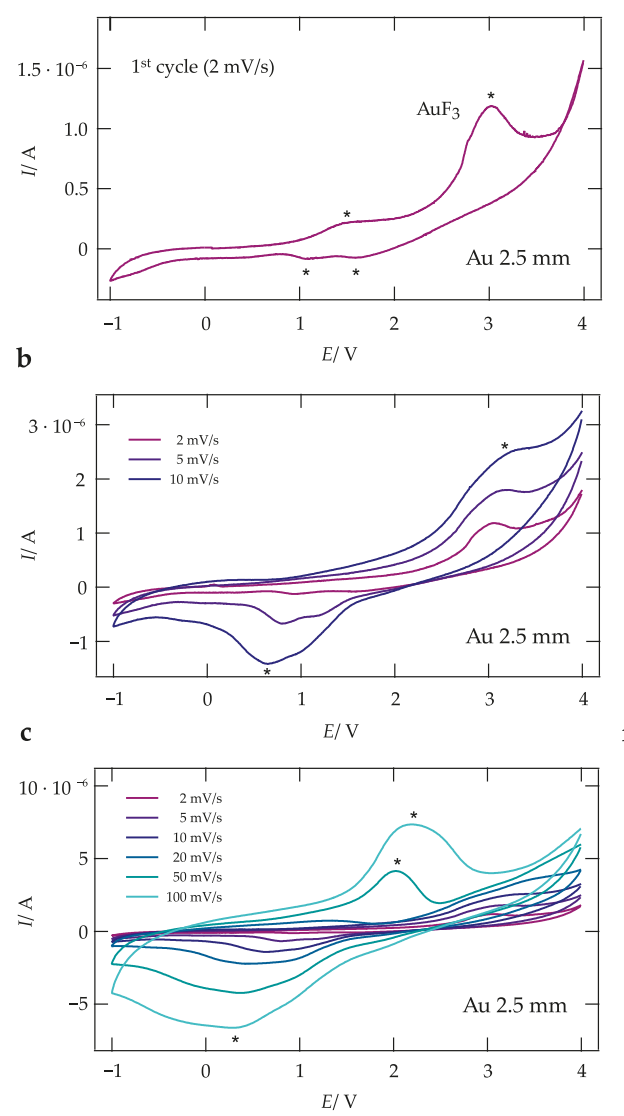

d
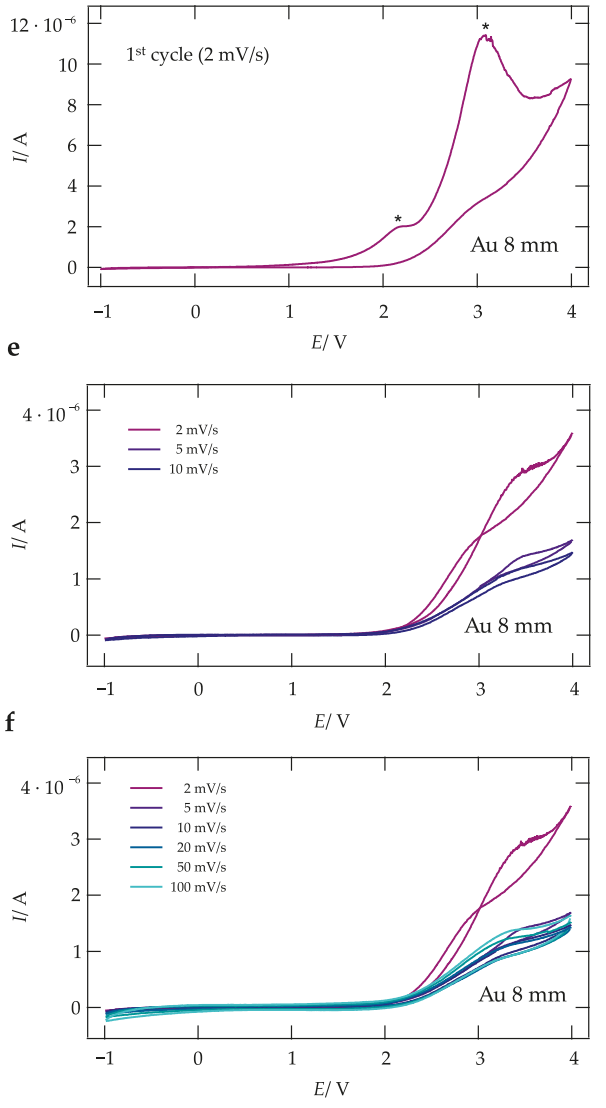

Figure 4. Cyclic voltamogram of cells with $\mathrm{La}_{0.9} \mathrm{Ba}_{0.1} \mathrm{~F}_{2.9}$ as solid electrolyte and Au working as electrode metal. The CVs were recorded at a temperature of $200{ }^{\circ} \mathrm{C}$, with scan rates ranging from $2 \mathrm{mV} / \mathrm{s}$ up to $0.1 \mathrm{~V} / \mathrm{s}$; working electrode diameters are $2.5 \mathrm{~mm}(\mathbf{a}-\mathbf{c})$ and $8 \mathrm{~mm}(\mathbf{d}-\mathbf{f})$. The current response of the first cycles are shown in $(\mathbf{a}, \mathbf{d})$.

Similarly to our observations with $\mathrm{Ag}$ as electrode, investigations of the $\mathrm{Au} \mid \mathrm{La}_{0.9} \mathrm{Ba}_{0.1} \mathrm{~F}_{2.9}$ interface by light microscopy revealed a color change at the border of the two phases (see Figure 5a,d). The change is seen after the CV measurements have been carried out, hence during cycling Au interdiffuses into the electrolyte phase. This observation is independent of the diameter of the working electrode used. Au interdiffusion is also supported by SEM images, using either the SE or the BSE detector. The originally clear border between the materials (Figure 5b) has become blurred (Figure 5e). EDX line scans across the border carried before and after cycling (Figure $5 c, f$ ) underpin our conclusion of Au migration as the distribution function of the elements changes from a step-like shape to a 
sigmoid-like one. In particular, also the F concentration profile (and the La profile as well) smears out, which indicates the formation of binary $\mathrm{Au}-\mathrm{F}$ compounds, possibly tysonite-type $\mathrm{La}_{1-x} \mathrm{Au}_{x} \mathrm{~F}_{3}$.

a

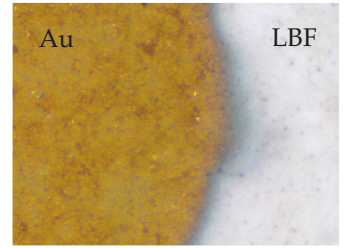

d

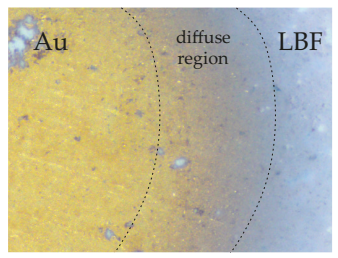

b

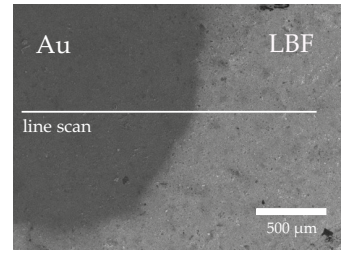

e

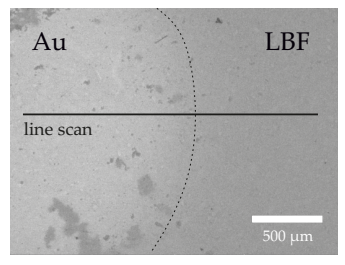

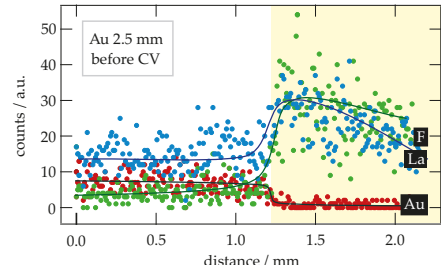

f

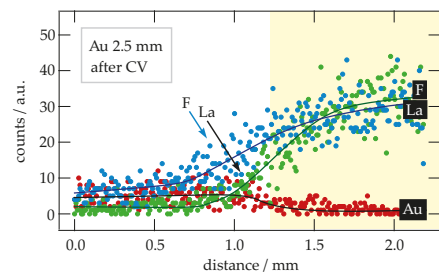

Figure 5. (a) Digital light microscopy image of a sample pellet with Au working electrode $(d=2.5 \mathrm{~mm})$ before the CV measurements were carried out. (b) SEM image (SE detector) of the sample pellet with the Au working electrode before $\mathrm{CV}$. The horizontal line indicates the run of the EDX line scan. (c) EDX line scan across the surface of the pellet, as depicted in (b), for the elements F, Au and La. The lines are only a guide to the eye. (d) Image taken by digital light microscopy of the cell after CV. (e) SEM image (backscattered electron (BSE) detector) of the cell with Au electrodes after the CV measurements. The horizontal line indicates the run of the EDX line scan. (f) EDX line scan across the surface of the pellet, as depicted in (e), for the elements F, Au and La. The lines serve as a guide to the eye.

The corresponding CVs of the sandwich cells with $\mathrm{Ni}$ as electrode material are shown in Figure 6. As evidenced by the slightly noisy signal, the measurements suffer a bit from contact issues.

The CV measurements on a cell with a $2.5 \mathrm{~mm}$ thick WE do not reveal any distinct current peaks. As in the case of the cells with Au electrodes, the diameter of the WE, see the curves obtained with cells equipped with a WE having a diameter of $8 \mathrm{~mm}$, yields somewhat different results at high scan rates; for instance, we see that at a scan rate of $0.1 \mathrm{~V} / \mathrm{s}$ a prominent current peak appears at $0.2 \mathrm{~V}$, which is, however, absent for WEs with a diameter of only $2.5 \mathrm{~mm}$. This peak is also seen at lower scan rates. Correspondingly, peaks with positive current and low intensity show up at ca. $3.4 \mathrm{~V}$, at least at lower scan rates. The latter peak dominates the current response also during the first cycle (see Figure $6 \mathrm{~d}, \mathrm{f})$. It has shoulders at $2.5 \mathrm{~V}$ and $1.2 \mathrm{~V}$, respectively. Note that the current amplitude turned out to be much larger for the very first cycle, indicating irreversible reduction/oxidation processes taking place at the $\mathrm{Ni} / \mathrm{La}_{0.9} \mathrm{Ba}_{0.1} \mathrm{~F}_{2.9}$ interface. The formation of $\mathrm{NiF}_{2}$ passive films on the surface of $\mathrm{Ni}$ is known and it seems that such a layer is also forming here. Cells with WE having diameters of 4 and $6 \mathrm{~mm}$, respectively, result in basically identical CVs as seen for the cells with a $2 \mathrm{~mm} \mathrm{WE}$. The corresponding responses are shown in Figure A3b,e.

Finally, in Figure 7, CVs of $\mathrm{Pt}^{\mid} \mathrm{La}_{0.9} \mathrm{Ba}_{0.1} \mathrm{~F}_{2.9} \mid \mathrm{Pt}$ cells with a WE having a diameter of $2.5 \mathrm{~mm}$ (Figure $7 \mathrm{a}$ ) or $8 \mathrm{~mm}$ (Figure $7 \mathrm{~b}$ ) are shown.

Again, scan rates were varied to range from $2 \mathrm{mV} / \mathrm{s}$ to $0.1 \mathrm{~V} / \mathrm{s}$. For cells with a WE having a diameter of $8 \mathrm{~mm}$ no distinct oxidation/reduction peaks are visible. This observation is in contrast to the situation of the cell with a $2.5 \mathrm{~mm}$ WE. Two shallow peaks with positive currents and at least one in the direction of negative current are seen. For the sake of completeness, the results from CV on cells with WE having diameters of $4 \mathrm{~mm}$ and $6 \mathrm{~mm}$ are shown in Figure A3c,f. 
a

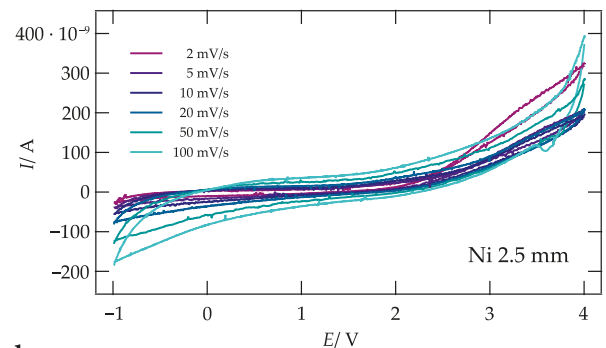

b

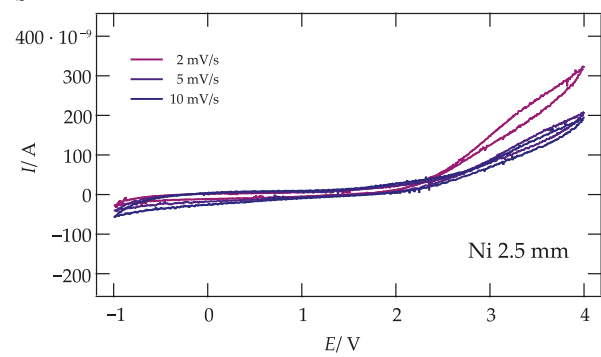

c

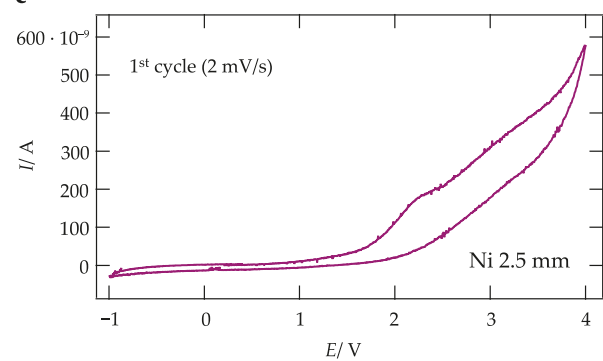

d

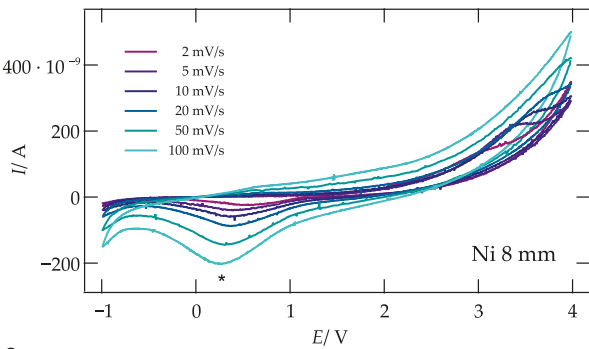

e

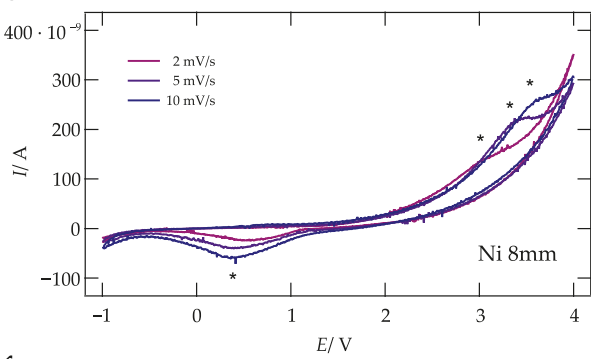

f

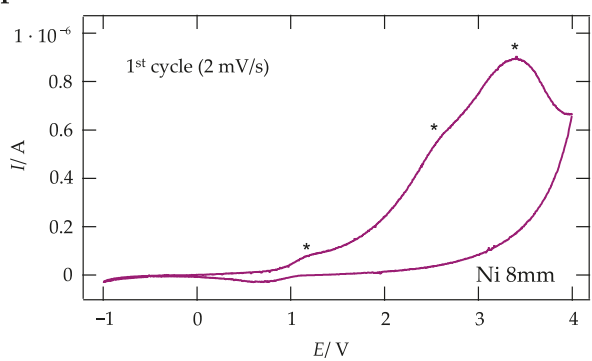

Figure 6. CVs of symmetrical cells with $\mathrm{La}_{0.9} \mathrm{Ba}_{0.1} \mathrm{~F}_{2.9}$ as electrolyte and $\mathrm{Ni}$ as electrode material. CVs were recorded at a temperature of $200^{\circ} \mathrm{C}$; scan rates ranged from $2 \mathrm{mV} / \mathrm{s}$ to to $0.1 \mathrm{~V} / \mathrm{s}$. The diameter of the working electrodes was either $2.5 \mathrm{~mm}(\mathbf{a}-\mathbf{c})$ or $8 \mathrm{~mm}(\mathbf{d}-\mathbf{f})$.

a

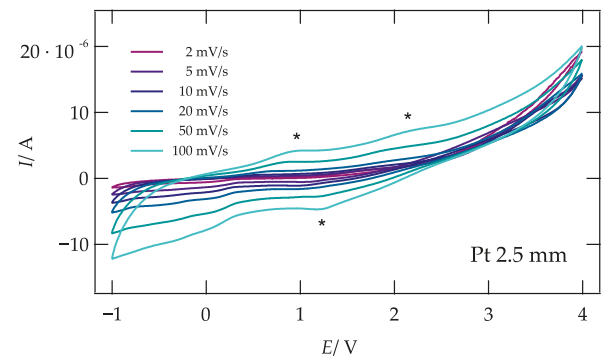

b

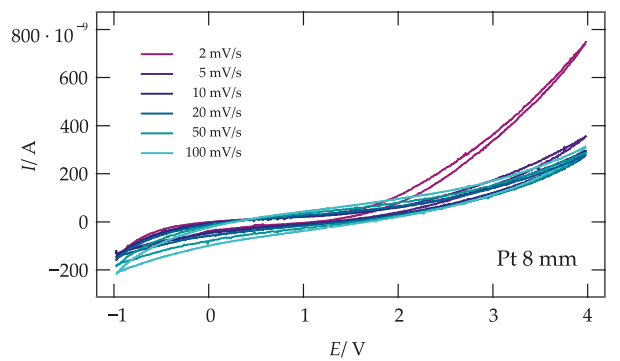

Figure 7. CVs of a $\mathrm{La}_{0.9} \mathrm{Ba}_{0.1} \mathrm{~F}_{2.9}$ cell with two Pt electrodes. The diameter of the WE was either $2.5 \mathrm{~mm}$ (a) or (b) $8 \mathrm{~mm}$. CVs were recorded at scan rates ranging from $0.002 \mathrm{~V} / \mathrm{s}$ to $0.1 \mathrm{~V} / \mathrm{s}$ at $200{ }^{\circ} \mathrm{C}$.

\section{Conclusions and Outlook}

We tested the electrochemical stability of several metal electrodes that might work as current collector materials in the first generation of fluorine-ion batteries. We see that most metals tested are 
not in stable contact with the studied nanocrystalline ionic conductor $\mathrm{La}_{0.9} \mathrm{Ba}_{0.1} \mathrm{~F}_{2.9}$. While $\mathrm{Cu}$ reacts on contact, also Ag, Au, Pt and Ni undergo complex electrochemical reactions showing instabilities at the interface between the metal current collector and the ceramic electrolyte. In addition, we also see a significant migration of the metals. This diffusion processes point toward the necessity of developing and using diffusion barrier layers in prospective fluoride-ion systems. While all the systems undergo degradation upon subsequent cycles in CV experiments, we also see that $\mathrm{Ni}$ is very likely the most efficient metal that is able to form a passivating layer at the metal l electrolyte interface.

Author Contributions: Conceptualization, I.H. and H.M.R.W.; methodology, I.H.; formal analysis, M.G.; investigation, M.G. and V.P.; data curation, M.G.; writing—original draft preparation, M.G.; writing—review and editing, H.M.R.W. and I.H.; visualization, M.G.; supervision, H.M.R.W.; project administration, H.M.R.W. and I.H.; funding acquisition, H.M.R.W.

Funding: This research received funding by the FFG K-project 'safe battery'.

Acknowledgments: We thank our colleagues at the ICTM (TU Graz) for helpful discussions.

Conflicts of Interest: The authors declare no conflict of interest.

\section{Abbreviations}

The following abbreviations are used in this manuscript:

FIB Fluorine Ion Battery

CV Cyclic Voltammetry

EIS Electrochemical Impedance Spectroscopy

SEM Scanning Electron Microscopy

CE Counter Electrode

WE Working Electrode

EDX Energy-Dispersive X-ray Spectroscopy

SE Secondary Electrons

BSE Backscattered Electrons

\section{Appendix A}

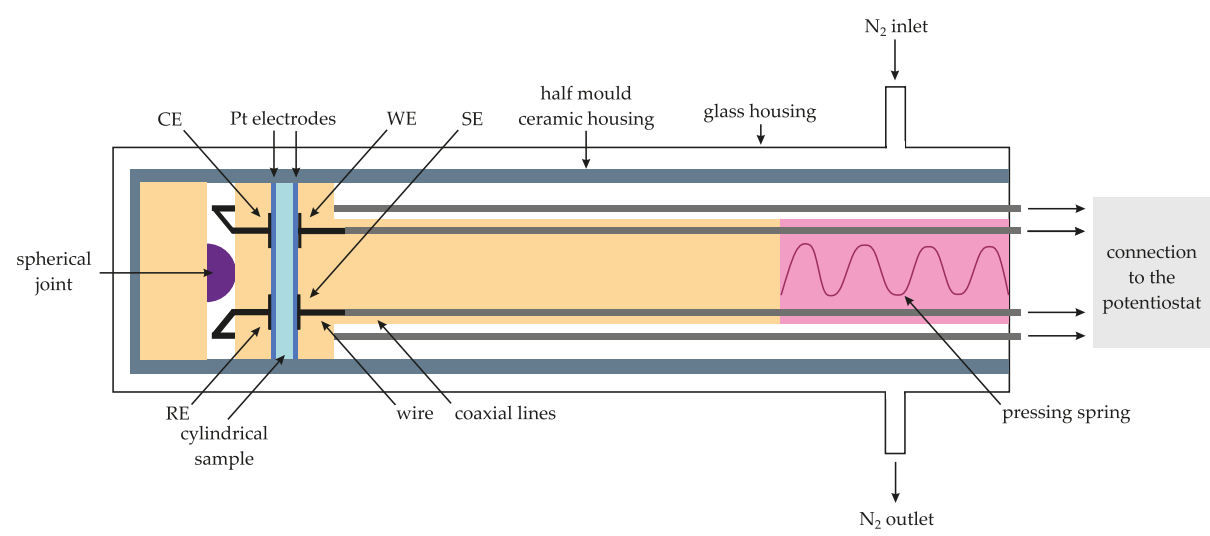

Figure A1. Scematic drawing of the cell set-up for conducting solid state Cyclic Voltammetry in a two-electrode set-up. 
a

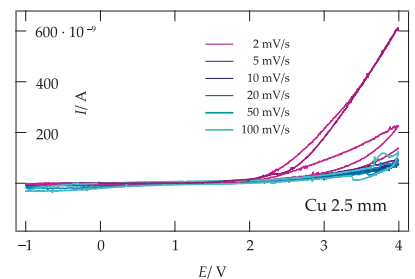

b

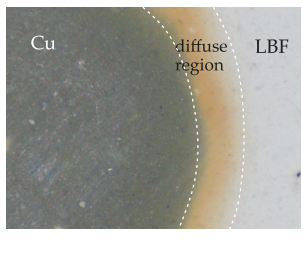

c

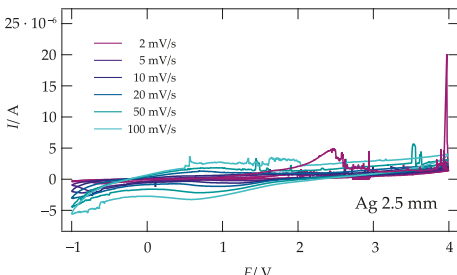

Figure A2. $\mathrm{CV}$ of a $\mathrm{La}_{0.9} \mathrm{Ba}_{0.1} \mathrm{~F}_{2.9}$ cell with $\mathrm{Cu}(\mathrm{a})$ and $\mathrm{Ag}(\mathrm{c})$ as electrode material $(d=2.5 \mathrm{~mm}$, $0.002 \mathrm{~V} / \mathrm{s}$ to $\left.0.1 \mathrm{~V} / \mathrm{s}, 200{ }^{\circ} \mathrm{C}\right)$. (b) Light microscopy image of a Cu cell $(d=2.5 \mathrm{~mm})$ after $\mathrm{CV}$. At the $\mathrm{Cu}$ l electrolyte interface a diffusive region with orange color appears.

$\mathbf{a}$

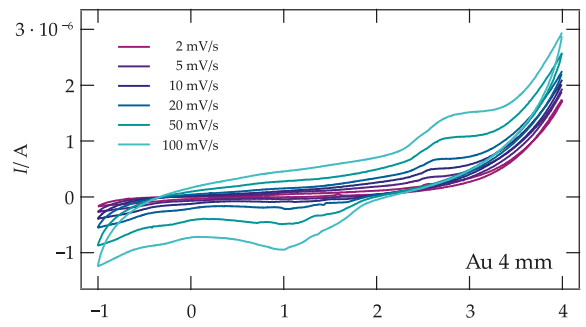

b

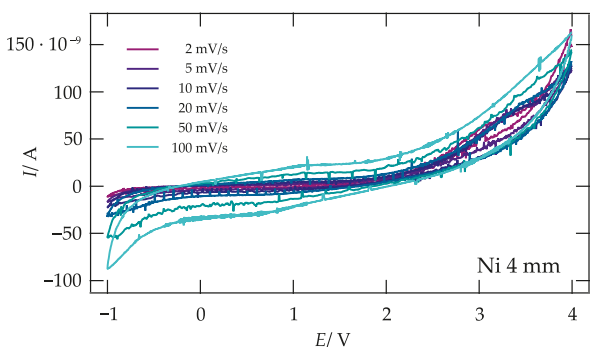

C

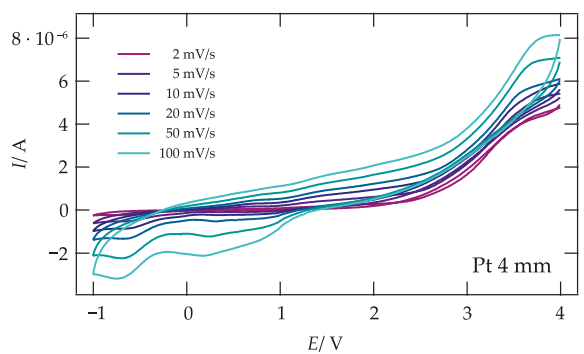

d

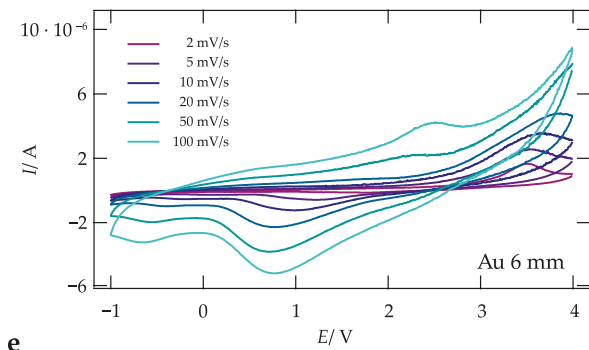

e

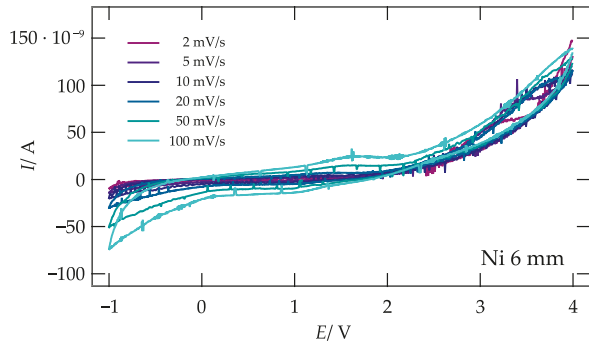

f

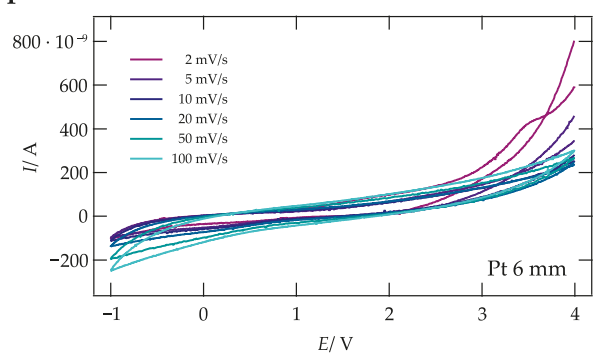

Figure A3. CVs for symmetric $\mathrm{La}_{0.9} \mathrm{Ba}_{0.1} \mathrm{~F}_{2.9}$ cells $\left(0.002 \mathrm{~V} / \mathrm{s}\right.$ to $\left.0.1 \mathrm{~V} / \mathrm{s}, 200{ }^{\circ} \mathrm{C}\right)$ with Au electrodes (WE $d=4 \mathrm{~mm}$ and $d=6 \mathrm{~mm}$ see (a,d)), Ni electrodes (WE $d=4 \mathrm{~mm}$ and $d=6 \mathrm{~mm}$ see $(\mathbf{e}, \mathbf{b})$ ), and Pt electrodes (WE $d=4 \mathrm{~mm}$ and $d=6 \mathrm{~mm}$ see $(\mathbf{c}, \mathbf{f})$ ).

\section{References}

1. Turcheniuk, K.; Bondarev, D.; Singhal, V.; Yushin, G. Ten Years Left to Redesign Lithium-Ion Batteries. Nature 2018, 559, 467-470. [CrossRef] [PubMed]

2. Vaalma, C.; Buchholz, D.; Weil, M.; Passerini, S. A Cost and Resource Analysis of Sodium-Ion Batteries. Nat. Rev. Chem. 2018, 3, 18013. [CrossRef] 
3. Faraday, M. Experimental Researches in Electricity, Art. 1339; Taylor and Francis: London, UK, 1893.

4. O'Keeffe, M. Phase Transitions and Translational Freedom in Solid Electrolytes. In Superionic Conductors; Springer: Boston, MA, USA, 1976; pp. 101-114.

5. Funke, K. Solid State Ionics: From Michael Faraday to green energy-The European dimension. Sci. Technol. Adv. Mater. 2013, 14, 043502. [CrossRef]

6. Takahashi, T. High Conductivity Solid Ionic Conductors: The Past and the Present. In High Conductivity Solid Ionic Conductors; World Scientific: Singapore, 1989; pp. 1-16.

7. Tubandt, C. Über Elektrizitätsleitung in festen kristallisierten Verbindungen. Zweite Mitteilung. Überführung und Wanderung der Ionen in einheitlichen festen Elektrolyten. Z. Anorg. Allg. Chem. 1921, 115, 105-126. [CrossRef]

8. Baukal, W. Ger. Offen. Galvanische Zelle mit dotiertem Calciumfluorid als Festelektrolyt. Germany Patent GWXXBX DE 2017128, 7 April 1977.

9. Kennedy, J.H.; Hunter, J.C. Thin-Film Galvanic Cell $\mathrm{Pb} / \mathrm{PbF}_{2} / \mathrm{PbF}_{2}, \mathrm{CuF}_{2} / \mathrm{Cu}$. J. Electrochem. Soc. 1976, 123, 10-14. [CrossRef]

10. Schoonman, J. A Solid-State Galvanic Cell with Fluoride-Conducting Electrolytes. J. Electrochem. Soc. 1976, 123, 1772-1775. [CrossRef]

11. Schoonman, J.; Wapenaar, K.; Overluizen, G.; Dirksen, G. Fluoride-Conducting Solid Electrolytes in Galvanic Cells. J. Electrochem. Soc. 1979, 126, 709-713. [CrossRef]

12. Schoonman, J.; Wolfert, A. Solid-State Galvanic Cells with Fast Fluoride Conducting Electrolytes. Solid State Ion. 1981, 3-4, 373-379. [CrossRef]

13. Anji Reddy, M.; Fichtner, M. Batteries based on Fluoride Shuttle. J. Mater. Chem. 2011, 21, 17059-17062. [CrossRef]

14. Reddy, M.A.; Fichtner, M. Fluoride Cathodes for Secondary Batteries. In Advanced Fluoride-Based Materials for Energy Conversion; Nakajima, T.; Groult, H., Eds.; Elsevier: Amsterdam, The Netherlands, 2015; pp. 51-76.

15. Thieu, D.T.; Fawey, M.H.; Bhatia, H.; Diemant, T.; Chakravadhanula, V.S.K.; Behm, R.J.; Kübel, C.; Fichtner, M. $\mathrm{CuF}_{2}$ as Reversible Cathode for Fluoride Ion Batteries. Adv. Fuct. Mater. 2017, 27, 1701051. [CrossRef]

16. Bhatia, H.; Thieu, D.T.; Pohl, A.H.; Chakravadhanula, V.S.K.; Fawey, M.H.; Kübel, C.; Fichtner, M. Conductivity Optimization of Tysonite-type $\mathrm{La}_{1-x} \mathrm{Ba}_{x} \mathrm{~F}_{3-x}$ Solid Electrolytes for Advanced Fluoride Ion Battery. ACS Appl. Mater. Interfaces 2017, 9, 23707-23715. [CrossRef] [PubMed]

17. Wapenaar, K.; Koesveld, J.V.; Schoonman, J. Conductivity Enhancement in Fluorite-Structured $\mathrm{Ba}_{1-x} \mathrm{La}_{x} \mathrm{~F}_{2+x}$ Solid Solutions. Solid State Ion. 1981, 2, 145-154. [CrossRef]

18. Gschwind, F.; Zao-Karger, Z.; Fichtner, M. A Fluoride-Doped PEG Matrix as an Electrolyte for Anion Transportation in a Room-Temperature Fluoride Ion Battery. J. Mater. Chem. A 2014, 2, 1214-1218. [CrossRef]

19. Davis, V.K.; Bates, C.M.; Omichi, K.; Savoie, B.M.; Momčilović, N.; Xu, Q.; Wolf, W.J.; Webb, M.A.; Billings, K.J.; Chou, N.H.; et al. Room-Temperature Cycling of Metal Fluoride Electrodes: Liquid Electrolytes for High-Energy Fluoride Ion Cells. Science 2018, 362, 1144-1148. [CrossRef] [PubMed]

20. Rongeat, C.; Anji Reddy, M.; Diemant, T.; Behm, R.J.; Fichtner, M. Development of New Anode Composite Materials for Fluoride Ion Batteries. J. Mater. Chem. A 2014, 2, 20861-20872. [CrossRef]

21. Zhang, L.; Reddy, M.A.; Fichtner, M. Electrochemical Performance of All-Solid-State Fluoride-Ion Batteries based on Thin-Film Electrolyte using Alternative Conductive Additives and Anodes. J. Solid State Electrochem. 2018, 22, 997-1006. [CrossRef]

22. Nowroozi, M.A.; Ivlev, S.; Rohrer, J.; Clemens, $\mathrm{O}$. $\mathrm{La}_{2} \mathrm{CoO}_{4}$ : A New Intercalation based Cathode Material for Fluoride Ion Batteries with Improved Cycling Stability. J. Mater. Chem. A 2018, 6, 4658-4669. [CrossRef]

23. Mohammad, I.; Chable, J.; Witter, R.; Fichtner, M.; Reddy, M.A. Synthesis of Fast Fluoride-Ion-Conductive Fluorite-Type $\mathrm{Ba}_{1-x} \mathrm{Sb}_{x} \mathrm{~F}_{2+x}(0.1<x<0.4)$ : A Potential Solid Electrolyte for Fluoride-Ion Batteries. ACS Appl. Mater. Interfaces 2018, 10, 17249-17256.

24. Dieudonne, B.; Chable, J.; Body, M.; Legein, C.; Durand, E.; Mauvy, F.; Fourcade, S.; Leblanc, M.; Maisonneuve, V.; Demourgues, A. The Key Role of the Composition and Structural Features in Fluoride Ion Conductivity in Tysonite $\mathrm{Ce}_{1-x} \mathrm{Sr}_{x} \mathrm{~F}_{3-x}$ Solid Solutions. Dalton Trans. 2017, 46, 3761-3769. [CrossRef]

25. Dieudonne, B.; Chable, J.; Mauvy, F.; Fourcade, S.; Durand, E.; Lebraud, E.; Leblanc, M.; Legein, C.; Body, M.; Maisonneuve, V.; et al. Exploring the $\mathrm{Sm}_{1-x} \mathrm{Ca}_{x} \mathrm{~F}_{3-x}$ Tysonite Solid Solution as a Solid-State Electrolyte: Relationships between Structural Features and Fast Ionic Conductivity. J. Phys. Chem. C 2015, 119, 25170-25179. [CrossRef] 
26. Raccichini, R.; Amores, M.; Hinds, G. Critical Review of the Use of Reference Electrodes in Li-Ion Batteries: A Diagnostic Perspective. Batteries 2019, 5, 12. [CrossRef]

27. Breuer, S.; Gombotz, M.; Pregartner, V.; Hanzu, I.; Wilkening, M. Heterogeneous F Anion Transport, Local Dynamics and Electrochemical Stability of Nanocrystalline $\mathrm{La}_{1-x} \mathrm{Ba}_{x} \mathrm{~F}_{3-x}$. Energy Storage Mater. 2019, 16, 481-490. [CrossRef]

28. Setup of The Impedance Measuring Cell (Novocontrol). Available online: https:/ /www.novocontrol.de/ brochures/BDS1200.pdf (accessed on 21 October 2019).

29. Irvine, J.T.S.; Sinclair, D.C.; West, A.R. Electroceramics: Characterization by Impedance Spectroscopy. Adv. Mater. 1990, 2, 132-138. [CrossRef]

30. Gombotz, M.; Lunghammer, S.; Breuer, S.; Hanzu, I.; Preishuber-Pflügl, F.; Wilkening, H.M.R. Spatial Confinement-Rapid 2D F ${ }^{-}$Diffusion in Micro- and Nanocrystalline $\mathrm{RbSn}_{2} \mathrm{~F}_{5}$. Phys. Chem. Chem. Phys. 2019, 21, 1872-1883. [CrossRef]

31. Preishuber-Pflügl, F.; Bottke, P.; Pregartner, V.; Bitschnau, B.; Wilkening, M. Correlated Fluorine Diffusion and Ionic conduction in the Nanocrystalline $\mathrm{F}^{-}$Solid Electrolyte $\mathrm{Ba}_{0.6} \mathrm{La}_{0.4} \mathrm{~F}_{2.4}-{ }^{19} \mathrm{~F} \mathrm{~T}_{1(\rho)}$ NMR Relaxation vs. Conductivity Measurements. Phys. Chem. Chem. Phys. 2014, 16, 9580-9590. [CrossRef]

32. Narayanan, S.; Epp, V.; Wilkening, M.; Thangadurai, V. Macroscopic and Microscopic $\mathrm{Li}^{+}$Transport Parameters in Cubic Garnet-Type " $\mathrm{Li}_{6.5} \mathrm{La}_{2.5} \mathrm{Ba}_{0.5} \mathrm{ZrTaO}_{12}$ " as Probed by Impedance Spectroscopy and NMR. RSC Adv. 2012, 2, 2553-2561. [CrossRef]

33. Lunghammer, S.; Ma, Q.; Rettenwander, D.; Hanzu, I.; Tietz, F.; Wilkening, H. Bulk and Grain-Boundary Ionic Conductivity in Sodium Zirconophosphosilicate $\mathrm{Na}_{3} \mathrm{Zr}_{2}\left(\mathrm{SiO}_{4}\right)_{2} \mathrm{PO}_{4}$ (NASICON). Chem. Phys. Lett. 2018, 701, 147-150. [CrossRef]

(C) 2019 by the authors. Licensee MDPI, Basel, Switzerland. This article is an open access article distributed under the terms and conditions of the Creative Commons Attribution (CC BY) license (http:/ / creativecommons.org/licenses/by/4.0/). 

Article

\title{
Activated Carbons from Thermoplastic Precursors and Their Energy Storage Applications
}

\author{
Hye-Min Lee ${ }^{1,2}$, Kwan-Woo Kim ${ }^{1,3}$, Young-Kwon Park ${ }^{4}$, Kay-Hyeok An ${ }^{5, *}$, Soo-Jin Park ${ }^{2, *}$ and \\ Byung-Joo Kim ${ }^{1, *}$ \\ 1 Research Center for Carbon Convergence Materials, Korea Institute of Carbon Convergence Technology, \\ Jeonju 54852, Korea; hmlee2014@hanmail.net (H.-M.L.); 01090063344@hanmail.net (K.-W.K.) \\ 2 Department of Chemistry, Inha University, Incheon 22212, Korea \\ 3 Department of Organic Materials \& Fiber Engineering, Chonbuk National University, Jeonju 54896, Korea \\ 4 School of Environmental Engineering, University of Seoul, Seoul 02504, Korea; catalica@uos.ac.kr \\ 5 Department of Nano \& Advanced Materials Engineering, Jeonju University, Jeonju 55069, Korea \\ * Correspondence: khandragon@jj.ac.kr (K.-H.A.); sjpark@inha.ac.kr (S.-J.P.); kimbj2015@gmail.com (B.-J.K.); \\ Tel.: +82-63-219-3710 (B.-J.K.)
}

Received: 27 March 2019; Accepted: 15 June 2019; Published: 19 June 2019

\begin{abstract}
In this study, low-density polyethylene (LDPE)-derived activated carbons (PE-AC) were prepared as electrode materials for an electric double-layer capacitor (EDLC) by techniques of cross-linking, carbonization, and subsequent activation under various conditions. The surface morphologies and structural characteristics of the PE-AC were observed by field-emission scanning electron microscope, Cs-corrected field-emission transmission electron microscope, and X-ray diffraction analysis, respectively. The nitrogen adsorption isotherm-desorption characteristics were confirmed by Brunauer-Emmett-Teller, nonlocal density functional theory, and Barrett-Joyner-Halenda equations at $77 \mathrm{~K}$. The results showed that the specific surface area and total pore volume of the activated samples increased with increasing the activation time. The specific surface area, the total pore volume, and mesopore volume of the PE-AC were found to be increased finally to $1600 \mathrm{~m}^{2} / \mathrm{g}, 0.86 \mathrm{~cm}^{3} / \mathrm{g}$, and $0.3 \mathrm{~cm}^{3} / \mathrm{g}$, respectively. The PE-AC also exhibited a high mesopore volume ratio of $35 \%$. This mesopore-rich characteristic of the activated carbon from the LDPE is considered to be originated from the cross-linking density and crystallinity of precursor polymer. The high specific surface area and mesopore volume of the PE-AC led to their excellent performance as EDLC electrodes, including a specific capacitance of $112 \mathrm{~F} / \mathrm{g}$.
\end{abstract}

Keywords: activated carbon; steam activation; low-density polyethylene; electric double layer capacitor

\section{Introduction}

Electric double-layer capacitors (EDLC) are reported to have better performance than secondary batteries in terms of power density ( $>4000 \mathrm{~W} / \mathrm{kg}$ ) and cycle stability ( $>100 \mathrm{k}$ cycles), but have lower energy density ( 1 to $5 \mathrm{Wh} / \mathrm{kg}$ ) [1-3]. As a result, many recent studies investigating EDLC have focused on increasing the energy density while maintaining their other advantages.

The critical factor for storing energy in EDLC is the physical electrostatic adsorption of electrolyte ions at the interface between the electrodes and the electrolyte $[4,5]$. Therefore, the ideal electrode materials for EDLC require a high specific surface area, optimal pore size distribution, and electrical stability for the fast transport of electrolyte ions, as well as high electrical conductivity for good electron movement $[1,4,5]$. Since the energy density of EDLC is proportional to the specific surface area of the active materials in the electrodes, many researchers have focused on developing activated carbon materials which can offer both high specific surface area and excellent electrical conductivity $[1,5]$. 
Nanocarbon materials such as carbon nanotubes and graphenes have high electrical conductivity, but they have the moderate specific surface area (under $300 \mathrm{~m}^{2} / \mathrm{g}$ ) and are expensive and even low-density, resulting in low capacitance per unit volume $[1,6]$. Although activated carbons have specifically lower electrical conductivity than nanocarbons, they are the most widely used active materials for EDLC due to their excellent high specific surface area (compared to graphene $[1,6]$ and carbon nanotube $[1,7,8]$ ), energy density, and price competitiveness [5,9].

Activated carbons (AC) can be produced in various ways, including the template method [10], a self-activation method [11,12], and physical/chemical activation methods [13-24]. The template method can easily control the pore structure (pore size and volume) of the resulting carbons, but it has a high process cost and low productivity. The self-activation method is a very simple process, but the specific surface area of the prepared AC is very low [11-15]. In commercial applications, AC is often produced by a physical activation method using crystallite oxidation and a chemical activation method using a dehydration reaction [7]. The chemical activation method can form more uniform pores and higher specific surface area with higher activation yields than the physical activation [14]. This is why many commercial AC are prepared using chemical activation methods [7]. However, despite the novel merits of chemical activation for the production of $\mathrm{AC}$, a physical activation method may be more attractive for the mass production of AC for EDLC, because it offers a significantly lower price than the AC produced by chemical methods.

Commercial EDLC often uses organic electrolytes because of their high voltage characteristics and stability. Storing the ions of the organic electrolytes requires the AC electrodes to have pore diameters of $0.68 \mathrm{~nm}$ or greater [25-27]. Among the various physical activation methods, two kinds of activation agents-steam $\left(\mathrm{H}_{2} \mathrm{O}\right)$ and carbon dioxide $\left(\mathrm{CO}_{2}\right)$-are generally selected for this purpose. From our previous reports [28-30], the $\mathrm{H}_{2} \mathrm{O}$ activation method was preferred for producing electrode materials for EDLC because it can form relatively wide micropores compared to $\mathrm{CO}_{2}$ activation.

The activation process, which involves the carbonization and oxidation of precursor materials such as biomass [24], coals [21,22], polymers [16-20], and even fuels [7,13], is often affected by the crystallite structures of the precursors. Many researchers have suggested that if the crystallite structure of the precursor can be controlled, activated carbons with excellent pore characteristics can also be produced using a physical activation method, under proper process conditions [13-17].

Among various precursors, polymers have a specifically homogeneous crystalline structure, and the crystallite structures of carbonized polymers (intermediate materials for activated carbons) can be controlled during the stabilization and carbonization steps [29,31]. Studies on the use of conventional polymers as precursors for AC have typically utilized thermosetting polymers, which have highly aromatic ring structures [20]. However, the physical oxidation of large sized crystallites is quite difficult, due to the high thermal stability of graphite-like crystallite structures produced by the heavy aromatic ring structure during the carbonization process $[16,17,29]$. This is why most studies are carried out using the chemical activation process.

Kim et al. [31] used low-density polyethylene (LDPE) as a carbon precursor by cross-linking. LDPE has a long ethylene chain with a branched structure and high crystallinity compared to other precursors $[16,19]$ The polymer chains in LDPE contain numerous branches of varying lengths that create substantial amounts of empty space between the polymer chains. In addition, LDPE is high-yield, low-cost, and contains very little ash.

This study investigated the synthesis of LDPE by the physical activation method to produce AC for EDLC with well-controlled pore characteristics by controlling the crystallite structure of the cross-linked and carbonized LDPE. Based on the results of previous studies [31], LDPE-based carbon precursors were prepared by a sulfuric acid cross-linking method. We prepared various low-density polyethylene derived activated carbons (PE-AC) and the electrochemical performance of the EDLC was measured in terms of the pore structure of the PE-AC. 


\section{Experiment}

\subsection{Materials and Cross-Linking}

In this study, LDPE (LG Chemical Co, Seoul, Korea, LUTENE MB9205, 31,000-100,000 g/mol, $0.915 \mathrm{~g} / \mathrm{cm}^{3}$ ) was used as a precursor and sulfuric acid (DaeJung Chem, 98\%, 7683-4100, Gyeonggi-Do, Korea) was used as a cross-linking agent. The cross-linking of LDPE was performed in the same way as in a previous study [29]. LDPE was cross-linked under the sulfuric acid condition of $170{ }^{\circ} \mathrm{C}$, which was the highest cross-link density in the previous study. The DSC peak ( $\mathrm{T}_{\mathrm{g}}$ or $\left.\mathrm{T}_{\mathrm{m}}\right)$ of cross-linked LDPE disappeared by increased cross-linked density at $170{ }^{\circ} \mathrm{C}$ [31]. The cross-linked LDPE was washed with distilled water to $\mathrm{pH} 7$ and then dried in an oven at $120^{\circ} \mathrm{C}$ for $24 \mathrm{~h}$. The cross-linked LDPE was set on an alumina boat which was then inserted in a self-made ( $\mathrm{SiC}$ heater, length $1000 \mathrm{~mm}$, diameter $100 \mathrm{~mm}$ ) alumina tubular furnace. The cross-linked LDPE was heated up to the $900{ }^{\circ} \mathrm{C}$ under $\mathrm{N}_{2}$ flow at the rate of $10^{\circ} \mathrm{C} / \mathrm{min}$ and was held for $1 \mathrm{~h}$ at the carbonization temperature [31]. The carbonization yield of the carbonized LDPE was observed to be about $58.3 \%$. Then, the gas flow was switched to $\mathrm{H}_{2} \mathrm{O}$ at a rate of $0.5 \mathrm{~mL} / \mathrm{min}$ and held for $10 \mathrm{~min}$ (PE-H-9-1), $20 \mathrm{~min}$ (PE-H-9-2), $30 \mathrm{~min}$ (PE-H-9-3), or $40 \mathrm{~min}$ (PE-H-9-4). The PE-AC were cooled under nitrogen gas (300 mL/min).

\subsection{Characterization}

The morphologies and microstructures of the PE-AC were observed by field-emission scanning electron microscopy (FE-SEM, SU8220, Hitachi, Japan) and Cs-corrected field-emission transmission electron microscopy (Cs-corrected FE-TEM, JEM-ARM200F, JEOL, Tokyo, Japan), respectively. The $X$-ray diffraction patterns were collected using a X-ray powder diffractometer ( $X^{\prime}$ Port PRO, PANalytical, Almelo, The Netherlands) with $\mathrm{Cu} \mathrm{K} \alpha$ at a scan rate of $2 \% \mathrm{~min}$. Nitrogen adsorption isotherms of the PE-AC were measured with BELSORP-Max (BEL Japan, Tokyo, Japan) at liquid nitrogen temperature. All sample were degassed for approximately $6 \mathrm{~h}$ at $573 \mathrm{~K}$, with the residual pressure maintained at $0.1 \mathrm{~Pa}$, or less. The specific surface area was calculated using the Brunauer-Emmett-Teller (BET) method [32]. The micropore and mesopore size distributions were estimated via the nonlocal density functional theory (NLDFT) [33] and Barrett-Joyner-Halenda (BJH) [34] methods, respectively.

\subsection{Electrochemical Tests}

An electrode was made using the prepared PE-AC by mixing PE-AC:conductive material:binder $=8: 1: 1$ wt. $\%$ using carbon black (Super-P, Timcal, Bodio, Switzerland) as the conductive material and binder of carboxy methyl cellulose (CMC, Dai-Ichi Kogyo Seiyaku Co., Ltd., Japan) \& styrene-butadiene rubber (SBR, BM400B, Zeon, Japan) (ratio CMC:SBR = 2:1, m:m). For the preparation of EDLC electrodes, CMC was dissolved in water to obtain a $2.0 \mathrm{wt} \%$ solution and equilibrated for $2 \mathrm{~h}$ at room temperature. The PE-AC and carbon black were added to the solution containing binder and dispersed with a planetary centrifugal mixer (AR-100, Thinky Co., Ltd., Tokyo, Japan) for $40 \mathrm{~min}$. The so-obtained slurry was casted immediately on aluminium foil (20 $\mu \mathrm{m}$, purity $>99.9 \%)$ by using a laboratory scale doctor blade coater, whose blade was set at $125 \mu \mathrm{m}$. The coated foil was dried in an ambient atmosphere oven at $80{ }^{\circ} \mathrm{C}$ over night. EDLC were constructed using CR2032 coin cells. The samples were punched into round electrodes $12 \mathrm{~mm}$ in diameter. Two symmetric electrodes were isolated using a cellulose paper separator (NKK, Kanagawa, Japan). The electrolyte was $1 \mathrm{~mol} / \mathrm{dm}^{3}$ tetraethylammonium tetrafluoroborate/propylene carbonate $\left(\left(\mathrm{C}_{2} \mathrm{H}_{5}\right)_{4} \mathrm{NBF}_{4} / \mathrm{C}_{4} \mathrm{H}_{6} \mathrm{O}_{3}\right)$. All electrochemical tests were performed at room temperature with a MACCOR Battery tester 4300 (Maccor Inc., Tulsa, OK, USA) and VSP electrochemical workstation (Bio-Logic Science Instruments, Grenoble, France). Galvanostatic charge/discharge tests (GCD) were performed at $2 \mathrm{~mA}$ constant current from 0.1 to $2.4 \mathrm{~V}$. Cyclic voltammetry (CV) were performed in the same potential range of GCD at scan rates of $30 \mathrm{mV} / \mathrm{s}$. The impedance plots were recorded in the frequency range $10 \mathrm{mHz}$ to 300 $\mathrm{kHz}$. The cells produced were measured based on the capacitance per unit weight, and calculated 
using only the weight of the active materials $(\mathrm{F} / \mathrm{g})$. The specific capacitance was calculated according to the GCD based on the following equation.

$$
\mathrm{C}_{\mathrm{g}}=\mathrm{i} \Delta \mathrm{t} / \mathrm{m} \Delta \mathrm{V}
$$

where $i$ is the discharge current (A), $\Delta t$ is the discharge time (s), $\mathrm{m}$ is the mass of the electrode (g), and $\Delta \mathrm{V}$ is the potential difference $(\mathrm{V})$.

\section{Results}

\subsection{Photo Images}

Figure 1 exhibits the surface changes in the LDPE pellets after cross-linking and carbonization, respectively. The LDPE pellet had a transparent color inherent to the polyolefin. The color of the cross-linked LDPE pellets changed to black and crater shapes were observed on the surface. For cross-linking, the LDPE pellets were exposed under sulfuric acid at $170^{\circ} \mathrm{C}$ for $60 \mathrm{~min}$. It is well-known that normal LDPE has a melting point of approximately $130-150{ }^{\circ} \mathrm{C}$. Because the temperature of the sulfuric acid was higher than the melting point of the LDPE, the sulfuric acid could be easily inserted between the polymer chains (LDPE can be swelled at high temperature) and produce good cross-linking (condensation) [31]. During the cross-linking (condensation), domains which have low molecular weight (it is well-known that all polymers contain a broad range of molecular weights) can be oxidized under severe acidic conditions, resulting in the formation of the crater-like structures on the surface of the cross-linked LDPE samples. The surface of the carbonized LDPE samples (Figure 1c) was very similar to that of the cross-linked one. It was concluded that the polymer structure was well maintained even after carbonization because of good cross-linking.
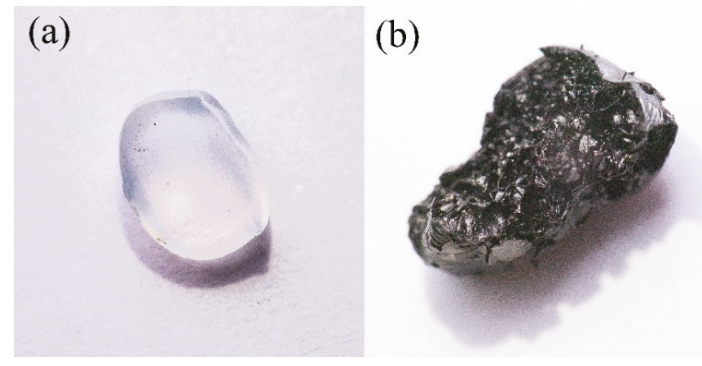

(c)

Figure 1. Photo image of (a) as-received low-density polyethylene (LDPE) pellet, (b) cross-linked LDPE sample, and (c) carbonized LDPE sample.

\subsection{FE-SEM Observation}

$\mathrm{H}_{2} \mathrm{O}$ activation is a process of generating pores by causing the oxidation of the precursor's crystallites by exposure to $\mathrm{H}_{2} \mathrm{O}$ vapor at a temperature higher than $900^{\circ} \mathrm{C}$. The surface morphology of the activated carbons is significantly changed by the oxidation of some crystallites on the surface. FE-SEM is a good analytical method for observing the morphology of activated carbon before and after the activation process.

Figure 2 shows the morphology of a carbonized LDPE sample and an PE-AC. Figure 2a is the SEM image of the carbonized LDPE sample. It is interesting to note that in Figure 1c many crater shapes can be observed in the carbonized LDPE sample, but the sample in Figure 2a has a smooth surface. This indicates that there was no pore development during the carbonization step. After $\mathrm{H}_{2} \mathrm{O}$ activation, the pore structures were observed in all samples (Figure $2 b-e$ ). As the activation time increased, the frequency of the pores (micro- and mesopores) increased gradually, and after $30 \mathrm{~min}$ of activation time many small pores were also found in inner areas, not only on surfaces. 

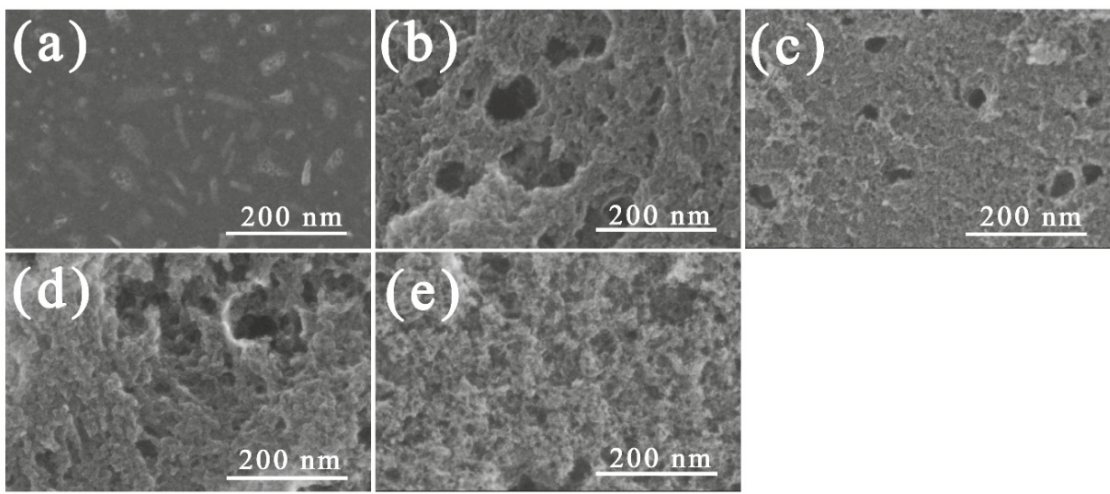

Figure 2. Field-emission scanning electron microscopy (FE-SEM) image of activated carbons with different activation times: (a) as-received (carbonized LDPE sample), (b) PE-H-9-1, (c) PE-H-9-2, (d) PE-H-9-3, and (e) PE-H-9-4.

This kind of pore development is typically not found in polymer-based AC because pore development normally proceeds from the surface to the inner area. It is possible that closed pores were formed at high temperature during the cross-linking or carbonization steps due to the swelled LDPE, and subsequently the closed pores and newly formed pores on the outer surface were finally connected with each other during the activation step.

In the sample exposed to $40 \mathrm{~min}$ of activation time, it was observed that the average size of the pores had been reduced and became homogenous. The explanation for this behavior is that the entire surface of the as-received sample was well-activated and the inner pores were fully exposed to the outer area at the same time. This is a clue that the specific surface area was dramatically enhanced after $40 \mathrm{~min}$ of activation time.

\subsection{Cs-corrected FE-TEM Observation}

Cs-corrected FE-TEM is a useful analytical method for observing the crystallite structure of carbonaceous materials. Figure 3 exhibits the crystallite structure of carbonized LDPE with amorphous domain and high graphitic domain complexes. In the magnified image (right), the dark part has a high graphitic domain and shows a layered structure similar to that of graphite, and it is confirmed that the bright part is amorphous domain or irregularly arranged planes (so-called hard carbon). Assuming that the bright part is oxidized to form pores, the expected pore shape can be very similar to the pore shape of the PE-AC observed in Figure 2.
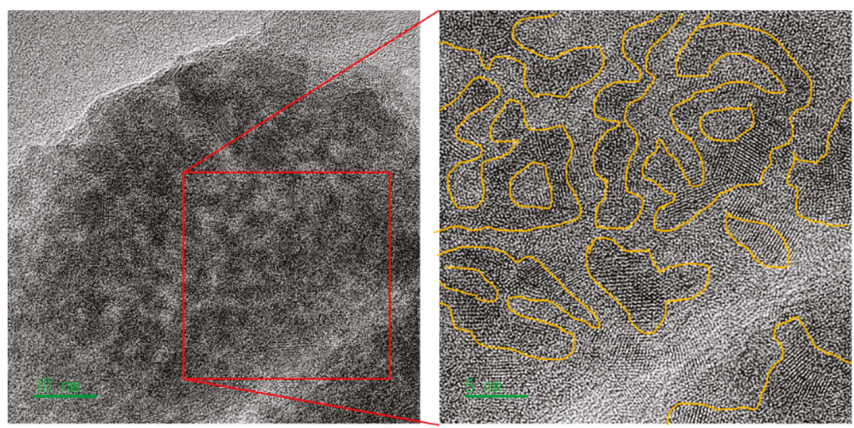

Figure 3. TEM image of carbonized LDPE sample. 
We have reported in previous our studies $[16,17]$ that amorphous or relatively small crystallines in the precursor structure are firstly oxidized in the preparation of AC through physical activation methods. This is the one of governing factors to determine average pore size and total pore volume of the resulting materials. Therefore, the LDPE precursor used in this study is presumed to have pores mainly due to oxidation of amorphous or relatively small crystallite. The crystallites portion (dark area) of the precursor may form pore walls in the manufactured AC. Thus, when observing the precursor on the Cs-corrected FE-TEM image in Figure 3, it can be assumed that the size of the developed pore is $\sim 5 \mathrm{~nm}$.

\subsection{X-Ray Diffraction Analysis}

X-ray diffraction (XRD) can easily analyze the crystallite structure of carbon materials. The crystallite structure of the AC was changed by oxidation of the precursor crystallite in the activation process. Figure 4 shows the results of the XRD analysis. As shown in Figure 4, all of the samples showed typical carbon peaks of $\mathrm{C}(002)$ and $\mathrm{C}(10 l)$ at $2 \theta$ of $23^{\circ}$ and $43^{\circ}$, respectively. Typically, graphite peaks are observed at 2 theta of $25^{\circ}$, but in this work $\mathrm{C}(002)$ were observed at $23^{\circ}$, indicating the carbon lattice was sparse and the lattice space was much wider than the highly crystallite materials. This type of XRD pattern is usually found in hard carbons or AC [14]. That is, AC is considered to have a mixed crystallite structure in which amorphous and graphitic domain are combined. Despite the increase in activation time, the $\mathrm{C}(002)$ and $\mathrm{C}(10 l)$ peaks were well maintained. Table 1 and Figure 5 exhibited the fitting results of the XRD.

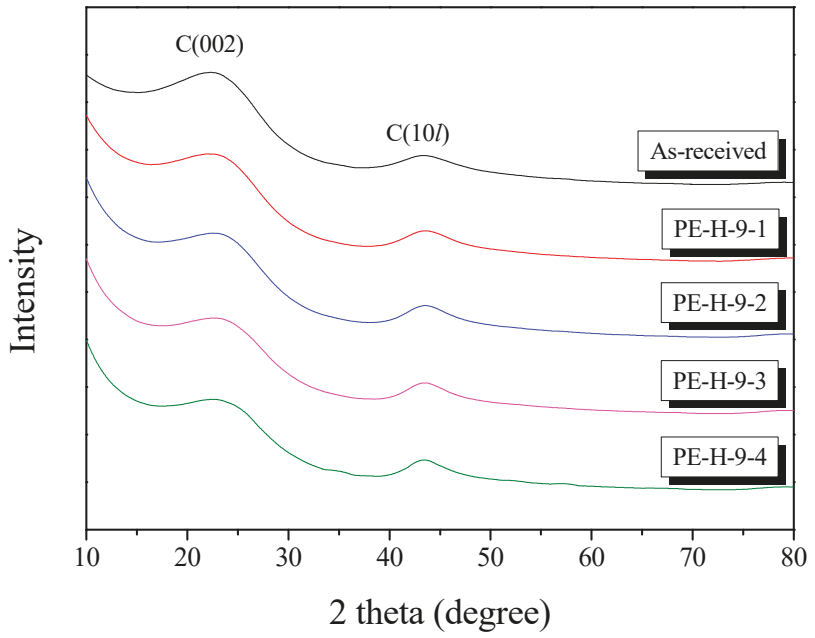

Figure 4. X-ray diffraction patterns of activated carbon for different activation times.

Table 1. Structural parameters of activated carbons with different activation times.

\begin{tabular}{|c|c|c|c|c|c|c|c|c|}
\hline \multirow[b]{2}{*}{ Sample } & \multicolumn{4}{|c|}{002 Peak } & \multicolumn{4}{|c|}{$10 l$ Peak } \\
\hline & $2 \theta$ & $\begin{array}{c}\mathrm{d}_{002} \\
(\AA)\end{array}$ & $\begin{array}{c}\text { FWHM } \\
(2 \theta)\end{array}$ & $\mathrm{L}_{\mathrm{c}}(\AA)$ & $2 \theta$ & $\begin{array}{l}\mathrm{d}_{10 l} \\
(\AA)\end{array}$ & $\begin{array}{c}\text { FWHM } \\
(2 \theta)\end{array}$ & $\mathrm{L}_{\mathrm{a}}(\AA)$ \\
\hline As-received & 22.61 & 3.93 & 10.15 & 7.99 & 44.10 & 2.05 & 7.18 & 24.43 \\
\hline PE-H-9-1 & 23.04 & 3.86 & 9.93 & 8.17 & 44.09 & 2.05 & 6.63 & 26.45 \\
\hline PE-H-9-2 & 23.52 & 3.78 & 9.30 & 8.73 & 44.09 & 2.05 & 6.27 & 27.97 \\
\hline PE-H-9-3 & 23.86 & 3.73 & 8.94 & 9.09 & 44.09 & 2.05 & 6.21 & 28.24 \\
\hline PE-H-9-4 & 23.84 & 3.73 & 9.09 & 8.94 & 44.00 & 2.06 & 6.02 & 29.12 \\
\hline
\end{tabular}




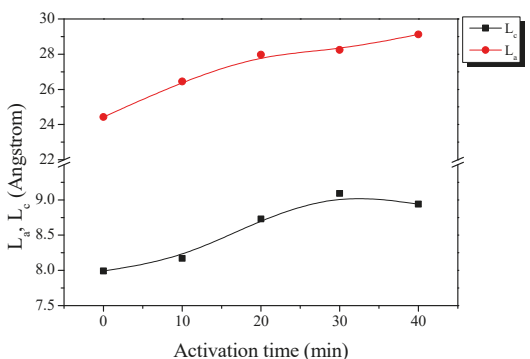

(a)

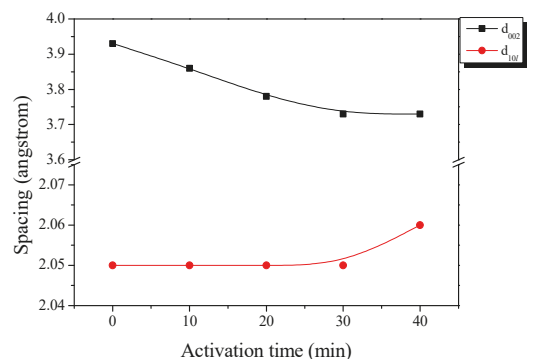

(b)

Figure 5. Structural characteristics of the activated carbons as a function of different activation times:

(a) structural parameters and (b) interplanar distance.

$\mathrm{L}_{\mathrm{a}}$ (meaning crystallite size) was increased with increasing activation time, and $\mathrm{L}_{\mathrm{c}}$ (meaning crystallite height) was increased up to $30 \mathrm{~min}$ of activation time. It is well known that amorphous regions and small graphitic crystalline in carbon precursors are preferentially oxidized [14,15]. Generally, the XRD data of carbon materials provides statistical data about the number of c crystallite aggregates rather than single crystalline. Therefore, the continuous increase in $\mathrm{L}_{\mathrm{a}}$ can be considered to indicate a relative increase due to the oxidation of amorphous regions or small graphitic crystalline. It may also be that $\mathrm{L}_{\mathrm{c}}$ was increased by the oxidization of amorphous regions or small layers of graphitic crystalline for up to $30 \mathrm{~min}$, which were then maintained.

The $\mathrm{d}_{002}$ of the carbonized LDPE sample was $3.93 \AA$, which is higher than those of other polymers or carbon precursors; it is normally observed to be in the range of 3.54 to $3.69 \AA$ [11-18]. The $\mathrm{d}_{002}$ may be relatively higher due to disordered lattice locations, caused by the sparse cross-linking density due to the aliphatic-based backbone of the LDPE precursors. As the activation time increased, the small crystallite lattices in the precursor were oxidized (removed) and then the total crystallite structure became denser, resulting in the decrease in $\mathrm{d}_{002}$. In PE-H-9-4 (the sample activated for $40 \mathrm{~min}$ ), $\mathrm{L}_{\mathrm{c}}$ was maintained and $\mathrm{L}_{\mathrm{a}}$ was slightly increased. This means that large crystals were not oxidized further at the edge area $\left(\mathrm{L}_{\mathrm{c}}\right)$ and small crystallites were continuously removed during the activation process $\left(\mathrm{L}_{\mathrm{a}}\right)$.

\section{5. $\mathrm{N}_{2} / 77 \mathrm{~K}$ Adsorption Isotherm Analysis}

In order to investigate pore development behaviors, $\mathrm{N}_{2} / 77 \mathrm{~K}$ adsorption isotherms were employed and the results are exhibited in Figure 6. The textural properties of the PE-AC were also analyzed and are listed in Table 2. In Figure 6, every curve exhibited Type I according to the IUPAC classification [35]. This means that most of the pores are micropores. The activation yield tends to decrease with the increase in the specific surface area of the PE-AC, indicating the oxidation of tiny crystallite lattices, which led to the increase in the micropores of the PE-AC.

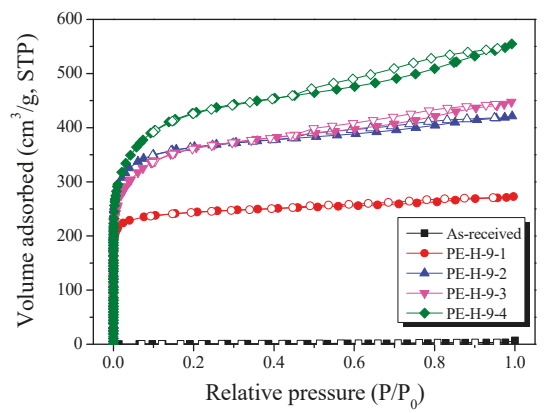

Figure 6. $\mathrm{N}_{2} / 77 \mathrm{~K}$ adsorption isotherms of activated carbons as a function of different activation times. 
Table 2. Textural properties of activated carbons with different activation times.

\begin{tabular}{|c|c|c|c|c|c|c|}
\hline Sample & $\begin{array}{l}\text { Activation } \\
\text { Conditions }\end{array}$ & $\begin{array}{l}S_{\text {BET }} 1 \\
\left(\mathrm{~m}^{2} / g\right)\end{array}$ & $\begin{array}{l}V_{\text {Total }}^{2} \\
\left(\mathrm{~cm}^{3} / \mathrm{g}\right)\end{array}$ & $\begin{array}{l}V_{\text {Meso }}{ }^{3} \\
\left(\mathrm{~cm}^{3} / \mathrm{g}\right)\end{array}$ & $\begin{array}{l}V_{\text {Micro }} 4 \\
\left(\mathrm{~cm}^{3} / \mathrm{g}\right)\end{array}$ & $\begin{array}{c}\text { Yield }^{5} \\
(\%)\end{array}$ \\
\hline As-received & - & 3 & 0.01 & 0.01 & 0.00 & - \\
\hline PE-H-9-1 & $900{ }^{\circ} \mathrm{C} \times 10 \mathrm{~min}$ & 950 & 0.42 & 0.05 & 0.37 & 70 \\
\hline PE-H-9-2 & $900^{\circ} \mathrm{C} \times 20 \mathrm{~min}$ & 1400 & 0.65 & 0.13 & 0.52 & 49 \\
\hline PE-H-9-3 & $900^{\circ} \mathrm{C} \times 30 \mathrm{~min}$ & 1370 & 0.69 & 0.20 & 0.49 & 35 \\
\hline PE-H-9-4 & $900{ }^{\circ} \mathrm{C} \times 40 \mathrm{~min}$ & 1600 & 0.86 & 0.30 & 0.56 & 29 \\
\hline
\end{tabular}

${ }^{1} \mathrm{~S}_{\mathrm{BET}}$ : Specific surface area; BET method; $\frac{P}{v\left(P_{0}-P\right)}=\frac{1}{v_{m c}}+\frac{c-1}{v_{m} c} \cdot \frac{P}{P_{0}} ;{ }^{2} \mathrm{~V}_{\mathrm{Total}}$ : Total pore volume; BET method; ${ }^{3}$

$\mathrm{V}_{\text {Meso }}$ : Mesopore volume; BJH method: $r_{p}=r_{k}+t\left(\mathrm{r}_{\mathrm{p}}=\right.$ actual radius of the pore; $\mathrm{r}_{\mathrm{k}}=$ Kelvin radius of the pore; $\mathrm{t}=$ thickness of the adsorbed film); ${ }^{4} \mathrm{~V}_{\text {Micro }}$ : Micropore volume; $\mathrm{V}_{\text {Total }}-\mathrm{V}_{\text {Meso }} ;{ }^{5}$ Yield: $\frac{\text { Weight of activated sample }}{\text { Weight of carbonized sample input }} \times 100$

In PE-H-9-4, the specific surface area and total pore volume were observed to be $1600 \mathrm{~m}^{2} / \mathrm{g}$ and $0.86 \mathrm{~cm}^{3} / \mathrm{g}$, respectively. It is interesting to note that the specific surface area predominantly increased up to $20 \mathrm{~min}$ of activation time and thereafter showed mild enhancement. Meanwhile, the mesopores gradually increased although the micropores were also increased. This result suggests the opening of the closed pores in the inner area which were self-formed during the cross-linking of the LDPE chains. In PE-H-9-3, the micropore volume decreased by 5\% compared to PE-H-9-2, while the mesopores of PE-H-9-3 were significantly enhanced. This pattern can be attributed to the oxidation of some preformed micropores during further activation, which helped form the mesopores, resulting in the decrease in the specific surface area of the PE-H-9-3.

It was observed that the hysteresis of the isothermal adsorption curve became stronger when the activation time increased. Type D hysteresis was observed in all the samples, which means that the mesopores can be wedge shaped [36]. The increase in hysteresis is considered to be due to the fact that the internal pores of the precursor that formed during the cross-linking process were opened to the outside during the activation process.

On the other hand, the hysteresis of PE-H-9-3 was larger than that of PE-H-9-2, and the start of the knee was observed in the micropore ranges in the lower pressure zone. As described in Table 2, this suggests the micropores that formed earlier converted to mesopores during further activation.

In order to observe the mesopores of the prepared PE-AC, the BJH equation was used to analyze the pore size distribution in the mesopore range. The results are shown in Figure 7. In general, the size distribution of the mesopores in PE-AC are observed to decrease gradually from 2 to $10 \mathrm{~nm}$ [13-20]. In the case of the PE-AC prepared in this study [21], it was observed that the mesopores were present over a wide region, up to $30 \mathrm{~nm}$. In addition, as the activation time was increased, the volume of the mesopores proportionally increased. These results are consistent with the changes observed when activating precursors that have well-formed domain crystallite structures. These results indicate that the characteristics of the LDPE precursor are more easily attributed to mesopore formation, and that the amorphous or relatively small crystallites which were formed during the sulfuric acid cross-linking process for stabilization (not melted) are easily converted to the mesopore structure.

The NLDFT method was used to observe the conversion of the micropores to mesopores in Figure 8. In the initial $10 \mathrm{~min}$ activation (PE-H-9-1), it was observed that micropores with diameters of $1 \mathrm{~nm}$ or less predominantly developed. However, it was confirmed that the micropores decreased significantly in the 20 min-activated sample (PE-H-9-2), and the number of mesopores significantly increased.

It was observed that there were fewer micropores in PE-H-9-3 than in the PE-H-9-2 and the mesopores were increased. This result is consistent with Figure 6. For the most-activated sample (PE-H-9-4), it was observed that the mesopores were developed over a wider area.

From the above results, it can be concluded that (1) the development of micropores, (2) the conversion of mesopores to micropores, and (3) the development of additional micropores (or the external protrusion of internal pores) occurred complexly and simultaneously. 


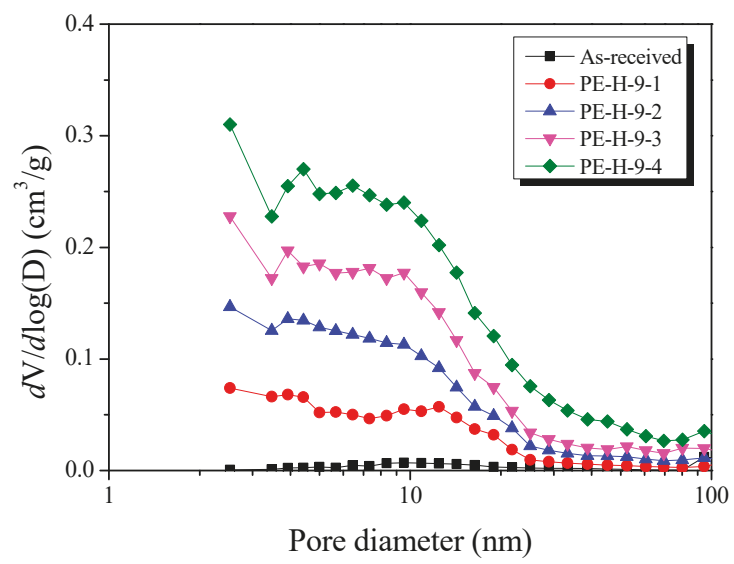

Figure 7. Pore size distribution of activated carbons with different activation times by Barrett-Joyner-Halenda (BJH) equation.

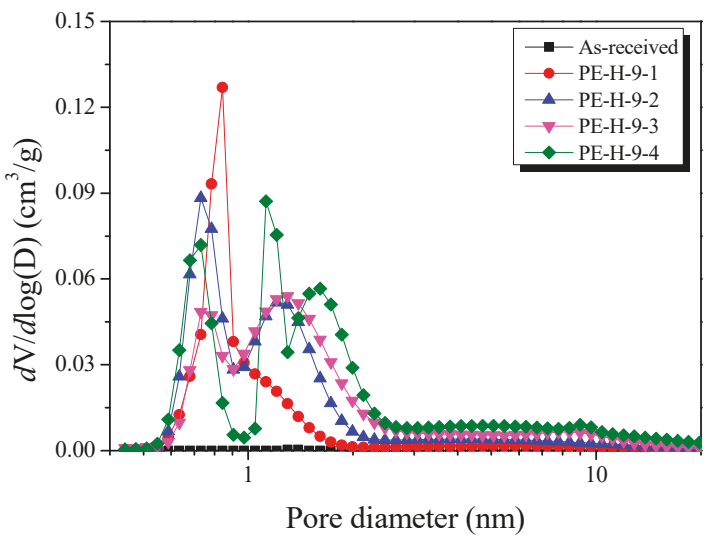

Figure 8. Pore size distribution of activated carbons with different activation times by nonlocal density functional theory (NLDFT) equation.

The above XRD and BET results suggest that the activation of the LDPE precursor has a unique characteristic. Generally, during activation using water vapor, the water vapor has difficulty penetrating into the precursor because water vapor has relatively large particles. As a result, the production yield and mesopore volume are not so high. However, in the present study, the activated sample (PE-H-9-4) had a production yield of $30 \%$, despite having a mesopore ratio of $35 \%$ and a high specific surface area of $1600 \mathrm{~m}^{2} / \mathrm{g}$. This is probably due to the fact that the internal pores generated inside the precursor during the cross-linking reaction of the LDPE were opened to the outside during the activation process, and this facilitated the penetration of the water vapor molecules. This reaction accelerated the oxidation of the small crystallites inside, and thus the $\mathrm{L}_{\mathrm{c}}$ and $\mathrm{L}_{\mathrm{a}}$ values were also increased.

\subsection{Electrochemical Properties}

GCD measurements were performed to determine the capacitance of the activated LDPE fabricated electrodes. The linear voltage-time dependence demonstrates the typical capacitive behavior of the cell. Figure 9 exhibits the GCD curves of the EDLCs made from PE-AC. The as-received sample showed almost no GCD behavior, probably due to the lack of pore characteristics, as observed in Figures 6-8. 
The GCD curves of PE-H-9-1 were observed to have few GCD times with nonlinear than the other PE-AC. These results indicate that the pore characteristics of PE-H-9-1 are inadequate for electrolyte ion storage and the capacitance is low.

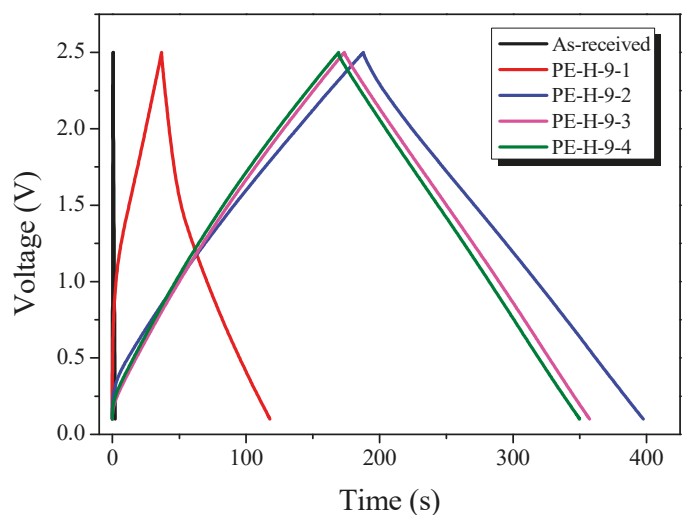

Figure 9. Charge-discharge curves of activated carbons with different activation times.

The GCD behavior of PE-H-9-2 to PE-H-9-4 is highly reversible; the discharge curves display linear behavior and are approximately symmetrical to the corresponding charge curves. The linear behavior of the GCD curves demonstrates the excellent capacitive characteristics of the PE-AC. It is known that IR drop is dependent on the conductivity and pore structure of the electrode materials. IR drop does not appear in the GCD curves of the PE-H-9-2 to PE-H-9-4 because the samples had an optimal pore structure.

Figure 10 shows the change in specific capacitance with GCD cycle. The specific capacitance increased with increasing activation time up to $30 \mathrm{~min}$. This result is due to the increased pore volume and diameter of the pores in the PE-AC as activation time increases. The reduction in specific capacitance over $30 \mathrm{~min}$ seems to have reduced the pore volume available for ion storage space by increasing the pore diameter. Stable capacitance retention was observed in the electrodes after five cycles. The specific capacitance of the PE-AC was compared with YP-50F from the Kuraray company. The specific capacitances of PE-H-9-3 and PE-H-9-4 were over 110 F/g, higher than that of YP-50F [37].

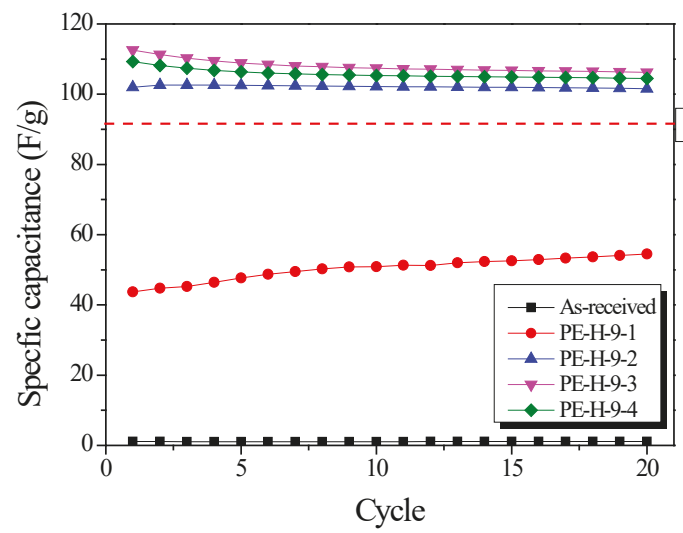

Figure 10. Variations in specific capacitance in relation to cycle number. The dotted red line denote the specific capacitance of commercial activated carbon for electric double-layer capacitor (EDLC). 
The cyclic voltammogram (CV) curves show the charge-discharge behaviors of the PE-AC, and the EDLC has the ideal shape of a quadrangle. Figure 11 shows the CV for the EDLC made from the PE-AC. The CV curves in Figure 11 are very similar to the GCD curve results.

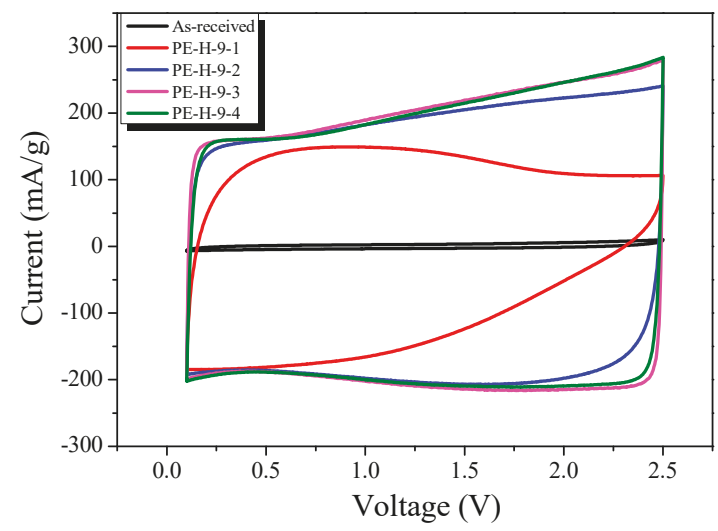

Figure 11. Cyclic voltammograms of activated carbons with different activation times.

The EDLC made from as-received PE and PE-H-9-1 displays unfavorable electrochemical performance, with more distortion in the CV curve. These results can be attributed to the difficulty of ion migration in the pores of the PE-AC.

PE-H-9-2 to PE-H-9-4 exhibited a nearly rectangular shape from 0.1 to $2.5 \mathrm{~V}$, which indicates efficient EDLC formation. This result implies rapid current response to the change in voltage from 0.1 to $2.5 \mathrm{~V}$ during charging and discharging. The specific capacitance values demonstrate an increasing tendency from as-received PE to PE-H-9-4. The current and area in the CV curve for PE-H-9-3 is apparently much larger than other PE-AC at the same scan rate. PE-H-9-3 shows the best specific capacitance compared to PE-H-9-2 and PE-H-9-4.

The Nyquist Plot is an analytical method that measures the equivalent series resistance (ESR) and Warburg resistance between electrodes and electrolytes. Figure 12 depicts the Nyquist plot of the EDLCs using PE-AC. In the Nyquist plot, the Warburg impedance of the EDLCs appears as a line with a $45^{\circ}$ slope. The Warburg impedance of PE-H-9-1 was observed to be very long, because the movement of ions into the pores was not smooth. The impedance results for PE-H-9-1 showed the same trend as the charging and discharging results and CV curves. After $20 \mathrm{~min}$ of activation time, the impedance of the PE-AC were observed as the typical Nyquist Plot shape of EDLCs with consisting of semicircle and Warburg impedances. As the activation time increased, the size of the semicircle increased, but the Warburg impedance decreased. Warburg impedance is considered to be due to the smooth movement of ions due to the increase of pore diameter.

PE-H-9-4 was expected to have the best specific capacitance because the specific surface area and pore volume were observed to be the highest. However, PE-H-9-4 showed the largest semicircle in the Nyquist plot and was found to have high resistance. In conclusion, it is speculated that PE-H-9-4 has a similar specific capacitance to $\mathrm{PE}-\mathrm{H}-9-2$ and $\mathrm{PE}-\mathrm{H}-9-3$ due to its high resistance despite having the best pore properties.

The specific capacitance of activated carbons reported in the surveyed literature is presented in Table 3. Because different experimental methods were used by various authors to determine the specific capacitance, the values reported are sometimes not consistent. Table 3 shows the experimental results of our previous studies using the same experimental methods such as electrolyte $\left(1 \mathrm{~mol} / \mathrm{dm}^{3}\right.$ $\left(\left(\mathrm{C}_{2} \mathrm{H}_{5}\right)_{4} \mathrm{NBF}_{4} / \mathrm{C}_{4} \mathrm{H}_{6} \mathrm{O}_{3}\right), \mathrm{CR} 2032$ coin cell, voltage range, and scan rate. It was confirmed that the prepared PE-AC in this study had higher specific capacitance than other precursor-based activated carbon with the similar specific surface area. In addition, PE-AC has a specific capacitance similar 
to that of pitch-based activated carbon, whose specific surface area is nearly double the difference. These results suggest that PE-AC has a pore structure and low resistivity suitable for EDLC than other precursor-derived activated carbon.

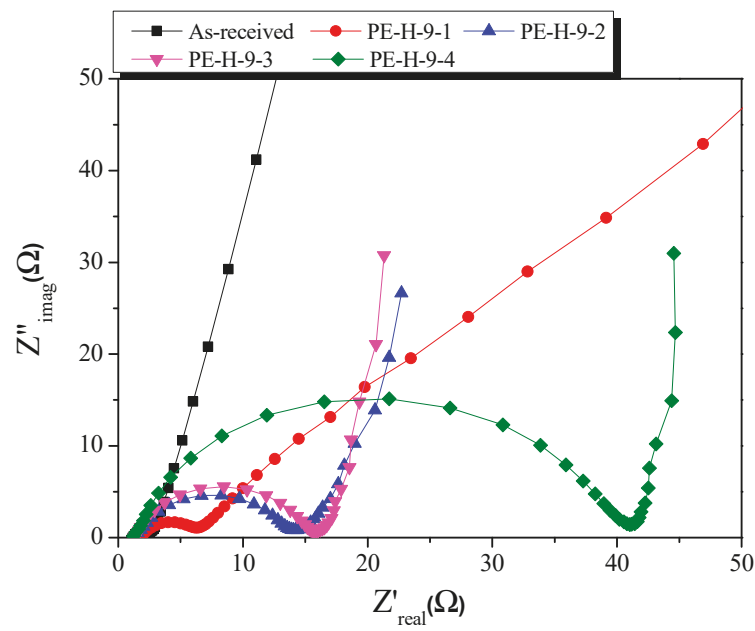

Figure 12. Nyquist plot of activated carbons with different activation times.

Table 3. Properties and characteristics of activated carbons as EDLC electrode materials with various precursor.

\begin{tabular}{|c|c|c|c|c|c|}
\hline Precursor & $\begin{array}{l}\text { Activation } \\
\text { Condition }\end{array}$ & $\begin{array}{c}\text { Specific } \\
\text { Surface Area }\end{array}$ & $\begin{array}{c}\text { Specific } \\
\text { Capacitance }\end{array}$ & Electrolyte & Reference \\
\hline LDPE & $\begin{array}{c}\mathrm{H}_{2} \mathrm{O} \\
900{ }^{\circ} \mathrm{C}, 30 \mathrm{~min}\end{array}$ & $1370 \mathrm{~m}^{2} / \mathrm{g}$ & $112 \mathrm{~F} / \mathrm{g}$ & \multirow{6}{*}{$\begin{array}{c}1 \mathrm{~mol} / \mathrm{dm}^{3} \\
\left(\mathrm{C}_{2} \mathrm{H}_{5}\right)_{4} \mathrm{NBF}_{4} / \mathrm{C}_{4} \mathrm{H}_{6} \mathrm{O}_{3}\end{array}$} & In this work \\
\hline Polyacrylonitrile & $\begin{array}{c}\mathrm{CO}_{2} \\
1000^{\circ} \mathrm{C}, 30 \mathrm{~min}\end{array}$ & $1530 \mathrm{~m}^{2} / \mathrm{g}$ & $64 \mathrm{~F} / \mathrm{g}$ & & [30] \\
\hline Polyacrylonitrile & $\begin{array}{c}\mathrm{KOH}, \\
800^{\circ} \mathrm{C}, 30 \mathrm{~min} \\
\end{array}$ & $1160 \mathrm{~m}^{2} / \mathrm{g}$ & $86 \mathrm{~F} / \mathrm{g}$ & & [20] \\
\hline Coke & $\begin{array}{c}\mathrm{CO}_{2} \\
1000^{\circ} \mathrm{C}, 60 \mathrm{~min}\end{array}$ & $1040 \mathrm{~m}^{2} / \mathrm{g}$ & $92 \mathrm{~F} / \mathrm{g}$ & & [21] \\
\hline Pitch & $\begin{array}{c}\mathrm{H}_{2} \mathrm{O} \\
900^{\circ} \mathrm{C}, 40 \mathrm{~min}\end{array}$ & $3230 \mathrm{~m}^{2} / \mathrm{g}$ & $113 \mathrm{~F} / \mathrm{g}$ & & [13] \\
\hline Polyurethane & $\begin{array}{c}\mathrm{CO}_{2} \\
1000^{\circ} \mathrm{C}, 60 \mathrm{~min}\end{array}$ & $1620 \mathrm{~m}^{2} / \mathrm{g}$ & $105 \mathrm{~F} / \mathrm{g}$ & & [38] \\
\hline
\end{tabular}

\section{Conclusions}

The process of producing AC from LDPE by $\mathrm{H}_{2} \mathrm{O}$ activation was optimized and the textural properties and electrochemical characteristics of the produced materials were confirmed by applying them in EDLC. The structural properties of the LDPE and the activation conditions were found to significantly affect the performance of the electrode materials. A longer activation time led to an PE-AC with higher specific surface area and larger pore size, but it was also found that a too high pore diameter reduced specific capacitance.

The structural characteristics of the precursor LDPE led to the production of an AC with a mesopore-rich pore structure. Under optimal activation conditions, the resulting high specific surface area and mesopore-rich pore structure with suitable pore sizes resulted in PE-AC that are ideal candidates for EDLC electrodes. As the activation time increased, the specific surface area and mesopore volume of the PE-AC increased to $1600 \mathrm{~m}^{2} / \mathrm{g}$ and $0.30 \mathrm{~cm}^{3} / \mathrm{g}$ (35\% of total pore volume), respectively. The 
PE-H-9-3 sample exhibited the highest specific surface area and the best electrochemical performance. These included the highest power, lowest ESR, and perfect reversible characteristics, as well as excellent maintenance of specific capacitance under high power operation. From the GCD characteristics, the PE-H-9-3 sample demonstrated the best results (112 F/g) of all the PE-AC.

Author Contributions: Conceptualization, S.-J.P. and B.-J.K.; methodology, S.-J.P. and B.-J.K.; validation, K.-W.K., Y.-K.P. and B.-J.K.; formal analysis, H.-M.L. and K.-W.K.; investigation, Y.-K.P. and K.-H.A.; resources, Y.-K.P., K.-H.A. and B.-J.K.; data curation, H.-M.L. and K.-W.K.; writing-original draft preparation, H.-M.L.; writing—review and editing, B.-J.K.; visualization, B.-J.K.; supervision, B.-J.K.; project administration, B.-J.K.; funding acquisition, B.-J.K.

Funding: This research was supported by the "A Study on the Design of Protective Woven Fabrics Using ACF Materials" funded by the Agency for Defense Development, Republic of Korea (UD170102ID). This research was supported by the Nano Material Technology Development Program through the National Research Foundation of Korea (NRF) funded by Ministry of Science and ICT (Project no. 2018M3A7B9086636).

Conflicts of Interest: The authors declare no conflict of interest.

\section{References}

1. Pham, D.T.; Lee, T.H.; Luong, D.H.; Yao, F.; Ghosh, A.; Le, V.T.; Kim, T.H.; Li, B.; Chang, J.; Lee, Y.H. Carbon nanotube-bridged graphene 3D building blocks for ultrafast compact supercapacitors. ACS Nano 2015, 9 , 2018-2027. [CrossRef] [PubMed]

2. Qu, W.H.; Xu, Y.Y.; Lu, A.H.; Zhang, X.Q.; Li, W.C. Converting biowaste corncob residue into high value added porous carbon for supercapacitor electrodes. Bioresour. Technol. 2015, 189, 285-291. [CrossRef] [PubMed]

3. Zhu, Y.; Murali, S.; Stoller, M.D.; Ganesh, K.J.; Cai, W.; Ferreira, P.J.; Pirkle, A.; Wallace, R.M.; Cychosz, K.A.; Thommes, M.; et al. Carbon-based supercapacitors produced by activation of graphene. Science 2011, 332, 1537-1542. [CrossRef] [PubMed]

4. Huang, J.; Sumpter, B.G.; Meunier, V. A universal model for nanoporous carbon supercapacitors applicable to diverse pore regimes, carbon materials, and electrolytes. Chem. Eur. J. 2008, 14, 6614-6626. [CrossRef] [PubMed]

5. Lobato, B.; Suárez, L.; Guardia, L.; Centeno, T.A. Capacitance and surface of carbons in supercapacitors. Carbon 2017, 122, 434-445. [CrossRef]

6. Zhang, L.L.; Zhou, R.; Zhao, X.S. Graphene-based materials as supercapacitor electrodes. J. Mater. Chem. 2010, 20, 5983-5992. [CrossRef]

7. Arcila-Velez, M.R.; Zhu, J.; Childress, A.; Karakaya, M.; Podila, R.; Rao, A.M.; Roberts, M.E. Roll-to-roll synthesis of vertically aligned carbon nanotube electrodes for electrical double layer capacitors. Nano Energy 2014, 8, 9-16. [CrossRef]

8. Obreja, V.V.N. On the performance of supercapacitors with electrodes based on carbon nanotubes and carbon activated material-A review. Physica E 2008, 40, 2596-2605. [CrossRef]

9. Kim, J.A.; Park, I.S.; Seo, J.H.; Lee, J.J. A development of high power activated carbon using the $\mathrm{KOH}$ activation of soft carbon series cokes. Trans. Electr. Electron. Mater. 2014, 15, 81-86. [CrossRef]

10. Liu, B.; Shioyama, H.; Jiang, H.; Zhang, X.; Xu, Q. Metal-organic framework (MOF) as a template for syntheses of nanoporous carbons as electrode materials for supercapacitor. Carbon 2010, 48, 456-463. [CrossRef]

11. Chen, Y.D.; Huang, M.J.; Huang, B.; Chen, X.R. Mesoporous activated carbon from inherently potassium-rich pokeweed by in situ self-activation and its use for phenol removal. J. Anal. Appl. Pyrolysis 2012, 98, 159-165. [CrossRef]

12. Lee, H.I.; Park, S. Facile fabrication of electrospun polyacrylonitrile/poly(vinylidene fluoride)-based carbon nanofibers for supercapacitor electrodes. Carbon Lett. 2017, 23, 79-83.

13. Lee, H.M.; Kwac, L.K.; An, K.H.; Park, S.J.; Kim, B.J. Electrochemical behavior of pitch-based activated carbon fibers for electrochemical capacitors. Energy Convers. Manag. 2016, 125, 347-352. [CrossRef]

14. Kim, D.W.; Kil, H.S.; Nakabayashi, K.; Yoon, S.H.; Miyawaki, J. Structural elucidation of physical and chemical activation mechanisms based on the microdomain structure model. Carbon 2017, 114, 98-105. [CrossRef] 
15. Yuan, H.Y.; Jin, B.; Meng, L.Y. Effect of the SBA-15 template and $\mathrm{KOH}$ activation method on $\mathrm{CO}_{2}$ adsorption by N-doped polypyrrole-based porous carbons. Carbon Lett. 2018, 28, 116-120.

16. Baek, J.; Lee, H.M.; Roh, J.S.; Lee, H.S.; Kang, H.S.; Kim, B.J. Studies on preparation and applications of polymeric precursor-based activated hard carbons: I. Activation mechanism and microstructure analyses. Microporous Mesoporous Mater. 2016, 219, 258-264. [CrossRef]

17. Baek, J.; Shin, H.S.; Chung, D.C.; Kim, B.J. Studies on the correlation between nanostructure and pore development of polymeric precursor-based activated hard carbons: II. Transmission electron microscopy and Raman spectroscopy studies. J. Ind. Eng. Chem. 2017, 54, 324-331. [CrossRef]

18. Hu, Z.; Srinivasan, M.P.; Ni, Y. Preparation of Mesoporous High-Surface-Area Activated Carbon. Adv. Mater. 2000, 12, 62-65. [CrossRef]

19. Teng, H.; Wang, S.C. Preparation of porous carbons from phenol-formaldehyde resins with chemical and physical activation. Carbon 2000, 38, 817-824. [CrossRef]

20. Lee, H.M.; Kim, H.G.; Kang, S.J.; Park, S.J.; An, K.H.; Kim, B.J. Effects of pore structures on electrochemical behaviors of polyacrylonitrile (PAN)-based activated carbon nanofibers. J. Ind. Eng. Chem. 2015, 21, 736-740. [CrossRef]

21. Lee, H.M.; Kim, H.G.; An, K.H.; Kim, B.J. The Effect of $\mathrm{CO}_{2}$ Activation on the Electrochemical Performance of Coke-Based Activated Carbons for Supercapacitors. J. Nanosci. Nanotechnol. 2015, 15, 8797-8802. [CrossRef] [PubMed]

22. Chang, P.; Qin, Q. Hierarchical porous carbon materials with ultrahigh specific surface area prepared from coal for supercapacitors. Carbon Lett. 2018, 25, 117-121.

23. Grigorova, E.; Khristov, M.; Stoycheva, I.; Tsyntsarski, B. Effect of activated carbon from polyolefin wax on the hydrogensorption properties of magnesium. Int. J. Hydrogen Energy 2017, 42, 26872-26876. [CrossRef]

24. Feng, D.; Zhao, Y.; Zhang, Y.; Zhang, Z.; Zhang, L.; Gao, J.; Sun, S. Synergetic effects of biochar structure and AAEM species on reactivity of $\mathrm{H}_{2} \mathrm{O}$-activated biochar from cyclone air gasification. Int. J. Hydrogen Energy 2017, 42, 16045-16053. [CrossRef]

25. Pilon, L.; Wang, H.; d'Entremont, A. Recent Advances in Continuum Modeling of Interfacial and Transport Phenomena in Electric Double Layer Capacitors. J. Electrochem. Soc. 2015, 162, A5158-A5178. [CrossRef]

26. Chmiola, J.; Yushin, G.; Gogotsi, Y.; Portet, C.; Simon, P.; Taberna, P.L. Anomalous Increase in Carbon Capacitance at Pore Sizes Less Than 1 Nanometer. Science 2006, 313, 1760-1763. [CrossRef] [PubMed]

27. Largeot, C.; Portet, C.; Chmiola, J.; Taberna, P.L.; Gogotsi, Y.; Simon, P. Relation between the ion size and pore size for an electric double-layer capacitor. J. Am. Chem. Soc. 2008, 130, 2730-2731. [CrossRef]

28. Lee, H.M.; Kang, H.R.; An, K.H.; Kim, H.G.; Kim, B.J. Comparative studies of porous carbon nanofibers by various activation methods. Carbon Lett. 2013, 14, 180-185. [CrossRef]

29. Lee, H.M.; An, K.H.; Kim, B.J. Effects of carbonization temperature on pore development in polyacrylonitrile-based activated carbon nanofibers. Carbon Lett. 2014, 15, 146-150. [CrossRef]

30. Lee, H.M.; Kim, H.G.; An, K.H.; Kim, B.J. Effects of pore structures on electrochemical behaviors of polyacrylonitrile-based activated carbon nanofibers by carbon dioxide activation. Carbon Lett. 2014, 15, 71-76. [CrossRef]

31. Kim, K.W.; Lee, H.M.; Kim, B.S.; Hwang, S.H.; Kwac, L.K.; An, K.H.; Kim, B.J. Preparation and thermal properties of polyethylene-based carbonized fibers. Carbon Lett. 2015, 16, 62-66. [CrossRef]

32. Brunauer, S.; Emmett, P.H.; Teller, E. Adsorption of gases in multimolecular layers. J. Am. Chem. Soc. 1938, 60, 309-319. [CrossRef]

33. Kierlik, E.; Rosinberg, M.L. Free-energy density functional for the inhomogeneous hard-sphere fluid: Application to interfacial adsorption. Phys. Rev. A 1990, 42, 3382-3387. [CrossRef] [PubMed]

34. Barrett, E.P.; Joyner, L.G.; Halenda, P.P. The determination at pore volume and area distributions in porous substances. I. computation from nitrogen isotherms. J. Am. Chem. Soc. 1951, 73, 373-380. [CrossRef]

35. Sing, K.S.W.; Everett, D.H.; Haul, R.A.W.; Moscou, L.; Pierotti, R.A.; Rouquerol, J.; Siemieniewska, T. Reporting physisorption data for gas/solid systems with special reference to the determination of surface area and porosity. Pure Appl. Chem. 1985, 57, 603-619. [CrossRef]

36. De Boer, J.H. The structure and properties of porous materials. In Proceedings of the Tenth Symposium of the Colston Research Society, London, UK, 24-27 March 1958; pp. 68-94. 
37. Baek, J.; An, K.H.; Chung, D.C.; Kim, B.J. Correlation studies between pore structure and electrochemical performance of activated polymer-based hard carbon with various organic and aqueous electrolytes. Int. J. Energy Res. 2018, 42, 2927-2939. [CrossRef]

38. Lee, H.M.; An, K.H.; Chung, D.C.; Jung, S.C.; Park, Y.K.; Park, S.J.; Kim, B.J. Comparison studies on pore development mechanisms of activated hard carbons from polymeric resins and their applications for electrode materials. Renew. Energy 2019, in press. [CrossRef]

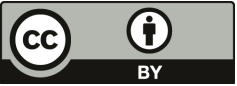

(C) 2019 by the authors. Licensee MDPI, Basel, Switzerland. This article is an open access article distributed under the terms and conditions of the Creative Commons Attribution (CC BY) license (http://creativecommons.org/licenses/by/4.0/). 

Article

\title{
Dual Substitution and Spark Plasma Sintering to Improve Ionic Conductivity of Garnet $\mathrm{Li}_{7} \mathrm{La}_{3} \mathrm{Zr}_{2} \mathrm{O}_{12}$
}

\author{
Zhencai Dong ${ }^{1,+}$, Chao $\mathrm{Xu}^{2,+}$, Yongmin $\mathrm{Wu}^{3}$, Weiping Tang ${ }^{3}$, Shufeng Song ${ }^{1, *}$, Jianyao Yao ${ }^{1, *}$, \\ Zhengyong Huang ${ }^{2}$, Zhaoyin Wen ${ }^{4}$, Li Lu ${ }^{5,6}$ and Ning $\mathrm{Hu}^{1,7,8, *}$ \\ 1 College of Aerospace Engineering, Chongqing University, Chongqing 400044, China; \\ 20163113037@cqu.edu.cn \\ 2 College of Electrical Engineering, Chongqing University, Chongqing 400044, China; \\ xuchao1995@cqu.edu.cn (C.X.); huangzhengyong@cqu.edu.cn (Z.H.) \\ 3 State Key Laboratory of Space Power-sources Technology, Shanghai Institute of Space Power-Sources, \\ Shanghai 200245, China; wuym2014@126.com (Y.W.); tangwp@sina.cn (W.T.) \\ 4 CAS Key Laboratory of Materials for Energy Conversion, Shanghai Institute of Ceramics, Chinese Academy \\ of Sciences, Shanghai 200050, China; zywen@mail.sic.ac.cn \\ 5 Department of Mechanical Engineering, National University of Singapore, Singapore 117575, Singapore; \\ luli@nus.edu.sg \\ 6 National University of Singapore Suzhou Research Institute, Suzhou 215024, China \\ 7 School of Mechanical Engineering, Hebei University of Technology, Tianjin 300401, China \\ 8 State Key Laboratory of Coal Mine Disaster Dynamics and Control, Chongqing University, \\ Chongqing 400044, China \\ * Correspondence: sfsong@cqu.edu.cn (S.S.); yaojianyao@cqu.edu.cn (J.Y.); ninghu@cqu.edu.cn (N.H.) \\ + These authors contributed equally to this work.
}

Received: 18 March 2019; Accepted: 8 May 2019; Published: 10 May 2019

\begin{abstract}
Garnet $\mathrm{Li}_{7} \mathrm{La}_{3} \mathrm{Zr}_{2} \mathrm{O}_{12}$ is one of the most promising solid electrolytes used for solid-state lithium batteries. However, low ionic conductivity impedes its application. Herein, we report Ta-doping garnets with compositions of $\mathrm{Li}_{7-\mathrm{x}} \mathrm{La}_{3} \mathrm{Zr}_{2-\mathrm{x}} \mathrm{Ta}_{\mathrm{x}} \mathrm{O}_{12}(0.1 \leq \mathrm{x} \leq 0.75)$ obtained by solid-state reaction and free sintering, which was facilitated by graphene oxide (GO). Furthermore, to optimize $\mathrm{Li}_{6.6} \mathrm{La}_{3} \mathrm{Zr}_{1.6} \mathrm{Ta}_{0.4} \mathrm{O}_{12}, \mathrm{Mg}^{2+}$ was select as a second dopant. The dual substitution of $\mathrm{Ta}^{5+}$ for $\mathrm{Zr}^{4+}$ and $\mathrm{Mg}^{2+}$ for $\mathrm{Li}^{+}$with a composition of $\mathrm{Li}_{6.5} \mathrm{Mg}_{0.05} \mathrm{La}_{3} \mathrm{Zr}_{1.6} \mathrm{Ta}_{0.4} \mathrm{O}_{12}$ showed an enhanced total ionic conductivity of $6.1 \times 10^{-4} \mathrm{~S} \mathrm{~cm}^{-1}$ at room temperature. Additionally, spark plasma sintering (SPS) was applied to further densify the garnets and enhance their ionic conductivities. Both SPS specimens present higher conductivities than those produced by the conventional free sintering. At room temperature, the highest ionic conductivity of $\mathrm{Li}_{6.5} \mathrm{Mg}_{0.05} \mathrm{La}_{3} \mathrm{Zr}_{1.6} \mathrm{Ta}_{0.4} \mathrm{O}_{12}$ sintered at $1000{ }^{\circ} \mathrm{C}$ is $8.8 \times 10^{-4} \mathrm{~S} \mathrm{~cm}^{-1}$, and that of $\mathrm{Li}_{6.6} \mathrm{La}_{3} \mathrm{Zr}_{1.6} \mathrm{Ta}_{0.4} \mathrm{O}_{12}$ sintered at $1050{ }^{\circ} \mathrm{C}$ is $1.18 \times 10^{-3} \mathrm{~S} \mathrm{~cm}^{-1}$.
\end{abstract}

Keywords: garnet; dual substitution; spark plasma sintering; conductivity

\section{Introduction}

Nowadays, commercial lithium ion batteries generally employ organic liquid electrolytes, which have caused a series of problems and hindered development of the batteries. The formation of lithium dendrites during cycling lurks between the solid-liquid interface because of the uneven distribution of current and lithium ions, causing safety issues. Moreover, the liquid electrolytes are flammable, exacerbating these safe issues. Therefore, the replacement of liquid electrolytes with solid ones for lithium batteries is of great significance [1,2]. All-solid-state lithium batteries have been widely studied for electric vehicles, rail transit, energy storage and aerospace fields, because of their promising energy density, long cycling life and excellent safety. As one of the most promising solid electrolytes, the lithium-rich garnet-type compound with a nominal composition of $\mathrm{Li}_{7} \mathrm{La}_{3} \mathrm{Zr}_{2} \mathrm{O}_{12}$ (LLZO) has 
many advantages, especially in Li-ion conductivity [3,4]. It has been shown that LLZO exists in two phases, namely a tetragonal phase with an inferior Li-ion conductivity of about $10^{-6} \mathrm{~S} \mathrm{~cm}^{-1}$ at room temperature, and a cubic phase with a superior Li-ion conductivity of about $10^{-4} \mathrm{~S} \mathrm{~cm}^{-1}$ at room temperature. In order to achieve higher conductivities, the content of Li is usually decreased below $7 \mathrm{Li}$ per formula unit, while the concentration of Li vacancies is increased in LLZO through substitution. It was reported that the replacement of $\mathrm{Zr}^{4+}$ with $\mathrm{Ta}^{5+}$ in LLZO is an effective route to increase the concentration of $\mathrm{Li}$ vacancies and to stabilize the cubic garnet [5]. The other effective solutions to reduce the $\mathrm{Li}$ content are through adding dopants like $\mathrm{Al}^{3+}, \mathrm{Ga}^{3+}$, etc. [6,7]. The principle is occupying the Li sites directly as the same as the substitution at the $\mathrm{Zr}$ sites. Among the dopants, $\mathrm{Mg}^{2+}$ has been reported as a sintering aid which can lower the sintering temperature and improve the relative density. $\mathrm{Mg}^{2+}$ serves as a sintering aid with a mechanism of grain-boundary diffusion and simultaneously suppresses the recrystallization [8]. The most common method for preparing garnet-type solid electrolytes is through the solid state method (SSR) and free sintering, which is widely applied in industry due to its low cost. However, under the condition of a high sintering temperature $\left(>1200{ }^{\circ} \mathrm{C}\right)$ and a long sintering time $(>16 \mathrm{~h})$, it is hard to obtain dense ceramic pellets (relative density $>90 \%$ ) by free sintering. As a result, various advanced sintering technologies have been developed to enhance the relative density, such as hot pressing, flowing oxygen sintering, field-assisted sintering and spark plasma sintering (SPS). It has been reported that the sintering theory of SPS, also famous as field assisted sintering technique (FAST) and pulsed electric current sintering (PECS), is different from the conventional sintering technique. In the sintering process, the DC current flowing through the graphite die generates huge local joule heat. Combining with the uniaxial high pressure, the contact area between particles starts to fuse, resulting in rapid densification $[9,10]$. This principle can effectively improve the relative density and lower the sintering temperature. Besides, it greatly shortens the sintering time and simplifies the process because the sinter does not need the mother powders to compensate the loss of lithium in the vacuum environment [11].

In this work, we investigated a Ta-doped garnet composed of $\mathrm{Li}_{7-\mathrm{x}} \mathrm{La}_{3} \mathrm{Zr}_{2-\mathrm{x}} \mathrm{Ta}_{\mathrm{x}} \mathrm{O}_{12}(\mathrm{x}=0.75,0.6$, $0.5,0.4,0.3,0.2,0.1)$ (LLZTO) through the traditional method. The preparation process was facilitated by graphene oxide (GO) and was divided into two procedures. Firstly, the raw material was calcined to a cubic precursor at $900{ }^{\circ} \mathrm{C}$ with $1 \mathrm{wt} . \%$ GO with respect to the total mass of the starting materials. The cubic precursor was then sintered at a relatively high temperature. By using GO as a sacrificial template, a nanoscale garnet powder with superior sinterability was produced [12,13]. Furthermore, the LLZTO composition was optimized, and Mg was served as the second dopant to further increase the conductivity. In order to compare with the conventional free sintering method and to further improve the ionic conductivity, the optimized Ta-doping and $\mathrm{Ta} / \mathrm{Mg}$ dual substituted samples were sintered via spark plasma sintering.

\section{Experimental}

\subsection{Synthesis and Free Sintering}

LLZTO powders were synthesized by a traditional solid-state method. The primary materials include $\mathrm{LiNO}_{3}$ ( $\geq 99.9 \%$, Shanghai Aladdin Biochemical Technology Co. Ltd, Shanghai, China), $\mathrm{MgO}$ (98.0\%, Shanghai Aladdin Biochemical Technology Co. Ltd, Shanghai, China), $\mathrm{La}_{2} \mathrm{O}_{3}(99.9 \%$, Shanghai Aladdin Biochemical Technology Co. Ltd, Shanghai, China), ZrO 2 (99.99\%, Shanghai Aladdin Biochemical Technology Co. Ltd, Shanghai, China), and $\mathrm{Ta}_{2} \mathrm{O}_{5}(99.5 \%$, Shanghai Aladdin Biochemical Technology Co. Ltd, Shanghai, China). During the sintering process, a portion of the lithium salt is decomposed into $\mathrm{Li}_{2} \mathrm{O}$ and lost at high temperature [14]. To compensate for the lithium loss, an excess of $\mathrm{LiNO}_{3}$ is added. Actually, we tried different amounts of $\mathrm{LiNO}_{3}$ excess and found that the 40 wt.\% excess was better. It was reported that the excess $\mathrm{Li}_{2} \mathrm{O}$ can densify the lithium garnet by forming glass-like compound at the grain-boundaries, and thus improve the ionic conductivity [15]. $\mathrm{La}_{2} \mathrm{O}_{3}$ was dried at $900{ }^{\circ} \mathrm{C}$ for $12 \mathrm{~h}$ to remove the moisture. A total amount of $1 \mathrm{wt} . \% \mathrm{GO}$ with respect to the 
total mass of the starting materials was added to inhibit the aggregation and to obtain the nano-grains of garnet powders. The preparation of GO adopted an improved Hummers method [16-19]. Firstly, a 10:1 mixture of concentrated $\mathrm{H}_{2} \mathrm{SO}_{4} / \mathrm{H}_{3} \mathrm{PO}_{4}(250: 25 \mathrm{~mL})$ was added to $2 \mathrm{~g}$ graphite flakes (XFNAN, $99.5 \mathrm{wt} . \%, 500 \mu \mathrm{m})$ and a slight exotherm was observed. Then, the mixed solution was placed in an ice bath, and $12 \mathrm{~g} \mathrm{KMnO}_{4}$ was slowly added. The solution was well-stirred after being transferred to a magnetic mixer with a constant temperature of $50{ }^{\circ} \mathrm{C}$. After cooling to room temperature, the mixture of $9.56 \mathrm{~mL} \mathrm{30 \%} \mathrm{H}_{2} \mathrm{O}_{2}$ and $134 \mathrm{~mL}$ deionized water was added to the above solution to end the oxidation reaction. To wipe off impurities such as $\mathrm{K}, \mathrm{P}$, and $\mathrm{Mn}$, it is necessary to control the purification process. The raw GO solution was filtered to remove solid impurities and dialyzed through a semi-permeable membrane to remove soluble impurities. Subsequently, the solution was separated into centrifuge tubes and washed by deionized water and dilute hydrochloric acid alternately until the solution approaching to a neutral $\mathrm{pH}$. Finally, the GO solution with a concentration of $3.1 \mathrm{mg} / \mathrm{mL}$ was obtained.

The stoichiometric materials with the GO solution were mixed and ball-milled for $4 \mathrm{~h}$ in 3-Methyl-1-butanol (98.5\%, Aladdin) with a planetary ball-mill machinery, in which zirconia balls and a jar were used. The milling powder was dried in an oven for $3 \mathrm{~h}$ at $90{ }^{\circ} \mathrm{C}$ and pressed into cylindrical pellets. The pellets were placed on a $\mathrm{MgO}$ ceramic wafer in an $\mathrm{Al}_{2} \mathrm{O}_{3}$ crucible so as to isolate from other elements contaminations. After calcined at $900{ }^{\circ} \mathrm{C}$ for $3 \mathrm{~h}$ in air, the pellets were ground to LLZTO powders, and the second ball-milling process was repeated. Then, the LLZTO powders were dried and pressed into cylindrical pellets. Similarly, the samples were covered with corresponding mother powers to reduce lithium loss and sintered at $1100{ }^{\circ} \mathrm{C}$ for $12 \mathrm{~h}$. The obtained ceramic pellets were polished using metallographic abrasive papers with grit numbers of 180, 600 and 1200, respectively. The chemical reactions occurring during the synthesis of LLZTO are as follows:

$$
\begin{gathered}
4(7-x) \mathrm{LiNO}_{3}+6 \mathrm{La}_{2} \mathrm{O}_{3}+4(2-\mathrm{x}) \mathrm{ZrO}_{2}+2 \mathrm{xTa}_{2} \mathrm{O}_{5}=4 \mathrm{Li}_{7-\mathrm{x}} \mathrm{La}_{3} \mathrm{Zr}_{2-\mathrm{x}} \mathrm{Ta}_{\mathrm{x}} \mathrm{O}_{12}+4(7-\mathrm{x}) \mathrm{NO}_{2} \uparrow+(7-\mathrm{x}) \mathrm{O}_{2} \uparrow \\
260 \mathrm{LiNO}_{3}+2 \mathrm{MgO}+60 \mathrm{La}_{2} \mathrm{O}_{3}+64 \mathrm{ZrO}_{2}+8 \mathrm{Ta}_{2} \mathrm{O}_{5}=40 \mathrm{Li}_{6.5} \mathrm{Mg}_{0.05} \mathrm{La}_{3} \mathrm{Zr}_{1.6} \mathrm{Ta}_{0.4} \mathrm{O}_{12}+260 \mathrm{NO}_{2} \uparrow+65 \mathrm{O}_{2} \uparrow
\end{gathered}
$$

\subsection{SPS Sintering}

The optimized Ta doping and $\mathrm{Mg} / \mathrm{Ta}$ dual substituted garnets were further sintered by SPS at different temperatures $\left(950^{\circ} \mathrm{C}, 100{ }^{\circ} \mathrm{C}\right.$ and $\left.1050{ }^{\circ} \mathrm{C}\right)$ for $10 \mathrm{~min}$. The SPS procedure was conducted on a SPS machine (SPS-211Lx, Fuji Radio Engineering Machinery Co., Ltd, Nagoya-shi, Japan) using a graphite mold (30 $\mathrm{mm}$ in height $\times 10.5 \mathrm{~mm}$ in diameter) with two corresponding punches $(10 \mathrm{~mm}$ in diameter). Prior to the SPS process, the above-mentioned ceramic chips after testing were re-ground and sieved to obtain uniform fine particles so that the powders could have a better sintering during the SPS procedure. In order to demold easily, the inserted sheets were used to separate the powders and the graphite mold. The SPS was conducted in the vacuum chamber and the heating rate was set to $50{ }^{\circ} \mathrm{C} \mathrm{min}^{-1}$. When the temperature was raised to the target sintering temperature, a static uniaxial pressure of $50 \mathrm{MPa}$ was applied to the samples. After holding for $10 \mathrm{~min}$, the specimens in the chamber were cooled naturally to $600{ }^{\circ} \mathrm{C}$ with pressure decreasing to $5 \mathrm{MPa}$, which contributes the densification of the samples during shrinking. Then, the pressure was removed to avoid the formation of cracks as the temperature naturally cooled down to room temperature. All the procedures were implemented through the setup program controlled under the automatic operation mode. The sintered samples obtained by SPS were polished by the same way as that for previous sintered pellets.

\subsection{Characterization}

The relative density was calculated using the following equation:

$$
\mathrm{d}=\frac{m}{\rho \pi r^{2} l} \times 100 \%
$$




$$
\rho=\frac{M Z}{N_{A} V}
$$

where, $m$ represents the mass, $r$ represents the radius, and $l$ represents the height of the cylinders. The relative density is the ratio of the measured density at room temperature to the theoretical density . . $M, Z$ and $N_{A}$ represent the molecular mass, number of molecular per unit cell, and Avogadro's constant, respectively. $V$ represents the cell volume which is decided by the lattice parameter. The final sample is a cylinder-shaped product. The phases of the powders calcined at $900{ }^{\circ} \mathrm{C}$ and $1100{ }^{\circ} \mathrm{C}$ were examined by X-ray diffraction (XRD, D2 PHASER, Bruker, Beijing, China) in the $2 \theta$ range of $10^{\circ}$ and $80^{\circ}$. The X-ray data were collected with a step of $0.01^{\circ}$ and a counting time of $0.3 \mathrm{~s}$ per step. The cross-sectional morphologies of the pellets were revealed by scanning electron microscopy (SEM, Phenom ProX, Eindhoven, The Netherlands) with an acceleration voltage of $15 \mathrm{kV}$. Electrochemical impedance spectroscopy (EIS) measurements were conducted on the polished pellets. Both surfaces of the pellet were coated with a silver paste as block electrodes. Since the garnet-type electrolyte is prone to react with moisture and carbon dioxide in the air, all ceramic pellets were encapsulated in Swagelok cells in a glove box filled with inert gas. The samples were measured in the temperature range of room temperature and $130{ }^{\circ} \mathrm{C}$. An amplitude of $10 \mathrm{mV}$ and a frequency of $1 \mathrm{MHz}-0.1 \mathrm{~Hz}$ were set on an Autolab PGSTAT302N System. The ionic conductivities were then calculated based on the following equation:

$$
\sigma=\frac{l}{\pi r^{2} R}
$$

where, $l$ represents the height of the cylinders, $r$ represents the radius and $R$ represents the resistance obtained from the impedance chart. Furthermore, the activation energy $E_{a}$, representing the migration barrier of ions, was calculated by the Arrhenius equation:

$$
\sigma \mathrm{T}=\operatorname{Aexp}\left(-E_{a} / \mathrm{kT}\right)
$$

where, A, k, and T represent the pre-exponential parameter, Boltzmann constant, and thermodynamic temperature, respectively.

\section{Results and Discussion}

LLZTO powder was synthesized by solid-state reaction with GO as the sacrificial template. As seen in Figure 1a,b, the grain size of the LLZTO powder is about 10-20 nm in the presence of GO, whereas, the grains are 20-30 nm in size and irregular morphology in the absence of GO. It is indicated that the regular and fine grains facilitated sinter, though the aggregation was not completely prevented by GO. The XRD patterns of the Ta-doping garnets with compositions of $\mathrm{Li}_{7-\mathrm{x}} \mathrm{La}_{3} \mathrm{Zr}_{2-\mathrm{x}} \mathrm{Ta}_{\mathrm{x}} \mathrm{O}_{12}(\mathrm{x}=0.75$, $0.6,0.5,0.4,0.3,0.2,0.1)$ calcined at $900{ }^{\circ} \mathrm{C}$ and sintered at $1100^{\circ} \mathrm{C}$ are shown in Figure $1 \mathrm{c}, \mathrm{d}$. As seen in Figure $1 \mathrm{c}$, all the components formed the cubic phase after calcined at $900{ }^{\circ} \mathrm{C}$ except in the range of $x \leq 0.2$, where the mixed cubic and tetragonal phases were found.

It should be noted that the garnets with compositions of $\mathrm{Li}_{6.9} \mathrm{La}_{3} \mathrm{Zr}_{1.9} \mathrm{Ta}_{0.1} \mathrm{O}_{12}$ and $\mathrm{Li}_{6.8} \mathrm{La}_{3} \mathrm{Zr}_{1.8} \mathrm{Ta}_{0.2} \mathrm{O}_{12}$ were not well-pelleted after sintering at $1100{ }^{\circ} \mathrm{C}$. Therefore, the XRD patterns of $\mathrm{Li}_{6.9} \mathrm{La}_{3} \mathrm{Zr}_{1.9} \mathrm{Ta}_{0.1} \mathrm{O}_{12}$ and $\mathrm{Li}_{6.8} \mathrm{La}_{3} \mathrm{Zr}_{1.8} \mathrm{Ta}_{0.2} \mathrm{O}_{12}$ are not presented in Figure $1 \mathrm{~d}$. As seen in Figure $1 \mathrm{~d}$, the garnets with compositions of $\mathrm{Li}_{6.7} \mathrm{La}_{3} \mathrm{Zr}_{1.7} \mathrm{Ta}_{0.3} \mathrm{O}_{12}$ and $\mathrm{Li}_{6.6} \mathrm{La}_{3} \mathrm{Zr}_{1.6} \mathrm{Ta}_{0.4} \mathrm{O}_{12}$ showed the single cubic garnet phase, whereas the garnets with the Ta content of above 0.4 contained some impurities. The single cubic phase indicates fast ion conduction while the impurities hinder ion conduction. The following EIS results also demonstrated the influence of Ta substitution on ionic conductivity. 

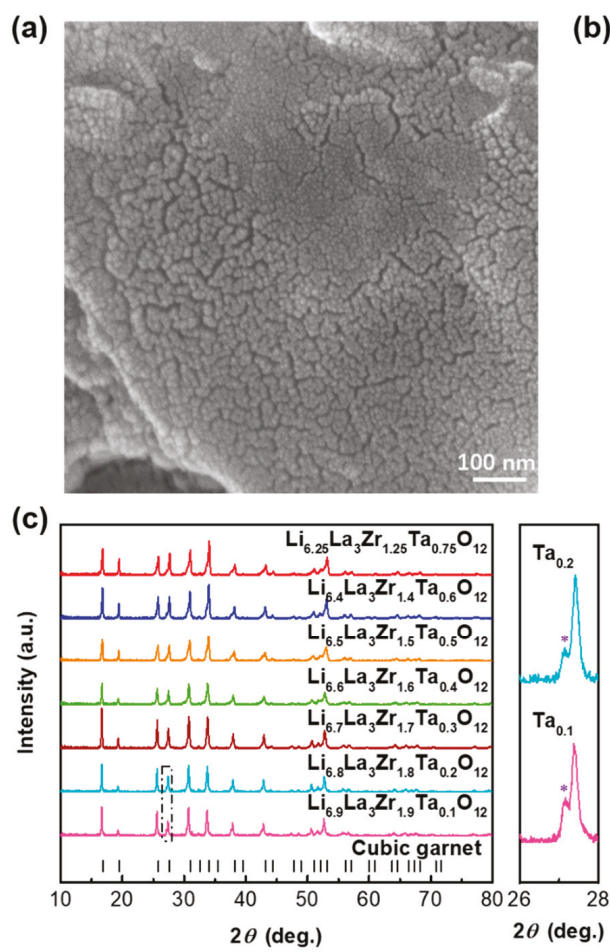

(b)

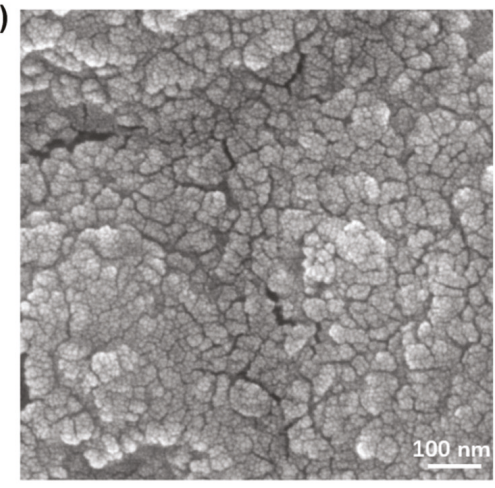

(d)

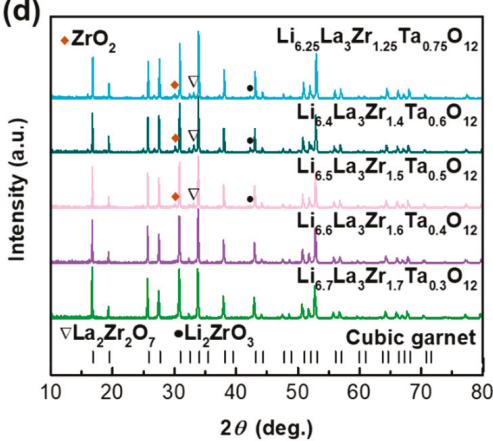

Figure 1. SEM of LLZTO calcined at $900{ }^{\circ} \mathrm{C}$ with GO (a) and without GO (b). The XRD results of the Ta-doping and Ta/Mg-dual substituted garnet calcined at $900{ }^{\circ} \mathrm{C}(\mathbf{c})$ and sintered at $1100{ }^{\circ} \mathrm{C}(\mathrm{d})$. The black vertical lines at the bottom represent the reference cubic garnet (PDF\#45-0109).

The relative densities and ionic conductivities of $\mathrm{Li}_{7-x} \mathrm{La}_{3} \mathrm{Zr}_{2-\mathrm{x}} \mathrm{Ta}_{\mathrm{x}} \mathrm{O}_{12}(\mathrm{x}=0.75,0.6,0.5,0.4,0.3,0.2$, $0.1)$ sintering by traditional methods are shown in Figure 2. The growing and following declining trend is for relative density to vary with addition of Ta. It is indicated that the enhancement of sinterability might have a significant impact on conductivities. Not unexpectedly, the ionic conductivity showed a noticeable variation. Obviously, it is increased firstly and then decreased with the substitution of Ta for $\mathrm{Zr}$. $\mathrm{Li}_{6.6} \mathrm{La}_{3} \mathrm{Zr}_{1.6} \mathrm{Ta}_{0.4} \mathrm{O}_{12}$ possessed the highest conductivity of about $5.6 \times 10^{-4} \mathrm{~S} \mathrm{~cm}^{-1}$. The increase in relative density is highly beneficial to ion conduction. However, it seems that the variation of ionic conductivity is not always consistent with that of relative density, which proves that relative density is not the unique factor affecting ion conductivity. Besides, the ion conduction was also determined by the crystal structure and the $\mathrm{Li}$ content. An excess substitution of $\mathrm{Ta}$ for $\mathrm{Zr}$ led to impurities and a low Li content, which in turn decreased the ionic conductivity. 


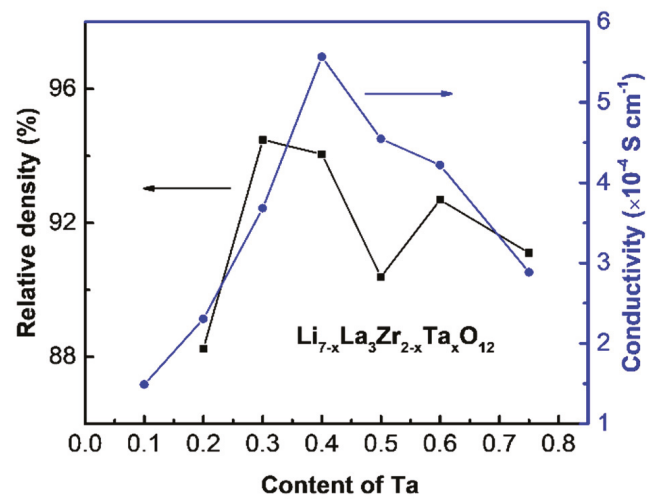

Figure 2. Relative density and ionic conductivity of LLZTO sintering pellets of various components.

The refined lattice parameters of LLZTO have been reported by some groups [20-24]. It can be seen from Table 1 that the lattice parameter of LLZTO increases with the increasing content of Ta. Based on the lattice parameters, the theoretical densities and corresponding relative densities are calculated by Equations (3) and (4).

Table 1. Corresponding lattice parameters reported in the literature and the calculated theoretical densities and relative densities of LLZTO.

\begin{tabular}{lcccc}
\hline \multicolumn{1}{c}{ Compound } & Lattice Parameter (Å) & Ref. & Theoretical Density $\left(\mathrm{g} \mathrm{cm}^{-\mathbf{3}}\right)$ & Relative Density (\%) \\
\hline $\mathrm{Li}_{6.25} \mathrm{La}_{3} \mathrm{Zr}_{1.25} \mathrm{Ta}_{0.75} \mathrm{O}_{12}$ & $12.91553(6)$ & {$[20]$} & 5.561 & 91.10 \\
$\mathrm{Li}_{6.4} \mathrm{La}_{3} \mathrm{Zr}_{1.4} \mathrm{Ta}_{0.6} \mathrm{O}_{12}$ & 12.923 & {$[21]$} & 5.551 & 92.69 \\
$\mathrm{Li}_{6.5} \mathrm{La}_{3} \mathrm{Zr}_{1.5} \mathrm{Ta}_{0.5} \mathrm{O}_{12}$ & 12.9340 & {$[23]$} & 5.410 & 90.24 \\
$\mathrm{Li}_{6.6} \mathrm{La}_{3} \mathrm{Zr}_{1.6} \mathrm{Ta}_{0.4} \mathrm{O}_{12}$ & 12.939 & {$[24]$} & 5.352 & 94.05 \\
$\mathrm{Li}_{6.7} \mathrm{La}_{3} \mathrm{Zr}_{1.7} \mathrm{Ta}_{0.3} \mathrm{O}_{12}$ & 12.9721 & {$[21]$} & 5.261 & 94.48 \\
$\mathrm{Li}_{6.8} \mathrm{La}_{3} \mathrm{Zr}_{1.8} \mathrm{Ta}_{0.2} \mathrm{O}_{12}$ & 12.9780 & {$[22]$} & 5.203 & 88.24 \\
\hline
\end{tabular}

We subsequently designed a dual substitution of $\mathrm{Mg}$ for $\mathrm{Li}$ and $\mathrm{Ta}$ for $\mathrm{Zr}$ with a composition of $\mathrm{Li}_{6.5} \mathrm{Mg}_{0.05} \mathrm{La}_{3} \mathrm{Zr}_{1.6} \mathrm{Ta}_{0.4} \mathrm{O}_{12}$ based on the optimal composition of $\mathrm{Li}_{6.6} \mathrm{La}_{3} \mathrm{Zr}_{1.6} \mathrm{Ta}_{0.4} \mathrm{O}_{12}$, because $\mathrm{Mg}$ is usually used as the sintering aid. As seen in Figure 3a, the XRD patterns show that $\mathrm{Li}_{6.5} \mathrm{Mg}_{0.05} \mathrm{La}_{3} \mathrm{Zr}_{1.6} \mathrm{Ta}_{0.4} \mathrm{O}_{12}$ exhibits a single cubic phase after calcined at $900{ }^{\circ} \mathrm{C}$, which would be a beneficial effect on the final sinter. $\mathrm{Li}_{6.5} \mathrm{Mg}_{0.05} \mathrm{La}_{3} \mathrm{Zr}_{1.6} \mathrm{Ta}_{0.4} \mathrm{O}_{12}$ demonstrated a single cubic phase after sintered at $1100{ }^{\circ} \mathrm{C}$. The cubic $\mathrm{Li}_{6.5} \mathrm{Mg}_{0.05} \mathrm{La}_{3} \mathrm{Zr}_{1.6} \mathrm{Ta}_{0.4} \mathrm{O}_{12}$ exhibited a relatively high conductivity of $6.1 \times 10^{-4} \mathrm{~S} \mathrm{~cm}^{-1}$ compared with that of $\mathrm{Li}_{6.6} \mathrm{La}_{3} \mathrm{Zr}_{1.6} \mathrm{Ta}_{0.4} \mathrm{O}_{12}$ (Figure 3b). The improved ionic conductivity is probably because the dual substitution promotes the densification and adjusts the Li content.

Figure $4 \mathrm{a}$ shows the relative densities and ionic conductivities of $\mathrm{Li}_{6.6} \mathrm{La}_{3} \mathrm{Zr}_{1.6} \mathrm{Ta}_{0.4} \mathrm{O}_{12}$ and $\mathrm{Li}_{6.5} \mathrm{Mg}_{0.05} \mathrm{La}_{3} \mathrm{Zr}_{1.6} \mathrm{Ta}_{0.4} \mathrm{O}_{12}$ sintered at different temperatures $\left(950{ }^{\circ} \mathrm{C}, 1000{ }^{\circ} \mathrm{C}\right.$, and $\left.1050{ }^{\circ} \mathrm{C}\right)$ by SPS. Since the $\mathrm{Mg}$ content is very low, the lattice parameter of $\mathrm{Li}_{6.5} \mathrm{Mg}_{0.05} \mathrm{La}_{3} \mathrm{Zr}_{1.6} \mathrm{Ta}_{0.4} \mathrm{O}_{12}$ should be similar with that of $\mathrm{Li}_{6.6} \mathrm{La}_{3} \mathrm{Zr}_{1.6} \mathrm{Ta}_{0.4} \mathrm{O}_{12}$ (12.939 $\AA$ [24]). For the relative density, both components showed a general increasing trend with the increase of SPS temperature, indicating that the increasing SPS temperature is in favour of densification. The room-temperature conductivity of the Ta-doping garnet $\mathrm{Li}_{6.6} \mathrm{La}_{3} \mathrm{Zr}_{1.6} \mathrm{Ta}_{0.4} \mathrm{O}_{12}$ was increased with the SPS temperature. $\mathrm{Li}_{6.6} \mathrm{La}_{3} \mathrm{Zr}_{1.6} \mathrm{Ta}_{0.4} \mathrm{O}_{12}$ possessed the highest total (bulk + grain boundary) ionic conductivity of $1.18 \times 10^{-3} \mathrm{~S} \mathrm{~cm}^{-1}$ after treating at a SPS temperature of $1050{ }^{\circ} \mathrm{C}$, while the $\mathrm{Mg} / \mathrm{Ta}$ dual substituted $\mathrm{Li}_{6.5} \mathrm{Mg}_{0.05} \mathrm{La}_{3} \mathrm{Zr}_{1.6} \mathrm{Ta}_{0.4} \mathrm{O}_{12}$ exhibited a different variation. $\mathrm{Li}_{6.5} \mathrm{Mg}_{0.05} \mathrm{La}_{3} \mathrm{Zr}_{1.6} \mathrm{Ta}_{0.4} \mathrm{O}_{12}$ showed the highest total ionic conductivity of $8.8 \times 10^{-4} \mathrm{~S} \mathrm{~cm}^{-1}$ after treating at a SPS temperature of $1000{ }^{\circ} \mathrm{C}$. It indicated that the relatively high lithium content resulted in a relatively high ionic conductivity under a similar densification 
condition. Clearly, the SPS procedure enhanced the ionic conductivity compared with the traditional solid-state reaction. Figure $4 \mathrm{~b}$ shows the dependence of the ionic conductivities on the temperatures for both $\mathrm{Li}_{6.6} \mathrm{La}_{3} \mathrm{Zr}_{1.6} \mathrm{Ta}_{0.4} \mathrm{O}_{12}$ and $\mathrm{Li}_{6.5} \mathrm{Mg}_{0.05} \mathrm{La}_{3} \mathrm{Zr}_{1.6} \mathrm{Ta}_{0.4} \mathrm{O}_{12}$ in the range between room temperature and $130{ }^{\circ} \mathrm{C}$. It can be seen that both samples have a great thermal stability and the activation energies of $\mathrm{Li}_{6.6} \mathrm{La}_{3} \mathrm{Zr}_{1.6} \mathrm{Ta}_{0.4} \mathrm{O}_{12}$ and $\mathrm{Li}_{6.5} \mathrm{Mg}_{0.05} \mathrm{La}_{3} \mathrm{Zr}_{1.6} \mathrm{Ta}_{0.4} \mathrm{O}_{12}$ were calculated to be $0.27 \mathrm{eV}$ and $0.32 \mathrm{eV}$, respectively.

(a)

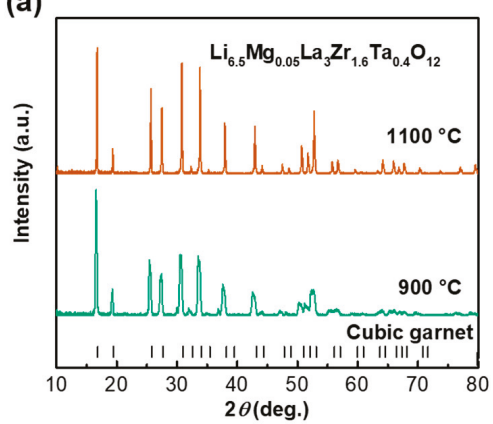

\section{(b)}

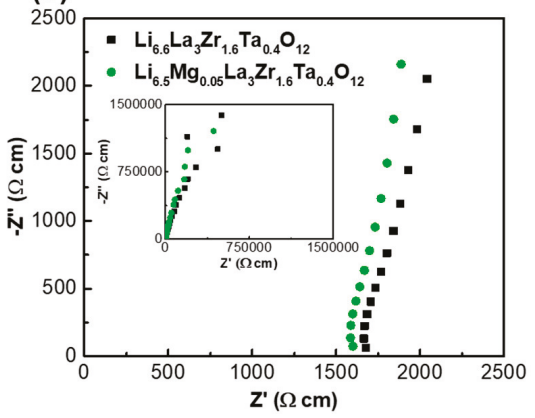

Figure 3. (a) $\mathrm{XRD}$ of $\mathrm{Li}_{6.5} \mathrm{Mg}_{0.05} \mathrm{La}_{3} \mathrm{Zr}_{1.6} \mathrm{Ta}_{0.4} \mathrm{O}_{12}$ treated at $900{ }^{\circ} \mathrm{C}$ and $1100{ }^{\circ} \mathrm{C}$. (b) Nyquist plots of $\mathrm{Li}_{6.6} \mathrm{La}_{3} \mathrm{Zr}_{1.6} \mathrm{Ta}_{0.4} \mathrm{O}_{12}$ and $\mathrm{Li}_{6.5} \mathrm{Mg}_{0.05} \mathrm{La}_{3} \mathrm{Zr}_{1.6} \mathrm{Ta}_{0.4} \mathrm{O}_{12}$ sintered by free sintering; the insets are impedance plots $(10 \mathrm{~Hz}-1 \mathrm{MHz})$ measured in air at room temperature.
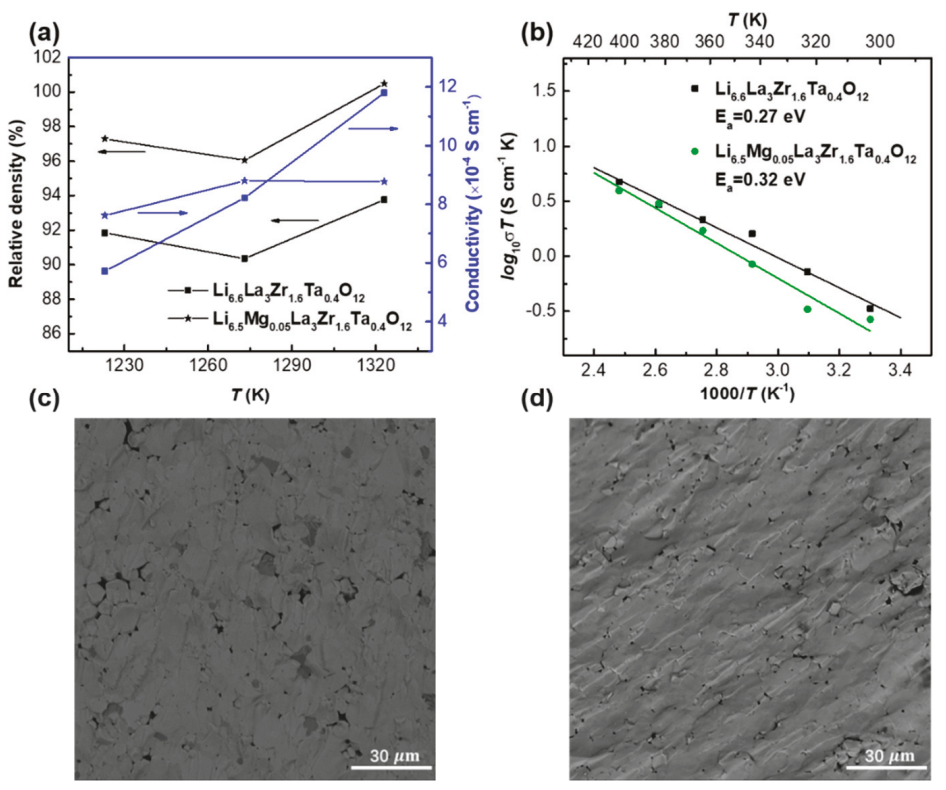

Figure 4. (a) Relative densities and ionic conductivities of $\mathrm{Li}_{6.6} \mathrm{La}_{3} \mathrm{Zr}_{1.6} \mathrm{Ta}_{0.4} \mathrm{O}_{12}$ and $\mathrm{Li}_{6.5} \mathrm{Mg}_{0.05} \mathrm{La}_{3} \mathrm{Zr}_{1.6} \mathrm{Ta}_{0.4} \mathrm{O}_{12}$ sintered by SPS at different temperatures. (b) Arrhenius plots of total ionic conductivities of $\mathrm{Li}_{6.6} \mathrm{La}_{3} \mathrm{Zr}_{1.6} \mathrm{Ta}_{0.4} \mathrm{O}_{12}$ and $\mathrm{Li}_{6.5} \mathrm{Mg}_{0.05} \mathrm{La}_{3} \mathrm{Zr}_{1.6} \mathrm{Ta}_{0.4} \mathrm{O}_{12}$ sintered by SPS. The dash points are experimental values and the solid lines are the fitting ones. The cross-section SEM of $\mathrm{Li}_{6.6} \mathrm{La}_{3} \mathrm{Zr}_{1.6} \mathrm{Ta}_{0.4} \mathrm{O}_{12}(\mathbf{c})$ and of $\mathrm{Li}_{6.5} \mathrm{Mg}_{0.05} \mathrm{La}_{3} \mathrm{Zr}_{1.6} \mathrm{Ta}_{0.4} \mathrm{O}_{12}(\mathbf{d})$ after conducting SPS at $1000{ }^{\circ} \mathrm{C}$. 
The cross-section SEM micrographs of the specimens obtained from the SPS process are shown in Figure 4c,d. It can be seen that SPS specimens possessed a remarkable densification, same with the previous reports $[9,10]$. The fracture only occurred within the grain, not at the grain boundary, indicating the cohesive force between particles was increased, which strengthened the integration of the grain boundary. The increased density of the microstructure improved the ion conduction.

The uniform distribution of garnet elements is illustrated in the EDS mapping. As shown in Figure 5, elements $\mathrm{La}, \mathrm{Zr}$, Ta, and $\mathrm{Mg}$ were uniformly distributed in the grains. There is no obvious trace of $\mathrm{Mg}$ in grain-boundaries, which proved that most of element $\mathrm{Mg}$ is probably integrated to the lattice.

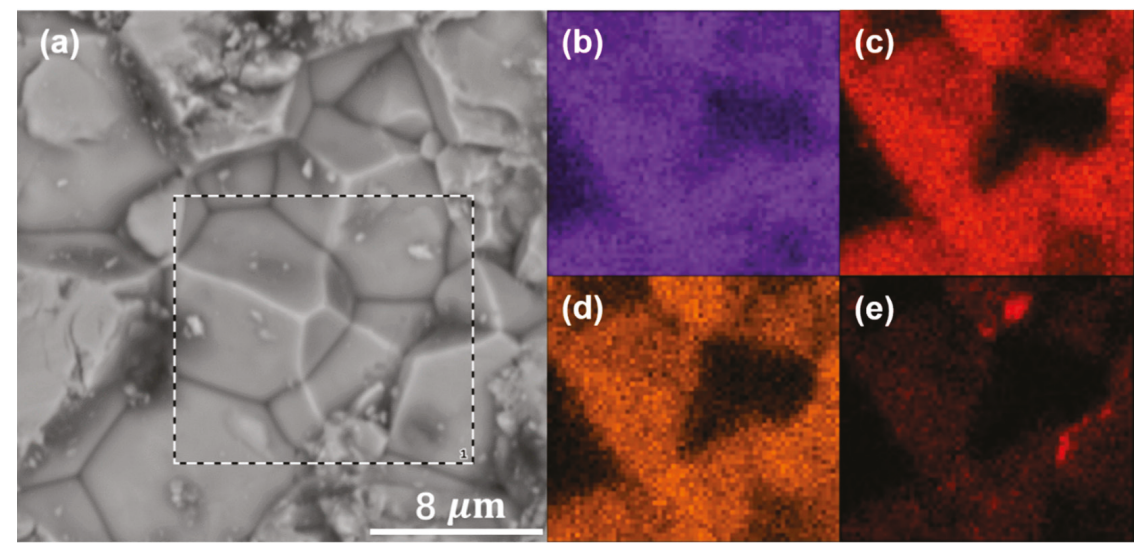

Figure 5. EDS mapping on the surface of $\mathrm{Li}_{6.5} \mathrm{Mg}_{0.05} \mathrm{La}_{3} \mathrm{Zr}_{1.6} \mathrm{Ta}_{0.4} \mathrm{O}_{12}$ sintered by SPS at $1050{ }^{\circ} \mathrm{C}$ : (a) mapping area, (b) La, (c) $\mathrm{Zr}$, (d) $\mathrm{Ta}$, and (e) $\mathrm{Mg}$.

\section{Conclusions}

In summary, the dual substitution of $\mathrm{Ta}$ for $\mathrm{Zr}$ and $\mathrm{Mg}$ for $\mathrm{Li}$ on the structure and performance of garnet $\mathrm{Li}_{7} \mathrm{La}_{3} \mathrm{Zr}_{2} \mathrm{O}_{12}$ is investigated. The newly-developed garnet with a composition of $\mathrm{Li}_{6.5} \mathrm{Mg}_{0.05} \mathrm{La}_{3} \mathrm{Zr}_{1.6} \mathrm{Ta}_{0.4} \mathrm{O}_{12}$ shows a single cubic phase and exhibits a relatively high total ionic conductivity of $6.1 \times 10^{-4} \mathrm{~S} \mathrm{~cm}^{-1}$, which is slightly higher than that of bare $\mathrm{Li}_{6.6} \mathrm{La}_{3} \mathrm{Zr}_{1.6} \mathrm{Ta}_{0.4} \mathrm{O}_{12}$. It may be because the dopant $\mathrm{Mg}$ facilitates the densification. Spark plasma sintering is further applied on $\mathrm{Li}_{6.6} \mathrm{La}_{3} \mathrm{Zr}_{1.6} \mathrm{Ta}_{0.4} \mathrm{O}_{12}$ and $\mathrm{Li}_{6.5} \mathrm{Mg}_{0.05} \mathrm{La}_{3} \mathrm{Zr}_{1.6} \mathrm{Ta}_{0.4} \mathrm{O}_{12}$. The results verify that the SPS process is an effective technology to densify the cubic garnet. Both $\mathrm{Li}_{6.6} \mathrm{La}_{3} \mathrm{Zr}_{1.6} \mathrm{Ta}_{0.4} \mathrm{O}_{12}$ and $\mathrm{Li}_{6.5} \mathrm{Mg}_{0.05} \mathrm{La}_{3} \mathrm{Zr}_{1.6} \mathrm{Ta}_{0.4} \mathrm{O}_{12}$ show dense microstructures at SPS temperature of $1000{ }^{\circ} \mathrm{C}$. $\mathrm{Li}_{6.6} \mathrm{La}_{3} \mathrm{Zr}_{1.6} \mathrm{Ta}_{0.4} \mathrm{O}_{12}$ possesses the highest room-temperature conductivity of $1.18 \times 10^{-3} \mathrm{~S} \mathrm{~cm}^{-1}$ after SPS treatment at $1050{ }^{\circ} \mathrm{C}$, while $\mathrm{Li}_{6.5} \mathrm{Mg}_{0.05} \mathrm{La}_{3} \mathrm{Zr}_{1.6} \mathrm{Ta}_{0.4} \mathrm{O}_{12}$ shows a conductivity of $8.8 \times 10^{-4} \mathrm{~S} \mathrm{~cm}^{-1}$ after SPS procedure at $1000^{\circ} \mathrm{C}$. It is indicated that the relatively high lithium content results in a high ionic conductivity under a similar densification condition.

Author Contributions: S.S. and N.H. conceived the ideas. Z.D. performed the synthesis and characterization of materials. C.X. carried out the SPS experiment part. S.S. and Z.D. analysed the data and wrote the paper. All authors discussed and commented on the paper.

Funding: This work was supported by the National Natural Science Foundation of China (No. 51702030, No. 11632004, and No. U1864208), Shanghai Aerospace Science and Technology Innovation Foundation (No. SAST2017-137), Chongqing University, the Fundamental Research Funds for the Central Universities (No. 2018CDXYHK0016), the Key Program for International Science and Technology Cooperation Projects of the Ministry of Science and Technology of China (No. 2016YFE0125900).

Conflicts of Interest: The authors declare no conflict of interest. 


\section{References}

1. Wang, Q.S.; Jiang, L.H.; Yu, Y.; Sun, J.H. Progress of enhancing the safety of lithium ion battery from the electrolyte aspect. Nano Energy 2019, 55, 93-114. [CrossRef]

2. Liu, X.Y.; Li, X.R.; Li, H.X.; Wu, H.B. Recent Progress of Hybrid Solid-State Electrolytes for Lithium Batteries. Chem.-Eur. J. 2018, 24, 18293-18306. [CrossRef] [PubMed]

3. Tsai, C.L.; Ma, Q.L.; Dellen, C.; Lobe, S.; Vondahlen, F.; Windmuller, A.; Gruner, D.; Zheng, H.; Uhlenbruck, S.; Finsterbusch, M.; et al. A garnet structure-based all-solid-state Li battery without interface modification: Resolving incompatibility issues on positive electrodes. Sustain. Energ. Fuels 2019, 3, 280-291. [CrossRef]

4. Yeandel, S.R.; Chapman, B.J.; Slater, P.R.; Goddard, P. Structure and lithium-ion dynamics in fluoride-doped cubic $\mathrm{Li}_{7} \mathrm{La}_{3} \mathrm{Zr}_{2} \mathrm{O}_{12}$ (LLZO) garnet for Li solid-state battery applications. J. Phys. Chem. C 2018, 122, 27811-27819. [CrossRef]

5. El-Shinawi, H.; Cussen, E.J.; Corr, S.A. Enhancement of the lithium ion conductivity of Ta-doped $\mathrm{Li}_{7} \mathrm{La}_{3} \mathrm{Zr}_{2} \mathrm{O}_{12}$ by incorporation of calcium. Dalton Trans. 2017, 46, 9415-9419. [CrossRef] [PubMed]

6. Allen, J.L.; Wolfenstine, J.; Rangasamy, E.; Sakamoto, J. Effect of substitution (Ta, Al, Ga) on the conductivity of $\mathrm{Li}_{7} \mathrm{La}_{3} \mathrm{Zr}_{2} \mathrm{O}_{12}$. J. Power Sources 2012, 206, 315-319. [CrossRef]

7. Wolfenstine, J.; Ratchford, J.; Rangasamy, E.; Sakamoto, J.; Allen, J.L. Synthesis and high Li-ion conductivity of Ga-stabilized cubic $\mathrm{Li}_{7} \mathrm{La}_{3} \mathrm{Zr}_{2} \mathrm{O}_{12}$. Mater. Chem. Phys. 2012, 134, 571-575. [CrossRef]

8. Yang, X.F.; Kong, D.B.; Chen, Z.P.; Sun, Y.Y.; Liu, Y.Q. Low-temperature fabrication for transparency Mg doping $\mathrm{Li}_{7} \mathrm{La}_{3} \mathrm{Zr}_{2} \mathrm{O}_{12}$ solid state electrolyte. J. Mater. Sci.-Mater. Electron. 2018, 29, 1523-1529. [CrossRef]

9. Zhang, Y.; Fei, C.; Rong, T.; Qiang, S.; Zhang, L. Field assisted sintering of dense Al-substituted cubic phase $\mathrm{Li}_{7} \mathrm{La}_{3} \mathrm{Zr}_{2} \mathrm{O}_{12}$ solid electrolytes. J. Power Sources 2014, 268, 960-964. [CrossRef]

10. Yamada, H.; Ito, T.; Basappa, R.H. Sintering mechanisms of high-performance garnet-type solid electrolyte densified by spark plasma sintering. Electrochim. Acta 2016, 222, 648-656. [CrossRef]

11. Baek, S.W.; Lee, J.M.; Kim, T.Y.; Song, M.S.; Park, Y. Garnet related lithium ion conductor processed by spark plasma sintering for all solid state batteries. J. Power Sources 2014, 249, 197-206. [CrossRef]

12. Benavente, R.; Pruna, A.; Borrell, A.; Salvador, M.D.; Pullini, D.; Penaranda-Foix, F.; Busquets, D. Fast route to obtain $\mathrm{Al}_{2} \mathrm{O}_{3}$-based nanocomposites employing graphene oxide: Synthesis and sintering. Mater. Res. Bull. 2015, 64, 245-251. [CrossRef]

13. Gordon, Z.D.; Yang, T.; Morgado, G.B.G.; Chan, C.K. Preparation of nano- and microstructured garnet $\mathrm{Li}_{7} \mathrm{La}_{3} \mathrm{Zr}_{2} \mathrm{O}_{12}$ solid electrolytes for Li-ion batteries via cellulose templating. ACS Sustain. Chem. Eng. 2016, 4, 6391-6398. [CrossRef]

14. Liu, K.; Ma, J.T.; Wang, C.A. Excess lithium salt functions more than compensating for lithium loss when synthesizing $\mathrm{Li}_{6.5} \mathrm{La}_{3} \mathrm{Ta}_{0.5} \mathrm{Zr}_{1.5} \mathrm{O}_{12}$ in alumina crucible. J. Power Sources 2014, 260, 109-114. [CrossRef]

15. Li, Y.Q.; Cao, Y.; Guo, X.X. Influence of lithium oxide additives on densification and ionic conductivity of garnet-type $\mathrm{Li}_{6.75} \mathrm{La}_{3} \mathrm{Zr}_{1.75} \mathrm{Ta}_{0.25} \mathrm{O}_{12}$ solid electrolytes. Solid State Ionics 2013, 253, 76-80. [CrossRef]

16. Chowdhury, T.; Zhang, L.; Zhang, J.; Aggarwal, S. Removal of arsenic(III) from aqueous solution using metal organic framework-graphene oxide nanocomposite. Nanomaterials 2018, 8, 1062. [CrossRef]

17. Hummers, W.S.; Offeman, R.E. Preparation of graphitic oxide. J. Am. Chem. Soc. 1958, 80, 1339. [CrossRef]

18. Marcano, D.C.; Kosynkin, D.V.; Berlin, J.M.; Sinitskii, A.; Sun, Z.Z.; Slesarev, A.; Alemany, L.B.; Lu, W.; Tour, J.M. Improved synthesis of graphene oxide. ACS Nano 2010, 4, 4806-4814. [CrossRef]

19. Zhang, Y.; Ma, J.; Bai, Y.; Wen, Y.; Zhao, N.; Zhang, X.; Zhang, Y.; Li, Q.; Wei, L. The preparation and properties of nanocomposite from bio-based polyurethane and graphene oxide for gas separation. Nanomaterials 2019, 9, 15. [CrossRef]

20. Logeat, A.; Koohler, T.; Eisele, U.; Stiaszny, B.; Harzer, A.; Tovar, M.; Senyshyn, A.; Ehrenberg, H.; Kozinsky, B. From order to disorder: The structure of lithium-conducting garnets $\mathrm{Li}_{7-\mathrm{x}} \mathrm{La}_{3} \mathrm{Ta}_{\mathrm{x}} \mathrm{Zr}_{2-\mathrm{x}} \mathrm{O}_{12}(\mathrm{x}=0-2)$. Solid State Ionics 2012, 206, 33-38. [CrossRef]

21. Thangadurai, V.; Narayanan, S.; Pinzaru, D. Garnet-type solid-state fast Li ion conductors for Li batteries: Critical review. Chem. Soc. Rev. 2014, 43, 4714-4727. [CrossRef]

22. Wang, Y.X.; Lai, W. High ionic conductivity lithium garnet oxides of $\mathrm{Li}_{7-\mathrm{x}} \mathrm{La}_{3} \mathrm{Zr}_{2-\mathrm{x}} \mathrm{Ta}_{\mathrm{x}} \mathrm{O}_{12}$ compositions. Electrochem. Solid State Lett. 2012, 15, A68-A71. [CrossRef] 
23. Li, Y.T.; Xu, B.Y.; Xu, H.H.; Duan, H.N.; Lu, X.J.; Xin, S.; Zhou, W.D.; Xue, L.G.; Fu, G.T.; Manthiram, A.; et al. Hybrid polymer/garnet electrolyte with a small interfacial resistance for lithium-ion batteries. Angew. Chem.-Int. Ed. 2017, 56, 753-756. [CrossRef]

24. Schleutker, M.; Bahner, J.; Tsai, C.L.; Stolten, D.; Korte, C. On the interfacial charge transfer between solid and liquid $\mathrm{Li}^{+}$electrolytes. Phys. Chem. Chem. Phys. 2017, 19, 26596-26605. [CrossRef]

(C) 2019 by the authors. Licensee MDPI, Basel, Switzerland. This article is an open access article distributed under the terms and conditions of the Creative Commons Attribution (CC BY) license (http://creativecommons.org/licenses/by/4.0/). 


\title{
On the Beneficial Effect of $\mathrm{MgCl}_{2}$ as Electrolyte Additive to Improve the Electrochemical Performance of $\mathrm{Li}_{4} \mathrm{Ti}_{5} \mathrm{O}_{12}$ as Cathode in $\mathrm{Mg}$ Batteries
}

\author{
Marta Cabello, Gregorio F. Ortiz *, Pedro Lavela and José L. Tirado \\ Departamento de Química Inorgánica e Ingeniería Química, Instituto Universitario de Investigación en Química \\ Fina y Nanoquímica (IUNAN), Universidad de Córdoba, Campus de Rabanales, Edificio Marie Curie, \\ E-14071 Córdoba, Spain; z22cabbm@uco.es (M.C.); iq1lacap@uco.es (P.L.); iq1ticoj@uco.es (J.L.T.) \\ * Correspondence: q72maorg@uco.es
}

Received: 6 March 2019; Accepted: 20 March 2019; Published: 26 March 2019

\begin{abstract}
Magnesium batteries are a promising technology for a new generation of energy storage for portable devices. Attention should be paid to electrolyte and electrode material development in order to develop rechargeable $\mathrm{Mg}$ batteries. In this study, we report the use of the spinel lithium titanate or $\mathrm{Li}_{4} \mathrm{Ti}_{5} \mathrm{O}_{12}$ (LTO) as an active electrode for $\mathrm{Mg}^{2+}$-ion batteries. The theoretical capacity of LTO is $175 \mathrm{~mA} \mathrm{~h} \mathrm{~g}^{-1}$, which is equivalent to an insertion reaction with $1.5 \mathrm{Mg}^{2+}$ ions. The ability to enhance the specific capacity of LTO is of practical importance. We have observed that it is possible to increase the capacity up to $290 \mathrm{~mA} \mathrm{~h} \mathrm{~g}^{-1}$ in first discharge, which corresponds to the reaction with $2.5 \mathrm{Mg}^{2+}$ ions. The addition of $\mathrm{MgCl}_{2} \cdot 6 \mathrm{H}_{2} \mathrm{O}$ to the electrolyte solutions significantly improves their electrochemical performance and enables reversible Mg deposition. Ex-situ X-ray diffraction (XRD) patterns reveal little structural changes, while X-ray photoelectron spectrometer (XPS) (XPS) measurements suggest $\mathrm{Mg}$ reacts with LTO. The $\mathrm{Ti}^{3+} / \mathrm{Ti}^{4+}$ ratio increases with the amount of inserted magnesium. The impedance spectra show the presence of a semicircle at medium-low frequencies, ascribable to $\mathrm{Mg}^{2+}$ ion diffusion between the surface film and LTO. Further experimental improvements with exhaustive control of electrodes and electrolytes are necessary to develop the $\mathrm{Mg}$ battery with practical application.
\end{abstract}

Keywords: $\mathrm{Li}_{4} \mathrm{Ti}_{5} \mathrm{O}_{12}$; magnesium batteries; cathodes; $\mathrm{MgCl}_{2}$

\section{Introduction}

Magnesium batteries are promising energy storage devices, due to their natural virtues, such as abundance, high theoretical volumetric capacity $\left(3832 \mathrm{~mA} \mathrm{~h} \mathrm{~cm}^{-3}\right)$, and operational safety [1-5]. However, the development of $\mathrm{Mg}$ batteries has been blocked by the lack of proper inorganic cathode materials, which commonly suffer from extremely slow kinetics of the insertion of $\mathrm{Mg}^{2+}$ into the intercalation host. Also, the development of suitable electrolytes is a "bottleneck" for the progress of practical Mg batteries.

Electrolytes containing ethereal solvents and organo-magnesium compounds are only partially appropriated for meeting the needs of functional devices in portable electronics and transportation applications [6-8]. Electrolytes based on inorganic Mg salts have also been considered, which show significant improvements in terms of stability and corrosion control of the cell components [9-11]. The compound $\delta-\mathrm{MgCl}_{2}$ shows a marked crystallographic disorder, reactivity, and solubility. The structure is built of concatenated $\mathrm{MgCl}_{2}$ repeating units, in which the $\mathrm{Mg}$ atoms are linked together by chloride bridges $[12,13]$ that provide unconventional properties to the solid. $\mathrm{Mg}(\mathrm{TFSI})_{2}$ (TFSI ${ }^{-}$: bis(trifluoromethanesulfonyl)imide) anions), a magnesium analogue of LiTFSI, dissolved in ionic liquids is a common additive in battery electrolytes [14]. Recently, stable and reversible 
magnesium plating/stripping was reported for $\mathrm{Mg}(\mathrm{TFSI})_{2}$ in dimethoxyethane (DME) and $\mathrm{Mg}(\mathrm{TFSI})_{2}$ in glyme, when $\mathrm{MgCl}_{2}$ or $\mathrm{Mg}\left(\mathrm{BH}_{4}\right)_{2}$ or anthracene was added [15-17]. The addition of chloride prevents the passivation of the $\mathrm{Mg}$ electrode and facilitates the $\mathrm{Mg}$ plating/stripping process, as a result of the formation of the binuclear complex, $\left[\mathrm{Mg}_{2}\left(\mu-\mathrm{Cl}_{2}\right]^{2+}\right.$, as an intermediate complex $[18,19]$. Additionally, the electrolyte, composed of magnesium triphenolate borohydride and $\operatorname{Mg}(\mathrm{TFSI})_{2}$, displays reversible $\mathrm{Mg}$ insertion/de-insertion in the $\mathrm{Mo}_{6} \mathrm{~S}_{8}$ Chevrel cathode phase delivering a capacity value of $94 \mathrm{~mA} \mathrm{~h} \mathrm{~g}^{-1}$ and $96 \%$ coulombic efficiency, as reported by Hebié et al. [17]. In these papers, it is claimed that the electrochemical performance of the TFSI-based electrolyte solutions is governed by their purity level. They achieved reversible $\mathrm{Mg}$ deposition leading to very high cycling efficiencies with purified DME/Mg(TFSI $)_{2} / \mathrm{MgCl}_{2}$ [16-20].

Among the other possible candidates to the cathode of $\mathrm{Mg}$ batteries, lithium titanate or $\mathrm{Li}_{4} \mathrm{Ti}_{5} \mathrm{O}_{12}$ (LTO) has been considered here. LTO is a well-known electrode material, with insertion properties useful for Li-ion and Na-ion batteries, that have been already studied [21-24]. It offers stable discharge plateaus at $1.55 \mathrm{~V} \mathrm{vs.} \mathrm{Li} / \mathrm{Li}^{+}$and $0.8 \mathrm{~V}$ vs. Na/Na ${ }^{+}$, which makes it safer and more stable than graphite. Up till now, little attention has been paid to its use in $\mathrm{Mg}$ batteries [25,26]. A different scientific approach was introduced by studying $\mathrm{Li}_{4} \mathrm{Ti}_{5} \mathrm{O}_{12}$ as cathode using hybrid $\mathrm{Mg}^{2+} / \mathrm{Li}^{+}$electrolytes in $\mathrm{Mg}$ batteries $[27,28]$. The concept of hybrid electrolyte, such as $\mathrm{Mg}^{2+} / \mathrm{Na}^{+}$, was also used for the sodium vanadate compound $\left(\beta-\mathrm{NaV}_{6} \mathrm{O}_{15}\right)$ [29]. In both cases, hybrid $\mathrm{Mg}^{2+} / \mathrm{Li}^{+}$and $\mathrm{Mg}^{2+} / \mathrm{Na}^{+}$electrolytes could synergistically exploit the advantages of $\mathrm{Li}^{+}, \mathrm{Na}^{+}$and $\mathrm{Mg}^{2+}$. In the former, $0.5 \mathrm{M} \mathrm{Mg}\left(\mathrm{BH}_{4}\right)_{2}$ $+1.5 \mathrm{M} \mathrm{LiBH}_{4}$ in tetraglyme (TG), and $0.4 \mathrm{M}(\mathrm{PhMgCl})_{2}-\mathrm{AlCl}_{3}+1.5 \mathrm{M} \mathrm{LiBH}_{4}$ in tetrahydrofuran (THF)-based mixed electrolyte, were used as the electrolyte, based solely on $\mathrm{Mg}$ salt $\left(0.5 \mathrm{M} \mathrm{Mg}\left(\mathrm{BH}_{4}\right)_{2}\right.$ or $\left.(\mathrm{PhMgCl})_{2}-\mathrm{AlCl}_{3}\right)$, did not exhibit any electrochemical performance.

In the present work, we study the electrochemical reaction of magnesium with LTO. For that purpose, a mixture of $\mathrm{Mg}(\mathrm{TFSI})_{2}$ and $\mathrm{MgCl}_{2} \cdot 6 \mathrm{H}_{2} \mathrm{O}$ salts in dimetoxyethane (DME) was used. We have found a negligible electrochemical reaction of magnesium with LTO, by using either, $\mathrm{Mg}(\mathrm{TFSI})_{2}$ in DME, or $\mathrm{MgCl}_{2} \cdot 6 \mathrm{H}_{2} \mathrm{O}$ in DME, separately. Therefore, the freshly prepared electrolyte (TFSI ${ }^{-}+\mathrm{Cl}^{-}$) could diminish the strong coulombic interaction between $\mathrm{Mg}^{2+}$ and the inorganic framework. Upon the first discharge, the ex-situ XRD and XPS measurements revealed negligible shifting of the $h k l$ reflections, and the appearance of $\mathrm{Ti}^{3+}$ on the surface of LTO particles, respectively. $\mathrm{Mg}^{2+}$ ion diffusion between the surface film and LTO is observed by electrochemical impedance spectra (EIS). The results, which were obtained by allowing water molecules to remain in the inorganic salt, may be useful in comparing with the results obtained by using the anhydrous salt.

\section{Experimental}

Lithium titanate was obtained by a sol-gel route. For the preparation of the precursor gel, $30.7 \mathrm{~mL}$ of titanium isopropoxide (purity 97\%, Sigma-Aldrich Química S.L., Madrid, Spain) was added to a solution containing $8.13 \mathrm{~g}$ of lithium acetate in $19.3 \mathrm{~mL}$ of ethanol. The mixture was heated at $100^{\circ} \mathrm{C}$ for $14 \mathrm{~h}$ under magnetic stirring. The amorphous compound obtained at this step was ground and further annealed at $800{ }^{\circ} \mathrm{C}$ in air for $8 \mathrm{~h}$. Manual grinding with lithium acetate, followed by additional annealing at $800^{\circ} \mathrm{C}$ in air for $8 \mathrm{~h}$, was needed to remove rutile impurities.

X-ray diffraction (XRD) patterns were recorded in a Bruker D8 Advance diffractometer (Bruker Española S.A., Madrid, Spain) with a LYNXEYE XE -High-Resolution Energy-Dispersive 1-D Detector and $\mathrm{Cu} \mathrm{K} \alpha$ radiation. From line broadening analysis by using Voigt functions, the crystallite size was calculated as the integral breadth-based volume-weighted column height (IB-LVol). The analysis of the chemical state was carried out in an X-ray photoelectron spectrometer (XPS) (SPECS Phobios 150 MCD) provided with $\mathrm{Mg} \mathrm{K} \alpha$ source. Powdered samples were placed onto $\mathrm{Al}$ foil and subjected to a high vacuum overnight $\left(5 \times 10^{-9} \mathrm{mbar}\right)$. For the ex-situ analysis, the electrode material was transferred to the XPS apparatus under an $\mathrm{Ar}$ atmosphere. The binding energy values were referred to the $\mathrm{C} 1 \mathrm{~s}$ line of the adventitious carbon located at $284.6 \mathrm{eV}$. 
The electrochemistry was performed in a three-electrode configuration using LTO as cathode, and $\mathrm{Mg}$ foil as anode and reference electrodes. The cells were assembled in an argon filled glove box under controlled $\mathrm{O}_{2}(2 \mathrm{ppm})$ and $\mathrm{H}_{2} \mathrm{O}(1 \mathrm{ppm})$ traces. The active material (LTO, 80\%) was mixed with PVdF $(10 \%)$ and carbon black (10\%). These components were dispersed in N-methyl-2-pyrrolidone, yielding a homogenous paste which is spread onto a $9 \mathrm{~mm}$ Ti foil (for cycling) and carbon paper (for cycling and ex-situ analyses). The electrode was vacuum dried at $120^{\circ} \mathrm{C}$ for $2 \mathrm{~h}$. The electrodes were separated by glass fiber disks (GF/A-Whatman) impregnated in the electrolyte solution. The composition of the electrolytes used in this study is the following: a) $0.50 \mathrm{M} \mathrm{Mg}(\mathrm{TFSI})_{2}+0.13 \mathrm{M} \mathrm{MgCl}_{2} \cdot 6 \mathrm{H}_{2} \mathrm{O}$ in DME (1,2-dimetoxyethane) b) $0.50 \mathrm{M} \mathrm{Mg}(\mathrm{TFSI})_{2}$ in DME, and c) $0.13 \mathrm{M} \mathrm{MgCl}_{2} \cdot 6 \mathrm{H}_{2} \mathrm{O}$ in DME. The role of water molecules was studied with the following electrolytes: a) $0.50 \mathrm{M} \mathrm{Mg}(\mathrm{TFSI})_{2}+0.13 \mathrm{M}$ $\mathrm{MgCl}_{2}$ in DME, b) $0.50 \mathrm{M} \mathrm{Mg}$ (TFSI $)_{2}+0.13 \mathrm{M} \mathrm{MgCl}_{2} \cdot 6 \mathrm{H}_{2} \mathrm{O}$ in DME $+0.5 \mathrm{M} \mathrm{H}_{2} \mathrm{O}$ and c) $0.50 \mathrm{M}$ $\mathrm{Mg}(\mathrm{TFSI})_{2}+0.13 \mathrm{M} \mathrm{MgCl}_{2} \cdot 6 \mathrm{H}_{2} \mathrm{O}$ in DME $+1.0 \mathrm{M} \mathrm{H}_{2} \mathrm{O}$. The purity of the reagents was as follows: $\mathrm{MgCl}_{2} \cdot 6 \mathrm{H}_{2} \mathrm{O}$ (Sigma Aldrich, $\geq 99.0 \%$ ), $\mathrm{Mg}(\mathrm{TFSI})_{2}$ (Aldrich, 99\%), and 1,2-Dimetoxyethane (Aldrich, $99.5 \%$ anhydrous).

The electrochemical impedance spectra were measured by using an SP-150 Biologic apparatus to determine the cell impedance. For this purpose, the three-electrode cells, with LTO as the working electrode, and $\mathrm{Mg}$ as counter and reference electrodes, were subjected to a few cycles. After the voltage relaxation pursuing a quasi-equilibrium state, the impedance spectra were measured by perturbing the open circuit voltage with an AC signal of $5 \mathrm{mV}$ from $100 \mathrm{kHz}$ to $0.001 \mathrm{mHz}$.

\section{Results and Discussions}

\subsection{Characterization of $\mathrm{Li}_{4} \mathrm{Ti}_{5} \mathrm{O}_{12}$}

Figure $1 \mathrm{a}$ shows the XRD pattern of the $\mathrm{Li}_{4} \mathrm{Ti}_{5} \mathrm{O}_{12}$. The diffraction peaks are located at $2 \theta=18.3^{\circ}$, $35.6^{\circ}, 36.3^{\circ}, 43.4^{\circ}, 47.5^{\circ}, 57.3^{\circ}, 62.9^{\circ}$, and $66.2^{\circ}$, and indexed in the $F d-3 m$ space group (JCPDS Card No. 49-0207), evidencing the spinel-type structure of $\mathrm{Li}_{4} \mathrm{Ti}_{5} \mathrm{O}_{12}$. Moreover, the refined lattice parameters of $\mathrm{Li}_{4} \mathrm{Ti}_{5} \mathrm{O}_{12}$ are coincident with those reported by Ohzuku et al. [30]. The average crystallite size, calculated from 111, 311 and 400 reflections, ranged between 82.5 and $98.5 \mathrm{~nm}$ (Table 1). The chemical composition and surface state for LTO was checked by X-ray photoelectron spectroscopy (XPS). As shown in Figure 1b, the peaks centered at 458.5 and $464.2 \mathrm{eV}$ are assigned to Ti2 $\mathrm{p}_{3 / 2}$ and Ti2 $\mathrm{p}_{1 / 2}$, which are characteristic of $\mathrm{Ti}^{4+}$ in LTO [31]. SEM images at different magnifications revealed that the particle size of the LTO was in the range of 300-500 nm (Figure 1c,d).

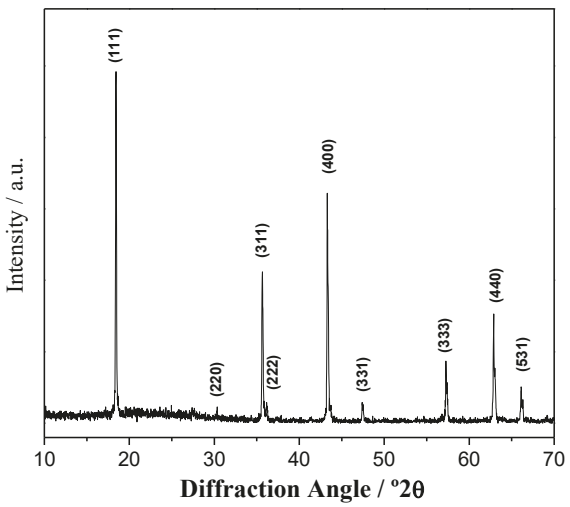

(a)

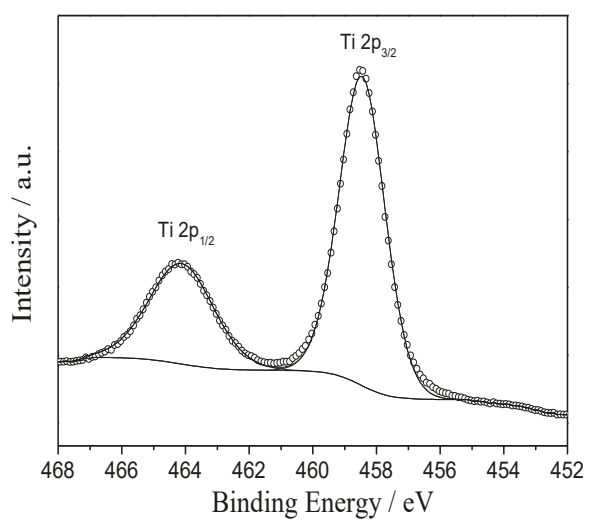

(b)

Figure 1. Cont. 


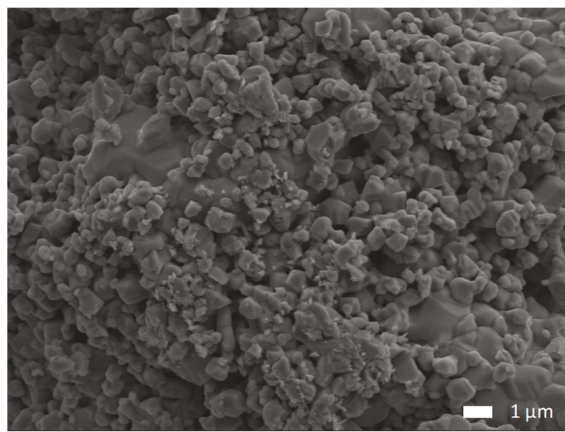

(c)

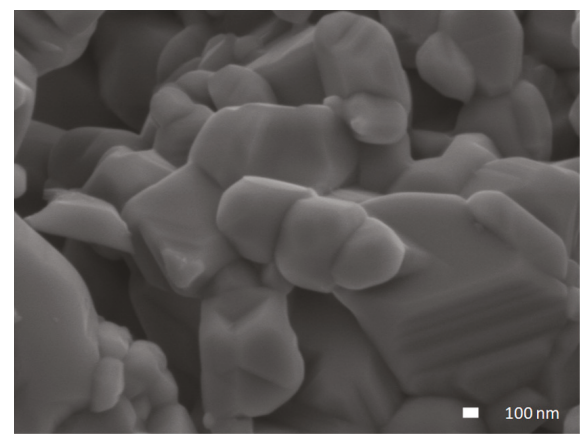

(d)

Figure 1. (a) X-ray diffraction pattern, (b) high-resolution X-ray photoelectron spectroscopy (XPS) spectra showing the Ti2p core levels, and (c,d) SEM images at different magnifications of LTO sample.

Table 1. Average crystallite size, unit cell parameters and quantitative analysis by peak-profile fitting for lithium titanate or $\mathrm{Li}_{4} \mathrm{Ti}_{5} \mathrm{O}_{12}$ (LTO) electrodes before and after magnesiation.

\begin{tabular}{|c|c|c|c|c|c|}
\hline & $\mathrm{Li}_{4} \mathrm{Ti}_{5} \mathrm{O}_{12}$ & $\mathrm{Mg}_{0.85} \mathrm{Li}_{4} \mathrm{Ti}_{5} \mathrm{O}_{12}$ & $\mathrm{Mg}_{1.5} \mathrm{Li}_{4} \mathrm{Ti}_{5} \mathrm{O}_{12}$ & $\mathrm{Mg}_{2} \mathrm{Li}_{4} \mathrm{Ti}_{5} \mathrm{O}_{12}$ & $\mathrm{Mg}_{2.5} \mathrm{Li}_{4} \mathrm{Ti}_{5} \mathrm{O}_{12}$ \\
\hline $\mathrm{IB} \mathrm{LVol}_{(111)} / \mathrm{nm}$ & 82.5 & 70.8 & 57.9 & 74.8 & 60.1 \\
\hline 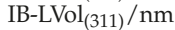 & 98.5 & 78.1 & 58.4 & 69.7 & 66.6 \\
\hline $\mathrm{IB}_{-\mathrm{LVol}_{(400)}} / \mathrm{nm}$ & 98.0 & 67.7 & 63.7 & 76.0 & 64.3 \\
\hline $\mathrm{a} / \AA$ & $8.325(2)$ & $8.387(1)$ & $8.387(2)$ & $8.389(2)$ & $8.398(2)$ \\
\hline $\mathrm{V} / \AA^{3}$ & $577.02(1)$ & $590.16(1)$ & $570.09(2)$ & $590.40(1)$ & $592.47(1)$ \\
\hline $\mathrm{Ti}^{4+} / \%$ & 100 & 78.7 & 64.4 & - & 33.6 \\
\hline $\mathrm{Ti}^{3+} / \%$ & 0 & 21.3 & 35.6 & - & 66.4 \\
\hline
\end{tabular}

\subsection{Cyclic Voltammetry with the $\mathrm{MgCl}_{2}$-Electrolyte and Control Experiments}

The cyclic voltammetry of LTO in the Mg cell using $0.5 \mathrm{M} \mathrm{Mg}(\mathrm{TFSI})_{2}+0.13 \mathrm{MgCl}_{2} \cdot 6 \mathrm{H}_{2} \mathrm{O}$ in DME electrolyte was recorded using two different voltage windows. No redox peaks were visible between $0.3-1.5 \mathrm{~V}$ (Figure 2d). However, the experiments, cycled between 0.1-2.5 V, indicating that the reversible peaks were at $1.2 \mathrm{~V}$ on discharge and $0.8 \mathrm{~V}$ on charge (Figure $3 \mathrm{a}$ ). A characteristic large peak starts to appear at about $1.5 \mathrm{~V}$ reaching a maximum at $1.8 \mathrm{~V}$. This peak can be related to the activation energy associated with the Mg stripping on the counter electrode. The observation of such peaks may be related to the unusual charge profile observed in the galvanostatic curve of LTO versus metallic Mg in three electrode cell during the charge process (Figure $3 b, c$ ). This is probably due to the changes in transport properties arising from the degree of magnesiation as discussed in the next sections.

Control experiments, with no active material, were performed (Figure 2a,b). The range of electrochemical stability of the mixed electrolyte solution $\mathrm{Mg}(\mathrm{TFSI})_{2}-\mathrm{MgCl}_{2} \cdot 6 \mathrm{H}_{2} \mathrm{O}$ in DME was studied by cyclic voltammetry and galvanostatic cycling (Figure 2a,c). The electrolyte solution is stable in the voltage range between $0.0-2.4 \mathrm{~V}$ vs. $\mathrm{Mg}^{2+} / \mathrm{Mg}^{0}$. The anodic peak at ca. $1.92 \mathrm{~V} \mathrm{vs.} \mathrm{Mg}^{2+} / \mathrm{Mg}^{0}$ is ascribed to the stripping of previously electroplated magnesium. The cyclic voltammograms using narrower voltage windows (0.3-1.5 V) did not exhibit any stripping/plating phenomena (Figure 2b). In addition, redox activity in the voltage range between ca. 0.0 and $2.0 \mathrm{~V}$ is not observed (Figure 2c) under galvanostatic regime at $0.1 \mathrm{C}$ rate. The comparison of cyclic voltammetry results between $\mathrm{Mg}(\mathrm{TFSI})_{2}+\mathrm{MgCl}_{2} \cdot 6 \mathrm{H}_{2} \mathrm{O}$ in DME and $\mathrm{Mg}(\mathrm{TFSI})_{2}$ in DME reveals that the plating/stripping process is more reversible when using a $\mathrm{Mg}(\mathrm{TFSI})_{2}+\mathrm{MgCl}_{2} \cdot 6 \mathrm{H}_{2} \mathrm{O}$ mixture than only $\mathrm{Mg}(\mathrm{TFSI})_{2}$, thus suggesting the occurrence of synergistic effects when using this combination [32]. 


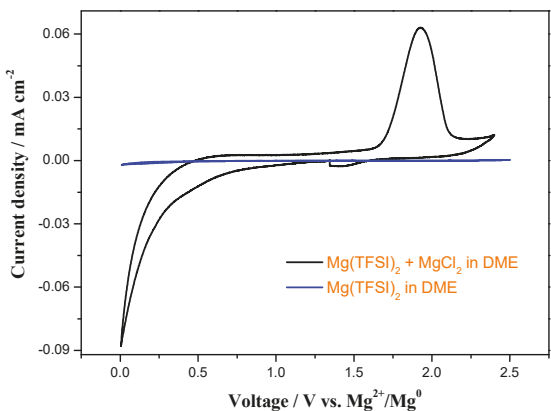

(a)

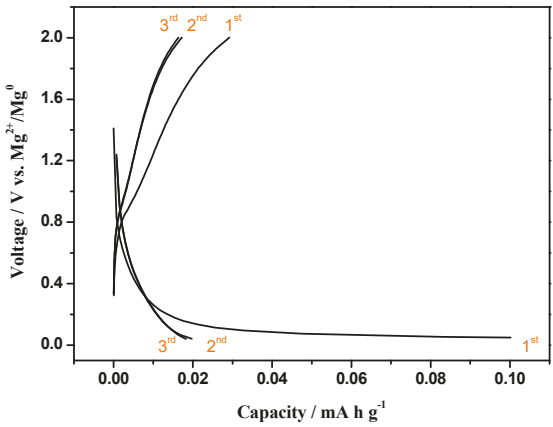

(c)

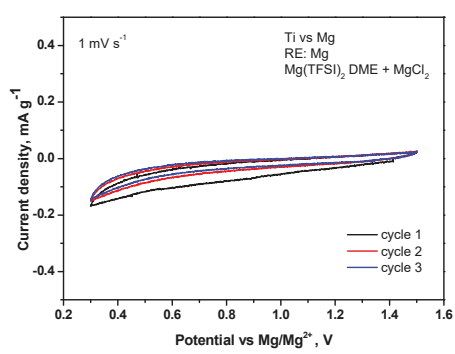

(b)

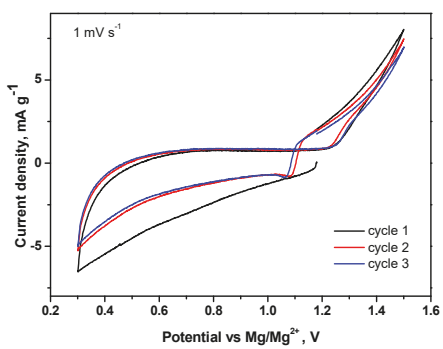

(d)

Figure 2. Control experiments without active material, using $0.5 \mathrm{M} \mathrm{Mg}(\mathrm{TFSI})_{2}+0.13 \mathrm{M} \mathrm{MgCl}_{2} \cdot 6 \mathrm{H}_{2} \mathrm{O}$, in DME electrolyte versus $\mathrm{Mg}$ as reference and counter electrode: $(\mathbf{a}, \mathbf{b})$ Cyclic voltammetry (CV) at $1 \mathrm{mVs}^{-1}$ using different voltage windows (a: $0-2.5 \mathrm{~V}, \mathrm{~b}: 0.3-1.5 \mathrm{~V}$ ). (c) Control experiments without active material under galvanostatic cycling at $0.1 \mathrm{C}$. (d) Cyclic voltammetry of LTO with $0.5 \mathrm{M} \mathrm{Mg}(\mathrm{TFSI})_{2}+0.13 \mathrm{M} \mathrm{MgCl}_{2} \cdot 6 \mathrm{H}_{2} \mathrm{O}$ in DME vs. $\mathrm{Mg}$ as reference and counter electrode. Note: The potential is plotted versus the $\mathrm{Mg}^{2+} / \mathrm{Mg}$ voltage of the reference electrode.

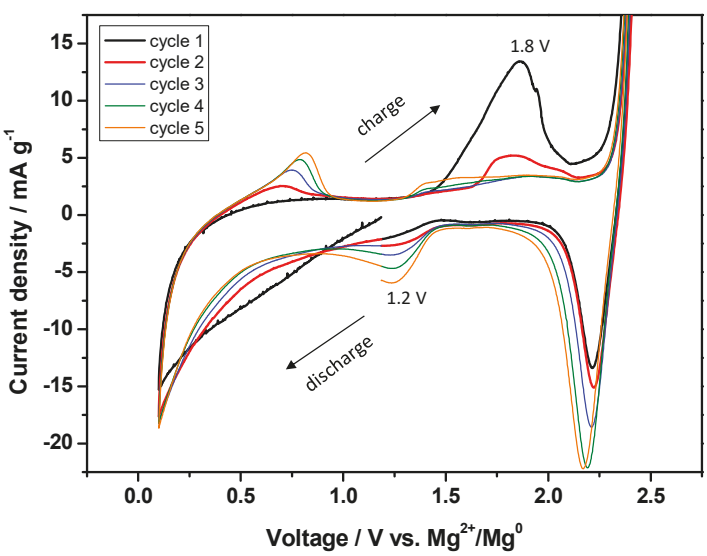

(a)

Figure 3. Cont. 


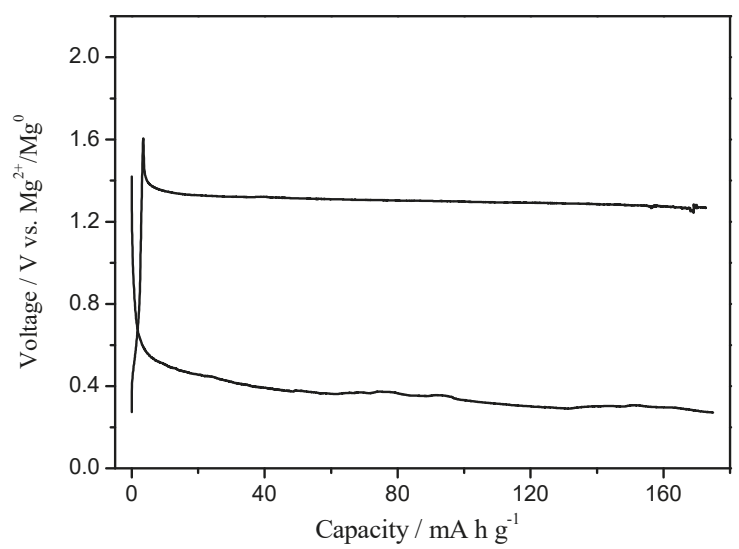

(b)

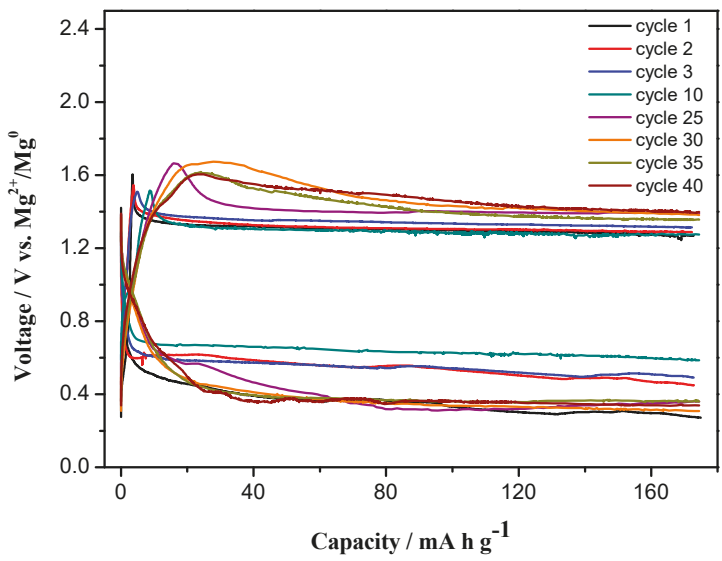

(c)

Figure 3. (a) Cyclic Voltammetry of LTO with $0.5 \mathrm{M} \mathrm{Mg}(\mathrm{TFSI})_{2}+0.13 \mathrm{M} \mathrm{MgCl}_{2} \cdot 6 \mathrm{H}_{2} \mathrm{O}$ in DME versus $\mathrm{Mg}$ as reference and counter electrode. Galvanostatic discharge/charge curves of LTO sample in a three-electrode $\mathrm{Mg}$ cell using: $(\mathbf{b}, \mathbf{c}) 0.5 \mathrm{M} \mathrm{Mg}(\mathrm{TFSI})_{2}+0.13 \mathrm{M} \mathrm{MgCl}_{2} \cdot 6 \mathrm{H}_{2} \mathrm{O}$ in DME cycled at $0.1 \mathrm{C}$.

\subsection{Extended Discharge and Capacity Retention}

The lithium insertion reaction mechanism in LTO has been previously studied [33]. In general, a structural change from spinel to a rock-salt phase takes place after LTO lithiation. A specific capacity of $175 \mathrm{~mA} \mathrm{~h} \mathrm{~g}^{-1}$ can be recorded in the $2.5-1 \mathrm{~V}$ voltage window versus lithium, which corresponds to the formation of $\mathrm{Li}_{7} \mathrm{Ti}_{5} \mathrm{O}_{12}$. A mixed valence of $\mathrm{Ti}^{3+} / \mathrm{Ti}^{4+}$ in the latter formula is deduced, meaning that there are two more electrons available for reduction $\left(\mathrm{Li}_{7}\left[\mathrm{Ti}_{2}{ }^{4+} \mathrm{Ti}_{3}{ }^{3+}\right] \mathrm{O}_{12}\right)$. It is possible to reach the $\mathrm{Li}_{9} \mathrm{Ti}_{5} \mathrm{O}_{12}$ composition by discharging the Li cell to $0 \mathrm{~V}$, delivering a maximum theoretical capacity of $290 \mathrm{~mA} \mathrm{~h} \mathrm{~g}^{-1}$ [33]. In order to achieve stable capacities in lithium batteries, extremely low voltage limits should be avoided, because the extra lithium-ion intercalation generates a decrease of the ion diffusivity and a large increase of the charge/discharge potential gap [33]. Similarly, our $\mathrm{Mg}$ cell, containing LTO as active material, was successfully discharged until $290 \mathrm{~mA} \mathrm{~h} \mathrm{~g}^{-1}$ (Figure 4a). However, an abrupt capacity fading to $<50 \mathrm{~mA} \mathrm{~h} \mathrm{~g}^{-1}$ was observed after the third cycle (inset of Figure 4a). In order to achieve stable cyclability, the voltage window was limited to the $0.25-1.6 \mathrm{~V}$ range vs. $\mathrm{Mg}^{2+} / \mathrm{Mg}^{0}$, in which LTO exhibits good cycling performance (Figure $4 \mathrm{~b}$ ). At the 40th cycle, LTO still delivered $175 \mathrm{~mA} \mathrm{~h} \mathrm{~g}^{-1}$, corresponding to a capacity retention near $99.9 \%$. These experiments 
were stopped by limiting $\Delta \mathrm{x}$ to $1.5 \mathrm{Mg}$. However, the capacity fades to 140 and $80 \mathrm{~mA} \mathrm{~h} \mathrm{~g}^{-1}$ when cycling at 0.2 , and $0.5 \mathrm{C}$, respectively (inset of Figure $4 \mathrm{~b}$ ). This behavior reflects the slow charge transfer kinetics or the slow diffusion of the $\mathrm{Mg}^{2+}$ ions in the LTO lattice or within the electrolyte. Although, further studies are necessary to improve the capacity retention of LTO under high rates, we have found the possibility of enhancing the specific capacity from 175 to $290 \mathrm{~mA} \mathrm{~h} \mathrm{~g}^{-1}$. The ability to enhance the specific capacity of LTO is useful and offers the opportunity to increase the energy density of $\mathrm{Mg}$ cells significantly.

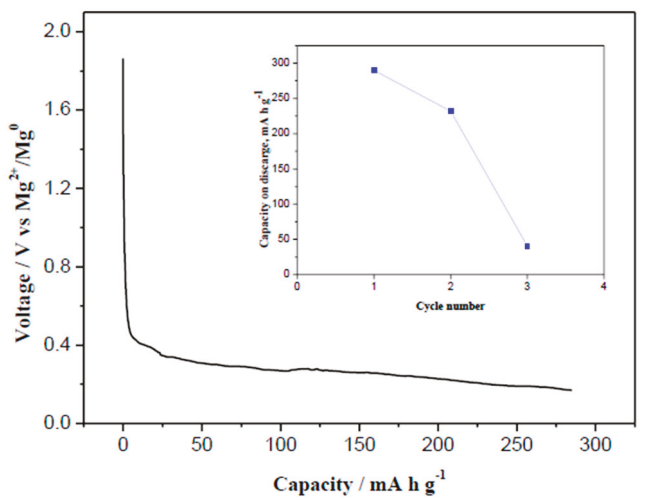

(a)

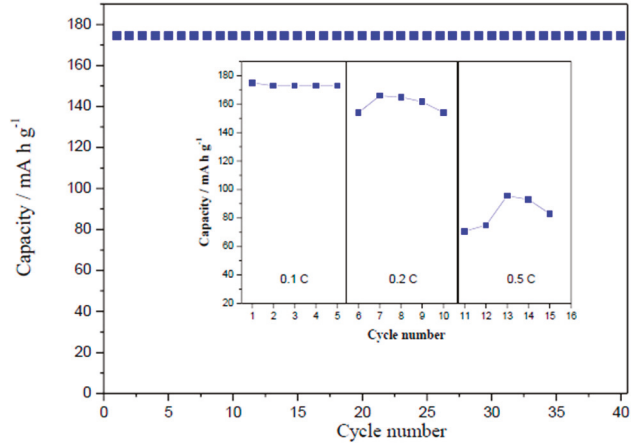

(b)

Figure 4. (a) Discharge curve of LTO until $290 \mathrm{~mA} \mathrm{~h} \mathrm{~g}^{-1}$ representing the reaction of magnesium with LTO using $0.5 \mathrm{M} \mathrm{Mg}(\mathrm{TFSI})_{2}+0.13 \mathrm{M} \mathrm{MgCl}_{2} \cdot 6 \mathrm{H}_{2} \mathrm{O}$ in DME electrolyte. Representative curve obtained for LTO/Mg cell for ex-situ XRD and XPS analysis. The inset in (a) represents the capacity retention during 3 cycles. (b) Capacity retention of LTO in $\mathrm{Mg}$ cell using $0.5 \mathrm{M} \mathrm{Mg}(\mathrm{TFSI})_{2}+0.13$ $\mathrm{MgCl}_{2} \cdot 6 \mathrm{H}_{2} \mathrm{O}$ in DME electrolyte with capacity cut-off. The inset in (b) represents the rate performance with voltage cut-off.

\subsection{Effect of $\mathrm{MgCl}_{2}$ in Electrolytes on Charge-Discharge Properties (with Capacity Cut-Off)}

A comparison of the effects of electrolyte composition on the electrochemical performance of LTO in Mg cells is shown in Figure 3b,c and Figures S1 and S2. The galvanostatic discharge/charge curves show important differences when cycled at $0.1 \mathrm{C}$ rate. LTO hardly delivers any capacity $\left(<5 \mathrm{~mA} \mathrm{~h} \mathrm{~g}^{-1}\right)$ when using $0.5 \mathrm{M} \mathrm{Mg}(\mathrm{TFSI})_{2}$ in DME based electrolyte, indicating that $\mathrm{Mg}^{2+}$ could not react with LTO (Figure S1). However, the addition of $0.13 \mathrm{M} \mathrm{MgCl}_{2} \cdot 6 \mathrm{H}_{2} \mathrm{O}$ improved the electrochemical performance (Figure 3b,c and Figure S2). Thus, the capacity delivered in first discharge is $175 \mathrm{~mA} \mathrm{~h} \mathrm{~g}^{-1}$. The first discharge plateau is observed between $0.4-0.3 \mathrm{~V}$, and then is shifted to $0.6-0.5 \mathrm{~V}$ ( $\mathrm{vs} . \mathrm{Mg}^{2+} / \mathrm{Mg}^{0}$ ) 
for second and successive cycles. However, the charge plateau is observed at about $1.35 \mathrm{~V}$ versus $\mathrm{Mg}^{2+} / \mathrm{Mg}^{0}$, during the first and successive cycles. An average potential difference $(\Delta \mathrm{E})$ of $0.75 \mathrm{~V}$ between charge and discharge was observed. The charge capacity was $174.7 \mathrm{~mA} \mathrm{~h} \mathrm{~g}^{-1}$ but presented an unusual profile, exhibiting $99.9 \%$ efficiency. Higher voltage hysteresis (ca $1.3 \mathrm{~V}$ ), and similar charge profiles have been observed in $\mathrm{TiS}_{2}$ cathodes [34]. A corrosion phenomenon could be discarded because the process is reversible within this voltage window. Tchitchekova et al. did not relate such charge profile to a characteristic redox behavior, but instead to a nucleation activation energy associated with Ca plating on the counter electrode [34]. Wu et al. appreciated $\mathrm{Mg}^{2+}$ intercalation and de-intercalation for LTO at 0.35 and $0.95 \mathrm{~V}$, resulting in $\Delta \mathrm{E}=0.6 \mathrm{~V}$, respectively [25]. Moreover, by decreasing the particle size, a different deintercalation potential, $\Delta \mathrm{E}$ and reversible capacity were observed. For instance, reversible capacities of 30 and $170 \mathrm{~mA} \mathrm{~h} \mathrm{~g}^{-1}$ were obtained for particle sizes ranging between $22-27$, and 3-4 $\mathrm{nm}$, respectively [25]. In our results, LTO with crystallite size ranging between $82.5-98.5 \mathrm{~nm}$ and particle size $300-500 \mathrm{~nm}$ reacted when using $0.5 \mathrm{Mg}(\mathrm{TFSI})_{2}$ and $0.13 \mathrm{M}$ $\mathrm{MgCl}_{2}$ in DME as electrolyte. Most probably, the different nature of the electrolyte and particle size justifies these observations.

As far as we know, studies on LTO in dual electrolytes $\left(\mathrm{Mg}^{2+}+\mathrm{Li}^{+}\right)$have only been previously reported in literature $[27,28]$. The $\mathrm{Mg} / \mathrm{LTO}$ cell discharges at $0.6 \mathrm{~V}$. However, the performance of the LTO active material should be compared with other earlier studied cathode materials. For instance, the $\mathrm{Mg} / 0.5 \mathrm{M} \mathrm{Mg}(\mathrm{TFSI})_{2}+0.07 \mathrm{M}$ anthracene $+0.1 \mathrm{M} \mathrm{MgCl}_{2}$ in diglyme $/ \mathrm{Mo}_{6} \mathrm{~S}_{8}$ cell displayed two plateaus at 1.1 and $0.95 \mathrm{~V}$ during cell discharge, corresponding to $\mathrm{Mg}^{2+}$ insertion in the inner and outer sites in the Chevrel phase, respectively [17]. During cell charge, two plateaus are also observed at 1.28 and $1.57 \mathrm{~V}$. A capacity value of $80 \mathrm{~mA} \mathrm{~h} \mathrm{~g}^{-1}$ was recorded upon the first discharge at the $\mathrm{C} / 20$ rate [17]. Another example is the $\mathrm{Mg} / 0.5 \mathrm{M} \mathrm{Mg}(\mathrm{TFSI})_{2}+0.5 \mathrm{M} \mathrm{MgCl}_{2}$ in THF electrolyte $/ \mathrm{Mo}_{6} \mathrm{~S}_{8}$ cell, in which a first discharge capacity of $67 \mathrm{~mA} \mathrm{~h} \mathrm{~g}^{-1}$ and plateaus at around 0.8 and $1.25 \mathrm{~V}$ in discharge and charge, respectively, were observed [15].

An outstanding scientific approach proposed by Nam et al. [35] involved the engagement of crystal water existing in the layered structure of $\mathrm{MnO}_{2}$ (Birnessite). These water molecules can effectively screen the electrostatic interactions between $\mathrm{Mg}^{2+}$ ions and the anions of the host-framework. Indeed, the desolvatation energy penalty can be mitigated since $\mathrm{Mg}^{2+}$ ions intercalate in the hydrated form, which suppresses the coulombic repulsion between cations and the host surface [36,37]. In the latter case, the $\mathrm{Mg} / 0.5 \mathrm{M}$ magnesium perchlorate $\left(\mathrm{Mg}\left(\mathrm{ClO}_{4}\right)_{2}\right)$ in acetonitrile with DI water $/ \mathrm{MnO}_{2}$ cell delivered a large reversible capacity of $231.1 \mathrm{~mA} \mathrm{~h} \mathrm{~g}^{-1}$ at $2.8 \mathrm{~V}^{\text {versus }} \mathrm{Mg}^{2+} / \mathrm{Mg}$ [35].

In order to distinguish different behaviours in the three electrodes cells, the voltage profiles $\left(\mathrm{E}_{\mathrm{CE}}, \mathrm{E}_{\mathrm{WE}}\right.$ and $\left.\mathrm{E}_{\mathrm{WE}}-\mathrm{E}_{\mathrm{CE}}\right)$ of LTO in a three electrode $\mathrm{Mg}$ cell are plotted versus time in Figure 5a,b. Galvanostatic measurements were carried out in $\mathrm{Mg}$ cells using $0.5 \mathrm{M} \mathrm{Mg}(\mathrm{TFSI})_{2}$ in DME as electrolyte (Figure 5a). A high polarization of about $0.6 \mathrm{~V}$ was observed from the first cycle. The over-potential indicates a rather difficult $\mathrm{Mg}$ plating/stripping and could be originated from (i) the presence of the native passive layer on $\mathrm{Mg}$ electrode and (ii) the reduction of impurities (oxygen, protic species, etc.) $[20,38]$.

In contrast, for $\mathrm{Mg}$ cells using $0.5 \mathrm{M} \mathrm{Mg}(\mathrm{TFSI})_{2}+0.13 \mathrm{M} \mathrm{MgCl}_{2} \cdot 6 \mathrm{H}_{2} \mathrm{O}$ in DME as electrolytes, the overpotential was significantly lowered to about $0.15 \mathrm{~V}$ in the first cycle, suggesting that the passivating layer was not formed on the $\mathrm{Mg}$ foil. The overpotential slightly increased to $0.2,0.26,0.31,0.36,0.41$, 0.43 , and $0.48 \mathrm{~V}$ from the second to eighth cycle. In spite of this slight increase of polarization (from 0.15 to $0.48 \mathrm{~V}$ ), the coulombic efficiency keeps around $99.9 \%$ on further galvanostatic discharge/charge cycling (Figure $3 \mathrm{c}$ and Figure S2a,b). Also, the shape of the voltage profile became rectangular and symmetric, which may correspond to the response of a pure resistance [17]. However, when increasing the water content in the electrolyte $\left(0.5 \mathrm{M} \mathrm{H}_{2} \mathrm{O}\right.$ and $\left.1.0 \mathrm{M} \mathrm{H}_{2} \mathrm{O}\right)$ we observed a higher polarization in $\mathrm{E}_{\mathrm{CE}}$ (Figure 5c). Surprisingly, when using anhydrous $\mathrm{MgCl}_{2}$, the large polarization is still visible (Figure 5c). In conclusion, the electrolyte containing $0.5 \mathrm{M} \mathrm{Mg}(\mathrm{TFSI})_{2}$ in DME $+0.13 \mathrm{M} \mathrm{MgCl}_{2} \cdot 6 \mathrm{H}_{2} \mathrm{O}$ exhibited the best electrochemical performance in terms of higher capacity and lower $\mathrm{E}_{\mathrm{CE}}$ polarization. 


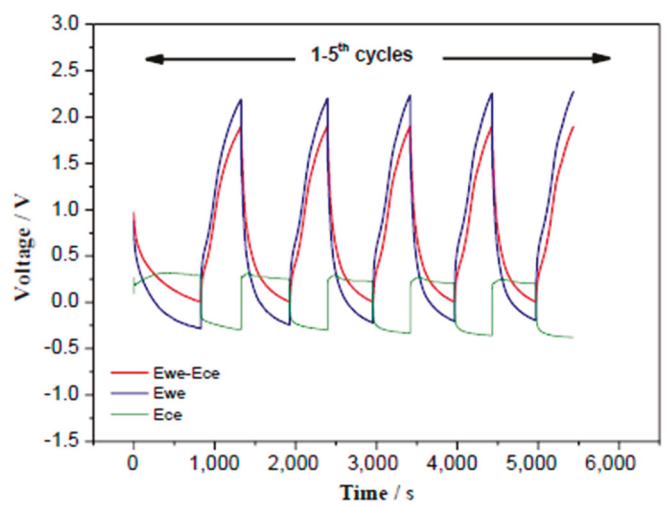

(a)

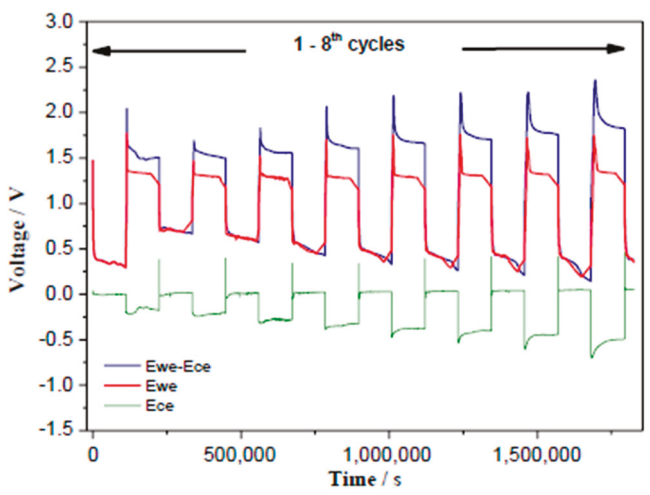

(b)

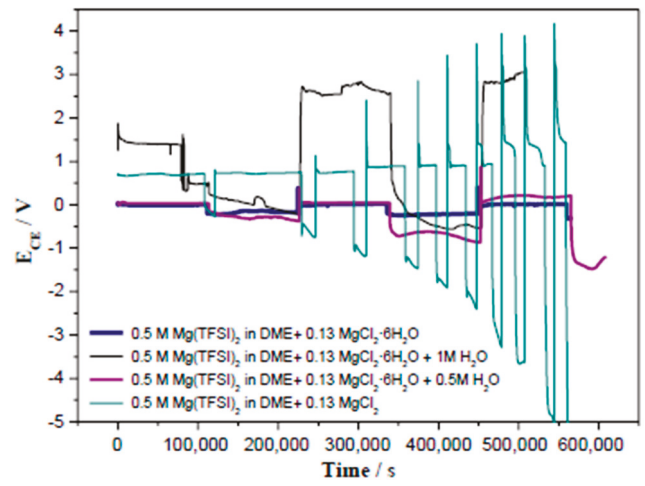

(c)

Figure 5. Voltage profiles $\left(\mathrm{E}_{\mathrm{CE}}, \mathrm{E}_{\mathrm{WE}}\right.$ and $\left.\mathrm{E}_{\mathrm{WE}}-\mathrm{E}_{\mathrm{CE}}\right)$ of $\mathrm{LTO}$ versus time in a three electrode $\mathrm{Mg}$ cell using different electrolytes: (a) $0.5 \mathrm{M} \mathrm{Mg}(\mathrm{TFSI})_{2}$ in DME, (b) $0.5 \mathrm{M} \mathrm{Mg}(\mathrm{TFSI})_{2}+0.13 \mathrm{M} \mathrm{MgCl}_{2} \cdot 6 \mathrm{H}_{2} \mathrm{O}$ in DME. (c) A comparison of $\mathrm{E}_{\mathrm{CE}}$ versus time of $\mathrm{Mg} / \mathrm{LTO}$ cell in four different electrolytes containing different amount of water. Note: $\mathrm{E}_{\mathrm{CE}}, \mathrm{E}_{\mathrm{WE}}$ and $\mathrm{E}_{\mathrm{WE}}-\mathrm{E}_{\mathrm{CE}}$ refers to the potential of the counter electrode, working electrode and the difference between them, respectively. 


\subsection{Change in the $\mathrm{Li}_{4} \mathrm{Ti}_{5} \mathrm{O}_{12}$ Lattice by the Charge-Discharge}

In order to understand the structural changes of $\mathrm{Li}_{4} \mathrm{Ti}_{5} \mathrm{O}_{12}$ during the discharge, in $\mathrm{Mg}$ cell with $\mathrm{Mg}(\mathrm{TFSI})_{2}+\mathrm{MgCl}_{2} \cdot 6 \mathrm{H}_{2} \mathrm{O}$ in DME electrolyte, ex-situ XRD experiments were performed (Figure 6). On discharging to 100, 175, $233 \mathrm{~mA} \mathrm{~h} \mathrm{~g}{ }^{-1}\left(\mathrm{x}=0.85,1.5\right.$ and 2 in $\left.\mathrm{Mg}_{\mathrm{x}} \mathrm{Li}_{4} \mathrm{Ti}_{5} \mathrm{O}_{12}\right)$. There were no observable changes in the position of the peaks. The results show that the XRD pattern is insensitive to subtle structural changes owing to the "zero-strain" of LTO. However, on discharging to $290 \mathrm{~mA} \mathrm{~h} \mathrm{~g}^{-1}$ $\left(\mathrm{x}=2.5\right.$ in $\left.\mathrm{Mg}_{\mathrm{x}} \mathrm{Li}_{4} \mathrm{Ti}_{5} \mathrm{O}_{12}\right)$, we observed a gradual shift of the 111, 311, 222 and 400 reflections to lower angles. The observed $\mathrm{d}_{111}=4.880 \AA$ for $\mathrm{x}=2.5$ is much higher than $\mathrm{d}_{111}=4.844 \AA$ for $\mathrm{x}=0$, which means an increase in lattice cell volume. It is worth noting that the 111, 311, 222 and 400 peaks show asymmetry. Also, the relative intensity of all peaks increased significantly for an $x=2.5$ value. These two changes do not agree with previous observations because a voltage limitation was imposed to reach $175 \mathrm{~mA} \mathrm{~h} \mathrm{~g}^{-1}$ [26,39]. From the structural point of view, the Mg insertion mechanism into LTO appears similar to that reported by Wu et al. $[25,26,28]$. Therefore, the mechanism of reaction can be written as follows:

$$
\begin{gathered}
\mathrm{Li}_{4} \mathrm{Ti}_{5} \mathrm{O}_{12}+1.5 \mathrm{Mg}^{2+}+3 \mathrm{e}^{-} \leftrightarrow \mathrm{Mg}_{1.5} \mathrm{Li}_{4} \mathrm{Ti}_{5} \mathrm{O}_{12} \\
\mathrm{Mg}_{1.5} \mathrm{Li}_{4} \mathrm{Ti}_{5} \mathrm{O}_{12}+1 \mathrm{Mg}^{2+}+2 \mathrm{e}^{-} \leftrightarrow \mathrm{Mg}_{2.5} \mathrm{Li}_{4} \mathrm{Ti}_{5} \mathrm{O}_{12}
\end{gathered}
$$

In the rock-salt structure, the $(8 a)$ positions are vacant, and $\mathrm{Li}^{+}$and $\mathrm{Mg}^{2+}$ ions are located the (16c) positions. It worth noting that the (8a) and (16c) positions are face sharing [30]. Most probably, the unusual discharge-charge profile of LTO in Mg cells (shown in Figure 3b,c) is due to changes in the transport properties arising from the degree of magnesiation (state of discharge). Indeed, it was previously established that these transport properties will have severe implication in cell kinetics, and asymmetric charge-discharge profiles have also been observed for LTO in liquid electrolytes. This asymmetry is attributed to the change of ionic conductivity during cycling. A core-shell model of the phase transition and a solid solution model were proposed [40-42].

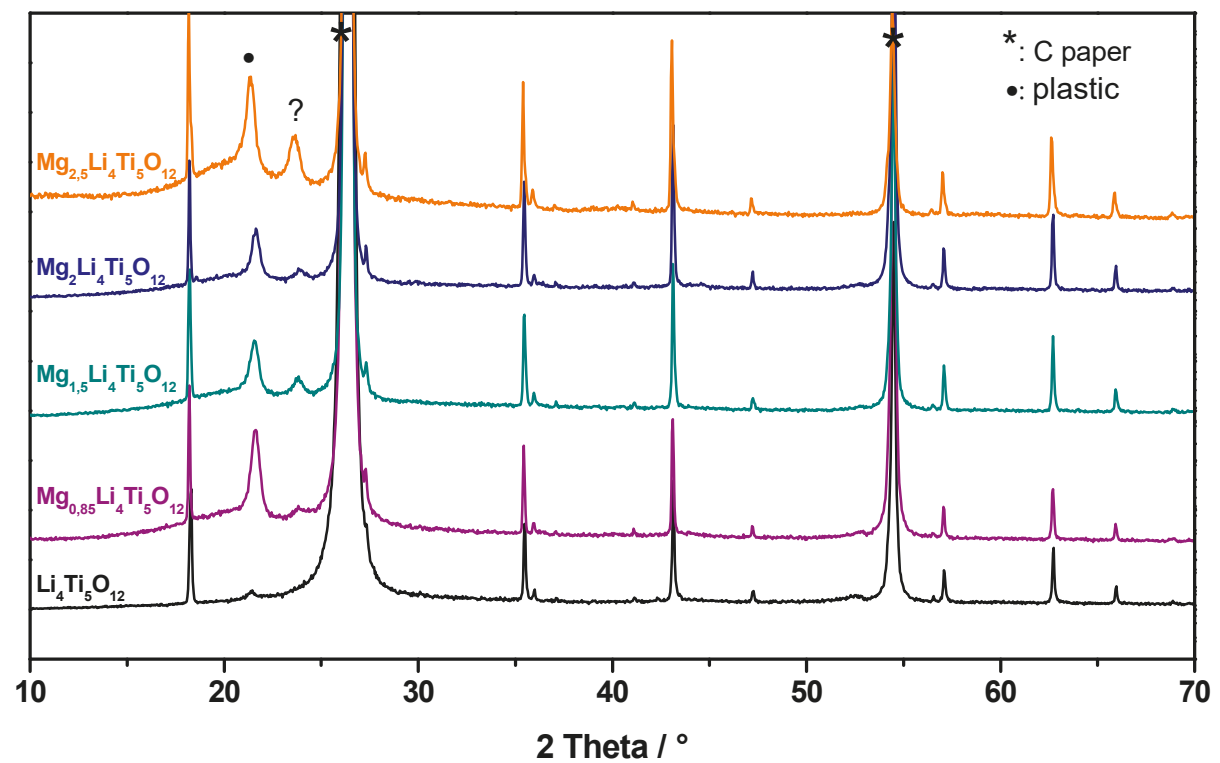

Figure 6. Cont. 

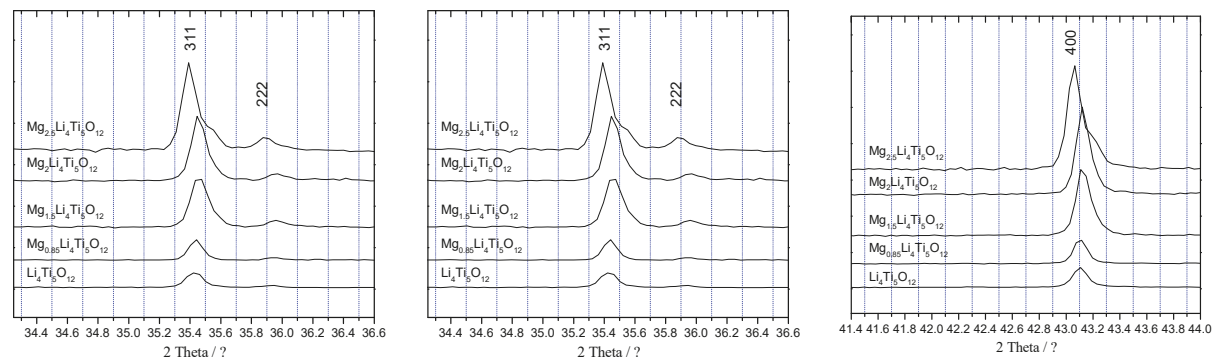

Figure 6. Ex-situ XRD patterns measured during the first discharge in the LTO/Mg cell with $0.5 \mathrm{M}$ $\mathrm{Mg}(\mathrm{TFSI})_{2}+0.13 \mathrm{M} \mathrm{MgCl}_{2} \cdot 6 \mathrm{H}_{2} \mathrm{O}$ in DME electrolyte. The XRD patterns were recorded at $\mathrm{x}=0,0.85$, 1.5, 2, and 2.5 ( $\mathrm{x}$ in $\mathrm{Mg}_{\mathrm{x}} \mathrm{Li}_{4} \mathrm{Ti}_{5} \mathrm{O}_{12}$ ) which correspond to 0, 100, 175, 233 and $290 \mathrm{~mA} \mathrm{~h} \mathrm{~g}{ }^{-1}$ capacity, respectively. Note: For the sake of clarity, the zoom of the 111, 311, 222 and 400 peaks is represented. The signal of plastic film is markerd with "." symbol. The "?" symbol denotes some unknown peak not ascribable neither to $\mathrm{C}$ (or Ti) substrate nor plastic.

\subsection{Changes in the Oxidation State by XPS}

Recently, the XPS technique has been used to investigate changes in the surface of titanium during the insertion reaction of alkali metals in LTO [26,43-45]. In this work, ex-situ XPS experiments were performed for $\mathrm{Mg}_{\mathrm{x}} \mathrm{Li}_{4} \mathrm{Ti}_{5} \mathrm{O}_{12}$ (with $\mathrm{x}=0,0.85,1.5$ and 2.5). Figure 7 shows the XPS spectra in the Ti2 $\mathrm{p}$ region. The pristine sample shows $458.5 \mathrm{eV}$ binding energies at the Ti2 $\mathrm{p}_{3 / 2}$ peak, which are typical of $\mathrm{Ti}^{4+}$. When discharging to $\mathrm{x}=0.85$, a new signal at $455.6 \mathrm{eV}$ is observed. This new signal at lower binding energy confirmed the formation of $\mathrm{Ti}^{3+}$ and the quantitative analysis by peak-profile fitting showed $21.3 \%$ of $\mathrm{Ti}^{3+}$. At $\mathrm{x}=1.5$ and 2.5 , the contribution of the $\mathrm{Ti}^{3+}$ signal increased up to $35.6 \%$ and $66.4 \%$ (Table 1). This is a clear evidence to prove titanium reduction to $\mathrm{Ti}^{3+}$ in $\mathrm{LTO}$. However, the $\mathrm{Ti}^{4+}$ signal was still present in the fully magnesiated sample $\left(\mathrm{Mg}_{2.5} \mathrm{Li}_{4} \mathrm{Ti}_{5} \mathrm{O}_{12}\right)$, most probably because the cell was charged and discharged in a non-equilibrium state and $\mathrm{Mg}^{2+}$ was not migrating fast enough to ensure the full charge transfer to the entire sample. This fact is commonly observed in related ex-situ experiments. Similarly, the $\mathrm{Ti}^{3+}$ content $(66.4 \%)$ detected by XPS when the $\mathrm{Mg} / \mathrm{LTO}$ cell is discharged to a nominal $x=2.5$ represents only $x=1.65$ in the intercalation compound. However, the intensity of the $\mathrm{Ti}^{3+}$ signal is much higher than that reported for LTO in Mg batteries [26], or in Li batteries [43-45]. The observed binding energies of Ti2 $\mathrm{p}_{3 / 2}$ and Ti2 $\mathrm{p}_{1 / 2}$ values indicated that the oxidation state of Ti-cations in the fully-discharged electrode can be assigned to $\mathrm{Ti}^{4+}$ and $\mathrm{Ti}^{3+}$. These results evidenced the electrochemical reaction of magnesium with LTO.

\subsection{Electrochemical Impedance Spectroscopy}

Electrochemical impedance spectroscopy is an excellent technique to study the kinetic response of electrode materials. It determines the resistance at the interphase between the working electrode and the electrolyte. Figure 8 shows the Nyquist diagrams of LTO electrode in $\mathrm{Mg}$ cells using $0.50 \mathrm{M} \mathrm{Mg}(\mathrm{TFSI})_{2}$ in DME with and without $0.13 \mathrm{M} \mathrm{MgCl}_{2} \cdot 6 \mathrm{H}_{2} \mathrm{O}$. These plots reveal different components of the cell resistance by fitting the spectra to the following equivalent circuit: $\left(R_{1}+\left(R_{2} / Q_{2}\right)+\left(R_{3} / Q_{3}+C_{3}\right)+W_{3}\right)$. $R_{1}$ refers to the ohmic drop at the electrolyte; $R_{2}$ is assigned to the migration of $\mathrm{Mg}$ ions through the surface film into the LTO particles and is calculated from the semicircle at high frequencies (this semicircle being invariant with potential). The charge transfer resistance $\left(R_{3}\right)$ can be calculated from the semicircle at medium-low frequencies and is ascribed to the transfer of magnesium through the film-mass interface coupled with interfacial capacitance and is potential-dependent. Q, W and C elements label constant phase element, Warburg impedance, and capacitor, respectively. The spectra of the different $\mathrm{Mg}$ cells, recorded at open circuit voltage (OCV), exhibit only one semicircle along the high to low frequency values (530 and $811 \mathrm{mHz}$ for $\mathrm{Mg} / 0.5 \mathrm{M}$ $\mathrm{Mg}(\mathrm{TFSI})_{2}+\mathrm{MgCl}_{2} \cdot 6 \mathrm{H}_{2} \mathrm{O} / \mathrm{LTO}$ and $\mathrm{Mg} / 0.5 \mathrm{M} \mathrm{Mg}(\mathrm{TFSI})_{2} / \mathrm{LTO}$, respectively). After the first discharge, 
the impedance spectrum of the $\mathrm{Mg} / 0.5 \mathrm{M} \mathrm{Mg}(\mathrm{TFSI})_{2}+\mathrm{MgCl}_{2} \cdot 6 \mathrm{H}_{2} \mathrm{O} / \mathrm{LTO}$ cell presents two defined semicircles and a Warburg element (slope of $45^{\circ}$ ), while the $\mathrm{Mg} / 0.5 \mathrm{M} \mathrm{Mg}(\mathrm{TFSI})_{2} / \mathrm{LTO}$ cell shows a similar profile to that at OCV. The observation of a second semicircle, in medium-low frequencies, represents the existence of a charge transfer resistance. This charge-transfer resistance is undoubtedly assigned to the migration of $\mathrm{Mg}^{2+}$ ions between the surface film and the LTO coupled with interfacial capacitance, followed by magnesium ion diffusion in the bulk particle. The $R_{3}$ values obtained in the first, second, and fifth discharge were 62,130 , and $150 \Omega \cdot \mathrm{cm}^{2}$, respectively. Curiously, the $R_{2}$ values increased from $13.2 \Omega \cdot \mathrm{cm}^{2}$ in the first cycle to $45 \Omega \mathrm{cm}^{2}$ in the fifth cycle. The data presented here allow us to infer the positive effects of $\mathrm{MgCl}_{2} \cdot 6 \mathrm{H}_{2} \mathrm{O}$, by facilitating the diffusion of magnesium through the active material, in contrast to a $\mathrm{MgCl}_{2} \cdot 6 \mathrm{H}_{2} \mathrm{O}$-free electrolyte.

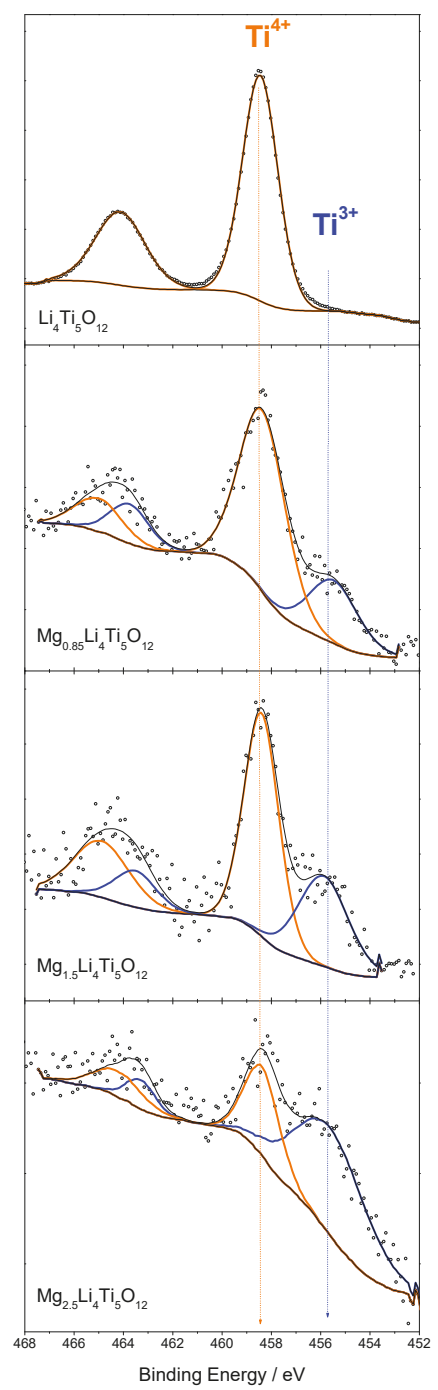

Figure 7. Ex-situ XPS spectra of LTO electrodes electrode in $0.50 \mathrm{M} \mathrm{Mg}(\mathrm{TFSI})_{2}+0.13 \mathrm{M} \mathrm{MgCl}_{2} \cdot 6 \mathrm{H}_{2} \mathrm{O}$ in DME as electrolyte at $\mathrm{x}=0,0.85,1.5$, and $2.5\left(\mathrm{x}\right.$ in $\mathrm{Mg}_{\mathrm{x}} \mathrm{Li}_{4} \mathrm{Ti}_{5} \mathrm{O}_{12}$ ) which correspond to 0, 100, 175 and $290 \mathrm{~mA} \mathrm{~h} \mathrm{~g}^{-1}$ capacity, respectively. 

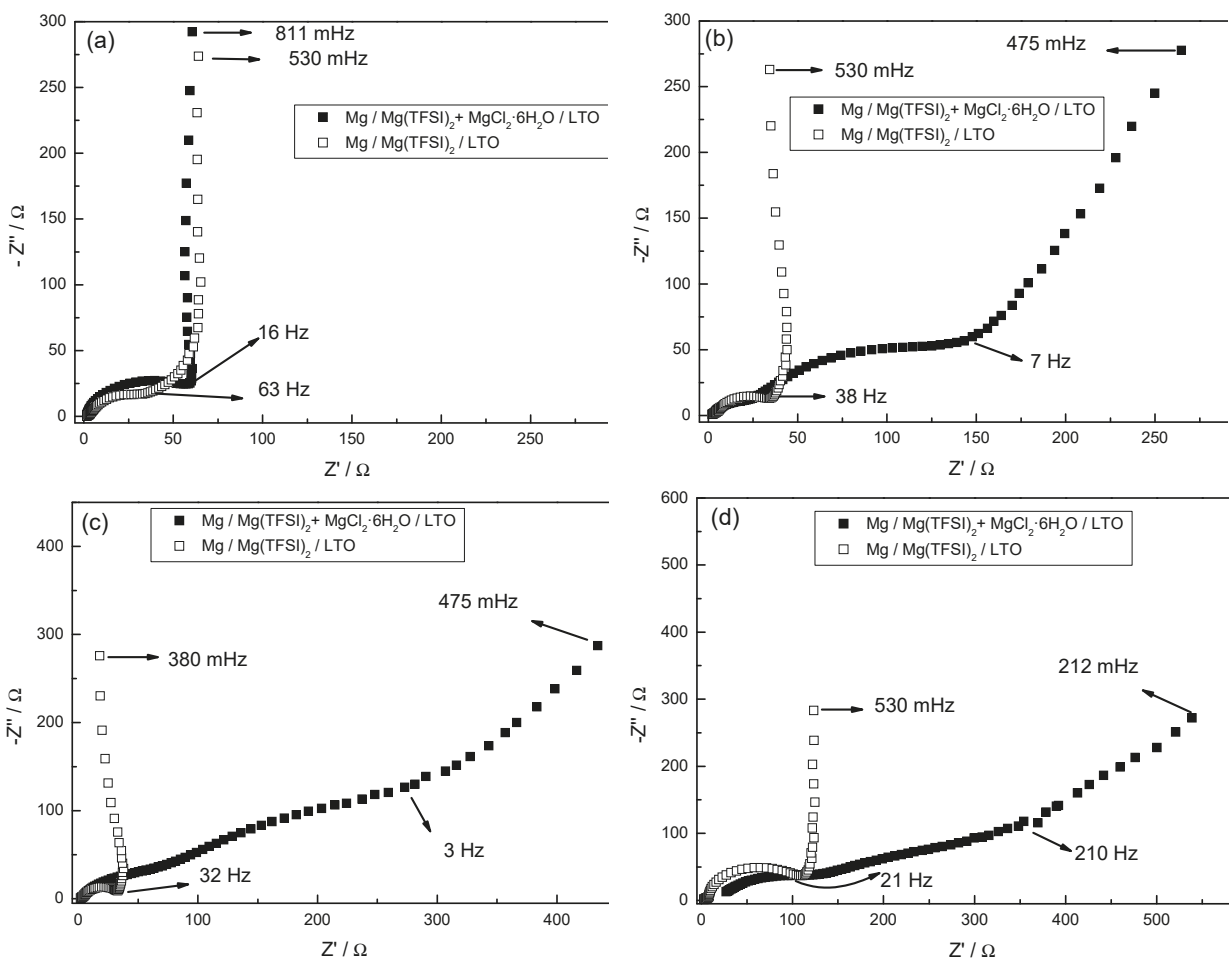

Figure 8. Nyquist plots of LTO electrode in Mg cells using two different electrolytes recorded at: (a) open circuit voltage (OCV), and after (b) first, (c) second and (d) fifth discharge. Rate: C/10. Note that the closed square symbols correspond to $\mathrm{Mg} / 0.50 \mathrm{M} \mathrm{Mg}(\mathrm{TFSI})_{2}+0.13 \mathrm{M} \mathrm{MgCl}_{2} \cdot 6 \mathrm{H}_{2} \mathrm{O}$ in DME/LTO cell, while the open square symbols correspond to $\mathrm{Mg} / 0.50 \mathrm{M} \mathrm{Mg}(\mathrm{TFSI})_{2}$ in DME/LTO cell.

The impedance of magnesium metal anodes is several orders of magnitude higher than in the insertion anodes of lithium-ion commercial cells. Currently, testing of new cathode materials in full cells is often vulnerable to the high impedance exhibited by the magnesium metal anode, which may reach $1 \mathrm{M} \Omega \cdot \mathrm{cm}^{2}$ [46]. The results presented here are useful to design scientific strategies for minimizing the impedance in $\mathrm{Mg}$ batteries.

\section{Conclusions}

In summary, we explored the properties of LTO electrodes for Mg batteries by using different electrolyte compositions. Using a fresh solution of $0.5 \mathrm{M} \mathrm{Mg}(\mathrm{TFSI})_{2}+0.13 \mathrm{M} \mathrm{MgCl}_{2} \cdot 6 \mathrm{H}_{2} \mathrm{O}$ in DME, the first discharge and charge profile displayed a plateau between $0.4-0.3 \mathrm{~V}$, and $1.35 \mathrm{~V} \mathrm{Mg}^{2+} / \mathrm{Mg}^{0}$, respectively. Then, the potential was maintained at $0.6-0.5 \mathrm{~V}$ on further discharges. Under these conditions, we obtained 175 and $290 \mathrm{~mA} \mathrm{~h} \mathrm{~g}{ }^{-1}$ capacities, which correspond to the formation of $\mathrm{Mg}_{1.5} \mathrm{Li}_{4} \mathrm{Ti}_{5} \mathrm{O}_{12}$, and $\mathrm{Mg}_{2.5} \mathrm{Li}_{4} \mathrm{Ti}_{5} \mathrm{O}_{12}$, respectively. The galvanostatic profiles exhibited a high polarization. Most probably, from an industrial point of view the reported results are not attractive. However, this work attempts to validate a proof of concept of rechargeable magnesium batteries.

Although further studies are necessary to improve the capacity retention of LTO over a large number of cycles, we have addressed the possibility to enhance the specific capacity from 175 to $290 \mathrm{~mA} \mathrm{~h}^{-1}$. The ability to enhance significantly the specific capacity of LTO is useful and offers the opportunity to increase the energy density of full cells. The ex-situ XRD patterns are insensitive to subtle structural changes from $\mathrm{x}=0-1.5$, while for $\mathrm{x}=2.5$ a shift of the $h k l$ reflections was 
recorded. Ex-situ XPS spectra evidenced changes in the oxidation state of titanium. Therefore, signals of $\mathrm{Ti}^{3+}(66.4 \%)$ and $\mathrm{Ti}^{4+}(33.6 \%)$ at the end of the discharge were obtained. While the charge transfer resistance for $\mathrm{Mg} / \mathrm{LTO}$ cell without $\mathrm{MgCl}_{2} \cdot 6 \mathrm{H}_{2} \mathrm{O}$ additive was not quantifiable, the surface film and the charge transfer resistance for $\mathrm{Mg} / \mathrm{LTO}$ cell with $\mathrm{MgCl}_{2} \cdot 6 \mathrm{H}_{2} \mathrm{O}$ additive were 13.2 and $62 \Omega \cdot \mathrm{cm}^{2}$, respectively. This study confirms the electrochemical activity of LTO towards magnesium in a $\mathrm{Mg}(\mathrm{TFSI})_{2}+\mathrm{MgCl}_{2} \cdot 6 \mathrm{H}_{2} \mathrm{O}$-based electrolyte.

Supplementary Materials: The following are available online at http://www.mdpi.com/2079-4991/9/3/484/s1, Figure S1. Galvanostatic discharge/charge curves of LTO sample in a three-electrode $\mathrm{Mg}$ cell using $0.5 \mathrm{M}$ $\mathrm{Mg}(\mathrm{TFSI})_{2}$ in DME. Figure S2. Galvanostatic discharge/charge curves of LTO sample in a three-electrode Mg cell using $0.5 \mathrm{M} \mathrm{Mg}(\mathrm{TFSI})_{2}+0.13 \mathrm{M} \mathrm{MgCl}_{2} \cdot 6 \mathrm{H}_{2} \mathrm{O}$ in DME electrolyte in different current collector: (a-c) Ti foil and (d) C paper.

Author Contributions: Formal analysis, M.C.; Investigation, M.C. and G.F.O.; Methodology, M.C.; Project administration, G.F.O.; Resources, P.L.; Supervision, J.L.T.; Validation, P.L. and J.L.T.; Writing-original draft, G.F.O.; Writing-review \& editing, G.F.O., P.L. and J.L.T.

Funding: This research was funded by Ministerio de Ciencia, Innovación y Universidades grant number MAT2017-84002-C2-1-R, ERDF funds and Junta de Andalucía grant number FQM288.

Acknowledgments: We also thank the Fine Chemistry Institute (IUNAN) and the central service research support at UCO (SCAI).

Conflicts of Interest: The authors declare no conflict of interest.

\section{References}

1. Gregory, T.D.; Hoffman, R.J.; Winterton, R.C. Nonaqueous electrochemistry of magnesium-Applications to energy-storage. J. Electrochem. Soc. 1990, 137, 775-780. [CrossRef]

2. Novak, P.; Desilvestro, J. Electrochemical insertion of magnesium in metal-oxides and sulfides from aprotic electrolytes. J. Electrochem. Soc. 1993, 140, 140-144. [CrossRef]

3. Yoo, H.D.; Shterenberg, I.; Gofer, Y.; Gershinsky, G.; Pour, N.; Aurbach, D. Mg rechargeable batteries: An on-going challenge. Energy Environ. Sci. 2013, 6, 2265-2279. [CrossRef]

4. Mohtadi, R.; Mizuno Beilstein, F. Magnesium batteries: Current state of the art, issues and future perspectives. Beilstein J. Nanotechnol. 2014, 5, 1291-1311. [CrossRef]

5. Piccolo, M.; Giffin, G.A.; Vezzu, K.; Bertasi, F.; Alotto, P.; Guarnieri, M.; Di Noto, V. Molecular Relaxations in Magnesium Polymer Electrolytes via GHz Broadband Electrical Spectroscopy. ChemSusChem 2013, 6, 2157-2160. [CrossRef] [PubMed]

6. Liebenow, C.; Yang, Z.; Lobitz, P. The electrodeposition of magnesium using solutions of organomagnesium halides, amidomagnesium halides and magnesium organoborates. Electrochem. Commun. 2000, 2, 641-645. [CrossRef]

7. Aurbach, D.; Weissman, I.; Gofer, Y.; Levi, E. Nonaqueous magnesium electrochemistry and its application in secondary batteries. Chem. Rec. 2003, 3, 61-73. [CrossRef]

8. Muldoon, J.; Bucur, C.B.; Gregory, T. Quest for Nonaqueous Multivalent Secondary Batteries: Magnesium and Beyond. Chem. Rev. 2014, 114, 11683-11720. [CrossRef] [PubMed]

9. Spahr, M.E.; Novak, P.; Haas, O.; Nesper, R. Electrochemical insertion of lithium, sodium, and magnesium in molybdenum(vi) oxide. J. Power Sources 1995, 54, 346-351. [CrossRef]

10. Doe, R.E.; Han, R.; Hwang, J.; Gmitter, A.J.; Shterenberg, I.; Yoo, H.D.; Pour, N.; Aurbach, D. Novel electrolyte solutions comprising fully inorganic salts with high anodic stability for rechargeable magnesium batteries. Chem. Commun. 2014, 50, 243-245. [CrossRef]

11. Kim, I.T.; Yamabuki, K.; Morita, M.; Tsutsumi, H.; Yoshimoto, N. Effects of alkoxide addition on the electrochemical deposition and dissolution in triglyme-based solution dissolving magnesium bis(trifluoromethanesulfonyl)amide. J. Power Sources 2015, 278, 340-343. [CrossRef]

12. Vittadello, M.; Stallworth, P.E.; Alamgir, F.M.; Suarez, S.; Abbrent, S.; Drain, C.M.; Di Noto, V.; Greenbaum, S.G. Polymeric delta- $\mathrm{MgCl}_{2}$ nanoribbons. Inorg. Chim. Acta 2006, 359, 2513-2518. [CrossRef]

13. Di Noto, V.; Lavina, S.; Longo, D.; Vidali, M. A novel electrolytic complex based on delta- $\mathrm{MgCl}_{2}$ and poly(ethylene glycol) 400. Electrochim. Acta 1998, 43, 1225-1237. [CrossRef] 
14. Giffin, G.A. Ionic liquid-based electrolytes for "beyond lithium" battery technologies. J. Mater. Chem. A 2016, 4, 13378-13389. [CrossRef]

15. Sa, N.; Pan, B.; Saha-Shah, A.; Hubaud, A.A.; Vaughey, J.T.; Baker, L.A.; Liao, C.; Burrell, A.K. Role of Chloride for a Simple, Non-Grignard Mg Electrolyte in Ether-Based Solvents. ACS Appl. Mater. Interfaces 2016, 8, 16002-16008. [CrossRef]

16. Hebié, S.; Ngo, H.P.K.; Leprêtre, J.C.; Iojoiu, C.; Cointeaux, L.; Berthelot, R.; Alloin, F. Electrolyte Based on Easily Synthesized, Low Cost Triphenolate-Borohydride Salt for High Performance, Mg(TFSI $)_{2}$-Glyme Rechargeable Magnesium Batteries. ACS Appl. Mater. Interfaces 2017, 9, 28377-28385. [CrossRef]

17. Hebié, S.; Alloin, F.; Iojoiu, C.; Berthelot, R.; Leprêtre, J.C. Magnesium Anthracene System-Based Electrolyte as a Promoter of High Electrochemical Performance Rechargeable Magnesium Batteries. ACS Appl. Mater. Interfaces 2018, 10, 5527-5533. [CrossRef] [PubMed]

18. Shterenberg, I.; Salama, M.; Gofer, Y.; Aurbach, D. Hexafluorophosphate-Based Solutions for Mg Batteries and the Importance of Chlorides. Langmuir 2017, 33, 9472-9478. [CrossRef] [PubMed]

19. Cheng, Y.; Stolley, R.M.; Han, K.S.; Shao, Y.; Arey, B.W.; Washton, N.M.; Mueller, K.T.; Helm, M.L.; Sprenkle, V.L.; Liu, J.; et al. Highly active electrolytes for rechargeable $\mathrm{Mg}$ batteries based on a $\left[\mathrm{Mg}_{2}(\mu-\mathrm{Cl})_{2}\right]^{2+}$ cation complex in dimethoxyethane. Phys. Chem. Chem. Phys. 2015, 17, 13307-13314. [CrossRef] [PubMed]

20. Shterenberg, I.; Salama, M.; Yoo, H.D.; Gofer, Y.; Park, J.-B.; Sun, Y.-K.; Aurbach, D. Evaluation of $\left(\mathrm{CF}_{3} \mathrm{SO}_{2}\right)_{2} \mathrm{~N}-(\mathrm{TFSI})$ based electrolyte solutions for Mg batteries. J. Electrochem. Soc. 2015, 162, A7118-A7128. [CrossRef]

21. Wilkening, M.; Iwaniak, W.; Heine, J.; Epp, V.; Kleinert, A.; Behrens, M.; Nuspl, G.; Bensch, W.; Heitjans, P. Microscopic Li Self-Diffusion Parameters in the Lithiated Anode Material $\mathrm{Li}_{4+\mathrm{x}} \mathrm{Ti}_{5} \mathrm{O}_{12}(0 \leq \mathrm{x} \leq 3)$ Measured by ${ }^{7}$ Li Solid State NMR. Phys. Chem. Chem. Phys. 2007, 9, 6199-6202. [CrossRef] [PubMed]

22. Zhang, N.; Liu, Z.; Yang, T.; Liao, C.; Wang, Z.; Sun, K. Facile Preparation of Nanocrystalline $\mathrm{Li}_{4} \mathrm{Ti}_{5} \mathrm{O}_{12}$ and Its High Electrochemical Performance as Anode Material for Lithium-Ion Batteries. Electrochem. Commun. 2011, 13, 654-656. [CrossRef]

23. Feng, X.; Zou, H.; Xiang, H.; Guo, X.; Zhou, T.; Wu, Y.; Xu, W.; Yan, P.; Wang, C.; Zhang, J.G.; et al. Ultrathin $\mathrm{Li}_{4} \mathrm{Ti}_{5} \mathrm{O}_{12}$ Nanosheets as Anode Materials for Lithium and Sodium Storage. ACS Appl. Mater. Interfaces 2016, 8, 16718-16726. [CrossRef] [PubMed]

24. Sun, Y.; Zhao, L.; Pan, H.; Lu, X.; Gu, L.; Hu, Y.S.; Li, H.; Armand, M.; Ikuhara, Y.; Chen, L.; et al. Direct Atomic-Scale Confirmation of Three-Phase Storage Mechanism in $\mathrm{Li}_{4} \mathrm{Ti}_{5} \mathrm{O}_{12}$ Anodes for Room-Temperature Sodium-Ion Batteries. Nat. Commun. 2013, 4, 1870-1879. [CrossRef] [PubMed]

25. Wu, N.; Yin, Y.X.; Guo, Y.G. Size-dependent electrochemical magnesium storage performance of spinel lithium titanate. Chem. Asian. J. 2014, 9, 2099-2102. [CrossRef]

26. Wu, N.; Lyu, Y.C.; Xiao, R.J.; Yu, X.; Yin, Y.X.; Yang, X.Q.; Li, H.; Gu, L.; Guo, Y.G. A highly reversible, low-strain Mg-ion insertion anode material for rechargeable Mg-ion batteries. NPG Asia Mater. 2014, 6, e120. [CrossRef]

27. Miao, Q.; NuLi, Y.; Wang, N.; Yang, J.; Wang, J.; Hirano, S. Effect of $\mathrm{Mg}^{2+} / \mathrm{Li}^{+}$mixed electrolytes on a rechargeable hybrid battery with $\mathrm{Li}_{4} \mathrm{Ti}_{5} \mathrm{O}_{12}$ cathode and $\mathrm{Mg}$ anode. RSC Adv. 2016, 6, 3231-3234. [CrossRef]

28. Wu, N.; Yang, Z.-Z.; Yao, H.-R.; Yin, Y.-X.; Gu, L.; Guo, Y.-G. Improving the Electrochemical Performance of the $\mathrm{Li}_{4} \mathrm{Ti}_{5} \mathrm{O}_{12}$ Electrode in a Rechargeable Magnesium Battery by Lithium-Magnesium Co-Intercalation. Angew. Chem. Int. Ed. 2015, 54, 5757-5761. [CrossRef] [PubMed]

29. Cabello, M.; Nacimiento, F.; Alcántara, R.; Lavela, P.; Ortiz, G.F.; Tirado, J.L. Nanobelts of Beta-Sodium Vanadate as Electrode for Magnesium and Dual Magnesium-Sodium Batteries. J. Electrochem. Soc. 2016, 163, A2781-A2790. [CrossRef]

30. Ohzuku, T.; Ueda, A.; Yamamoto, N. Zero-strain insertion material of $\mathrm{Li}\left[\mathrm{Li}_{1 / 3} \mathrm{Ti}_{5 / 3}\right] \mathrm{O}_{4}$ for rechargeable lithium cells. J. Electrochem. Soc. 1995, 142, 1431-1435. [CrossRef]

31. Hao, Y.J.; Lai, Q.Y.; Liu, D.Q.; Xu, Z.U.; Ji, X.Y. Synthesis by citric acid sol-gel method and electrochemical properties of $\mathrm{Li}_{4} \mathrm{Ti}_{5} \mathrm{O}_{12}$ anode material for lithium-ion battery. Mater. Chem. Phys. 2005, 94, 382-387. [CrossRef]

32. Muldoon, J.; Bucur, C.B.; Gregory, T. Fervent Hype behind Magnesium Batteries: An Open Call to Synthetic Chemists-Electrolytes and Cathodes Needed. Angew. Chem. Int. Ed. 2017, 56, 12064-12084. [CrossRef] 
33. Han, C.; He, Y.B.; Wang, S.; Wang, C.; Du, H.; Qin, X.; Lin, Z.; Li, B.; Kang, F. Large Polarization of $\mathrm{Li}_{4} \mathrm{Ti}_{5} \mathrm{O}_{12}$ Lithiated to $0 \mathrm{~V}$ at Large Charge/Discharge Rates. ACS Appl. Mater. Interfaces 2016, 8, 18788-18796. [CrossRef]

34. Tchitchekova, D.; Ponrouch, A.; Verrelli, R.; Broux, T.; Frontera, C.; Sorrentino, A.; Barde, F.; Biskup, N.; Arroyo-de Dompablo, M.E.; Palacin, M.R. Electrochemical Intercalation of Calcium and Magnesium in $\mathrm{TiS}_{2}$ : Fundamental Studies Related to Multivalent Battery Applications. Chem. Mater. 2018, 30, 847-856. [CrossRef]

35. Nam, K.W.; Kim, S.; Lee, S.; Salama, M.; Shterenberg, I.; Gofer, Y.; Kim, J.-S.; Yang, E.; Park, C.S.; Kim, J.S.; et al. The High Performance of Crystal Water Containing Manganese Birnessite Cathodes for Magnesium Batteries. Nano Lett. 2015, 15, 4071-4079. [CrossRef] [PubMed]

36. Mizuno, Y.; Okubo, M.; Hosono, E.; Kudo, T.; Zhou, H.; Ohishi, K. Suppressed Activation Energy for Interfacial Charge Transfer of a Prussian Blue Analog Thin Film Electrode with Hydrated Ions $\left(\mathrm{Li}^{+}, \mathrm{Na}^{+}\right.$, and $\mathrm{Mg}^{2+}$ ). J. Phys. Chem. C 2013, 117, 10877-10882. [CrossRef]

37. Mizuno, Y.; Okubo, M.; Hosono, E.; Kudo, T.; Ohishi, K.; Okazawa, A.; Kojima, N.; Kurono, R.; Nishimura, S.-I.; Yamada, A. Electrochemical $\mathrm{Mg}^{2+}$ intercalation into a bimetallic CuFe Prussian blue analog in aqueous electrolytes. J. Mater. Chem. A 2013, 1, 13055-13059. [CrossRef]

38. Ha, S.-Y.; Lee, Y.-W.; Woo, S.W.; Koo, B.; Kim, J.-S.; Cho, J.; Lee, K.T.; Choi, N.-S. Magnesium (II) bis (trifluoromethane sulfonyl) imide-based electrolytes with wide electrochemical windows forrechargeable magnesium batteries. ACS Appl. Mater. Interfaces 2014, 6, 4063-4073. [CrossRef] [PubMed]

39. Aldon, L.; Kubiak, P.; Womes, M.; Jumas, J.C.; Olivier-Fourcade, J.; Tirado, J.L.; Corredor, J.I.; Pérez Vicente, C. Chemical and electrochemical Li-insertion into the $\mathrm{Li}_{4} \mathrm{Ti}_{5} \mathrm{O}_{12}$ spinel. Chem. Mater. 2004, 16, 5721-5725. [CrossRef]

40. Li, D.; He, P.; Li, H.; Zhou, H. An unsymmetrical lithium-ion pathway between charge and discharge processes in a two-phase stage of $\mathrm{Li}_{4} \mathrm{Ti}_{5} \mathrm{O}_{12}$. Phys. Chem. Chem. Phys. 2012, 14, 9086-9091. [CrossRef]

41. Crain, D.J.; Zheng, J.P.; Roy, D. Electrochemical examination of core-shell mediated $\mathrm{Li}^{+}$transport in $\mathrm{Li}_{4} \mathrm{Ti}_{5} \mathrm{O}_{12}$ anodes of lithium ion batteries. Solid State Ionics 2013, 240, 10-18. [CrossRef]

42. Zhu, Y.R.; Yin, L.C.; Yi, T.F.; Liu, H.; Xie, Y.; Zhu, R.S. Electrochemical performance and lithium-ion intercalation kinetics of submicron-sized $\mathrm{Li}_{4} \mathrm{Ti}_{5} \mathrm{O}_{12}$ anode material. J. Alloys Compd. 2013, 547, 107-112. [CrossRef]

43. Song, M.S.; Benayad, A.; Choi, Y.M.; Park, K.S. Does $\mathrm{Li}_{4} \mathrm{Ti}_{5} \mathrm{O}_{12}$ need carbon in lithium ion batteries? Carbon-free electrode with exceptionally high electrode capacity. Chem. Commun. 2012, 48, 516-518. [CrossRef]

44. Song, M.S.; Kim, R.H.; Baek, S.W.; Lee, K.S.; Park, K.; Benayad, A. Is $\mathrm{Li}_{4} \mathrm{Ti}_{5} \mathrm{O}_{12}$ a solid-electrolyte-interphasefree electrode material in Li-ion batteries? Reactivity between the $\mathrm{Li}_{4} \mathrm{Ti}_{5} \mathrm{O}_{12}$ electrode and electrolyte. J. Mater. Chem. A 2014, 2, 631-636. [CrossRef]

45. Verde, M.G.; Baggetto, L.; Balke, N.; Veith, G.M.; Seo, J.K.; Wang, Z.; Meng, Y.S. Elucidating the Phase Transformation of $\mathrm{Li}_{4} \mathrm{Ti}_{5} \mathrm{O}_{12}$ Lithiation at the Nanoscale. ACS Nano 2016, 10, 4312-4321. [CrossRef] [PubMed]

46. Bucur, C.B.; Gregory, T.; Oliver, A.G.; Muldoon, J. Confession of a Magnesium Battery. J. Phys. Chem. Lett. 2015, 6, 3578-3591. [CrossRef] [PubMed]

(C) 2019 by the authors. Licensee MDPI, Basel, Switzerland. This article is an open access article distributed under the terms and conditions of the Creative Commons Attribution (CC BY) license (http:/ / creativecommons.org/licenses/by/4.0/). 
Article

\title{
Non-Isothermal Crystallisation Kinetics of Carbon Black- Graphene-Based Multimodal-Polyethylene Nanocomposites
}

\author{
Ibrahim A. Ahmad ${ }^{1}$, Hyun-Kyung Kim ${ }^{1,2, *}$, Suleyman Deveci ${ }^{3}$ and R. Vasant Kumar ${ }^{1, *}$ \\ 1 Department of Materials Science and Metallurgy, University of Cambridge, 27 Charles Babbage Rd, \\ Cambridge CB3 0FS, UK; iaiaa2@cam.ac.uk \\ 2 Gwangju Bio/Energy R\&D Center, Korea Institute of Energy Research (KIER), 270-25 Samso-ro, Buk-gu, \\ Gwangju 61003, Korea \\ 3 Innovation Centre, Borouge Pte Ltd., PO BOX 6951 Abu Dhabi, UAE; suleyman.deveci@borouge.com \\ * Correspondence: hkk28@cam.ac.uk (H.-K.K.); rvk10@cam.ac.uk (R.V.K.); Tel.: +44-(0)-1223-331953 (H.-K.K.); \\ +44-(0)-1223-334327 (R.V.K.)
}

Received: 9 December 2018; Accepted: 11 January 2019; Published: 18 January 2019

\begin{abstract}
The effect of carbon black (CB) and microwave-induced plasma graphene (g) on the crystallisation kinetics of the multimodal high-density polyethylene was studied under non-isothermal conditions. The non-isothermal crystallisation behaviour of the multimodal-high-density polyethylene (HDPE), containing up to $5 \mathrm{wt} . \%$ graphene, was compared with that of neat multimodal-HDPE and its carbon black based nanocomposites. The results suggested that the non-isothermal crystallisation behaviour of polyethylene (PE)-g nanocomposites relied significantly on both the graphene content and the cooling rate. The addition of graphene caused a change in the mechanism of the nucleation and the crystal growth of the multimodal-HDPE, while carbon black was shown to have little effect. Combined Avrami and Ozawa equations were shown to be effective in describing the non-isothermal crystallisation behaviour of the neat multimodal-HDPE and its nanocomposites. The mean activation energy barrier $(\Delta \mathrm{E})$, required for the transportation of the molecular chains from the melt state to the growing crystal surface, gradually diminished as the graphene content increased, which is attributable to the nucleating agent effect of graphene platelets. On the contrary, the synergistic effect resulting from the PE-CB nanocomposite decreased the $\Delta E$ of the neat multimodal-HDPE significantly at the lowest carbon black content.
\end{abstract}

Keywords: non-isothermal crystallisation kinetics; multi-modal polymer; graphene-based polymer nanocomposite; carbon black fillers.

\section{Introduction}

Multimodal high-density polyethylene (HDPE) is an engineered thermoplastic semi-crystalline polymer, which is widely used in films, pressure pipes, bottles, tubes and cables jacketing [1-5]. It is a hybrid of at least two distinct polyethylene components, wherein each constituent has different density and different molecular weight fractions [3,4]. This allows flexibility in engineering its microstructure to meet the desired balance of properties for concrete practical applications. Nevertheless, multimodal HDPE can be further improved, for example, with the addition of fillers or reinforcements, in order to overcome deficiencies in their mechanical or thermal properties [6-18]. However, the crystallisation kinetics of the final product can be influenced, for example, not only by the nature of the added fillers but also by changing the molar mass (M), the breadth of molecular weight distribution (MWD), and/or the mode of MWD [1,2,5,6,11,13,15,19-24]. The spherulitic growth rate is found to increase as molar mass reduces, while polymers with broader and/or bimodal MWD lead to an increased peak crystallisation temperature and overall crystallisation rate [1,2,5,6,11,15,19-23]. 
Graphene has recently emerged as a very promising breakthrough material in the field of polymer nanocomposites and has attracted considerable scientific interest [7]. A large number of studies have reported numerous property enhancements attained from the use of graphene in polymer nanocomposites, such as superior mechanical, thermal, gas barrier, electrical and flame retardant properties $[7,8]$. Carbon black is also widely used as a speciality additive in multimodal high-density polyethylene (HDPE) for enhancing properties such as wear resistance and jetness [9,10,12]. It is very well-known and widely used with multimodal-HDPE for pressure pipes and power cable jacketing applications [12]. The incorporation of such fillers or reinforcements may significantly affect the crystallisation behaviour of the multimodal-HDPE, as the matrix is a semi-crystalline polymer with both crystalline and amorphous regions [11]. A number of studies have reported on the effect of nanofillers, such as carbon nanotubes, diamond, graphite, talc, $\mathrm{CaCO}_{3}, \mathrm{SiO}_{2}, \mathrm{TiO}_{2}, \mathrm{BaSO}_{4}$, on the crystallisation kinetics of HDPE [11,13,24-33]. As an example, J-W. Huang et al. reported a decrease in the spherulite size and degree of crystallinity and an increase in peak crystallisation temperature and overall crystallisation rate with the addition of inorganic fillers [26]. J. Kim et al. observed that the introduction of the multiwalled carbon nanotubes to the HDPE hindered the chain ordering, thus increasing the time required to reach $50 \%$ of relative crystallinity, despite the increase in the onset and peak crystallisation temperatures [13]. The mechanism of the primary and secondary crystallisation processes has a profound impact on the arrangement, size and morphology of the crystallites, as well as the degree of crystallinity, thus affecting the mechanical and physical properties of the semi-crystalline polymers $[1,5,11,26,34-36]$. Therefore, a change in the crystallisation kinetics can alter properties such as modulus, barrier properties, post extrusion shrinkage, post-mould shrinkage and/or warpage, transparency or clarity, sagging, processing cycle times and heat resistance in HDPE [11]. Also, a knowledge of the conditions affecting the crystallisation kinetics is crucial for optimising the processing parameters. For example, inappropriate selection of the processing variables leads to many defects in injection-moulded artefacts such as warpage, dimensional instability, shrinkage and so forth. [30]. Moreover, a non-uniform wall thickness, shape distortion, ovality, and waviness are a result of cross-sectional and axial thermal-gradient variations in pipe extrusion [37].

Polymer crystallisation is a process that essentially involves two consecutive steps, namely the nucleation and growth of the crystal nucleus [6,19,34-36]. A fundamental kinetic model of the polymer crystallisation process, during both isothermal and non-isothermal conditions, provides the necessary framework for a better understanding of the influence of the nanofillers on the crystallisation behaviour and crystal morphology of the multimodal-HDPE. In general, crystallisation is often considered to take place under idealised isothermal conditions, which greatly simplifies the mathematical and thermodynamic analysis. However, it fails to account for the effect that the varying cooling rates and crystallisation temperatures have on the final properties of the polymer in real-world applications $[2,11,13,24,26,28,29,34-36]$. Therefore, it is of great practical significance to simulate industrial processes in order to study the crystallisation kinetics, as industrial processes often occur under non-isothermal conditions. In our previous study, we reported a novel method for the preparation of a high-performance polymer-graphene nanocomposite using a co-rotating intermeshing twin-screw extruder [8]. The project was conducted on one metric ton of a commercial polymer and more than one kilogram of graphene, on a semi-industrial scale extrusion system that can be scaled up to full industrial scale production. Accordingly, this article aims to study the effect of exfoliated microwave-induced plasma graphene on the crystallisation kinetics of the high molecular weight multimodal-HDPE, the polymer which undergoes crystallisation from the melt state during industrial processing and structural development, under non-isothermal conditions. A commercial carbon black/multimodal HDPE nanocomposite product is considered as a bench mark in this study, for the sake of comparison with new multimodal-HDPE, based on graphene. The incorporation of $0.1-5 \mathrm{wt} . \%$ carbon black or graphene nanofillers led the crystallisation kinetics of the multimodal-HDPE to behave differently in non-isothermal conditions. It is therefore important to understand the difference between the effect of these two nanomaterials on the crystallisation behaviour of the multimodal HDPE, as 
replacing the nanofiller, for example carbon black by graphene, requires a consequent optimisation of the processing parameters. The crystallisation kinetics were further explored, in an attempt to better understand the different roles, which the latter nanofillers play in the crystallisation processes of multimodal-HDPE. In this regard, a model proposed by T. Liu et al. on the basis of H. E. Kissinger, Avrami, and Ozawa equations were incorporated for better understanding of the crystallisation behaviours $[11,13,24,25,29,38,39]$. The H. E. Kissinger equation allows for the interpretation of the heterogeneous nucleation mechanism by estimating the activation energy barrier for nucleation, while T. Liu et al. model is utilised to fit the experimental results to allow better descriptions of non-isothermal kinetics by providing a relationship between the cooling rates and crystallisation temperature [38,39]. This study is of fundamental importance to the optimisation of processing variables, aiming to provide supplementary information about the non-isothermal crystallisation kinetics of carbon black and graphene-based multimodal-HDPE prepared by melt intercalation method. The results of this research provide greater insight into different processing factors, affecting the multimodal HDPE-graphene nanocomposite crystallisation performance and criterion for effectively producing the next generation of black multimodal-polyethylene compounds for use in high-pressure pipes, automotive and energy cable applications. This would, therefore, contribute to a better understanding of the relationship among processing-structure-property of the multimodal-HDPE and its nanocomposites. To the best of our knowledge, little research, if any, has studied and compared the crystallisation kinetics of multimodal-HDPE induced by a bottom-up graphene with a commercial multimodal-HDPE induced by a carbon black with an average primary particle size of $20 \mathrm{~nm}$.

\section{Experimental}

\subsection{Materials}

Unstabilised, high density polyethylene powders, produced with Ziegler Natta catalyst via a proprietary Borstar process (Borouge, United Arab Emirates), melt flow rate of $7.5 \mathrm{~g} / 10 \mathrm{~min}\left(190{ }^{\circ} \mathrm{C}\right.$, $21.6 \mathrm{~kg}), \mathrm{Mw}=280 \mathrm{~kg} /$ mole, $\mathrm{Mn}=8.49 \mathrm{~kg} /$ mole and $\mathrm{Mw} / \mathrm{Mn}=33$ and a density of $950 \mathrm{~kg} / \mathrm{m}^{3}$. Antioxidants masterbatch containing Irgafos 168 and Irganox 1010 were added to the polymers at $0.5 \mathrm{wt} . \%$ for optimum stabilisation during processing. Graphene powder was obtained from FVG Cambridge Nanosystems company (Cambridge, United Kingdom), with $\geq 96 \%$ carbon purity, bulk density of $0.0266 \mathrm{~g} / \mathrm{mL}$, flake thickness $<1.0 \mathrm{~nm}$ with an average lateral size range of 150-500 nm. Carbon Black powder was provided by Orion Engineered Carbons GmbH (Frankfurt am Main, Germany), with $\geq 92 \mathrm{cc} / 100 \mathrm{~g}$ oil absorption number, ash content of $0.10 \%$, Sulphur content of $0.10 \%$, tint strength of $103 \%$, average primary particle size of $20 \mathrm{~nm}$ and a density of $1.7-1.9 \mathrm{~g} / \mathrm{cm}^{3}$ at $20^{\circ} \mathrm{C}$.

\subsection{Nanocomposite Preparation}

Both multimodal-HDPE/graphene (PE-g) and multimodal-HDPE/carbon black (PE-CB) were prepared via melt-intercalation method using Coperion ZSK 18 twin extruder having a screw diameter of $18 \mathrm{~mm}$ and a barrel length of $720 \mathrm{~mm}(\mathrm{~L} / \mathrm{D}=40)$. The screw rotation speed was $600 \mathrm{rpm}$, barrel temperature profile was in the range of $170-240{ }^{\circ} \mathrm{C}$ and feed rate was between $1-2 \mathrm{~kg} / \mathrm{h}$. For more information, the reader is directed to our previous work [8].

The nanofillers and a dry polyethylene powder were fed separately into the extruder via a spiral flow screw Brabender ISC-CM plus feeder. The nanofillers were fed at 0.1, 0.5, 1, 2 and $5 \mathrm{wt}$.\% loadings. In order to prevent the polymer from degrading, an antioxidant masterbatch was simultaneously added through a side feeder, with the total loading of $0.5 \mathrm{wt} . \%$. The extruded pellets were subsequently compression moulded to about $0.4 \mathrm{~mm}$ thickness, following ISO 293 under $5 \mathrm{MPa}$, at a temperature of $200{ }^{\circ} \mathrm{C}$. This was undertaken via a compression moulding platen press (Dr. Collin P $400 \mathrm{M}$, Germany), for an overall programming cycle of $32 \mathrm{~min}$ at a heating and cooling rate of $15^{\circ} \mathrm{C} / \mathrm{min}$. The specimens were successively conditioned at $23 \pm 2{ }^{\circ} \mathrm{C}$ and $50 \pm 5 \%$, for at least $48 \mathrm{~h}$, prior to being tested. 


\subsection{Characterisation}

Polarised light microscopy (PLM) analyses were conducted on a ZEISS Axio scope.A1 HAL 100/HBO 100, operated with an AxioCam MRc 5 camera and an AxioVision software. Film samples were sectioned to a thickness of $15 \mu \mathrm{m}$, using a fully automated rotary microtome Leica RM2265 (Leica microsystems, Wetzlar, Germany). Samples were cooled by DSC at $2.5^{\circ} \mathrm{C} / \mathrm{min}$ prior to being analysed under the polarised light. ImageJ software was used to calculate the mean particle size of the nanoparticle agglomerates and the \%area fraction $\left(200 \times 200 \mu \mathrm{m}^{2}\right)$ upon the optical light microscopy and transmission electron microscopy (TEM) images.

Transmission electron microscopy (TEM) was performed using Hitachi HT7700, at an accelerating voltage of $120 \mathrm{kV}$. Film samples were cryo-sectioned to a thickness of $\sim 80 \mathrm{~nm}$ at $-125^{\circ} \mathrm{C}$, using Leica EM UC7/FC7 Cryo-Ultra-microtome.

Thermogravimetric analysis (TGA) was carried out with Q500 TGA (TA instruments, New Castle, UK) with a heating rate of $10{ }^{\circ} \mathrm{C} / \mathrm{min}$ from room temperature to $1000{ }^{\circ} \mathrm{C}$ in a nitrogen atmosphere. High-Resolution (Hi-Res)-Dynamic mode was performed with sensitivity of 2.00 and a resolution of $4{ }^{\circ} \mathrm{C}$.

Rheological behaviour of the samples was studied using stress-controlled rotational rheometer (Anton Paar Physica MCR 301 with CTD450 heating unit) at $190{ }^{\circ} \mathrm{C}$ under a nitrogen atmosphere. The compression moulded sample, weighing $1.5 \mathrm{~g}$ and with measurements of $25 \mathrm{~mm}$ in diameter and 1.5 $\mathrm{mm}$ in thickness was conditioned at $40^{\circ} \mathrm{C}$ for $48 \mathrm{~h}$. The sample was then placed onto a $25 \mathrm{~mm}$ parallel plate fixture and trimmed to a thickness of $1.2 \mathrm{~mm}$ by slowly lowering the upper plate. The dynamic frequency sweep was conducted from 500 to $0.0154 \mathrm{rad} / \mathrm{s}$ at $5 \%$ strain. The reason for starting from the maximum frequency was to avoid sample degradation under high temperature and low angular frequency speed. The polydispersity index $(P D I)$ was calculated as follows [40]:

$$
P D I=\frac{100000}{G^{\prime}\left(\omega_{C O P}\right)}, \quad \omega_{C O P}=\omega\left(G^{\prime}=G^{\prime \prime}\right)
$$

where $G^{\prime}$ is the storage shear modulus, $G^{\prime \prime}$ is the loss shear modulus, $\omega$ is the angular frequency and $\omega_{\mathrm{COP}}$ is the crossover angular frequency point obtained from the intersection of storage modulus and loss modulus in a log-log scale of a frequency sweep test.

Differential scanning calorimetry (DSC) was performed in a $\mathrm{N}_{2}$ atmosphere $(50 \pm 5 \mathrm{~mL} / \mathrm{min}$ ), using approximately $5 \mathrm{mg}$ of the sample, sealed in $\mathrm{Al}$ pans with TA Instruments Q2000. The samples were melted at $200{ }^{\circ} \mathrm{C}$, then held for $10 \mathrm{~min}$ to eliminate the thermal history and subsequently cooled to $0{ }^{\circ} \mathrm{C}$ at cooling rates of $2.5,5,10$ and $20^{\circ} \mathrm{C} / \mathrm{min}$, respectively. The samples were again held at $0{ }^{\circ} \mathrm{C}$ for $10 \mathrm{~min}$ and subsequently heated to $180^{\circ} \mathrm{C}$ at the same cooling rates as the prior cooling rate, in order to obtain the DSC exotherms. Heat flow, as a function of time and temperature, was recorded during both crystallisation and melting processes for consequent data analysis.

The peak crystallisation temperature $\left(T_{\mathrm{c}}\right)$ was determined from the temperature at maximum heat flow of crystallisation peak.

The following equation:

$$
\% X_{\mathrm{c}}=\frac{\Delta H_{v}}{\left(1-\mathrm{W}_{f}\right) \Delta \mathrm{H}_{v}{ }^{\circ}} \times 100 \%
$$

was used to calculate the degree of crystallinity $\left(X_{\mathcal{C}}\right)$ of the polymers, where $\Delta H_{v}$ is the enthalpy of fusion determined from the experiment, $\Delta \mathrm{H}_{v}{ }^{\circ}$ is the enthalpy of fusion of the $100 \%$ crystalline polymer $\left(\Delta \mathrm{H}_{v}{ }^{\circ}=290 \mathrm{~J} / \mathrm{g}\right)$ and $W_{f}$ is the weight fraction of the filler content in HDPE [2,34-36,41].

\section{Results and Discussion}

The dispersion and distribution of graphene and carbon black were assessed by TEM and light microscopy, as shown in Figure 1. More information about the details of our experimental 
protocol can be found in the literature [8]. Graphene monolayers are transparent under an optical microscope, opacity of $2.3 \pm 0.1 \%$, and the optical loss become greater in the wrinkled and overlapped samples [42,43]. L. J. Cote et al. found that the average light scattering from the wrinkled region is about 3.7 times that of the overlapped areas [43]. On the other hand, carbon black is composed of primary particles that are permanently fused together, through the covalent bonds, into an aggregate structure (see Figure S2) [44]. Each primary particle is made up of imperfect crystallites of turbostratic graphite structure, which are twisted into each other throughout the aggregates $[44,45]$. They are welded in the aggregate and are neither discrete nor do they have physical boundaries between them. Due to the production and storage conditions, the aggregates join together into agglomerates by van der Waal's interactions [45]. The mean particle size of the carbon black agglomerates and the $\%$ area fraction $\left(200 \times 200 \mu \mathrm{m}^{2}\right)$ were around $0.9 \mu \mathrm{m}^{2}$ and 0.4 respectively, as shown in Figure 1 and supplementary Figure S1. However, the mean particle size of the detected graphene agglomerates was $0.95 \mu \mathrm{m}^{2}$ and the \%area fraction was less than 0.006 . The \%area fraction and mean particle size were calculated based on TEM and light microscopy analysis and graphene particles of less than $0.05 \mu \mathrm{m}^{2}$ or $500 \mathrm{~nm}$ were excluded from the calculations. A decrease in the \%area fraction means a better distribution and fewer agglomerates. The figure was higher with carbon black as the fused aggregate sizes are commonly bigger than graphene monolayers. As shown from the TEM images in Figure 1, graphene platelets were thoroughly dispersed and distributed within the polymer matrix. However, carbon black images showed good distribution with different agglomerate sizes, though containing small sizes, which is normal in carbon black-based polymer nanocomposites $[12,44,45]$. Note that PE-CBs were used as a benchmark in this study in the interest of comparison.
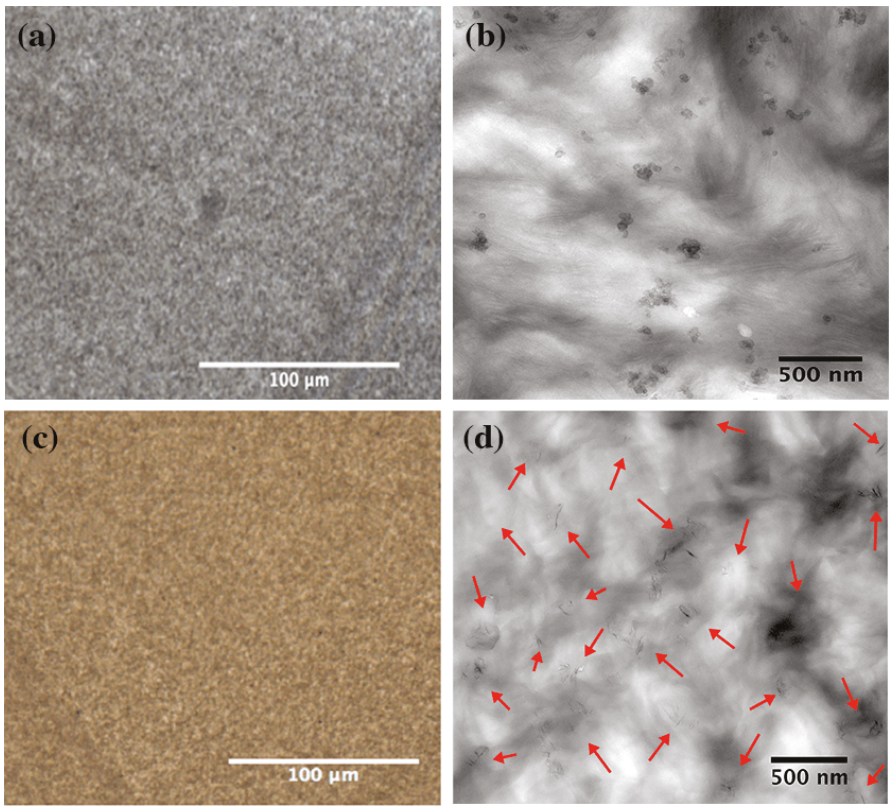

Figure 1. Light microscopy (left) and TEM images (right) show the dispersion and distribution of (a,b) carbon black and (c,d) graphene platelets within the multimodal-HDPE matrix. The red arrows show the distribution of graphene platelets throughout the polymer matrix. The TEM and light microscopy images were taken at $10 \mathrm{k}$ and $20 \times$, respectively.

The dispersion and distribution of the nanofillers within the polymer matrix were further investigated by the rheological measurements [40,46-48]. The influence of the nanofillers on the 
viscoelastic response of the polymer is revealed from the change in the absolute values of the storage $\left(G^{\prime}\right)$ and loss $\left(G^{\prime \prime}\right)$ moduli, as well as their frequency dependence [40,46-48]. The pseudoplastic, non-Newtonian behaviour of the viscoelastic polymer is presented in Figure 2a. At a high shear rate, all the polymers exhibited shear thinning behaviour, which resulted in a decrease of extensional viscosity. The melt viscosity of the neat multimodal-HDPE increased with the addition of the both nanofillers, though the relative increase gradually lessened at a high shear rate.

(a)

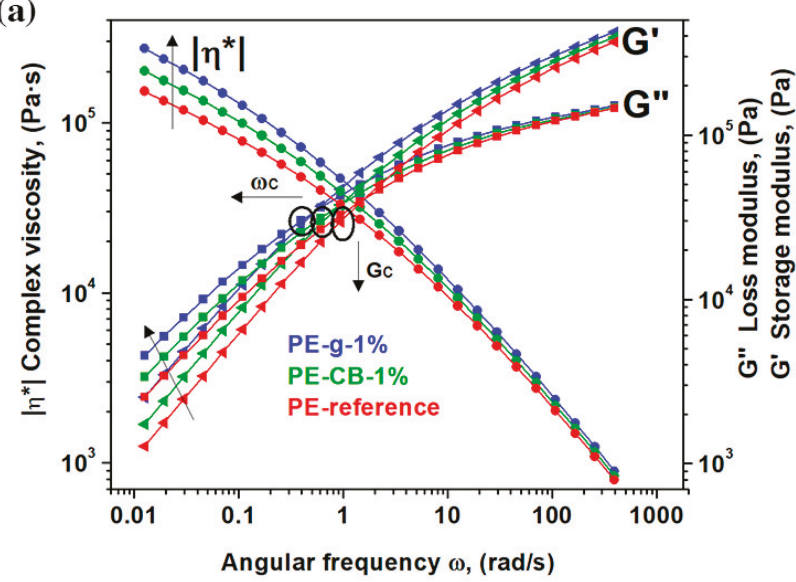

(b)

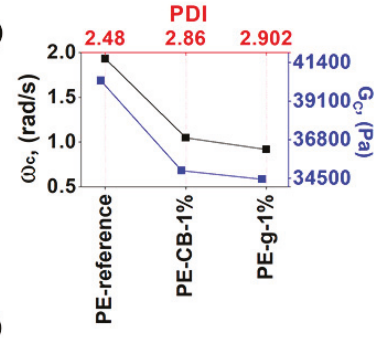

(c)

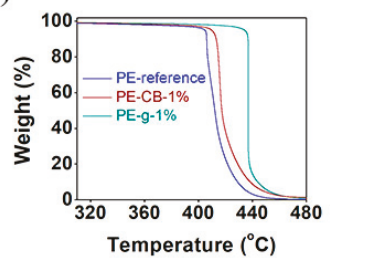

Figure 2. Thermal stability and rheological behaviours of the multimodal-HDPE and its nanocomposites (a) Dynamic frequency sweep measurements of the multimodal-HDPE reference (PE), PE-CB- $1 \%$ and PE-g- $1 \%$, measured at $190{ }^{\circ} \mathrm{C}$. (b) The polydispersity index (PDI) of the neat polymer and its nanocomposites, calculated based on the crossover frequency point $\left(\omega_{\mathrm{C}}\right)$ and the crossover modulus point $\left(G_{C}\right)$ in a log-log scale. (c) Thermogravimetric thermograms of the neat multimodal-HDPE, PE-CB-1\% and PE-g- $1 \%$, in $\mathrm{N}_{2}$ atmosphere.

The presence of the nanofillers considerably increased the pseudoplasticity at a low shear rate. At the angular frequency of $0.0154 \mathrm{rad} / \mathrm{s}$, the complex viscosity of the neat multimodal-HDPE increased from $0.19 \mathrm{MPa} \cdot \mathrm{s}$, to $0.34 \mathrm{MPa} \cdot \mathrm{s}$ and $0.25 \mathrm{MPa} \cdot \mathrm{s}$ at $1 \mathrm{wt} . \%$ loading of graphene and carbon black, respectively. Similarly, the loss and storage moduli of the neat polymer increased by a value of $\sim 36 \%$ and $\sim 32 \%$ with $1 \mathrm{wt} . \%$ loading of carbon black and by a value of $\sim 99 \%$ and $\sim 78 \%$ at $1 \mathrm{wt} . \%$ loading of graphene, respectively. The greater amount of storage and loss moduli of the reinforced polymer is attributed to the formation of a strong interfacial bonding between the polymer matrix and the high-modulus nanofillers, which has accordingly reduced the loss tangent, therefore the polymer became more elastic $[8,13,28-30]$. The thorough dispersion and distribution of the nanofillers, as well as the strong interfacial bonding, led to a decrease in the degree of the chain mobility of the polymers, thus suppressing the shear flow of the polyethylene macromolecular chains [6].

As shown in Figure $2 b$, the crossover modulus point $\left(G_{C}\right)$ and crossover angular frequency point $\left(\omega_{\mathrm{C}}\right)$ of the reinforced polymers have shifted to a lower range. The addition of $1 \mathrm{wt} . \%$ of graphene decreased the $G_{C}$ and $\omega_{C}$ of multimodal-HDPE by a value of $15 \%$ and $53 \%$, respectively, while it decreased by a value of $13 \%$ and $46 \%$ with the $1 \mathrm{wt} . \%$ loading of the carbon black. These differences can be attributed to the specific surface area which each nanofiller can offer the polymer matrix through its specific dimensions $[6,25]$. The shift of the $\omega_{C}$ to the lower region indicates that the reinforced polymers exhibited higher average molar mass and/or branched (entanglement) molecules [8,40]. The later shift observed in PE-g can be attributed to formation of the jammed network structure, arising from the thorough dispersion and distribution of graphene platelets within the polymer matrix, which probably constrained the movement of the polymer chains $[8,14,48,49]$. Nevertheless, 
the shift of the $G_{C}$ to the lower region upon the addition of nanofillers possibly arose also from exposing the neat polymer to a high temperature, under a combination of high shear and elongation forces, for a prolonged period of time. The weight average molar mass $(\mathrm{Mw})$ and z-average molar mass (Mz) of the neat multimodal-HDPE powder decreased from $280 \mathrm{~kg} / \mathrm{mol}$ and $2099 \mathrm{~kg} / \mathrm{mol}$, to $207 \mathrm{~kg} / \mathrm{mol}$ and $1131 \mathrm{~kg} / \mathrm{mol}$, respectively, after being extruded in the conditions described in the experimental section (see the supplementary Table S2). Thus, the nanofiller-polymer likely induced an antioxidant synergistic effect, protecting the polymer from degradation $[9,10,12,16]$ This is evident from the increase in the polydispersity index (PDI) of the reinforced polymers, compared with the neat multimodal-HDPE, for example, the larger is the PDI, the broader the molecular weight distribution. The advantages of synergistic effect of nanofillers are further confirmed via thermogravimetric analyses, represented in Figure 2c.

As shown from the TGA thermograms in Figure $2 \mathrm{c}$ and Table 1 , the onset degradation temperature of the polymer reinforced with $1 \mathrm{wt} . \%$ loading of graphene increased significantly, by more than $32{ }^{\circ} \mathrm{C}$, while a temperature increase of only $6{ }^{\circ} \mathrm{C}$ was achieved with $1 \mathrm{wt} . \%$ loading of carbon black. The onset degradation temperature at $5 \%$ mass loss (T5\%) of the neat polymer, increased from $405^{\circ} \mathrm{C}$ to $410{ }^{\circ} \mathrm{C}$ with $1 \mathrm{wt} . \%$ loading of carbon black but to $\sim 435^{\circ} \mathrm{C}$ with $1 \mathrm{wt} . \%$ loading of graphene. This indicates that the nanofillers acted as a thermal barrier and improved the thermal stability of the polymers. The large aspect ratio of graphene, with platelet structure, likely offered a larger interfacial surface with the polymer matrix, which in turn slowed the diffusion of the decomposition products from a jammed network structure created in the nanocomposite $[8,18,19,50,51]$. Therefore, the homogenous dispersion and distribution of the graphene platelets, as well as strong interfacial bonding, are likely capable of forming a continuous network-structured protective layer, which notably reduces the heat release rate during the pyrolysis process $[8,17,18,50,52]$. However, the dimensional structure of the carbon black may have rendered it unable to form a continuous interconnected network structure in the polymer matrix.

Table 1. TGA data analysis of the neat multimodal-HDPE, PE-CB- $1 \%$ and PE-g- $1 \%$.

\begin{tabular}{ccccc}
\hline Sample & T5\%, $\left({ }^{\circ} \mathbf{C}\right)$ & $\mathbf{T} 30 \%,\left({ }^{\circ} \mathbf{C}\right)$ & T50\%, $\left({ }^{\circ} \mathrm{C}\right)$ & T80\%, $\left({ }^{\circ} \mathbf{C}\right)$ \\
\hline PE-reference & 405 & 406.8 & 409 & 419.3 \\
PE-g- $\%$ & 435 & 437 & 437 & 438 \\
PE-CB- $1 \%$ & 409.8 & 415 & 417 & 429
\end{tabular}

$\mathrm{T} 5 \%, \overline{\mathrm{T} 30 \%}$, T50\% and T80\%, are the onset temperatures at $5 \%, 30 \%, 50 \%$ and $80 \%$ mass loss, respectively.

Figure 3a and the supplementary Figure S3, show the differential scanning calorimetry (DSC) scans recorded at different cooling rates for the neat multimodal-HDPE and its nanocomposites. The exothermic crystallisation events were quenched from the molten state at constant rates of 2.5, 5, 10, $20^{\circ} \mathrm{C} / \mathrm{min}$ and the magnitude of parameters is summarised in Table 2 and the supplementary Table S1. As evident from the DSC thermograms, with an increasing cooling rate, the peak crystallisation temperature $\left(T_{\mathrm{c}}\right)$ exhibited broader shape and shifted gradually to a lower temperature. The value of $T_{\mathrm{c}}$ increased from $114.8^{\circ} \mathrm{C}$ to $119.8^{\circ} \mathrm{C}$ for pristine multimodal-HDPE, when decreasing the cooling rate from 20 to $2.5^{\circ} \mathrm{C} / \mathrm{min}$. In general, nucleation at a lower degree of undercooling tends to be sporadic and only a relatively small number of nuclei are obtained during the melt crystallisation [36]. At higher cooling rates, the time interval becomes sufficiently shorter in order that the random tangled molecules in the melt to align, form nuclei throughout the melt and then grow by the addition of further molecular chains $[2,6,11,36,51]$. 
(a)
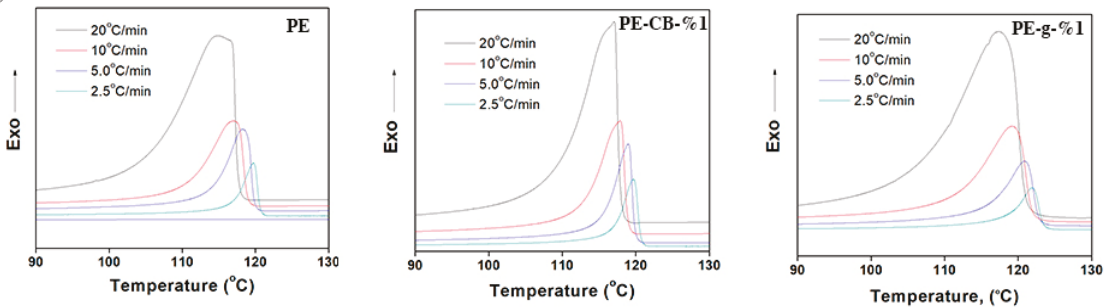

(b)
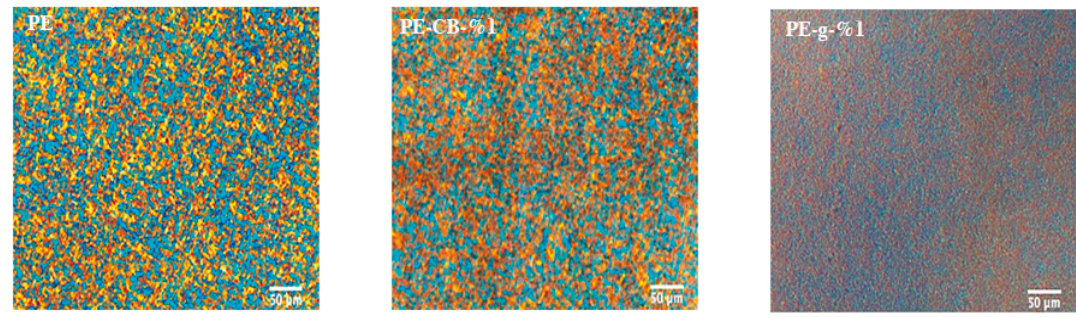

(c)

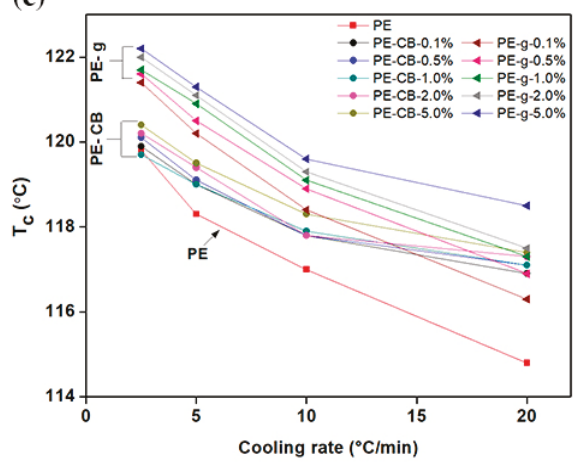

Figure 3. The effect of carbon black and graphene on the crystallisation kinetics of the multimodal-HDPE. (a) Non-isothermal DSC traces of the neat multimodal-HDPE, PE-CB-1\% and PE-g-1\%. (b) PLM micrographs represent the effect of graphene and carbon black on the spherulitic morphology of the multimodal-HDPE. (c) Effect of carbon black and graphene fillers on the peak crystallisation temperature $\left(T_{\mathrm{c}}\right)$ of the multimodal-HDPE at different cooling rate.

Table 2. Nano-isothermal crystallisation parameters of multimodal-HDPE, PE-g and PE-CB.

\begin{tabular}{|c|c|c|c|c|c|c|c|c|c|c|}
\hline Sample & $\begin{array}{c}\Phi, \\
\left({ }^{\circ} \mathrm{C} / \mathrm{min}\right)\end{array}$ & $\begin{array}{l}T_{0} \\
\left({ }^{\circ} \mathrm{C}\right)\end{array}$ & $\begin{array}{l}T_{\mathrm{c}} \\
\left({ }^{\circ} \mathrm{C}\right)\end{array}$ & $\begin{array}{c}T_{0}-T_{\mathrm{c}} \\
\left({ }^{\circ} \mathrm{C}\right)\end{array}$ & $\begin{array}{l}T_{0.5} \\
\left({ }^{\circ} \mathrm{C}\right)\end{array}$ & $\begin{array}{c}t_{0.5} \\
\text { (min) }\end{array}$ & $\begin{array}{l}\Delta H_{\mathrm{c}} \\
(\mathrm{J} / \mathrm{g})\end{array}$ & $\begin{array}{l}T_{\mathrm{f}} \\
\left({ }^{\circ} \mathrm{C}\right)\end{array}$ & $\begin{array}{c}t, \\
(\mathrm{~min})\end{array}$ & $\begin{array}{l}X_{\mathrm{c}} \\
(\%)\end{array}$ \\
\hline \multirow[t]{4}{*}{ Neat HDPE } & 20 & 120.3 & 114.8 & 5.5 & 112.0 & 0.5 & 184 & 50.1 & 3.5 & 70 \\
\hline & 10 & 121.4 & 117.0 & 4.4 & 114.2 & 0.8 & 187 & 50.2 & 7.1 & 71 \\
\hline & 5 & 121.7 & 118.3 & 3.4 & 116.1 & 1.3 & 193 & 50.3 & 14.3 & 71 \\
\hline & 2.5 & 122.5 & 119.8 & 2.7 & 117.7 & 2.1 & 199 & 50.1 & 29.0 & 71 \\
\hline \multirow[t]{4}{*}{ PE-CB-1.0\% } & 20 & 120.2 & 117.1 & 3.1 & 113.5 & 0.4 & 179 & 50.3 & 3.5 & 69 \\
\hline & 10 & 121.4 & 117.9 & 3.5 & 115.1 & 0.7 & 184 & 50.1 & 7.1 & 70 \\
\hline & 5 & 121.8 & 119.0 & 2.8 & 116.6 & 1.1 & 188 & 50.1 & 14.3 & 70 \\
\hline & 2.5 & 122 & 120.1 & 2.3 & 117.6 & 1.9 & 191 & 50.2 & 28.7 & 70 \\
\hline PE-g-1.0\% & 20 & 127.4 & 117.3 & 10.1 & 113.5 & 0.8 & 176 & 49.9 & 3.9 & 69 \\
\hline
\end{tabular}


Table 2. Cont.

\begin{tabular}{|c|c|c|c|c|c|c|c|c|c|c|}
\hline Sample & $\begin{array}{c}\Phi, \\
\left({ }^{\circ} \mathrm{C} / \mathrm{min}\right)\end{array}$ & $\begin{array}{l}T_{0} \\
\left({ }^{\circ} \mathrm{C}\right)\end{array}$ & $\begin{array}{c}T_{\mathrm{c}} \\
\left({ }^{\circ} \mathrm{C}\right)\end{array}$ & $\begin{array}{c}T_{0}-T_{\mathrm{c}} \\
\quad\left({ }^{\circ} \mathrm{C}\right)\end{array}$ & $\begin{array}{l}T_{0.5} \\
\left({ }^{\circ} \mathrm{C}\right)\end{array}$ & $\begin{array}{c}t_{0.5} \\
(\mathrm{~min})\end{array}$ & $\begin{array}{l}\Delta H_{\mathrm{c}} \\
(\mathrm{J} / \mathrm{g})\end{array}$ & $\begin{array}{l}T_{\mathrm{f}} \\
\left({ }^{\circ} \mathrm{C}\right)\end{array}$ & $\begin{array}{c}t \\
\text { (min) }\end{array}$ & $\begin{array}{l}X_{\mathrm{c}} \\
(\%)\end{array}$ \\
\hline & 10 & 128.1 & 119.1 & 9.0 & 115.5 & 1.3 & 181 & 50.2 & 7.8 & 69 \\
\hline & 5 & 128.4 & 120.9 & 7.5 & 117.4 & 2.3 & 186 & 50.1 & 15.7 & 69 \\
\hline & 2.5 & 128.5 & 121.7 & 6.6 & 118.4 & 4.1 & 191 & 50.2 & 31.3 & 70 \\
\hline
\end{tabular}

$\Phi$ is the cooling rate; $T_{0}, T_{\mathrm{c}}$ and $T_{\mathrm{f}}$ denote for the onset, crystallisation, end crystallisation temperatures, respectively; $T_{0.5}$ and $t_{0.5}$ are the temperature and time required to reach $50 \%$ of relative crystallinity, respectively.

A rapid decrease in temperature is accompanied by an increase in the viscosity, thereby the transport of material to the growth point becomes more difficult and eventually reduces the growth rate [6]. Hence, a higher degree of supercooling was required to initiate the crystallisation process, in such a way that the exothermic peaks became broader. In addition, the associated enthalpy of crystallisation $\left(\Delta H_{\mathrm{c}}\right)$ decreased where the cooling rate was elevated, as indicated in Table 2 and supplementary Table S1. The recorded enthalpy change by DSC is normally quoted as the amount of energy associated with the exotherm or endotherm per unit mass of the material analysed $[6,36]$. Likewise, thermal conductivity and annealing effects vary upon cooling rates [53-57]. The gradual decrease of the enthalpy upon the addition of nanofiller can be attributed to the proportional diminution (dilution effect) of the polyethylene concentration in the nanocomposite, as a result of the linear relationship between the latent heat and mass percentage [53-57]. Furthermore, the reduction of the polymer macromolecules' freedom in the vicinity of the nanofillers, could result in less entropy and thereby decreases the enthalpy change. This can be due to either interfacial interaction or chain confinement induced by the continuous network-structure formed between the closely packed nanoparticles.

At a relatively high temperature, just below the melting temperature, the sufficient thermal energy available allows the necessary motion to take place and release the residual stresses. Therefore, the lamella crystals become thicker when held at high temperature for a longer time (annealing effects) $[6,36,53-57]$. Accordingly, the gradual decrease in $\Delta H_{\mathrm{c}}$ at higher cooling rates, can also be attributed to thermal conductivity limitations, as well as lowered annealing effects. At a given cooling rate, $T_{\mathrm{c}}$ of multimodal-HDPE filled with graphene shifted to higher temperatures, as shown in Table 2 and supplementary Table S1. As shown in Figure $3 \mathrm{~b}$, the relative shift of $T_{\mathrm{c}}$ was clearly evident at the lowest graphene content. Afterward, the shift continued to gradually ascend as the concentration of graphene was increased, accompanied by a broadening of the peak (see Figure 3a and the supplementary Figure S3). For example, the value of $T_{\mathrm{c}}$ increased from $114.8^{\circ} \mathrm{C}$ to $116.3^{\circ} \mathrm{C}$ and $117.3^{\circ} \mathrm{C}$ for pristine HDPE filled with 0.1 and $1.0 \mathrm{wt} . \%$ of graphene respectively, at the cooling rate of $20^{\circ} \mathrm{C} / \mathrm{min}$. These changes in crystallisation behaviour can be attributed to the nucleation that took place heterogeneously on the distributed nanofillers bodies throughout the polymer matrix $[6,11,36]$. The foreign surfaces introduced by nanofillers reduced the barrier activation energy required to create a new surface and so lowered the degree of undercooling. This latter subject will be discussed further later in this study. On the other hand, the relative shift of $T_{\mathrm{c}}$ increased marginally at the lowest content of carbon black, except for the cooling rate of $2.5^{\circ} \mathrm{C} / \mathrm{min}$, where no change was observed. Nonetheless, at higher concentrations the value of $T_{\mathrm{c}}$ remained somewhat unchanged.

A polarised light microscope was used to examine the spherulitic morphology of the polymers, as shown in Figure $3 \mathrm{~b}$. The spherulites in the polymer filled with $1 \mathrm{wt} . \%$ of graphene became smaller, denser and homogenously distributed throughout the polymer matrix. On the other hand, the size of spherulites after incorporating $1 \mathrm{wt} . \%$ of carbon black became relatively larger and distributed within the polymer matrix almost uniformly. This implies that the nanofillers were homogenously dispersed and distributed throughout the polymer matrix. The spherulite radius $r$ is related to the time $(t)$ and spherulite growth rate $(v)$ through an equation in the form of $r=v t$, which is valid until the spherulites touch each other $[6,36,58,59]$. The decrease in spherulite sizes indicates that graphene 
fillers lowered the growth rate of the polymer, while the situation is apparently reversed where the carbon black is presence. A uniform distribution of the spherulite sizes can generally lead, for example, to a reduction in the post extrusion shrinkage, post-mould shrinkage and/or warpage, as well as a greater transparency by reducing the size of the scattering centres [11].

The relative degree of crystallinity $\left(X_{T}\right)$ as a function of crystallisation temperature can be calculated using the following equation

$$
\mathrm{X}_{\mathrm{T}}=\frac{\int_{T_{0}}^{T} \frac{(d H)}{(d T)} d T}{\int_{T_{0}}^{T_{f}} \frac{(d H)}{(d T)} d T}
$$

where $d H / d T$ is the enthalpy of crystallisation evolved within an infinitesimal temperature range, $T_{0}$ is the onset crystallisation temperature, $T$ denotes the arbitrary crystallisation temperature and $T_{f}$ refers to the end temperature of crystallisation [24,34-36,54]. The calculated relative crystallinity values of the cooling exotherms at different cooling rates are shown in Figure 4a and the supplementary Figure S4. Evidently, the crystallisation process exhibited reversed sigmoidal kinetic curves in all samples, which is common in most semicrystalline polymers as reported elsewhere [11,36]. The sigmoidal function features an induction period followed by an accelerated growth and final prominent saturation (plateau region). The lag phase and rapid growth shown in Figure 4a and the supplementary Figure S4, are often referred to as nucleation and crystal growth processes respectively [11,28], whereas the following slow crystallisation phase is attributed to the presence of secondary crystallisation [60]. Crystallisation occurred at a lower temperature when the cooling rate was increased. At a given cooling rate, $T_{0}$ of the multimodal-HDPE filled with graphene shifted significantly to higher temperatures, as shown in Table 2 and supplementary Table S1. The relative shift of $T_{0}$ was clearly evident even at the lowest graphene content $(0.1 \mathrm{wt} . \%)$ and continued to increase gradually as the concentration of graphene grew. For example, the value of $T_{0}$, increased from $120.3{ }^{\circ} \mathrm{C}$ to $123.6{ }^{\circ} \mathrm{C}$ for PE-CB- $1 \%$ and to $127.4{ }^{\circ} \mathrm{C}$ for PE-g- $0.1 \%$, at the cooling rate of $20^{\circ} \mathrm{C} / \mathrm{min}$. However, the relative value of $\mathrm{T}_{0}$ remained almost the same for the PE-CB, regardless of the concentration of carbon black. 

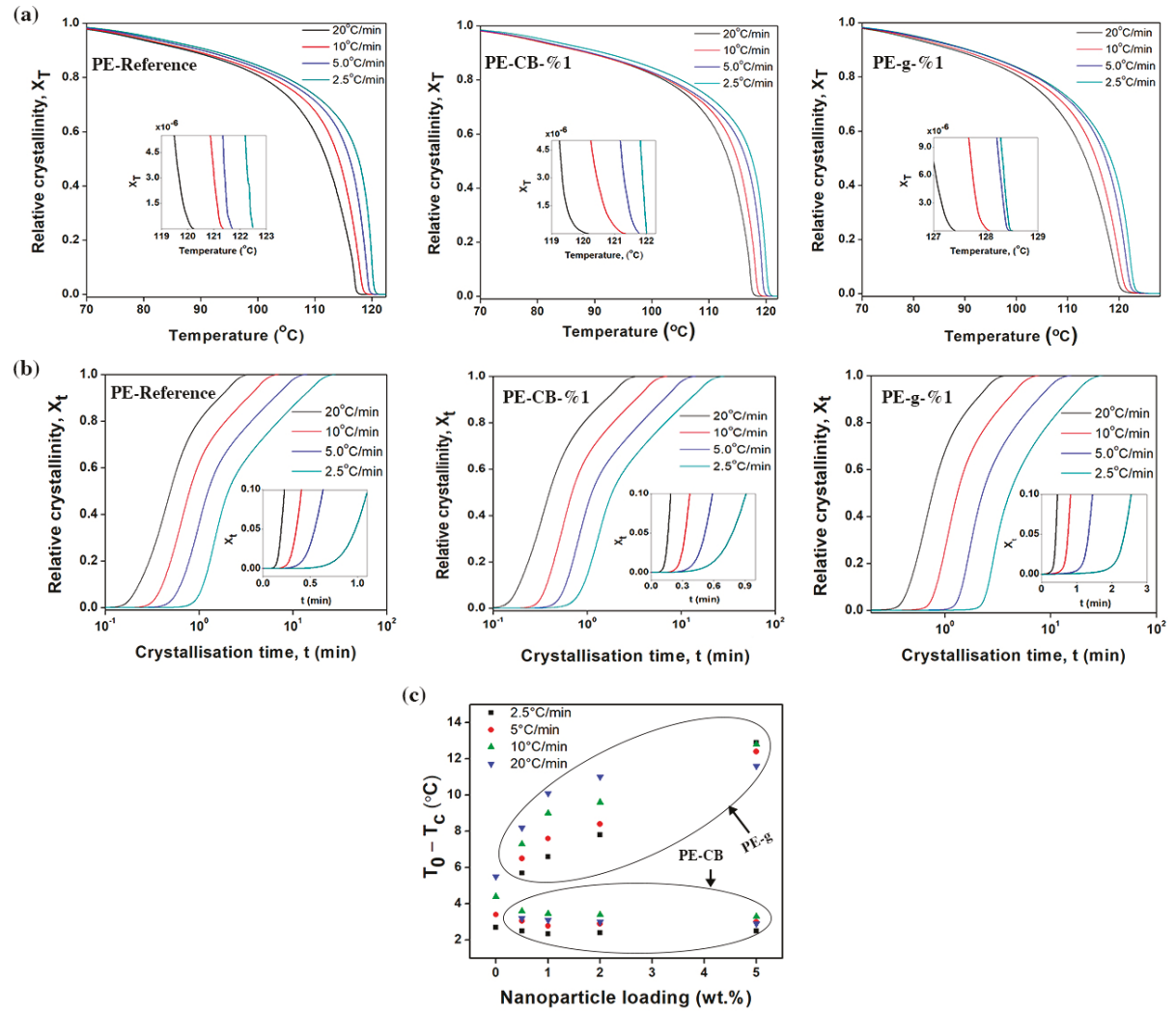

Figure 4. The effect of carbon black and graphene on non-isothermal crystallisation kinetics of the multimodal-HDPE. (a) Relative crystallinity evolution as a function of crystallisation temperature $\left(X_{T}\right)$ for the neat multimodal-HDPE, PE-CB-1\% and PE-g-1\%, occurred under non-isothermal conditions. The onset temperature of crystallisation at different cooling rates are presented in the inset. (b) Relative crystallinity evolution as a function of crystallisation time $\left(X_{t}\right)$ for the neat multimodal-HDPE, PE-CB-1\% and PE-g-1\%, occurred under non-isothermal conditions. The incubation period at different cooling rates are shown in the inset. (c) Effect of carbon black and graphene on $\left(T_{0}-T_{\mathcal{c}}\right)$ of the multimodal-HDPE at different cooling rates.

The difference between the onset and the peak crystallisation temperatures $\left(T_{0}-T_{\mathrm{c}}\right)$ is widely used as an indicator of spherulitic growth rate; the larger the difference, the lower the rate of growth in the spherulites [60-62]. The values of $\left(T_{0}-T_{\mathrm{c}}\right)$ are listed in Table 2 and in the supplementary Table S1. As shown in Figure $4 \mathrm{c}$, addition of graphene caused the value of $\left(T_{0}-T_{\mathrm{c}}\right)$ to increase. With a $1 \mathrm{wt}$. $\%$ loading, it was increased by $144 \%, 121 \%, 105 \%$ and $84 \%$ at the cooling rate of $2.5,5,10$, and $20{ }^{\circ} \mathrm{C} / \mathrm{min}$, respectively. The value of $\left(T_{0}-T_{\mathrm{c}}\right)$ gradually became larger with increasing graphene content. On the other hand, the relative value of $\left(T_{0}-T_{c}\right)$ decreased at the lowest content of carbon black, especially at the cooling rate $\geq 10^{\circ} \mathrm{C} / \mathrm{min}$ and thereafter remained invariable at higher concentrations. These results are in concurrence with the PLM images, that is, the bigger the spherulite radius, the greater the rate of spherulitic growth $(r=v t)$. In non-isothermal crystallisation, the arbitrary crystallisation temperature $T$ is associated with the crystallisation time $t$ through the following equation of the form

$$
t=\frac{\left|T_{\mathrm{o}}-T\right|}{\Phi}
$$


where $\Phi$ is the cooling rate [11]. The relative degree of crystallinity can accordingly be transformed as a function of time $\left(X_{t}\right)$ by converting the temperature on the $x$-axis to time scale, as shown in Figure $4 \mathrm{~b}$ and supplementary Figure S5.

The magnitude of parameters obtained from Figure $4 \mathrm{~b}$ and Figure S5 are listed in Table 2 and in the supplementary Table S1. At a given cooling rate, the time taken to complete the crystallisation $t$, relatively increased for the polymers filled with graphene, especially when decreasing the cooling rate. The value of $t$ grew linearly, in concurrence with the increase in the concentration of graphene (see Figure $5 \mathrm{c}$,d). With a $1 \mathrm{wt} . \%$ loading, for example, it was increased from 3.5, 7.1, 14.3 and $29 \mathrm{~min}$ to $3.9,7.8,15.7$ and $31.3 \mathrm{~min}$, at the cooling rate of $2.5,5,10,20^{\circ} \mathrm{C} / \mathrm{min}$, respectively. Interestingly, the time required to reach $50 \%$ of relative crystallinity $\left(t_{0.5}\right)$ extended significantly with the addition of graphene, especially at the cooling rate of $\leq 10^{\circ} \mathrm{C} / \mathrm{min}$. As a further example, in PE-g- $1 \%$, the value of $t_{0.5}$ increased from $0.5,0.8,1.2$ and 2.1 to $0.8,1.3,2.3$ and $4.1 \mathrm{~min}$, at the cooling rate of 2.5, 5, 10, $20{ }^{\circ} \mathrm{C} / \mathrm{min}$, respectively. The marginal increase in the value of $\left(t-t_{0.5}\right)$, indicates that the time-lag occurring as a result of a longer incubation period. On the other hand, a slight decrease in $t_{0.5}$ and $t$ was generally observed with the addition of carbon black, as shown in Figure 5a,b. The value of $t_{0.5}$ remained almost saturated when the carbon black content reached $1 \mathrm{wt} . \%$ and higher. These results are in agreement with the PLM images, that is, the spherulite radius is directly proportional to the rate of spherulitic growth $(r=v t)$. This means that the crystallisation kinetics of PE-CB and PE-g were dominated by the nucleation process. As graphene has a huge surface area, it has introduced a large number of nucleation sites through which the crystallisation initiated and occurred at higher temperatures. The effect of graphene is consistent with most of the results reported in the literature on the effect of nucleating agents upon the behaviour of crystallisation in HDPE, with the exception of the declining rate of the crystallisation [11]. Nonetheless, a decrease in the crystallisation rate was observed with nanofillers that behave like graphene and produce a jammed-network structure in polymers $[13,17,24,26,34,47,63]$. The three-dimensional networks (entanglements) induced by the graphene platelets possibly presented an obstacle to crystallisation and led the polymer molecules to adjust their configuration over a longer period of time. This suggests why the induction time was longer, especially as the nucleation tends to be sporadic at reduced degree of undercooling [6,27]. Furthermore, the increase of the melt viscosity caused by graphene platelets, through the three-dimensional network structure and/or synergetic effect advantages, made the transport of the materials to the growth point more difficult, resulting in a decreased growth rate $[59,64]$. F. C. Chiu et al., found that the density of nuclei was higher for the polyethylene with higher molar mass, so this could be another reason for the increase in $T_{0}[12,64]$. Contrastingly, carbon black was shown to have little effect on the crystallisation kinetics of multimodal-HDPE, conceivably because of its surface properties. 
(a)

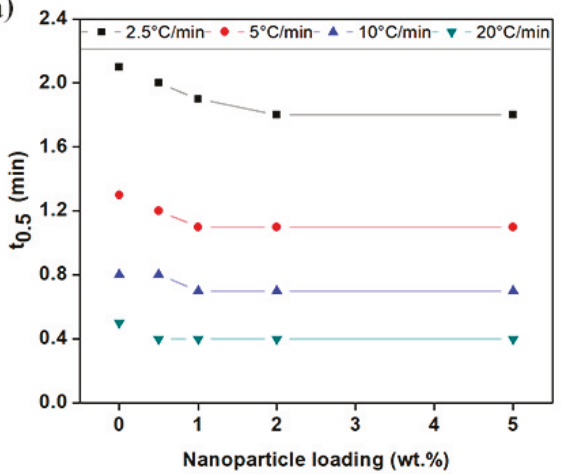

(c)

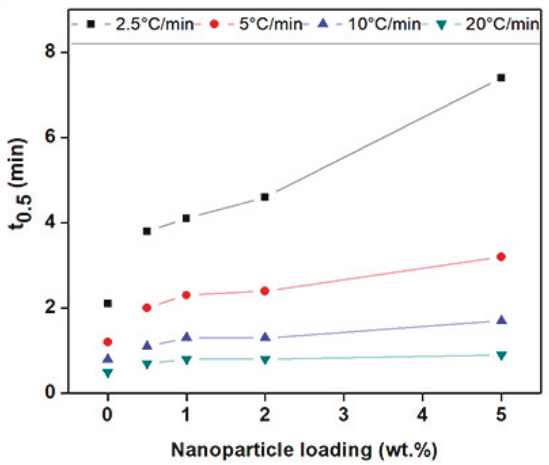

(b)

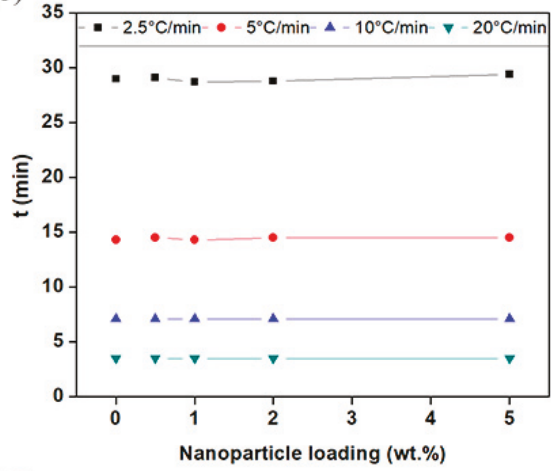

(d)

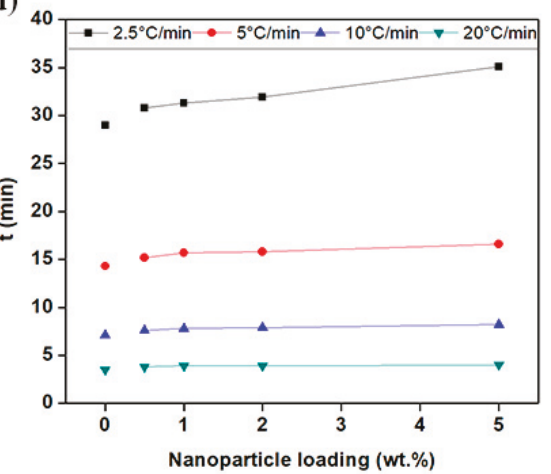

Figure 5. The influence of $(\mathbf{a}, \mathbf{b})$ carbon black and $(\mathbf{c}, \mathbf{d})$ graphene fillers on $\mathrm{t}_{0.5}$ and overall crystallisation $\mathrm{t}$ of the multimodal-HDPE at different cooling rates.

Carbon black acting as a nucleating agent in polyethylene has never yet been reported according to the author's knowledge. Many studies, such as those by S. Song et al. [1], A. Krumme et al. [2], T. Wu et al. [5], L. Balzano et al. [20], Y. An et al. [21], I. Dukovski and M. Muthukumar [23] and M. Gahleitner et al. [65], reported on the effect of the MWD breadth, MWD mode and the long chain molecules on the crystallisation behaviour of the polymers. Provides studies have shown that the presence of the high molar mass chains in a polyethylene with a bimodal or broad MWD can lead the crystallisation to occur at a higher temperature through an action of fluid shear. It is well-established that the specific volume of the polymer decreases upon cooling and thus a certain degree of shear flow is expected to be induced in the system. A pre-existing shear flow may also have been introduced in the compounding extruder and/or in the compression moulding during samples preparation for analysis. As a consequence, the relative change in the crystallisation kinetics of PE-CB is suggested to be mainly due to the synergistic advantage induced by carbon black. The incorporation of carbon black protected the MWD and/or the long chain molecules from becoming narrower or shorter, respectively. This is consistent with the results published by J. Wang et al. on a synergistic advantage obtained from the addition of carbon nanotubes on the crystallisation kinetics of isotactic polypropylene [15].

Using an appropriate model to account for the varying temperatures and cooling rates allows better understanding of the crystallisation kinetics under typical non-isothermal conditions. Various scientists, such as Ziabicki, K. Nakamura et al., Jeziorny, Ozawa, R. M. Patel et al., Dietz, T. Liu et al., have proposed numerous models to describe the non-isothermal crystallisation kinetics of semicrystalline polymers $[11,22,23,38]$. Among these models, a model proposed by T. Liu et al. was the most acclaimed and most successful approach in explaining the non-isothermal crystallisation kinetics 
of polyethylene and nanofillers-based polyethylene nanocomposites, such as carbon nanotubes, carbon black, graphene, diamond, graphite, $\mathrm{CaCO}_{3}, \mathrm{SiO}_{2}, \mathrm{TiO}_{2}[11,24-29,38]$. The study derived a new kinetic equation by combining the Avrami equation $\left(X_{t}=1-\exp \left(-Z_{t} t^{n}\right)\right)$ with the Ozawa equation $\left(X_{T}=\left(1-\exp \left[-\frac{K_{T}}{\Phi^{m}}\right]\right)\right)$, where $Z_{t}$ is the overall crystallisation rate constant as a function of time, exponent $n$ is a kinetic constant, $K_{T}$ is a cooling function related to the rate of overall crystallisation and changes as a function of temperature and $m$ is the Ozawa exponent based on the dimensions of the crystal growth [38]. Rearranging and combining the Ozawa and Avrami equations leads to a kinetic equation that provides a relationship between the cooling rate $\Phi$ and arbitrary crystallisation temperature $\mathrm{T}$, namely

$$
\log Z_{t}+n \log t=\log K_{\mathrm{T}}-m \log \Phi
$$

and can further be rewritten as

$$
\log \Phi=\log F_{\mathrm{T}}-a \log t
$$

where the parameter $F_{\mathrm{T}}=\left[K_{T} / Z_{\mathrm{t}}\right]^{1 / m}$ refers to the cooling or heating rate required to achieve a certain relative degree of crystallinity at a unit crystallisation time and a is the ratio of Avrami exponent $n$ to Ozawa exponent $m$, that is, $a=n / m$.

Parameters $F_{T}$ and $-a$ can be determined from the intercept and slope of the $\log \varphi$ versus $\log$ $t$ plot respectively, as shown in Figure 6a-c and supplementary Figure S6. According to Equation (6), the series of linear relationships with coefficient of determination $r^{2} \geq 0.998$, was observed at a given relative degree of crystallinity, indicating that the T. Liu et al. model could aptly describe the non-isothermal crystallisation kinetics of the multimodal-HDPE, PE-g and PE-CB. The kinetic parameter $F_{T}$ as a function of relative degree of crystallinity and the nanofiller content, is shown in Figure 6d, for the multimodal-HDPE, PE-CB and PE-g, representing the cooling rate required for every sample to achieve a certain degree of relative crystallinity at a unit crystallisation time. It was directly proportional to the relative degree of crystallinity, while values of $a$ were almost the same. The marginal changes in the values of $a$, ranged from 1 to 1.3 , which also indicates that the combined Avrami-Ozawa equations suitably describes the non-isothermal crystallisation kinetics of the multimodal-HDPE, PE-g and PE-CB, as reported elsewhere [11,24-30,33-36]. As shown and discussed earlier in the present study, $X_{t}$ became larger, at a unit crystallisation time, by increasing the cooling rate and the crystallisation roll-off occurred at around a 70\% degree of crystallinity, which is characteristic of slow or secondary crystallisation. In general, $F_{T}$ values of the neat HDPE and PE-CB were almost the same and increased in a similar pattern across the entire degree of relative crystallinity. A slight decrease in $F_{T}$ was observed when the polyethylene was loaded with $\geq 1 \mathrm{wt} . \%$ carbon black content, which is consistent with the results observed earlier in this study. 


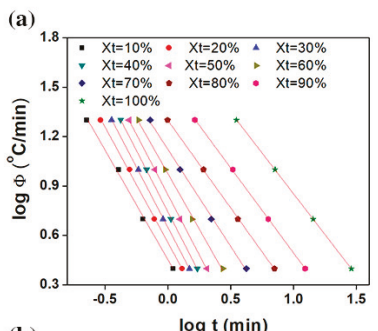

(b)

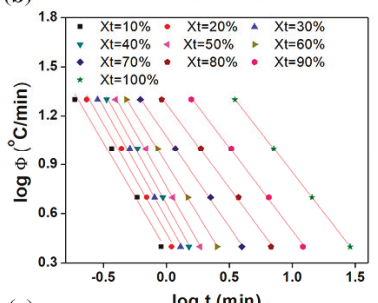

(c)

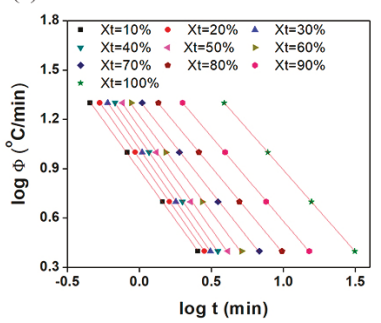

(d)

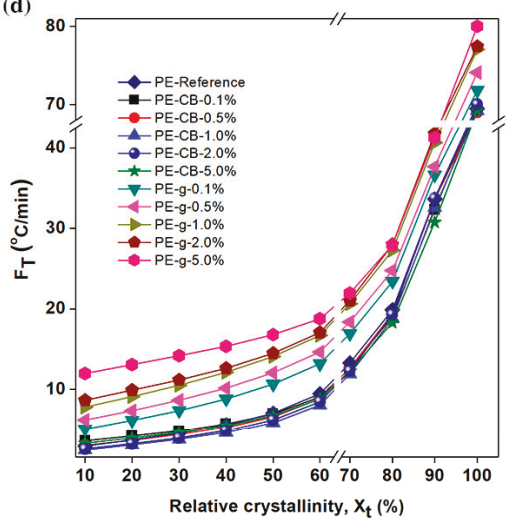

(e)

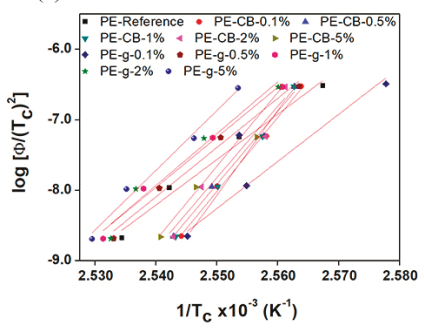

(f)

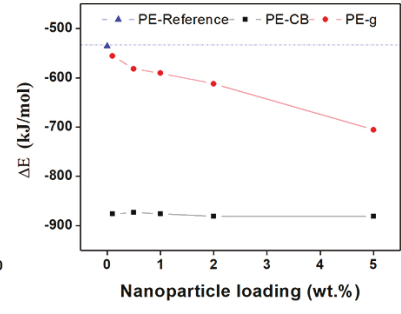

Figure 6. Plots of combined Avrami-Ozawa and H. E. Kissinger equations. Plots of log $\Phi$ versus $\log t$ from the combined Avrami-Ozawa equations for (a) neat multimodal-HDPE, (b) PE-CB-1\% and (c) PE-g-1\%, during the non-isothermal crystallisation. (d) The kinetic parameter $F_{T}$ as a function of relative degree of crystallinity, for the multimodal-HDPE and its nanocomposites with different nanofiller loadings of $0.1,0.5,1,2,5 \mathrm{wt} . \%$. Plot of (e) $\log \left[\Phi /\left(T_{\mathcal{c}}\right)^{2}\right]$ versus $1 / T_{\mathcal{c}}$ with $\mathrm{r}^{2}>0.985$ and (f) $\Delta E$ values as a function of nanoparticle concentration obtained from the $H$. E. Kissinger equation for the neat multimodal-HDPE, PE-CB and PE-g.

The $F_{T}$ parameter of PE-CB-1\% decreased from $2.8,7$ and $69.5^{\circ} \mathrm{C} / \mathrm{min}$ to $2.4,5.8$ and $69.2{ }^{\circ} \mathrm{C} / \mathrm{min}$ at $X_{\mathrm{t}}$ of $10 \%, 50 \%$ and $100 \%$, respectively. This is a confirmation that carbon black did not form a continuous network structure, most probably because of its dimensionality. However, the relative increase in $F_{\mathrm{T}}$ was clearly evident even at the lowest graphene content and continued to gradually rise as the concentration of graphene became larger, especially at $X_{t}<70 \%$. The $F_{\mathrm{T}}$ value of the multimodal-HDPE filled with 1 wt. \% graphene, increased from $2.8,7$ and $69.5^{\circ} \mathrm{C} / \mathrm{min}$ to $7.8,14.1$ and $77.1{ }^{\circ} \mathrm{C} / \mathrm{min}$ at $X_{\mathrm{t}}$ of $10 \%, 50 \%$ and $100 \%$, respectively. This is indicative of a slower crystallisation process compared with the neat HDPE and/or HDPE filled with CB and it is related to the difficulty of crystallisation process to progress further due to the entangled-network structure induced by graphene platelets. These results are consistent with what was observed and discussed earlier in this study. Accordingly, knowledge of the conditions affecting the crystallisation kinetics is crucial for optimising the processing parameters, as this can affect the final properties of the product which includes warpage/shrinkage control, mechanical and optical clarity or an alteration of the cycle time in moulding or extrusion [11]. In pipe manufacturing, for example, the thermal gradient across the pipe wall generates residual stress within the pipe, as the crystallisation in the core region is slower than the inner and outer surfaces that are cooled down by a water spray [1,3]. A replacement of the nanofiller, such as carbon black by graphene, requires a consequent optimisation of the processing parameters. 
At a given cooling rate, the relative degree of crystallinity at the peak crystallisation temperature ranges between $11 \%$ and $30 \%$ for all the polymers. The mean activation energy barrier $(\Delta E)$ required for the molecular chains to transport from the melt state to the growing crystal surface, in non-isothermal systems, was calculated in this study, using the following H. E. Kissinger equation $[19,34-36,38,39]$

$$
\frac{d\left[\log \frac{\Phi}{T_{c}^{2}}\right]}{d\left(\frac{1}{T_{c}}\right)}=-\frac{\Delta E}{R}
$$

where $R$ is the universal gas constant. The higher the value of $\Delta E$, the more difficult the transportation of macromolecular chains to the growing surface. These can generally result either from higher viscosity or restriction in the polymer chains as previously discussed in the present study. The activation energies obtained from the slope of the straight-lines in a $\log \left(\frac{\Phi}{T_{c}^{2}}\right)$ versus $\frac{1}{T_{c}}$ plot in Figure 6e, are plotted as a function of nanoparticle content in Figure $6 f$. The dashed line represents the $\Delta E$ of the neat multimodal-HDPE, which was $-535 \mathrm{~kJ} / \mathrm{mol}$. The value of $\Delta E$ decreased gradually to $-556,-582$, $-591,-612$ and $-705 \mathrm{~kJ} / \mathrm{mol}$ when increasing the concentration of graphene to $0.1,0.5,1,2,5 \mathrm{wt} . \%$, respectively. However, the relative value of $\Delta E$ decreased significantly to $-876 \mathrm{~kJ} / \mathrm{mol}$ at the lowest carbon black content of $0.1 \mathrm{wt} . \%$ and remained almost saturated at higher concentration. In general, the decrease in the activation energy barrier is attributable to the role of the nanoparticles as a nucleating agent. The results indicate that graphene is likely to perform two functions in the multimodal-HDPE matrix. The platelets acted as nucleating agents and accelerated the primary nucleation, which was manifested by the gradual decrease in $\Delta E$ and the increase in $T_{0}$ and $T_{\mathrm{c}}$. However, the presence of the jammed network structure slowed the diffusion of the polymer chains into the crystalline lattice, thus lowering the overall crystallisation rate, as confirmed by the increase in $F_{\mathrm{T}}, t_{0.5}$ and $t$. On the other hand, the change in crystallisation kinetics of the multimodal-HDPE, associated with the addition of carbon black, is suggested to be a result of the synergistic effects. This occurs where the longer macromolecular chains and broader MWD accelerated the crystallisation of PE-CB as confirmed from the values of $\Delta E, t_{0.5}, T_{\mathrm{c}}, F_{\mathrm{T}}$, as well as rheological results.

\section{Conclusions}

The crystallisation kinetics of the multimodal-HDPE behaved differently with the addition of 0.1 to $5 \mathrm{wt}$ \% carbon black or graphene, under non-isothermal conditions. The non-isothermal crystallisation behaviour of the PE-g nanocomposites relied heavily on both the graphene content and cooling rate. The relative peak crystallisation temperature of PE-g increased with decreasing the cooling rate for a given graphene content and increased gradually with an increase in the concentration of graphene at a given cooling rate. Incorporation of graphene caused a change in the mechanism of nucleation and crystal growth of multimodal-HDPE crystallites, with the effect being more evident at the lowest graphene content. At a given cooling rate, the nucleation initiated at a higher temperature and continued to increase with the graphene content. Similarly, the incubation period as well as the time required to reach $50 \%$ of relative crystallinity $t_{0.5}$ increased significantly with the addition of graphene and continued to increase gradually with an increasing content of graphene. However, the spherulitic growth rate decreased at the lowest graphene content and continued its gradual descent with the increasing amount of graphene content. On the other hand, the non-isothermal crystallisation behaviour of the PE-CB nanocomposites relied on the cooling rate only and the effect of carbon black content as a nucleating agent was found to be marginal, with the exception of the peak crystallisation temperature which increased gradually in concurrence with the carbon black content. At a given cooling rate, the relative onset crystallisation temperature of $\mathrm{PE}-\mathrm{CB}$ remained almost unchanged with the addition of the carbon black. Also, a slight increase in the spherulitic growth rate accompanied a relative decrease in $\mathrm{t}_{0.5}$ which was observed upon addition of $0.1 \%$ carbon black and these remained almost unchanged with further addition. 
Combined Avrami-Ozawa equations proposed by Liu et al. was found to be effective in describing the non-isothermal crystallisation kinetics of the multimodal-HDPE, PE-CB and PE-g nanocomposites. The cooling rate required to achieve certain degree of crystallinity increased gradually as the graphene content increased. The relative kinetic parameter $F_{\mathrm{T}}$ of the multimodal-HDPE filled with $1 \mathrm{wt} . \%$ graphene increased from $2.8,7.0$ and $69.5{ }^{\circ} \mathrm{C} / \mathrm{min}$ to $7.8,14.1$ and $77.1{ }^{\circ} \mathrm{C} / \mathrm{min}$ at $X_{\mathrm{t}}$ of $10 \%, 50 \%$ and $100 \%$, respectively. However, a slight decrease in $F_{\mathrm{T}}$ values was observed when the multimodal-HDPE loaded with $\geq 1 \mathrm{wt}$. $\%$ carbon black content. Using the H. E. Kissinger equation, the activation barrier energy of the multimodal-HDPE decreased gradually with an increasing the graphene concentration, while it rose by $64 \%$ at the lowest carbon black content. However, the value of $\Delta E$ remained almost unchanged as the content of carbon black increased. For PE-g, graphene platelets acted as nucleating agents and introduced foreign surfaces, which in turn reduced the barrier activation energy required for the crystallisation. However, the presence of the jammed network structure introduced by graphene platelets retarded the diffusion of the polymer chains into the crystalline lattice and thus slowing the primary crystallisation. Contrastingly, carbon black was shown to have little effect as a heterogeneous nucleating agent on the crystallisation kinetics of multimodal-polyethylene, possibly because of its surface properties.

Supplementary Materials: The following are available online at http:/ / www.mdpi.com/2079-4991/9/1/110/s1, Figure S1: Light microscopy images of the multimodal-HDPE loaded with $1.0 \mathrm{wt} . \%$ of carbon black (left) and graphene (right). The images were processed using ImageJ software, Figure S2: TEM images of (a) carbon black and (b) graphene platelets. The images of carbon black were taken under Hitachi HT7700, at an accelerating voltage of $120 \mathrm{kV}$. Whereas JEOL JEM2100FCs Field Emission TEM, with CEOS aberration corrected illumination system at an accelerating voltage of $200 \mathrm{kV}$, was used to image the graphene platelets, Figure S3: Non-isothermal DSC traces of PE-CB and PE-g as a function of nanofiller content, Figure S4: Relative crystallinity evolution as a function of crystallisation time $\left(X_{T}\right)$ for the PE-CB and PE-g at $0.1,0.5,2,5 \mathrm{wt} . \%$, occurred under non-isothermal conditions. The onset temperature of crystallisation at different cooling rates are presented in the inset, Figure S5: Relative crystallinity evolution as a function of crystallisation time $\left(X_{t}\right)$ for the PE-CB and PE-g at $0.1,0.5,2,5 \mathrm{wt} . \%$, occurred under non-isothermal conditions. The incubation period at different cooling rates are presented in the inset, Figure S6: Plots of $\log \Phi$ versus $\log t$ from the combined Avrami-Ozawa equations for the multimodal-HDPE filled with graphene or carbon black at $0.1,0.5,2,5 \mathrm{wt} . \%$, during the non-isothermal crystallisation, Table S1: Nano-isothermal crystallisation parameters of neat HDPE, PE-g and PE-CB, Table S2: Average molecular weights for the neat multimodal-HDPE before and after extrusion.

Author Contributions: Conceptualization, I.A.A.; Formal analysis, I.A.A.; Funding acquisition, I.A.A. and R.V.K.; Investigation, I.A.A.; Methodology, I.A.A.; Supervision, H.-K.K. and R.V.K.; Validation, I.A.A.; Visualization, I.A.A., H.-K.K. and S.D.; Writing-original draft, I.A.A.; Writing—review \& editing, I.A.A. and R.V.K.

Funding: This research was funded by Abu Dhabi National Oil Company (ADNOC) and Borouge Pte. Ltd., grant code LJGK GAAA and the APC was funded by ADNOC.

Acknowledgments: This work was conducted under the framework of the Research and Development Program of the Korea Institute of Energy Research (KIER) (B8-2432-04) and ADNOC.

Conflicts of Interest: The authors declare no conflict of interest.

\section{References}

1. Song, S.; Wu, P.; Ye, M.; Feng, J.; Yang, Y. Effect of small amount of ultra high molecular weight component on the crystallization behaviors of bimodal high density polyethylene. Polymer 2008, 49, 2964-2973. [CrossRef]

2. Krumme, A.; Lehtinen, A.; Viikna, A. Crystallisation behaviour of high density polyethylene blends with bimodal molar mass distribution: 2. Non-isothermal crystallization. Eur. Polym. J. 2004, 40, 371-378. [CrossRef]

3. DesLauriers, P.J.; McDaniel, M.P.; Rohlfing, D.C.; Krishnaswamy, R.K.; Secora, S.J.; Benham, E.A.; Maeger, P.L.; Wolfe, A.R.; Sukhadia, A.M.; Beaulieu, B.B. A comparative study of multimodal vs. bimodal polyethylene pipe resins for PE-100 applications. Polym. Eng. Sci. 2005, 45, 1203-1213. [CrossRef]

4. Chatzidoukas, C.; Kanellopoulos, V.; Kiparissides, C. On the production of polyolefins with bimodal molecular weight and copolymer composition distributions in catalytic gas-phase fluidized-bed reactors. Macromol. Theor. Simul. 2007, 16, 755-769. [CrossRef] 
5. Wu, T.; Yu, L.; Cao, Y.; Yang, F.; Xiang, M. Effect of molecular weight distribution on rheological, crystallization and mechanical properties of polyethylene-100 pipe resins. J. Polym. Res. 2013, 20, 271. [CrossRef]

6. Young, R.J.; Lovell, P.A. Introduction to Polymers, 3rd ed.; CRC Press: New York, NY, USA, 2011.

7. Kuilla, T.; Bhadra, S.; Yao, D.; Hoon, N.; Bose, S.; Hee, J. Recent advances in graphene based polymer composites. Prog. Polym. Sci. 2010, 35, 1350-1375. [CrossRef]

8. Ahmad, I.; Koziol, K.; Deveci, S.; Kim, H.-K.; Kumar, R. Advancing the use of high-performance graphene-based multimodal polymer nanocomposite at scale. Nanomaterials 2018, 8, 947. [CrossRef]

9. Hawkins, W.L.; Hansen, R.H.; Matreyek, W.; Winslow, F.H. The effect of carbon black on thermal antioxidants for polyethylene. J. Appl. Polym. Sci. 1959, 1, 37-42. [CrossRef]

10. Mwila, J.; Miraftab, M.; Horrocks, A.R. Effect of carbon black on the oxidation of polyolefins-An overview. Polym. Degrad. Stab. 1994, 44, 351-356. [CrossRef]

11. Seven, K.M.; Cogen, J.M.; Gilchrist, J.F. Nucleating agents for high-density polyethylene-A review. Polym. Eng. Sci. 2016, 56, 541-554. [CrossRef]

12. The Global Market for Carbon Black Report, 1st ed.; Future Markets, Inc.: Edinburgh, Scotland, 2017.

13. Kim, J.; Kwak, S.; Hong, S.M.; Lee, J.R.; Takahara, A.; Seo, Y. Nonisothermal crystallization behaviors of nanocomposites prepared by in situ polymerization of high-density polyethylene on multiwalled carbon nanotubes. Macromolecules 2010, 43, 10545-10553. [CrossRef]

14. Mcnally, T.; Pötschke, P.; Halley, P.; Murphy, M.; Martin, D.; Bell, S.E.J.; Brennan, G.P.; Bein, D.; Lemoine, P.; Quinn, J.P. Polyethylene multiwalled carbon nanotube composites. Polymer 2005, 46, 8222-8232. [CrossRef]

15. Wang, J.; Yang, J.; Deng, L.; Fang, H.; Zhang, Y.; Wang, Z. More dominant shear flow effect assisted by added carbon nanotubes on crystallization kinetics of isotactic polypropylene in nanocomposites. ACS Appl. Mater. Interfaces 2015, 7, 1364-1375. [CrossRef] [PubMed]

16. Qiu, Y.; Wang, Z.; Owens, A.C.E.; Kulaots, I.; Chen, Y.; Kane, A.B.; Hurt, R.H. Antioxidant chemistry of graphene-based materials and its role in oxidation protection technology. Nanoscale 2014, 6, 11744-11755. [CrossRef] [PubMed]

17. El Achaby, M.; Qaiss, A. Processing and properties of polyethylene reinforced by graphene nanosheets and carbon nanotubes. Mater. Des. 2013, 44, 81-89. [CrossRef]

18. Kashiwagi, T.; Du, F.; Douglas, J.F.; Winey, K.I.; Harris, R.H.; Shields, J.R. Nanoparticle networks reduce the flammability of polymer nanocomposites. Nat. Mater. 2005, 4, 928-933. [CrossRef] [PubMed]

19. Shan, H.; Lickfield, G.C. Crystallization kinetics study of polyethylene. Int. J. Polym. Anal. Charact. 2007, 12, 327-338. [CrossRef]

20. Balzano, L.; Rastogi, S.; Peters, G. Self-nucleation of polymers with flow: The case of bimodal polyethylene. Macromolecules 2011, 44, 2926-2933. [CrossRef]

21. An, Y.; Holt, J.J.; Mitchell, G.R.; Vaughan, A.S. Influence of molecular composition on the development of microstructure from sheared polyethylene melts: Molecular and lamellar templating. Polymer 2006, 47, 5643-5656. [CrossRef]

22. Balzano, L.; Kukalyekar, N.; Rastogi, S.; Peters, G.W.M.; Chadwick, J.C. Crystallization and dissolution of flow-induced precursors. Phys. Rev. Lett. 2008, 100, 048302. [CrossRef]

23. Dukovski, I.; Muthukumar, M. Langevin dynamics simulations of early stage shish-kebab crystallization of polymers in extensional flow. J. Chem. Phys. 2003, 118, 6648-6655. [CrossRef]

24. Shehzad, F.; Thomas, S.P.; Al-Harthi, M.A. Non-isothermal crystallization kinetics of high density polyethylene/graphene nanocomposites prepared by in-situ polymerization. Thermochim. Acta 2014, 589, 226-234. [CrossRef]

25. Shi, X.; Wang, J.; Jiang, B.; Yang, Y. Influence of nanofiller dimensionality on the crystallization behavior of HDPE/carbon nanocomposites. J. Appl. Polym. Sci. 2013, 128, 3609-3618. [CrossRef]

26. Huang, J.-W.; Wen, Y.-L.; Kang, C.-C.; Tseng, W.-J.; Yeh, M.-Y. Nonisothermal crystallization of high density polyethylene and nanoscale calcium carbonate composites. Polym. Eng. Sci. 2008, 48, 1268-1278. [CrossRef]

27. Mercier, J.P. Nucleation in polymer crystallization: A physical or a chemical mechanism? Polym. Eng. Sci. 1990, 30, 270-278. [CrossRef]

28. Adhikari, A.R.; Lozano, K.; Chipara, M. Non-isothermal crystallization kinetics of polyethylene/carbon nanofiber composites. J. Compos. Mater. 2012, 46, 823-832. [CrossRef] 
29. Jiasheng, Q.; Pingsheng, H. Non-isothermal crystallization of HDPE/nano-SiO 2 composite. J. Mater. Sci. 2003, 38, 2299-2304. [CrossRef]

30. Yang, B.; Deng, Y.-L.; Li, G.-J.; Miao, J.-B.; Xia, R.; Qian, J.-S.; Chen, P.; Liu, J.-W. Solidification behavior of high-density polyethylene (HDPE) during injection molding: Correlation between crystallization kinetics and thermal gradient field. IOP Conf. Ser. Mater. Sci. Eng. 2015, 87, 012020. [CrossRef]

31. Nezhad, H.Y.; Thakur, V.K. Effect of morphological changes due to increasing carbon nanoparticles content on the quasi-static mechanical response of epoxy resin. Polymers 2018, 10, 1106. [CrossRef]

32. Miculescu, M.; Thakur, V.K.; Miculescu, F.; Voicu, S.I. Graphene-based polymer nanocomposite membranes: A review. Polym. Adv. Technol. 2016, 27, 844-859. [CrossRef]

33. Muhulet, A.; Miculescu, F.; Voicu, S.I.; Schütt, F.; Thakur, V.K.; Mishra, Y.K. Fundamentals and scopes of doped carbon nanotubes towards energy and biosensing applications. Mater. Today Energy 2018, 9, 154-186. [CrossRef]

34. Banks, W.; Gordon, M.; Roe, R.-J.; Sharples, A. The crystallization of polyethylene I. Polymer 1963, 4, 61-74. [CrossRef]

35. Van Drongelen, M.; Roozemond, P.C.; Troisi, E.M.; Doufas, A.K.; Peters, G.W.M. Characterization of the primary and secondary crystallization kinetics of a linear low-density polyethylene in quiescent- and flow-conditions. Polymer 2015, 76, 254-270. [CrossRef]

36. Mandelkern, L. Crystallisation of Polymers: Volume 2. Kinetics and Mechanisms, 2nd ed.; Cambridge University Press: Cambridge, UK, 2004.

37. Hiesgen, G.; Saul, K.; Rauwendaal, C. Rauwendaal. Temperature induced dimensional variation in extrusion. AIP Conf. Proc. 2016, 1779, 030005.

38. Liu, T.; Mo, Z.; Wang, S.; Zhang, H. Nonisothermal melt and cold crystallization kinetics of poly(aryl ether ether ketone ketone). Polym. Eng. Sci. 1997, 37, 568-575. [CrossRef]

39. Kissinger, H.E. Variation of peak temperature with heating rate in differential thermal analysis. J. Res. Natl. Bur. Stand. 1956, 57, 217. [CrossRef]

40. Mezger, T.G. The Rheology Handbook, 4th ed.; Vincentz Network: Hanover, Germany, 2014.

41. Cebe, P.; Thomas, D.; Merfeld, J.; Partlow, B.P.; Kaplan, D.L.; Alamo, R.G.; Wurm, A.; Zhuravlev, E.; Schick, C. Heat of fusion of polymer crystals by fast scanning calorimetry. Polymer 2017, 126, 240-247. [CrossRef]

42. Nair, R.R.; Blake, P.; Grigorenko, A.N.; Novoselov, K.S.; Booth, T.J.; Stauber, T.; Peres, N.M.R.; Geim, A.K. Fine structure constant defines visual transparency of graphene. Science 2008, 320, 1308. [CrossRef]

43. Cote, L.J.; Kim, J.; Zhang, Z.; Sun, C.; Huang, J. Tunable assembly of graphene oxide surfactant sheets: Wrinkles, overlaps and impacts on thin film properties. Soft Matter 2010, 6, 6096-6101. [CrossRef]

44. Albers, P.; Maier, M.; Reisinger, M.; Hannebauer, B.; Weinand, R. Physical boundaries within aggregates-Differences between amorphous, para-crystalline, and crystalline Structures. Cryst. Res. Technol. 2015, 50, 846-865. [CrossRef]

45. Levy, L.; Chaudhuri, I.S.; Krueger, N.; McCunney, R.J. Does carbon black disaggregate in lung fluid? A critical assessment. Chem. Res. Toxicol. 2012, 25, 2001-2006. [CrossRef] [PubMed]

46. Tang, D.; Li, S.; Yang, J.; Su, J.; Yang, Q.; Kong, M.; Huang, Y.; Liao, X. Nonisothermal and isothermal crystallization behavior of isotactic polypropylene/chemically reduced graphene nanocomposites. Polym. Compos. 2017, 38, E342-E350. [CrossRef]

47. Wu, D.; Cheng, Y.; Feng, S.; Yao, Z.; Zhang, M. Crystallization behavior of polylactide/graphene composites. Ind. Eng. Chem. Res. 2013, 52, 6731-6739. [CrossRef]

48. Zhang, Q.; Rastogi, S.; Chen, D.; Lippits, D.; Lemstra, P.J. Low percolation threshold in single-walled carbon nanotube/high density polyethylene composites prepared by melt processing technique. Carbon 2006, 44 , 778-785. [CrossRef]

49. Liu, K.; Andablo-Reyes, E.; Patil, N.; Merino, D.H.; Ronca, S.; Rastogi, S. Influence of reduced graphene oxide on the rheological response and chain orientation on shear deformation of high density polyethylene. Polymer 2016, 87, 8-16. [CrossRef]

50. Kashiwagi, T. Polymer combustion and flammability-Role of the condensed phase. Symp. Combust. 1994, 25, 1423-1437. [CrossRef]

51. Xiong, H.; Gao, Y.; Li, H.M. Non-isothermal crystallization kinetics of syndiotactic polystyrene-polystyrene functionalized SWNTs nanocomposites. eXPRESS Polym. Lett. 2007, 1, 416-426. [CrossRef] 
52. Gorrasi, G.; Bugatti, V.; Milone, C.; Mastronardo, E.; Piperopoulos, E.; Iemmo, L.; Di Bartolomeo, A. Effect of temperature and morphology on the electrical properties of PET/conductive nanofillers composites. Compos. Part B Eng. 2018, 135, 149-154. [CrossRef]

53. Valentini, L.; Biagiotti, J.; López-Manchado, M.A.; Santucci, S.; Kenny, J.M. Effects of carbon nanotubes on the crystallization behavior of polypropylene. Polym. Eng. Sci. 2004, 44, 303-311. [CrossRef]

54. Wang, W.; Yang, X.; Fang, Y.; Ding, J.; Yan, J. Preparation and thermal properties of polyethylene glycol/expanded graphite blends for energy storage. Appl. Energy 2009, 86, 1479-1483. [CrossRef]

55. Dietz, W. Effect of cooling on crystallization and microstructure of polypropylene. Polym. Eng. Sci. 2016, 56, 1291-1302. [CrossRef]

56. Fischer, E.W. Effect of annealing and temperature on the morphological structure of polymers. Pure Appl. Chem. 1972, 31, 113-131. [CrossRef]

57. Wang, W.; Zhao, G.; Wu, X.; Zhai, Z. The effect of high temperature annealing process on crystallization process of polypropylene, mechanical properties, and surface quality of plastic parts. J. Appl. Polym. Sci. 2015, 132, 42773. [CrossRef]

58. Raimo, M. Estimation of polymer nucleation and growth rates by overall DSC crystallization rates. Polym. J. 2011, 43, 78-83. [CrossRef]

59. Magill, J.H.; Li, H.M. Crystallization kinetics and morphology of polymer blends of poly(tetramethyl-p-silphenylene siloxane) fractions. Polymer 1978, 19, 416-422. [CrossRef]

60. Jain, S.; Goossens, H.; van Duin, M.; Lemstra, P. Effect of in situ prepared silica nano-particles on non-isothermal crystallization of polypropylene. Polymer 2005, 46, 8805-8818. [CrossRef]

61. Beck, H.; Ledbetter, H. DTA study of heterogeneous nucleation of crystallization in polypropylene. J. Appl. Polym. Sci. 1965, 9, 2131-2142. [CrossRef]

62. Mareri, P.; Bastide, S.; Binda, N.; Crespy, A. Mechanical behaviour of polypropylene composites containing fine mineral filler: Effect of filler surface treatment. Compos. Sci. Technol. 1998, 58, 747-752. [CrossRef]

63. Zheng, W.; Lu, X.; Wong, S.-C. Electrical and mechanical properties of expanded graphite-reinforced high-density polyethylene. J. Appl. Polym. Sci. 2004, 91, 2781-2788. [CrossRef]

64. Chiu, F.-C.; Fu, Q.; Hsieh, E.T. Molecular weight dependence of melt crystallization behavior and crystal morphology of low molecular weight linear polyethylene fractions. J. Polym. Res. 1999, 6, 219-229. [CrossRef]

65. Gahleitner, M.; Bernreitner, K.; Neil, W. Influence of molecular structure on crystallization behaviour and mechanical properties of polypropylene. Polym. Test. 1995, 14, 173-187. [CrossRef]

(C) 2019 by the authors. Licensee MDPI, Basel, Switzerland. This article is an open access article distributed under the terms and conditions of the Creative Commons Attribution (CC BY) license (http:/ / creativecommons.org/licenses/by/4.0/). 


\title{
Review \\ Sustainable Biomass Activated Carbons as Electrodes for Battery and Supercapacitors-A Mini-Review
}

\author{
Glaydson Simões dos Reis ${ }^{1, *}$, Sylvia H. Larsson ${ }^{1}$, Helinando Pequeno de Oliveira ${ }^{2}$, \\ Mikael Thyrel ${ }^{1}$ and Eder Claudio Lima ${ }^{3}$ \\ 1 Department of Forest Biomaterials and Technology, Swedish University of Agricultural Sciences, Biomass \\ Technology Centre, SE-901 83 Umeå, Sweden; sylvia.larsson@slu.se (S.H.L.); mikael.thyrel@slu.se (M.T.) \\ 2 Institute of Materials Science, Federal University of Sao Francisco Valley, Juazeiro, BA 48920-310, Brazil; \\ helinando.oliveira@univasf.edu.br \\ 3 Institute of Chemistry, Federal University of Rio Grande do Sul (UFRGS), Av. Bento Gonçalves 9500, \\ Porto Alegre 91501-970, Brazil; profederlima@gmail.com \\ * Correspondence: glaydsonambiental@gmail.com or glaydson.simoes.dos.reis@slu.se
}

Received: 30 June 2020; Accepted: 14 July 2020; Published: 18 July 2020

\begin{abstract}
Some recent developments in the preparation of biomass carbon electrodes (CEs) using various biomass residues for application in energy storage devices, such as batteries and supercapacitors, are presented in this work. The application of biomass residues as the primary precursor for the production of CEs has been increasing over the last years due to it being a renewable source with comparably low processing cost, providing prerequisites for a process that is economically and technically sustainable. Electrochemical energy storage technology is key to the sustainable development of autonomous and wearable electronic devices. This article highlights the application of various types of biomass in the production of CEs by using different types of pyrolysis and experimental conditions and denotes some possible effects on their final characteristics. An overview is provided on the use of different biomass types for the synthesis of CEs with efficient electrochemical properties for batteries and supercapacitors. This review showed that, from different biomass residues, it is possible to obtain CEs with different electrochemical properties and that they can be successfully applied in high-performance batteries and supercapacitors. As the research and development of producing CEs still faces a gap by linking the type and composition of biomass residues with the carbon electrodes' electrochemical performances in supercapacitor and battery applications, this work tries to diminish this gap. Physical and chemical characteristics of the CEs, such as porosity, chemical composition, and surface functionalities, are reflected in the electrochemical performances. It is expected that this review not only provides the reader with a good overview of using various biomass residues in the energy storage applications, but also highlights some goals and challenges remaining in the future research and development of this topic.
\end{abstract}

Keywords: biomass carbon electrodes; battery and supercapacitors; structure-performance relationship

\section{Introduction}

The conversion of biomass residues into bio-based materials can provide opportunities for biomass-based industries by reducing costs and even creating value from their by-products [1-4]. Biomass-derived activated carbons (ACs) can be obtained with tailored properties to meet the tremendous need for low-cost, high-performance, porous carbons for sustainable technologies, such adsorbents water and air purifications [5]. However, AC is one of the most common materials for fabricating electrodes in electrochemical storage devices [6-8]. 
ACs are usually in the form of powder. However, they can also be synthesised in different morphologies, such as thin films, monoliths, or fibres. Powders are commonly used for conventional electrode fabrication [6]. ACs might have a sizeable geometric surface area, which results in a low-pressure drop at high flow rates, making them very useful as adsorbents and supports for catalysts or water remediation in environmental applications [5-9]. ACs have also shown promising results as electrodes for batteries and supercapacitors [7-9]. ACs have a hierarchic pore network with large mesopores that facilitate ion transport and meso- and micropores with available sites for ion storage that enable high-performance energy storage [7-9].

Supercapacitors and batteries are critical enabling technologies and at the centre of vast global research, initiatives to meet the rising global demand for clean, sustainable energy [10-13]. Supercapacitors (SCs) are systems that store and deliver energy via ion electrosorption or rapid redox-processes to enable high discharge rates while batteries rely on more sluggish (bulk) redox-processes, such as ion intercalation or conversion reactions $[10,13]$. Compared to supercapacitors, most batteries have a higher specific energy and lower specific power, which makes them extremely suitable for mobile energy storage applications [10-13]. Supercapacitors are more employed for short-term energy storage systems or burst-mode power delivery, such as balancing grid-scale power spikes, the recuperation of braking energy, and the starting of cars, because of their elevated power density, fast charge/discharge rates, and long-lasting cycle life [10-13].

Supercapacitors and batteries are both composed of electrodes with a performance critically dependent on intrinsic properties of constitutive materials such as high surface area and electrical conductivity $[7,10-15]$. To date, various electrode materials, including transition metal oxides and hydroxides and conductive polymers, have been explored for high-performance energy storage devices [10-15]. In most of these systems, the carbon in some form is needed to ensure electrical conductivity considering the high resistivity of many metal oxide materials since easy electron transportation is required in the direction of the electrode-electrolyte interface. Several carbon sources such as carbon black, activated carbon, graphene, carbon nanotubes, carbide-derived carbon, or carbon aerogels have been employed as sole electrode materials or components for hybrid electrodes $[9,10,16,17]$. Many of these carbon materials suffer from energy- and time-consuming synthesis procedures and rely on non-sustainable carbon sources, such as by-products from the petrol industry. By employing carbon materials from biomass, it is possible to simplify the process significantly and to switch to a renewable and eco-friendly feedstock $[5,9,18,19]$. The facility of the employment of the biomasses for the preparation of carbon-based electrodes consists of the fact that a large variety of biomass residues can be easily found and this makes the process cheaper and easier to be implemented since costs related to the purchase/transportation of the precursors are avoided. Besides, the biomass waste-generating companies can even pay for the activated carbon/electrode companies to receive the biomass residues because this could be even lesser expensive than other treatments or landfilling process.

The utilisation of biomass to produce value-added products would have at least two simultaneous impacts, namely (i) environmental pollution control and (ii) wealth creation (through the synthesis of hi-tech materials) in an essential step in the direction to the circular economy applied in energy storage devices that preconise a "trash-to-treasure" cycle.

For the fabrication of the energy storage devices preparation of carbon electrodes, ACs can serve, thereby, either as the sole electrode material (for ion electrosorption via supercapacitors- as a promising electron double-layer capacitive (EDLC) material) or as a tunable substrate to attach heteroatoms $(\mathrm{O}, \mathrm{N}, \mathrm{H}$, etc.) capable of boosting their electrochemical performances [9,17-21]. The preparation of ACs can be done by pyrolysis and hydrothermal processes, and their quality and properties are affected by many factors, including the type of precursors, type of pyrolysis, pyrolysis conditions, and type of activation (chemical and or physical) [18-21]. Therefore, more fundamental studies are needed to optimise the properties of the final product (ACs) specifically for their applications as energy storage devices. 
The current state-of-the-art presents a large gap between our ability to produce different carbon electrodes (CEs) from biomasses and how resulting properties are connected to the electrochemical performances of the CEs in supercapacitor and battery applications. This work tries to diminish this gap by explicitly focusing on the correlation of carbon properties after pyrolysis and ACs electrochemical properties resulting therefrom. Also, this work discusses that different pyrolysis methods and biomass can provide AC electrodes with optimised energy storage metrics.

\section{Energy Storage Devices (Battery and Supercapacitors)}

The most common electrochemical energy storage devices include Li-ion batteries (LIBs) and SCs [10-14], which both provide huge potential and promising solutions since they can efficiently store energy from sustainable sources. The electrochemical processes occurring in SCs and batteries differ through their charge-storage metrics. LIBs, which are the most used ones, build on the insertion of $\mathrm{Li}^{+}$ that favours redox reactions at electrodes/electrolytes in a diffusion-controlled slow process.

A battery consists of one or more electrochemical cells $[9,12,15]$ that are applied to store chemical energy for conversion into electrical energy. The energy is released through redox reactions that occur between both carbon or any electrode materials and the electrolytes $[9,12,15]$. Both devices are typically composed of electrodes, i.e., a cathode (a positive electrode) and an anode (negative electrode), as well as an electrolyte that allows ions transport, a separator that separates the two electrodes, and current collectors that allow current to flow out of the cell to perform work.

The flow of electrons is favoured by an electric current that takes place from oxidisation in the anodes, which in turn provoke a reduction at the cathode. Batteries can keep our devices working for many hours, days and weeks, due to high energy density, but, on the other hand, they can take hours to recharge when they run down $[9-15,22]$ since the characteristic power density for these systems is typically low.

For applications that need rapid power delivery and recharging, supercapacitors (also called electrochemical capacitors) are the most appropriate devices. Applications in short-term energy storage and regenerative braking, such as the recuperation of braking energy and the starting of cars, are mostly employed while the battery is mostly employed for mobile energy storage applications such as a battery for cars, computers, etc. [9-15,22].

Two primary mechanisms prevail in the overall energy storage in supercapacitors: the electrical double layer capacitance (EDLC) and the pseudo-capacitance. EDLC results from adsorption-dislodging of ions at an interface electrolyte-electrode. The most promising materials applied as EDLC candidates are carbon allotropes. Devices based on EDLC materials are characterised by high power but low specific capacitance. On the other hand, the pseudo-capacitance is favoured by redox reactions at the surface of electrodes classified as a faradaic process. Despite the low conductivity of some pseudocapacitive (metal oxide layers), conducting polymers (CPs) present outstanding electrical conductivity properties that enable their use as a binder for SCs. As for disadvantages, the low stability and poor mechanical properties of CPs can be considered. To circumvent these drawbacks, the development of hybrid materials based on carbon derivatives and pseudocapacitors tends to synergically reinforce the potential of both components (EDLC and pseudo-capacitance), as previously reported in [23-25].

EDLC prototypes store charges by adsorbing electrolyte ions onto the electrode's surfaces $[10,12]$. There are no redox reactions to make them work, so the response to changes in potential without diffusion limitations is rapid and leads to high power $[10,12]$. However, the charge is contained on the surface, so the energy density of EDLCs is lesser than that of batteries $[10,12]$.

Batteries and SCs rely on electrochemical processes, although each has and work through different mechanisms that determine their relative energy and power density. Traditionally, batteries and SCs work as symbiotic devices. The SC readily transferred energy, while the storage capacity of a rechargeable battery filled the needs of a power bank [9-15,22]. Both devices seemed to be unparalleled in their respective fields. The supercapacitor exhibits huge power density, while the battery presents 
very high energy density. Recently advanced supercapacitors have come to market that breaks down that barrier. It is worth mentioning that different strategies have been considered to improve the energy in supercapacitors. In addition to the above-described development of hybrid composites (EDLC + pseudocapacitance), which are responsible for an improvement in the specific capacitance (Spe.Cap) of the device, the electrochemical window is another critical parameter for improvement in the energy density $\left(E=\frac{1}{2} C V^{2}\right)$. The higher potential window has been successfully reached from an asymmetric arrangement of electrodes (battery-like and SC-like electrodes), allowing that potential window can be higher than $1 \mathrm{~V}$.

Porous carbons are widely desired and employed as efficient electrodes due to their large specific surface area (SSA), well-developed porosity, and pore-size distribution, which can be tailored for a more suitable structure to the size of the electrolyte ions providing higher conductivity, and good physicochemical stability. Furthermore, the AC's porous surface can be modified with some functionalities that can improve their electrochemical performances, which is explained and discussed later in Section 5.3.

\section{Biomass Carbon Sources and Composition as Raw Material for Carbon Electrodes (CEs)}

Carbon is one of the most critical elements for humankind. It is essential in people's lives as well as for industrial processes as a raw material $[2,5,22]$. Due to its diverse electronic properties, carbon materials have a wide range of structures and properties according to their $\mathrm{C}-\mathrm{C}$ bonding $[2,5,22]$. In light of these statements, strategies for the development of carbon materials such as nanofibers, graphene, graphite, etc., have been implemented which have successfully resulted in developments in carbon science applications and technology $[5,7,8,26]$. It can be said that carbon materials almost include the properties of all the materials on the earth, such as the hardest and softest, insulators, adsorbents, conductors and semiconductors, thermal conductors, and insulators, etc. [2,5,22]. With the evolution of science and technology, carbon utilisation seems to contain unlimited possibilities of turning it into useful materials and development.

Another essential aspect is that sources of carbons can be easily found everywhere in the world, mainly from forest and animal residues, as so-called biomass. International Union of Pure and Applied Chemistry (IUPAC) defines biomass as material produced by biological growth (plants, microorganisms, animals, etc.) [27], It is also an applied term to the use of these biomaterials for energy production (heat or electricity), or in various industrial processes as a raw substance for a range of products [27]. Unlike fossil fuel, biomass can be considered a renewable material because its inherent energy depends uniquely on the sun to grow and can regrow in a relatively short time.

Each year, billions of metric tons of organic residues are generated all over the world from activities of farming and crop production, food industries, animal husbandry, etc., requiring tremendous efforts to develop systems in which production, conversion, and utilisation of these residues are carried out efficiently and under environmentally sustainable conditions [28-31]. Therefore, it is imperative to explore and employ renewable and natural sources of energies to replace fossil sources, encouraging us to seek greener and more efficient energy technologies to meet the increasing demands for energy and eco-friendly materials [28-31].

It has been shown in the literature that there are a variety of materials synthesised from heterogeneous biomass precursors [1,3-9,17-21,32]. These carbon materials might exhibit different properties and structures that are in function of the biomass type and initial composition. Many reports in the literature correlate the properties of the selected biomasses with the electrochemical metrics of CEs made from them.

The composition of the biomass can play an essential role in the performance of CE for energy storage devices since it will influence the properties of the final AC properties. Table 1 shows the main components of several biomasses in terms of hemicellulose, cellulose, and lignin. Biomass rich in cellulose can be successfully employed to synthesise cellulose-based carbons for electrodes $[35,36]$. During the thermal treatment of the biomass precursors, hemicellulose, cellulose, and lignin decompose 
at different rates and within distinct temperature ranges [4]. While lignin is pyrolysed over an extensive temperature range and shows the behaviour characteristic of solid fuels, hemicellulose and cellulose decomposition is sharp in a narrow temperature range [4]. These differences certainly provide ACs with different properties, which also lead to CEs with different electrochemical metrics.

Table 1. Main composition of some agricultural biomass and residues.

\begin{tabular}{ccccc}
\hline Biomass Precursor & Hemicellulose (\%) & Cellulose (\%) & Lignin (\%) & Ref. \\
\hline Coconut husk & 23.7 & 0.52 & 3.54 & {$[33]$} \\
\hline Sugarcane bagasse & $27-32$ & $32-44$ & $19-24$ & {$[34]$} \\
\hline Hardwood stem & $24-40$ & $40-50$ & $18-25$ & {$[34]$} \\
\hline Softwood stems & $25-35$ & $45-50$ & $25-35$ & {$[34]$} \\
\hline Sunflower shell & 34.6 & 48.4 & 17 & {$[34]$} \\
\hline Bamboo & $15-26$ & $26-43$ & $21-31$ & {$[34]$} \\
\hline Banana residues & 14.8 & 13.2 & 14.0 & {$[34]$} \\
\hline Cocoa pod husks & 37 & 35.4 & 14.7 & {$[34]$} \\
\hline
\end{tabular}

Nevertheless, the carbon content in cellulose-rich materials can reach 50\% [34]. However, after carbonisation, this content may increase above $80 \%$ or even $95 \%$ for ACs, which is interesting since it can lead to an elevated and developed porosity [37]. The high cellulose content also plays a crucial role in developing mesopore structure in ACs while lignin, for example, can promote the formation of layered structure and maximisation of micropores during the preparation of AC [38].

Zhuo et al. [39] fabricated CE from activated carbon made from cellulose, $\left(1364 \mathrm{~m}^{2} \mathrm{~g}^{-1}\right)$ with excellent electrochemical performance. It presented a Spe.Cap of $328 \mathrm{~F} \mathrm{~g}^{-1}$ at $0.5 \mathrm{~A} \mathrm{~g}^{-1}$ as well as outstanding cycling stability with $96 \%$ of the capacitance retention after 5000 charges/discharge cycles. In another work [40], micro/mesoporous carbon was successfully obtained from cellulose and used to make CE for supercapacitors. The fabricated CE displayed specific capacitances of $160 \mathrm{~F} \mathrm{~g}^{-1}$ at $0.2 \mathrm{~A}$ $\mathrm{g}^{-1}$ and also exhibited very excellent cycle stability.

Lignin-rich materials are also useful as alternative raw precursor materials for CE preparation [41]. In typical biomass, lignin links between cellulose and hemicellulose. Tian et al. [41] fabricated electrodes by using lignin as primary raw material and reported that due to its high SSA and wide pore size distribution, the derived lignin electrode exhibited high specific capacitance equal to $328 \mathrm{~F}$ $\mathrm{g}^{-1}$ at $0.2 \mathrm{~A} \mathrm{~g}^{-1}$. It also presented very good cycling stability (97\% capacitance retention after 10000 cycles). Also, the derived lignin electrode delivered a high energy density $\left(6.9 \mathrm{~W} \mathrm{~h} \mathrm{~kg}^{-1}\right)$ at $50 \mathrm{~W} \mathrm{~kg}^{-1}$. Lin et al. produced lignin-based porous carbon by simple chemical activation with $\mathrm{KOH}$ followed by pyrolysis [42]. The obtained CE presented good capacitance performance (165 F g $\mathrm{F}^{-1}$ at $\left.0.05 \mathrm{~A} \mathrm{~g}^{-1}\right)$ and outstanding cycling stability (97\% over 5000s). The CE also exhibited an energy density of $5.7 \mathrm{Wh} \mathrm{kg}^{-1}$ at a power density of $15 \mathrm{~W} \mathrm{~kg}^{-1}$.

Hemicellulose can also be an attractive raw material for AC preparation for making CE. For instance, Wang et al. [43] extracted hemicellulose from hemp stem and treated it hydrothermally followed chemical activation with $\mathrm{KOH}$. The obtained hemicellulose-derived CE exhibited excellent electrochemical performance (capacitance of $318 \mathrm{Fg}^{-1}$ ), which is attributed to abundant micropores and oxygen functionalities.

\section{Thermal Process for Carbon Electrodes Preparation and Heating Process Considerations}

It is well reported that several pyrolysis methods can be employed to prepare useful ACs $[43,44]$. However, conventional pyrolysis, hydrothermal carbonisation (HTC), and microwave heating are the most used ones, and all of them can yield AC with exciting properties. These methods present different ways of heating inside the reactor; conventional pyrolysis and hydrothermal occur via conduction and/or 
convection while microwave occurs via electromagnetic waves $[45,46]$. The heating in microwaves generates fewer energy losses to the environment and consequently has more considerable energy savings when compared to conventional pyrolysis $[45,46]$.

Compared to the conventional process, microwave heating is directly related to the internal heating of the material. In this sense, energy is transferred from the interaction between molecules or atoms, representing the transformation of electromagnetic energy in thermal energy. In contrast, in heating processes based on conduction, convection, and radiation, heat is transferred from the surface of the material towards the centre. Figure 1 schematises how the heating profiles move concerning the material.

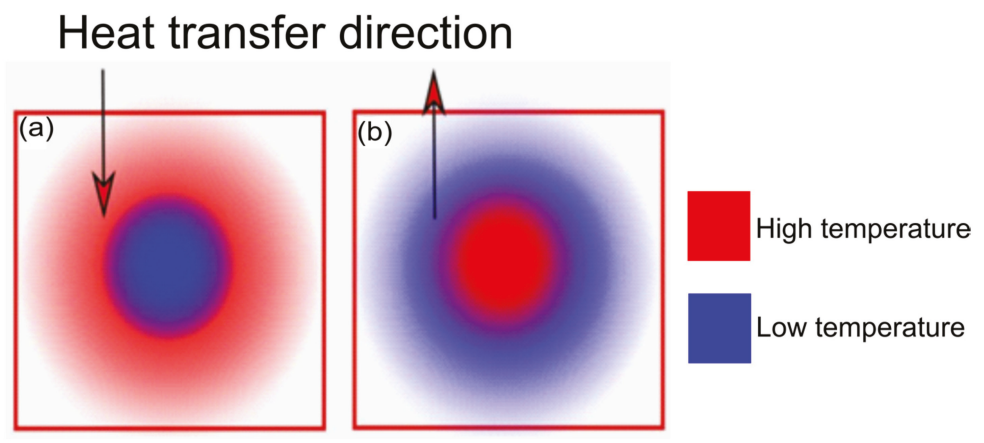

Figure 1. - Schematic diagram of temperature distribution, in the (a) conventional pyrolysis and HTC and (b) microwave heating.

Since microwaves are capable of penetrating the material that will then retain this energy, heat is generated throughout the sample [46,47]. The uniformity of the heating will depend on the sample size and microwave penetration depth [46,47].

Some advantages of microwave heating when compared to the conventional heating are related to the fact that microwaves provide the heating of the material in the absence of contact, the energy (heating) is transferred with speed and uniformity and at the same rate of volumetric heating, and has a high level of safety and automation potential [46,47]. Additionally, such a system offers advantages of fast start-up and processing execution and high energy efficiency (in terms of the amount of energy involved in the quantity effectively absorbed) [46,47].

HTC process is usually carried out in subcritical water at much lower temperatures when compared to other pyrolysis methods. The biomass or any precursor is heated in a hermetic reactor under the autogenous pressure [48]. However, when other methods are compared with HTC, conventional pyrolysis presents some advantages such relatively simple process which is more mature and easier to be industrialised while the microwave is still being tried to be adapted to be industrialised. However, HTC has several advantages. For instance, since the carbonisation reaction is carried out in the water, no drying process is required for HTC. Moreover, using HTC the ash content, in the AC composition, increases (as is with all the carbonisation methods) but to a lesser extent due to the continuously washing condition into the liquid phase, and this can improve the AC electrochemical performances since ash can hinder it [49].

However, in terms of which method is the most appropriate for producing ACs with improved and better characteristics, there is not yet a categorical conclusion to be drawn. In the international literature, there are several controversial takeaways and conclusions. The right thing to do should be to analyse each case based on the type of biomass and what the application of the produced ACs because what influences the final quality of an $\mathrm{AC}$ is a set of factors and not just the method of heating itself, such as operating conditions and type of raw material that is being used [46,47]. 
For instance, Hoffmann et al. [50] prepared ACs (by HTC) from potato residues and applied them as carbon electrodes (CE) for SCs. They found that the HTC method provided AC with very high carbon content, and this reflected in good electrochemical performance (Spe.Cap of up to $134.15 \mathrm{~F} \mathrm{~g}^{-1}$ ). They reported that pseudocapacitive effects explain the relatively high capacity due to the high O-content in the carbon (8.9 wt.\%).

In another work, Liu et al. [51] produced ACs from palm residues by microwave method, which yield ACs with very high specific surface area (SSA) $\left(344 \mathrm{~m}^{2} \mathrm{~g}^{-1}\right)$. The microwave carbon displayed high Spe.Cap of $226.0 \mathrm{~F} \mathrm{~g}^{-1}$ at $0.5 \mathrm{~A} \mathrm{~g}^{-1}$ as well as an excellent performance on a charge-discharge process with an energy density of $72.3 \mathrm{Wh} \mathrm{kg}^{-1}$ at a power density of $1.4 \mathrm{~kW}$ $\mathrm{kg}^{-1}$ and $50.0 \mathrm{Wh} \mathrm{kg}^{-1}$ at $28.8 \mathrm{~kW} \mathrm{~kg}^{-1}$.

Conventional pyrolysis is by far the most applied method for preparing CEs. Hou et al. [52] used rice biomass to fabricate $\mathrm{CE}$, and the final materials also exhibited interesting electrochemical properties, e.g., the Spe.Cap of $218 \mathrm{~F} \mathrm{~g}^{-1}$ at $80 \mathrm{~A} \mathrm{~g}^{-1}$ in $6 \mathrm{M} \mathrm{KOH}$ and high energy-density of $104 \mathrm{Wh}$ $\mathrm{kg}^{-1}\left(53 \mathrm{Wh} \mathrm{L}^{-1}\right.$ ) by using ionic electrolytes.

These studies suggest that whatever method is used to prepared ACs and CEs, they can successfully be employed to make efficient $C E$ with improved electrochemical properties.

\section{Preparation of ACs Through the Chemical Activation Process}

The preparation of ACs usually consists of employing a thermal treatment followed by further activation (physical and/or chemical) that can take place either in a single or two-stage process.

In the chemical activation step, the biomass is combined and mixed with chemical reagents $\left(\mathrm{ZnCl}_{2}, \mathrm{KOH}, \mathrm{NaOH}, \mathrm{H}_{3} \mathrm{PO}_{4}, \mathrm{~K}_{2} \mathrm{CO}_{3}\right.$, and $\left.\mathrm{FeCl}_{3}\right)$ at desired ratios to obtain ACs with desired properties $[9,28-31,44-46,53-56]$. This step is essential in which the pyrolysis and activation are simultaneously performed which might have a significant influence in the pyrolytic decomposition of the precursor and, therefore, resulting in the development of highly porous structures and functionalities on the carbon surface [54-57]. $\mathrm{ZnCl}_{2}$ and $\mathrm{KOH}$ are the most employed chemical reagents for preparing ACs $[54,57]$. The chemical activation step has the advantage of producing ACs with high developed porosity and elevated SSA.

Lv et al. [57] reported the preparation of ACs with and without the activation of peanut shell using $\mathrm{KOH}$. Thereby, it was found out that the $\mathrm{KOH}$ activation induces the higher number of nanoscale pores before pyrolysis (see Figure 2).

(a)

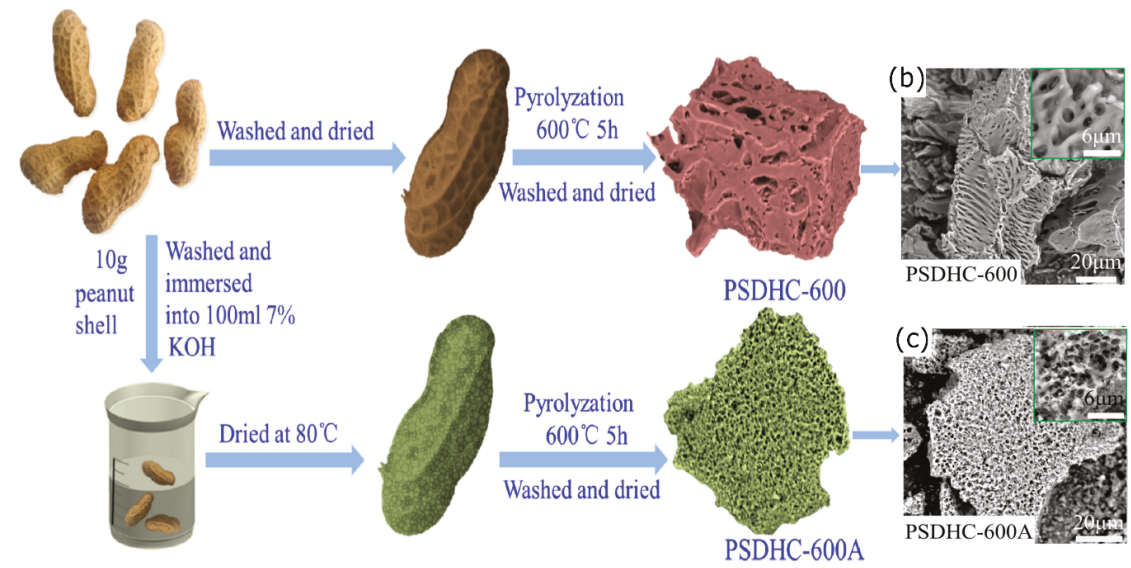

Figure 2. (a) Effect of the chemical treatment on the AC properties, $(\mathbf{b}, \mathbf{c})$ SEM images of the ACs. Figure reproduced and adapted from reference [57] with permission from Elsevier. 
Due to the capillarity infiltration of $\mathrm{KOH}$ liquid, a number of micro and mesopores can be developed into the biomass structure, thus the pyrolysis of which leads to a much finer porous structure of PSDHC-600A when compared to PSDHC-600. The finer porous structure facilitates the penetration of the electrolyte, which reduces the ion diffusion distances, providing more and efficient sites for ions storage.

Chen et al. [58] prepared ACs using tobacco stem as a precursor by mixing $\mathrm{KOH}, \mathrm{K}_{2} \mathrm{CO}_{3}$, and $\mathrm{ZnCl}_{2}$ as chemical activation reagents. The effects of the impregnation ratio and activating agents were evaluated on AC structures. The properties of the ACs were better developed by using $\mathrm{ZnCl}_{2}$. Moreover, it yielded ACs with various oxygen, hydroxyl, and ester functional groups on ACs surfaces and excellent thermostability.

The difference of the chemical reagents in carbon structures is further observed in Figure 3. It shows significant differences in their morphologies (between raw materials and AC samples). The tobacco biomass displayed a rough surface with tiny porosity (see Figure 3a,b), while AC surfaces presented massive amounts of pores structures that were created by the chemical activation (see Figure $3 \mathrm{c}-\mathrm{g}$ ).
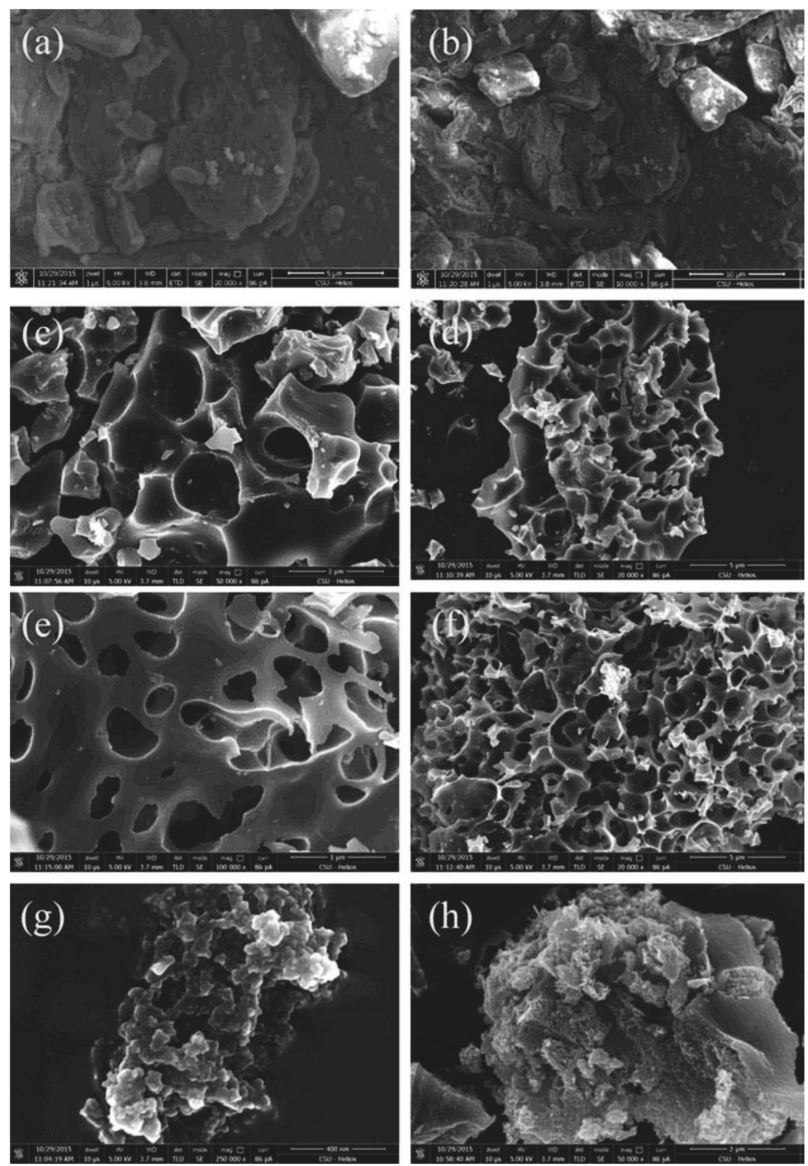

Figure 3. SEM images of (a,b) raw tobacco stem and AC samples: (c,d) activated with $\mathrm{KOH}$, $(\mathbf{e}, \mathbf{f})$ activated with $\mathrm{K}_{2} \mathrm{CO}_{3}$, and $\left(\mathbf{g}\right.$,h) activated with $\mathrm{ZnCl}_{2}$ [58]. Figure reproduced from reference [58] with permission from Taylor \& Francis. 
There are also observed significant differences between the ACs prepared by the different activation agents. Different pore sizes and shapes could be observed mainly for those ACs prepared with $\mathrm{KOH}$ (see Figure $3 \mathrm{c}, \mathrm{d}$ ) and $\mathrm{K}_{2} \mathrm{CO}_{3}$ (see Figure 3e,f), presented certain similarity in their morphologies. However, comparatively, the activation with $\mathrm{ZnCl}_{2}$ yielded $\mathrm{AC}$ with sponge-like morphology (see Figure 3g,h), and much smaller pore sizes which resulted in a much higher SSA.

Dos Reis et al. [56] prepared ACs from sewage sludge by comparing chemical activation reagents $\left(\mathrm{KOH}\right.$ and $\left.\mathrm{ZnCl}_{2}\right)$. The $\mathrm{KOH}$-treated AC obtained the smaller SSA $\left(186 \mathrm{~m}^{2} \mathrm{~g}^{-1}\right)$ than the $\mathrm{ZnCl}_{2}$-prepared carbon $\left(192 \mathrm{~m}^{2} \mathrm{~g}^{-1}\right)$. However, the $\mathrm{KOH}$ AC presented a higher presence of functional groups on its surface, and this would probably influence the electrochemical performance, since, for instance, nitrogen, oxygen, and phosphorous functionalities can enhance the electrochemical effects by improving the wettability of porous carbon in contact with electrolytes [55,59-65].

\subsection{Effect of the Physical Characteristics of Biomass Carbon Electrodes for Lithium-Ion Battery (LIBs)}

Ion diffusion is of considerable importance to the electrochemical performances of the CEs, mainly in the charge-discharge processes of batteries $[12,14,52]$. In this sense, CEs from biomass with high surface area and developed porosity is highly desired for LIBs because it can diminish the Li-ions diffusion pathways and to optimise a large electrode/electrolyte interface, which is beneficial for electrochemical reactions and therefore improving its metrics [59-64].

In this sense, materials used as electrodes might play a crucial role in the whole energy storage systems [63-65]. Graphite and graphene are some of the most popular anode material for LIBs [61]. However, the Li-storage capacity of graphite is not high enough to meet the demand of electric devices. However, the graphite has low both capacity $\left(372 \mathrm{~mA} \mathrm{~h} \mathrm{~g}{ }^{-1}\right)$ and the rate performance, which is difficult to commercially popularise [61].

Thus, to enhance Li-storage capacity, efforts have been made to reach the application of porous ACs from biomasses for electrodes fabrication [66-72]. Many kinds of research have been devoted to the feasibility of preparation of CEs from biomasses, mainly due to the significant existence of micro-, meso-, and macropores that have huge effects on their electronic structure and electrochemical performance, such as reduced diffusion length for $\mathrm{Li}^{+}$ions and electrons and improved reversible capacity (RC).

Another important consideration is that porous carbons can be easily prepared through thermal, physical, and chemical activations. These activation methods can provide carbon materials with various structures and textures, morphologies, crystallinities, and electronic features which are desirable features for CE fabrication and energy storage devices.

Some main electrochemical metrics such as initial Coulombic efficiency, rate capability and RC are compared in Table 2 to evaluate the efficiency of the carbon electrodes from biomasses for LIBs. It is observed that the biomass carbon electrodes with higher SSA are inclined to exhibit higher Coulombic efficiencies. For instance, Selvamani et al. [62] found an initial coulombic efficiency of $90 \%$ with a CE with an SSA of $1980 \mathrm{~m}^{2} \mathrm{~g}^{-1}$ and Hernández-Rentero et al. [63] found an efficiency higher than $99 \%$ for a CE with SSA of $1662 \mathrm{~m}^{2} \mathrm{~g}^{-1}$ while Lotfabad et al. [64] found a coulombic efficiency of $55 \%$ for a CE with an SSA of $130 \mathrm{~m}^{2} \mathrm{~g}^{-1}$ (see Table 2). However, Zhang et al. [61] fabricated a CE from rice straw and, among the reports shown in Table 2, it exhibited the highest SSA but not the best electrochemical performances. 


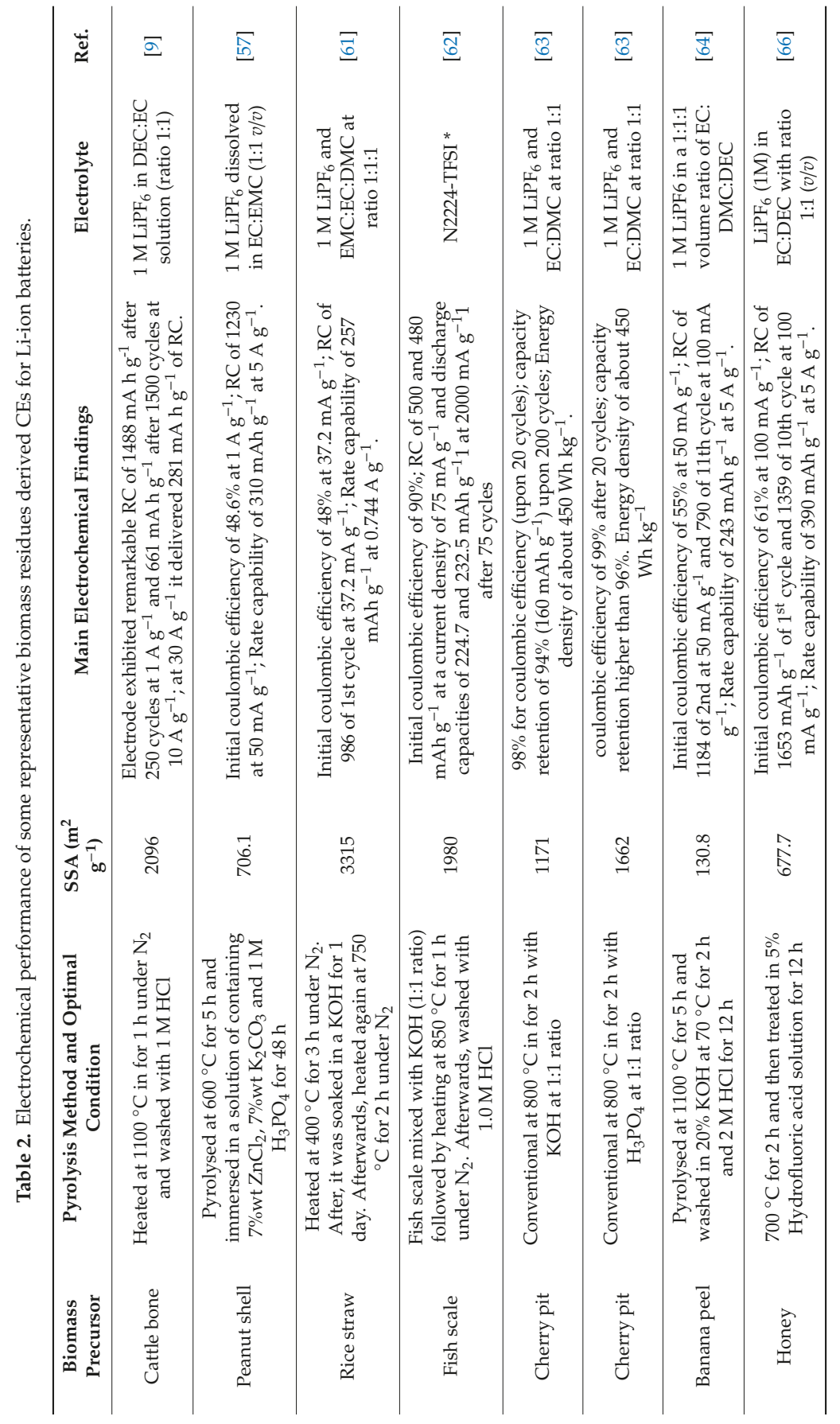




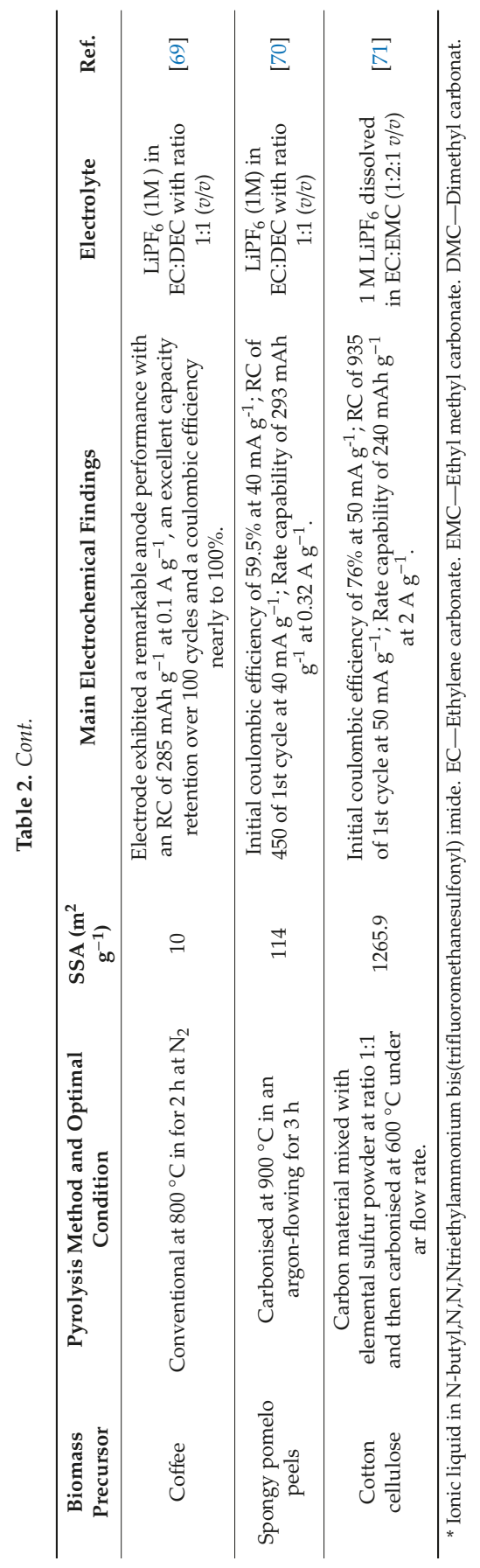


Many reports in the literature indicate the role that SSA plays in the electrochemical process, although it is not the only parameter to be considered [52,59,65]. In terms of physical features of the $\mathrm{CE}$, the combination of macro-, meso-, and micropores might enhance the CE performances in terms of i) electrode wettability and electrolyte accessibility which are mainly facilitated by the presence of macro- and mesopores [61,65], although the hydrophobicity of the CE also influences the wettability process $[65,66]$ ii) ion diffusion rate, and iii) charge transport kinetics at the $\mathrm{CE} /$ electrolyte interphase which is mainly potentialised by the presence of the micropores [60]. Therefore, together with the high specific surface area, the simultaneous presence of various types of pore sizes into the CE allows for the enhancement of their electrochemical performances in energy storage devices [60,65-73].

Zhang et al., [66] evaluated porosity effect on the electrochemical metrics of CE for LIBs and found exciting results. They reported that the excellent electrochemical performances were reached because of the high presence of mesopores. They related that the dilated interlayer spacings $(0.387-0.395 \mathrm{~nm})$ positively affected the $\mathrm{Li}^{+}$intercalation.

Also, the high SSA maximised the electrode/electrolyte interfaces for the charge-transfer reaction. Moreover, a large amount of ordered mesoporous in the AC structure can serve as $\mathrm{Li}^{+}$deposit and also potential pathways for diffusion of electrolyte which speedy the kinetic process of ions diffusion in $\mathrm{CE}$ surfaces and structures, leading to better electrochemical performance metrics (as illustrated in Figure 4).

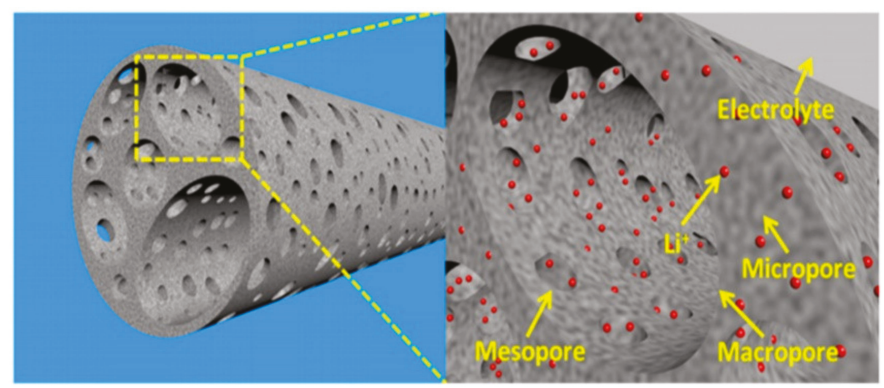

Figure 4. Scheme of the porous structure and $\mathrm{Li}^{+}$storage system. Figure reproduced from reference [67] with permission from Royal Society of Chemistry.

The effect of carbon structure was studied and highlighted by Peng et al. [68] using Moringa oleifera leaves as a precursor to produce highly porous AC (HCPC) with multidirectional porosity that was used as CE for efficient DLCs (see Figure 5).

a

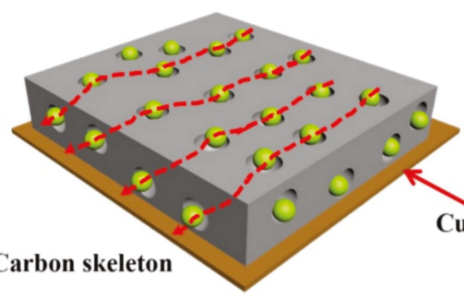

Conventional active carbon with microporosity as single-direction channels for ion transfer

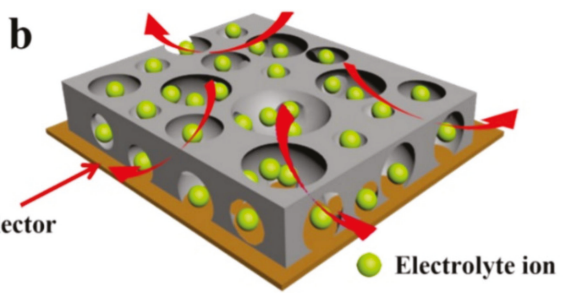

Bio-inspired HCPCs with interconnected porosity as multi-direction channels for fast ion transport

Figure 5. Scheme of different ion channels in (a) conventional AC with single direction porosity and (b) HCPC with multidirectional porosity for ion transfer. Figure reproduced from reference [68] with permission from Americam Chemical Society. 
Figure 5a shows conventional AC with dominant microporous structures with single-directional ion channels, which provides more reduced accessibility for electrode ions to transfer into the internal pore structure and thus resulting in poor electrochemical performances. Compared to the conventional commercial AC, the prepared highly porous N-doped AC (Figure 5b) exhibited improved characteristics and advantages, such as: (i) highly crumpled and wider pores on its surface structure promote an enhancing in the ion adsorption due to the increase of the number of active sites which maximise the useful storage of the charges; (ii) a large number of interconnected macropores might act as the ion deposit to storage electrolyte ions and enhance the access and availability of the interface between electrolyte and CE; (iii) high multidirectional porosity can also promote important channels for rapid and efficient ion transportation and transference; (iv) by increasing $\mathrm{O}$ - and $\mathrm{N}$ - atoms on AC surface enhance the wettability and the conductivity of electrons, which leads to advantage gains in the rapid charge transfer.

\subsection{Biomass Carbon Electrodes for Double Layer Supercapacitors (DLCs)}

Supercapacitors or electrochemical double-layer capacitors (DLCs) can store and deliver the electrostatic charge through ion adsorption on the surface of the electrically conductive porous CEs [72,73]. Thus, CEs with very high specific surfaces and appropriate pore distribution can also achieve very high capacities and are the critical factors for DLCs to provide active sites and channels to maximise the contact between interface $\mathrm{CE} / \mathrm{electrolyte}$ and increase the adsorption of electrolyte ions $[74,75]$.

Because of its high power density and long cycling life, DLCs have attracted very much attention over the last years, in comparison to LIBs and fuel cells [76]. However, some limitations hinder their practical applications, such as low-energy densities $\left(\sim 8 \mathrm{Wh} \mathrm{kg}^{-1}\right)$ [77]. Therefore, to fulfil the essential demands of energy, novel and efficient CEs must be designed for highly efficient DLCs through simple, low-cost, and environmentally sustainable technologies routes [78].

Advanced carbon materials including graphene, carbon nanotubes, and templated carbons are the most commonly employed CE materials for commercially efficient DLCs due their useful cycle lifetime, high specific capacitance and high maximum power density [79-81]. However, high energy and costs are required to obtain these materials. Moreover, the process of their preparation is complicated, which makes it difficult for large-scale production $[9,12]$.

Therefore, it is imperative to find ways and materials to fabricate lower cost and efficient CEs with comparable electrochemical performances from ample and renewable natural resources for SCs applications, and biomasses constitute one of the solutions.

Vast and exciting reports are shown in the literature concerning the production of bio-based CEs from different biomasses by applying different thermal, physical and chemical treatments to apply them in SCs application, as shown in Table 3. From these studies, different takeaways and outcomes have been achieved regarding CE for SCs which some of them were that (i) high carbon content, graphite-like and microporous structures positively influence the electric conductivity [70,81-87] and (ii) high electric conductivity leads to better electrochemical performance and high capacitances $[64,82]$. 


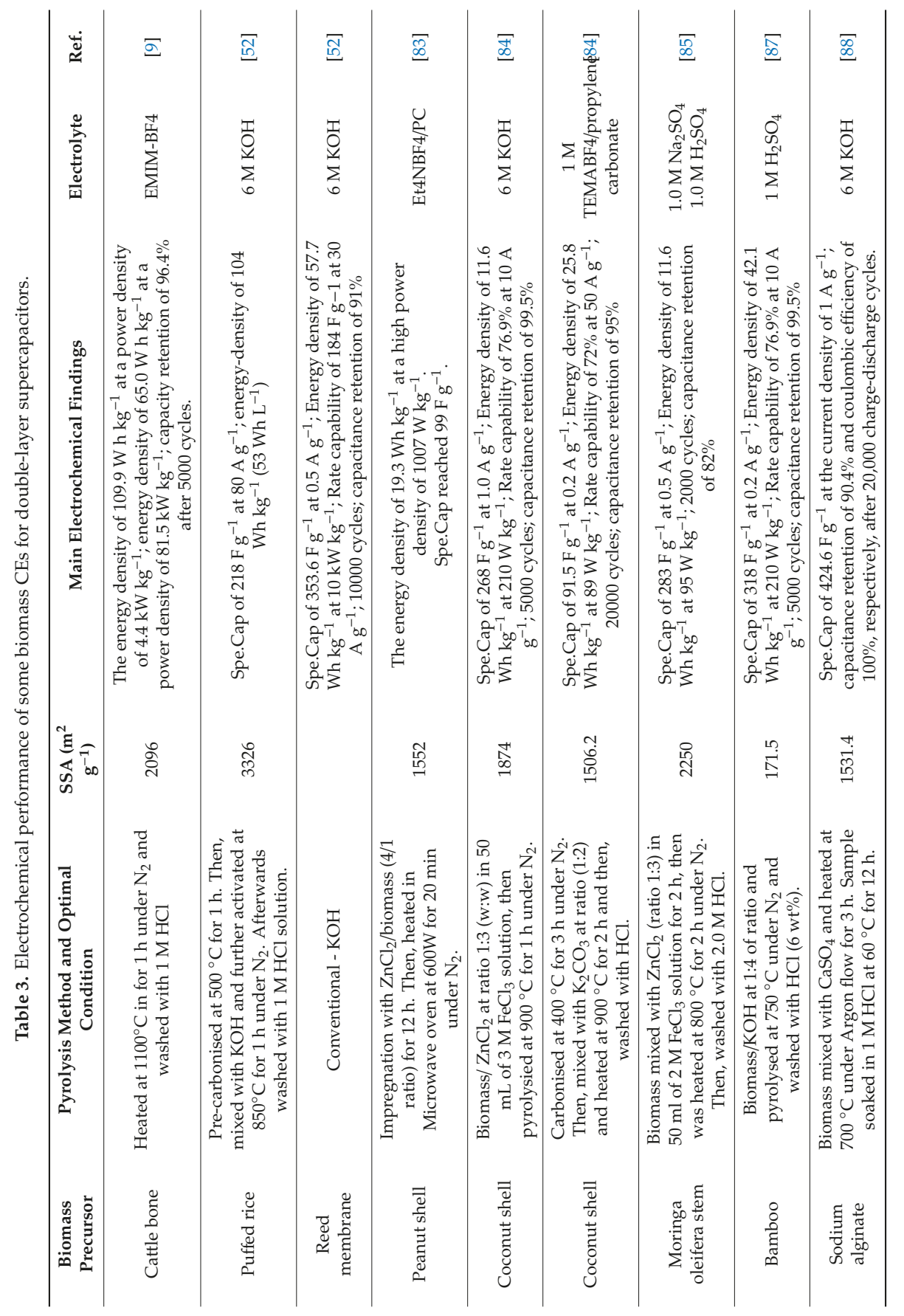




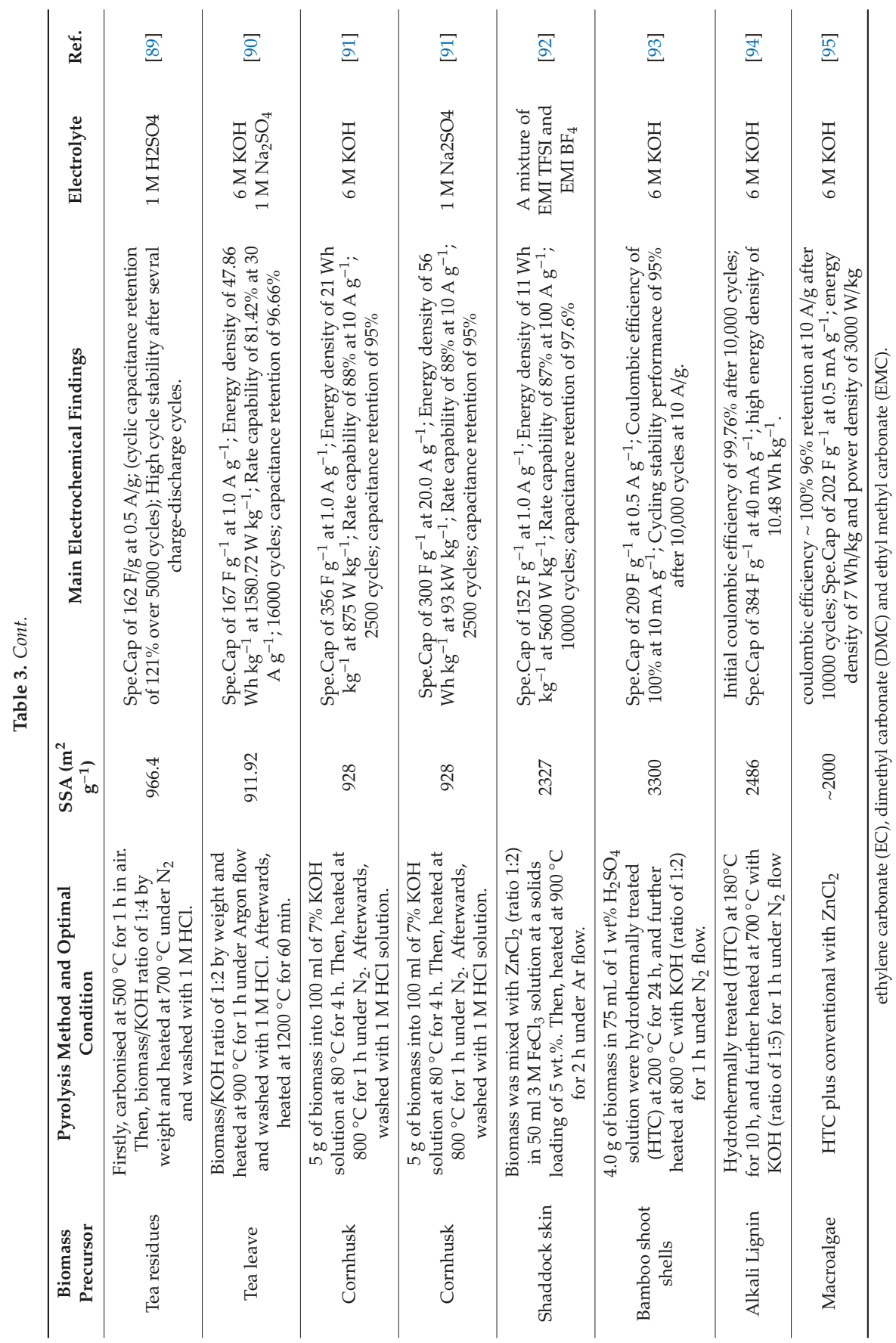


Xia et al. [88] developed porous CEs by pyrolysing O-rich biomass (sodium alginate). At the optimal experimental condition, the $\mathrm{CE}$ delivered a high Spe.Cap of up to $424.6 \mathrm{~F} \mathrm{~g}^{-1}$ in $6 \mathrm{M} \mathrm{KOH}$ electrolyte at $1 \mathrm{~A} \mathrm{~g}^{-1}$. The $\mathrm{CE}$ also presented good cyclic stability with the capacitance retention of $90 \%$ after 20,000 charge-discharge cycles. The excellent electrochemical performance of the CE was attributed to both hierarchical macro-/meso-/micro porous structures as well as the abundant presence of oxygen functional groups.

In another study, Moringa oleifera leaves were used as raw biomass for CEs preparation [86]. The fabricated CEs showed very high electrochemical performances such as capacitance retention higher than $90 \%$ when the current density is increased from 1.0 to $50 \mathrm{~A} \mathrm{~g}^{-1}$ and efficient cycling stability over 20000 cycles. Also, CEs resented the high specific energy of $21.6 \mathrm{Wh} \mathrm{kg}^{-1}$.

He et al. [83] also used biomass residues from peanut shells to prepare CEs for SCs. The ACs were prepared by using $\mathrm{ZnCl}_{2}$ chemical activation followed by microwave pyrolysis. It was found that the SCs made from it displayed a high energy density of $19.3 \mathrm{Wh} \mathrm{kg}^{-1}$ at a high power density of $1007 \mathrm{~W}$ $\mathrm{kg}^{-1}$ in $1 \mathrm{M} \mathrm{Et}_{4} \mathrm{NBF}_{4} / \mathrm{PC}$ electrolyte, and a Spe.Cap of $99 \mathrm{~F} \mathrm{~g}^{-1}$, highlighting that the employed method of preparation was highly efficient to produce CEs with high electrochemical performance for SCs.

\subsection{Effect of Functional Groups on Electrochemical Performances of the CEs}

Functional groups on surface carbons are influenced by the precursor materials as well as the activation process $[96,97]$. The presence of functional groups is related to the degradation performance and ageing of AC in organic electrolytes [98-100]. Therefore, to diminish this degradation, it is recommended to produce functional group-free ACs $[99,100]$. However, the same functional groups that hinder the electrochemical performances in organic electrolytes can be beneficial in non-organic electrolytes by providing extra capacitance through a pseudocapacitive mechanism [100,101].

Furthermore, surface-functional groups including nitrogen, oxygen and phosphorous can considerably increase the electrochemical effects as well as improving the wettability of porous carbon with electrolytes, increasing so the electrochemical performances of the electrodes [102-104].

Ding et al. [100] related that an appropriate number of functional groups on the CE surface can enhance the electrochemical stability window, which can be reflected by high energy and power density. It is also related that the presence of certain functionalities (e.g. $\mathrm{O}-\mathrm{C}=\mathrm{O}$ or $\mathrm{C}=\mathrm{O}$ ) induced higher capacitance to carbon materials and that the proper functional groups hinder the potential shift of the CEs.

However, an elevated amount of functionalities on the CE surface is reflected in a high quantity of irreversible redox products that remains inside ACs' pores, resulting in a faster capacitance fade concerning the ACs with lesser functional groups. Cao et al. [104] related that the amount of O- functional groups play a significant influence on the electrochemical SCs efficiency having CE as electrodes.

Widmeir et al. [105] prepared different carbons and concluded that the surface functionality could strongly affect the initial open-circuit voltage (OCV) and the potential shift of the CEs through the time. The large quantity of O-groups explained the high initial OCV of $\mathrm{AC}$ (modified by $\mathrm{HNO}_{3}$ ), while the lower OCV of AC (reduced by $\mathrm{Ar} / \mathrm{H}_{2}$ ) was due to lesser presence of O-groups on AC structure.

Elmouwahidi et al. [106] prepared ACs using argan seed shells as a biomass source through $\mathrm{KOH}$ active reagent. They evaluated the effect of the presence of functional groups on electrochemical performances. They concluded that O-rich ACs exhibited the lowest Spe.Cap (259 F/g at $125 \mathrm{~mA} / \mathrm{g}$ ) and capacity retention $(52 \%$ at $1 \mathrm{~A} / \mathrm{g})$, because of the presence of surface carboxyl groups that hindered electrolyte diffusion into the CE pores.

On the other hand, they also concluded that N-rich ACs presented the highest Spe.Cap (355 F/g at $125 \mathrm{~mA} / \mathrm{g})$ as well as highest retention ( $93 \%$ at $1 \mathrm{~A} / \mathrm{g})$, because of the pseudo-capacitance effects of $\mathrm{N}$ functionalities.

Yang et al. [107] applied four carbons with different oxygen and nitrogen contents as well as different porosities. The effect of both functional groups and porosity were evaluated on the 
electrochemical properties of these carbons. It was found that the electrochemical activity increased in the order of oxygen contents.

They also found that even the carbon with the largest surface area but lower oxygen content had much lower specific capacitance than samples with higher oxygen contents, which suggests the importance of oxygen functional groups on electrochemical properties of the carbon electrodes because the oxygen groups can enhance electrolyte wettability and reactions in aqueous electrolytes.

\subsection{Biomass Carbon Electrodes for Pseudo-Capacitance/ EDLC Hybrid Devices (HSCs)}

An important procedure to reinforce the electrochemical performance of energy storage devices refers to the association of characteristic adsorption of ions by EDLC prototypes with faradaic reactions from pseudocapacitors. The incorporation of pseudocapacitive components into biomass-based carbon electrodes for the production of efficient SCs and batteries takes place from the development of asymmetric devices (strategy to improve the operating voltage window from the use of complementary working potential electrodes) or exploring the carbon-based structures as a support for the growth of pseudocapacitors layers. In the last case, the outstanding properties of biomass-based carbon electrodes (such as high surface area, porosity and electrical conductivity) can be conveniently explored to create nucleation sites for pseudocapacitors growth with an integration level required to reduce the interfacial resistance [108,109].

The production of biomass-derived carbon structures and transition metal oxide composites makes use of the porous structure of carbon derivatives to incorporate seeds and to provide the growth of metal oxide structures based on materials such as cobalt oxide, iron-oxide, nickel-cobalt, etc.

However, the typical low conductivity of resulting structures is a barrier that has been successfully circumvented by the development of composites with conducting polymers due to their high intrinsic conductivity of candidates such as polypyrrole and polyaniline. Despite these superior properties, the low mechanical resistance and low cycle life of CPs-based supercapacitors require a strong interaction of a covering layer with carbon-based systems to reach a desirable energy density in all-solid devices [110].

Arthisree and Madhuri [111] reported the development of green synthesised graphene quantum dots and polyaniline reaching high current density $\left(670 \mathrm{mAg}^{-1}\right)$ and a specific capacitance of $105-578 \mathrm{Fg}^{-1} \mathrm{~cm}^{-2}$. Yu et al. reported a two-step process for the synthesis of composites based on biomass-derived 3D aerosol loaded with polypyrrole particles in supercapacitors with an areal capacitance of $419 \mathrm{mF} \mathrm{cm}^{-2}$ [112].

\section{Future Perspectives and Current Challenges}

The development of renewable carbon materials represents a "sustainable way" to the energy storage-based industry. However, the challenge in this process involves a reasonable degree of complexity that represents a multifactor correlation process involving porosity, conductivity, and flexibility for the resulting device. The production of genuinely flexible energy storage devices is a requisite for wearable electronics, and it can be considered as a process that depends on the substrate preparation procedure in which the electrical response must be nearly invariant under mechanical efforts. On the other hand, the performance of the energy storage devices depends on the available surface area and good conductivity level for charge transport. In general, the increase in the porosity yields a decrease in the electrical response (conductivity) of devices. As a consequence, the design of this 3-factor problem requires a more sophisticated solution in which the optimal condition for each factor can be far from the best performance for the final device. The design of renewable carbon material-based energy storage devices must consider a multifactor study in which the correlation of these properties is critical for the overall response of supercapacitor/battery. 


\section{Conclusions}

Enormous efforts need to be focused on developing new methods to produce materials more sustainably to ensure a smooth shift to a sustainable society. Regarding energy storage, tremendous advances have already been achieved in producing bio-based electronics. For such applications, biomass plays a significant role due to its inherent structural and chemical diversity. The literature has shown a variety of materials synthesised from heterogeneous biomass precursors for energy storage devices based on carbon electrodes. There is a lack of systematic studies correlating the electrochemical performance with the precursor physical-chemical characteristics.

This study provided insight into using suitable biomasses for the fabrication of CEs with efficient electrochemical performances for battery and supercapacitors. An in-depth comparison with the literature showed that biomass residues are already a reality in being promising candidates for high-performance carbon electrodes for battery and supercapacitors.

For instance, physical and chemical characteristics of the CEs reflected in parameters such as the effects of porosity, chemical composition, and surface functionalities on the electrochemical performance are also affected by the intrinsic conductivity of the resulting material. The influence and role of the different biomasses and their components during the thermochemical treatment (conventional pyrolysis, microwave process, and HTC) as well as their experimental conditions. Synergies between the types of biomass and their compositions on the fabrication of carbon electrodes have essential influences on their electrochemical performances.

Biomasses can provide ACs with very high SSA and developed porosity with different pore structures which make them very suitable for electrochemical applications. The quality of the activated carbons can be determined by a proper pyrolysis method as well as the conditions that can optimise the properties of the final ACs and CEs.

Author Contributions: Conceptualisation, G.S.d.R.; Investigation, G.S.d.R.; Data curation, G.S.d.R.; Writing—original draft, G.S.d.R.; Funding acquisition, S.H.L.; Supervision, S.H.L.; Writing—review \& editing, S.H.L., H.P.d.O., M.T. and E.C.L. All authors have read and agreed to the published version of the manuscript.

Funding: This research was funded by Treesearch Postdoctoral program, Bio4Energy, a Strategic Research Environment appointed by the Swedish government, and the Swedish University of Agricultural Sciences.

Conflicts of Interest: The authors declare no conflict of interest.

\section{References}

1. Shahabuddin, M.; Krishna, B.B.; Bhaskar, T.; Perkins, G. Advances in the thermo-chemical production of hydrogen from biomass and residual wastes: Summary of recent techno-economic analyses. Bioresour. Technol. 2020, 299, 122557. [CrossRef] [PubMed]

2. Kaza, S.; Yao, L.; Bhada-Tata, P.; Woerden, V.F. What a Waste 2.0: A Global Snapshot of Solid Waste Management to 2050. International Bank for Reconstruction and Development; The World Bank: Washington, DC, USA, 2018.

3. Tripathi, M.; Sahu, J.N.; Ganesan, P. Effect of process parameters on production of biochar from biomass waste through pyrolysis: A review. Renew. Sustain. Energy Rev. 2016, 55, 467-481. [CrossRef]

4. Cagnon, B.; Py, X.; Guillot, A.; Stoeckli, F.; Chambat, G. Contributions of hemicellulose, cellulose and lignin to the mass and the porous properties of chars and steam activated carbons from various lignocellulosic precursors. Bioresour. Technol. 2009, 100, 292-298. [CrossRef] [PubMed]

5. Marsh, H.; Reinoso, F.R. Activated Carbon; Elsevier: Amsterdam, The Netherlands, 2006.

6. Ioannidou, O.; Zabaniotou, A. Agricultural residues as precursors for activated carbon production-A review. Renew. Sustain. Energy Rev. 2007, 11, 1966-2005. [CrossRef]

7. Wang, Y.; Qu, Q.; Gao, S.; Tang, G.; Liu, K.; He, S.; Huang, C. Biomass-derived carbon as binder-free electrode materials for supercapacitors. Carbon 2019, 155, 706-726. [CrossRef]

8. Kostoglou, N.; Koczwara, C.; Prehal, C.; Terziyska, V.; Babic, B.; Matovic, B.; Constantinides, G.; Tampaxis, C.; Charalambopoulou, G.; Steriotis, T.; et al. Nanoporous activated carbon cloth as a versatile material for hydrogen adsorption, selective gas separation and electrochemical energy storage. Nano Energy 2017, 40, 49-64. [CrossRef] 
9. Niu, J.; Shao, R.; Liang, J.; Dou, M.; Li, Z.; Huang, Y.; Wang, F. Biomass-derived mesopore-dominant porous carbons with large specific surface area and high defect density as high-performance electrode materials for Li-ion batteries and supercapacitors. Nano Energy 2017, 36, 322-330. [CrossRef]

10. Simon, P.; Gogotsi, Y.; Dunn, B. Where do batteries end and supercapacitors begin? Science 2014, 343, 1210-1211. [CrossRef]

11. Lee, J.; Srimuk, P.; Fleischmann, S.; Su, X.; Hatton, T.A.; Presser, V. Redox-electrolytes for non-flow electrochemical energy storage: A critical review and best practice. Progress Mat. Sci. 2019, 101, 46-89. [CrossRef]

12. Miller, J.R.; Burke, A.F. Electrochemical capacitors: Challenges and opportunities for real-world applications. Electrochem. Soc. Interface 2008, 17, 53.

13. Conway, B.E.; Pell, W.G.; Liu, T.C. Diagnostic analyses for mechanisms of self-discharge of electrochemical capacitors and batteries. J. Power Sources 1997, 65, 53-59. [CrossRef]

14. Zhou, G.; Li, F.; Cheng, H.-M. Progress in flexible lithium batteries and future prospects. Energy Environ. Sci. 2014, 7, 1307-1338. [CrossRef]

15. Larcher, D.; Tarascon, J.M. Towards greener and more sustainable batteries for electrical energy storage. Nat. Chem. 2015, 7, 19-29. [CrossRef]

16. Nie, Y.F.; Wang, Q.; Yi, H.T.; Chen, X.Y.; Zhang, Z.J. Remarkable capacitive enhancement of templated carbon materials by the redox additive electrolyte of p-phenylenediamine. RSC Adv. 2015, 5, 65100-65109. [CrossRef]

17. Xu, D.; Hu, W.; Sun, X.N.; Cui, P.; Chen, X.Y. Redox additives of Na2MoO4 and KI: Synergistic effect and the improved capacitive performances for carbon-based supercapacitors. J. Power Sources 2017, 341, 448-456. [CrossRef]

18. Wang, J.; Zhang, X.; Li, Z.; Ma, Y.; Ma, L. Recent progress of biomass-derived carbon materials for supercapacitors. J. Power Sources 2020, 451, 227794. [CrossRef]

19. Zhang, L.; Liu, Z.; Cui, G.; Chen, L. Biomass-derived materials for electrochemical energy storages. Prog. Polym. Sci. 2015, 43, 136-164. [CrossRef]

20. Rana, A.; Baig, N.; Saleh, T.A. Electrochemically pretreated carbon electrodes and their electroanalytical applications-A review. J. Electroanal. Chem. 2019, 833, 313-332. [CrossRef]

21. Tojo, T.; Sakurai, K.; Muramatsu, H.; Hayashi, T.; Yang, K.S.; Jung, Y.C.; Yang, C.M.; Endo, M.; Kim, Y.A. Electrochemical role of oxygen-containing functional groups on activated carbon electrode. RSC Adv. 2014, 4, 62678-62683. [CrossRef]

22. Liu, P.; Wang, Y.; Liu, J. Biomass-derived porous carbon materials for advanced lithium-sulfur batteries. J. Energy Chem. 2019, 34, 171-185. [CrossRef]

23. Alcaraz-Espinoza, J.J.; de Oliveira, H.P. Flexible supercapacitors based on a ternary composite of polyaniline/ polypyrrole/graphite on gold-coated sandpaper. Electrochim. Acta 2018, 274, 200-207. [CrossRef]

24. Lima, R.M.A.P.; Alcaraz-Espinoza, J.J.; da Silva, F.A.G., Jr.; de Oliveira, H.P. Multifunctional wearable electronic textiles using cotton fibers with polypyrrole and carbon nanotubes. ACS Appl. Mater. Interfaces 2018, 10, 13783-13795. [CrossRef]

25. Alcaraz-Espinoza, J.J.; de Melo, C.P.; de Oliveira, H.P. Fabrication of highly flexible hierarchical polypyrrole/carbon nanotube on eggshell membranes for supercapacitors. ACS Omega 2017, 2, 2866-2877. [CrossRef] [PubMed]

26. Hoheisel, T.N.; Schrettl, S.; Szilluweit, R.; Frauenrath, H. Nanostructured carbonaceous materials from molecular precursors. Angew. Chem. Int. Ed. 2010, 49, 6496-6515. [CrossRef] [PubMed]

27. Nagel, B.; Dellweg, H.; Gierasch, L.M. Glossary for chemists of terms used in biotechnology (IUPAC Recommendations 1992). Pure Appl. Chem. 1992, 64, 143-168. [CrossRef]

28. Umpierres, C.S.; Thue, P.S.; Reis, G.S.d.; de Brum, I.A.S.; Lima, E.C.; de Alencar, W.A.; Dias, S.L.P.; Dotto, G.L. Microwave activated carbons from Tucumã (Astrocaryum aculeatum) waste for efficient removal of 2nitrophenol from aqueous solutions. Environ. Technol. 2018, 39, 1173-1187. [CrossRef]

29. Leite, A.B.; Saucier, C.; Lima, E.C.; dos Reis, G.S.; Umpierres, C.S.; Mello, B.L.; Shirmardi, M.; Dias, S.L.P.; Sampaio, C.H. Activated carbons from avocado seed: Optimisation and application for removal several emerging organic compounds. Environ. Sci. Pollut. Res. 2018, 25, 7647-7661. [CrossRef] 
30. Cunha, M.R.; Lima, E.C.; Cimirro, N.F.G.M.; Thue, P.S.; Dias, S.L.P.; Gelesky, M.A.; Dotto, G.L.; Reis, G.S.d.; Pavan, F.A. Conversion of Eragrostis plana Nees leaves to activated carbon by microwave-assisted pyrolysis for the removal of organic emerging contaminants from aqueous solutions. Environ. Sci. Pollut. Res. 2018, 25, 23315-23327. [CrossRef]

31. Kasperiski, F.M.; Lima, E.C.; Umpierres, C.S.; Reis, G.S.d.; Thue, P.S.; Lima, D.R.; Dias, S.L.P.; Saucier, C.; da Costa, J.B. Production of porous activated carbons from Caesalpinia ferrea seed pod wastes: Highly efficient removal of captopril from aqueous solutions. J. Clean. Prod. 2018, 197, 919-929. [CrossRef]

32. Thangavel, R.; Kannan, A.G.; Ponraj, R.; Kaliyappan, K.; Yoon, W.S.; Kim, D.W.; Lee, Y.S. Cinnamon-Derived Hierarchically Porous Carbon as an Effective Lithium Polysulfide Reservoir in Lithium-Sulfur Batteries. Nanomaterials 2020, 10, 1220. [CrossRef]

33. Abioye, A.M.; Ani, F.N. Recent development in the production of activated carbon electrodes from agricultural waste biomass for supercapacitors: A review. Renew. Sustain. Energy Rev. 2015, 52, 1282-1293. [CrossRef]

34. Saidur, R.; Abdelaziz, E.A.; Demirbas, A.; Hossain, M.S.; Mekhilef, S. A review on biomass as a fuel for boilers. Renew. Sustain. Energy Rev. 2011, 15, 2262-2289. [CrossRef]

35. Zu, G.; Shen, J.; Zou, L.; Wang, F.; Wang, X.; Zhang, Y.; Yao, X. Nanocellulose-derived highly porous carbon aerogels for supercapacitors. Carbon 2016, 99, 203-211. [CrossRef]

36. Shan, D.; Yang, J.; Liu, W.; Yan, J.; Fan, Z. Biomass-derived three-dimensional honeycomb-like hierarchical structured carbon for ultrahigh energy density asymmetric supercapacitors. J. Mater. Chem. 2016, 4, 13589-13602. [CrossRef]

37. Gupta, V.K.; Carrott, P.J.M.; Singh, R.; Chaudhary, M.; Kushwaha, S. Cellulose: A review as natural, modified and activated carbon adsorbent. Bioresour. Technol. 2016, 216, 1066-1076.

38. Xue, Y.; Du, C.; Wu, Z.; Zhang, L. Relationship of cellulose and lignin contents in biomass to the structure and RB-19 adsorption behavior of activated carbon. New J. Chem. 2018, 42, 16493-16502. [CrossRef]

39. Zhuo, H.; Hu, Y.; Tong, X.; Zhong, L.; Peng, X.; Sun, R. Sustainable hierarchical porous carbon aerogel from cellulose for high-performance supercapacitor and $\mathrm{CO}_{2}$ capture. Ind. Crop. Prod. 2016, 87, 229-235. [CrossRef]

40. Tian, X.; Zhu, S.; Peng, J.; Zuo, Y.; Wang, G.; Guo, X.; Zhao, N.; Ma, Y.; Ma, L. Synthesis of micro- and mesoporous carbon derived from cellulose as an electrode material for supercapacitors. Electrochim. Acta 2017, 241, 170-178. [CrossRef]

41. Tian, J.; Liu, Z.; Li, Z.; Wang, W.; Zhang, H. Hierarchical S-doped porous carbon derived from by-product lignin for high-performance supercapacitors. RSC Adv. 2017, 7, 12089-12097. [CrossRef]

42. Zhang, W.; Lin, H.; Lin, Z.; Yin, J.; Lu, H.; Liu, D.; Zhao, M. 3D hierarchical porous carbon for supercapacitors prepared from lignin through a facile template-free method. ChemSusChem 2015, 8, 2114-2122. [CrossRef]

43. Wang, Y.; Yang, R.; Li, M.; Zhao, Z. Hydrothermal preparation of highly porous carbon spheres from hemp (Cannabis sativa L.) stem hemicellulose for use in energy-related applications. Ind. Crop. Prod. 2015, 65, 216-226. [CrossRef]

44. Reis, G.S.D.; Wilhelm, M.; Silva, T.C.A.; Rezwan, K.; Sampaio, C.H.; Lima, E.C.; Souza, S.M.A.G.U. The use of design of experiments for the evaluation of the production of surface rich activated carbon from sewage sludge via microwave and conventional pyrolysis. Appl. Thermal Eng. 2016, 93, 590. [CrossRef]

45. Ao, W.; Fu, J.; Mao, X.; Kang, Q.; Ran, C.; Liu, Y.; Zhang, H.; Gao, Z.; Li, J.; Liu, G.; et al. Microwave-assisted preparation of activated carbon from biomass: A review. Renew. Sustain. Energy Rev. 2018, 92, 958-979. [CrossRef]

46. Huang, Y.; Chiueh, P.; Kuan, W.; Lo, S. Microwave pyrolysis of lignocellulosic biomass: Heating performance and reaction kinetics. Energy 2016, 100, 137-144. [CrossRef]

47. Yuen, F.K.; Hameed, B.H. Recent developments in the preparation and regeneration of activated carbons by microwaves. Adv. Colloid Interface Sci. 2009, 149, 19-27. [CrossRef]

48. Peng, C.; Peng, C.; Zhai, Y.; Zhu, Y.; Wang, T.; Xu, B.; Wang, T.; Li, C.; Zeng, G. Investigation of the structure and reaction pathway of char obtained from sewage sludge with biomass wastes, using the hydrothermal treatment. J. Clean. Prod. 2017, 166, 114-123. [CrossRef]

49. Reza, M.T.; Lynam, J.G.; Uddin, M.H.; Coronella, C.J. Hydrothermal carbonisation: Fate of inorganics. Biomass Bioenergy 2013, 49, 86-94. [CrossRef]

50. Hoffmann, V.; Jung, D.; Alhnidi, M.J.; Mackle, L.; Kruse, A. Bio-based carbon materials from potato waste as electrode materials in supercapacitors. Energies 2020, 13, 2406. [CrossRef] 
51. Liu, C.; Chen, W.; Hong, S.; Pan, M.; Jiang, M.; Wu, Q.; Mei, C. Fast microwave synthesis of hierarchical porous carbons from waste palm boosted by activated carbons for supercapacitors. Nanomaterials 2019, 9, 405. [CrossRef]

52. Hou, J.; Jiang, K.; Tahir, M.; Wu, X.; Idrees, F.; Shen, M.; Cao, C. Tunable porous structure of carbon nanosheets derived from puffed rice for high energy density supercapacitors. J. Power Sources 2017, 371, 148-155. [CrossRef]

53. Xu, B.; Chen, Y.; Wei, G.; Cao, G.; Zhang, H.; Yang, Y. Activated carbon with high capacitance prepared by $\mathrm{NaOH}$ activation for supercapacitors. Mater. Chem. Phys. 2010, 124, 504-509. [CrossRef]

54. Theydan, S.K.; Ahmed, M.J. Optimisation of preparation conditions for activated carbons from date stones using response surface methodology. Powder Technol. 2012, 224, 101-108. [CrossRef]

55. Sivachidambaram, M.; Vijaya, J.J.; Kennedy, L.J.; Jothiramalingam, R.; Al-Lohedan, H.A.; Munusamy, M.A.; Elanthamilane, E.; Merlin, J.P. Preparation and characterization of activated carbon derived from the Borassus flabellifer flower as an electrode material for supercapacitor applications. New J. Chem. 2017, 41, 3939-3949.

56. Reis, G.S.d.; Adebayo, M.A.; Lima, E.C.; Sampaio, C.H.; Prola, L.D.T. Activated carbon from sewage sludge for preconcentration of copper. Anal. Lett. 2016, 49, 541-555. [CrossRef]

57. Lv, W.M.; Wen, F.S.; Xiang, J.Y.; Zhao, J.; Li, L.; Wang, L.M.; Liu, Z.Y.; Tian, Y.J. Peanut shell derived hard carbon as ultralong cycling anodes for lithium and sodium batteries. Electrochim. Acta 2015, 176, 533-541. [CrossRef]

58. Chen, R.; Li, L.; Liu, Z.; Lu, M.; Wang, C.; Li, H.; Ma, W.; Wang, S. Preparation and characterisation of activated carbons from tobacco stem by chemical activation. J. Air Waste Manag. Assoc. 2017, 67, 713-724. [CrossRef] [PubMed]

59. Yang, H.; Yu, X.; Meng, H.; Dou, P.; Ma, D.; Xu, X. Nanoengineered three-dimensional hybrid $\mathrm{Fe}_{2} \mathrm{O}_{3} @ \mathrm{PPy}$ nanotube arrays with enhanced electrochemical performances as lithium-ion anodes. J. Mater. Sci. 2015, 50, 5504-5513. [CrossRef]

60. Yu, W.; Wang, H.; Liu, S.; Mao, N.; Liu, X.; Shi, J.; Liu, W.; Chen, S.; Wang, X. N O-codoped hierarchical porous carbons derived from algae for high-capacity supercapacitors and battery anodes. J. Mater. Chem. A 2016, 4, 5973-5983. [CrossRef]

61. Zhang, F.; Wang, K.X.; Li, D.G.; Chen, J.S. Hierarchical porous carbon derived from rice straw for lithium-ion batteries with high-rate performance. Electrochem. Commun. 2009, 11, 130-133. [CrossRef]

62. Selvamani, V.; Ravikumarc, R.; Suryanarayanan, V.; Velayutham, D.; Gopukumar, S. Fish scale derived nitrogen-doped hierarchical porous carbon-A high rate performing anode for lithium-ion cell. Electrochim. Acta 2015, 182, 1-10. [CrossRef]

63. Hernández-Rentero, C.; Marangon, V.; Olivares-Marín, M.; Gómez-Serrano, V.; Caballero, Á.; Morales, J.; Hassoun, J. Alternative lithium-ion battery using biomass-derived carbons as an environmentally sustainable anode. J. Colloid Interface Sci. 2020, 573, 396-408. [CrossRef] [PubMed]

64. Lotfabad, E.M.; Ding, J.; Cui, K.; Kohandehghan, A.; Kalisvaart, W.P.; Hazelton, M.; Mitlin, D. High-density sodium and lithium-ion battery anodes from banana peels. ACS Nano 2014, 8, 7115-7129. [CrossRef]

65. Iakunkov, A.; Skrypnichuk, V.; Nordenström, A.; Shilayeva, E.A.; Korobov, M.; Prodana, M.; Enachescu, M.; Larsson, S.H.; Talyzin, A. Activated graphene as a material for supercapacitor electrodes: Effects of surface area, pore size distribution and hydrophilicity. Phys. Chem. Chem. Phys. 2019, 32, 17901-17912. [CrossRef] [PubMed]

66. Zhang, Y.; Chen, L.; Meng, Y.; Xie, J.; Guo, Y.; Xiao, D. Lithium and sodium storage in highly ordered mesoporous nitrogen-doped carbons derived from honey. J. Power Sources 2016, 335, 20-30. [CrossRef]

67. Chen, L.; Zhang, Y.; Lin, C.; Yang, W.; Meng, Y.; Guo, Y.; Li, M.; Xiao, D. Hierarchically porous nitrogen-rich carbon derived from a wheat straw as an ultrahigh-rate anode for lithium-ion battery. J. Mater. Chem. A 2014, 2, 9684-9690. [CrossRef]

68. Peng, L.; Cai, Y.; Luo, Y.; Yuan, G.; Huang, J.; Hu, C.; Dong, H.; Xiao, Y.; Liang, Y.; Liu, Y.; et al. Bio-inspired highly crumpled porous carbons with multidirectional porosity for high rate performance electrochemical supercapacitors. ACS Sustain. Chem. Eng. 2018, 6, 12716-12726.

69. Luna-Lama, F.; Rodríguez-Padron, D.; Puente-Santiago, A.R.; Munoz-Batista, M.J.; Caballero, A.; Balu, A.M.; Romero, A.A.; Luque, R. Non-porous carbonaceous materials derived from coffee waste grounds as highly sustainable anodes for lithium-ion batteries. J. Cleaner Prod. 2019, 207, 411-417. [CrossRef] 
70. Sun, X.L.; Wang, X.H.; Feng, N.; Qiao, L.; Li, X.; He, D.Y. A new carbonaceous material derived from biomass source peels as an improved anode for lithium-ion batteries. J. Anal. Appl. Pyrolysis 2013, 100, 181-185. [CrossRef]

71. Yun, Y.S.; Jin, H.-J. Electrochemical performance of heteroatom-enriched amorphous carbon with hierarchical porous structure as anode for lithium-ion batteries. Mater. Lett. 2013, 108, 311-315. [CrossRef]

72. Mendoza-Sánchez, B.; Gogotsi, Y. Synthesis of two-dimensional materials for capacitive energy storage. Adv. Mater. 2016, 28, 6104-6135. [CrossRef]

73. Xu, Y.; Shi, G.; Duan, X. Self-assembled three-dimensional graphene macrostructures: Synthesis and applications in supercapacitors. Acc. Chem. Res. 2015, 48, 1666-1675. [CrossRef] [PubMed]

74. Gogotsi, Y.; Simon, P. True performance metrics in electrochemical energy storage. Science 2011, 334, 917-918. [CrossRef] [PubMed]

75. Zhang, G.; Song, Y.; Zhang, H.; Xu, J.; Duan, H.; Liu, J. Radially aligned porous carbon nanotube arrays on carbon fibers: A hierarchical 3D carbon nanostructure for high-performance capacitive energy storage. Adv. Funct. Mater. 2016, 26, 3012-3020. [CrossRef]

76. Wang, Y.; Song, Y.; Xia, Y. Electrochemical capacitors: Mechanism, materials, systems, characterisation and applications. Chem. Soc. Rev. 2016, 45, 5925-5950. [CrossRef]

77. Ma, Q.; Yu, Y.; Sindoro, M.; Fane, A.G.; Wang, R.; Zhang, H. Carbon-based functional materials derived from waste for water remediation and energy storage. Adv. Mater. 2017, 29, 1605361-1605379. [CrossRef]

78. Dutta, S.; Bhaumik, A.; Wu, K.C.W. Hierarchically porous carbon derived from polymers and biomass: Effect of interconnected pores on energy applications. Energy Environ. Sci. 2014, 7, 3574-3592. [CrossRef]

79. Wang, X.; Sun, G.; Routh, P.; Kim, D.-H.; Huang, W.; Chen, P. Heteroatom-doped graphene materials: Syntheses, properties and applications. Chem. Soc. Rev. 2014, 43, 7067-7098. [CrossRef]

80. Su, F.; Poh, C.K.; Chen, J.S.; Xu, G.; Wang, D.; Li, Q.; Lin, J.; Lou, X.W. Nitrogen-containing microporous carbon nanospheres with improved capacitive properties. Energy Environ. Sci. 2011, 4, 717-724. [CrossRef]

81. Li, X.; Cai, W.; An, J.; Kim, S.; Nah, J.; Yang, D.; Piner, R.; Velamakanni, A.; Jung, I.; Tutuc, E.; et al. Large-area synthesis of highquality and uniform graphene films on copper foils. Science 2009, 324, 1312-1314. [CrossRef]

82. Patel, N.; Okabe, K.; Oya, A. Designing carbon materials with unique shapes using polymer blending and coating techniques. Carbon 2002, 40, 315-320. [CrossRef]

83. He, X.; Ling, P.; Qiu, J.; Yu, M.; Zhang, X.; Yu, C.; Zheng, M. Efficient preparation of biomass-based mesoporous carbons for supercapacitors with both high energy density and high power density. J. Power Sources 2013, 240, 109-113. [CrossRef]

84. Sun, L.; Tian, C.; Li, M.; Meng, X.; Wang, L.; Wang, R.; Yin, J.; Fu, H. From coconut shell to porous graphene-like nanosheets for high-power supercapacitors. J. Mater. Chem. A 2013, 1, 6462-6470. [CrossRef]

85. Xia, J.; Zhang, N.; Chong, S.; Li, D.; Chen, Y.; Sun, C. Three-dimensional porous graphene-like sheets synthesised from biocarbon via low-temperature graphitisation for a supercapacitor. Green Chem. 2018, 20, 694-700. [CrossRef]

86. Cai, Y.; Luo, Y.; Dong, H.; Zhao, X.; Xiao, Y.; Liang, Y.; Hu, H.; Liu, Y.; Zheng, M. Hierarchically porous carbon nanosheets derived from Moringa oleifera stem as electrode material for high-performance electric double-layer capacitors. J. Power Sources 2017, 353, 260-269. [CrossRef]

87. Chen, H.; Liu, D.; Shen, Z.; Bao, B.; Zhao, S.; Wu, L. Functional biomass carbons with hierarchical porous structure for supercapacitor electrode materials. Electrochim. Acta 2015, 180, 241-251. [CrossRef]

88. Xia, L.; Huang, H.; Fana, Z.; Hu, D.; Zhang, D.; Khan, A.S.; Usman, M.; Pan, L. Hierarchical macro-/meso-/microporous oxygen-doped carbon derived from sodium alginate: A cost-effective biomass material for binder-free supercapacitors. Mater. Des. 2019, 182, 108048. [CrossRef]

89. Sankar, S.; Ahmed, A.T.A.; Inamdar, A.I.; Im, H.; Im, Y.B.; Lee, Y.; Kim, D.Y.; Lee, S. Biomass-derived ultrathin mesoporous graphitic carbon nanoflakes as stable electrode material for high-performance supercapacitors. Mat. Des. 2019, 169, 107688. [CrossRef]

90. Song, X.; Ma, X.; Li, Y.; Ding, L.; Jiang, R. Tea waste-derived microporous active carbon with enhanced double-layer supercapacitor behaviors. Appl. Surface Sci. 2019, 487, 189-197. [CrossRef]

91. Song, S.; Ma, F.; Wu, G.; Ma, D.; Geng, W.; Wan, J. Facile self-templating large scale preparation of biomass-derived 3D hierarchical porous carbon for advanced supercapacitors. J. Mater. Chem. A 2015, 3, 18154-18162. [CrossRef] 
92. Tian, W.; Gao, Q.; Tan, Y.; Li, Z. Unusual interconnected graphitised carbon nanosheets as the electrode of high-rate ionic liquid-based supercapacitor. Carbon 2017, 119, 287-295. [CrossRef]

93. Huang, G.; Wang, Y.; Zhang, T.; Wua, X.; Cai, J. High-performance hierarchical N-doped porous carbons from hydrothermally carbonised bamboo shoot shells for symmetric supercapacitors. J. Taiwan Inst. Chem. Eng. 2019, 96, 672-680. [CrossRef]

94. Wu, Y.; Cao, J.-P.; Zhao, X.-Y.; Zhuang, Q.-Q.; Zhou, Z.; Huang, Y.; Wei, X.-Y. High-performance electrode material for electric double-layer capacitor based on hydrothermal pre-treatment of lignin by $\mathrm{ZnCl}_{2}$. Appl. Surf. Sci. 2020, 508, 144536. [CrossRef]

95. Ren, M.; Jia, Z.; Tian, Z.; Lopez, D.; Cai, J.; Titirici, M.M.; Jorge, A.B. High-performance n-doped carbon electrodes obtained via hydrothermal carbonisation of macroalgae for supercapacitor applications. ChemElectroChem 2018, 5, 2686-2693. [CrossRef]

96. Lima, D.R.; Hosseini-Bandegharaei, A.; Thue, P.S.; Lima, E.C.; de Albuquerque, Y.R.T.; dos Reis, G.S.; Umpierres, C.S.; Dias, S.L.P.; Tran, H.N. Efficient acetaminophen removal from water and hospital effluents treatment by activated carbons derived from Brazil nutshells. Colloids Surfaces A 2019, 583, 123966. [CrossRef]

97. Thue, P.S.; Umpierres, C.S.; Lima, E.C.; Lima, D.R.; Machado, F.M.; Reis, G.S.d.; Silva, R.S.; Pavan, F.A.; Tran, H.N. Single-step pyrolysis for producing magnetic activated carbon from tucumã (Astrocaryum aculeatum) seed and nickel(II) chloride and zinc(II) chloride. Application for removal of nicotinamide and propranolol. J Hazard. Mat. 2020, 398, 122903. [CrossRef] [PubMed]

98. Nguyen, Q.D.; Wu, Y.-H.; Wu, T.-Y.; Deng, M.-J.; Yang, C.-H.; Chang, J.-K. Gravimetric/volumetric capacitances, leakage current, and gas evolution of activated carbon supercapacitors. Electrochim. Acta 2016, 222, 1153-1159. [CrossRef]

99. Hall, P.J.; Mirzaeian, M.; Fletcher, S.I.; Sillars, F.B.; Rennie, A.J.; Shitta-Bey, G.O.; Wilson, G.; Cruden, A.; Carter, R. Energy storage in electrochemical capacitors: designing functional materials to improve performance. Energy Environ. Sci. 2010, 3, 1238-1251. [CrossRef]

100. Ding, Z.; Trouillet, V.; Dsoke, S. Are functional groups beneficial or harmful on the electrochemical performance of activated carbon electrodes? J. Electrochem. Soc. 2019, 166, A1004-A1014. [CrossRef]

101. Liu, C.; Koyyalamudi, B.B.; Li, L.; Emani, S.; Wang, C.; Shaw, L.L. Improved capacitive energy storage via surface functionalization of activated carbon as cathodes for lithium ion capacitors. Carbon 2016, 109, 163-172. [CrossRef]

102. Abbas, Q.; Mirzaeian, M.; Ogwu, A.A.; Mazur, M.; Gibson, D. Effect of physical activation/surface functional groups on wettability and electrochemical performance of carbon/activated carbon aerogels based electrode materials for electrochemical capacitors. Int. J. Hydrogen Energy 2020, 45, 13586-13595. [CrossRef]

103. Hulicova-Jurcakova, D.; Kodama, M.; Shiraishi, S.; Hatori, H.; Zhu, Z.H.; Lu, G.Q. Nitrogen-enriched nonporous carbon electrodes with extraordinary supercapacitance. Adv. Funct. Mater. 2009, 19, 1800-1809. [CrossRef]

104. Cao, H.; Peng, X.; Liu, M.Z.P.; Xua, B.; Guo, J. Oxygen functional groups improve the energy storage performances of graphene electrochemical supercapacitors. RSC Adv. 2018, 8, 2858-2865. [CrossRef]

105. Widmaier, M.; Krüner, B.; Jäckel, N.; Aslan, M.; Fleischmann, S.; Engel, C.; Presser, V.J. Carbon as quasi-reference electrode in unconventional lithium-salt containing electrolytes for hybrid battery/supercapacitor devices. J. Electrochem. Soc. 2016, 14, 163.

106. Elmouwahidi, A.; Zapata-Benabithe, Z.; Carrasco-Marín, F.; Moreno-Castilla, C. Activated carbons from $\mathrm{KOH}$-activation of argan (Argania spinosa) seed shells as supercapacitor electrodes. Bioresour. Technol. 2012, 111, 185-190. [CrossRef]

107. Yang, W.; Li, Y.; Feng, Y. High electrochemical performance from oxygen functional groups containing porous activated carbon electrode of supercapacitors. Materials 2018, 11, 2455. [CrossRef] [PubMed]

108. Lyu, L.; Seong, K.D.; Ko, D.; Choi, J.; Lee, C.; Hwang, T.; Cho, Y.; Jin, X.; Zhang, W.; Pang, H.; et al. Recent devel as electrode materials for supercapacitors. Mater. Chem. Front. 2019, 3, 2543-2570. [CrossRef]

109. Zhang, Y.; Liu, X.; Wang, S.; Li, L.; Dou, S. Bio-nanotechnology in high-performance supercapacitors. Adv. Energy Mater. 2017, 7, 1700592. [CrossRef]

110. Peng, Z.; Wang, C.; Zhang, Z.; Zhong, W. Synthesis and enhancement of electroactive biomass/polypyrrole hydrogels for high-performance flexible all-solid-state supercapacitors. Adv. Mater. Interfaces 2019, 6, 1901393. [CrossRef] 
111. Arthisree, D.; Madhuri, W. Optically active polymer nanocomposite composed of polyaniline, polyacrylonitrile and green synthesised graphene quantum dot for supercapacitor application. Int. J. Hydrog. Energy 2020, 45, 9317-9327. [CrossRef]

112. Yua, M.; Hana, Y.; Li, Y.; Li, J.; Wang, L. Polypyrrole-anchored cattail biomass-derived carbon aerogels for high performance binder-free supercapacitors. Carbohydr. Polym. 2018, 199, 555-562. [CrossRef]

(C) 2020 by the authors. Licensee MDPI, Basel, Switzerland. This article is an open access article distributed under the terms and conditions of the Creative Commons Attribution (CC BY) license (http://creativecommons.org/licenses/by/4.0/). 


\title{
Correction: Ahmad, I.A., et al. Non-Isothermal Crystallisation Kinetics of Carbon Black-Graphene-Based Multimodal-Polyethylene Nanocomposites. Nanomaterials, 2019, 9, 100
}

\author{
Ibrahim A. Ahmad ${ }^{1}$, Hyun-Kyung Kim ${ }^{1,2}, *$, Suleyman Deveci ${ }^{3}$ and R. Vasant Kumar ${ }^{1, *}$ \\ 1 Department of Materials Science and Metallurgy, University of Cambridge, 27 Charles Babbage Rd, \\ Cambridge CB3 0FS, UK; iaiaa2@cam.ac.uk \\ 2 Gwangju Bio/Energy R\&D Center, Korea Institute of Energy Research (KIER), 270-25 Samso-ro, Buk-gu, \\ Gwangju 61003, Korea \\ 3 Innovation Centre, Borouge Pte Ltd., PO BOX 6951, Abu Dhabi, UAE; suleyman.deveci@borouge.com \\ * Correspondence: hkk28@cam.ac.uk (H.-K.K.); rvk10@cam.ac.uk (R.V.K.); \\ Tel.: +44-(0)-1223-331953 (H.-K.K.); +44-(0)-1223-334327 (R.V.K.)
}

Received: 1 March 2019; Accepted: 6 March 2019; Published: 7 March 2019

In the published paper [1], there was a typo error mistake in Equation (5), which was supposed to be expressed as "log $Z_{t}+n \log t=\log K_{T}-m \log \Phi^{\prime \prime}$ instead of "log $Z t+n \log t=\log K_{\mathrm{T}}-m \mathrm{l}^{\prime}$.

The changes do not affect the scientific results. We apologize for any inconvenience caused to the readers by the error. The manuscript will be updated, and the original will remain online on the webpage for the article, including a reference to this Correction.

\section{Reference}

1. Ahmad, I.A.; Kim, H.-K.; Deveci, S.; Kumar, R.V. Non-isothermal crystallisation kinetics of carbon blackgraphene-based multimodal-polyethylene nanocomposites. Nanomaterials 2019, 9, 100. [CrossRef] [PubMed]

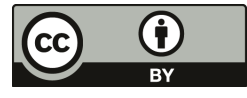

(C) 2019 by the authors. Licensee MDPI, Basel, Switzerland. This article is an open access article distributed under the terms and conditions of the Creative Commons Attribution (CC BY) license (http:/ / creativecommons.org/licenses/by/4.0/). 

MDPI

St. Alban-Anlage 66

4052 Basel

Switzerland

Tel. +41616837734

Fax +41 613028918

www.mdpi.com

Nanomaterials Editorial Office

E-mail: nanomaterials@mdpi.com www.mdpi.com/journal/nanomaterials

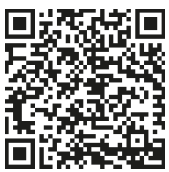



MDPI

St. Alban-Anlage 66

4052 Basel

Switzerland

Tel: +41 616837734

Fax: +41 613028918 